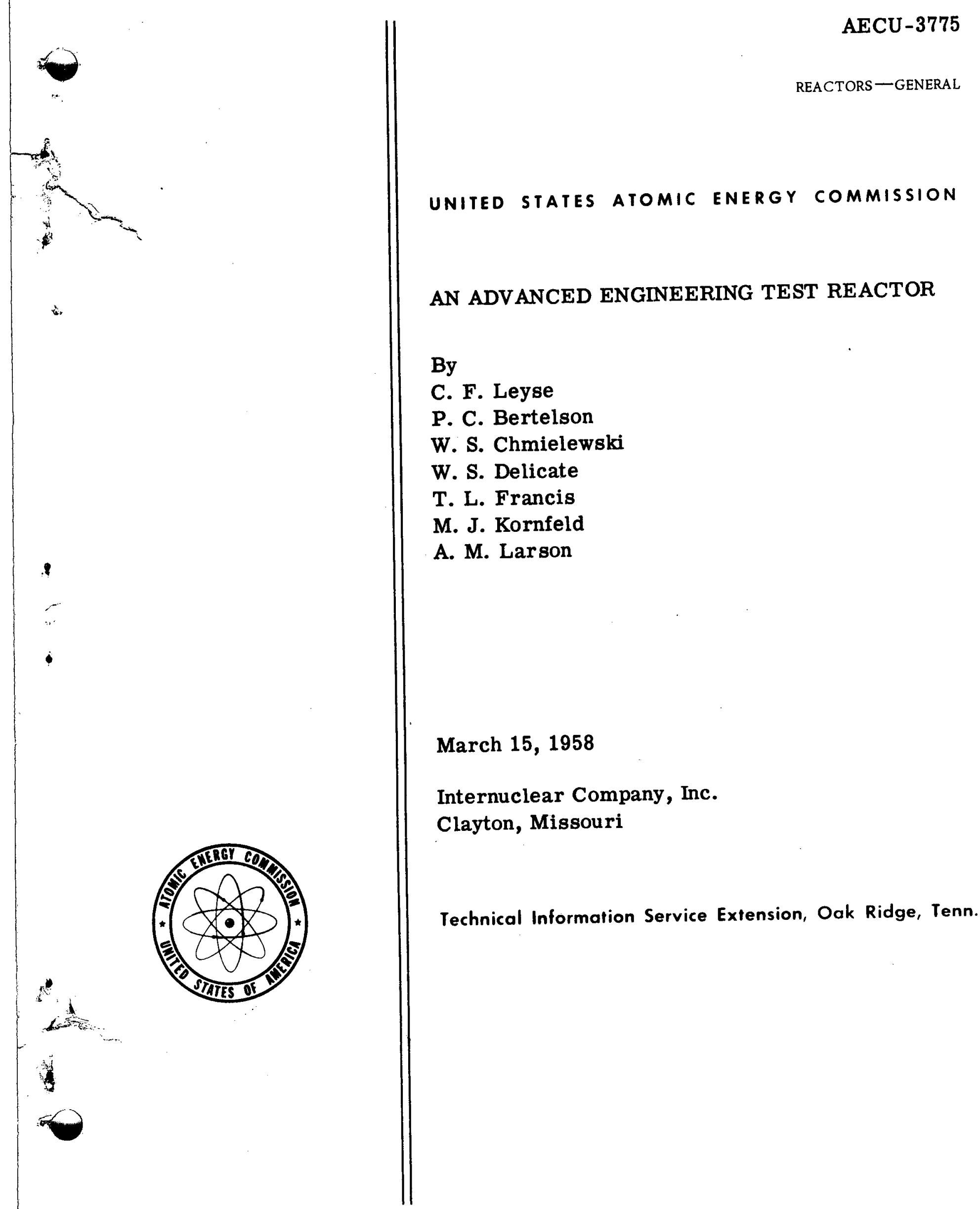




\section{DISCLAIMER}

This report was prepared as an account of work sponsored by an agency of the United States Government. Neither the United States Government nor any agency Thereof, nor any of their employees, makes any warranty, express or implied, or assumes any legal liability or responsibility for the accuracy, completeness, or usefulness of any information, apparatus, product, or process disclosed, or represents that its use would not infringe privately owned rights. Reference herein to any specific commercial product, process, or service by trade name, trademark, manufacturer, or otherwise does not necessarily constitute or imply its endorsement, recommendation, or favoring by the United States Government or any agency thereof. The views and opinions of authors expressed herein do not necessarily state or reflect those of the United States Government or any agency thereof. 


\section{DISCLAIMER}

Portions of this document may be illegible in electronic image products. Images are produced from the best available original document. 
Other issues of this report may bear the number INTERNUC-23.

\section{LEG A L NOTICE}

This report was prepared as an account of Government sponsored work. Neither the United States, nor the Commission, nor any person acting on behalf of the Commission:

A. Makes any warranty or representation, express or implied, with respect to the accuracy, completeness, or usefulness of the information contained in this report, or that the use of any information, apparatus, method, or process disclosed in this report may not infringe privately owned rights; or

B. Assumes any liabilities with respect to the use of, or for damages resulting from the use of any information, apparatus, method, or process disclosed in this report.

As used in the above, "person acting on behalf of the Commission" includes any employee or contractor of the Commission to the extent that such employee or contractor prepares, handles or distributes, or provides access to, any information pursuant to his employment or contract with the Commission.

This report has been reproduced directly from the best available copy.

Printed in USA. Price $\$ 5.00$. Available from the Office of Technical Services, Department of Commerce, Washington 25, D. C. 
AECU -3775

\title{
AN ADVANCED ENGINEERING \\ TEST REACTOR
}

\begin{abstract}
Work Performed for the Chicago Operations office

U. S. Atomic Energy Commission Contract No. AT $(11-1)-579$
\end{abstract}

\author{
by : \\ C. F. Leyse \\ P. C. Bertelson \\ W. S. Chmielewski \\ W. S. Delicate \\ T. I. Francis \\ M. J. Kornfeld \\ A. M. Larson
}

INTERNUCLEAR COMPANY, Inc. Clayton, Missouri

March 15, 1958 
In December, 1956, the Chicago Operations office of the U.S.Atomic Energy Commission requested Internuclear company to conduct a survey of reactor concepts and submit recommendations for a reactor system or systems which would meet certain requirements for an Advanced Engineering Test Reactor. The requirements, which were comparable to those outlined in Appendix 1.0, involved thermal neutron fluxes of 1015 to $1.5 \times 1015 \mathrm{n} / \mathrm{cm}^{2}-\mathrm{sec}$ in water-, gas-, and liquid-metal cooled test loops. In its report* to the Commission, Internuclear Company recommended a facility consisting of seven separate reactor systems, one for each major fuel assembly test 10op. Each reactor is of the "flux-trap" type and consists of a central test hole surrounded consecutively by annular regions of light water, fully-enriched core of aluminum plate-type fuel assemblies, and heavy water, the latter serving as the reflector.

In September 1957, the Commission requested Internuclear Company to conduct further studies toward optimization of such reactors and to prepare a preliminary conceptual design based on the results. The study was limited to light water cooled and heavy water reflected flux-trap reactors. The basic requirements for the test holes of the reactor are outlined in Appendix 1.0 .

This report is submitted in fulfillment of the contract with the commission. The report is divided into three principal parts: Part A describes a concept for an Advanced Engineering Test Reactor; Part $B$ presents the results of various investigations with regard to alternative design possibilities; and the Appendices present detailed information regarding the nuclear and engineering calculations.

Internuclear Company is indebted to many organizations for their assistance during the course of this study. It is impossible to give proper credit to all who furnished information and advice on the many problems encountered in this study of a new concept in test reactors. However, acknowledgement is given to those organizations which have been particularly helpful. Personnel of the Technical and operations staffs of Phillips Petroleum Company made helpful comments on the initial work reported in INTERNUC-9 and also gave valuable advice regarding desirable features in a test reactor. Personnel engaged in fuel assembly development at Oak Ridge National Laboratory, Babcock and Wilcox Company, Metals and Controls Corporation, Sylvania Corning Nuclear Corporation, and General Electric Company were helpful by providing information

* Elgert, O.J., Leyse, C.F。, Ott, D。G。, "Preliminary Investigations for an Advanced Engineering Test Reactor," INTERNUC-9 February 22, 1957. 
on recent fuel fabrication technology and advice on the feasibility of various fuel assembly designs. The Chicago and Idaho Operations Offices of the AEC were helpful in obtaining special information, particularly information on engineering and construction cost experience at the National Reactor Testing Statiori. The St.Louis representative of the Marley Company furnished valuable special data on the cost and performance of cooling towers. Personnel of the Aluminum Company of America gave valuable assistance in establishing the design features, materials, and costs of the reactor core vessel and the through-tube. 
I.0 Introduction...................... 3

$2.0 \quad$ General Description.................... 5

2.1 Reactor Units.................... 6

2.2 Reactor Facility.................. 7

2.3 Reactor Data Summary............... 8

2.3 .1 Overall Performance............ 8

2.3.2 Reactor Data................. 9

2.3 .3 Reactor Cooling system........... 11

2.3 .4 Shielding................... 12

3.0 Reactor Description.................... 13

3.1 Through-Tube..................... 13

3.1 .1 operating Conditions............ 14

3.1 .2 Fabrication.................. 14

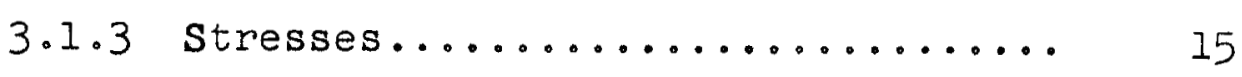

3.2 Moderator Annulus................... 17

3.3 Reactor Core Assembly................ 17

3.3 .1 Fuel Assemoly................. 18

3.3 .2 Control Rods................... 18

3.3 .3 Core stmucture................. 19

3.4 Reactor Vessel...................... 19

3.4 .1 stresses..................... 20

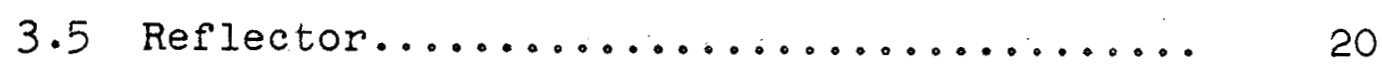

3.6 Thermal shield................... 20 
TABLE OF CONTENTS - PART A (continued)

Page No.

3.7 Blological Shield................. 20

3.8 Control and Instrumentation........... 21

3.8.1 Safety Control.............. 21

3.8 .2 Shim Control............... 22

3.8.3 Regulation Control............ 22

3.8.4 Radiation Monitoring........... 24

4.0 Experimental Facilities................. 25

4.1 Test Loop Facilities................ 25

4.2 Capsule Holes in Moderator Annulus....... 26

4.3 Capsule Holes in Reflector............ 27

4.4 Instrumentation and Control.......... 27

5.0 Reactor Cooling Systems................ 28

5.1 Primary Cooling System.............. 28

5.1.1 Reactor Core Cooling........... 28

5.1 .2 Major Equipment............. 32

5.1.3 Shutdown and Emergency Cooling.... 38

5.2 Reflector Cooling System............ 38

5.2.1 Heat Generation in Reflector...... 38

5.2 .2 Reflector Heat Removal......... 38

5.2 .3 Major Equipment............. 39

5.3 Test Loop Cooling................. 41

5.4 Secondary Cooling System............ 42

5.4 .1 Heat Load................. 42

5.4 .2 Major Equipment............ 42 
TABLE OF CONTENTS - PART A (continued)

6.0 Nuclear Characteristics............... 45

6.1 Nuclear Reference Reactors........... 45

6.2 Summary of Nuclear Characteristics....... 46

6.3 System Power Level................ 48

6.4 Fuel Loading and Core Lifetime......... 48

6.4.I Fission Product Poisoning........ 49

6.4.2 Effect of Uniform Core Poisoning on Critical Fuel Concentrations.... 49

6.4.3 Fuel Burnup and Initial Core Loading................... 50

6.4.4 Initial Excess Multiplication Factor.................... 50

6.5 Neutron Flux Distribution............ 50

6.5.1 Radial Neutron Flux Distributions.. 50

6.5.2 Two-Dimensional Calculations and Neutron Flux Plots.......... 51

6.6 Reactivity Coefficients............. 52

6.6.1 The Mass Coefficient of Reactivity. 52

6.6.2 Poison Coefficient of Reactivity... 52

6.6.3 The Uniform Temperature Coefficient of Reactivity......... 52

6.6.4 The Void Coefficient of Reactivity. 53

6.6.5 The Prompt Neutron Lifetime....... 54

6.7 Reflector Control Effects............. 55 
TABLE OF CONTENTS - PART A (continued)

Page No.

6.8 Experiment Comparisons............. 55

6.8.1 Comparison with the Engineering Test Reactor.................. 55

6.8 .2 Gas-Cooled Experiments......... 58

6.8.3 Fast Flux Experiment........... 59

7.0 Shielding and Material Heating............. 60

7.1 Gamma Heating and Radiation Intensities... 60

7.2 Heating in Reactor Components.......... 60

7.2 .1 Through-Tube ................ 60

7.2 .2 Reactor Vessel............... 61

7.2 .3 Reflector.....................61

7.2 .4 Thermal Shields.............. 61

7.2 .5 Blological Shield............. 61

7.3 Biological Shielding............... 61

7.3.1 Radial Concrete Thickness........ 62

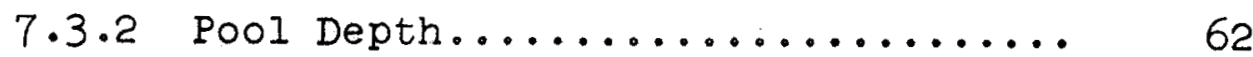

7.3.3 Primary Coolant System.......... 62

7.3.4 Experimental Loop System......... 62

8.0 Reactor Facility Arrangement............. 63

8.1 Reactor Bullaing.................. 63

8.1 .1 Reactors................. 63

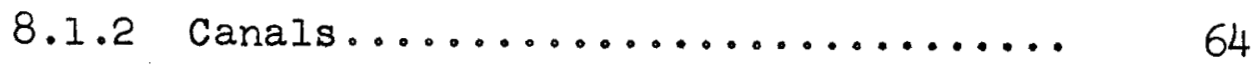

8.1.3 Experimental Loop Equipment Rooms.. 64

8.1.4 Reflector Cleanup and

Heat Exchanger Room............ 64 
TABLE OF CONTENTS - PART A (continued)

Page No.

8.1.5 Control Rooms and Amplifier Room... 64

8.1.6 Primary Heat Exchanger Room....... 65

$\pi$

8.1 .7 Pump Room................. 65

8.1.8 Emergency Equipment........... 66

8.2 Office Building................. 66

8.3 Cooling Towers................... 67

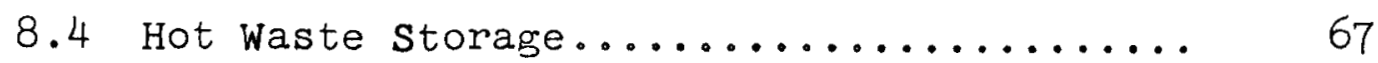

9.0 Reactor Operational Procedure.............. 68

9.1 Normal Startup and Shutdown............ 68

9.2 Refueling...................... 69

9.3 Experiment Access................... 69

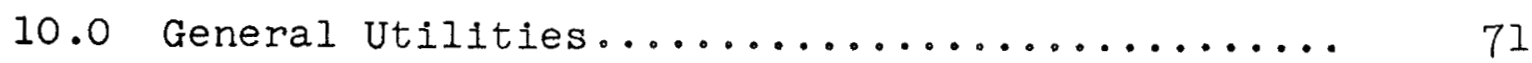

10.1 steam........................... 71

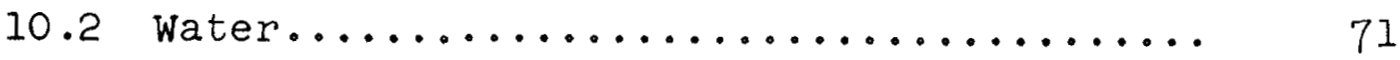

10.2.1 Treated water.............. 71

10.2 .2 Demineralized water........... 71

10.3 Electrical Power................. 72

10.4 Compressed Air.................. 72

10.5 Acid storage.................. 72

10.6 Sewage Disposal................. 72

11.0 Radioactive waste Disposal............... 73

11.1 Solid wastes................... 73

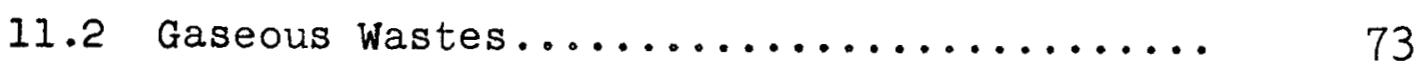

11.3 Liquid Wastes................... 73 
TABLE OF CONTENTS - PART A (continued)

Title

12.0 Research and Development Program........... 12.I Critical Experiments - Nuclear Mock-up...

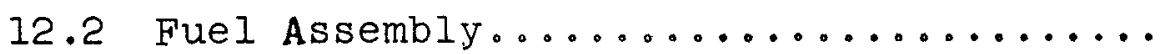

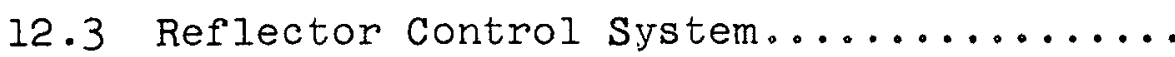

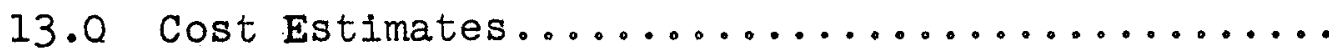

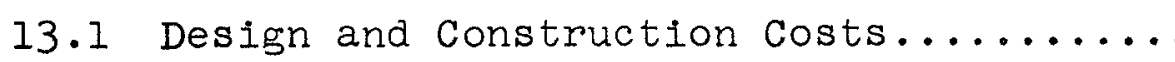

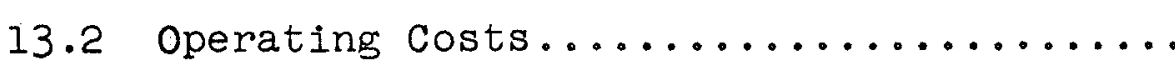

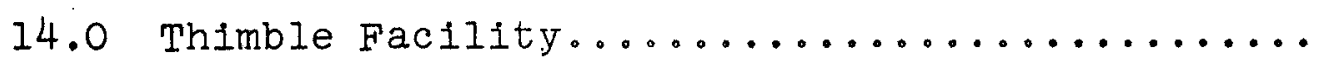

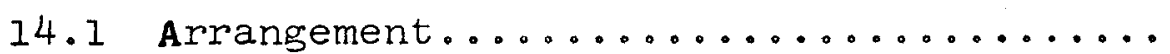

14.2 Experimental Facilities.

14.3 Components.

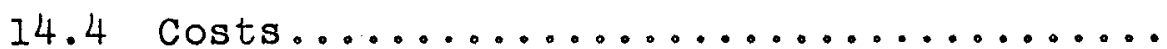

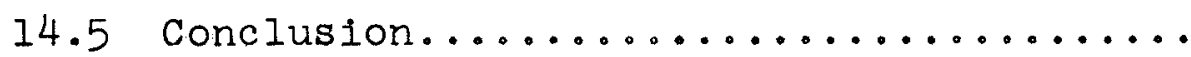

Page No.

75

75

78

79

81

81

81

89

89

89

90

90

91 
TABLE OF CONTENTS - PART B

Title

Page No.

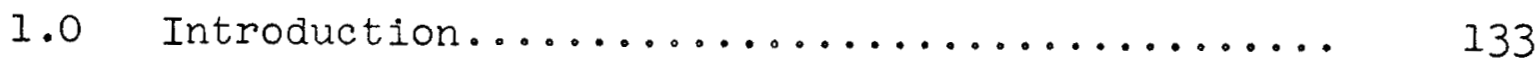

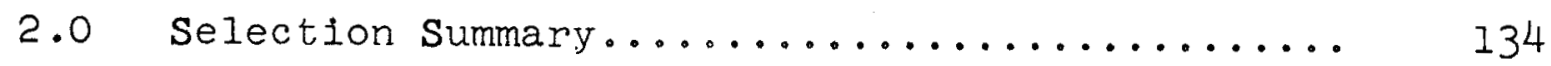

2.1 General Characteristics.............. 134

2.1.I Core-Reflector Assembly......... 134

2.1.2 System Pressure............. 135

2.1.3 Core Coolant Flow............ 135

2.2 Fuel Assembly.................. 136

2.3 Reactor Control................. 136

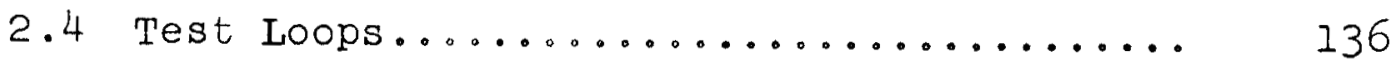

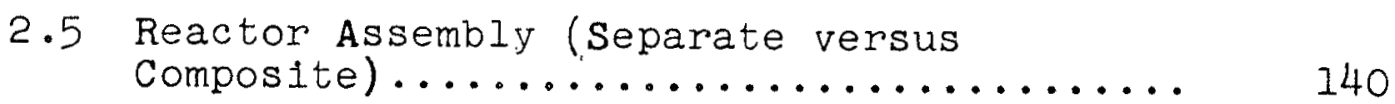

2.6 Reactor Shield.................. 140

2.7 Primary Coolant Loop............... 140

2.8 Secondary Coolant Loop............... 140

2.9 Controls and Instrumentation.......... 145

2.10 General Arrangement................ 145

3.0 Nuclear Characteristics................ 147

3.1 General Considerations.............. 147

3.1.1 Basic Geometry and Reactor 148

Calculations.................. 148

3.1 .2 Core Height................ 148

3.1.3 Core Thickness................. 149

3.1.4 Core Metal-water Ratio and Coolant. 150

3.1.5 Moderator Annulus Thickness, Test

Hole Size, and Test Hole

Composition.................... 
TABLE OF CONTENTS - PART B (continued)

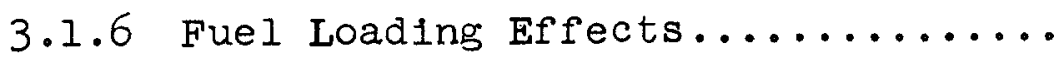

153

3.1.7 Reflector Thickness and Criticality

153

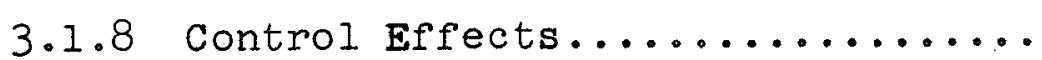

154

3.2 Single Loop Reactor................. 155

3.2.I Through-Type Loops............. 155

3.2.2 Thimble-Type Loops............ 157

3.3 Composite Reactor.................. 157

3.4 General Summary..................... 159

4.0 Reactor Core Heat Transfer............... 166

4.1 Non-Boiling Forced Convection.......... 166

4.2 Forced Convection Nucleate Bolling....... 168

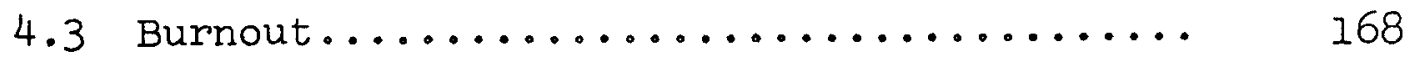

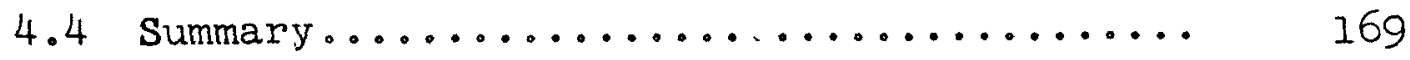

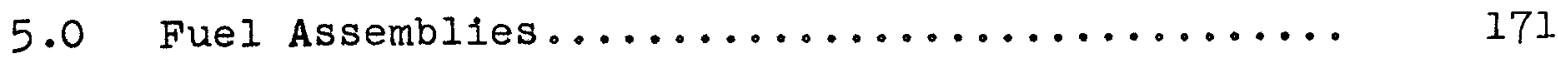

5.1 Fuel Assembly Geometry.............. 171

5.2 Materials and Costs.................. 175

5.3 Construction................... 176

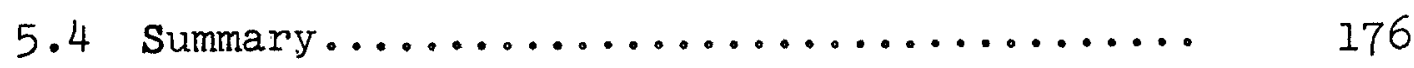

6.0 Reactor Control Schemes................ 177

6.1 Safety Control................... 177

6.1.1 Mechanical Shim-Safety Rods....... 177

6.1.2 Reflector-Level Safety Control..... 179 


\section{TABLE OF CONTENTS - PART B (continued)}

6.2 Shim Control....................

6.2.1 Mechanical Shim-Safety Rods........ 180

6.2 .2 Reflector-Level Shim........... 180

6.2.3 Reflector-Chemical Shim......... 181

6.3 Regulation....................... 183

6.4 Cost Comparison................... 183

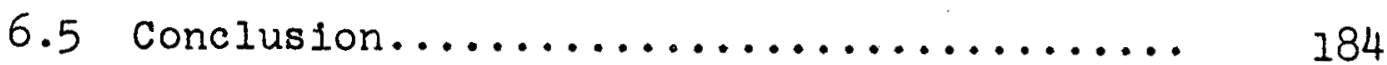

7.0 Stresses in Reactor Core Vessel and Loop Tubes. 186

7.1 Material Selection................. 186

7.2 Reactor Core Vessel................. 187

7.3 Loop Tubes....................... 187

7.3 .1 Loop Tube Cooling.............. 188

7.3.2 Liquid Metal and Gas-Cooled

Loop Tubes.................... 191

$7 \cdot 3.3$ Pressurized Water-Cooled

Loop Tubes.................... 192

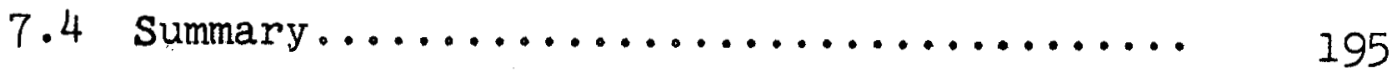

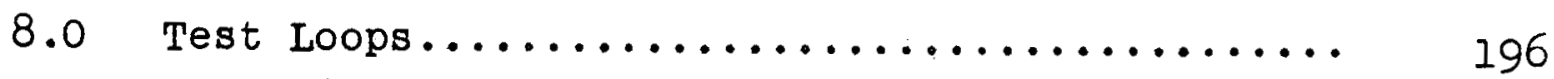

8.1 Reactor Power....................... 196

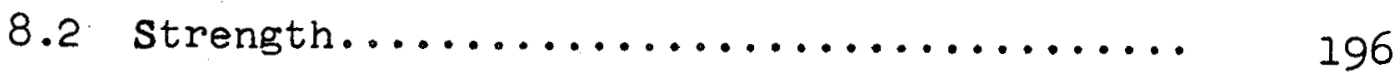

8.3 Experiment Handling................. 197

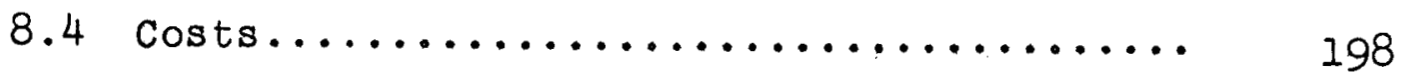

8.5 Conclusions....................... 198 
Page No.

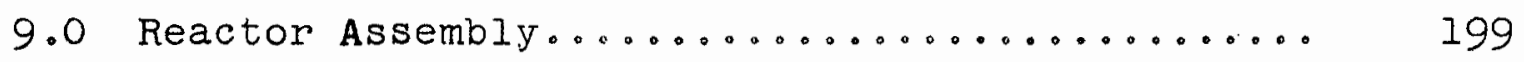

9.1 Reactor Power................... 199

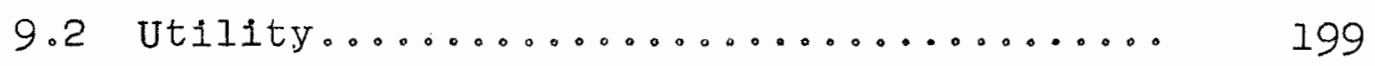

9.3 operating staff................ 200

9.4 Costs.......................... 200

9.5 Conclusions.................... 200

10.0 Cooling Systems...................... 202

10.1 Primary Cooling System.............. 202

10.2 Secondary Cooling System............. 205

10.3 Selection of Cooling Tower Conditions.... 207

11.0 Reactor Controls and Instrumentation......... 209

11.1 Individual Controls............... 209

11.2 Common Control Rooms............... 210

11.3 Combined Control Room............... 210

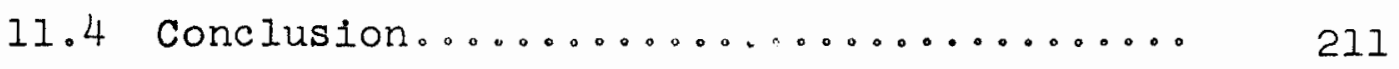

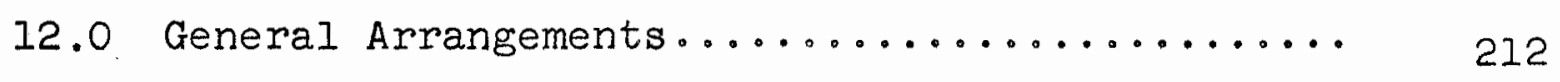

12.1 Descriptions...................... 212

12.1.1. Composite Reactor Facility ..... 212

12.1.2 Common Shield Reactor Facility... 213

12.1.3 Single Shield Reactor Facility... 213

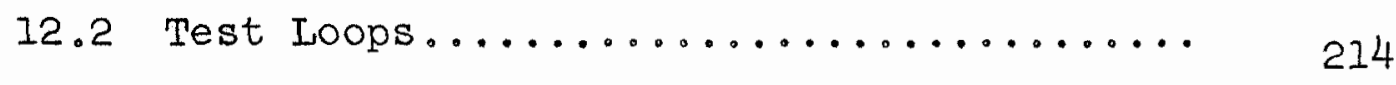

12.3 Reactor Control schemes ............ 214

12.4 Design and Construction ............ 214

12.5 Conclusion.................... 215 
Al.0 Test Facility Requirements.............. 269

A2.0 Nuclear Calculations.................. 270

A2.I Nuclear Theory Associations......... 270

A2.1.1 One-Dimensional, Three-Group,

Multiregion Methods.......... 270

A2.1.2 Two-Dimensional, Three-Group,

Multiregion Methods.......... 272

A2.1.3 One-Dimensional, One-Group,

$P(3)$ Spherical Harmonics

Solution to the Boltzmann

Equation.................. 273

A2.1.4 Normalization and Application of Non-Eigenvalue Problem

Solutions................. 275

A2.2 Nuclear Constants............... 276

A2.2.1 Atomic Densities and Temperature Correction Factors.......... 277

A2.2.2 Absorption and Fission Cross Sections.................. 278

A2.2.3 Absorption by Core Poisons..... 281

A2.2.4 Diffusion Coefficients........ 284

A2.2.5 Ages and Slowing Down Cross Sections.................. 285

A2.2.6 Treatment of Void Regions...... 287

A2.2.7 Critical Experiment Calculations 292

A3.0 Reactor Heat Transfer and Fluid Flow

Calculations......................... 295 
A4.0 Fuel Assembly Plate Curvature Calculations.... 299

A4.1 Derivation of Equation.............. 299

A4.2 Numerica] Evaluation............. 300

A4.3 Accuracy....................... 301

A5.0 Reflector Drop Time Calculation............ 302

A6.0 Heat Generation and Shielding Calculation..... 304

A6.1 Gamma Heating.................. 304

A6.2 Neutron Heating................ 307

A6.3 Total Heating in Reactor Components..... 309

A6.4 Shielding..................... 309

A7.0 Equations for Stress Calculations.......... 311

A7.1 Thermal Stress Calculations.......... 311

A7.I.I Uniform Internal Heating....... 311

A7.1.2 Stresses Due to Heat

Transmitted................ 313

A7.1.3 Variable Internal Heating...... 314

A7.2 Stresses Due to Pressure............ 314

A7.3 Combined Stresses................. 314

A8.0 Fuel Loading in Cores with Plate-Type Fuel

Assemblies............................ 316 
PART A

A CONCEPT FOR AN

ADVANCED ENGINEERING TEST REACTOR 


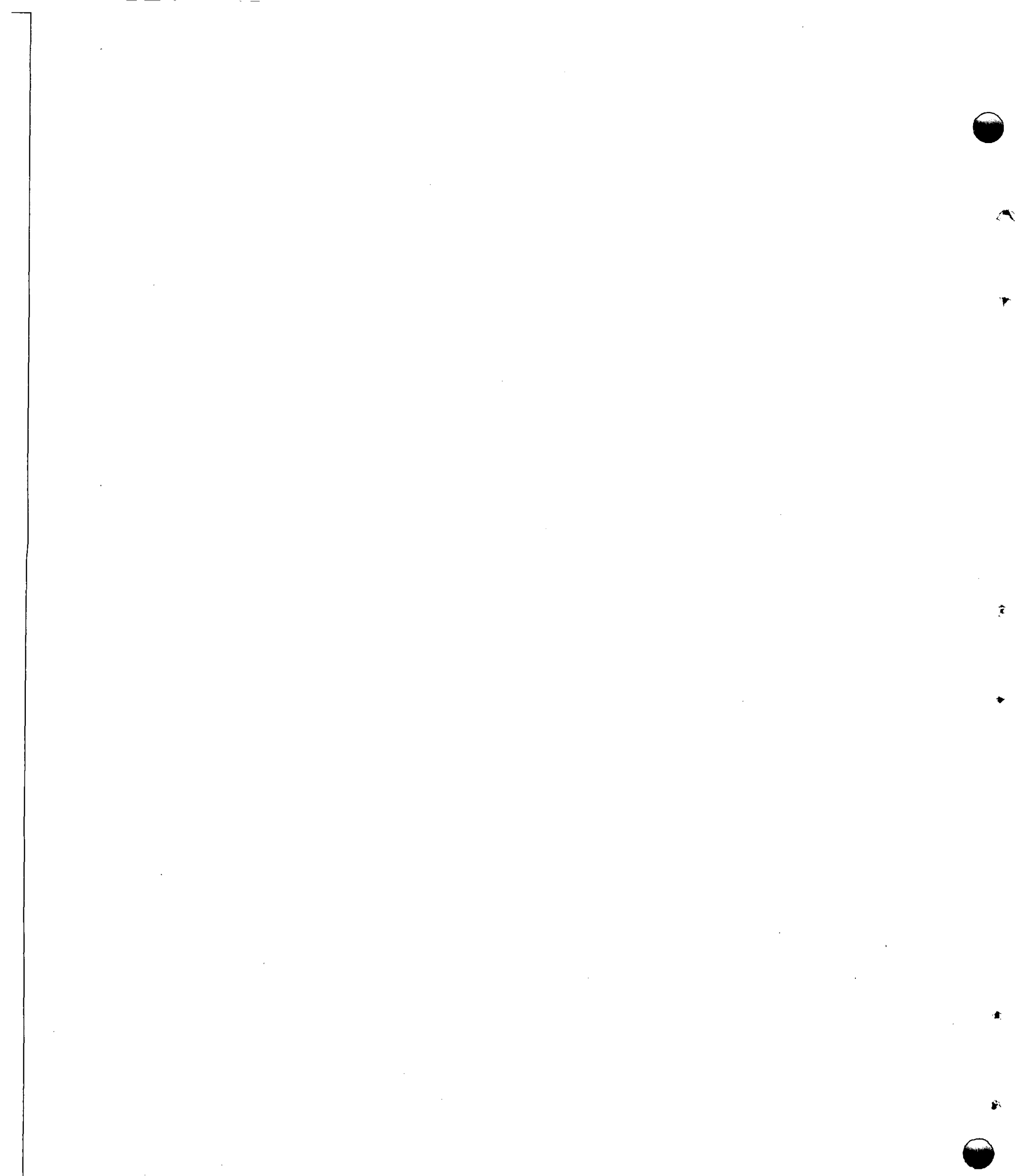




\subsection{INTRODUCTION}

The Advanced Engineering Test Reactor (AETR) is designed primarily for the engineering test of prototype fuel assemblies at average thermal neutron fluxes of $1.5 \times 1015 \mathrm{n} / \mathrm{cm}^{2}-\mathrm{sec}$ and higher.

The concept described is the result of further work on a concept originally proposed by Internuclear Company. *,** The present concept is basically similar to that developed in the previous work. However, there are some significant differences that have evolved as a result of the recent work. Many of these represent major improvements in the overall concept. Undoubtedly the major improvement is the fuel assembly, which has involutecurved fuel plates with non-uniform fuel loading. The involute curvature is such that the core annulus is completely and uniformly filled with fuel plates of one size. The non-uniform loading of the fuel plates gives an esstentially flat radial power distribution. Another improvement is the lowering of the head of the reactor vessel from above canal level to about 11 feet below the canal water level. This improves the utility of the reactor with regard to fuel and experiment changes. A major improvement is the overall untility of the facility has been accomplished by an arrangement in which each reactor is a separate unit, and all controls for the reactor, experimental loop, primary cooling, and other process systems associated with each reactor are grouped in a single control room. This arrangement provides efficient use of operating personnel.

In addition to the above, although certainly not in the nature of an improvement, the reactor power level necessary to meet the test hole neutron flux specifications has increased substantially. Whereas INTERNUC-9 quoted a power of $570 \mathrm{Mw}$ for the seven reactors, the design power of the present concept is $980 \mathrm{Mw}$. Part of this is due to the increase in the flux requirements in some holes from $1015 \mathrm{n} / \mathrm{cm}^{2}-\mathrm{sec}$ to $1.5 \times 1015 \mathrm{n} / \mathrm{cm}^{2}-\mathrm{sec}$, and also due to the fact that the $980 \mathrm{Mw}$ of the present concept produces higher fiuxes than specified in the two water-cooled loops. However, if the results of both INTERNUC-9 and this report are compared on the basis of meeting the test hole fluxes specified in Appendix 1.0, the reactor powers are $700 \mathrm{Mw}$ and $920 \mathrm{Mw}$, respectively. The 30\% increase in power is due primarily to the following changes in calculational methods. Nuclear constants obtained by more detailed considerations in this report differ somewhat from those of INTERNUC-9, particularly for light water. A check calculation comparing the two sets of constants indicates a power increase of about $20 \%$ due to the change in the nuclear constants. The nuclear constants used for this study have been checked against

* Elgert, $0 . J$. , Leyse, $C_{\circ} F_{\circ}$, Ott, D.G., "Preliminary Investigations for an Advanced Engineering Test Reactor," INTERNUC-9 February 22, 1957.

* Leyse, C.F。, Leonard, D.H., INTERnuC-9 Addendum, April 16, 1957 
a flux-trap critical experiment ( $\mathrm{H}_{2} \mathrm{O}-$ reflected) and found to give a multiplication factor $1 \%$ to $2 \%$ higher than the measured value. Thus the design power levels of the present concept are believed to be slightly higher than those needed to meet neutron flux specifications, but are also more realistic than the INTERNUC-9 estimates. In INTERNUC-9 the reactors with gas-cooled and liquid-metal-cooled test loops are based on an empty test hole while in this report they are based on sodium in the the test hole. Because of difficulties in estimating the effects of large voids in a reactor, the present results, which give about a 10\% higher reactor power, are considered more accurate

The AETR concept represents a system which has been optimized for minimum overall operating cost.

This results in reactors with through-type rather than thimble-type test loop facilities, since the latter require about $15 \%$ greater reactor power to meet test hole neutron flux specificiations. This factor alone represents an increase of about $\$ 1,500,000$ in the yearly operating costs. Approximately 85\% of the increase is due to increases in the cost of providing reactor fuel. However, the use of through - tube rather than thimble-type test loops results in a facility which, although only by a small amount, is not of minimum construction cost.

It is estimated that the AETR, consisting of seven separate reactors, can be built in three years at a cost of about $\$ 32,000,000$. Approximately $\$ 450,000$ of development is necessary before the final core and control system design specifications can be set. The estimated annual operating cost is $\$ 14,122,000$, of which $\$ 8,450,000$ is for U235 burnup and fuel.

In the interest of economy, or to let development follow a more normal course, an alternate to the above may be attractive. This alternate, which involves construction of only a single reactor, is described in chapter 14.0. The estimated cost of a single $100 \mathrm{Mw}$ reactor, with a thimble-type loop facility rather than a through-tube as in the above, is slightly over $\$ 3,000,000$. This type installation can be in operation two years after beginning design. 


\subsection{GENERAL DESCRIPTION}

The Advanced Engineering Test Reactor is designed to test relatively large components, principally fuel assemblies, in very high thermal neutron fluxes. The facility specifications require average unperturbed thermal neutron fluxes of $1.5 \times 10^{15}$ $\mathrm{n} / \mathrm{cm}^{2}-\mathrm{sec}$ in seven test loops suitable for 30-inch long test sections of 3 to 7 inches diameter. The test loops are cooled by liquid metal or gas at temperatures up to $2000^{\circ} \mathrm{F}$ and pressure up to $300 \mathrm{psi}$, or by water at temperatures up to $650^{\circ} \mathrm{F}$ and pressures up to $2000 \mathrm{psia.}$ (See Appendix 1.0)

The above requirements are met by a facility (Figure 8.E) consisting of seven separate reactor systems, one for each major test loop (Figure 3.A). The total design power level of the seven reactor systems is 980 Mw. This is composed of $170 \mathrm{MW}$ each for four Type-A reactors with 7 -inch diameter test holes for gas or liquid metal-cooled test assemblies and $100 \mathrm{Mw}$ each for three Type-B reactors with 4-inch diameter test holes for water, gas, or liquid metal-cooled tests. Each reactor has its own primary coolant system and is entirely independent of the operation of the others.

Each reactor is a cylindrical "flux-trap" with a light water island, a light water cooled aluminum plate-type core, and a $\mathrm{D}_{2} \mathrm{O}$ reflector (Figures 3.A, 3.B, 3.C). The core annulus surrounds the light water island in the center of which is the experimental loop through-tube. With the given specifications for experiment length, the dimensions of the various regions in the reactor have been optimized to give the specified test section flux with minimum reactor power.

Each reactor is integrated with its test 10op, 10op equipment, cooling system, storage canal, controls, and associated building into a single unit, (Figures 8.B, 8.C, 8.D) which is self-sufficient except for utilities, cooling tower, and waste disposal. These units which are incorporated in a single large building (Figure $8 . E$ ) are separate from each other in operation, vapor containment, and in shielding, but are functionally related to allow maintenance and inspection of all electrical equipment and coolant pumps from one area.

The facility is planned for, and assumed to be located adjacent to the north side of the present MTR-ETR side at the National Reactor Testing Station in Idaho. The planning for utilities, cooling towers, and climatic conditions is based on this location. 


\section{I Reactor Units}

In designing this reactor, considerable thought was given to the types of fuel assembly experiments for which the reactor might be used. Obviously a high unperturbed thermal flux is of little use unless a substantial portion of it can be maintained in a useful experiment. The factors which lower the test section flux are principally high thermal neutron absorption and poor neutron moderation, or a combination of the two. Therefore, although some reactor units are primarily for water-cooled tests, all units have been designed on the basis of meeting the $1.5 \times 1015 \mathrm{n} / \mathrm{cm}^{2}-\mathrm{sec}$ (unperturbed) neutron flux specification in sodium-filled test holes. Since sodium is a poor moderator and absorbs substantial quantities of neutrons the perturbed thermal neutron fluxes in test fuel assemblies will generally be very close to the unperturbed flux in the sodium-filled test holes. In section 6.8.2; the average thermal neutron flux in a typical gas-cooled fuel assembly test is shown to be about $10 \%$ higher than the unperturbed flux in a sodium-filled test hole. In water-cooled fuel assembly tests the average thermal neutron flux can generally be expected to exceed $1.5 \times 1015 \mathrm{n} / \mathrm{cm}^{2}-\mathrm{sec}$. Therefore, the sizing of all reactors on the basis of sodium in the test holes assures that the perturbed fluxes with fuel-bearing test assemblies will generally be near or greater than the design value of $1.5 \times 10^{15} \mathrm{n} / \mathrm{cm}^{2}-\mathrm{sec}$.

Typical neutron flux distributions in the AETR reactors are shown by Figures $6.9,6 . H$, and $6 . I$. The design thermal neutron flux of $1.5 \times 1015 \mathrm{n} / \mathrm{cm}^{2}-\mathrm{sec}$ in the test holes is higher by a factor of four to seven than that in the reactor core. In the reflector the thermal neutron flux peak is $1.4 \times 1015 \mathrm{n} / \mathrm{cm}^{2}-\mathrm{sec}$ in the Type-A ( $170 \mathrm{Mw})$ reactors and about $1.1 \times 1015 \mathrm{n} / \mathrm{cm}^{2}-\mathrm{sec}$ in the Type-B $(100 \mathrm{MW}$ ) reactors.

For a given power the test hole flux increases as the annular core is made thinner, at least in the range of suitable core thicknesses. Since reducing the core thickness raises the power density needed for an arbitrary flux level, heat transfer establishes the minimum practical core thickness and therefore a high core power density is desirable. The AETR core is designed to give maximum test hole flux for a given maximum power density. The special involute plate fuel assemblies (Figures 3.C, 3.D, 3.F) completely and uniformly fill the core annulus. The radial power distribution is flattened by preferentially loading the fuel plates (Figure 5.C)。

A novel feature of the AETR design is the general dependence on the reflector for all safety and shim control. By this means, the control device does not perturb the experimental test hole flux. The heavy water reflector is split into two annuli. The inner annulus forms the safety reflector which can be dropped 
rapidly to scram the reactor. The outer annulus forms the shim reflector which is used for shim control by varying the boron (poison) content of the heavy water.

The reactors are designed for a maximum power density of 2.9 Mw/liter and an average power density of $2.11 \mathrm{Mw} / 1$ iter. The light water primary coolant flows through the core with a velocity of $40 \mathrm{ft} / \mathrm{sec}$, maintaining the maximum surface temperature of the fuel plates below $400^{\circ} \mathrm{F}$.

While the AETR is designed primarily for the testing of prototype fuel assemblies, provisions for the irradiation of capsules and other small experiments are included. These consist of six 0.75 -inch holes in the moderator annulus and eight 1.5 -inch holes in the reflector of each reactor. The maximum thermal neutron flux in the test holes in the moderator annulus is $2 \times 1015 \mathrm{n} / \mathrm{cm}^{2}-\mathrm{sec}$ or greater, while that in the reflector test holes is $1.1 \times 1015 \mathrm{n} / \mathrm{cm}^{2}-\mathrm{sec}$ or greater.

\subsection{Reactor Facility}

The land required for an AETR facility is about 1,000,000 sq ft. This is slightly more than the area of the ETR plant site since the AETR has a larger reactor building and considerably more cooling towers (see Figure 8.A).

Tentatively the AETR is located directly north of and adjacent to the MTR-ETR site. There is space for expansion in this direction, which is generally crosswind from the other testing reactors. A second advantage for this location is that the AETR can employ the wells and water treating plant of the MTR (with some expansion).Also, with some modification the same electrical supply, both normal and alternate, can probably serve all the reactors. However, additional roads and paving are necessary to serve the AETR area and buildings.

The general arrangement of the reactors, associated equipment, and buildings on a unit basis serves three prime purposes. First, the reactor and experimental loop rooms of each reactor are isolated from the others so that contamination from accidents in one does not spread and force shut-down of all reactors. Second, the arrangement is attractive for construction purposes, since it permits completion of one unit at a time without causing complications in the construction or operation of others. Third, the arrangement is attractive from an operational standpoint since it isolates the major operational functions associated with each reactor, thereby minimizing the possibilities of confusing the various reactors and loops. With regard to the latter, all the controls for the reactor, experimental loops, reactor cooling systems, etc., for each reactor are located in one room. This minimizes the number of personnel necessary to operate the facility. 


\subsection{Reactor Data Summary}

\subsubsection{Overall Performance}

Test Hole Coolant

Number of reactors

Power

Annulär core,

Test Assembly (for design)

Neutron Flux, $1015 \mathrm{n} / \mathrm{cm}^{2}$-sec

Average in loop test hole

Thermal

Intermediate

Fast

Peak thermal in $\mathrm{H}_{2} \mathrm{O}$ moderator annulus

Average in core

Thermal

Intermediate

Fast

Peak thermal in reflector

$\frac{\text { Type-A }}{\frac{\text { Sodium }}{4}} \frac{\text { Type-B }}{1} \frac{\text { Sodium }}{2} \frac{\mathrm{H}_{2} \mathrm{O}}{2}$

Mw

170

$100 \quad 100$

Mw

48

$15 \quad 15$

$\begin{array}{lll}1.5 & 1.5 & 2.1 \\ 0.75 & 0.65 & 0.53 \\ 1.6 & 1.4 & 1.05 \\ 2.3 & 2.0 & 2.2 \\ & & \\ 0.36 & 0.31 & 0.31 \\ 0.85 & 0.66 & 0.66 \\ 2.52 & 1.96 & 1.96 \\ 1.4 & 1.1 & 1.1\end{array}$

\section{Fuel Mass}

Cold, clean,critical reactor

$\begin{array}{llll}\mathrm{kg} \mathrm{U}^{235} \quad 5.1 \quad 4.0 & 4.3\end{array}$

Initial new core loading

$\begin{array}{lll}\mathrm{kg} \mathrm{U} U^{235} & 11.3 \quad 9.0 \quad 9.0\end{array}$

Hot, poisoned, depleted critical

kg U235

$7 \cdot 3$

5.9

6.1 reactor

Burnup

\% 35

$35 \quad 30$

Core life, days at full power

$19 \quad 26 \quad 30$


Reactor

Test Assembly Coolant

Excess multiplication (k) requirements:

Burnup Compensation

Equilibrium xenon and samarium

Other fission products

Temperature defect

Total control required

Prompt neutron lifetime, hot depleted core

\subsubsection{Reactor Data}

Core

Height

Outside diameter

Active core thickness

Volume

Full power

Power density, $\underset{\max }{\operatorname{avg}}$

Metal-to-water ratio

Coolant

Loop Test Hole

Inside diameter

Test volume
Type-A

Sodium
Type-B

Sodium
$\mathrm{H}_{2} \mathrm{O}$
0.038
0.0348
0.033
\% $\quad-0.003$
$-0.003$
$-0.003$
क 0.16
0.16
0.14

$\%$

sec $\quad 3.2 \times 10^{-4}$

0.077

0.066

$0.048 \quad 0.044$

Type-A

in

in

in

$\mathrm{ft}^{3}$

liters

MW

Mw/liter

Mw/liter
36

18.16

2.70

2.72

76.9

170

2.1

2.9

0.685

$\mathrm{H}_{2} \mathrm{O}$

7.0

0.80

22.7
Type-B

36

14.16

2.07

1.66

45.2

100

2.1

2.9

0.685

$\mathrm{H}_{2} \mathrm{O}$

in

$\mathrm{ft}^{2}$

liters
4.0

0.26

7.4 
Reactor Data (Continued)

Type-A Type-B

Fuel Assembly

Type

Involute plate

Coolant gap

in

0.073

0.073

Plate thickness

in

0.050

0.050

Fuel plates per assembly

18

14

Assemblies per core

20

18

$\mathrm{U}^{235}$ per assembly

gm

565

500

Fuel alloy, uranium

(highly enriched)

wt $\% 30$

40

Fuel alloy, aluminum

wt $\%$

70

60

Aluminum clad thickness, min. in

0.013

0.013

Reflector

Material

$\mathrm{D}_{2} \mathrm{O}$

Thickness

in

24

Height

in

60

Control

Safety reflector

Thickness

Total reactivity worth

3\% $\Delta \mathrm{k} / \mathrm{k}$ removed

30\% $\Delta \mathrm{k} / \mathrm{k}$ removed

Shim reflector

Thickness

Reactivity worth $\mathrm{cm}$

\% $\Delta \mathrm{k} / \mathrm{k}$

sec

$\mathrm{sec}$

$\mathrm{cm}$

क $\Delta k / k$
20

43

0.09

0.26 


\subsubsection{Reactor Cooling System}

Total reactor power level

Mw

980

Primary and secondary coolant

water

Core Cooling

Type-A

Type-B

Pressure at core inlet

psia

300

300

Pressure drop in core

psia

79

79

Temperature at core outlet

${ }^{\circ} \mathrm{F}$

130

130

Temperature at core outlet

${ }^{\circ} \mathrm{F}$

252

252

Saturation temperature at

${ }^{\circ} \mathrm{F}$

390

390

Maximum fuel plate temperature ${ }^{\circ} \mathrm{F}$

380

380

Heat transfer area

$f t^{2}$

554

328

Flow area

$f t^{2}$

0.562

0.331

Coolant velocity

$\mathrm{ft} / \mathrm{sec}$

40

40

Heat flux, average

Btu/ften $h r$

$1.05 \times 10^{6}$

$1.05 \times 106$

Heat flux, maximum

Btu/f $r^{2}-h r$

$1.44 \times 10^{6}$

$1.44 \times 10^{6}$

Average power density

Mw/liter

2.11

2.11

Maximum power density

Mw/liter

2.90

2.90

Burnout power density

Mw/Iiter

10.6

10.6

Primary Cooling System

(One system serves each reactor)

Flow rate

Heat exchanger in parallel

Heat exchanger area

Primary coolant pumps per reactor

Head

Motor power gpm

10,725

3

$f t^{2}$

31,200

3

ft $\mathrm{H}_{2} \mathrm{O} \quad 180$

200

hp
6,300

2

20,800

2

180

175 
Reactor Cooling System(Continued)

Secondary Cooling System

(Common system serves all reactors)

Design heat load

Mw

1080

Flow rate

gpm

95,000

Cooling tower on temperature

${ }^{\circ} \mathrm{F}$

160

cooling tower off temperature

${ }^{\circ} \mathrm{F}$

90

Design wet bulb temperature

${ }^{\circ} \mathrm{F}$

65

Cooling towers, total number

16

Secondary coolant pumps

Head
Motor power

ft $\mathrm{H}_{2} \mathrm{O}$

90

hp

200

2.3.4 Shielding

Source Power (Type-A only)

Annular reactor core

Test assembly

Mw

170

MW

47

Source Flux

$\mathrm{Mev} / \mathrm{sec}$

$9.16 \times 10^{19}$

Radial Shield

$\mathrm{D}_{2} \mathrm{O}$

Thermal shield and structure (steel)

Barytes concrete

Dose rate at outer surface

Vertical Shield

$\mathrm{H}_{2} \mathrm{O}\left(130^{\circ} \mathrm{F}\right)$

ft

ft

$\mathrm{mr} / \mathrm{hr}$

Dose rate at water surface
24

10.25

60

0.1
21.5

0.5

1.3 


\subsection{REACTOR DESCRIPTION}

The seven reactor units of the AETR are of two sizes: Type-A unit with a 7-inch I.D. test hole, and Type-B unit with a 4-inch I.D. test hole. While the test hole sizes and core sizes of the Type-A and Type-B reactor units are different, the mechanical arrangement of the two are similar. Figure 3.A shows an elevation of the reactor, and Figure $3 . B$ shows a cross section at the reactor midplane. Figures 3.C and 3.D show core cross sections for the Type-A and Type-B reactors, respectively. Comparison of the latter two figures shows that the core of the Type-B reactor is both thinner and of smaller diameter than that of the Type-A reactor. Both types have a 24-inch thick $\mathrm{D}_{2} \mathrm{O}$ reflector. Except for the differences outlined above the mechanical arrangement and sizes of components of Type-A and Type-B reactor units are identical.

As shown by Figure 3.A, the top of the reactor vessel is at the bottom of a 13-foot deep reactor shield pool. This arrangement, with the experimental loop tube terminating just below the reactor vessel head, is particularly desirable in the testing of water cooled test assemblies, since it permits the removal and transfer of the test assembly directly to the canal without use of a coffin. A bulkhead can be inserted between the reactor pool and the canal so that the reactor pool can be drained. This is necessary for the removal of liquid-metalcooled or gas-cooled fuel assemblies.

The reactor vessel consists of two parts: a permanent outer shell constructed of stainless steel and containing the thermal shields, and a removable inner shell constructed of aluminum alloy and integral with the reflector tanks. The arrangement permits complete removal of all reactor components within the outer reactor vessel.

\subsection{Through-Tube}

The through-tube is the portion of the experimental test loop that is contained within the reactor vessel. It holds the test fuel assembly in position and contains the test loop coolant. Therefore the temperatures and pressures are a maximum in the through-tube. In addition, the neutron and gamma fluxes approach their highest values éther in or near the through-tube. Each through-tube consists of one or more inner liners of stainless steel, and an outer aluminum tube. The through-tube is constmucted so that the aluminum tubes serve as the pressure-tube, there being only negligible pressure difference across the stainless steel liner(s). The discussions below are primarily with regard to the aluminum pressure tube, since the stainless liners do not present any significant design problems. 
3.1.1 Operating Conditions

There are three factors which limit the through-tube wall thickness. The specified 300 or 2000-psi maximum internal pressure leads to one lower limit. For a depressurized test loop, the 300 psi primary coolant pressure can cause the throughtube to buckle. This is the more severe lower limit for the wall thickness in the gas and liquid metal-cooled loops. The upper limit of thickness is set in each instance by a combination of the cooling scheme and thermal stress since all the throughtubes have similar internal heat generation rates.

The high temperature liquid metal and gas-cooled loop tubes are insulated internally with 0.3 -inch void space or diatomaceous silica around the high temperature $\left(2000^{\circ} \mathrm{F}\right)$ liner which is assumed to be 0.062 -inch stainless steel with a 4-inch or 7 -inch inside diameter. The outside of the through-tube is therefore cooled by a high velocity stream of primary reactor coolant initally at $130^{\circ} \mathrm{F}$. This coolant bypasses the core and flows through an 0.080 -inch annulus around the through-tube. This cooling scheme is shown. by Figure 7.B of Part B.

The water-cooled through-tubes are cooled on the outside as described above, and on the inside by a second stream of water from a bypass off the pressurized-water test 100p. This cooling scheme is shown by Figure 7.C of Part B.

3.1.2 Fabrication

Since thermal stresses are important in the through-tube design and proportional to temperature gradients across the tube wall, an obvious material for the through-tube is an aluminum alloy with relatively high strength and thermal conductivity. Worth noting is the fact that aluminum has smaller gamma energy absorption than all denser structural materials. This decreases the internal heat generated and lowers the possible thermal stresses.

Reviewing the above, as discussed further in Section 7.1 of Part $B$, both Internuclear and the technical staff of a large fabricator picked 2014 aluminum alloy with a T-6 temper as the preferred material. This alloy has very high strength, superior high-temperature properties compared to other aluminum alloys, and a good record of commercial acceptance for heavy-duty truck and aircraft structures.

Although this material has not received formal acceptance for conventional pressure vessels under the ASME Pressure Vessel Code, it has long been accepted under the same code for forgings.

It is planned to manufacture the through-tube from an aluminum extrusion. This is more economical than forging, and gives a one-piece tube of equal strength. For this reason it is believed that if necessary the through-tube can recieve ASME approval even though extruded vessels are not covered by the 
code. The through-tube is conventionally machined to size with a support shoulder near one end. The Inner surface is polished to reduce radiant heat transfer from high-temperature tests. A threaded joint connects the through-tube to the test loop at the bottom of the reactor. A slip-on flange machined to fit and welded to the through-tube provides for connection to the loop above the reactor.

\section{1 .3 Stresses}

The stresses in the water-cooled loop tube are based on the assumption that the cooling streams maintain both surfaces of the aluminum tube at the same temperature. For the 90 watts/cc internal heating (Appendix 6.0) and 2000 psi in the test 100p, the expected stresses are as follows:

\section{Table $3 . a$}

Stresses in Pressurized Water Loop Tube

Stress, psi

\begin{tabular}{lccc} 
Stress & $\begin{array}{c}\text { Inside } \\
\left(4.75^{\prime \prime} \text { ID }\right)\end{array}$ & $\begin{array}{c}\text { Outside } \\
\left(5.75^{\prime \prime} \text { OD }\right)\end{array}$ \\
\cline { 3 - 3 } Pressure & 10,595 & 8,595 \\
Thermal & 3,060 & 2,780 \\
Combined & 13,655 & 11,375
\end{tabular}

These calculations are conservative in that zero pressure is assumed for the primary coolant which is normally at 300 psi. This introduces a factor by which the pressure stress is reduced if the $300 \mathrm{psi}$ pressure primary loop pressure is maintained all the time the loop tube is pressurized. This is a reasonable assumption since the reactor cannot operate at power without primary loop pressure. A second conservative factor is that the 90 watts/cc is assumed uniform across the entire pressure wall and is slightly higher than the average of the heating results reported in the Appendix 6.0. Balanced against the above is the fact that cooling may vary so that, for example, both walls of the through-tube may be at different temperature, thereby setting up extra thermal stresses.

With stresses as given in Table 3.a the through-tube meets all the strength requirements of the ASME Unfired Pressure Vessel Code. For example, the maximum combined stress is slightly below 14,000 psi which is the maximum allowable under the code for a temperature of $250^{\circ} \mathrm{F}$. Cooling is expected to maintain the aluminum at $230^{\circ} \mathrm{F}$ or less, as reported in section 7.3 , Part B. 
While the code is a guide, it does not guarantee safety. The ultimate strength of 2014-T6 alloy is 57,800 psi. Based on this there is a factor of safety of 4.2 in the stress in the tube. This is sufficient assuming care in manufacture. These values have been discussed with the technical staff of one fabricator who expressed a willingness to guarantee the throughtube for this service.

The through-tubes for gas-cooled or liquid metal-cooled loops are cooled from the outside surface only. With external cooling only, the thermal stresses are about double for the same tube wall thickness. Also flow of heat across the insulating void increases the temperature gradient in the 10op tube wall and adds to the thermal stresses. Fortunately however the loop pressure is only $300 \mathrm{psi}$. Assuming 90. watts/cc, no external pressure, and 10,700 Btu/hr-ft2 transferred from the loop coolant to the through-tube the stresses in the high-temperature 1oop tube are as follows:

Table $3 \cdot b$

Stresses in 7-inch High-Temperature Through-Tube

\begin{tabular}{|c|c|c|}
\hline \multirow[b]{2}{*}{ Stress } & \multicolumn{2}{|c|}{ Stress, psi } \\
\hline & $\left(7^{\text {Inside }}=\right.$ & $\begin{array}{r}\text { Outside } \\
\left(8.5^{\prime \prime} \text { OD) }\right.\end{array}$ \\
\hline $\begin{array}{l}\text { Pressure } \\
\text { Thermal }\end{array}$ & 3257 & 2957 \\
\hline $\begin{array}{l}\text { Internal generation } \\
\text { transferred from loop } \\
\text { Combined }\end{array}$ & $\begin{array}{r}-3300 \\
347 \\
-390\end{array}$ & $\begin{array}{r}6250 \\
325 \\
9532\end{array}$ \\
\hline
\end{tabular}

The design for a 4-inch gas or liquid metal-cooled throughtube is similar in every respect, but the stresses are less than for this 7 -inch tube. Numerical results for both tubes are reported more completely in Chapter 7.0 of Part B. In every instance the maximum stress is below the maximum allowable under the Pressure Vessel Code. None of the stresses given in Tables $3 . a$ and $3 . b$ increase the likelihood of the through-tube collapsing if it is depressurized and the primary coolant pressure remains at $300 \mathrm{psi}$. Therefore, the allowable external working pressures alone establish the ability of the tube to withstand 300 psi external pressures. These are stated below on the basis of an unsupported through-tube length of ten feet. 
Table 3.c

Allowable External Pressures for Through-Tubes

$\begin{array}{lc}\frac{\text { Through-Tube }}{\text { P-in gas or liquid metal-cooled }} & 387 \\ \text { 4-in gas or liquid metal-cooled } & 417 \\ \text { 4-in pressurized water-cooled } & 870\end{array}$

It is clear from comparing the stresses, that the aluminum through-tube (designed for 2000 psi water loop) for the small reactor (Type B) can also be used for liquid metal-cooled or gas-cooled loops. However, a through-tube designed for a liquid metal-cooled or gas-cooled loop for elther the Type-A or Type-B reactor cannot be safely used for 2000 psi pressurized water loops.

\subsection{Moderator Annulus}

The moderator within the core annulus is reactor core cooling water $\left(\mathrm{H}_{2} \mathrm{O}\right)$ which is maintained somewhat stagnant by core structure (Section 3.3.3) between the bottom of the fuel elements and the cooling shroud around the through-tube. Small holes in the plate beneath the moderator annulus permit a low flow rate through the annulus and thereby keep the moderator annulus temperature near $170^{\circ} \mathrm{F}$.

Within the moderator annulus the AETR thermal neutron flux reaches its maximum value of $2.3 \times 1015 \mathrm{n} / \mathrm{cm}^{2}-\mathrm{sec}$ in the Type-A reactor. Six 0.75-in ID aluminum tubes in the moderator annulus as shown in.Figure 3.E provide for irradiations of small capsules in this flux. Leakage of primary coolant water through the capsule tube provides capsule cooling.

\subsection{Reactor Core Assembly}

A large number of the mechanical components within the AETR pressure vessel (aside from fluids and plumbing) are portions of the reactor core assembly. The components can be summarized by describing their consecutive insertion starting with the complete reactor vessel.

Initially the core structure is lowered within the reactor vessel and bolted to four supporting pads at the bottom of the central reactor shell (See Figures $3 . A$ and $3 . E$ ). The throughtube support spider is bolted to the reactor vessel at the expansion joint below the top head. The through-tube is inserted into the support and threaded into the test loop at the bottom head of the reactor. Fuel assemblies are loaded into the core annulus. A circular annulus which is hinged and split for removal is placed above the fuel assemblies and clamped to hold the fuel assemblies down. 
3.3.1 Fuel Assembly

In order to minimize the power density in the AETR core, a fuel plate assembly is developed which completely and uniformly fills the core annulus. In order to flatten the radial power distribution a scheme is developed for preferential radial fuel loading wherein more fuel is added to the center of each fuel plate to flatten the radial power distribution and reduce power peaking at the core edges. The relative merits of this type fuel assembly are discussed thoroughly in Chapter 5.0 of Part $B$. The basis for the fuel plate thickness and spacing are discussed in Chapter 4.0 of Part B.

The fuel assembly, which uses involute carved plates, is shown by Figure 3.F. The plates are aluminum clad, with aluminum-uranium alloy meat. The meat thickness varies along the width of the plate as shown by Figure 5.C. This particular type of fuel loading gives an essentially flat radial power distribution in the reactor. The minimum cladding thickness is 13 mils if the uranium concentration in the meat is 30 wt $\%$ for the Type-A reactor and $40 \mathrm{wt}$ of for the Type-B reactor. The fuel assemblies have no end boxes but each of the side plates has a machined vee at the bottom which fits into a tapered seat in the core support structure. These recessed seats are located at 18-degree intervals around the core annulus. Normal core flow plus gravity holds the fuel assemblies in place against this bottom support. The fuel elements are clamped in place from the top.

This type fuel assembly has been discussed with several fabricators. The major problems in development of the fuel assembly are in the non-uniform fuel distribution. However, these are apparently not great since based on estimates by three manufacturers of fuel assemblies, the total development cost for the assembly is expected to be about $\$ 10,000$.

\subsubsection{Control Rods}

The reactor uses chemical control in the reflector for shim control and the inner portion of the reflector is dropped for safety or scram. It is possible that the reactor may operate satisfactorily without a regulating rod, but this will probably not be established until this type of reactor is built and operated with reflector control. Therefore two control rods are located in two of the eight capsule tubes in the $\mathrm{D}_{2} \mathrm{O}$. These are near the inside edge of the reflector where thermal neutron flux reaches a maximum.

The rods are driven from beneath using a rack and pinion drive and a motor outside the biological shield. Such control rods have been developed for the APPR and can be easily adapted to the AETR, where operating conditions are less severe. 
$\underline{3.3} .3$ Core Structure

The core structure is an annular aluminum tank, internally braced, which surrounds the moderator annulus (See Figure 3.D). Two concentric circular rings suitably notched to seat the fuel assembly side plates are attached to the bottom of the core structure. The structure is supported from the bottom by four webs which bolt to the four pads within the reactor pressure shell beneath the core.

There are perforations in the structure for the flow of coolant through the moderator annulus. Six 0.75 -inch ID tubes in the moderator annulus provide for capsule irradiation. Other cooling water bypasses the core to flow through the thin annulus between the core structure and the through-tube. Tapered slots at the top of the core strucutre assist in aligning fuel assemblies in the core annulus by engaging a pin in the top of each assembly.

3.4 Reactor VesseI

The top of the reactor vessel (Figure $3 . A$ ) is at the bottom of the reactor shield pool. By removing the head of the reactor vessel the entire core is accessible for maintenance.

The inner (aluminum) shell of the reactor decreases to 19.5 inches diameter around the core so that the reflector tank is outside the reactor vessel and can operate at atmospheric pressure. Also, design of a suitable reactor vessel may be difficult if the reflector is contained within the pressure vessel. In order to cool the thermal shields outside the reflector, the reactor vessel opens into an annular tank surrounding the thermal shields.

The inner portion of the reactor is a weldment composed of two semi-elliptic heads forged from 5454 aluminum alloy and welded to opposite ends of a cylindrical shell around the core. This central tube is a 2014 aluminum alloy extrusion which is heat treated and machined before welding. Loss of strength at the welds is compensated for in the design by using extra thickness at the joints. The reflector tank and associated piping is part of the same assembly. The entire aluminum assembly is lowered within the outer shell of the reactor vessel and bolted in place using flanges which are accessible from above. The upper flange is connected to the vessel through a flexible member to allow for thermal expansion.

The remainder of the vessel is stainless steel fabricated conventionally from 1 -in and 1.5 -in plates. There are four 12-in nozzles in the top of the vessel for incoming primary coolant, and four in the top of the annular tank surrounding the thermal shields for outgoing primary coolant. 


\section{4 .1 Stresses}

The operating stresses in the outer reactor vessel do not exceed $14,000 \mathrm{psi}$. This is moderate for stainless steel construction. In the aluminum end bells, the working stress is about 8100 psi. This gives a safety factor of four based on the yield strength at operating temperatures.

Most critical from a strength aspect is the cylindrical central portion of the inner reactor shell next to the reactor core. Here, the internal heat generation of 90 watts/cc can induce severe thermal stresses. Assuming this heating rate uniform and effective cooling only from the inner wall, the thermal stress in the 0.50 -in aluminum vessel wall is 8250 psi. The pressure stress at the inner wall is $5704 \mathrm{psi}$ and the maximum combined stress is $13,954 \mathrm{ps} 1$. This is less than the allowable stress and gives a factor of safety of 4.1 for the $2014-\mathrm{T} 6$ alloy.

\subsection{Reflector}

The reflector consists of two concentric annuli of $\mathrm{D}_{2} \mathrm{O}$ totaling 24-in thickness and contained in two aluminum tanks welded to the inner reactor vessel.

The inner reflector, i.e., the safety control, is designed to drop rapidly for emergency shutdown. The outer reflector, i.e., the shim control, compensates for fuel burnup and other gradual effects through gradual removal of dissolved boric acid poison. The equipment required for these reflectors is discussed in Sections 3.8 and 5.2 .

\subsection{Thermal Shield}

There are three stainless steel thermal shields, 2, 2.5, and 3 inches thick located at reactor height between the two $1.5-$ inch reactor vessel walls outside the reflector. With the thicknesses indicated and the calculated values of exponentially attenuated internal heating, the thermal stresses are all less than $1000 \mathrm{psi}$. These stresses coupled with the low concrete heating (section 3.7) indicate that some of the thermal shields may be eliminated to give a less expensive thermal shield.

\subsection{Biological Shield}

Outside the thermal shield and the reactor vessel, five feet of barytes concrete provides the full biological shield. Largely due to the above thermal shields and the thick D2O reflector, the values of internal heating within the concrete are very low. With a maximum calculated value of 0.0002 watts/ $c c$ and exponential attenuation, the maximum temperature difference within the concrete is $12^{\circ} \mathrm{F}$ if both surfaces are at the same temperature. 


\subsection{Control and Instrumentation}

The entire reactor and the principal experimental loop are both controlled from a single control room. In this way the reactor operator and the $100 p$ operator can assist one another and at least partially anticipate the response of the reactor and test loop.

The instrumentation is not described in detail, but incorporates most of the same components and systems found acceptable in use at the MTR and the ETR. Greater emphasis is instead placed upon the means for achieving control.

There are three types of control which may be necessary for the AETR: safety, shim, and regulating control. Safety control is used to guarantee rapid and complete shutdown while shim control compensates for fuel burnup and other gradual changes in reactivity. Regulating control compensates for the rapid and almost continuous nomal small changes in reactor multiplication due to thermal and other transients. A summary of the instruments for the reflector control systems is given in Table $3 . d$.

\subsubsection{Safety Control}

The safety control system (See Figure 3.G) is a reflector level control further described in section 6.2 of part B. The reflector tank is so constructed that the reflector begins its fall from a point 0.5 -foot above the core centerline. From this position, a 30 percent reactivity decrease is acheived in 0.26 seconds (See Figure 6.E of Part B).

The two portions of the reflector safety control annulus are separated by an aluminum plate perforated with one hundred 0.5 inch diameter holes. These holes permit the required cooling flow, but restrict back flow of the heavy water into the dropping lower portion of the reflector during a scram. After a scram, about 13 seconds are required for the upper portion of the reflector to drain into the lower portion.

To initiate a scram, bypass lines are opened. These bypass lines short circuit the water jet eductors which raise and circulate the heavy water in the safety reflector. The bypass lines allow the gas, which replaces the heavy water in the reflector, to flow with a sufficiently low resistance to give short reflector drop times. The calculated resistance is based on that of eight 1.5-inch diameter pipes. To insure achieving the calculated drop times, even if two of the valves should fail closed, ten 1.5-inch diameter bypass lines are included. During reactor operation these lines are closed by solenoid valves. To open the valves, i.e scram the reactor, the solenoids are de-energized and the spring-loaded valves open. 


\subsubsection{Shim Control}

The shim control system (See Figure 3.D) is designed to maintain a solution of $\mathrm{D}_{3} \mathrm{BO}_{3}$ in the reflector. To insert shim poison into the reactor, a solenold valve is opened, allowing a saturated solution of deuterated boric acid to enter the reflector. To remove shim poison from the reactor, a fraction of the borated heavy water is bypassed through a deuterated ion exchange column. The ion exchange column consists of anion $r e$ resin to remove the $\mathrm{D}_{2} \mathrm{BO}_{3}$ ion and a small amount of cation resin to remove cationic corrosion products. This and other reflector systems are further discussed in Section 5.2 .3 .

\subsubsection{Regulation Control}

With conventional control rod shim systems, a regulating rod is required to smooth small oscillations in reactor power. However, with a chemical shim system it is not certain that such regulation is needed. To be sure that adequate reactor control is available two regulating rods are included.

Table $3 . d$

Reflector Control Instruments

\begin{tabular}{|c|c|c|}
\hline $\begin{array}{l}\text { Instrument } \\
\text { No. }\end{array}$ & $\begin{array}{l}\text { Type of } \\
\text { Instrument }\end{array}$ & Function \\
\hline 1 & Liquid level indicator & $\begin{array}{l}\mathrm{D}_{2} \mathrm{O} \text { liquid level indica- } \\
\text { tion }\end{array}$ \\
\hline 2 & Temperature controller & $\begin{array}{l}\text { Control temperature by } \\
\text { varying coolant flow }\end{array}$ \\
\hline 3 & $\begin{array}{l}\text { Flow recorder, controller } \\
\text { and alarm }\end{array}$ & $\begin{array}{l}\text { Control flow of } \mathrm{D}_{2} \mathrm{O} \\
\text { through eductor }\end{array}$ \\
\hline 4 & Flow recorder & Record $\mathrm{D}_{2} \mathrm{O}$ flow \\
\hline 5 & $\begin{array}{l}\text { Temperature recorder and } \\
\text { controller }\end{array}$ & $\begin{array}{l}\text { Control temperature by } \\
\text { varying coolant flow }\end{array}$ \\
\hline 6 & Flow recorder and control & $\begin{array}{l}\text { Record and control flow } \\
\text { through resin column }\end{array}$ \\
\hline $7 \mathrm{~A}, 7 \mathrm{~B}$ & Conductivity recorder & $\begin{array}{l}\text { Measure and record con- } \\
\text { ductivity of } \mathrm{D}_{2} \mathrm{O}: \\
\mathrm{A} \text {. before cleanup } \\
\mathrm{B} \text {. after cleanup }\end{array}$ \\
\hline
\end{tabular}


Table 3.d(Continued)

Instrument

No.

5)

11

$12 \mathrm{~A}, 12 \mathrm{~B}$

13

14

21

22

23

24

25

$26 \mathrm{~A}, 26 \mathrm{~B}$

$27 \mathrm{~A}, 27 \mathrm{~B}$

28
Type of

Instrument

Differential pressure indicator

Liquid level recorder

Radiation recorder and alarm

Temperature recorder and controller

Flow recorder and controller

Flow recorder and controlzer

Flow recorder and controlier

Flow recorder and controller

Conductivity recorder

Radiation recorder and alarm

Temperature recorder and controlier

Lịquid level recorder

Liquid level recorder and alarm

Differential pressure indication
Function

Indicate pressure arop across resin column

Measure and record liquid level in drain tank

Measure radiation dose rate in stack gas

Control temperature of gas :

A. entering recombiner

$B$. leaving recombiner

Control $\mathrm{O}_{2}$ addition

Control blanket gas flow rate

Control flow of $\mathrm{D}_{2} \mathrm{O}$ in shim reflector

Control flow of $\mathrm{D}_{2} \mathrm{O}$ in resin column

Measure conductivity of $\mathrm{D}_{2} \mathrm{O}$ from resin column

Indicate leak of radioactivity to secondary coolant system

Control temperature by varying coolant flow

Record $\mathrm{D}_{2} \mathrm{O}$ level in:

$A$. the dump tank

$B$. the shim reflector

Record and give alarm of high and low liquid level in:

A. $\mathrm{D}_{2} \mathrm{O}$ head tank

B. $\mathrm{D}_{3} \mathrm{BO}_{3}$ solution tank

Indicate pressure arop across resin bed 


\subsubsection{Radiation Monitoring}

Area monitors sense gross gamma radiation levels in the working areas which are likely locations for high radiation exposure and areas from which contamination tends to spread. These monitors are large ionization chambers centraliy located which continuously record the dose rate and which can sound an alarm at an arbitrary radiation level. Area monitors are located in each reactor room, each experimental loop equipment room, and in the general access area between fuel assembly storage carzls. On this basis it is expected that portable survey meters are sufficient for checking the areas which are normally unoccupied.

Air monitors continuously record the presence of radioactive particles in air from the reactor rooms, the experimental loop equipment room, and from the general access area. These monitors can also register alarms so that personnel can evacuate an area with high levels of particulate activity.

As in the ETR, a single hand-and-foot monitor near the locker room provides a means to detect contamination on operating personnel. By careful operating practice, this can prevent personnel from inadvertently spreading radioactive contamination outside the reactor building.

There are a number of monitors to sense unusual levels of radiation in the process fluids, both for proper plant operation as well as for biological protection. These monitors can operate automatic reactor safety circuits, alarm circuits or warning lights, and can actuate signals, blinkers, etc., at more than one location. The streams continuously monitored include primary coolant (for $\mathrm{N}^{16}$ activity and fission products), secondary coolant, and stack gas. Intermittent sampling is used to monitor operation of the bypass demineralizer since the resin bed requires six months to load itself with corrosion products. 


\subsection{EXPERIMENTAL FACILITIES}

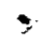

$\checkmark$

The prime purpose of the AETR is to provide fuel assembly test facilities which are better, particularly in higher neutron flux, than those of existing test reactors. To meet the requirements of seven major test holes (see Appendix 1.0), seven reactors, of two sizes, are provided. The flux trap reactors give average thermal neutron fluxes of $1.5 \times 1015 \mathrm{n} / \mathrm{cm}^{2}-\mathrm{sec}$ or greater in these test holes. The other feature which enhances the utility of the AETR for experimental use is that each reactor is part of an integrated unit designed around one test loop. This means that there are no interactions from other major reactor experiments, and that unscheduled shutdowns due to other experiments are minimized. Also, since there is only one major experiment per reactor the time for scheduled shutdowns is minimized. In addition, the reactor room and experimental loop room assoclated with each reactor are isolated by gas tight construction. This means that except for severe accidents, each reactor test loop is in almost every way separate, independent, and completely available to serve one experimenter. Thus radioactive contamination is readily contained within the individual areas and release of radioactivity due to a mishap with one reactor or test loop does not force shutdown and/or evacuation of the entire facility.

4.1 Test Ioop Facilities

Each Type-A reactor has a central test hole which accomodate liquid-metal-cooled or gas-cooled test fuel assemblies up to 7 inches diameter. The four Type-A reactors satisfy the requirements (see Appendix 1.0) for three 7-inch and one 5-inch test loops. Each Type-B reactor has a central test hole which accomodates pressurized-water-cooled, liquid-metal-cooled, or gas-cooled test fuel assemblies up to 4 inches diameter. The three Type-B reactors satisfy the requirements for two 3 -inch and one 4-inch test loops. The through-tube of the Type-A reactor is designed for gas or liquid metal at $2000^{\circ} \mathrm{F}$ and 300 psi as the loop coolant; it is not suitable for pressurized water experiments. One through-tube of the Type-B reactor is designed for water at $2000 \mathrm{psi}$ and $6500 \mathrm{~F}$ as the $100 \mathrm{p}$ coolant. The other is designed for liquid-metal and gas-cooled experiments.

The test hole fluxes are computed for the 7 -in and the 4-in test holes since for the same reactor power, smaller test holes have higher test hole fluxes. The average fluxes over a 30-in long test hole filled with 100 p coolants for typical
experiments (as discussed in section 6.8) are given in Table experiments (as discussed in Section 6.8) are given in Table 4.a.

With the reactor located beneath a pool which shields both the core and the through-tube, the effectiveness of the reactor is enhanced as an experimental tool in several ways. The re- 
moval of water-cooled test assemblies is very simple since the assemblies can be transferred directly from the through-tube and reactor pool into the canal (see figures 8.B, 8.C). This convenlent transfer from test hole to canal may make it attractive to install a temporary or permanent hot cell above or adjacent to the canal. Installation of beam tubes through the water above the reactor, would provide exceptionally intense neutron and gamma beams for physics research or cross section measurement.

Table 4. a

Average Neutron Fluxes in Central Test Holes of Type-A and Type-B reactors

\begin{tabular}{cccc} 
Reactor & Type-A & \multicolumn{2}{c}{ Type-B } \\
Test hole coolant & Sodium & Sodium & $\mathrm{H}_{2} \mathrm{O}$ \\
Test hole I.D., in & 7 & 4 & 4 \\
Average flux, $1015 \mathrm{n} / \mathrm{cm}^{2}-\mathrm{sec}$ & & & \\
Thermal & 1.50 & 1.50 & 2.10 \\
Intermediate & 0.75 & 0.65 & 0.53 \\
Fast & 1.62 & 1.44 & 1.05
\end{tabular}

With only one major test hole per reactor there is unusual latitude in the type of equipment used and studies which may be pursued.

\subsection{Capsule Holes in Moderator Annulus}

When the test holes are filled with materials which absorb neutrons appreciably but moderate little or not at all, the highest thermal neutron fluxes occur in the 1.5 -in water annulus between the core and the through-tube. For example, these fluxes reach $2.3 \times 1015 \mathrm{n} / \mathrm{cm}^{2}-\mathrm{sec}$ in the Type-A reactor when the test hole is sodium-filied. In order to use this flux capsules up to 0.75 inches in diameter can be inserted in tubes which pass through the moderator annulus. The tubes are a part of the reactor core structure and are cooled by water which bypasses the core. Since the moderator thermal neutron flux is high, the test assembly flux may be sensitive to capsules which have high neutron absorption. 
4.3 Capsule Holes in Refilector

Six larger (1.5-in I.D.) capsule holes are provided in the safety reflector. The thermal neutron flux in these capsule holes reaches a peak value of $10^{15} \mathrm{n} / \mathrm{cm}^{2}-\mathrm{sec}$. These capsule holes are of good size, but are not intended for test loop use. Capsules irradiated in these holes are also cooled by primary coolant water which bypasses the core. Upon capsule removal, the capsule tubes are plugged in order to restrict the amount of bypassed water.

4.4 Instrumentation and control

It is anticipated that the particular loop initially installed in each reactor will be used for a relatively long time, and that complete changes in the type of loop associated with a reactor will be very infrequent.

Therefore instrumentation for the test loop is "permanently" installed in the AETR control room. Some of this may have to be altered for specific experiments, but indicators and/or recorders for: test assembly fuel plate temperature; loop power; test loop thermal neutron flux; and, temperature, pressure, and flow for the test loop and test loop heat exchanger coolant streams, are provided. Unusual instruments required for a particular experiment are installed as needed.

The consolidation of the experiment controls and the reactor controls in one room is probably a unique feature of of the AETR. Not only does this reduce the amount of display and communication equipment, but the operators can aid one another to enhance the effectiveness of the reactor for operation of the single test loop. This feature simplifies the task of operating the reactor and the test loop and reduces the number of operating personnel required for safe efficient operation. 


\subsection{REACTOR COOLING SYSTEMS}

The reference design for the AETR facility consists of four Type-A reactors having a power-level of $170 \mathrm{MW}$ each and three Type-B reactors having a power level of 100 Mw each, all reactors having through-tube test facilities. Table $5 . a$ outlines the cooling systems provided for these reactors. Figure 5.A is a schematic of the primary cooling system provided for the Type-A reactors. The schematic of the common secondary cooling system is shown in Figure 5.G.

In addition to the cooling systems provided for the removal of heat from the reactor cores, there are cooling systems for the $\mathrm{D}_{2} \mathrm{O}$ reflectors and the major test loops. The reflector cooling systems are discussed in detail, but only general treatment is given to the experiment cooling systems because few experimental heat removal requirements are known. With the exception of the liquid metal-cooled test loops, it is assumed that water from the secondary cooling system is used to remove the heat from the test loop coolants and also the $\mathrm{D}_{2} \mathrm{O}$ reflector.

\subsection{Primary Cooling System}

The primary cooling system for the Type-A reactors is shown in Figure 5.A The primary cooling system for the Type-B reactors is the same as that shown in Figure 5.A except that two rather than three banks of heat exchangers are required and the flow rates are lower. This is outlined in Table 5.a The reasons for the series-parallel arrangement of heat exchangers are given in Part B, Section 10.3.2.

\subsubsection{Reactor Core Cooling}

The annular core of the Type-A reactor consists of 20 fuel assemblies - each consisting of 16 curved, 3.43" $\times 37^{\prime \prime}$ 50-mil fuel plates. The core for the Type-B reactor consists of 18 fuel assemblies - each consisting of 14 curved, $2.50^{\prime \prime} \times 37^{\prime \prime}$ 50-mil fuel plates. In order to determine if these cores can be cooled by pressurized water flowing through the core, a parameter study, reported in section 4.0 Part B, was conducted.

On the basis of this study the Type-A and Type-B reactors are designed for a maximum power density of $2.9 \mathrm{Mw} /$ liter. Although the study indicates an optimum coolant gap of about 75 mils for a 50-mil fuel plate, the design coolant gap is $73 \mathrm{mils}$ in order to use an even number of fuel assemblies. The water velocity through the core is $40 \mathrm{ft} / \mathrm{sec}$. 
Table $5 . a$

Reactor Cooling System

\begin{tabular}{|c|c|c|}
\hline & Type A & Type B \\
\hline Design power level, Mw & 170 & 100 \\
\hline $\begin{array}{l}\text { Number of heat exchangers } \\
\text { in parallel }\end{array}$ & 3 & 2 \\
\hline Core inlet temperature, ${ }^{\circ} F$ & 130 & 130 \\
\hline $\begin{array}{l}\text { Core outlet temperature } \\
\quad(\text { bulk), of }\end{array}$ & 240 & 240 \\
\hline $\begin{array}{l}\text { Primary flow rate at core } \\
\text { inlet temperature, gpm }\end{array}$ & 10,725 & 6,300 \\
\hline Secondary flow rate at $90^{\circ} \mathrm{F}$, gpm & 16,660 & 9,800 \\
\hline Heat exchange area, $f t^{2}$ & 31,200 & 20,800 \\
\hline Primary pumps & 3 & 2 \\
\hline Cooling tower on temperature, ${ }^{\circ} F$ & 160 & 160 \\
\hline Cooling tower off temperature, ${ }^{\circ} F$ & 90 & 90 \\
\hline Design wet bulb temperature, ${ }^{\circ} F$ & 65 & 65 \\
\hline
\end{tabular}


Table 5.b

Summary of Core Cooling Data

Core Geometry: Right Circular Annulus

Thermal power, Mw

I.D., in

O.D., in

Core helght, in

Volume, ft3

Heat transfer area, $f t^{2}$

Flow area, $f^{2}{ }^{2}$

Operating pressure at top of core, psia

Saturation temperature at top of core, OF

Coolant velocity, $\mathrm{ft} / \mathrm{sec}$

Pressure drop across core, psi

Operating pressure at core

exit, psia

Saturation temperature at core exit, ${ }^{\circ} \mathrm{F}$

Core inlet temperature, ${ }^{\circ} \mathrm{F}$

Core outlet temperature, ${ }^{\circ} \mathrm{F}$

Average coolant temperature, OF

Max. fuel-plate surface temperature, ${ }^{\circ} F$

Power density, Mw/liter average maximum

Burnout power density, at

"hot spot", Mw/liter

Max/av power distribution radial

axial

over-all

Hot channel factors coolant temperature rise film temperature rise
Type A

170

12.500

18.160

36

2.84

554

0.562

110

9.750

14.160

36

328

1.67

0.331

300

417

40

79

221

390

130

252

191

380

2.11

2.90

10.6

1.09

1.26

1.37

1.275

1.350 
Reactor core cooling is designed to keep the maximum temperature of the fuel-plate "hot spot" at or below the saturation temperature of the local cooling water. With aluminum fuel assemblies it is desirable to limit the "hot spot" temperature to 4000F. Therefore a coolant pressure at the core entrance of $300 \mathrm{psia}$ is selected. This results in a saturation temperature of approximately $400^{\circ} \mathrm{F}$ at the fuel plate "hot spot". The maximum heat flux including hot channel effects is only $27 \%$ of the burnout power density. The pertinent core cooling data are summarized in Table $5 . b$.

Axial Power Distribution

The axial power distribution in the reactor core, obtained by a two-dimensional analysis of the Type-A reactor is shown by Figure 5.B. The maximum-to-average power ratio is 1.26 and the maximum-to-minimum ratio is 2.03 .

Radial Power Distribution

The radial maximum-to-average power ratio in the core is about 2.0 for uniform fuel loading. The thermal neutron flux rises sharply near the edges of the core resulting in a power density, at the inner edge of the core, of about two and a half times that at the center of the core. Since the cooling system must be designed for the highest local power density, it is advantageous to lower the maximum-to-average ratio. In the AETR, the radial maximum-to-average power ratio is reduced by preferentially loading the core with more fuel in the low thermal flux regions and less in the high flux regions. The method for accomplishing this is shown in Figure 5.C. Fabrication of such fuel plates requires development costing approximately $\$ 5,000$ to $\$ 10,000$. To allow for burnout effects and discrepancies in fabricating plates with the desired fuel distribution, a radial maximum-to-average temperature power ratio of 1.09 is allowed in the AETR.

Pressure Drop, Flow, and Temperature

The 40-ft/sec water velocity, the 0.050 -inch fuel plate thickness and the 0.073 -inch coolant gap are all selected from the parametric heat transfer study (Section 4.0 Part B). Figures 5.D and 5.E show axial profiles of the fuel plate surface and bulk coolant temperatures for the Type-A and Type-B reactors. These curves are valid for both the Type-A and Type-B reactors since both are designed for the same maximum power density and have similar axial and radial power distributions. The calculations for these curves assume the axial power distribution shown by Figure 5.B. Perturbations in heat transfer are taken into account in the profiles shown in Figure 5.D. Figure 5.E shows the axial profiles of the 
fuel-plate surface temperature and the bulk water coolant temperatures without "hot channel factors".

As shown in Figure 5.D, the maximum fuel plate surface temperature is $380^{\circ} \mathrm{F}$ if "hot channel factors" are used. These results differ from the parameter study in that the maximum surface temperatures are below the coolant saturation temperatures. No radial mixing of the coolant is taken into account in the parameter study, but it is assumed in Figures 5.D and 5.E. That is, the eoolant temperature at any radial point is assumed to be the radial average for that particular height. Figure 5.E shows the maximum fuel plate temperature to be $320^{\circ} \mathrm{F}$ if "hot channel factors" are not used.

The pressure drop through the core is 79 psi including entrance and exit losses. The heat transfer areas for the Type-A and Type-B core are $554 \mathrm{ft} 2$ and $328 \mathrm{ft} 2$ respectively. In both the average power density is $2.11 \mathrm{Mw} / \mathrm{liter}$, which corresponds to a heat flux of $1.05 \times 10^{6} \mathrm{Btu} / \mathrm{hr}-\mathrm{ft} \mathrm{t}^{2}$. Applying the over-all maximum-to-average power ratio, the maximum density is $2.90 \mathrm{Mw} /$ Iiter which corresponds to a heat flux of $1.44 \times 10^{6}$ Btu/hr-ft2.

As discussed previously, the maximum fuel plate surface temperature is $3800 \mathrm{~F}$. This is the temperature of the surface in contact with the water. Assuming a thermal conductivity of $118 \mathrm{Btu} / \mathrm{hr}-\mathrm{ft}-\mathrm{O}_{\mathrm{F}}$ for the fuel region and the cladding, the maximum temperature at the central plane of the fuel plate is approximately $405^{\circ} \mathrm{F}$.

At the $40 \mathrm{ft} / \mathrm{sec}$ design coolant velocity, the burnout power density is $10.6 \mathrm{Mw} /$ liter (Section 4.0, Part B). The maximum operating power density is then only $27 \%$ of the burnout power density and is adequate for safety.

\subsubsection{Major Equipment}

The following sections describe the major equipment used in the AETR primary coolant system. In the interests of economy, standard equipment is specified wherever possible. The major items discussed are: heat exchangers, pumps, pressurizer, cleanup systems, piping, instrumentation and control.

\section{Heat Exchangers}

The heat exchangers for cooling the primary water of the AETR are fixed tube sheet, tube and shell types with single tube and single shell passes. Two heat exchangers, with the primary coolant flowing in series through the tube sides and 
the secondary coolant flowing in parallel through the shell sides, form a heat exchanger bank as shown in Figure 5.A. The Type-A reactor requires three of these heat exchanger banks in parallel while the Type-B reactor requires only two of these banks in parallel. Table 5.c outlines the design data for the heat exchangers, which are all of one size. Table 5.d outlines the operating conditions. Materials of construction are type 304 stainless steel for the tubes, tube sheets, and heads, and carbon steel for the shell and baffles.

The shut-down heat exchangers are also fixed tube sheet, shell and tube type heat exchangers with single tube and shell passes. The design data for these are also listed in Table 5.c. One shutdown heat exchanger is used for each reactor. The shutdown pump circulates primary coolant through the shut-down heat exchanger at about $350 \mathrm{gpm}$ to remove the $500-800 \mathrm{kw}$ of decay heat from the reactor core when the reactor is shut down and the top closure is removed. For this reason, the shutdown heat exchanger is located in the same area as the water cleanup equipment.

\section{Table $5 . c$}

Primary Loop Heat Exchanger Design Data

Primary Shutdown

Shell O.D. (nominal), in 36 12

Number of tubes 1590 170

Tube O.D., in $5 / 8$

$5 / 8$

Tube gauge, BWG

16

16

Tube pitch, in

$13 / 16$

$13 / 16 \Delta$

Cooled length of tube, ft

20

15

Baffle spacing (nominal) in

24

6

Pumps

Three pumps are used in each of the primary coolant systems for the Type-A reactors, but only two pumps are used for each of the Type-B reactors. To handle the system flow, pressure, and pressure drop requirements with a minimum of leakage and shaft deflection, the pumps are horizontally split-case, doublevolute, double-suction type centrifugal pumps. Additional pump specifications and operating conditions are outlined in Table $5 . e$. 
Table 5.d

Primary Loop Heat Exchanger Operating Conditions

Type-A Reactor

Heat Exchanger

A
Type-B Reactor Heat Exchanger

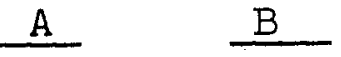

Tube Side:

$\begin{array}{lllll}\text { Inlet temp, }{ }_{F} & 240 & 166 & 240 & 166 \\ \text { Outlet temp, }{ }_{F} & 166 & 130 & 166 & 130 \\ \text { Av velocity, ft/sec } & 3.8 & 3.8 & 3.4 & 3.4\end{array}$

Shell Side:

Inlet temp, ${ }^{\circ} F$

outlet temp, ${ }^{\circ}$

Av velocity, ft/sec

Service Coefficient,

$\mathrm{BTU} / \mathrm{hr}-\mathrm{ft} \mathrm{CO}_{\mathrm{F}}$.

Heat Removed, Btu/hr
90

184

4.0

388

$1.30 \times 10^{8}$
90

90

90

136

184

136

4.0

$3 \cdot 5$

3.5

355

342

313

$6.32 \times 10^{7} 1.15 \times 10^{8}$

$5.56 \times 10^{7}$ 


\section{Table 5.e}

Primary Loop Pump Design Data and Operating Conditions

Type A Type B

Flow, gpm

3575

3150

Head, $\mathrm{ft}-\mathrm{H}_{2} \mathrm{O}$

180

180

Discharge line, in

10

10

Suction line, in

12

12

Impeller diameter, in

$14-1 / 2$

$14-1 / 2$

Impeller speed, RPM

1760

1760

Motor, BHP

200

175

Fluid temperature, ${ }^{\circ} \mathrm{F}$

130

130

System pressure, psi

300

300

Materials of construction

Impeller

304 SS

304 SS

Casing

Cast iron Cast iron 
The shutdown pump is the same type as the primary pumps. Its design capacity, however, is $350 \mathrm{gpm}$ against a $75-\mathrm{ft}$ head of water. During shutdowns while the top closure is removed from the reactor vessel, this pump circulates primary coolant through the shutdown heat exchanger and the reactor. The shutdown pump is also tied into the main heat exchanger circuit so that it may be used to circulate primary coolant in the main system when a low cooling capacity is desired for an extended period of time.

\section{Pressurizer}

The pressurizer is a 2-foot diameter, 8-foot long stainless steel tank. It is heated by five externally mounted electric heaters of $2-\mathrm{kW}$ capacity each. These heaters surround pipes extending from the side of the tank, as shown schematically in Figure 5.A, through which water flows in natural convection to produce steam and maintain the system pressure at 300 psi. The output of the heaters is controlled by PRCA-1-A through a Thyratron control unit. The liquid level in the tank (affected by leakage from the system) is maintained by LRCA-1-A which controls flow control valve IFV5 to add more water to the system, when required, or valve IFV6 to drain water from the system when it is too full. The latter situation will usually occur only when the system is being brought up to operating temperature. In addition to controlling water level, LRCA-1-A is also tied into the Thyratron unit to prevent it from operating when the liquid level in the tank is below the top entrance of the heating pipe. The pressurizer tank and heating pipes are heavily insulated to limit heat loss.

\section{Water Cleanup}

The water cleanup system provided is shown schematically in Figure 5.A. A by-pass stream of $5 \mathrm{gpm}$ is passed through this system continuously to maintain the purity of the primary coolant at about 1 ppm. Ordinarily, only one filter and demineralizer unit is used at a time, the other being serviced or on standby. Each branch of the clean-up system is capable of handling a flow as high as $10 \mathrm{gpm}$ and all three units may be used simultaneously, if required. The major equipment items are: a heat exchanger, a flow control valve and related instrumentation, two 10-micron porous stainless steel filter units, two mixed-bed demineralizers and appropriate conductivity cells to indicate the water purity and the effectiveness of the clean-up system. The heat exchanger has sufficient capacity to cool $20 \mathrm{gpm}$ from $1300 \mathrm{~F}$ to $1000 \mathrm{~F}$. The flow control valve and instrumentation are sized to control the flow in the range from 4-20 gpm. Table $5 . f$ lists additional information on the mixed-bed demineralizers. 
$\underline{T a b l e ~} 5.1$

Primary Loop Demineralizer

$\begin{array}{ll}\text { Bed volume, ft } 3 & 3 \\ \text { Tank diameter, in } & 15 \\ \text { Overall height, in } & 40 \\ \text { Pipe connections, in-schedule } & 1-40 \\ \text { Maximum flow rate, gpm } & 10 \\ \text { Life expectancy, months } & 6-9\end{array}$

Piping

All primary coolant system piping is $304 \mathrm{LC}$ stainless steel to minimize corrosion. The pipe sizes for a primary cooling system for a Type-A reactor are shown by Figure 5.A. The sizes for the Type-B reactor are similar except that the main primary loop is 16-inch rather than 20-inch diameter pipe.

Flow rates, temperatures and pressures in the primary coolant system are controlled by a combination of flow, temperature and pressure sensing instruments and flow control valves as shown schematically in Figure 5.A.

Temperature outputs from TRCA-1-A and TI-2-A and a flow output from FRCA-I are fed into the Reactor Power Recorder to indicate reactor power level. Outputs from these three instruments and from DPRA-1-G, PRCA-1-A and PRA-I-B are fed into reactor scram and/or set-back circuits to reduce power level or scram the reactor whenever unsafe conditions exist in the primary coolant circuit.

other instruments sense and indicate or record: the differential pressure across each of the primary pumps; the differential pressure across each of the clean-up system filters; the differential pressure across each of the cleanup system demineralizers; the flow rate of the clean-up system, and the conductivity of the primary coolant at the inlet and outlet to the clean-up system.

All major valves in the primary coolant system, with the exception of flow control valves and those for the shutdown heat-exchanger and pump, are manually-operated wedge-type 
gate valves. The inlet and outlet valves to the shut-down heat exchanger and pump are remore-control, motor-operated wedge-type gate valves.

5.1.3 Shutdown and Emergency cooling

Under ordinary conditions, the primary and secondary coolant flows are maintained for about five minutes after the reactor is shut down. After this both the primary and secondary coolant flow rates and the system pressure are reduced. When the core decay heat and system pressure are low enough, the primary coolant is diverted through the shutdown heat exchanger and pump. The reactor top closure may now be opened safely.

The present plan at the National Reactor Testing Station is to install a second independent power line directly to the MTR-ETR site. Quick-closing circuit breakers can shift from one power line to the other in less than 0.30 seconds. This gives failure-free power with no time limitation on the emergency capability. Correspondingly, the reactors may not operate if either of these power lines is inoperative. The scheme is much less expensive than installing and maintaining batteries plus motor-generators for fallure-free power with diesel generators as the backup emergency power source. In accordance with the above, emergency power for instruments and pumps is considered equivalent to the regular power source.

\subsection{Reflector Cooling System}

The reflector, which controls the reactor, consists of an unpoisoned safety reflector annulus and a poisoned shim reflector outer annulus. Since the systems for purification, poison addition and removal, and $\mathrm{D}_{2} \mathrm{O}$ recombination are intimately associated with the reflector cooling system, all these facilities are described.

\subsection{Heat Generation in Reflector}

The two major sources of heat in the reflector are (1), neutron slowing down, and (2), attenuation of gamma radiation. The methods of calculation are discussed in Appendix 6.0. The resulting heat generation rates are shown in Table 5.9 .

5.2.2 Reflector Heat Removal

The heavy water in each reflector is circulated through a heat exchanger where it is cooled to $120^{\circ} \mathrm{F}$ before being retumed to the reflector tank. The resultant flow rates are given in Table 5.h. 
Table 5.8

Reflector Heating

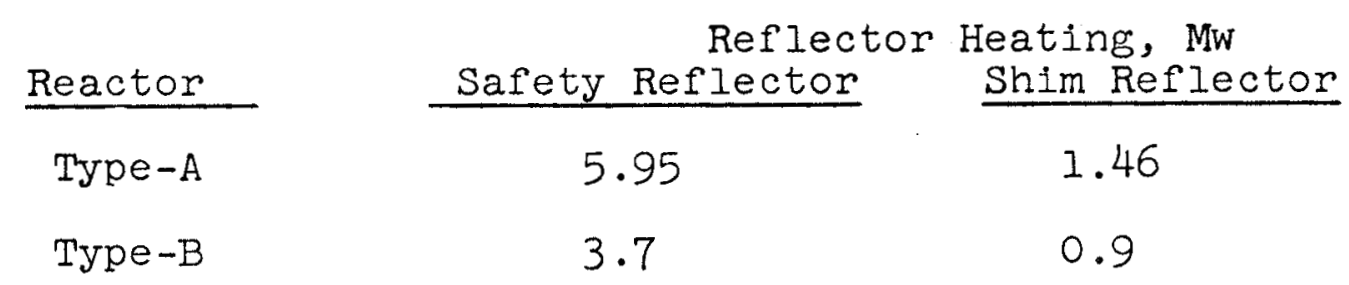

Table $5 . \mathrm{h}$

Flow Rates in Reflector Systems

\begin{tabular}{|c|c|c|}
\hline & \multicolumn{2}{|c|}{ Flow Rate, gpm } \\
\hline Reactor & Safety Reflector & Shim Reflector \\
\hline Type-A & 925 & 225 \\
\hline Type-B & 560 & 140 \\
\hline
\end{tabular}

5.2.3 Major Equipment

The flow diagrams, Figures 3.C and 3.D show the major equipment for the reflector safety and shim control systems. The equipment consists of heat exchangers, pumps, recombiners, heavy water cleanup systems, and instrumentation.

To protect the heavy water from contamination with light water and corrosion products, the systems are constructed of welded aluminum or stainless steel. For neutron economy all structural material inside the radiation shield is aluminum.

\section{Heat Exchangers}

The design data for the heat exchangers for cooling the reflector $\mathrm{D}_{2} \mathrm{O}$ for the Type-A and Type-B reactors are given in Table 5.i with their operating conditions. All of the heat exchangers are single-pass, shell, and tube type with heavy water on the tube side. To protect the heavy water, the tubes, tube sheets, and end bonnets are made of stainless steel and are welded in place. The shells are standard steel, designed for 150-psi working pressures.

Blanket Gas

Both reflectors are surrounded by helium blankets to protect the isotopic purity of the heavy water, However to 
Table 5.1

Reflector Heat Exchangers

Heat Exchange Data

Reactor and Reflector Types

\begin{tabular}{|c|c|c|c|}
\hline \multicolumn{2}{|c|}{ Type-A } & \multicolumn{2}{|c|}{ Type-B } \\
\hline Safety & Shim & Safety & Shim \\
\hline 21 & 10 & 21 & 10 \\
\hline 1686 & 356 & 1686 & 356 \\
\hline $3 / 8^{\prime \prime}$ & 16 BWG & $29 / 64 "$ & \\
\hline 124 & 156 & 106 & 120 \\
\hline 24 & $12^{\prime \prime}$ & 24 & 12 \\
\hline $\begin{array}{l}160 \\
120 \\
4.1\end{array}$ & $\begin{array}{l}160 \\
120 \\
8.6\end{array}$ & $\begin{array}{l}160 \\
120 \\
2.5\end{array}$ & $\begin{array}{l}160 \\
120 \\
5.1\end{array}$ \\
\hline
\end{tabular}

Shell Side:

Inlet, $O_{F}$

Outlet, OF

Average velocity $\mathrm{ft} / \mathrm{sec}$

Overall Heat Transfer coefficient, Btu/hr-ft $t^{\circ}{ }^{\circ} \mathrm{F}$
90

130

2.9

380
90

130

3.4

90

130

1.7

405

270

300 
allow the safety reflector to operate successfully, the blanket gas system of the shim reflector is maintained separate from that of the safety reflector. See Figure 5.F.

The blanket gas system consists of a gas heater, a catalytic recombiner, a gas cooler, and a venting system. The gas heater and the gas cooler are required to heat the gas entering and to cool the gas leaving the catalytic recombiner. The recombiner, a bed of platinized aluminum pellets, is designed to recombine the deuterium gas formed by radioalytic decomposition of the $\mathrm{D}_{2} \mathrm{O}$. The blanket gas systems are tied into a vent system through which the blanket gas may be vented to the atmosphere via the exhaust stack.

Heavy Water Cleanup

Each of the reflectors is provided with an ion exchange column for removing corrosion products. The ion exchange system for removing corrosion products and boric acid from the shim reflector is described in Section 3.8.2. The ion exchange system of the safety reflector consists of a small mixed bed resin column. A flow rate of about $0.5 \mathrm{gpm}$ is maintained through the resin bed.

\subsection{Test Loop Cooling}

The heat to be removed from the test $100 \mathrm{p}$ is produced almost entirely by fission in the test fuel assembly. However, there is a small amount of gamma and neutron heating in the loop tubes extending through the reactor core. In order to estimate the heat load to the secondary cooling system and to establish a basis for design of the in-core portions of the loop tubes, it is assumed that the average power density of the test fuel assemblies is the same as that of the reactor core. This appears to be a reasonable assumption since the average power density (2.I Mw/lit) of the AETR is about a factor of ten greater than that of existing power reactors, and a factor of two greater than that of planned power reactors or reactor prototypes. With regard to the latter, the Experimental Breeder Reactor-2 (EBR-2), which is designed for a power density of $1 \mathrm{Mw} /$ liter, has the highest power density of reactors planned for construction in the United States.

With an average power density of $2.1 \mathrm{Mw} /$ liter, experiments in the 7-inch and 4-inch test holes produce about $48 \mathrm{Mw}$ and $15 \mathrm{Mw}$, respectively. While the heat from water-cooled loops is generally removed by secondary cooling systems using water as coolant, this is not necessarily true for the gas-cooled and liquid metal-cooled loops which are generally at temperatures high enough to make air cooling satisfactory. Also, if air is 
used as the primary coolant for a gas-cooled fuel assembly test, a once-through system can be used. Therefore, it appears that it is practical to size the secondary system to include capacity to remove heat from fuel assembly tests in all reactors. The secondary cooling system is sized at $1080 \mathrm{Mw}$ which is $100 \mathrm{Mw}$ above the total reactor power. This provides heat removal capacity for all reactors and for experimental test assemblies (at $2.1 \mathrm{Mw} / 1$ iter) in all reactors except two of the Type-A reactors.

\subsection{Secondary Cooling System}

The common secondary cooling system for the AETR reactor complex is shown schematically in Figure 5.G. It consists of sixteen individual heat rejection units ali located in a common area. Each unit has a cooling tower and basin, a pump, valves, and the necessary instrumentation.

2.4.1 Heat Load

The design heat load of the secondary cooling system is $1080 \mathrm{Mw}\left(3.7 \times 10^{9} \mathrm{Btu} / \mathrm{hr}\right)$ which is $100 \mathrm{Mw}$ more heat than would be produced by all seven reactors in the complex operating simultaneously.

It is anticipated that secondary cooling water may be used to remove the heat from some of the test loops and the $100 \mathrm{Mw}$ excess capacity is primarily for this purpose. The $100 \mathrm{Mw}$ excess capacity also reduces the restrictions on shut down of cooling towers for clean-out and repair.

5.4.2 Major Equipment

The major equipment in the secondary coolant circuit consists of: cooling towers and basins, pumps, valves, piping, and instrumentation.

Cooling Towers

The general design data for cooling tower units are given in Table 5.j. Commercially available cooling tower units are specified to minimize costs.

The cooling tower basins have the same length and width dimensions as those given above for the cooling towers, and are 6 feet deep to provide a 10-minute holdup for the secondary coolant. There are two parallel rows of eight basins each with 100 feet between rows. The reinforced concrete basins have covered pump pits. 
Table $5 . j$

Design Data for an Individual Cooling Tower Unit

On tower temperature, ${ }^{\circ} F$

160

off tower temperature, ${ }^{\circ} \mathrm{F}$

90

Wet bulb temperature, ${ }^{\circ} \mathrm{F}$

65

Flow rate, gom (at $90^{\circ} \mathrm{F}$ )

6600

Heat rejection rate, Btu/hr

$2.3 \times 10^{8}$

Length (overall), ft

52

Width (overall), ft

Height (overall), ft

Draft

Forced

Fan motor, hp

75

Number of fans/unit

Table $5 . \mathrm{k}$

\section{Design Data for Secondary Cooling System Pumps}

Flow, gpm

6600

Head, $f^{\prime} t-\mathrm{H}_{2} \mathrm{O}$ 90

Discharge line, in

Impeller diameter, in

Impelier speed, rpm

Motor, BHP 200

Pump efficiency, \%

Fluid temperature, ${ }^{\circ}$

- System pressure, psia

40

Materials of construction

Cast iron or steel

Number required 
Pumps

The pumps for the secondary coolant are vertically mounted, submerged, double-suction, double-volute types. Pump specifications and design operating conditions are given in Table $5 . \mathrm{k}$.

\section{Valves and Piping}

The major valves in the secondary coolant circuit are 16-inch butterfly or swing-check types. The flow control valves for the makeup water are 4 -inch air-operated valves. All valves are made of cast iron or carbon steel. All piping not supplied by the cooling tower manufacturer is carbon steel. The sizes of the pipe for various portions of the system are shown in Figure 5.G.

Instruments

Each cooling tower unit is supplied with a temperature indicator, and a liquid level indicator controller and alarm. The latter instrument controls the flow of makeup cooling water to the cooling tower basin.

Make-up Water Treatment

A inaximum of 7700 gpm of relatively pure makeup water must be supplied to the 16 cooling tower units. It is assumed that facilities at the NRTS can be enlarged to meet this requirement. Therefore, no water treatment facilities are specified herein. 


\subsection{NUCLEAR CHARACTERISTICS}

The general geometric and material effects on the concentric annular "flux-trap" reactor concept are examined thoroughly in Section 3.0 of Part $B$, where the power requirements for several systems and reactor arrangements are compared. These power requirements are not intended to represent the absolute power levels for each system since they are based on clean critical reactors. The additional core fuel loading and control effects necessary to make the system operational are expected, on the basis of this early study, to increase the total power requirements. Therefore, these, and other nuclear characteristics of the Type-A and Type-B reference reactor types are described more completely in this section. The methods and nuclear constants used for the calculations are discussed in Appendix 3.0 .

\section{I Nuclear Reference Reactors}

Two basic configurations are selected for the reference reactors. These are termed Types $A$ and $B$. The Type-A reactor which has a 7-inch I.D. test hole, is used for the three 7-inch and the one 5-inch I.D. Iiquid-metal or gas-cooled 1oops. The Type-B reactor, which has a 4-inch $I . D$. test hole, is used for the 3-inch and 4-inch I.D. water-cooled loops and the 3-inch liquid-metal or gas-cooled loop. This arrangement is similar to the two-sized arrangement discussed in Section 3.2.1 and shown in Table 3.c of Part B. The Type-A reactor described in this table is nearly identical with the Type-A reactor shown in Figure 2.C. Iikewise, the Type-f unit, except for a slighty thicker core, is nearly identical with the Type-B unit shown in Figure 2.D. The Type-A and Type-B nuclear reference reactors are shown in Figure $6 . \mathrm{A}$.

A comparison of Figure 6.A with Figures $3 . \mathrm{C}$ and $3 . \mathrm{D}$ indicates some slight discrepancies exist. First, the fine structure of the final design is represented by appropriate aluminum walls. This was done primarily for convenience, but can easily be justified in diffusion theory calculations. Also, shown in Part $B$ to have only slight effect on the reactor power and reactivity. Also, based on hindsight, the region thicknesses in the nuclear reference reactor could have been selected differently than shown to represent more nearly the final design dimensions. The reason for permitting these slight variations is that the nuclear reference reactors shown in Figure 6.A are identical to arrangements used in part B for many calculations. Therefore, in order to apply most efficiently the effort expended, the nuclear reference reactor model was selected as shown. The core length is $91.44 \mathrm{~cm}$ ( 36 inches) and the axial buckling is $0.005225 \mathrm{~cm}^{-2}$. 
Since it was impractical to thoroughly investigate both reactor sizes (Type-A and Type-B), the majority of the information presented herein is for the Type-A reactor. The primary purpose of including the Type-B reference reactor is to show the difference in the neutron flux distributions in the Type-B reactors with sodium-filled and water-filied test holes

\subsection{Summary of Nuclear Characteristics}

Table 6. a presents the results of the various nuclear calculations described in the following sections. The Type-A nuclear reference reactor is used in all the detailed calculations. The Type-B nuclear reference reactor is used only to find the radial neutron flux distributions (Section 6.5) and to determine relative power requirements. The results obtained for the Type-A reactor have been extrapolated and applied to the Type-B reactor in order to estimate the fuel loading and core lifetime (see section 2.3).

$$
\begin{aligned}
& \frac{\text { Table } 6.2}{\text { Summary of Nuclear Characteristics of }} \\
& \frac{\text { Type-A Reference Reactors }}{}
\end{aligned}
$$

Core

$\begin{array}{lll}\text { Power } & \text { Mw } & 170 \\ \text { Volume } & \text { liters } & 68.9 \\ \text { Metal-water ratio } & - & 1.0 \\ \text { Operating temperature } & \circ \mathrm{F} & 170\end{array}$

Test hole

$\begin{array}{lll}\text { Volume } & \text { Iiters } & 23.3 \\ \text { Contents } & { }^{-} & \text {sodium } \\ \text { Temperature } & { }^{\circ} & 1000\end{array}$

Average test hole fluxes

(30-in)

Thermal

Intermediate

Fast

Peak thermal flux in water moderator

Average core fluxes

Thermal

Intermediate

Fast

$$
\begin{array}{ll}
1015 \mathrm{n} / \mathrm{cm}^{2}-\mathrm{sec} & 1.5 \\
1015 \mathrm{n} / \mathrm{cm}^{2}-\mathrm{sec} & 0.75 \\
1015 \mathrm{n} / \mathrm{cm}^{2}-\mathrm{sec} & 1.62 \\
1015 \mathrm{n} / \mathrm{cm}^{2}-\mathrm{sec} & 2.29
\end{array}
$$

$1015 \mathrm{n} / \mathrm{cm}^{2}-\mathrm{sec}$

$1015 \mathrm{n} / \mathrm{cm}^{2}-\mathrm{sec}$ $1015 \mathrm{n} / \mathrm{cm}^{2}-\mathrm{sec}$

0.36

0.85

2.52 
Table 6.a (Continued)

Average reilector fluxes*

Thermal

Intermediate

Fast

Fuel mass

Cold, critical

Initial core loading**

Hot poisoned, depleated

Core life (full power)

Fuel burnup

Excess multiplication requirements (keff-l)

Burnup (fuel depletion) Equilibrium xenon and samarium

other fission products

Temperature

Total

Prompt neutron lifetime

(hot, poisoned, depleted)

Uniform temperature coefficient of reactivity

Moderator annulus

Core Annulus

Reflector

Total room temperature to operating temperature reactivity

Uniform void coefficient of reactivity
$1015 \mathrm{n} / \mathrm{cm}^{2}-\mathrm{sec}$

$1015 \mathrm{n} / \mathrm{cm}^{2}-\mathrm{sec}$

$1015 \mathrm{n} / \mathrm{cm}^{2}-\mathrm{sec}$

0.59

0.60

0.55 $k g$ U235

$\mathrm{kg} U 235$

$\mathrm{kg} U 235$

days

per cent
5.1

11.3

7.3

19

35

seconds

$$
\begin{aligned}
& +0.077 \\
& +0.048 \\
& +0.038 \\
& -0.003 \\
& +0.16
\end{aligned}
$$

$3.2 \times 10^{-4}$

$\% \frac{\Delta K}{K} /{ }^{\circ} \mathrm{F}$

$+0.0109$

\%o $\frac{\Delta K}{K} /{ }^{\circ} \mathrm{F}$

$-0.00833$

$\% \frac{\Delta K}{\mathrm{~K}} /{ }^{\circ} \mathrm{F}$

$-0.00674$

$\% \frac{\Delta \mathrm{K}}{\mathrm{K}}$

$+0.373$

Moderator annulus

Core annulus

Reflector

$$
\text { reactiv }
$$

Core annulus

* In 16-cm thickness adjacent to the core

* Based on a fuel concentration of $4.2 \times 1020$
$+0.119$

$$
\begin{array}{ll}
\frac{\Delta K}{K} / \frac{\Delta V}{V} & -0.119 \\
\frac{\Delta K}{\mathrm{~K}} / \frac{\Delta V}{V} & -0.266
\end{array}
$$

atoms U235 


\subsection{System Power Level}

The total reactor power for a system similar to this system consisting of four Type-A and three Type-B reactors is found to be $858 \mathrm{Mw}$ (Section 3.0 Part B) for cold clean critical reactors. The added fuel and control effects necessary to make the reactor system operational increases the total reactor power.

The operational power levels for this system are shown in Table 6.b. The required power for the Type-A reactor, which is $170 \mathrm{Mw}$, was determined from a calculation in which the Type-A reference reactor is loaded with $11.3 \mathrm{~kg}$ of $\mathrm{U} 235$. This fuel loading corresponds to a reactor lifetime at full power of 19 days, as discussed in section 6.4 . The reactor control was simulated by the addition of a " $I / v$ " type poison in the reflector region beginning $16-\mathrm{cm}$ into the reflector from the core reflector wall. As long as the reactor control is affected in the reflector region, e.g. by reflector poison, or variation of reflector thickness, the power requirements and neutron flux distributions in the core and test hole are nearly independent of the method used. This is more fully discussed in section 6.7. The reactor powers for the Type-B reactors are determined from the powers for the just-critical reference reactors by correcting them for the decreased core thickness and increased fuel loading. The Type-B reactor core is sized to operate at the same maximum power density as the Type-A core.

Table 6.b

Reactor Powers for Reference Systems

Quantity Type

Test Composition

\begin{tabular}{c}
$\begin{array}{c}\text { Reactor Power* } \\
\text { Level, Mw }\end{array}$ \\
\hline $\begin{array}{c}170 \\
70 \\
100\end{array}$
\end{tabular}

Total Power for 7 reactors

$920 \mathrm{Mw}$

* Average thermal neutron flux in test region $=1.5 \times 1015 \mathrm{n} / \mathrm{cm}^{2}-\mathrm{sec}$

6.4 Fuel Loading and Core Lifetime

The fission product poisoning and fuel burnup effects are calculated assuming uniform effects throughout the core region. This method has been found to underestimate the fission product poisoning under some circumstances**. However, it is beyond the scope of this work to perform the space-dependent perturbation necessary to predict these effects accurately.

**Wolfe, B.,"Predicting Reactivity at High Burnup", Nucleonics 16 No. 3, (1958). 


\subsubsection{Fission Product Poisoning}

Two of the principal fission product poisons, xenon and samarium, reach equilibrium concentrations after relatively short periods of reactor operation. The xenon reaches $99.8 \%$ of equilibrium after 2.5 days of operation and the samarium reaches $80 \%$ of equilibrium after about 5 days of operation. The equilibrium samarium poisoning equals 0.011 (See Appendix Section A2.2.3) is flux-independent, and therefore is considered time-independent for cycles longer than about 5 days. The equilibrium xenon concentration dependence on average thermal neutron flux is illustrated in Figure A2.B of Appendix 2.0 . The flux dependence and therefore the time dependence of the equilibrium xenon poisoning approaches a value of 0.0498 asymptotically as the thermal neutron flux increases. For all practical purposes this flux level is reached in the Type-A and Type-B reference reactors at design power levels. Therefore the total value of xenon and samarium poisoning, 0.0608 , is assumed to be time and flux independent, providing the reactor has been in operation about 5 days at full power. The poisoning of the remaining "low cross-section" fission products is shown in Figure A2.C of the Appendix to be a function of fuel burnup or fraction of total fuel burned. The equation describing this effect is valid only for thermal nvt in the range of 1019 to 1022 . This restriction is met for the Type-A and Type-B reactors after a few hours of full power operation. The total fission product poisoning as a function of fuel burnup is shown in Figure 6.B. This curve overestimates the poison effects for times shorter than about 5 days of full power operation, i.e., before equilibrium samarium is attained. For 35 percent fuel burnup the fission product poisoning is 0.1095 .

6.4.2, Effect of Uniform Core Poisoning on Critical Fuel Concentrations

The effects of uniform core poisoning are evaluated for the Type-A reactor with a $60-\mathrm{cm}$ thick reflector. A criticality search was conducted for various uniform fuel concentrations by assuming a " $1 / \mathrm{v}$ " absorber distributed uniformly in the core. The results are shown in Figure 6.C. Curves 2 and 3 are estimates for Type-B reactors containing sodium and water loops and having calculated clean critical fuel concentrations of

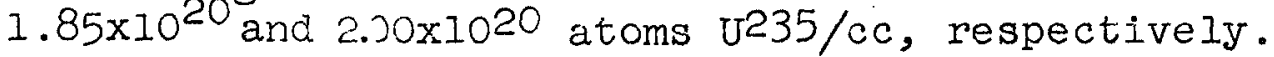

The poisoning for $35 \%$ burnup in the Type-A reactor is 0.1095 , and the fuel concentration for criticality with this poison is $2.73 \times 10^{20}$ atoms $\mathrm{U}^{235} / \mathrm{cc}$ with a $60-\mathrm{cm}$ thick reflector. Also, since $35 \%$ fuel burnup has been assumed the initial fuel concentration is calculated to be $2.73 \times 10^{20} /(1-.35)=4.20 \times 10^{20}$ atoms U235 cc. The fuel consumed is $1.47 \times 10^{20}$ ators U235 cc. 


\subsubsection{Fuel Burnup and Initial Core Loading}

The fuel burned is related directly to core power and length of operation, as indicated in Figure 6.D. In the Type-A reactor about 19 days at full power are permitted if $1.47 \times 10^{20}$ atoms $\mathrm{U} 235 / \mathrm{cc}$ are burned. This provides a three-week cycle in which two-days are allowed for shutdown activites. Figure $6 . E$ shows the initial fuel concentration for various core lifes for the Type-A reactor.

6.4 .4 Initial Excess Multiplication Factor

Figure 6.F, which is based on Figure 3.M of Part B, shows the initial excess multiplication required for various core lifetimes. This curve shows that if high fuel loadings and high burnups are practical with regard to fabrication, the core lives can be substantially increased without large increases in the initial multiplication factor.

\subsection{Neutron Flux Distributions}

The three group neutron flux distributions are determined using diffusion theory calculations according to the methods and constants which are thoroughly discussed in Appendix 2.0 . Since some of the more important regions in the Type-A and Type-B reactors are relatively small, the flux distributions calculated using diffusion theory may be questionable. Therefore, a $\mathrm{P}(3)$ solution to the transport equation was made to determine the thermal group neutron flux distribution for an arrangement similar to the small Type-B reactor. The results, which are presented in Appendix 2.1.3, indicate that the diffusion theory solutions are adequate for describing the thermal neutron flux distributions. The one-dimensional calculations are valuable in predicting the radial midplane flux distribtuions for the Type-A and Type-B reactors. However, the annular arrangement of the reactors does not permit a reasonable analysis for the axial flux distributions with onedimensional methods. Therefore two-dimensional calculations are necessary in order to evaluate the axial characteristics of the reactor.

\subsubsection{Radial Neutron Flux Distributions}

The radial flux distributions for the Type-A and Type-B reactors are shown in Figures $6 . G, 6 . H$, and $6 . I$. These fluxes were calculated using a $30-\mathrm{cm}$ thick radial reflector. The shapes of the flux distributions correspond nearly to the initial fully-loaded reactor, when control is affected by uniformly poisoning the outer region of the $60-\mathrm{cm}$ thick reflector. The fluxes in all regions, other than the reflector itself, are reasonably insensitive to the control method as long as the control is accomplished in the reflector region. 
This is discussed more fully in section 6.7. Figures 6.H and 6.I illustrate the difference in flux distributions for the Type-B reactor with sodium and water-filled test loops.

The radial flux distributions were calculated using an axial buckling value of $0.0005225 \mathrm{~cm}-2$ to account for the axial neutron leakage. This was calculated using a 36 -inch 19144 $\mathrm{cm})$ core height and an assumed reflector savings of $23 \mathrm{~cm}$. These numbers were selected at the outset of the study conducted in Section 3.1 of Part B. The core length was estimated on the basis that the axial thermal neutron flux distribution would not vary more than 50\% over 30 inches length of the test hole. The reflector savings value was selected to be consistent with the preliminary work on this design* since no better estimate could be made until the two-dimensional calculations were made. These assumptions are found to be very accurate from the two-dimensional analysis. The predicted system criticality agrees within one per cent using the one and twodimensional calculations, and the midplane radial flux distributions nearly coincide with each other.

\subsubsection{Two-Dimensional Calculations and Neutron Flux Plots}

Two-dimensional calculations are made for the Type-A reactor arrangement in order to more fully evaluate the axial effects and to establish the validity of the axial buckling assumptions made in the one-dimensional radial calculations. The Type-A reactor model which is used in this $r-z$ type calculation is illustrated in Figure $6 . J$. The radial arrangement at the reactor midplane corresponds identically with the radial arrangement shown in Figure 6. A for the Type-A nuclear reference reactor. Again, as in the radial flux calculations discussed in Section 6.5.1, the radial reflector thickness is $30 \mathrm{~cm}$. The active core height is 36 inches $(91.44 \mathrm{~cm}$ ) and the radial reflector blanket extends 18 inches $(45 \mathrm{~cm}$ ) above and below the ends of the active core. Since the Type-A reactor design has a through-tube type test loop arrangement as shown in Figure 2.A, the effective lengths of the test region, moderator annulus, coolant water annulus, and the appropriate walls, are simulated by extending these regions infinitely in the axial direction.

The fast, intermediate, and thermal topological flux plots are shown in Figures 6.K, 6.L, and 6.M. The dimension scale for these plots corresponds to the reactor model shown in Figure 6.J. The fast flux reaches a maximum value in the fuel region at the reactor midplane, and decreases in all directions from this point. The intermediate flux is slowly varying and has a

* Elgert, O.J., Leyse, C.F。, ott, D.G., Report INTERNUC-9, "Preliminary Investigations for an Advanced Engineering Test Reactor." (1957) 
mild peak occuring in the same vicinity as the fast flux peak. Distinct thermal flux peaks occur in the moderator annulus, reflector, and water coolant region just beyond the end of the active core. A large thermal flux depression occurs in the fuel region with the lowest point being near the end of the core.

The axial neutron flux distributions along the centerline of the sodium-filled test hole in the Type-A reactor are shown in Figure 6.N. The flux data is taken from the two-dimensional calculations, and the maximum-to-average thermal flux over 30 inches of the test hole length is 1.15 . The maximum-tominimum value over this length is 1.59 and the deviation from the average is $+15.0 \%$ to $-27.5 \%$. The axial flux distribution in the core (at $r=20 \mathrm{~cm}$ ) is shown in Figure 6.0. The thermal flux peaking in the coolant beyond the end of the fuel region is clearly illustrated. The axial core power distribution obtained from this same problem is used in the heat transfer calculations. This distribution is shown in Figure 5.B. The longitudinal maximum-to-average power determined from this Figure is 1.26 .

The effective multiplication factor determined by the one and two-dimensional problems agree within one percent. This indicates that the axial buckling term used in the onedimensional calculations is quite accurate. Also, since the radial midplane flux distributions agree so well, the use of one buckling term for all regions is seen to be a reasonable assumption.

\subsection{Reactivity Coefficients}

The coefficients of reactivity of most interest are the mass coefficient, poison coefficient, temperature coefficient and void coefficient.

\subsection{The Mass Coefficient of Reactivity}

The reactivity variation with mass is illustrated in Figure 6.P for the Type-A nuclear reference reactor.

\section{6 .2 Poison Coefficient of Reactivity}

In lieu of a curve showing the reactivity variation with poison, the critical fuel concentration is shown as a function of uniform core poisoning. This plot, which is useful in predicting initial fuel loadings is shown in Figure 6.C.

\subsubsection{The Uniform Temperature Coefficient of Reactivity}

The temperature coefficient of reactivity of the TypeA nuclear reference reactor is calculated by changing the region temperature uniformly from the operating temperature to room 
temperature $\left(68^{\circ} \mathrm{F}\right)$. Normally the core temperature coefficient of reactivity is of most interest, but in this annular reactor arrangement the temperature coefficients for the moderator and reflector regions are also of interest because of their effects on reactor criticality. The results of these calculations are shown in Tabile 6.c.

\section{Table 6.c}

Uniform Temperature Coefficients of Reactivity for the Type-A Reactor

$\begin{array}{llllll}\frac{\text { Case }}{1} & \frac{\text { Region }}{\text { All regions }} & \frac{\text { Change }}{68^{\circ} \mathrm{F} \text { to } 170^{\circ} \mathrm{F} *} & \text { Total } \frac{\Delta \mathrm{K}}{\mathrm{K}} & \frac{\Delta \mathrm{K}}{\mathrm{K}} / \Delta \mathrm{T} \\ 2 & \text { Water moderator } & 68^{\circ} \mathrm{F} \text { to } 170^{\circ} \mathrm{F} & +1.113 \% & \text { +0.0109\% } \frac{\Delta \mathrm{K}}{\mathrm{K}} /{ }^{\circ} \mathrm{F} \\ 3 & \text { Core } & 68^{\circ} \mathrm{F} \text { to } 170^{\circ} \mathrm{F} & -0.850 \% & -0.00833 \% \frac{\Delta \mathrm{K}}{\mathrm{K}} /{ }^{\circ} \mathrm{F} \\ 4 & \mathrm{D}_{2} \mathrm{O} \text { reflector } & 68^{\circ} \mathrm{F} \text { to } 170^{\circ} \mathrm{F} & -0.687 \% & -0.00674 \% \frac{\Delta \mathrm{K}}{\mathrm{K}} /{ }^{\circ} \mathrm{F}\end{array}$

* Central sodium region changed from $68^{\circ} \mathrm{F}$ to $1000^{\circ} \mathrm{F}$

Case-1 of Table 6.c shows the effect of simultaneously changing the temperature of all the reactor regions from $68^{\circ} \mathrm{F}$ to operating temperatures. This net effect is positive because of the large positive contribution resulting from the decrease in sodium thermal absorption when its temperature is increased to $1000^{\circ} \mathrm{F}$. The positive temperature coefficient in the $\mathrm{H}_{2} \mathrm{O}$ moderator annulus results from an increase in core thermal utilization factor as the moderation decreases in the $\mathrm{H}_{2} \mathrm{O}$ annulus. Fewer fast neutrons are thermalized, and as a result fewer neutrons are absorbed in the test region and moderator annulus as the moderator density decreases with increasing temperature. The core temperature coefficient is negative, and this is desirable from the standpoint of reactor safety, since an automatic decrease in reactivity is introduced when a power excursion raises the core temperatures. The reflector temperature coefficient is also negative, since reducing the density of the $\mathrm{D}_{2} \mathrm{O}$ decreases moderation and increases neutron leakage.

\subsubsection{The Void Coefficient of Reactivity}

In order to estimate this effect, the core water density of the Type-A reactor was uniformly reduced by 5 percent of its normal value. The core void coefficient is then defined by the expression $\frac{\Delta K}{K} / \frac{\Delta V}{V}$ where $\frac{\Delta K}{K}=\frac{K^{\prime}-K}{K^{\prime}}$ and $\frac{\Delta V}{V}=\frac{\text { void volume }}{\text { water volume }}$ 
$K^{\prime}$ is the effective multiplication factor after the void addition. The definition is sometimes called the steam void coefficient because the void is related to the core water volume rather than to the entire core volume. For this annular reactor arrangement, the void coefficient in the other reactor regions are also important. Therefore similar type calculations are made for the moderator annulus and reflector. These results are shown in Table 6.d.

\section{Table 6.d}

Uniform Void Coefficient of Reactivity for the Type-A Reactor

\begin{tabular}{|c|c|c|c|c|}
\hline Case & Region & Change & Total $\frac{\Delta \mathrm{K}}{\mathrm{K}}$ & $\frac{\Delta \mathrm{K}}{\mathrm{K}} / \frac{\Delta \mathrm{V}}{\mathrm{V}}$ \\
\hline $\begin{array}{l}\frac{1}{2} \\
3\end{array}$ & $\begin{array}{l}\text { Water Moderator } \\
\text { Core } \\
\text { Reflector }\end{array}$ & $\begin{array}{l}\text { Add } 5 \% \text { voids } \\
\text { Add } 5 \% \text { voids* } \\
\text { Add } 5 \% \text { voids }\end{array}$ & $\begin{array}{l}+0.597 \% \\
-0.594 \% \\
-1.331 \%\end{array}$ & $\begin{array}{l}+0.119 \\
-0.119 \\
-0.266\end{array}$ \\
\hline
\end{tabular}

* The 5\% uniform volds are added in the core coolan't only

The void coefficient of reactivity in the moderator region is positive, which means that a loss of the moderator annulus water could, under certain circumstances, cause a power excursion. The void coefficient for the core is negative and this, of course, is highly desirable since this effect provides an automatic negative reactivity introduction in the event of a power surge where steam bubbles might be formed. The reflector void coefficient is even more highly negative than the core, which illustrates the potential for using the reflector for reactor control.

6.6.5 The Prompt Neutron Lifetime

The kinetic properties and many of the safety features of a reactor are generally dependent on the prompt neutron generation or lifetime. The techniques used for solving the diffusion equations are adapted to simple estimations of the prompt neutron lifetimes according to the methods of Goertzel.* Briefly, the method is based on the amount of reactivity change resulting from the introduction of a small amount of " $1 / \mathrm{v}$ " absorber in all reactor regions. Accordingly, the prompt neutron lifetime $l$, is found using the relationship

$$
\ell=-\frac{1}{\alpha} \frac{K^{i}-K}{K^{\prime}}
$$

* Reactor Handbook, Volume I, p 531 
Where $\alpha$ is the froduct of the point macroscopic absorption cross section and corresponding neutron velocity for the added poison (which is constant for a " $I / V^{\prime \prime}$ absorber) and $K^{\prime}$ is the perturbed multiplication factor.

The prompt neutron lifetime for the Type-A nuclear reference reactor in the not, poisoned, depleted condition is $3.34 \times 10^{-4}$ seconds. This neutron lifetime is highly favorable towards easy reactor control, since it is a factor of four or more longer than that of highly enriched aluminum-water reactors with MTR-type cores.

\subsection{Reflector Control Effects}

In order to estimate the total reactivity available if the inner portion of the $\mathrm{D}_{2} \mathrm{O}$ reflector is dropped, calculations were made using the Type-A nuclear reference reactor. First, the density of $D_{2} \mathrm{O}$ in a $20-\mathrm{cm}$ thick annulus adjacent to the outer core wall was varied and these results are shown in Figure 6.2 . The $-43 \%$ total reactivity effect for the completely void $20-\mathrm{cm}$ thick region is estimated by a linear extrapolation from the calculated points for void fractions of 0.5 and 0.75 . Also, the thickness of this region was varied for cases in which the region contains a 0.75 void fraction. These results are shown in Figure $6 . R$. On the basis of the above, the reactivity worth of the safety reflector is estimated to be about 40-50\%.

The worth of distributed poisons in the reflector are discussed in Section 3.1 .8 of Part $B$.

6.8 Experiment Comparisons

Several comparisons are made herein to assist in evaluation of the AETR as an engineering test facility. These include a comparison witn the Engineering Test Reactor (ETR), an evaluation of a typical gas-cooled experiment, and an evaluation of a modification that enhances the reactor suitability for fast flux experiments.

\subsubsection{Comparison with the Engineering Test Reactor}

Neutron flux distributions are available for the ETR which show the neutron fluxes in the in-core test holes when they contain aluminum (with $7 \%$ water) ${ }^{*}$ Since it is desirable to compare the AETR against other test reactors on as equitable a basis as practical, calculations were made for the Type-A reactor with the same aluminum-water mixture in the test hole. The results for the aluminum-filled test hole are given, along with those for a sodium-filled test hole, in Table 6.e.

* Kaiser Engineers and General Electric Company, IDo-24020, "Engineering Test Reactor, Engineering Design and Safeguards Report", 1956. 
Table 6.e

Comparison of Sodium and Aluminum in Test Hole of Type-A Reactor

Test Hole Composition

\begin{tabular}{|c|c|c|}
\hline & Sodium & Aluminum $\left(7 \% \mathrm{H}_{2} \mathrm{O}\right)$ \\
\hline Reactor Power & $170 \mathrm{Mw}$ & $170 \mathrm{MW}$ \\
\hline Reactivity change & 0 & $-0.80 \%$ \\
\hline $\begin{array}{l}\text { Average thermal neutron } \\
\text { flux in test, } \mathrm{n} / \mathrm{cm}^{2}-\mathrm{sec}\end{array}$ & $1.5 \times 10^{15}$ & $1.58 \times 10^{15}$ \\
\hline $\begin{array}{l}\text { Average intermediate } \\
\text { neutron flux in test, } \\
\mathrm{n} / \mathrm{cm}^{2}-\mathrm{sec}\end{array}$ & $0.749 \times 10^{15}$ & $0.570 \times 10^{15}$ \\
\hline $\begin{array}{l}\text { Average fast neutron } \\
\text { flux in test, } \\
\mathrm{n} / \mathrm{cm}^{2}-\mathrm{sec}\end{array}$ & $1.62 \times 10^{15}$ & $1.61 \times 1015$ \\
\hline
\end{tabular}

With the results in Table 6.e and the above mentioned flux distributions for the ETR, a reasonable comparison of the AETR and ETR can be made. The comparison is made on the basis of the test loop volume, thermal neutron flux, and reactor power level. The comparison is made between the nine in-core test holes in the ETR and the Type-A and Type-B AETR designs. Assuming the tests are of equal length since both reactor cores are 36 inches high, the useful volume is directly proportional to the cross sectional area of the in-core loop tube. In the AETR this is the cross sectional area of the test hole but in the ETR the usable size is smaller than the nominal hole size since the loop tube is fitted inside the test hole. The useful inside diameters given in Table 6.f for the ETR are estimates of the maximum sizes of 10op tubes that can be incorporated in the ETR for gas-cooled and watercooled tests at conditions comparable to those specified for the AETR (See Appendix 1.0). For the ETR it is assumed that the loop tube produces no flux perturbation and the average thermal neutron fluxes in the test holes are as shown in Figure 4.32 of IDO-24020*. The products of the thermal neutron flux and test hole volumes for each reactor are tabulated in Table 6.f, totalled, and divided by the reactor power to give values which serve as the basis for comparison of the ETR and AETR. The ratio of these values for the AETR to those for the ETR are given at the bottom of the table and indicate the magnitude of the superiority of the AETR over the ETR in pro-

* IDO-24020, op. cit. 
ducing more usable flux per unit reactor power.

Table 6.f

Compärison of AETR with ETR

\begin{tabular}{|c|c|c|c|c|c|c|}
\hline \multicolumn{3}{|c|}{ Test Hole Av $\varnothing_{\mathrm{mH}}$} & \multicolumn{2}{|c|}{ Gas-Cooled Loop } & \multicolumn{2}{|c|}{ Water-Cooled Loop } \\
\hline No, & $\begin{array}{l}\text { Size } \\
\text { in. }\end{array}$ & $\frac{10^{14}}{\mathrm{n} / \mathrm{cm}^{2}-\mathrm{sec}}$ & $\begin{array}{l}\text { Loop I } \\
\text { in. }\end{array}$ & $\begin{array}{l}\phi_{\mathrm{TH}} \times V_{\mathrm{T}^{*}} \\
1018 \\
\mathrm{n}-\mathrm{cm} / \mathrm{sec}\end{array}$ & $\begin{array}{c}\text { Loop ID } \\
\text { in. }\end{array}$ & $\begin{array}{l}\phi_{\mathrm{TH}} \times V_{T^{*}}{ }_{10}{ }^{n-c m / s e c} \\
\text { - }\end{array}$ \\
\hline \multicolumn{7}{|c|}{ ETR } \\
\hline $\begin{array}{l}1 \\
1 \\
3 \\
4\end{array}$ & $\begin{array}{l}9 \times 9 \\
6 \times 9 \\
6 \times 6 \\
3 \times 3\end{array}$ & $\begin{array}{l}1.56 \\
1.66 \\
1.64 \\
2.36\end{array}$ & $\begin{array}{l}7.4 \\
4.6 \\
4.6 \\
2.1\end{array}$ & $\begin{array}{r}4.00 \\
1.64 \\
4.86 \\
1.94 \\
12.44\end{array}$ & $\begin{array}{l}6 \\
3.5 \\
3.5 \\
1.5\end{array}$ & $\begin{array}{l}2.63 \\
0.95 \\
0.95 \\
0.99 \\
5.42\end{array}$ \\
\hline \multicolumn{7}{|c|}{ AETR-Type A } \\
\hline 1 & 7 ID & 15.8 & 7.0 & 36.2 & 7.0 & 36.2 \\
\hline \multicolumn{7}{|c|}{ AETR-Type B } \\
\hline 1 & $4 I D$ & 15.8 & 4.0 & 11.8 & 7.0 & 11.8 \\
\hline \multicolumn{7}{|c|}{$\phi_{\mathrm{TH}} \mathrm{V}_{\mathrm{T}} / \mathrm{MW}$} \\
\hline & & & \multicolumn{2}{|c|}{ Gas-Cooled Loop } & \multicolumn{2}{|c|}{ Water-Cooled Loop } \\
\hline \multicolumn{2}{|c|}{$\begin{array}{l}\text { ETR } \\
\text { AETR-Type } \\
\text { AETR-Type }\end{array}$} & $\begin{array}{l}A \\
B\end{array}$ & \multicolumn{2}{|c|}{$\begin{array}{r}7.1 \times 10^{16} \\
21.3 \times 1016 \\
11.8 \times 1016\end{array}$} & \multicolumn{2}{|c|}{$\begin{array}{l}3.16 \times 10^{16} \\
21.3 \times 1016 \\
11.8 \times 10^{16}\end{array}$} \\
\hline
\end{tabular}

Ratio of $\phi_{T E:} V_{T} / M W$ of AETR to that of ETR

\begin{tabular}{|l|c|c|}
\hline & Gas-Cooled Loop & Water-Cooled Loop \\
\cline { 2 - 3 } AETR-Type A & 3.0 & 6.75 \\
AETR-Type B & 1.66 & 3.74 \\
\hline
\end{tabular}

${ }^{*} V_{\mathrm{T}}=$ volume of test loop in core,cc. 
In addition to the above, the AETR thermal neutron flux levels art six to nine times higher than those in the ETR. The estimated operating cycles of both reactors are three weeks, but the AETR will probably give substantially greater reactor operating time since there is only one test loop per reactor.

\section{8 .2 Gas-Cooled Experiments}

A typical gas-cooled reactor experiment consisting of Beo with 50\% homogenized voids to account for coolant passages and a uniform fuel concentration of $0.5 \times 10^{20}$ atoms U235/cc was arbitrarily assumed to fill the test hole of Type-A AETR. The results of these calculations are given in Table 6.8 .

Table 6.g

Effect of a Typical Gas-Cooled Fuel Assembly in the Test Hole of the Type-A AETR

Test Loop Composition

Sodium Gas-Cooled Experiment*

Reactor core power

Test power

Reactivity, $\frac{\Delta \mathrm{k}}{\mathrm{k}}$

Average thermal neutron

flux in test, $\mathrm{n} / \mathrm{cm}^{2}-\mathrm{sec}$

Average intermediate neutron

flux in test, $\mathrm{n} / \mathrm{cm}^{2}-\mathrm{sec}$

Average fast neutron flux

in test $\mathrm{n} / \mathrm{cm}^{2}-\mathrm{sec}$
$170 \mathrm{Mw}$

0

o

$1.5 \times 10^{15}$

$0.749 \times 10^{15}$

$1.62 \times 10^{15}$
$170 \mathrm{Mw}$

$8.5 \mathrm{Mw}$

$+4.44 \%$

$1.65 \times 10^{15}$

$0.890 \times 10^{15}$

$2.13 \times 10^{15}$

*The typical gas-cooled experiment is arbitrarily represented by BeO at $1000^{\circ} \mathrm{F}$ with $50 \%$ void fraction for cooling with uniform fuel concentration of $0.5 \times 10^{20}$ atoms $0235 / \mathrm{cc}$.

The use of sodium in the test hole in design and selection of the AETR thus appears to have been reasonable and realistic. The thermal neutron flux in the gas-cooled test assembly is about $10 \%$ greater than the specified $1.5 \times 10^{15} \mathrm{n} / \mathrm{cm}^{2}-\mathrm{sec}$ unperturbed thermal neutron $f$ lux and therefore the AETR design appears to be particularly suited for such gas-cooled tests. 
6.8.3 Fast Flux Experiment

Calculations were made in anticipation of a need to conduct high fast flux reactor experiments in the AETR. In order to enhance the fast neutron flux in the test hole the moderator annulus of the Type-A design was assumed replaced by aluminum. The results for this modification are promising and are shown in Table 6.h.

\section{Table 6.h}

Effect of Substituting Aluminum for the Water in the Moderator Annulus

Reactor power

Reactivity, $\frac{\Delta \mathrm{K}}{\mathrm{K}}$

Average thermal neutron flux

in test, $\mathrm{n} / \mathrm{cm}^{2}-\mathrm{sec}$

Average intermediate neutron

flux in test, $\mathrm{n} / \mathrm{cm}^{2}-\mathrm{sec}$

Average fast neutron flux in test, $\mathrm{n} / \mathrm{cm}^{2}-\mathrm{sec}$

Radial maxirum-to-average power
Moderator Annulus Composition

$\mathrm{H}_{2} \mathrm{O} \quad$ Aluminum

$170 \mathrm{Mw}$

$170 \mathrm{Mw}$

0

$+1.55 \%$

$1.5 \times 10^{15}$

$0.204 \times 10^{15}$

$0.749 \times 10^{15} \quad 1.084 \times 10^{15}$

$1.62 \times 10^{15}$

$3.03 \times 10^{15}$

1.69

1.94

The test hole fluxes (in sodium) are drastically changed, but with slight variation in reactivity. Similar changes in the test hole fluxes can also be realized by substituting a void for the moderator annulus water. 


\subsection{SHIELDING AND MATERIAL HEATING}

Since both the shielding and material heating are aspects of the same problem, and dependent on reactor power, they are discussed together.

The final average power density in the Type A reactor is $21 \mathrm{Mw} /$ liter. It is this value with allowances for axial peaking at the midplane which is used as the radiation source. The reactor experiment is assumed to have the same power density, which is much greater than the power density of present and planned power reactors (see section 5.3).

\section{T.I Gamma Heating and Radiation Intensities}

Within the core region, radiation levels are very high due to the power density of the reactor and its experiments. While only the maximum (midplane) levels are discussed, it should be realized that the radiation levels decrease toward the ends of the reactor.

The maximum gamma heating occurs at points nearest the core as listed in the Appendix 6.0. This can amount to 90 watts/cc or 33 watts/gm in the aluminum through-tube around a large experiment. The radiation field itself at the same point is about $1.3 \times 1015 \mathrm{Mev} / \mathrm{cm}^{3}-\mathrm{sec}$.

7.2 Heating in Reactor Components

Values of total gamma and neutron heating for various reactor components are discussed below. Heating rates are shown graphicaliy in Figure $A 6 . A$ in the Appendix.

\subsubsection{Through-Tube}

The through-tube heating rate depends greatly on the type of experiment under test. Aside from the experiment power, various coolants have different degrees of self-shielding. Thus it is reasonable to expect that the gamma heating rate will be greater around a gas-cooled test core than around a liquid metal-cooled core at the same power density.

On the basis of water-cooled test assemblies operating at the same power density as the reactor core the maximum heating rate is estimated to be 90 watts/cc at the inner surface and about 70 watts/cc at the outer surface of the through-tube of a Type-A reactor. 


\subsubsection{Reactor Vessel}

The heating at the inside surface of the reactor shell, which is about one-quarter inch from the active core, is a maximum of 90 watts/cc. At the outer surface the heating rate is about 70 watts/cc.

7.2.3 Reflector

Heating in the reflector at the surface next to the reactor core is 37.5 watts/cc. The overall average heating in the reflector is 3.0 watts/cc, $74 \%$ from gammas and the rest from fast neutrons. The total heat generated in the reflector is about 6.0 Mw during full-power operation of the Type-A reactor.

7.2.4 Thermal Shields

Heating in the thermal shields is entirely due to gamma ray absorption since fast neutrons, although detectible, are insignificant from a thermal point of view. The maximum heating in the inner surface of the inner thermal shield is 0.9 watts/cc. This decreases to 0.43 watts/cc in the second thermal shield, and to 0.17 watts/ce in the third. For the thicknesses shown, the thermal stresses set up in the thermal shields are less than 1000 psi.

\subsubsection{Biological Shield}

The maximum heating in the barytes concrete biological shield, at the inner surface, is 0.002 watts/cc. On the basis of equal temperatures on both sides of the shield, a conductivity of $0.87 \mathrm{Btu} / \mathrm{hr}-\mathrm{OF}-\mathrm{ft}$, and exponential attenuation, the maximum temperature rise in the shield is only $12{ }^{\circ} \mathrm{F}$ and this occurs at a point 9 inches from the inner surface. This is low enough to prevent excessive thermal stresses and cracking of the concrete. The inner surface of the concrete is cooled by a small stream of the reactor inlet water at $130^{\circ} \mathrm{F}$ which is routed through cooling coils. Under these thermal conditions the concrete does not lose its water of hydration, which is essential for fast neutron shielding.

\subsection{Biological Shielding}

The shielding of the AETR is based upon exposure of operating personnel to no more than one-tenth the tolerance exposure of $100 \mathrm{mr}$ per week during normal reactor operation at full-power.

As in other reactor operations, the bulk of the radiation exposure may well come from unplanned incidents during maintenance or reactor service operations. While supervision and 
health physics evaluation on the spot are indispensible, the reactor service facilities planned are conventional and similar to those in use at the ETR and the MTR. Therefore no attempt is made to estimate reactor service radiation exposure on a quantitative basis.

However, radiation exposure through the primary reactor shields is calculated and discussed in the paragraphs below.

\subsubsection{Radial Concrete Thickness}

In a radial direction the core is shielded successively by $\mathrm{D}_{2} \mathrm{O}$, stainless steel thermal shields, and barytes concrete. Due to the two-foot thick reflector and the thermal shields near the core, the attenuation required in the concrete is reduced. Based on calculated doses for various concrete thicknesses, five feet is selected as satisfactory and safe (see Figure A6.B). For this thickness, the dose rate at the outer shield surface is $0.1 \mathrm{mr} / \mathrm{hr}$.

\subsubsection{Pool Depth}

The reactor is situated beneath a pool of water 21.5 feet deep. Water allows simple core and experiment replacement when the pressure vessel is opened and at the same time can furnish a dependable bulk shield.

Assuming the water above the reactor at an average temperature of $130^{\circ} \mathrm{F}$, the dose rate at the surface of the water abuve the steel slab which covers the reactor pressure vessel is 1.3 $\mathrm{mr} / \mathrm{hr}$. This is considered high, but it can be reduced further through the use of additional shields above the reactor during full-power operation.

\subsubsection{Primary coolant System}

The shielding of the primary coolant of the AETR is based on a comparison with the ETR. The AETR and the ETR have about the same thermal neutron flux and water velocity in the core. Therefore, the activity of the primary coolants of both are about the same, assuming that the purity of the coolants are equal. Accordingly, shielding of all primary coolant pipes follows ETR practice, and the plpes are shielded by four feet of concrete or its equivalent at all points between the reactor and the heat exchanger building.

\section{3 .4 Experimental Loop System}

The experimental loop equipment is located in a basement level loop room adjacent to each reactor. This room is never entered during reactor operation. It is shjelded from the rooms above and below by three feet of ordinary concrete. This provides shielding adequate for highly radioactive loop equipment. 


\subsection{REACTOR FACILITY ARRANGENENT}

The AETR installation occupies an area of approximately 1,000,000 sq ft due north of the existing MTR-ETR side. The principal facilities of the AETR consist of two buildings, the reactor building and office building, cooling towers, and a hot waste storage tank. The layout is shown by Figure 8.A. Also shown are the ventilation building, stack, cooling tower, and retention basin. The capacities of the present MTR-ETR sewage Qisposal, water treatment, and steam plant facilities are expanded to provide for the AETR.

\subsection{Reactor Building}

The reactor building is $320^{\prime} \mathrm{x} 164^{\prime}$, rises 41 feet above grade, and has a 40-ft depth below grade (See Figures $8 . B$ and 8.E). The reactor building (Figure 8.E) contains eight sections, four sections on each side of a central $40^{\prime} \times 164^{\prime}$ access area. Seven of these sections are identical containing a reactor and its supporting equipment such as the canal, experimental loop equipment, reflector system, heat exchangers, reactor and experiment controls, amplifiers, and emergency equipment. The general arrangement of each of these reactor units is shown by Figures 8.B, 8.C, 8.D. The eighth section is used for a general service area for hot waste processing equipment, and compressors for air-cooled experiments. Except for the specific requirements for seven major test loops, this area would normally be used for an eighth reactor unit.

The two main working levels in the reactor building are the basement and first floor. Two rooms, the sub-pile room and the room for reflector cleanup and heat exchangers, are located below basement level. The lower floor levels are served by a passenger elevator and a freight elevator and are also accessible through stairways and hatches. The floors and walls are concrete. Except for the primary heat exchanger room, the roof construction consists of steel decking and built-up roofing. The roof of the primary heat exchanger room consists of 3 -ft thick concrete to provide biological shielding.

\subsubsection{Reactors}

The general arrangement of the reactors in the building is shown by Figures $8 . \mathrm{B}, 8 . \mathrm{D}, 8 . \mathrm{E}$. The reactor core is located slightly below the basement floor level. The top of the pool is 3-ft above the reactor room floor. The reactor room is $41^{\prime} \times{ }^{\prime}$ ' $x$ 4I' high. The 3-ft thick concrete floor in the reactor room serves as the reactor work area as well as a biological shield from experimental equipment at the basement level. Equipment in the room includes a 30 -ton and a 5-ton crane. 
The sub-pile room is located directly below the reactor, inside the biological shield. This room provides access to the reactor bottom head and the bottom end of the through-tube. Access to the room is through the reflector systems room.

\section{1 .2 Canals}

Each canal consists of three sections: a working section in each of two adjacent reactor rooms, and a storage section located in the general access area. The water depth in the canal is 21 feet. The water is supplied from the demineralized storage tanks and is continually purged to keep the activity below a permissible level. Although, each canal is common to two reactor rooms and the general access area, the walls between these rooms extend down into the water a distance of one foot. This provides a seal between the rooms so that contamination does not spread from one to the others. The storage canal provides space for spent fuel, irradiated test assemblies, and irradiated equipment. The work canal serves as passageway between the reactor and storage canal. Using long-handled grappling tools, spent fuel assemblies and irradiated equipment are transferred from the reactor pool to the working canal.

\subsubsection{Experimental Loop Equipment Rooms}

The experimental loop equipment room for each test loop is located adjacent to the reactor and immediately below the reactor room. Contained in the room are the heaters, heat exchangers, pumps and motors necessary for the test facilities. Location of the room near the reactor minimizes test loop piping. Access to the room is provided through hatches in the ceiling and through a shielding door. Hatches are also provided for instrumentation and test leads. The 3-ft thick wall serves as structural support and biological shielding.

\subsubsection{Reflector Cleanup and Heat Exchanger Room}

The reflector cleanup and heat exchanger room for each unit is located adjacent to the reactor and immediately below the experimental loop equipment room. The room is below the basement and at the sub-pile room level. Contained in the room are the reflector facilities, such as heat exchangers, recombining equipment, cleanup equipment, pumps, motors and the reflector dump tank. The reflector poisoning equipment for the reactor control system is also located in this room. The room is entered through ceiling hatches from the experimental loop equipment room or through a shielding door to the stairway.

\subsubsection{Control Rooms and Amplifier Room}

The reactor and experiment control room for each unit is located on the first floor between the reactor room and the primary heat exchanger room. Contained in the room are the 
controls and instrumentation for the reactor, the experimental loop, the primary and secondary coolant systems, the bypass demineralizer system, and the experimental air heaters, as well as radiation monitoring recorders.

The amplifier room is located at the basement level and directly below the control room. The electrical distribution systems, transformers, circuit breakers, and power supplies for controls and instrumentation are located in this area. There are no walls separating the equipment associated with the different reactors and thus there are two large amplifier rooms, one on each side of the reactor building.

\subsubsection{Primary Heat Exchanger Room}

The heat exchanger room adjoins the control rrom at the first floor level and is approximately $40^{\prime} \times 38^{\prime} \times 20^{\prime}$ high with concrete walls, floor and roof. Thls room houses the primary coolant heat exchanger, water cleanup equipment, and pressurizer.

For the Type-A reactor, the major items of equipment include three parallel banks of shell-and-tube heat exchangers, a shutdown heat exchanger, two banks of water cleanup equipment each including a filter and demineralizer, and a pressurizing tank. The Type-B reactor requires only two banks of shell-and-tube heat exchangers in parallel. A bank of heat exchangers consists of two heat exchangers with the primary coolant flowing in series through the tube sides, and the secondary coolant flowing in parallel through the shall sides.

The primary coolant supply and return lines are conncected with the reactor vessel through a vertical pipe chase and a horizontal concrete pipe trench. The vertical pipe chase is located between the pump room and the amplifier room and the pipe trench is beneath the basement level. The secondary coolant supply and return lines are connected to the cooling towers through the pipe chase and trench but branch off to a second pipe trench leading to the cooling towers. Removal of heat exchanger room equipment for replacement or repair is accomplished through an opening in the outer wall which is sealed with removable concrete blocks. Personnel can approach the heat exchangensia a manhole and a ladder from the pump room.

8.1 .7 Pump Room

The pump room is adjacent to the amplifier room (although separated by the vertical pipe chase) directly below the heat exchanger room. The pumps for the individual reactors are not separated by walls and thus a single long room houses all the primary coolant pumps and motors for the reactors on one side of the reactor building. The pumps are located in separate shielded caves to permit direct maintenance on one while others, 
and the reactor, are in operation. The motors are located on the opposite side of a shielding wall and are connected to the pumps by extended drive shafts.

The major items of equipment for each Type-A reactor include three 4000-gpm pumps with 200 horsepower motors to circulate primary coolant, a 350 gpm pump and 10 horsepower motor for shutdown and emergency cooling. The Type-B reactor equipment is identical, except there is one less primary coolant pump and motor. For both pump rooms, the controls and operating instruments are located in the respective reactor control room. A 7.5 -ton traveling crane to remove and relocate pump pit shielding is included in each of the two pump rooms.

\subsubsection{Emergency Equipment}

For each of the seven reactors, the emergency equipment consists of the following items:

1. One 350 gpm pump paralleling the primary coolant pumps. This pump is also utilized during normal reactor shutdown.

2. A back-pressure valve controlled by a pressure controller and connected to the frequency detection relay.

3. An electric power frequency-measuring device and various flow, pressure, and temperature measuring devices in the primary loop.

4. A 120-cubic foot surge tank containing approximately 300 gallons of water and 80 cubic feet of air.

5. An 8-inch pipe line from the plant main fire loop with a manual connection to the primary coolant system.

The emergency power is obtained from an alternate, independent power line from outside the NRTS area. A quick-closing circuit breaker shifts from normal to the alternate power line in 0.3 seconds. This is less expensive to build and less expensive to maintain than the equivalent failure-free battery capacity plus backup diesel-electric emergency power.

8.2 Office Building

The office building adjoins the south wall of the reactor building (See Figure 8.A). It is a $41^{\prime} \times 92^{\prime} \times 24^{\prime}$ high steelframe and concrete-block stmucture with a basement and two above ground stories. Gas-tight doors, located in the common wall, provide entrance to the reactor building, general access area and to both control rooms nearest the office building. Since each amplifier room extends the full building width, since the 
control rooms are interconnected, and since each reactor room opens onto the general access area, there are at least three routes to every reactor from the office building.

\subsection{Cooling Towers}

Sixteen large commercially available cooling towers are used in the secondary system. The associated secondary pumps and motors are located at the towers and include sixteen 6600-gpm pumps and sixteen 200 HP motors. The location of the cooling towers is shown by Figure 8.A.

8.4 Hot Waste Storage

The hot waste storage tank is located immediately west of the reactor building. This location minimizes the length of the stainless steel piping between the hot waste storage and the potential sources of high activity waste. 
9.0 REACTOR OPERATIONAL PROCEDURE

An AETR facility resembles existing test reactors in that is has storage canals, primary and secondary coolant systems, heat exchangers, loop test equipment and a relatively short reactor operating cycle.

Barring accidents and scrams due to test loop malfunction, an AETR should start operating, for instance, on a Monday and shut down on a Friday, 19 days later. This allows every third weekend for refueling, maintenance, experiment removal, and reactor cleanup. Such a cycle keeps the reactor operating over $90 \%$ of the time.

However, this facility is unique in that it has but a single major test $100 \mathrm{p}$ per reactor. The reactor is also unusual in its high power density, annular configuration, and reflector controls. In these respects, operational procedures vary from those of conventional testing reactors.

\subsection{Normal Startup and Shutdown}

Before attempting startup, the test loop is brought up to temperature by means of heaters or by operating the test loop circulating pumps. This is a safety precaution since calculations indicate that the test loop may have a positive temperature coefficient.

Concurrently, secondary coolant flow to each of the reflector heat exchangers is initiated. Then the reflector circulating pumps are turned on to mix the reflector $\mathrm{D}_{2} \mathrm{O}$ thoroughly. The outer reflector solution is checked to see that there is a high concentration of boric acid in it.

The pure $\mathrm{D}_{2} \mathrm{O}$ of the inner safety reflector is pumped from a sump through an eductor (Figure 3.G). The eductor vacuum is ineffectual when the bypass valves are open, their normal position when the reactor is shutdown or without instrument power. For startup, the valve is closed electrically and eductor vacuum raises the safety reflector to the top of its annulus. The reactor is still subcritical due to the heavily poisoned outer reflector, and it can be immediately made greatly subcritical by opening the bypass valve and dropping the safety reflector.

By closing a control valve, (Figure $3 . \mathrm{H}$ ) a progressively greater proportion of poisoned $\mathrm{D}_{2} \mathrm{O}$ from the reflector-shim can be bypassed through an ion-exchange column which removes boric acid gradualiy (or intermittently) until the reactor becomes critical. Orifices and pump size prevent poison removal at a rapid rate. From this point on, gradual temperature, burnup, and experimental effects are compensated for by changes 
in poison concentration in the shim reflector.

Shutdown is the reverse process. Poison can be added to make the reactor subcritical and the safety reflector can be aropped to scram the reactor in minimum time. Coolant flows are continued for ten minutes to remove decay heat. After this, reflector cooling can be terminated and the primary coolant circulated by means of the shutdown and emergency cooling pump. After removal of spent fuel assemblies, this pump can also be stopped.

\subsection{Refueling}

Full primary coolant flow is maintained until ten minutes after shutdown, at which time core heat generation is less than $2 \%$ of full power. Following this same ten-minute period, which allows nuclides with short half-lives to decay, the primary loop water is sampled to determine whether it should be retained, purified, or replaced.

The primary stystem, by this time well below $200^{\circ} \mathrm{F}$, is isolated from the main pumps and heat exchangers. The reactor vessel is vented to atmospheric pressure and cooled henceforth by the $350 \mathrm{gpm}$ shutdown pump and heat exchanger.

After flushing the reactor vessel with demineralized water the reactor vessel cover plate is removed using extension wrenches from above the reactor pool. The fuel elements are unlocked and lifted from the core individually by means of a grappling tool which is manually inserted from the top of the reactor through about twenty feet of water. Each spent fuel assembly is lifted into the reactor pool from the core annulus and is transferred directly to the canal through the bulkhead opening (See Figures 3.A, 8.D).

New fuel assemblies are introduced from the top of the reactor one at a time. The bottom of each of the fuel assembly side plates is machined to form an aligning vee. This enables each assembly to slide between adjacent assemblies and to mate with a tapered seat which accurately locates each assembly around the annulus.

\subsection{Experiment Access}

Pressurized water experiments are introduced into the through-tube by opening the tube at a flange ten feet above the reactor core (See Figure 3.A). As convenient, this may or not require a reduced water level in the reactor vessel. Normally bolts from this flange can be removed from above the reactor vessel. However, the radiation level is low enough after the reactor is shut down that direct access may be obtained, even if the fuel elements are not removed. Provided 
the test loop is uncontaminated, experiment removal is similar except that the water in the reactor vessel is at its full height. The experiment is removed using a long-handled tool and transferred directly to the canal through the bulkhead opening. If the experiment ruptures, it may be placed directiy in a coffin following removal from the test loop.

Handing of gas-cooled experiments requires that the water level in the reactor pool and vessel be at a level below the top of the through-tube. Gas-cooled experiments are introduced through the top of the through-tube by removing the shielded plug shown in Figure 3.A. Removal is more difficult and requires the use of a heavy, shielded coffin which can be mounted on the reactor vessel above the through-tube. The coffin is a special piece of equipment which includes a shielding plug that is lowered within the through-tube to engage the experiment. cooling of the experiment to remove shutdown heat may be necessary during the entire removal process. It is proposed that a flexible exhaust line be used to exhaust air through the coffin to the stack, and thereby cool the experiment when it is in the coffin.

The removal of liquid metal-cooled experiments is the most difficult. They can probably be removed most simply and safely by dumping and flushing liquid metal from the through-tube after the experiment has decayed long enough to make air cooling feasible. Then an air exhaust line is connected to the lonp and the air is exhausted through a filter to the stack. After removing the shield plug in the top of the through-tube, a coffin, also with an air exhaust line attached, is set in place above the reactor vessel. The experiment is lifted into the coffin and transported to a temporary storage location. Insertion is the reverse process without the coffin. Details for flushing air from the through-tube, melting the liquid metal previous ly dumped, and loop startup are uncertain, but could be similar to liquid metal loop practice at the ETR or elsewhere. 


\subsection{GENERAL UTILITIES}

In a facility the size of the AETR there is a large demand for general utilities such as steam, water, compressed air, electrical power, etc. It is therefore necessary to consider the quantity of these utilities required in order to determine whether or not there is a sufficient supply available at the NRTS. The utilities considered in this section are those required for the reactors and their directly related auxiliaries and do not include what may be necessary to supply the experimental facilities.

\subsection{Steam}

The major use of steam in the AETR facility is for space heating. It is estimated that the maximum demand for this use is about 25,000 $\mathrm{lb} / \mathrm{hr}$. Steam is also used for decontaminating equipment and the maximum demand for this use is estimated to be about $1500 \mathrm{lb} / \mathrm{hr}$. In addition, steam may be used to prevent icing of the cooling towers during severe winter weather. However, due to the high operating temperatures of the secondary coolant, it is doubtful. that the demand for this use should ever exceed abolt. $2000 \mathrm{lb} / \mathrm{hr}$. A low pressure steam supply ( $230 \mathrm{psi}$ ) of $28,500+\omega / \mathrm{hr}$ is adequate for all the above uses.

A relatively small. quantity of high pressure steam is requi red for the primary coolant system pressurizers and the radioactive liquid wastie system decontamination still. The maximum demand for this service occurs only when several reactors are shut down simultaneously and is expected to be below $500 \mathrm{Ib} / \mathrm{hr}$.

\subsection{Water}

Water is widely used in testing reactor facilities and adequate supplies of several kinds of water are necessary.

\subsubsection{Treated Water}

The major use for treated water in the AETR facility is as makeup water for the cooling towers. The maximum demand estimated for this use is $7700 \mathrm{gpm}$. However, for long term continuous use, the average demand for treated water should not exceed about $6500 \mathrm{gpm}$.

\subsubsection{Demineralized Water}

Potable water is used in all showers, lavatories and drinking fountains throughout the facility. The peak demand load for potable water is estimated to be about $250 \mathrm{gpm}$. 


\subsection{Electrical Power}

The estimated normal continuous demand on the AETR facility electrical supply lines is $8500 \mathrm{kw}$. The supply circuits, however, should be sized for a peak demand load of about $11,000 \mathrm{kw}$. The primary and secondary coolant pump motors and the cooling tower fan motors comprise about $75 \%$ of the normal continuous load.

\subsection{Compressed Air}

Low pressure compressed air is required for instruments and air-operated valves. The estimated maximum continuous demand for this service is 500 SCFM. High pressure compressed air may also be required. The magnitude of the demand for this service is difficult to estimate but it is not expected to exceed 200 SCFM.

\subsection{Acid Storage}

Acid storage is required for decontamination and for regenerating demineralizers. The estimated total capacity necessary for both purposes is 10,000 gallons.

\subsection{Sewage Disposal}

Sewage disposal facilities for a maximum of about 350 people are required. 


\subsection{RADIOACTIVE WASTE DISPOSAL}

This section is primarily concerned with the radioactive wastes generated by the facility itself and not those created by the experimental facilities. Solid, gaseous and liquid wastes are considered. Liquid wastes present a considerably greater proklem than solid or gaseous wastes.

11.1 Solid Wastes

Used fuel elements are the greatest source of solld radioactive matter generated by the AETR facility. These are processed at the Idaho Chemical Processing Plant (ICPP) so they present no waste disposal problem. Temporary storage space is provided for used fuel elements in the reactor canal. The only other solid radioactive wastes produced by the facility are: (a) used demineralizer beds and filters, (b) radioactive parts removed from defective equipment, (c) solid wastes produced juring contamination. Special equipment is provided for the removal and handling of radioactive demineralizer beds and filters and both of the other types of waste are periodically disposed of by crews from the Central Facilities staff of the National Reactor Testing Station. Methods for removing and handling highly radioactive equipment are primarily the responsibility of the health physics staff and no special difficulties are anticipated in this regard for the AETR.

\subsection{Gaseous Wastes}

The only truly gaseous radioactive waste produced by the AETR facility is a small amount of radioactive decomposition products from the $\mathrm{D}_{2} \mathrm{O}$ reflectors. The quantity and activity level of the $\mathrm{D}_{2} \mathrm{O}$ decomposition products is too small to constitute a disposal problem. They are continuously recombined to conserve the deuterium. Consequently very little gas is discharged from the system.

Alrborne radioactive particulate matter may occasionally by produced practically anywhere within the reactor building. This is carried out of the building via the ventilation ducts and the particulate matter is removed by the exhaust filters. Ultimately, this type of airborne waste is treated as a solid waste in the form of used filters.

\subsection{Liquid Wastes}

Radloactive liquid constitutes the bulk of the waste disposal problem for the AETR facility. Such wastes are ordinarily produced by: (a) leakage from the primary coolant systems, (b) leakage from the reflector systems, (c) filter and demineralizer 
bed wash and drain solutions, and (d) decontamination. It is also conceivable that a fuel element rupture may occur and, in this case, large quantities of high activity-level liquid waste may be produced.

The liquid waste storage and disposal system for the AETR is shown schematically in Figure 1l.A. All drain lines from the bullding, with the exception of the service drains, discharge directly into one of the two 10,000-gallon temporary storage tanks. These tanks are located in a concrete vault below the level of the sub-pile rooms. It is anticipated that the liquid waste concentration equipment may be located in the corner of the building not occupied by a reactor. The permanent radioactive liquid waste storage tank, with a capacity of 20,000 gallons, is located in a below-grade concrete vault some distance from the reactor building.

The temporary radioactive waste storage tanks have sufficient capacity to take all of the primary coolant from one reactor. The 250,000 galion retention basin has sufficient capacity for all the water from approximately four cooling tower basins. 


\subsection{RESEARCH AND DEVELOPMENT PROGRAM}

The following sections outline the areas in which research and development appear necessary. Research and development programs proposed and the cost and time schedules for such programs are estimated. The total estimated research and development costs are $\$ 445,000$, including construction of a mock-up, but not including the costs of $\mathrm{D}_{2} \mathrm{O}$ and $\mathrm{U}^{235}$.

\subsection{Critical Experiments - Nuclear Mock-up}

It appears that an AETR-type reactor can be designed and built without the benefit of critical experiments. This is particularly true if only one reactor unit is built and therefore optimization is not critical. However, even if a program involving construction of the whole AETR facility (seven reactors) is undertaken, the value of critical experiments is questionable. The reasons for this are given in the following paragraphs.

In a reactor of this type, $1 . e .$, fully-enriched test reactor, the critical mass is not a relatively important item provided the reactor can be loaded with enough fuel for satisfactory operation. In the AETR, the core size is based on heat transfer considerations and it is possible to increase the fuel loadings about $25-50 \%$. It is not necessary that the first loading of the reactor be the optimum, e.g., the full loading of the MTR fuel assemblies has been increased several times since it first went into operation (note that critical experiments were done for the MTR). Therefore since the fuel loading of the AETR can also be later modified if required, there appears to be no need to establish the critical mass by experiment.

The major design criteria for the AETR involve the neutron flux specifications in test holes of given sizes and containing certain coolants. In the nuclear studies of the AETR it is shown that, for the test hole requirements, (see Appendix 1.0) the optimum thickness of the water moderator annulus between the test hole and the core is $4 \mathrm{~cm}$. This same result was obtained in both the current work and that reported in INTERNUC-9*, even though there were appreciable differences in the nuclear constants (particularly those for water) used in the two studies. The major difference between the results of INTERNUC-9 and the present results in that for a given geometry, the test hole thermal neutron flux per Mw

* 0. J. Elgert, et al, INTERNUC-9, "Preliminary Investigations

- for an Advanced Engjineering Test Reactor" (February 1957) 
of reactor power is lower in the latter. This results in a higher reactor power, and a slightly thicker reactor core in order to provide the necessary heat transfer area. The thickness of the AETR cores are based on heat removal characteristics and reactor power levels. Therefore, the major difference between the actual nuclear characteristics of the AETR and the calculated characteristics is that the neutron flux in the test hole may be higher or lower than the calculated values. This only means that the reactor is not optimized for the specified $\left(1.5 \times 10^{15} \mathrm{n} / \mathrm{cm}^{2}-\mathrm{sec}\right.$ unperturbed) test hole thermal neutron flux. Since the test hole thermal neutron flux is perturbed more by the test hole composition than by minor changes in the reactor geometry and composition, there is no real justification for completely optimizing the reactor for a fictitious test hole composition.

The other major reactor parameters that critical experiments yield are data on the core metal-water ratio and the reflector thickness. Calculations show that the core metal-towater ratio has little effect on the test hole flux and therefore, the core metal-water ratio is based primarily on heat transfer considerations. However, even if the test hole flux does depend quite strongly on the core metal-water ratio, it cannot be changed greatly within heat transfer and fuel loading limitations. The reflector thickness (2-feet) is such that good neutron economy is achieved with reasonable thickness. Substantial changes in its thickness do not greatly affect the neutron flux in the test hole, and it is unlikely that critical experiments yield information that clearly indicates a need for a thicker or thinner reflector.

The above discussions indicate that even a rather extensive critical experiment program does not yield information which results in any significant changes in the geometry of the AETR. However, the program neglects completely the reflector control systems, which are probably the major uncertainties in the AETR design. While the non-nuclear development outlined in Sectior. 12.3 helps considerably in establishing the feasibility of these systems, it appears that operation of these two systems in conjunction with an active nuclear assembly is desirable before construction of the AETR. Since these systems are used for reactor control, and their operation is therefore related to the neutron lifetime in the reactor, they should be operated in conjunction with an active nuclear assembly of neutron Iifetime comparable to the AETR. While this can be accomplished with a critical facility, the installation of the reflector control system in an existing critical facility is probably difficult and in any event costly considering the short time it is used. A more attractive program involves the construction of a nuclear mock-up of an AETR. This 
program, which although slightly more expensive initially, gives a facility which would have continued valuable use during AETR construction and operation.

It is proposed that to satisfy the development needs of the AETR, a nuclear mock-up of a unit be constructed on or adjacent to the planned AETR site. A location adjacent to the MTR-ETR site is particularly suitable because of the other facilities available. The suggested facility consists of a low-cost installation similar to those of SPERT and OMRE projects. The reactor mock-up and all its equipment are housed in a $40^{\prime} \times 60^{\prime}$ Butler-type building on a concrete slab floor. At one end of the building are two pits: an 8-foot diameter, 12-foot deep pit to house the reactor; and an adjacent $12^{\prime} \times 12^{\prime} \times 10^{\prime}$ deep pit for the reflector control systems. The reactor assembly, which rests on the bottom of the water-filled reactor pit, consists of the reactor core assembly, reflector tanks, and the aluminum portion of the reactor vessel as shown in Figure 3.A. A shim-safety rod is installed in the central test hole of the reactor. This rod is used to remove and add reactivity to simulate normal full scale reactor operation and check the response of the reflector control system to such changes. The nuclear mock-up is a "zero power" installation and is cooled by natural convection of the water in the reactor p1t. The reactor control room is at the end of the building opposite the reactor. The estimated cost of this installation is given in Table 12.a.

Table 12.a

Estimated Cost of an AETR Nuclear Mock-up Facility

Site, excavation, building

Reactor assembly

Reflector control systems

Shim-safety rod

Reactor control panel and instruments

Miscellaneous equipment and instruments

Engineering Design

Contingency
$\$ 35,000$

20,000

45,000

5,000

40,000

$\$ \frac{20,000}{\$ 165,000}$

35,000

20,000

$\$ \overline{220,000}$

The above cost does not include fuel assemblies, which are estimated to cost $\$ 20,000$ including the development outined in section 12.2. It also does not include the cost of $\mathrm{D}_{2} \mathrm{O}$ and U235, which are about $\$ 300,000$ each. The above described facility can be designed, constructed, and placed in operation in nine months. 
Besides giving needed information on the operational characteristics of the reflector control systems, the AETR nuclear mock-up can be used to obtain much nuclear information. Since it is an exact duplicate of one AETR-type reactor the information is probably more representative than that from critical experiments. Information such as the following can be obtained.

1. Temperature and void coefficients for the test hole, moderator annulus, core, and reflector

2. Effects of various materials in the test hole

3. Effects of various materials in the moderator annulus

4. Effects of metal-water ratio in the core

5. Neutron flux distributions

6. Effects of shim poison in reflector on neutron fluxes in the test hole

7. Core power distributions

During the first year of operation, when much of the above information is being obtained, a staff of four technical and two non-technical are required to operate the facility. These operations costs, which are considered as part of development, are then about $\$ 130,000$.

After construction of the AETR facility, the nuclear mock-up would serve a valuable purpose as a facility for the nuclear check-out of experiments before they are placed in a reactor.

\subsection{Fuel Assembly}

The fuel assembly (Figure 3.F) described in Section 3.3.1 is designed specifically for an annular core and is unique in that assemblies of this type completely and uniformly fill an annular core with plates of constant thickness and spacing. The fuel plates are preferentially loaded to reduce the radial maximum-to-average power ratio in the core (see Figure 5.C). As is pointed out in the selection of this assembly (section 5.0 Part B), very nominal research and/or development costs are anticipated in the fabrication of the assembly because of previous industrial experience with curved plate, MTR-type fuel assemblies. The major development appears to be in preferentially loading the fuel plates. After consultation with: Babcick and Wilcox Company of Lynchburg, Virginia; 
Metals and Controls Company of Attleboro, Massachusetts; and General Electric Company of San Jose, California; the total cost of development, including preferential loading, is esinated at $\$ 10,000$. The estimated time required for development is four months. It is expected that the preferentially loaded plates can be fabricated economically by one of the following methods:

1. Machine meat and clad to shape; hot and cold roll to size

2. Extrude meat and clad to shape; hot and cold roll to size

\subsection{Reflector Control System}

The reflector control system of the AETR is of a new and unproven type, and certain developmental work is necessary. The development work outlined below is that which is associated only with the non-nuclear characteristics of the systems. This work should be done prior to and irrespective of further development undertaken for determining the overall suitability of the system to control the reactor.

The non-nuclear operating characteristics of the safety reflector can be fairly well established by a scaled-down system. This proposed pilot-plant model, using $\mathrm{H}_{2} \mathrm{O}$ rather than $\mathrm{D}_{2} \mathrm{O}$, is about a one-tenth scale model of the safety-reflector system. All the equipment is scaled down to one-tenth the flow and one-tenth the flow area. It is obvious that the height of the safety reflector regions must be as in the full scale system. However, the cross sectional area of the by-pass lines, and reflector are only one-tenth of full scale and the latter is circular rather than annular. The primary objectives of the tests undertaken with the safety reflector model are:

1. Determine suitability of eductor system for raising water level and circulating water in the safety reflector

2. Determine position vs time curve for dropping of reflector water level after scram

It is estimated that the above development will take about 4 -months to complete and will cost $\$ 20,000$.

The development necessary regarding the non-nuclear operating characteristics of the shim-reflector are concerned primarily with the feasible rates of addition and removal of poison from water $\left(\mathrm{H}_{2} \mathrm{O}\right.$ rather than $\left.\mathrm{D}_{2} \mathrm{O}\right)$ and the control and 
measurement thereof. The pilot plant for development of the shim reflector system can again be a scaled down model. Because of the larger volume, a scale-down factor of onetwentieth to one-fiftieth is suggested. It is estimated that the above development will take about 6-months to complete and will cost about $\$ 55,000$. 


\section{$13.0 \quad$ COST ESTIMATES}

The following estimates indicate that the AETR described herein can be completed in about three years at a cost of about $\$ 32,000,000$. This does not include the $\$ 445,000$ estimated for research and development. The estimated annual operating cost is $\$ 14,261,000$, of which $\$ 8,450,000$ is the cost of providing fuel for the reactor.

13.1 Design and Construction Costs

It is estimated that 4 to 6 months of development work may have to precede detailed design of the AETR. Detailed design can start concurrently with the development work. However, about 6 months of detailed design is desirable before start of construction. The facility can be complete and ready to operate 30 months after construction starts. Therefore, it is estimated that the AETR can be an operating facility about three years after a firm decision to build it.

Table 13.a presents a cost estimate of the seven-reactor AETR concept with buildings and equipment as shown by Figures 3.A-3.F, 5.A, 5.G, 8.A-8.E, and II.A

The construction cost estimate is based primarily on engineering and construction cost information for the NRTS and the ETR. This information*, ** furnished by the Idaho Operations Office of the AEC, was of inestimable value in preparing the construction costs.

13.2 Operating Costs

A proposed shift operating crew for the AETR is outlined in Table 13.b. This list does not include malntenance personnel that may also ordinarily be on shift work. The total estimated operating staff and the estimated cost thereof is given in Table 13.c.

Table 13.d summarizes the estimated costs of providing fuel for the AETR and are based on the reactors operating at full power $85 \%$ of the time.

Table 13.e sumnarizes the estimated annual cost of materials and services. The use charges for $\mathrm{D}_{2} \mathrm{O}$ are based on a $4 \%$ charge on $\$ 2,500,000$ worth of $\mathrm{D}_{2} \mathrm{O}$ at $\$ 28 / 1 \mathrm{~b}$. The make-up costs for $\mathrm{D}_{2} \mathrm{O}$ are based on a $D_{2} O$ loss of 3 liters/day.

* Construction Project Final Cost Report - Engineering Test Reactor, by Kaiser Engineers for Idaho Operations Office of USAEC .

* Engineering and Construction - Typical Unit cost Report, by Phillips Petroleum Company for Idaho Operations Office of USAEC . 
Table $13 . \mathrm{a}$

Construction cost Summary - AETR

A. Reactor Vessel \& Contents

Reactor pressure vessels fittings \$ 850,000 Core vessel and reflector tank assemb ly

Fuel assemblies (lst loading) Thermal shields 200,000 70,000 300,000

$\$ 1,420,000$

B. Handling Equipment

Fuel coffins (2) Fuel storage racks Miscellaneous handing tools Fuel cut-off saws Experiment handling coffins (3)
70,000

10,000

15,000

15,000

120,000

C. Reactor Building structure

Excavation and backfill Building concrete (common)

Shield and pool (common and barytes concrete)

Structural steel

Flooring and roofing

Insulation

Miscellaneous building fixtures

$\begin{array}{r}110,000 \\ 3,000,000 \\ 540,000 \\ 1,350,000 \\ 80,000 \\ 50,000 \\ 250,000 \\ \hline\end{array}$

$5,380,000$

D. Reactor Building Equipment

Cranes (7 30-ton, 2 10-ton,

1 40-ton;

Service elevators (2 5-ton)

Heating and ventilating

Plumbing (water, steam,

Electric service (outlets, lights, wiring, etc.)

Compressed air service

communications equipment

$$
\begin{array}{r}
375,000 \\
20,000 \\
250,000 \\
500,000 \\
325,000 \\
75,000 \\
55,000
\end{array}
$$


(Table 13.a Continued)

E. Primary Cooling System

Piping and valves

Heat exchangers

Pumps and motors

Water clean-up equipment

Pressurizer systems

$$
\begin{array}{r}
1,350,000 \\
2,210,000 \\
180,000 \\
80,000 \\
100,000 \\
\hline
\end{array}
$$

F. Secondary Cooling System

Piping and valves

Pipe trenches (includes electrical conduit)

Basins, cooling tower and retention cooling towers

Pumps and motors
910,000

500,000

360,000

640,000

120,000

$2,530,000$

G. Reflector System

Piping and valves

Heat exchangers

Pumps and motors

Water clean-up equipment

Recombiner system

Drain collection and recovery system

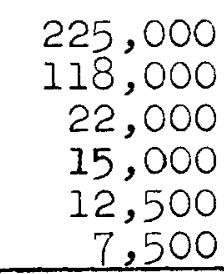

400,000

H. Instrumentation

Reactor

Primary cooling system

Secondary cooling system

Reflector cooling system

Waste treatment and disposal

Radiation monitoring
$1,700,000$

$1,000,000$

400,000

280,000

30,000

$530,0,00$ 
(Table 13.a Continued)

I. Waste Treatment and Disposal

$$
\begin{aligned}
& \text { Piping and valves } \\
& \text { Concentrating still } \\
& \text { Temporary storage tanks } \\
& \text { Permenent storage tanks } \\
& \text { Pumps and motors } \\
& \text { Concrete tank vaults }
\end{aligned}
$$

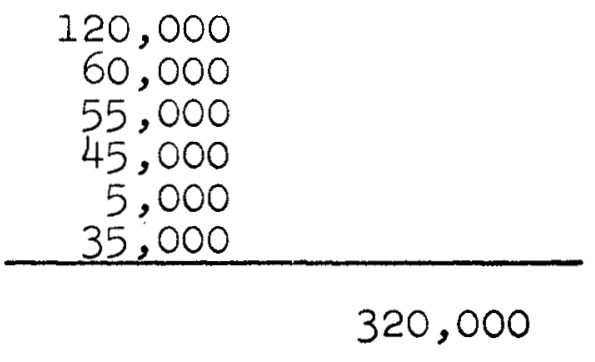

J. Auxiliaries

Demineralizers and demineralizer $\mathrm{H}_{2} \mathrm{O}$ storage

$\mathrm{D}_{2} \mathrm{O}$ storage and distribution system Stack

Waste water disposal

Sewage plant

Pumping station $(8,000 \mathrm{gpm}$ capacity) Water treatment plant (7000 gpm capacity)

Electrical substation and distribution system

Fire protection system

$$
\begin{array}{r}
50,000 \\
25,000 \\
100,000 \\
15,000 \\
150,000 \\
320,000 \\
750,000
\end{array}
$$

$2,000,000$

650,000

4,060,000

K. Site Development

200,000

Total Materials \& Construction

$24,000,000$

Engr. Design \& Supervision (15\%)

$3,600,000$

Contingency (15\%)

$4,140,000$

$\$ 31,740,000$ 
Table $13 . b$

\section{Shift Operating Crew}

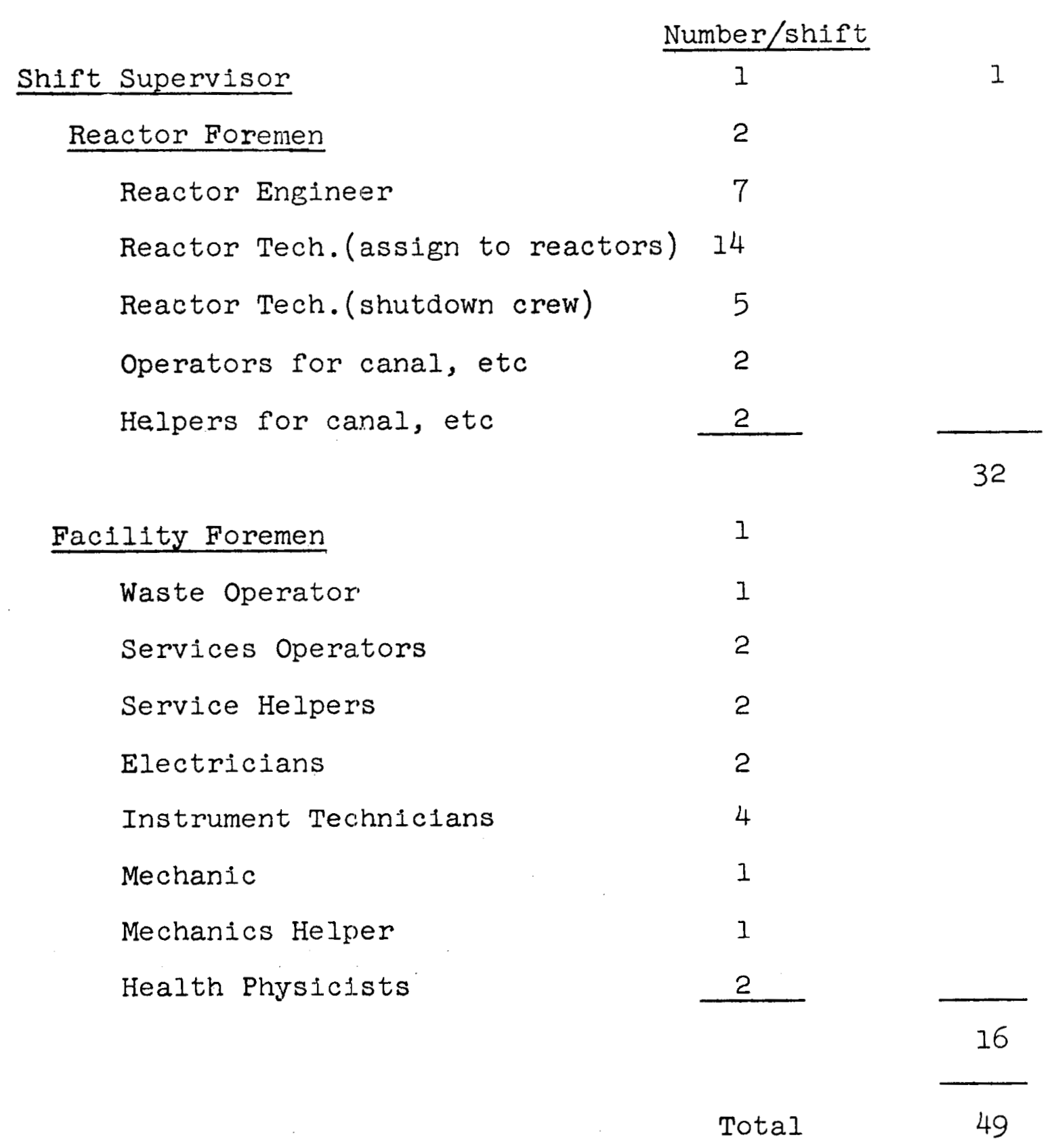


Table 13.c

AETR Manpower Estimate

Title

Operations

Day superintendent

Asst. day supt.

Shift supervisor

Facility shift foremen

Reactor shift foremen

Reactor engineers

Reactor technicians

Operators

Waste operators

Services operators

Services helpers

Helpers

Electricians

Instrument technicians

Mechanics

Mechanic helpers
Number $\quad \begin{aligned} & \text { Annual } \\ & \text { Salary }\end{aligned}$

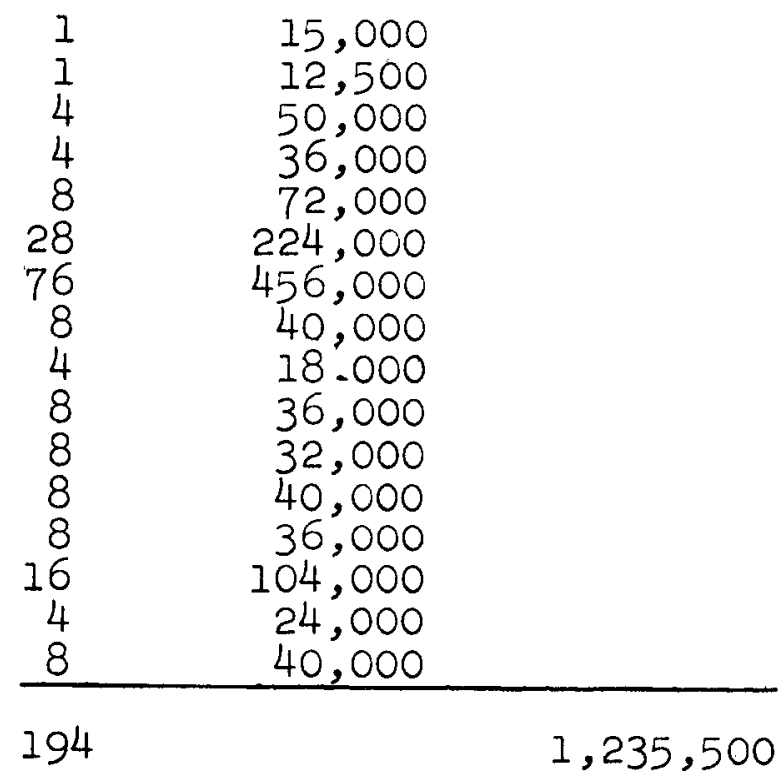

Health Physics

Supervisor

Assistant supervisor

Shift health physicists

Sub total

\begin{tabular}{lrl}
1 & 10,000 & \\
1 & 9,000 & \\
8 & 64,000 & \\
\hline 10 & & 83,000
\end{tabular}

Engineering

Project engineers

Plant engineers

\begin{tabular}{rr}
14 & 112,000 \\
8 & 64,000 \\
\hline
\end{tabular}

Sub total

22

176,000 


$$
\text { (Table 13.c Continued) }
$$

Title $\quad$ Number $\begin{aligned} & \text { Annual } \\ & \text { Salary }\end{aligned}$

Maintenance

Supervisor

Assistant supervisor

Foremen

Welders

Welders helpers

Pipe fitters

Pipe fitters helpers

Mechanics

Instrument technicians

Electricians

Sub total

\begin{tabular}{lll}
1 & 12,500 & \\
1 & 10,000 & \\
4 & 28,000 & \\
4 & 24,000 & \\
2 & 10,000 & \\
4 & 24,000 & \\
2 & 10,000 & \\
8 & 48,000 & \\
8 & 48,000 & \\
4 & 24,000 & \\
\hline 38 & &
\end{tabular}

Secretarial

Secretaries

Clerks

\begin{tabular}{rr}
$\begin{array}{r}8 \\
8\end{array}$ & $\begin{array}{r}32,000 \\
28,000\end{array}$ \\
\hline 16 & 60,000 \\
280 & $1,793,000$
\end{tabular}

Total

sub total

280

Social Security and Personnel Benefits (15\%) 269,000

$\$ 2,062,000$ 
Table 13.d

Reactor Fuel Costs

Item

Burn-up

Fabrication

Processing

Transportation charges

Total
Annual Cost

$\$ 6,700,000$

900,000

750,000

100,000

$8,450,000$

Table 13,e

Materials and Services

Item

$\mathrm{D}_{2} \mathrm{O}$ use charge

$\mathrm{D}_{2} \mathrm{O}$ make-up

Electricity

Fue 1

Operating chemicals

Demineralizer beds and filters

Maintenance supplies

Tool and equipment replacement

Telephone

Miscellaneous

Total

Annual Cost

$\$ 100,000$

75,000

400,000

75,000

150,000

65,000

250,000

35,000

20,000

40,000

$1 \longdiv { 2 1 0 , 0 0 0 }$

\section{Table 13.f}

\section{Overall Operating Cost Summary}

Capital charges (8\% of Table 13.a) Operating staff (Table 13.c) Reactor fuel costs (Table 13.d) Materials and services (Table 13.e) Total
$\$ 2,539,000$

2,062,000

$8,450,000$

1,210,000

$14,261,000$ 


\subsection{THIMBLE FACILITY}

From the reactor selection description of Part-B there may be noted a number of attractive features for a testing reactor designed around a thimble-type loop tube.

The selection of the through-tube type reactor described previously is based on minimum overall operating cost. However, it may be desirable to proceed on a more modest scale than that necessary for the construction of a facility with seven reactors. If consideration is given to the construction of only one reactor rather than seven, then the thimble reactor with a core the size of the Type-B reactor is a logical choice. Its construction cost is less than that of a through-type reactor and it is more versatile with respect to experiment handling. This type facility could accommodate water-cooled test assemblies up to 4 inches diameter and liquid-metal-cooled or gas-cooled test assemblies up to 3.3 inches diameter.

14.1 Arrangement

In an effort to capitalize on the potential simplicity of a thimble-type testing reactor, a reactor layout was developed and is shown in Figure 14.A. While similar in many respects to the AETR design, the absence of a through-tube permits simpler reactor vessel construction. In order further to reduce construction costs, since there are no concrete walls or shielding needed for a sub-pile room, the lower portion of the reactor pressure vessel is lowered into an excavation and is backfilled with earth. The vessel is supported from the upper flange area and located beneath the reactor pool, similar to the AETR and separated from the canal by a removable bulkhead. Within the building, the reactor is located the same way as shown in the single reactor facility drawings, 8.B, 8.C, and 8.D.

\subsection{Experimental Fac1lities}

The thimble facility is based on the smaller Type-B reactor core with the thimble-type loop tube. Thus it can perform many of the irradiations specified for the 4-in test hole. This is true because the thimble design has substantially the same thickness of water moderator around the test section as the Type-B through-tube. Thus the thimble can perform pressurized water experiments with $2.1 \times 10^{15} \mathrm{n} / \mathrm{cm}^{2}$-sec average test hole at a power of $100 \mathrm{Mw}$, the same as the through-tube.

For gas and liquid metal-cooled experiments the thimble is best made of the same diameter as the through-tube for the Type-B core in order to provide sufficient thickness of moderator water around the tube. The facility can then obtain the specified flux, at $100 \mathrm{Mw}$ rated power, in a test assembly of about 3.3 inches diameter. 


\subsection{Components}

Except for the items discussed below, the components required for the minimum facility are the same as those described for the AETR.

The loop tube is the principal component which differs from those described heretofore. To accommodate the same size test assembly, the thimble must be of larger diameter than the through tube. The larger size coupled with the end closure nakes manufacture of the thimble more difficult than that of the through-tube.

The reactor pressure vessel is similar, to the AETR, but is simpler since no thermal shields and no bottom access are required. The principal saving in construction cost is expected from the substitution of soil backfill for the usual steel and concrete thermal shielding with the thought that radiation damage or heating in the soil outside the reactor pressure vessel wall is not serious so long as the integrity of the pressure vessel is maintained by careful structural design.

\subsection{Costs}

By amending the figures for construction cost given in Chapter 13.0 for the decreases in reactor power to $100 \mathrm{MW}$ instead of $170 \mathrm{Mw}$ and the simplification in the building and reactor vessel, the following figures are obtained.

\section{Table $14 . \mathrm{a}$}

\section{Construction Costs for Minimum Facility}

\section{Item}

Reactor Vessel and Contents

Handiing Equipment

Reactor Building Structure

Reactor Building Equipment

Primary Cooling System

Secondary Cooling System

Reflector System

Instrumentation

Waste Treatment and Disposal (MTR Facilities)

Auxiliaries (MTR stack, fire, water and sewage

Site Development

Total Materials and Construction

Engineering Design and Supervision (15\%)

Contingency $(15 \%)$
Cost

$\$ 120,000$

60,000

600,000

250,000

400,000

190,000

40,000

420,000

20,000

200,000

$\$ \frac{30,000}{2,330,000}$

349,500

402,000

$\$ \overline{3,081,500}$ 


\subsection{Conclusion}

The above costs, a little under $10 \%$ of the cost of the full AETR facility, represent the thimble facility by itself. They are based on using MTR auxiliaries as indicated. The building costs can be further reduced by using the type of construction used for the SPERT and OMRE facilities. This type installation is attractive if there is a desire to build only one AETR-type reactor, and do it in minimum time and at minimum cost. A thimble-type reactor can be in operation in less than two years after the project is initiated. 
Figure 3.A Reactor Elevation

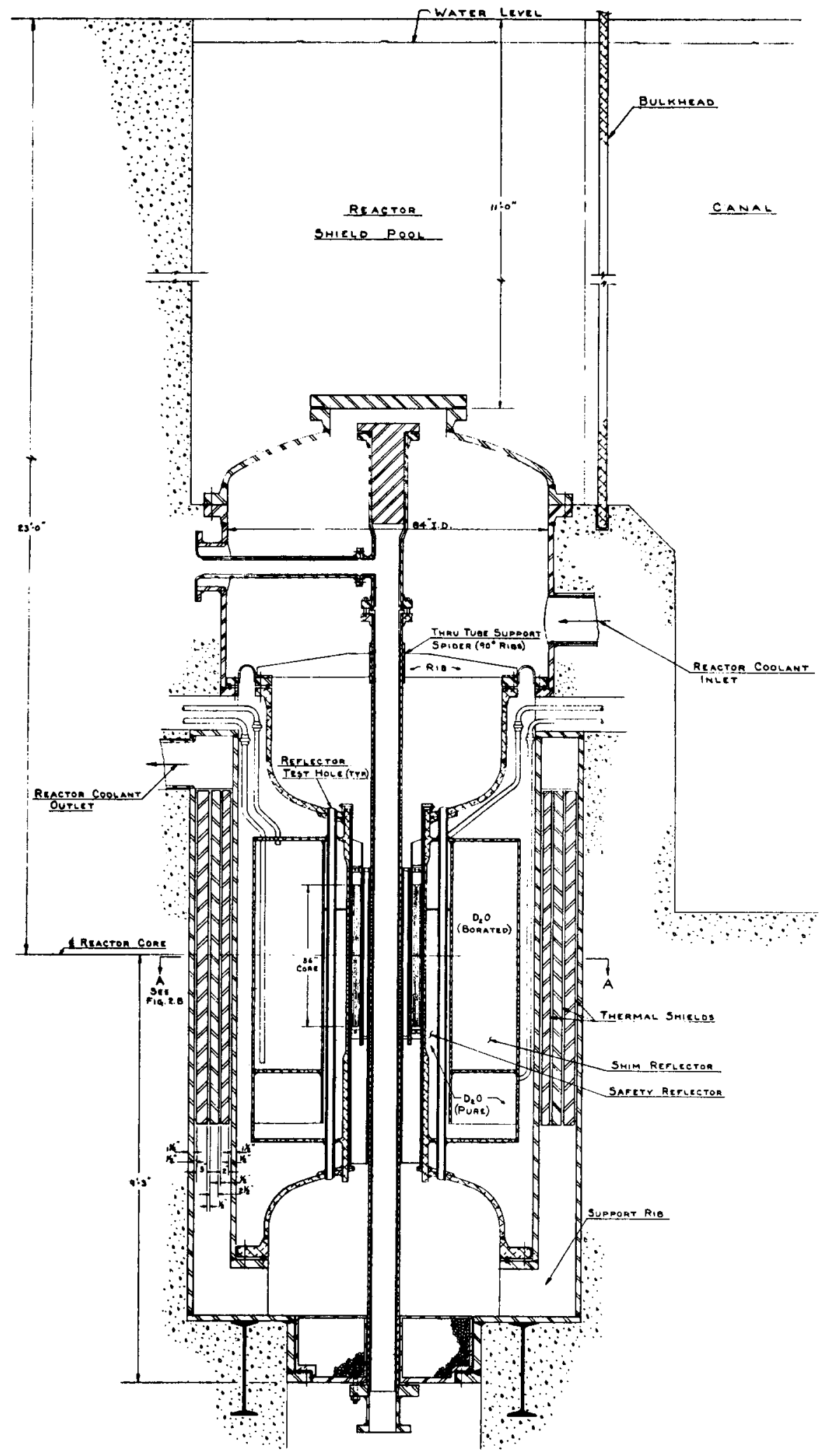

Fig. 3.A 
Figure 3.B Reactor Mid-Plane Cross Section

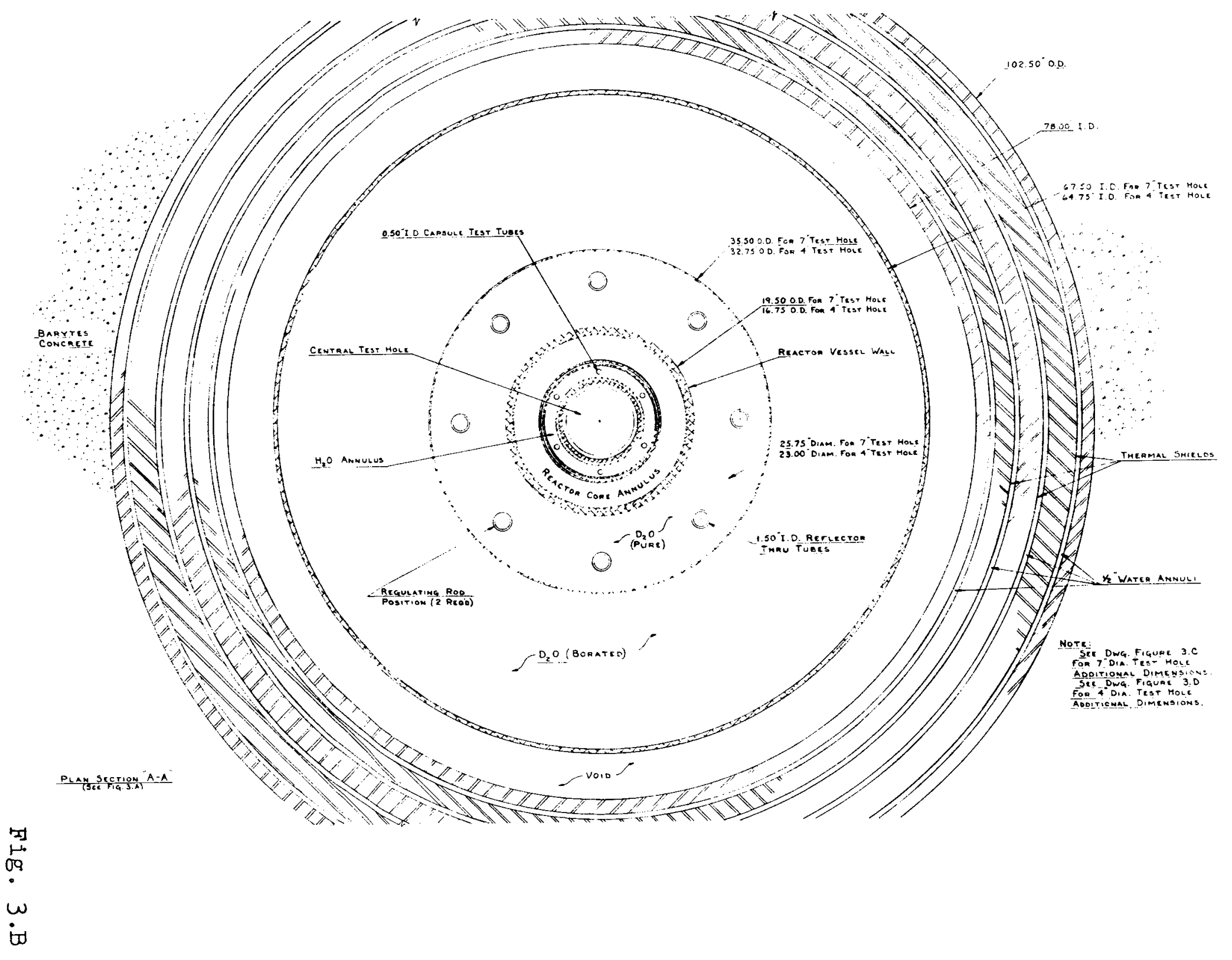


94

Figure 3.C Type A Reactor-Core Cross Section

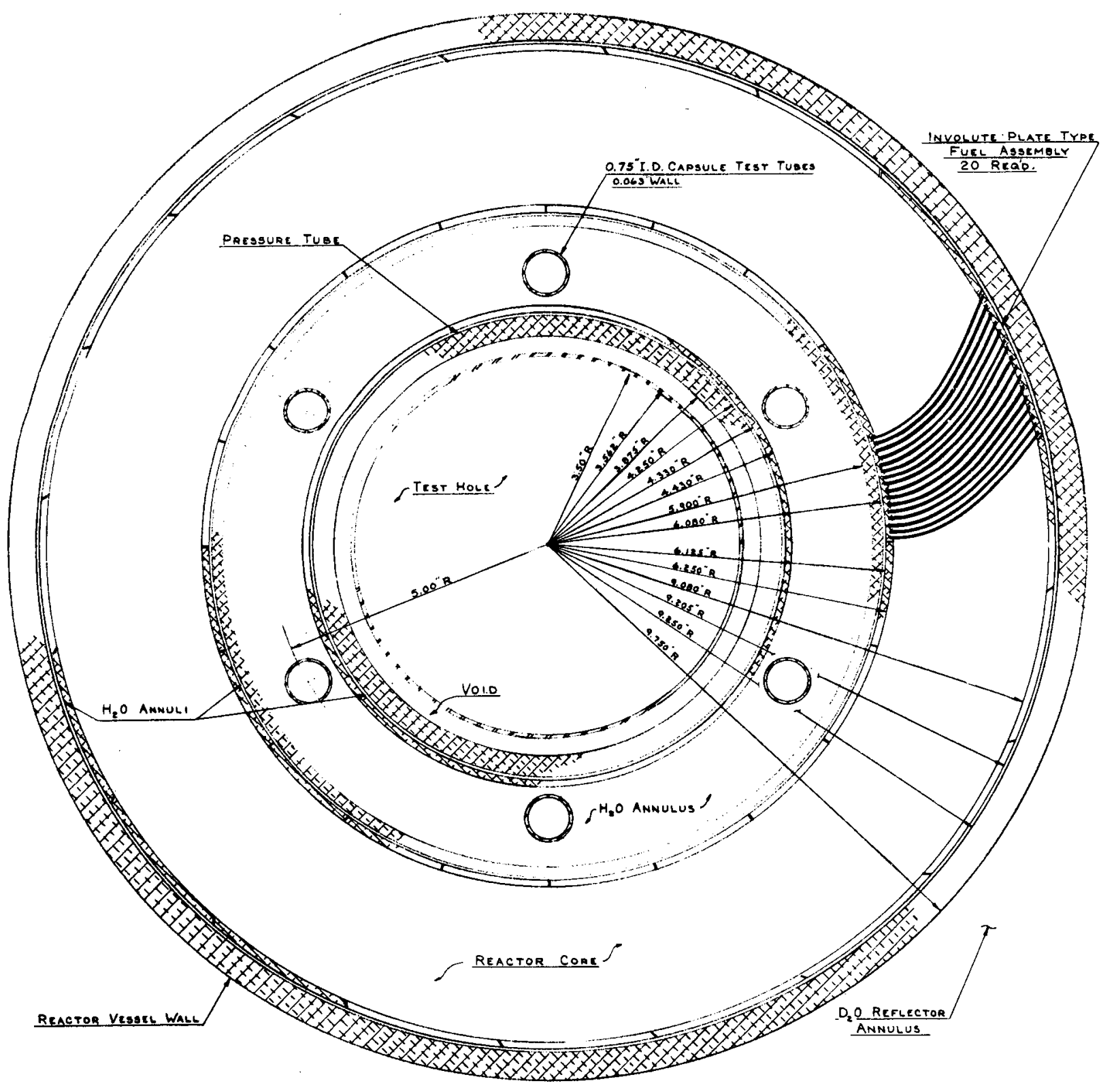

Fig. 3.C 
Figure 3.D Type-B Reactor-Core Cross Section

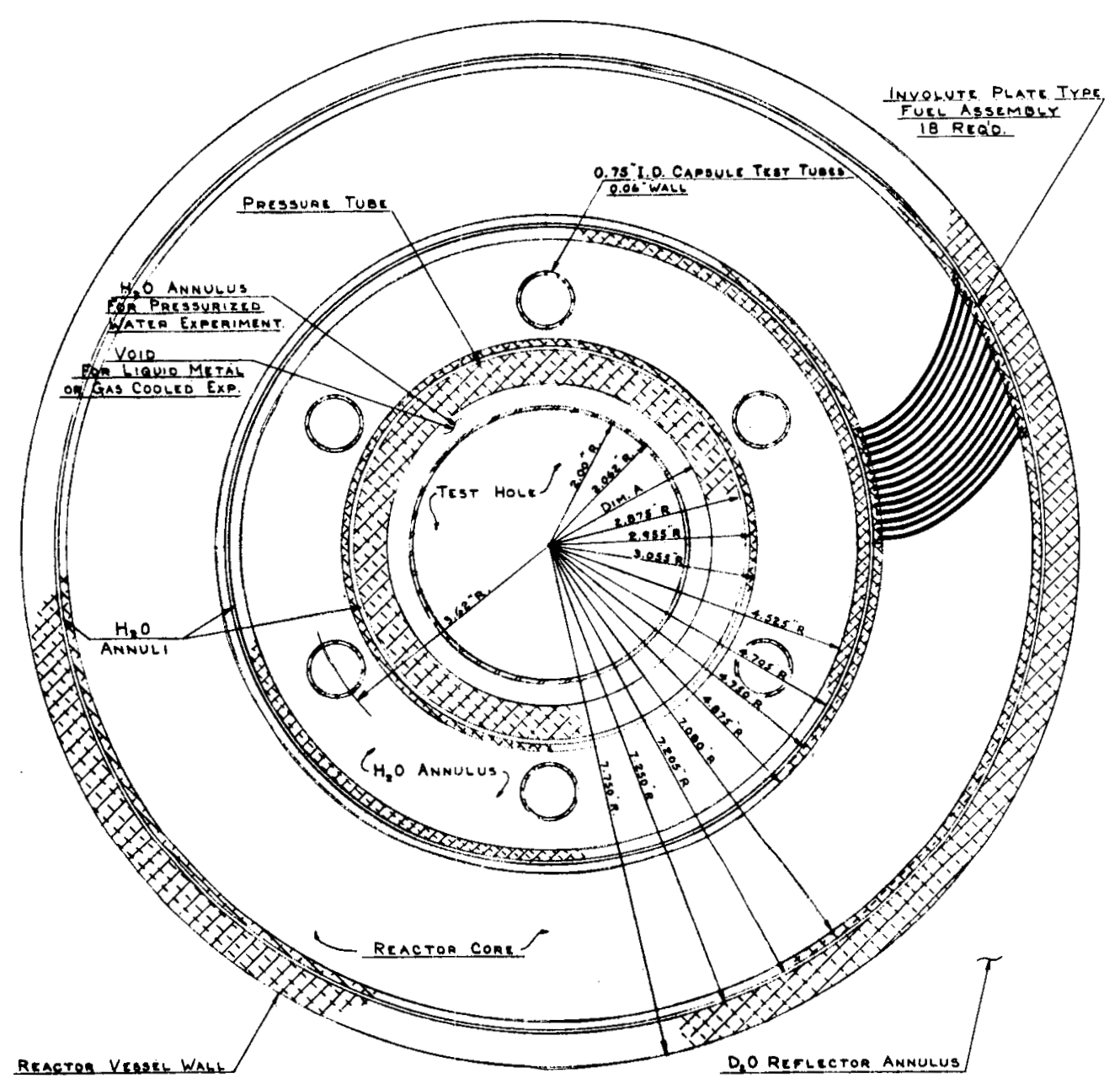

Fig. 3.D

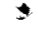


Figure 3.E Reactor Core Structure-Vertical Section
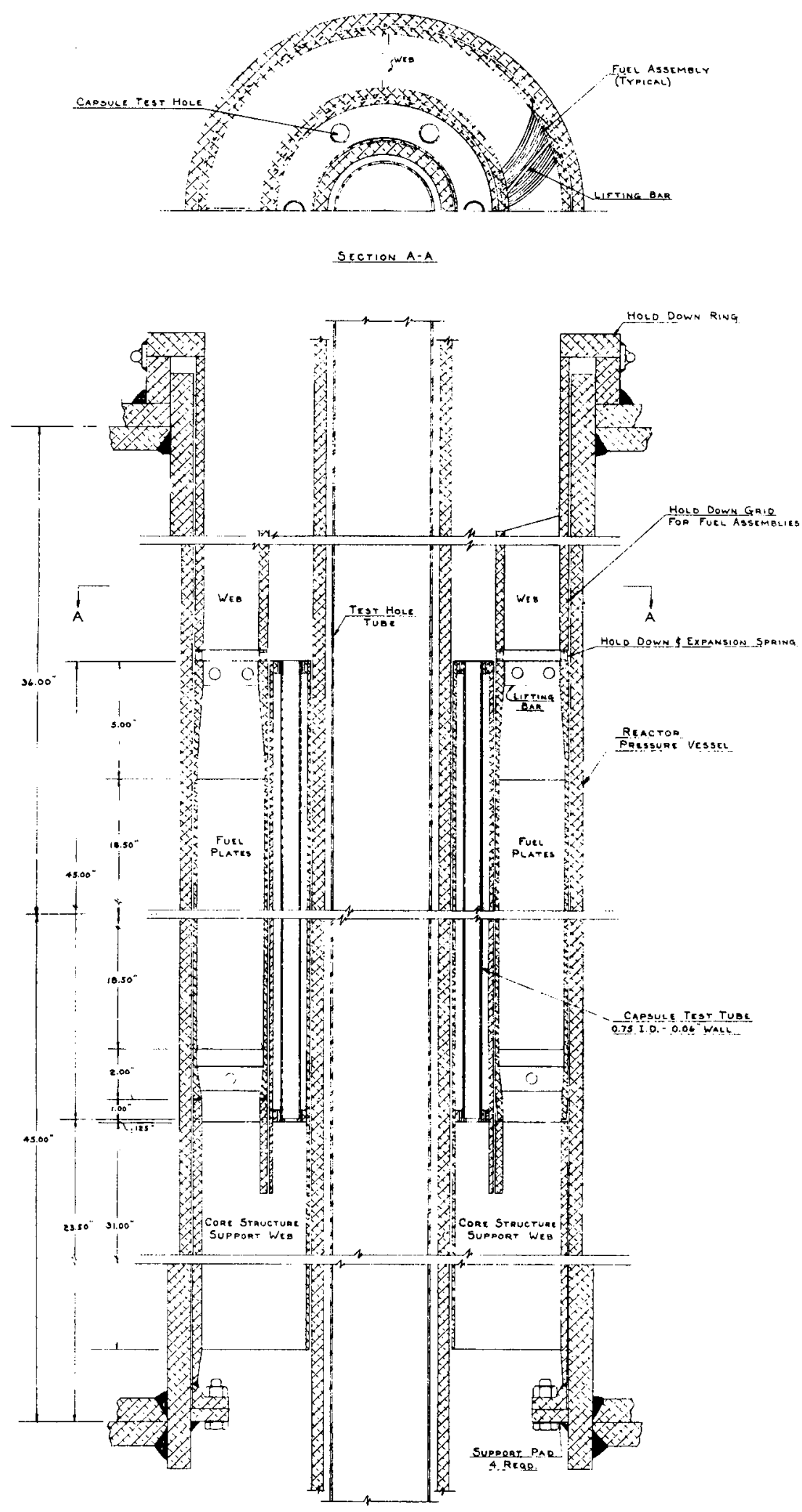

Fig. 3.E 
Figure 3.F Fuel Assembly
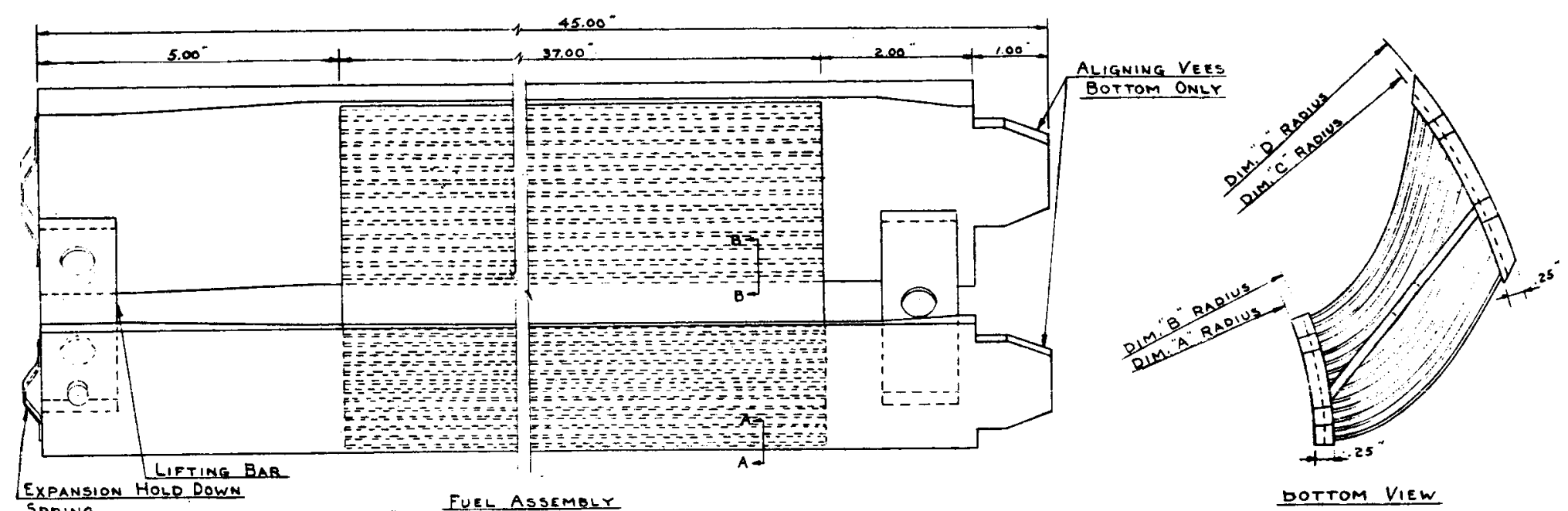

4"DiA. FUEL ASSEMGLL Scale: Full Sizz
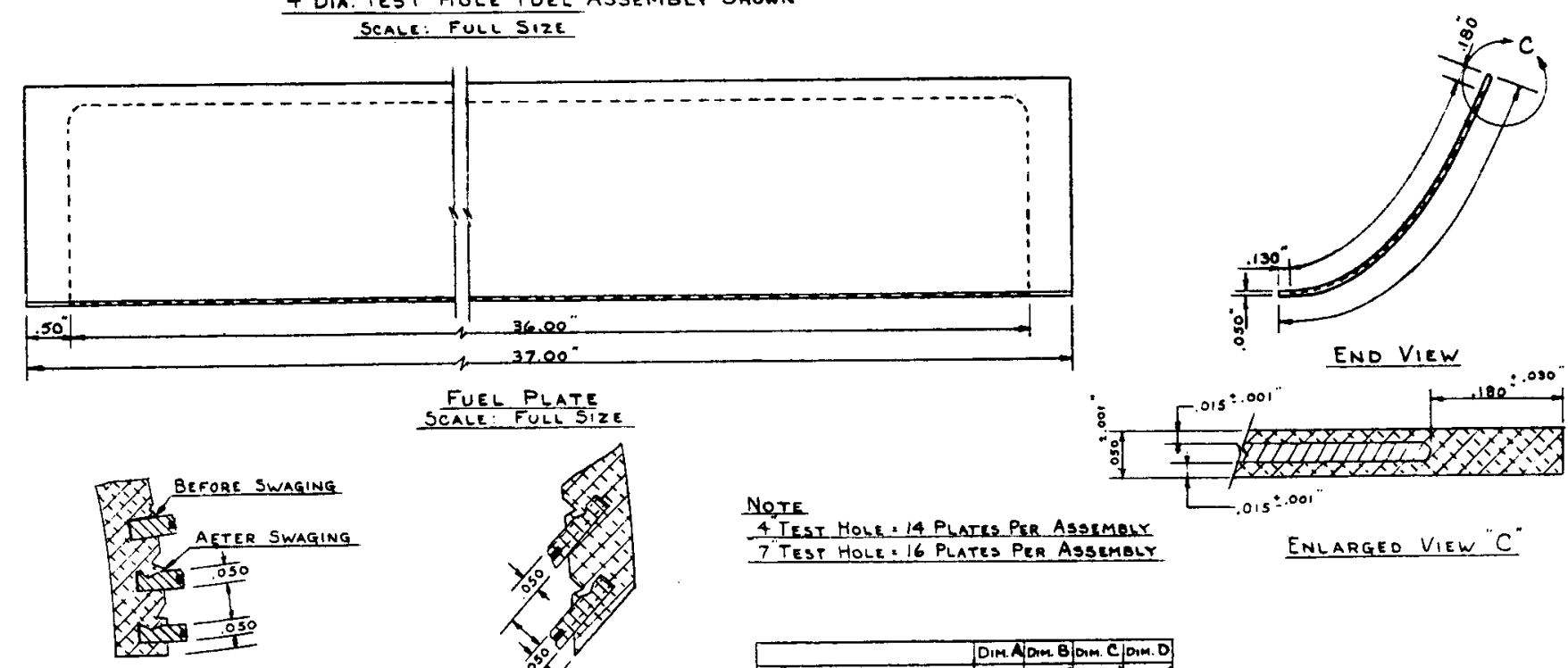

H. ENLARGED SECT."A-A"

OQ SCALE: 10 TIMES SIZE

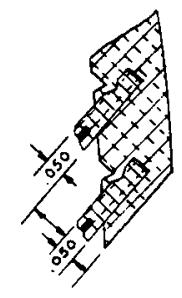

Nore

4 TEST HOLE 14 PLATES PER Asgemolr 7 TEST HOLE. 16 PLATES PER ASSEMBLT

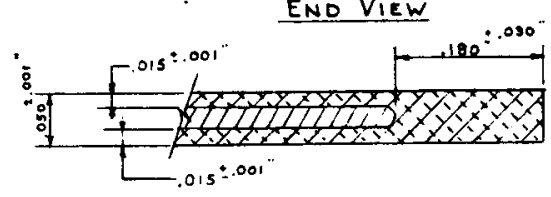

ENLARGED VIEW"

ENLARGED SECT. B-B

4. Dim A Jam Bjam Cjom. D

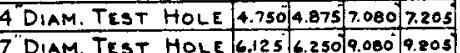

SCALE: 10 TIMES SIZE

7 DiAM. TEST HOLE 6.125 6.250]9.080 9.205 
Figure 3.G. Safety Control System

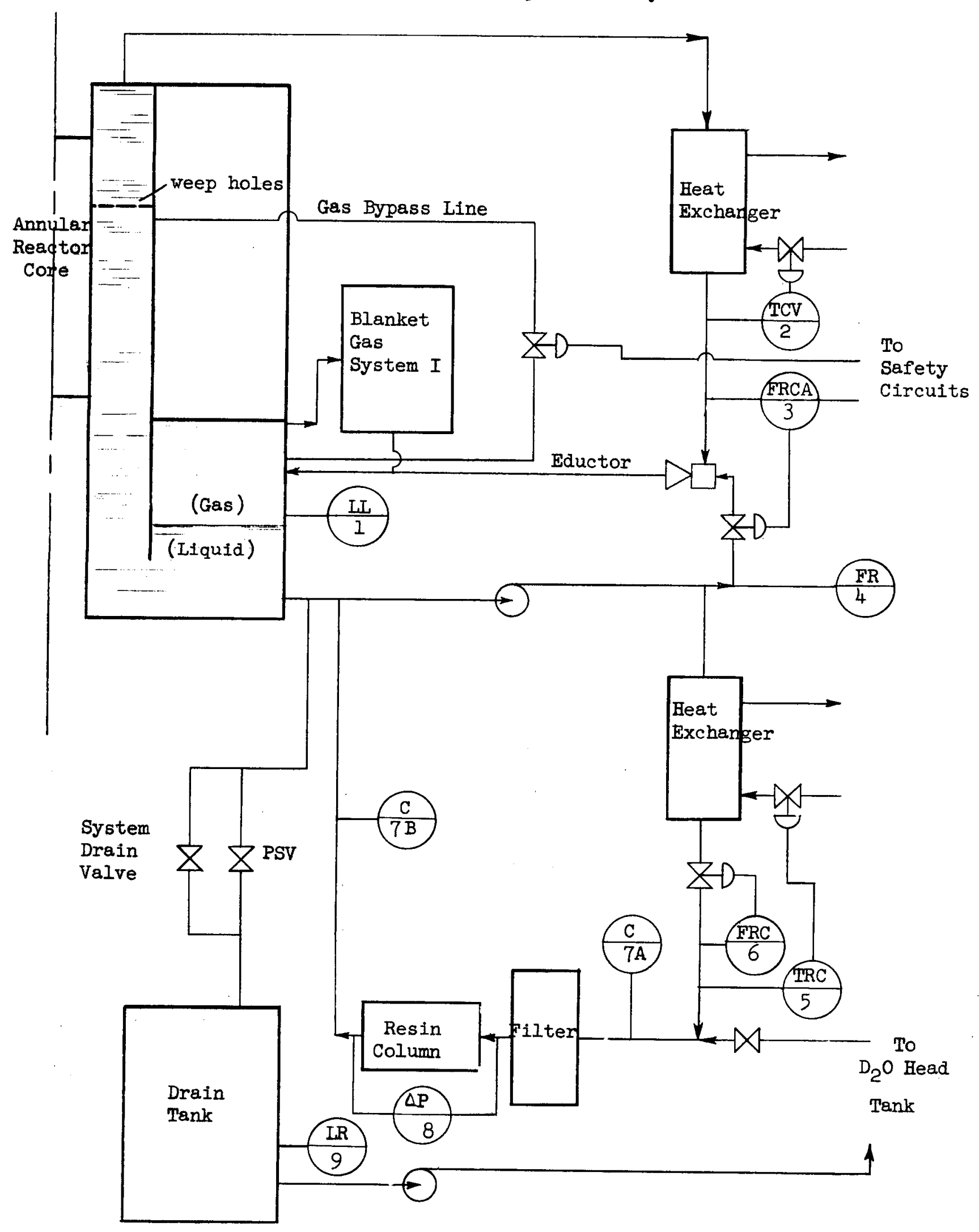

Fig. 3.G 
Figure 3.H. Shim Control System

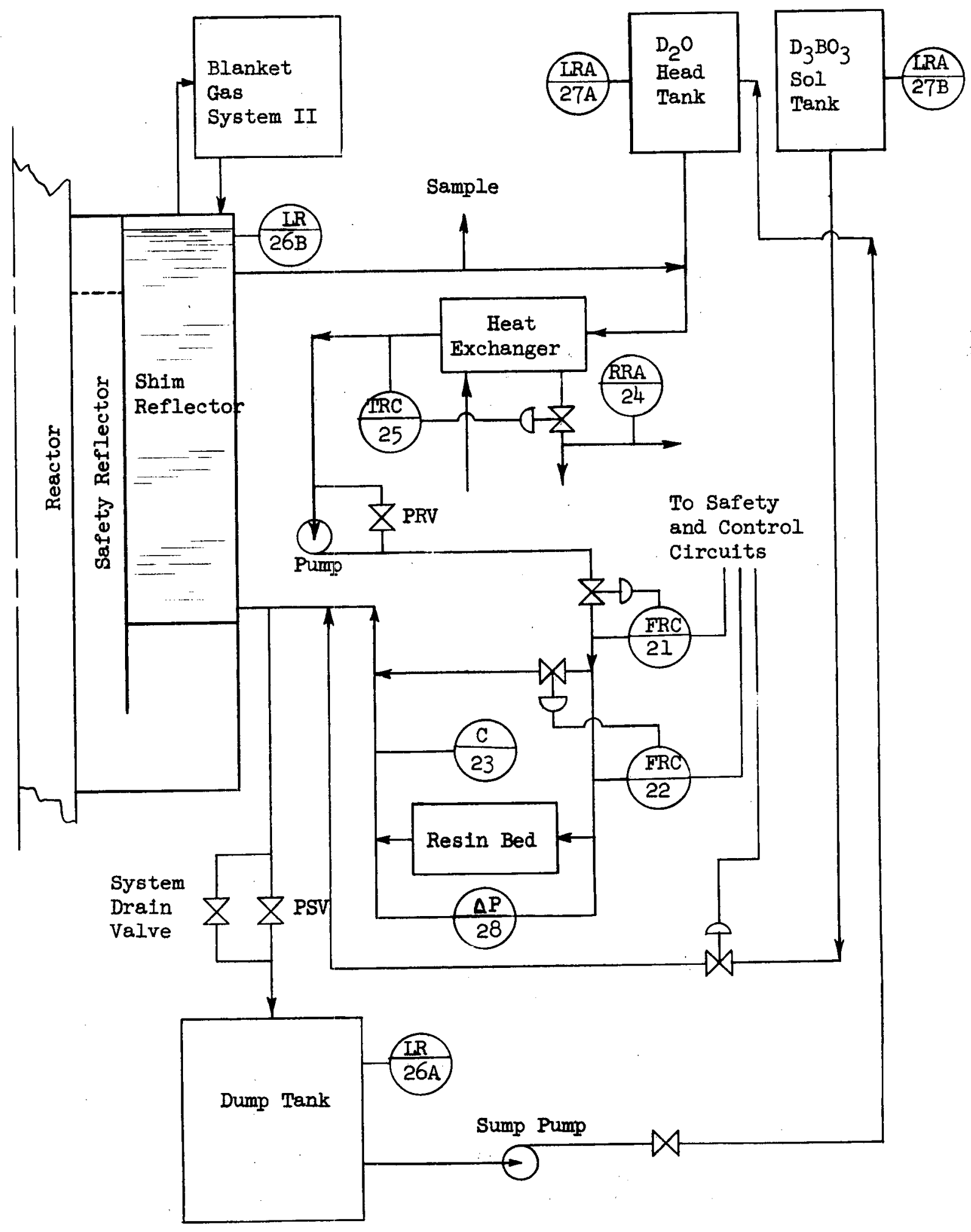

Fig. 3.H 
Figure 5:A Primary Coolant System for Type-A Reactor

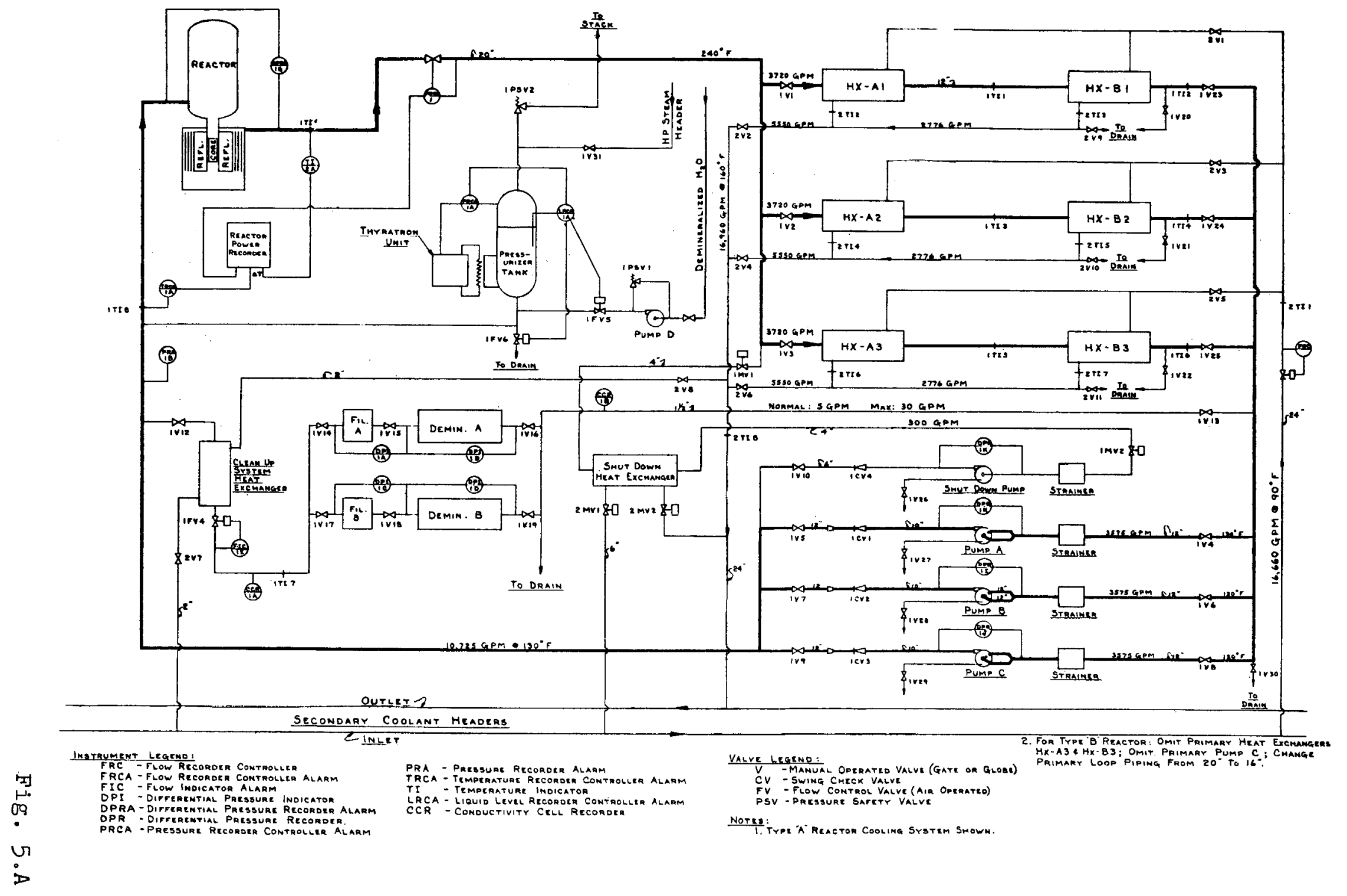


Figure 5.B AETR Axial Power Distribution

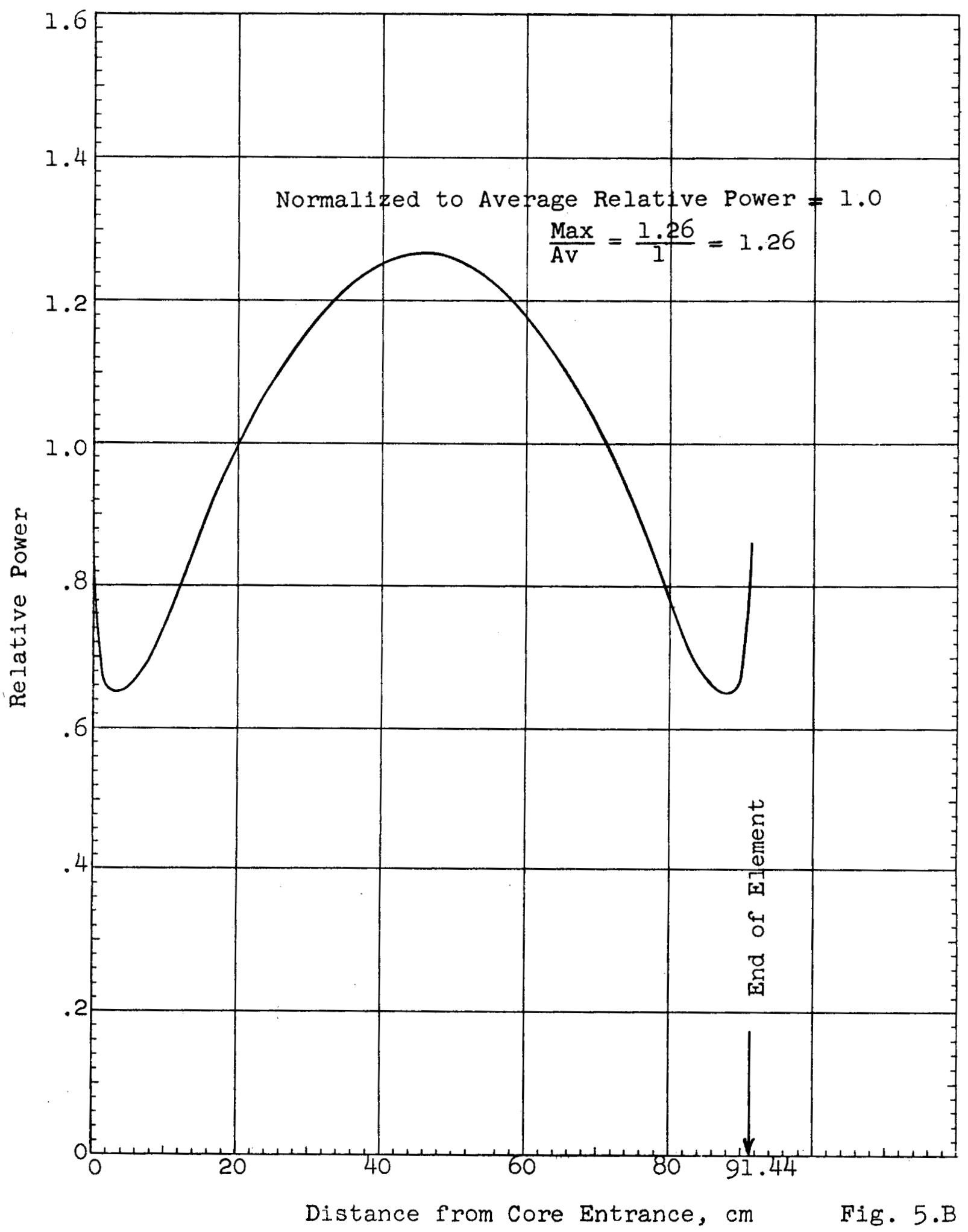


Figure 5.C Cross Section of a Preferentially Loaded

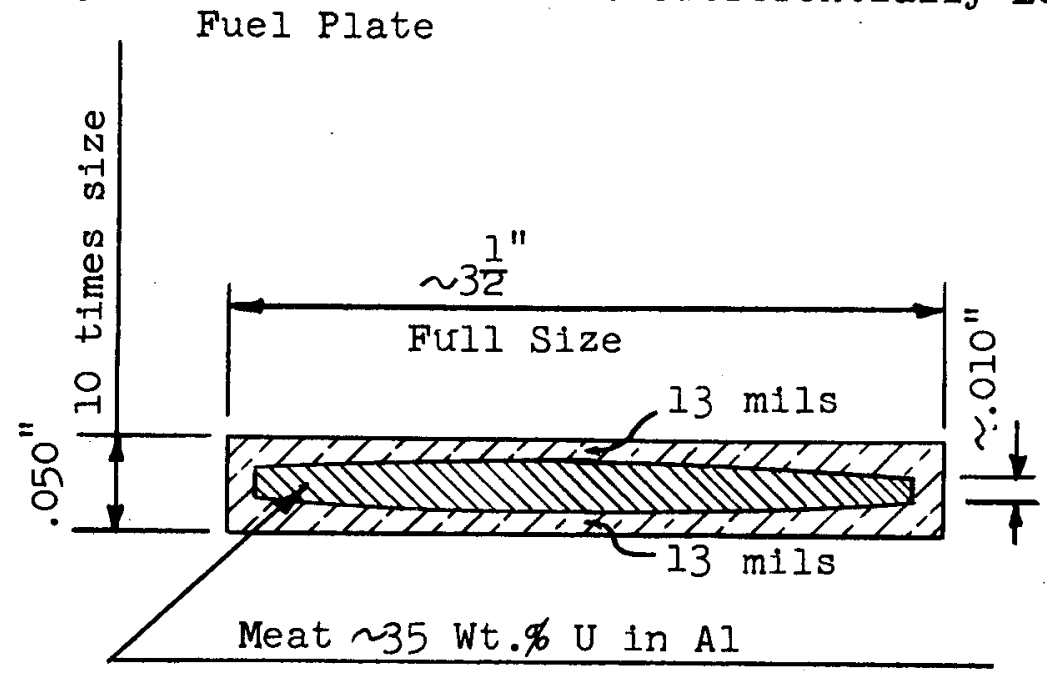

Enlarged Section Thru Fuel Plate Before Bending

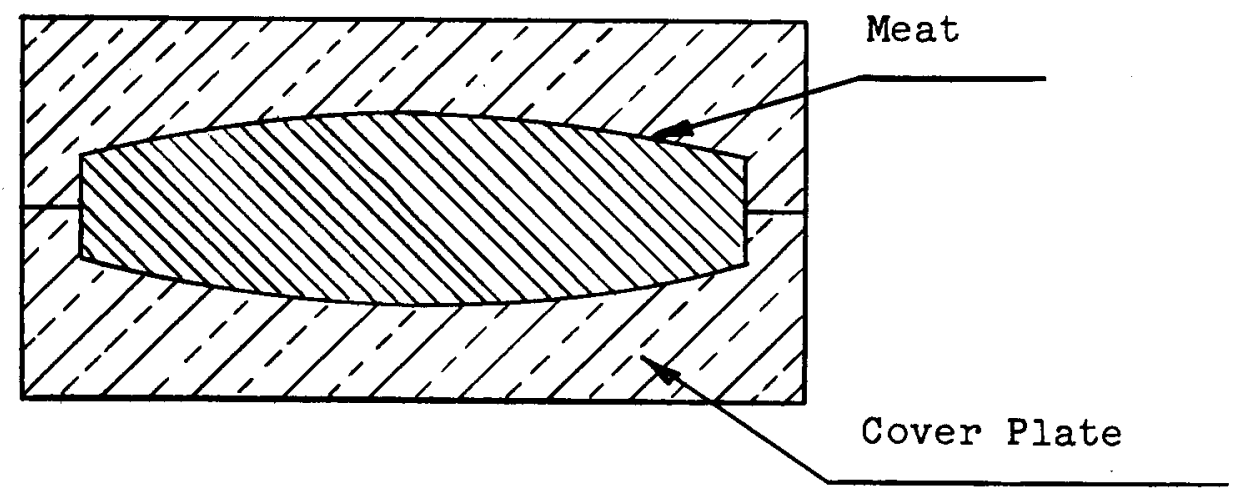

Fig: $5 . C$ 
Figure 5.D Fuel Plate Surface Temperature and Bulk Water Temperature (With Hot Channel Factors)

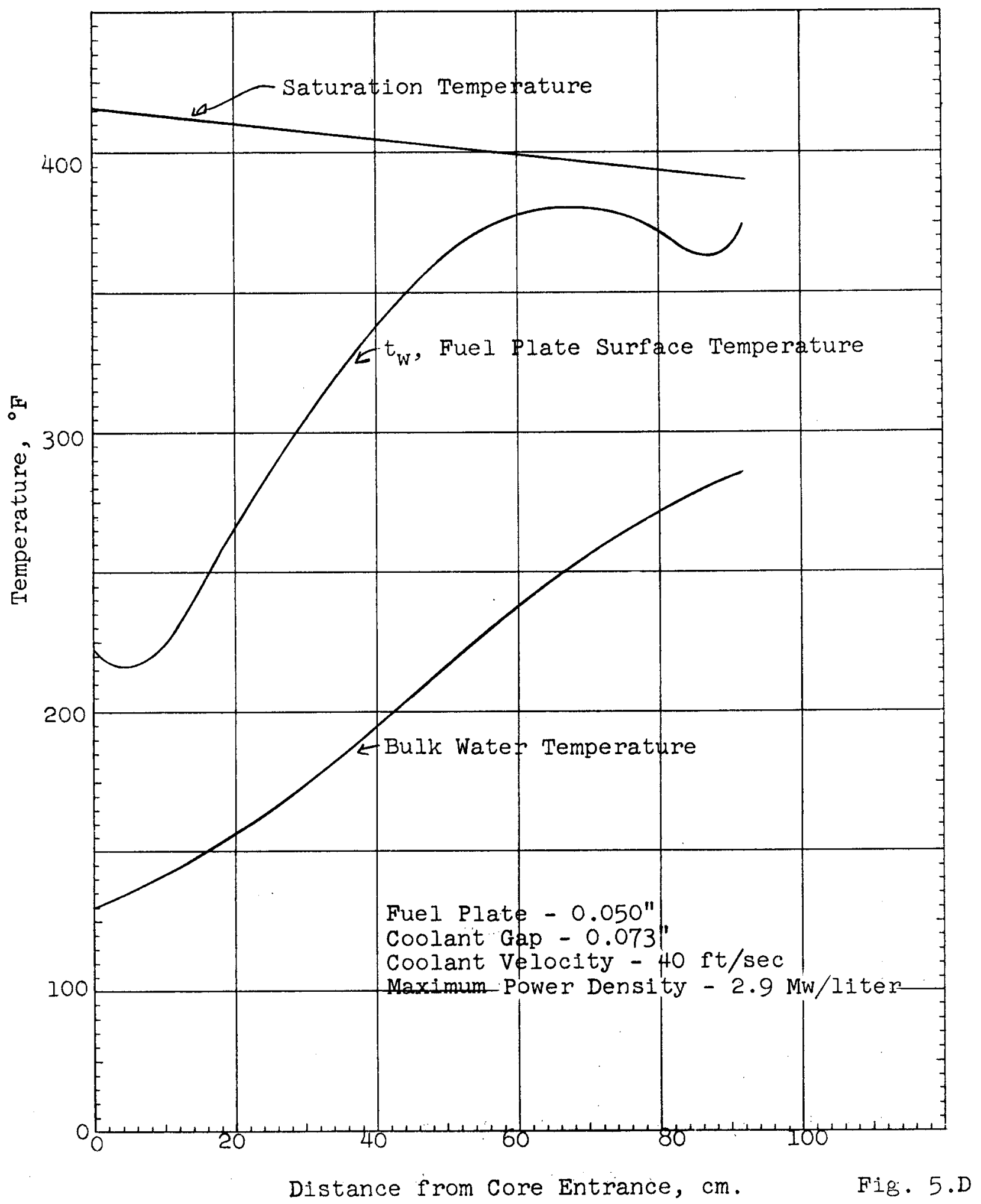


Figure 5.E Fuel Plate Surface Temperature and Bulk Water Temperature (Without Hot Channel Factors)

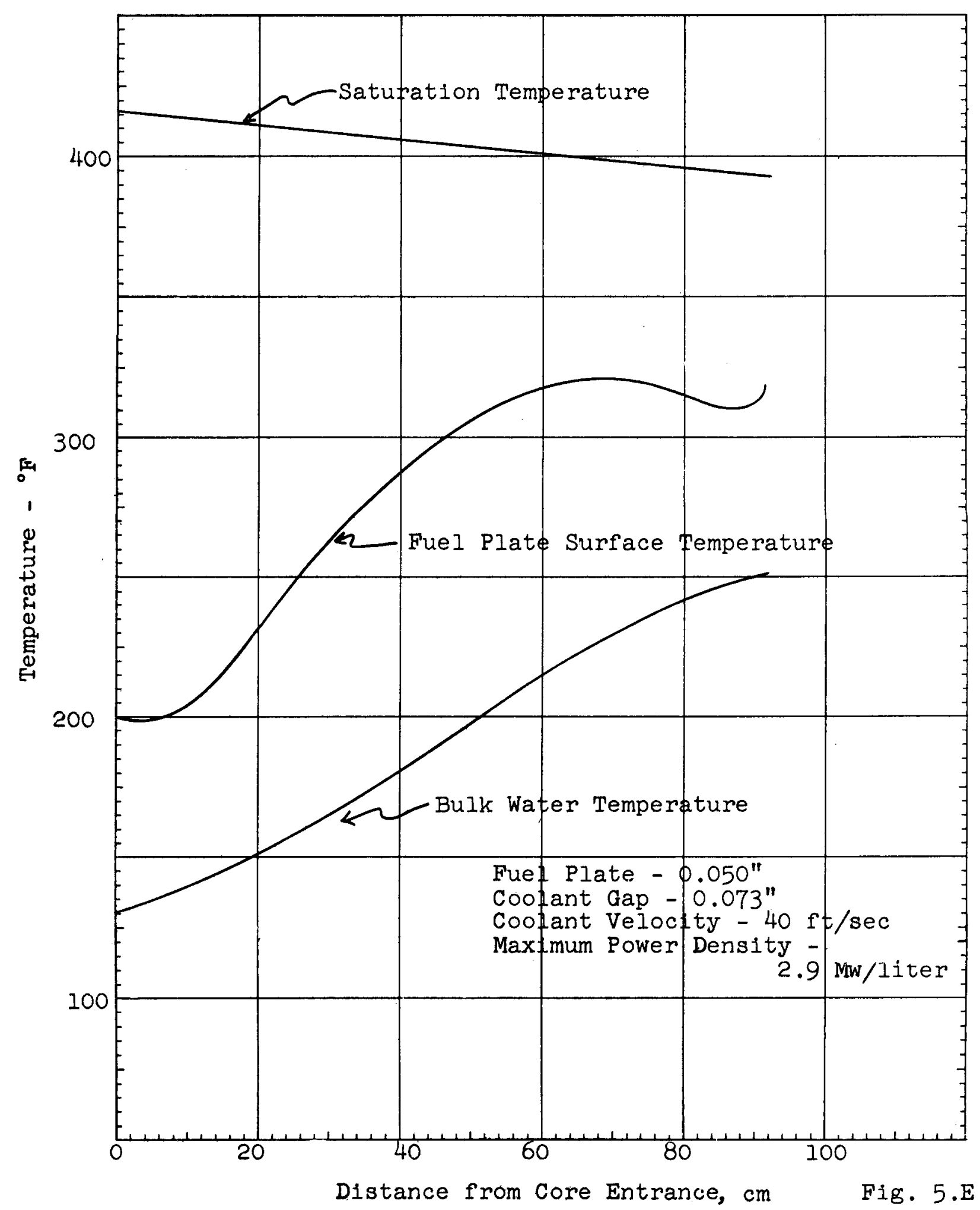


Figure 5.F. Blanket Gas System

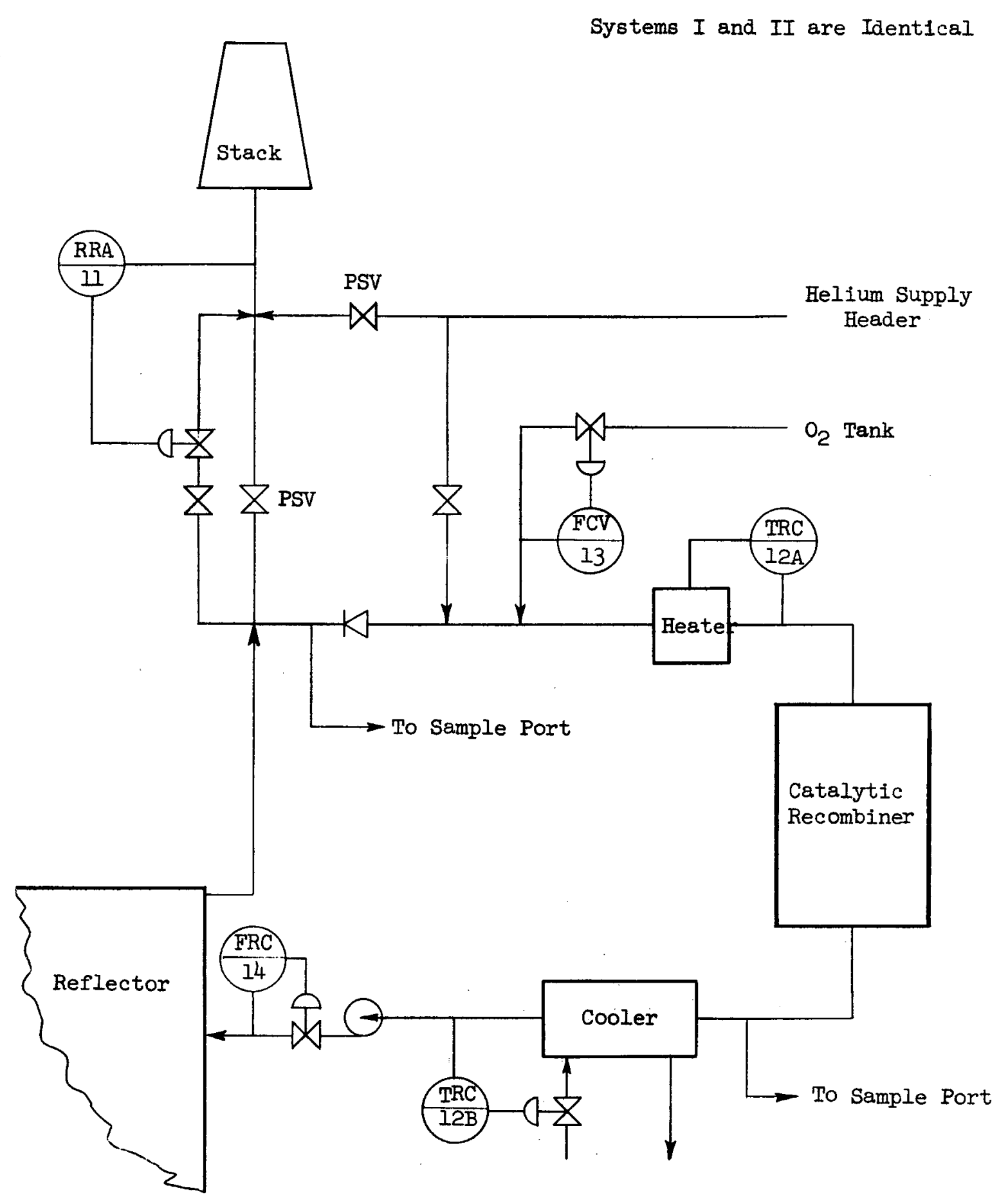

Fig. 5.F. 
Figure 5.G Secondary Coolant System.

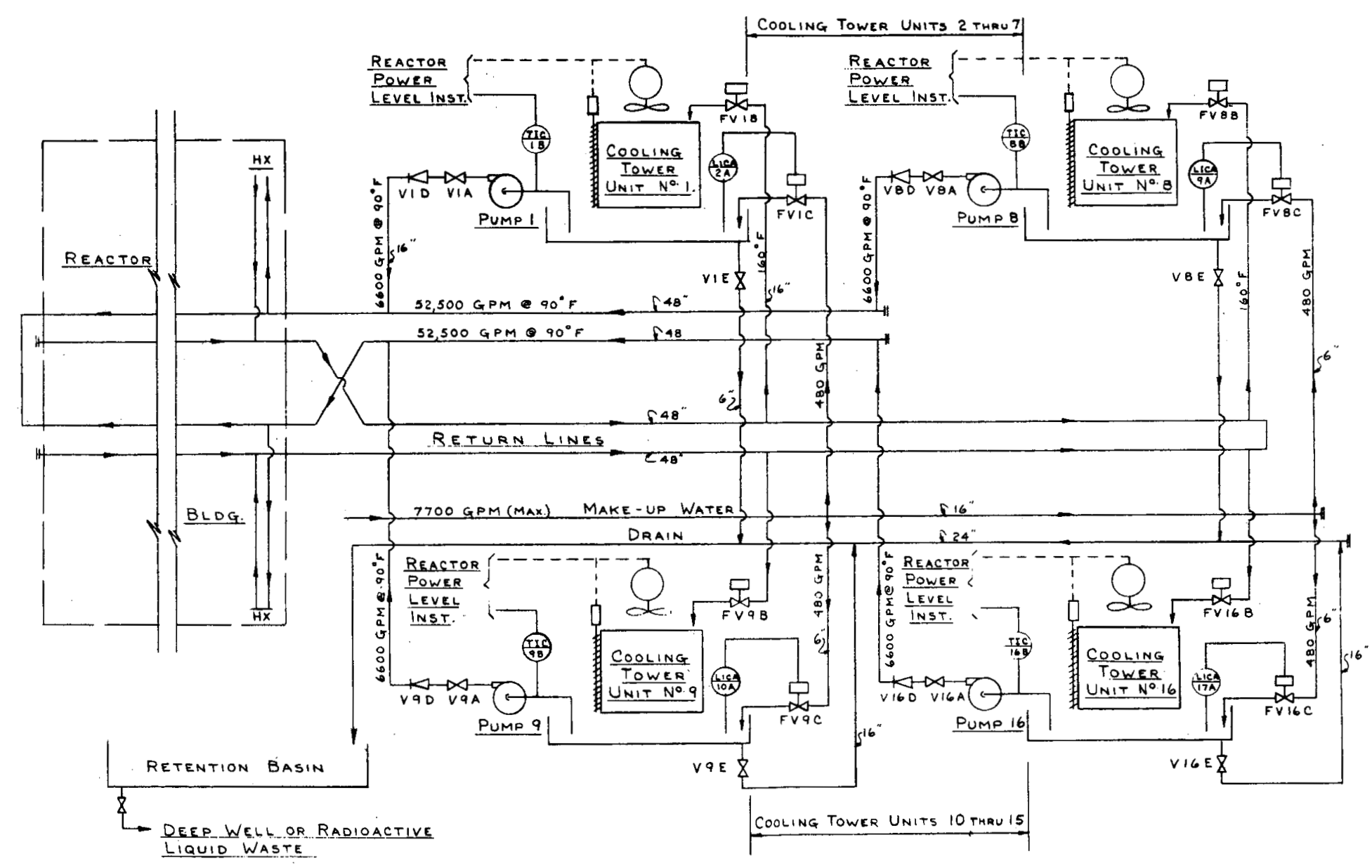

$\stackrel{0}{0.09}$

u

- 2 
Figure 6.A The Type-A and Type-B Nuclear Reference Reactors

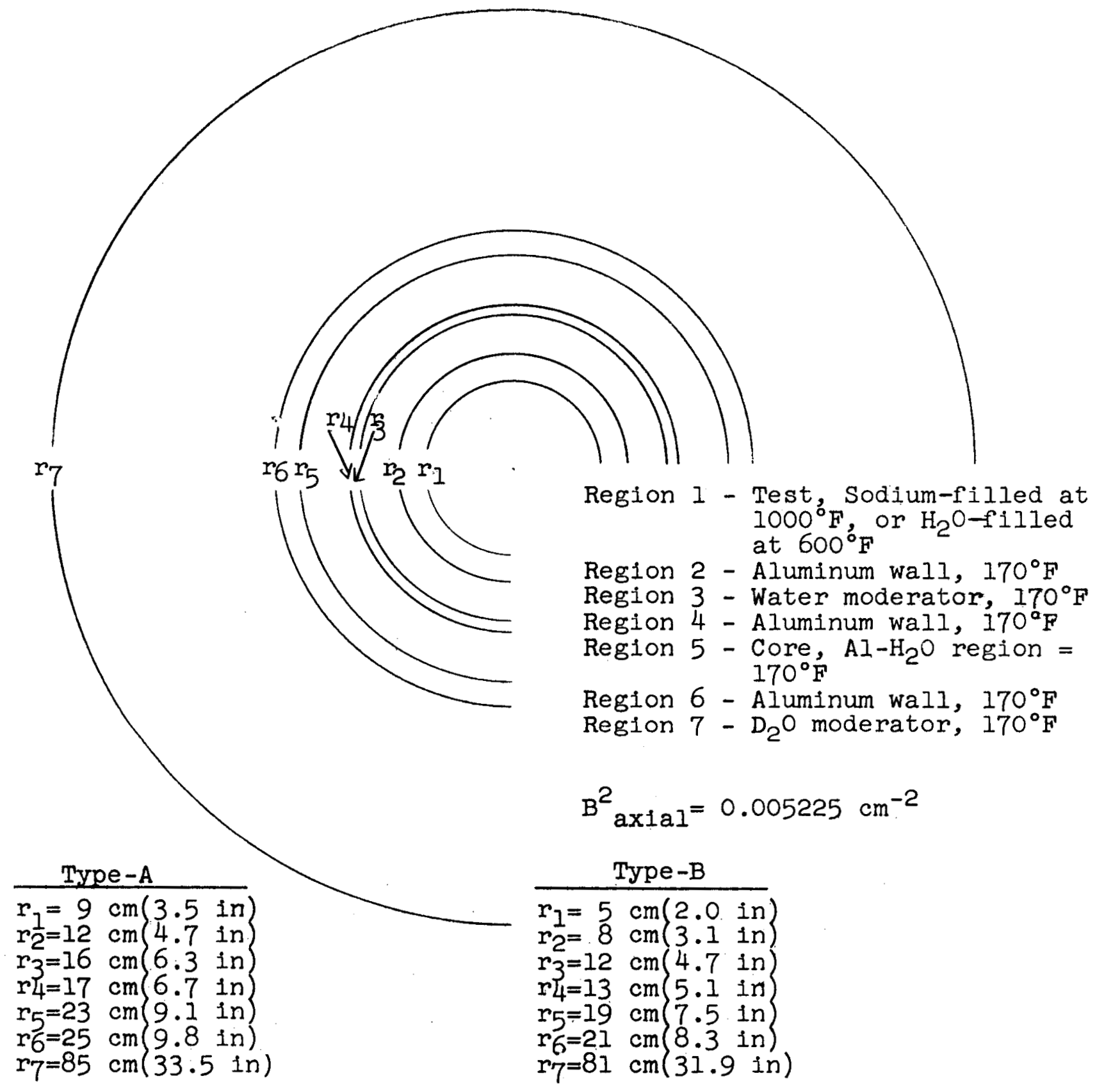

Fig. 6.A 
Figure 6.B Total Fission Product Poisoning as a Function of Fuel Burnup

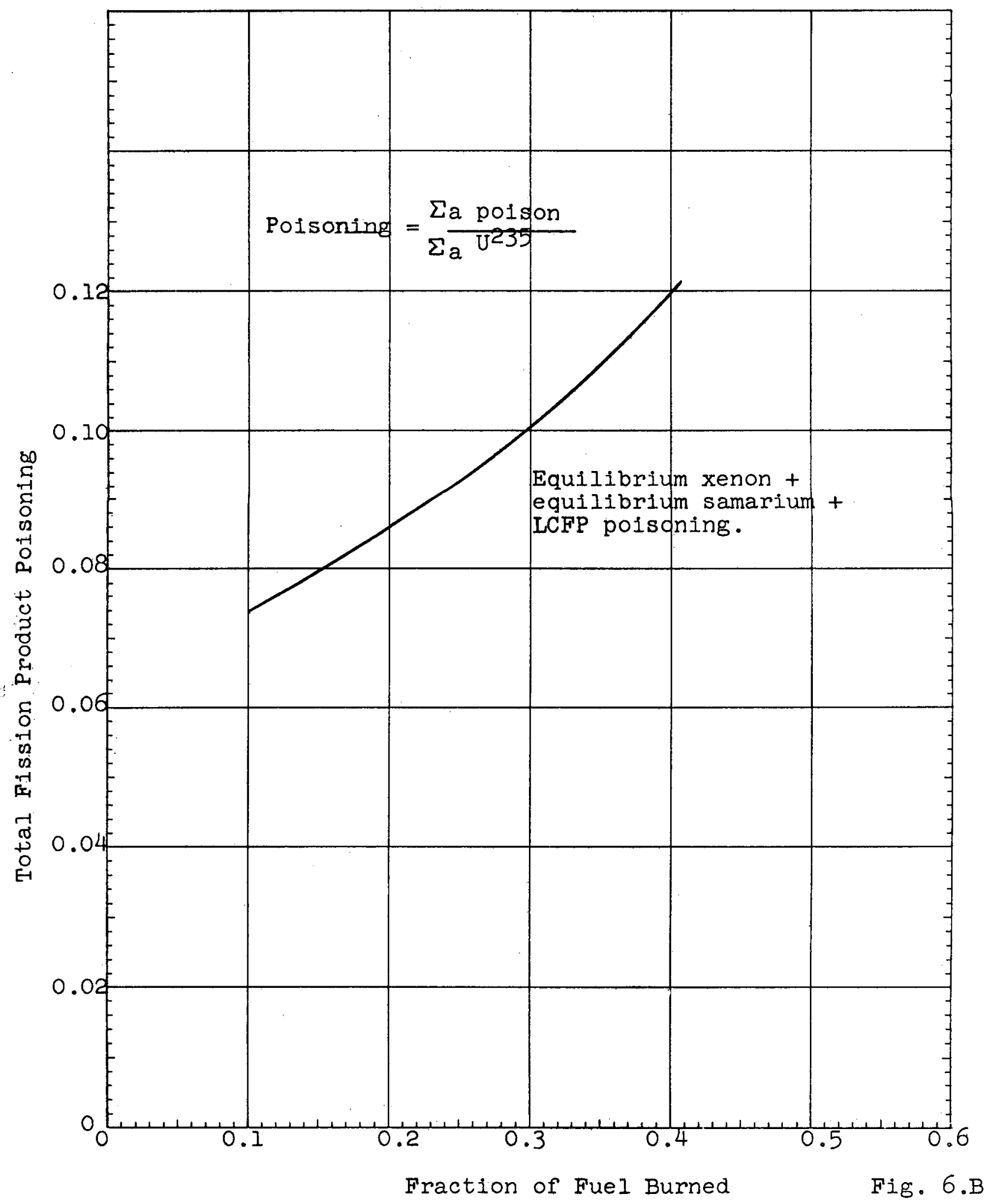


Figure 6.C Effect of Uniform Core Polsoning on Critical Fuel Concentration

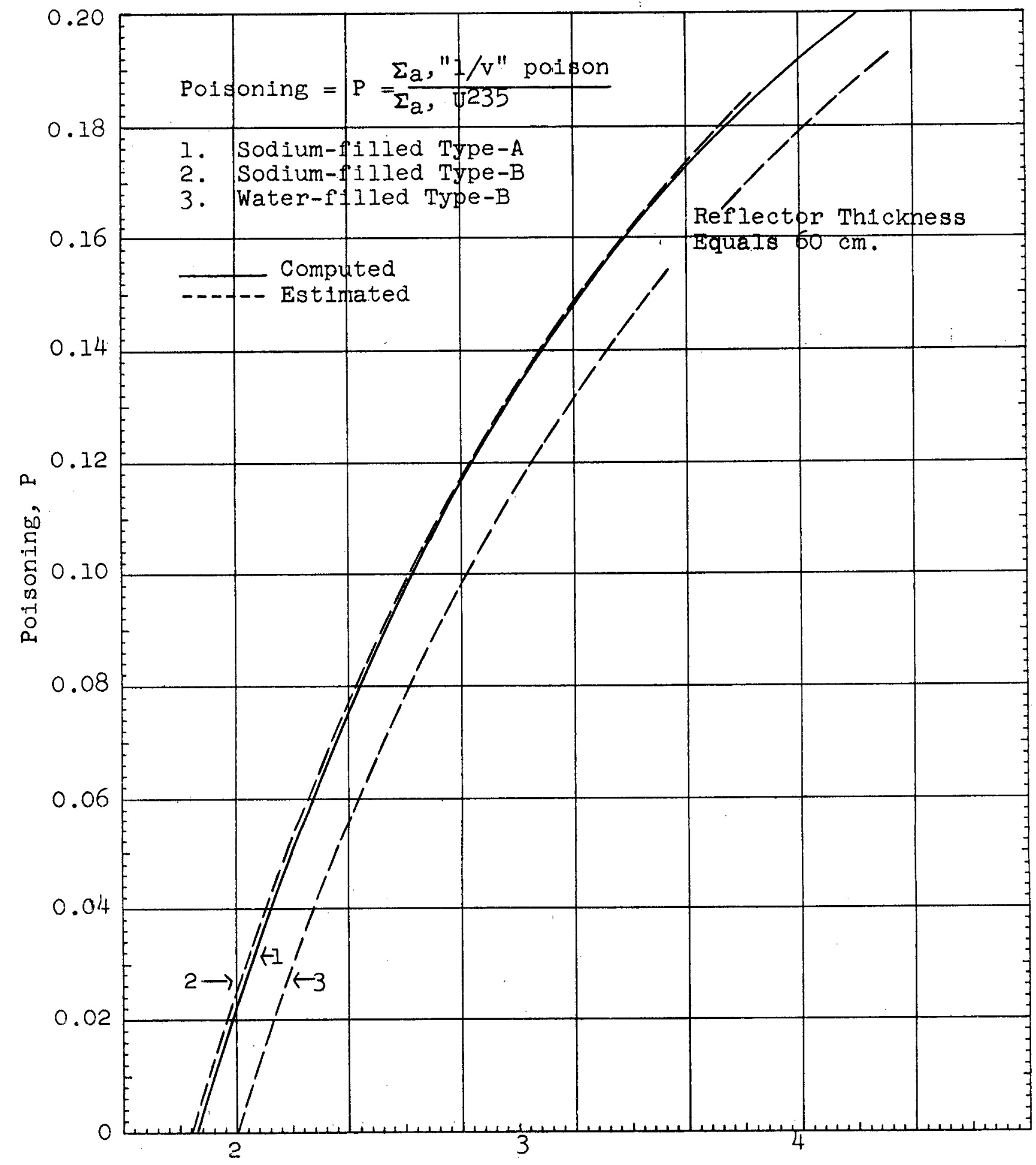

Critical Fuel Concentration, $10^{20}$ atoms U235/cc Fig. 6.C 
Figure 6.D Fuel Burnup for the Reference Reactors as Functions of Time.

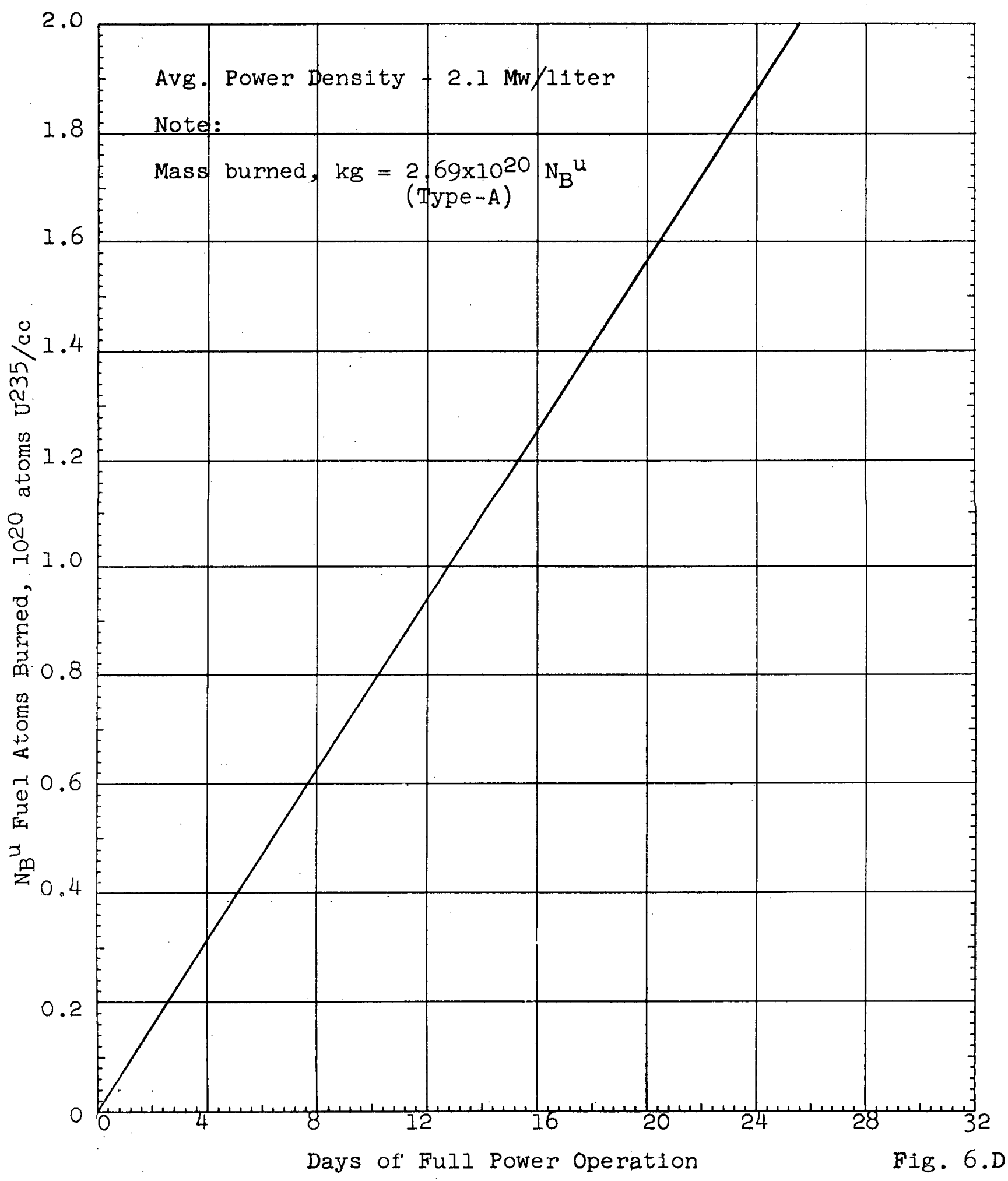


Figure 6.E Core Lifetime Variation with Initial Fuel Concentration - Type-A Reactor

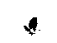

,

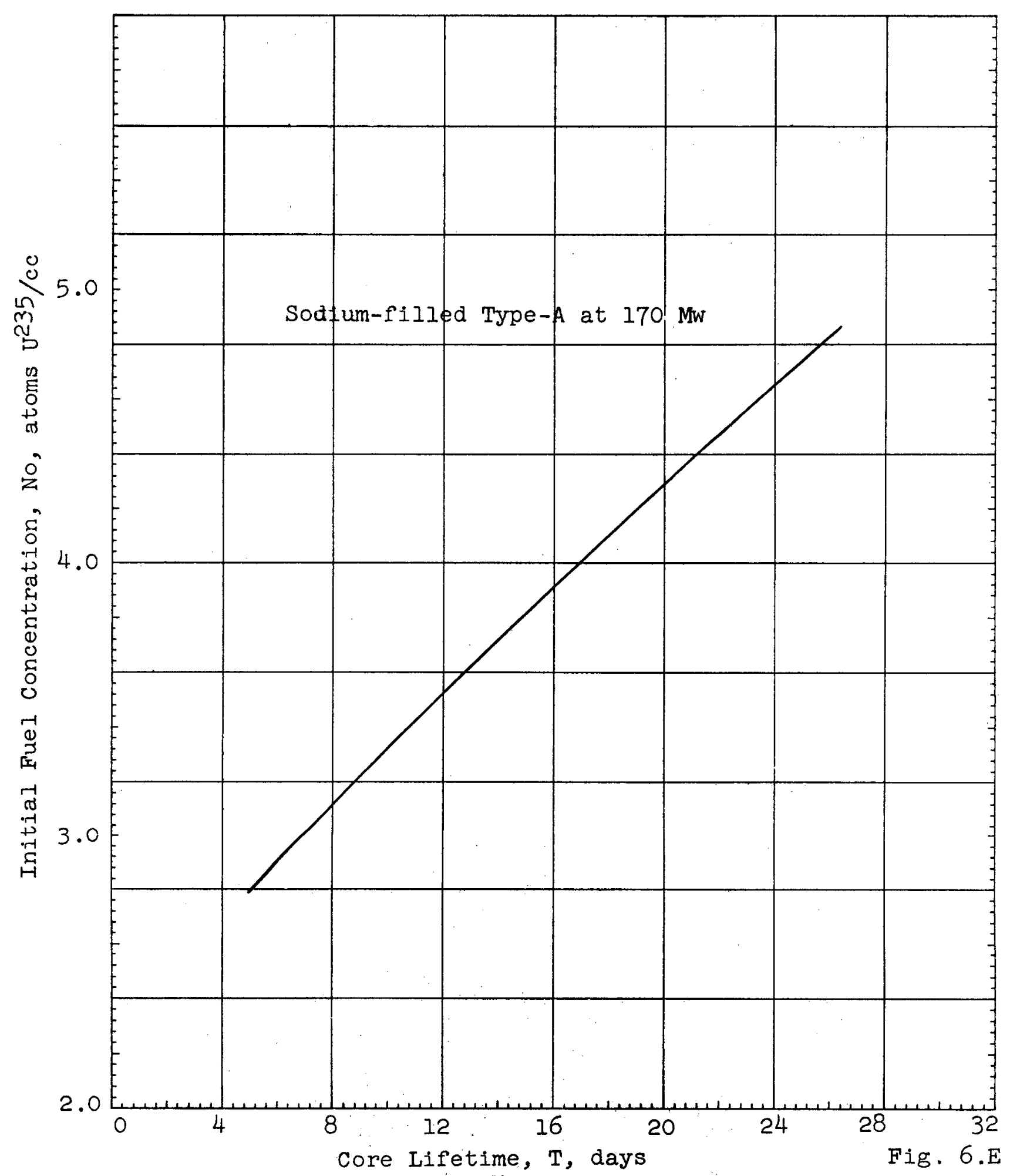


Figure 6.F Initial Excess Multiplication Variation with Core Lifetime-Type-A Reactor

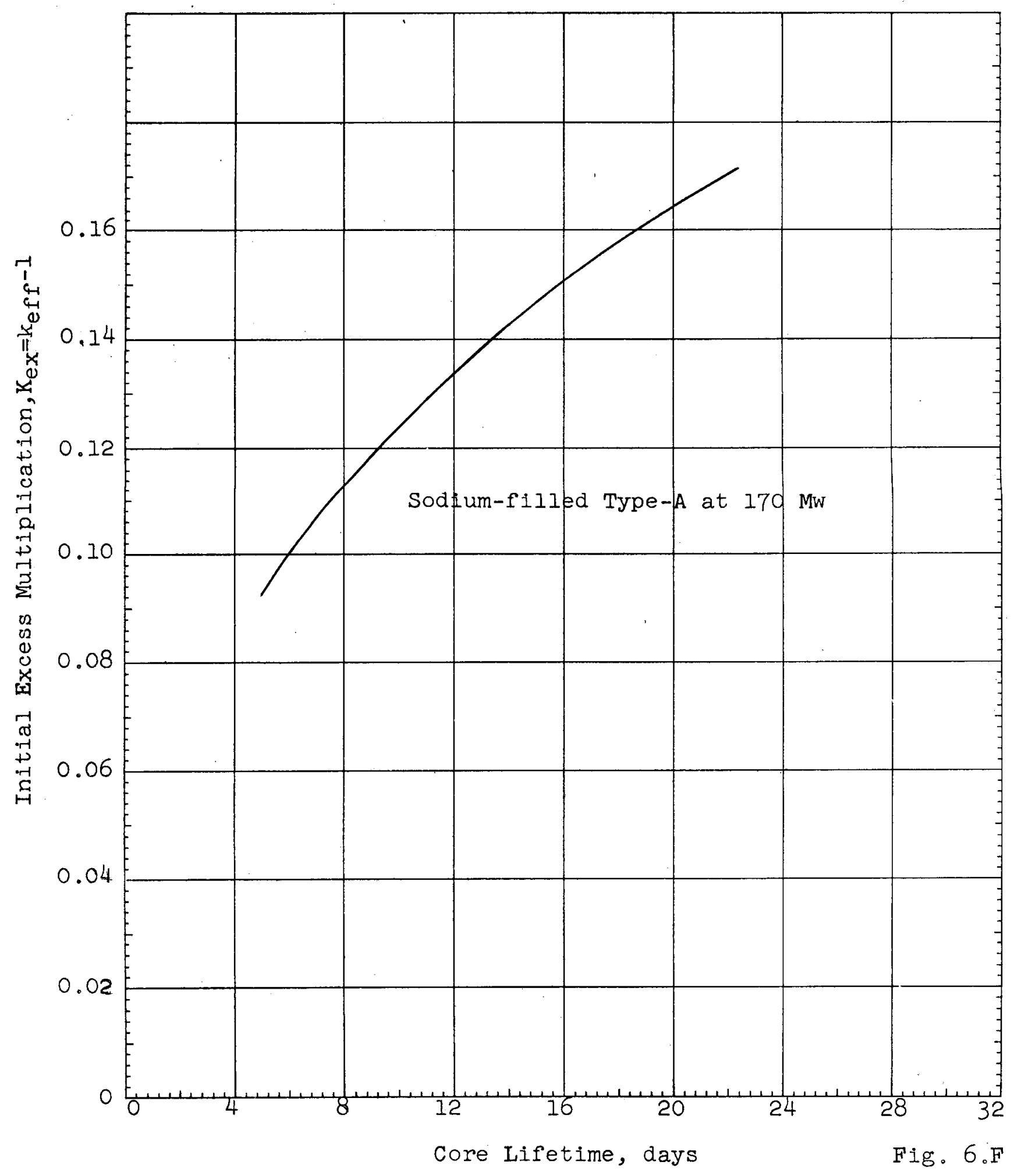


Figure 6.G Radial Neutron Flux Distribution at Midplane in Type-A Reference Reactor

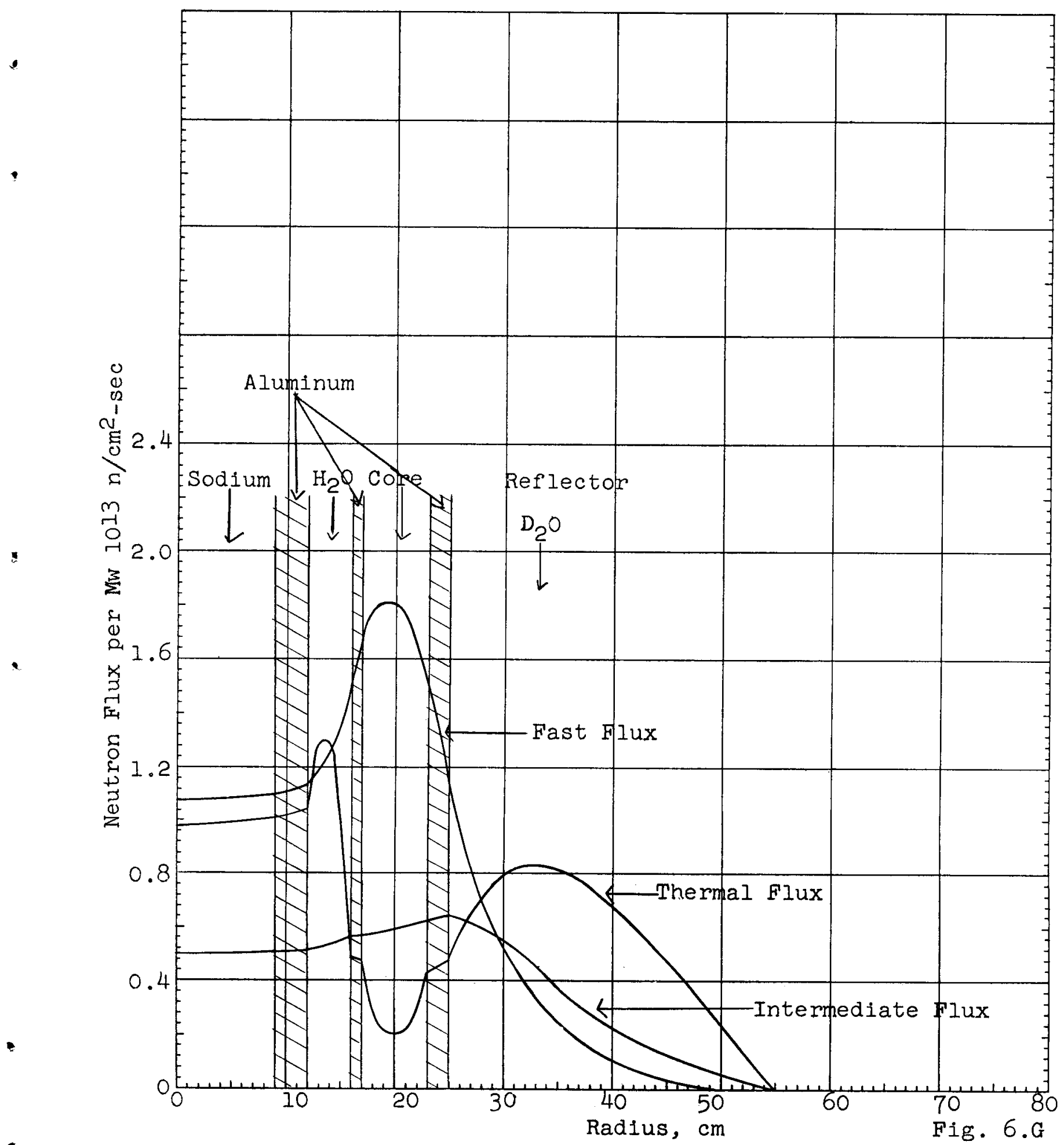


114

Figure 6.H Radial Neutron Flux Distribution at Midplane

in Type-B Reference Reactor with Sodium-Filled

Test Hole.

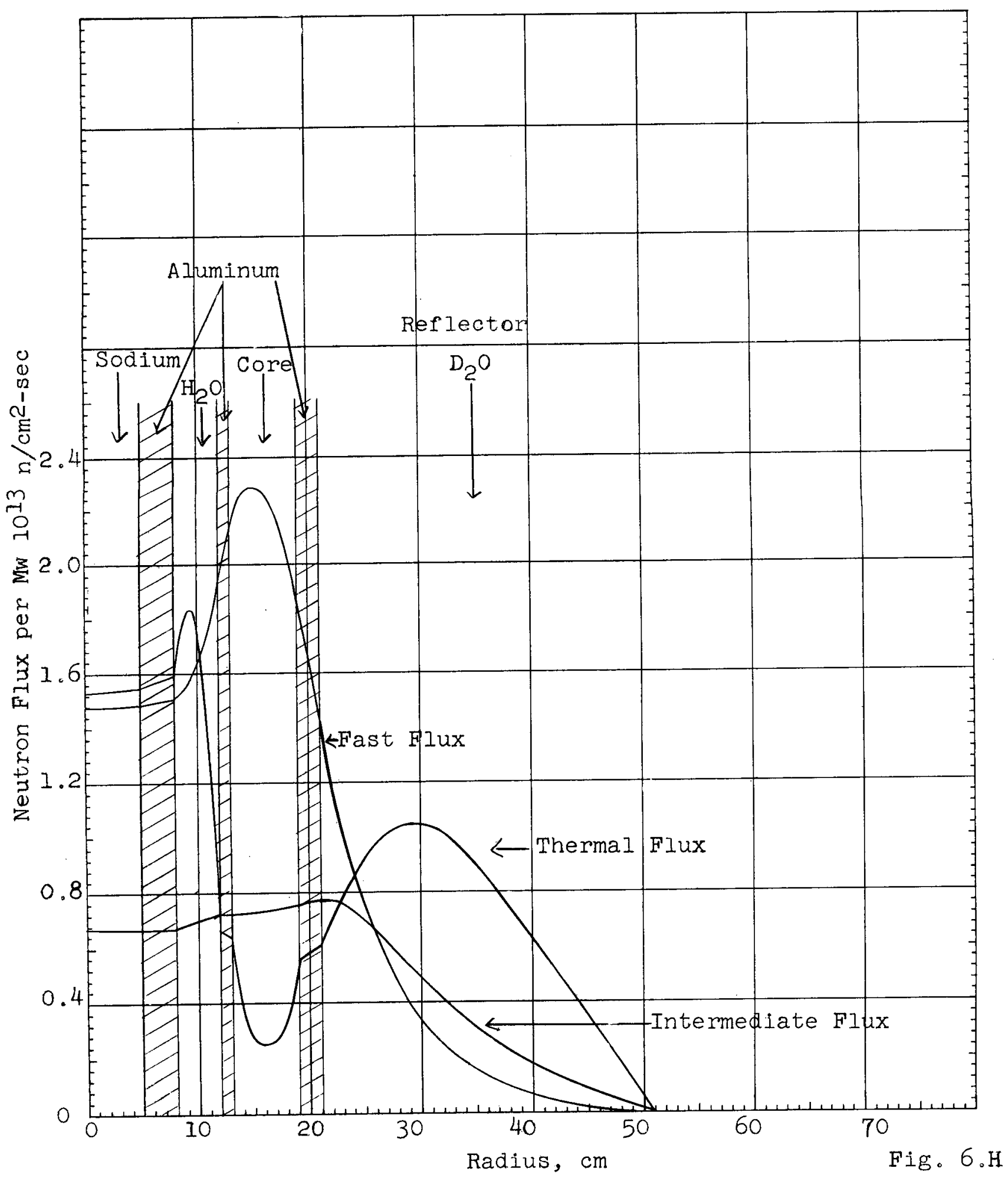


Figure 6.I Radial Neutron Flux Distribution of Midplane in

Type-B Reference Reactor with $\mathrm{H}_{2} \mathrm{O}-\mathrm{Filled}$ Test Hole

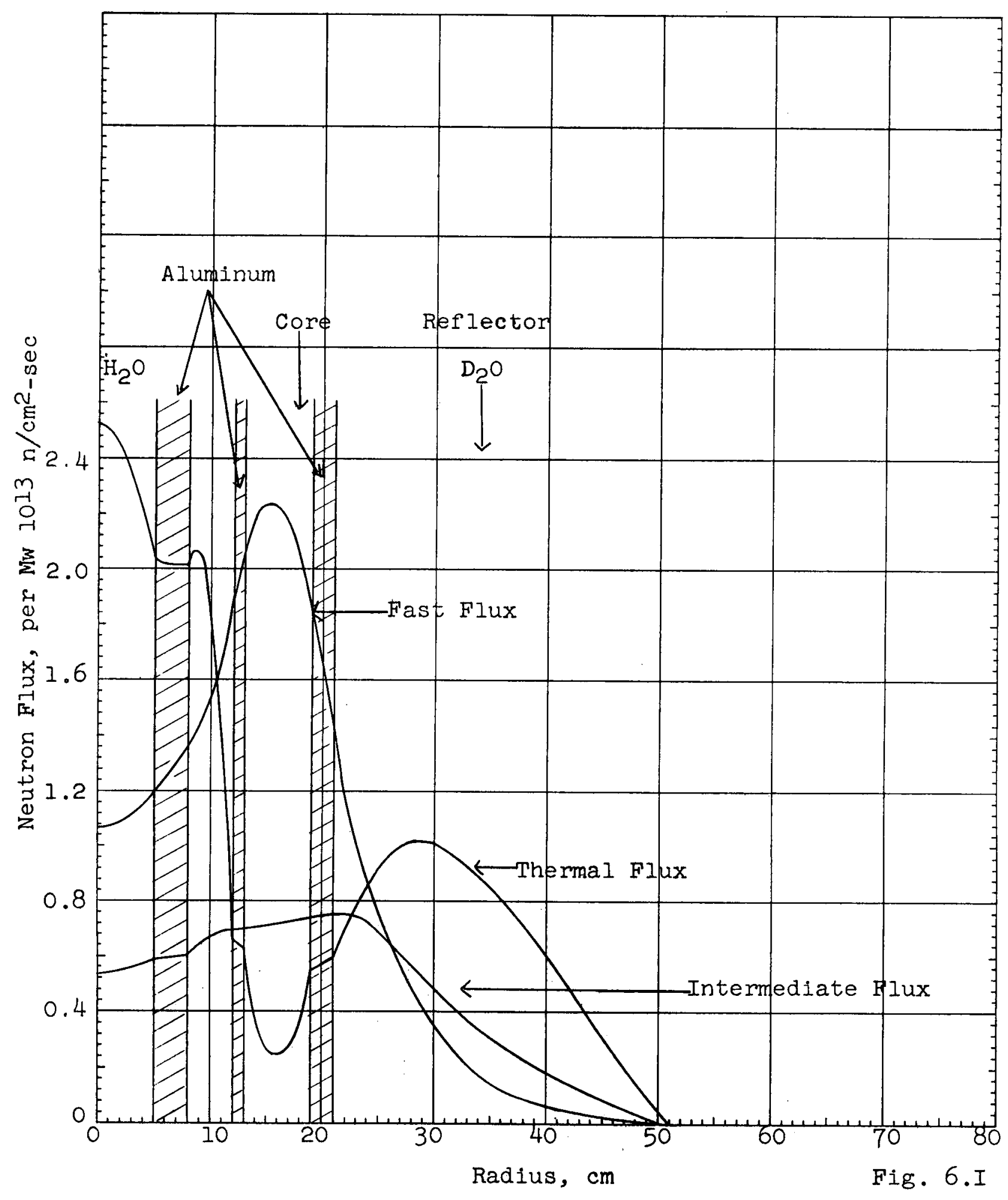


Figure 6.J Model for Two-Dimensional Calculations-Type-A Reactor

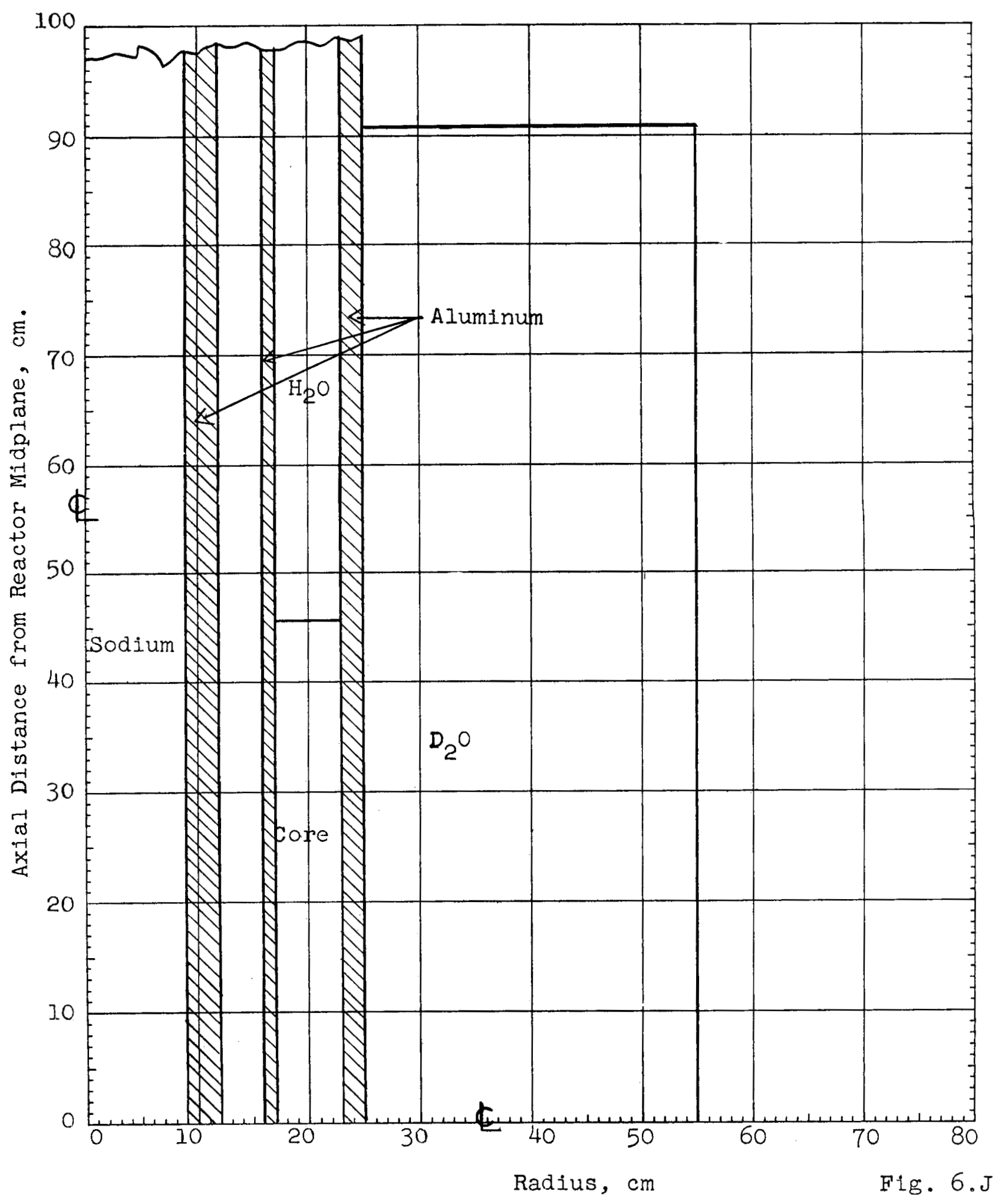


Figure 6.K Fast Energy Group Two-Dimensional Neutron Flux Distribution for Type-A Reactor

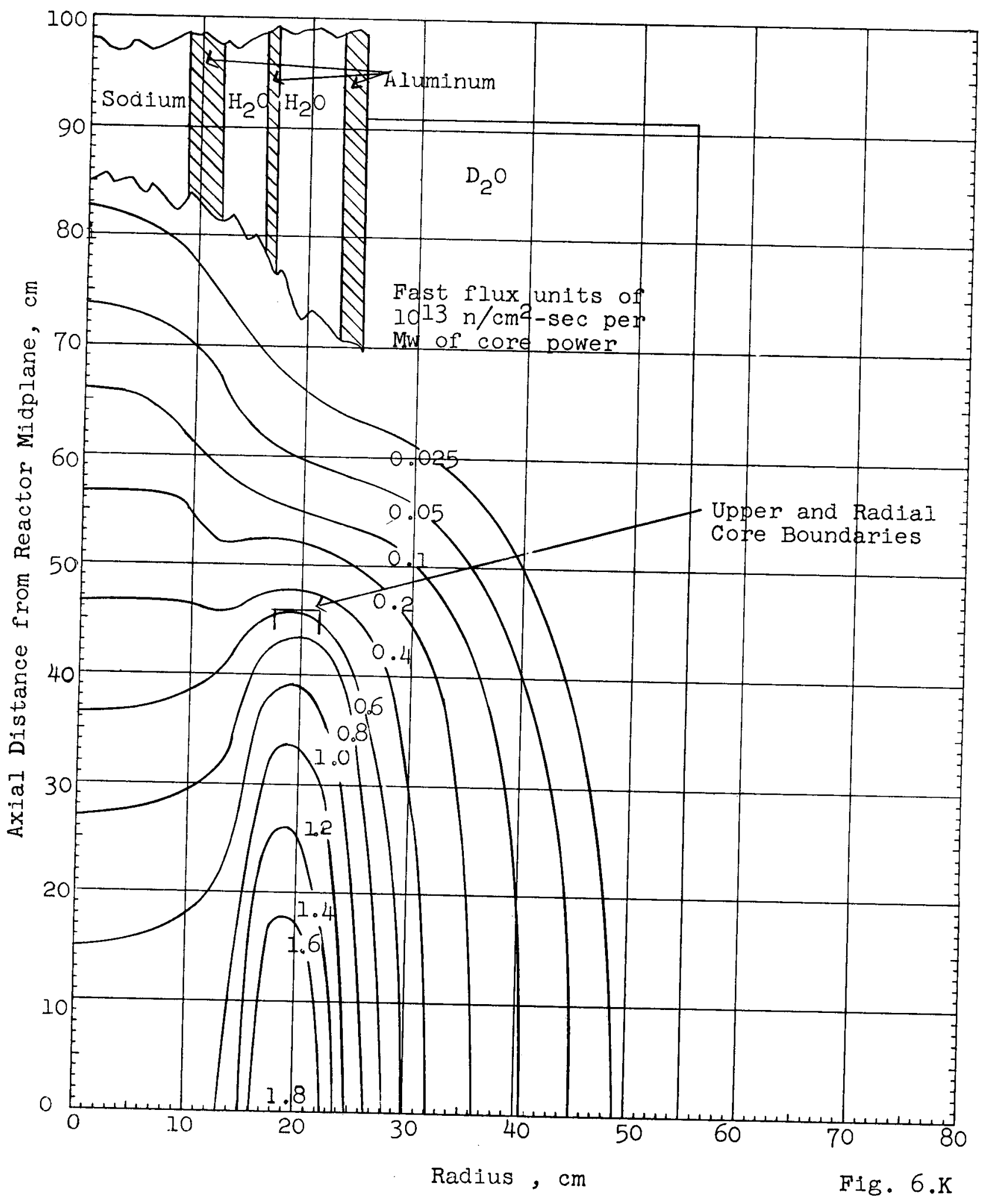


Figure 6.I Intermediate Energy Group Two-Dimensional Neutron Flux Distribution for Type-A Reactor

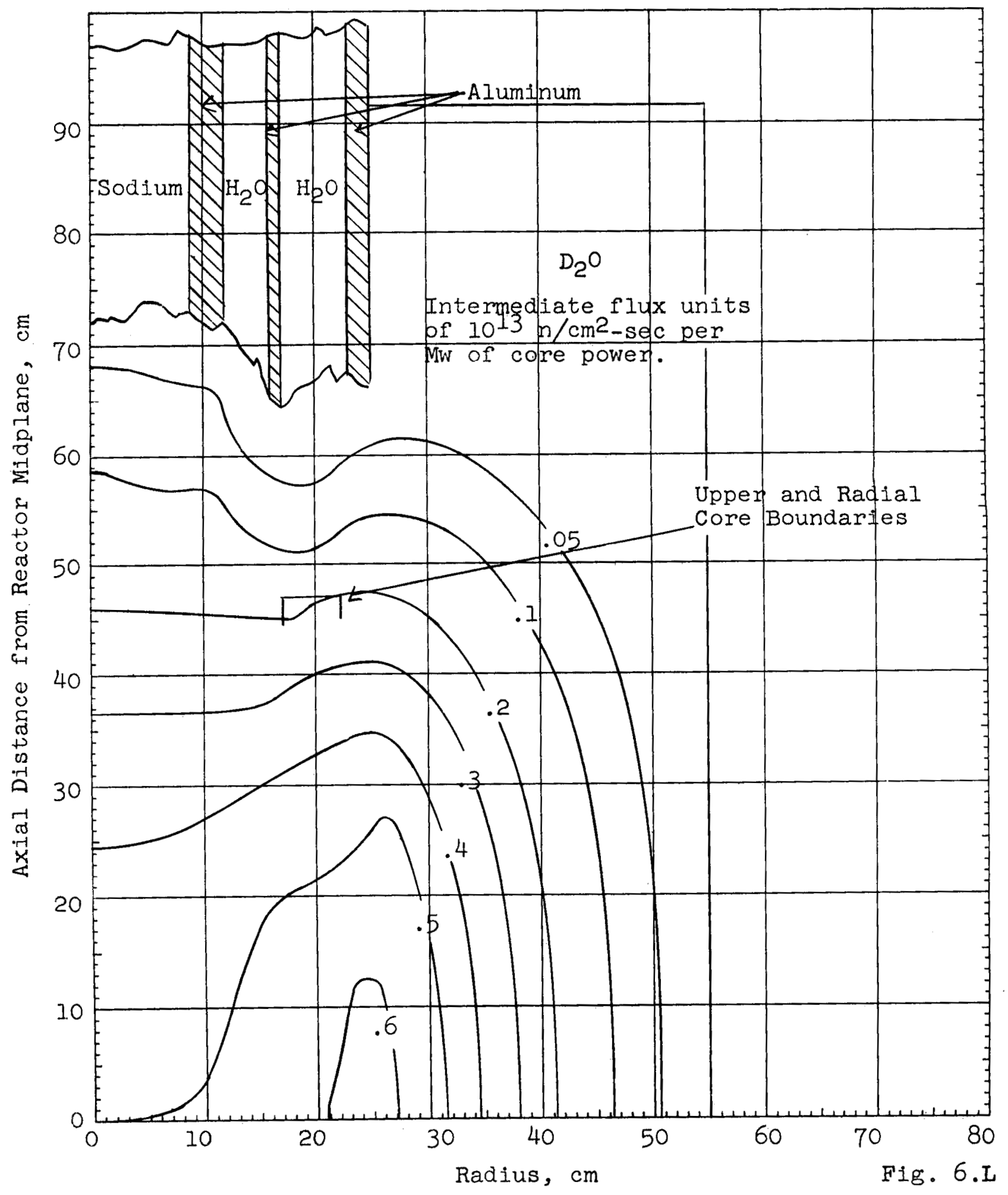


Figure 6.M Thermal Energy Group Two-Dimensional Neutron

Flux Distribution for Type-A Reactor

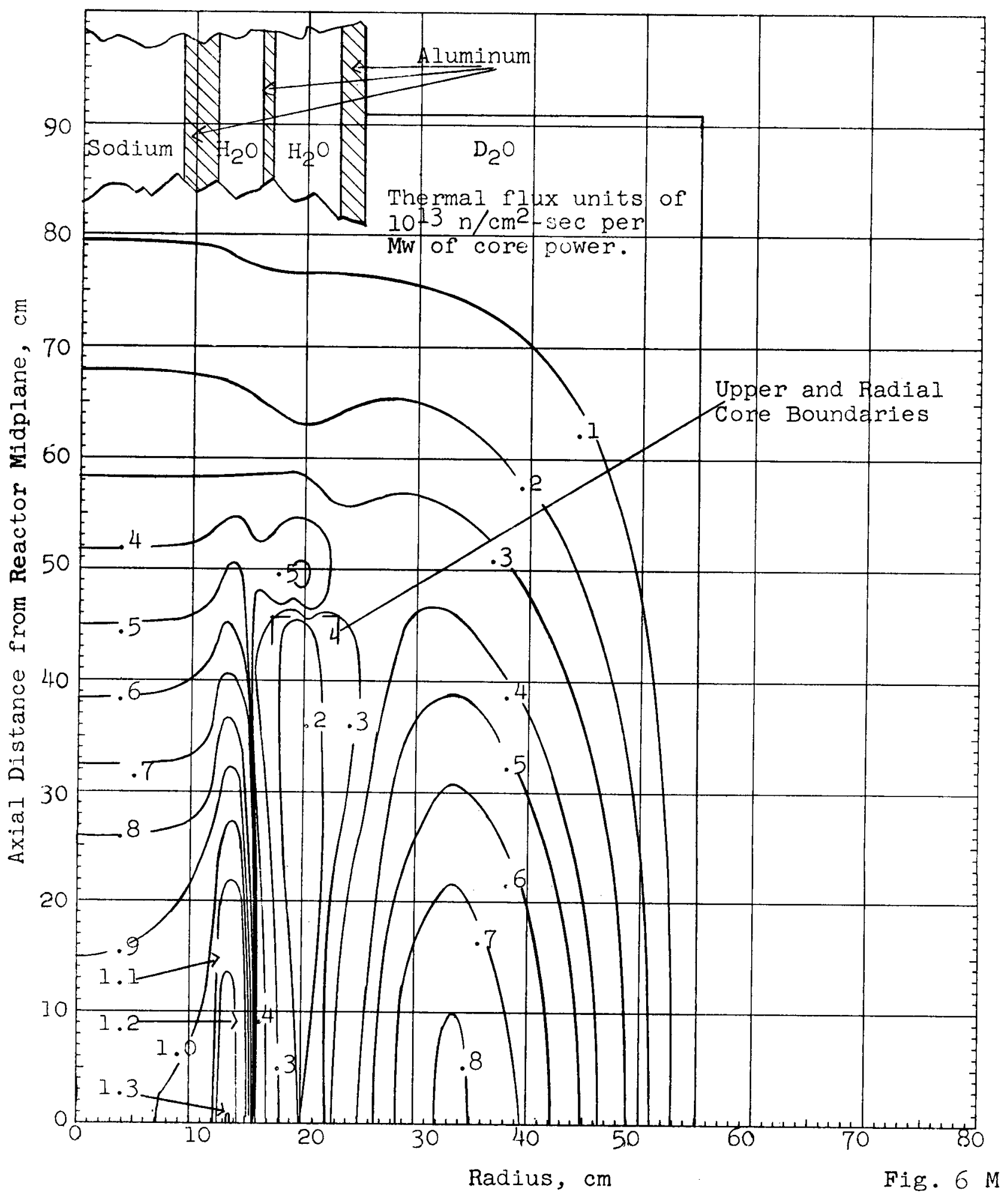


Figure 6.N Axial Neutron Flux Distribution Along Centerline of Sodium-Filled Test Hole in Type-A Reactor

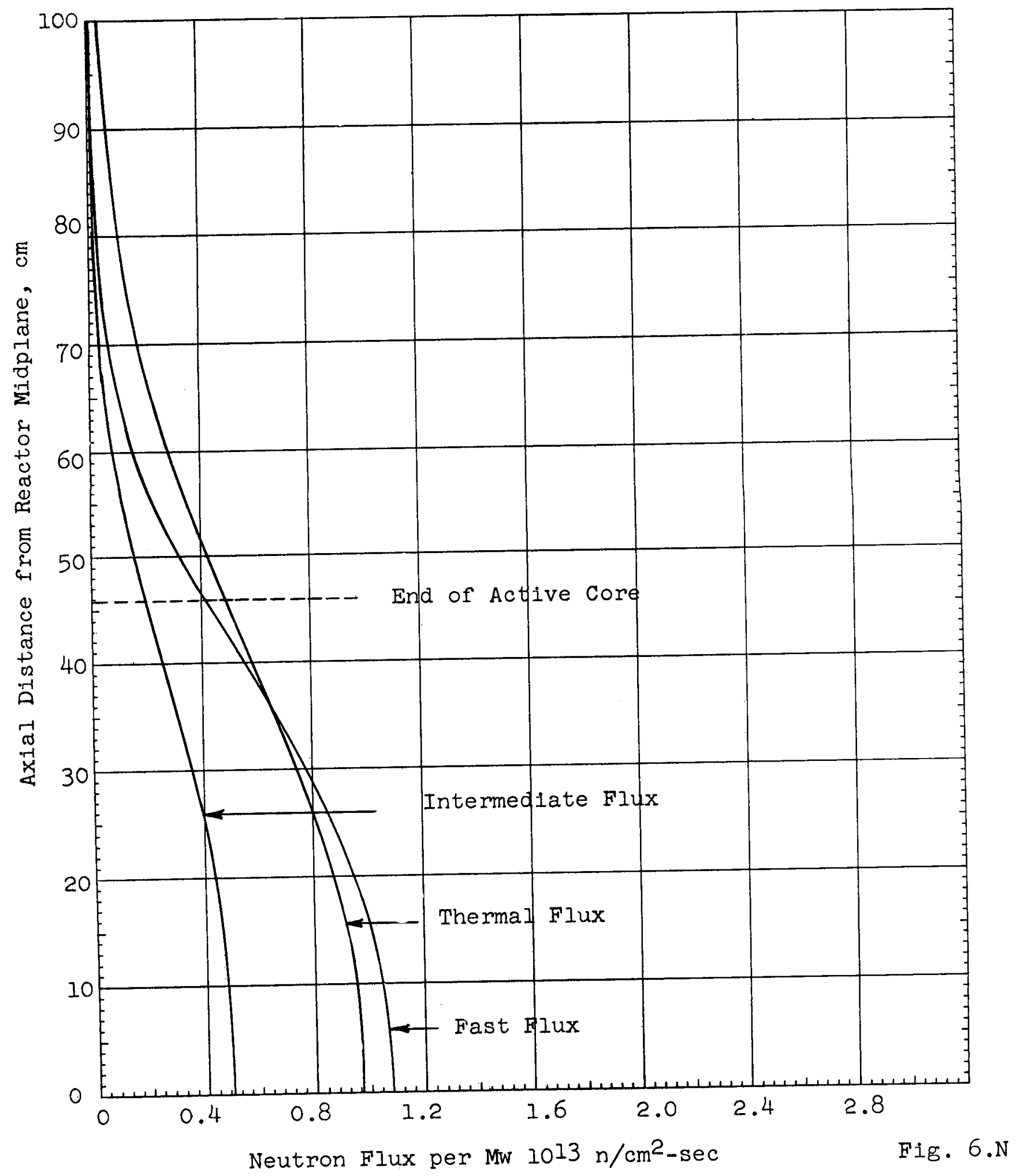


Figure 6.0 Axial Neutron Flux Distribution Along Fuel
Assembly Centerline in Type-A Reactor

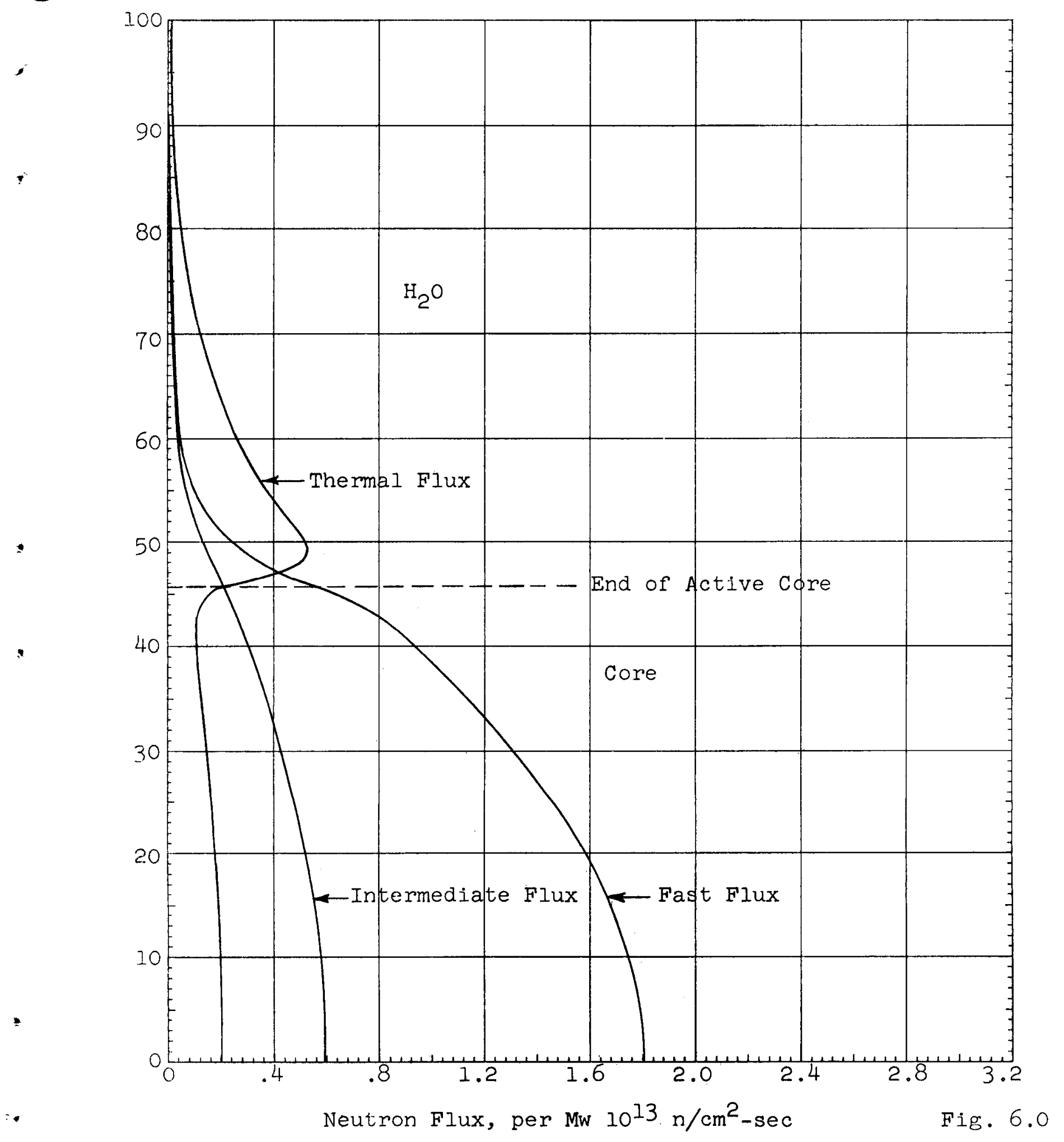


Figure 6.P Reactivity Variation With Fuel Mass for Hot, Clean Type-A Reactor

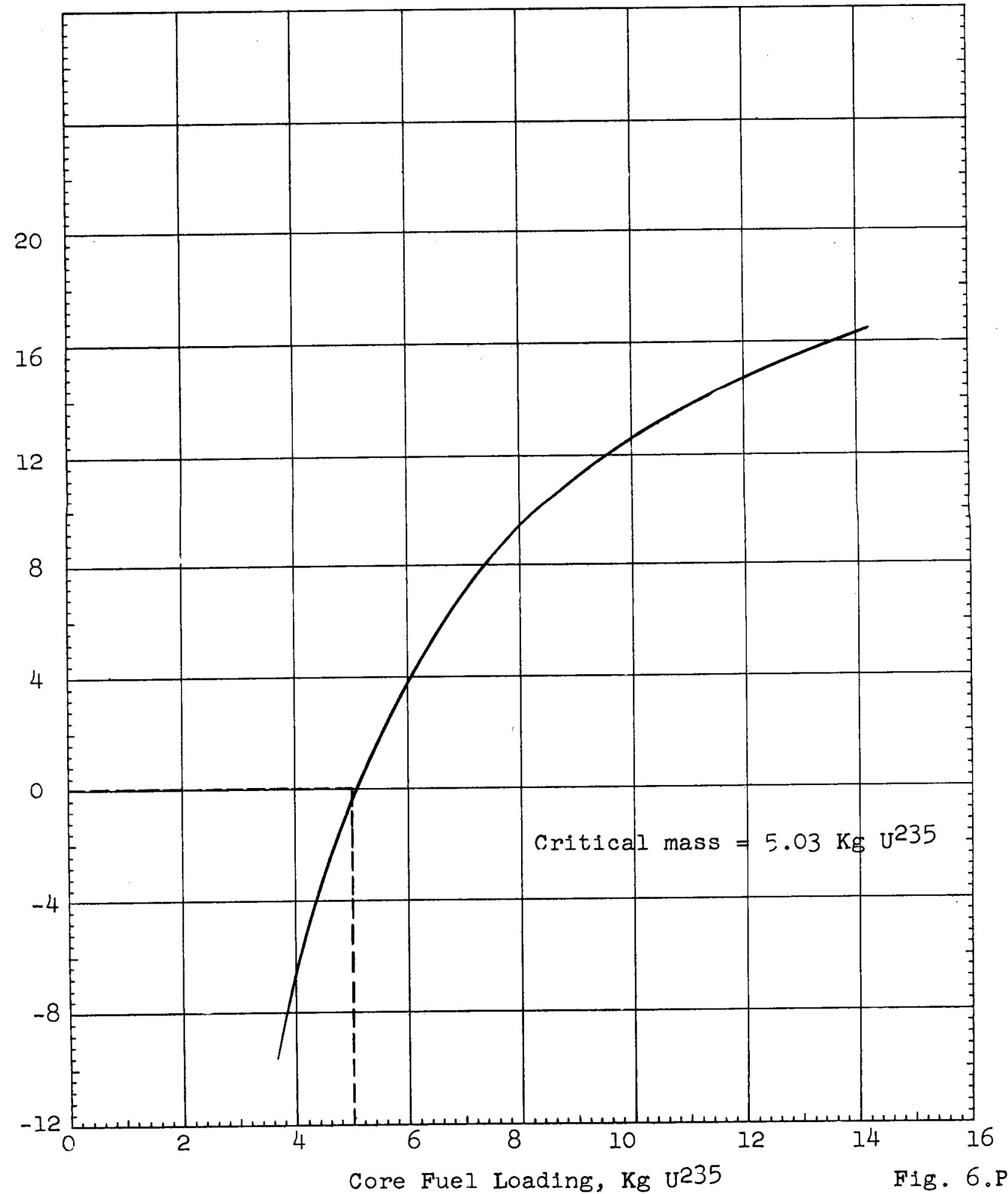


Figure 6.Q Reactivity Effects of Void in $20-\mathrm{cm}$ Thick Reflector Annulus Adjacent to the Core.

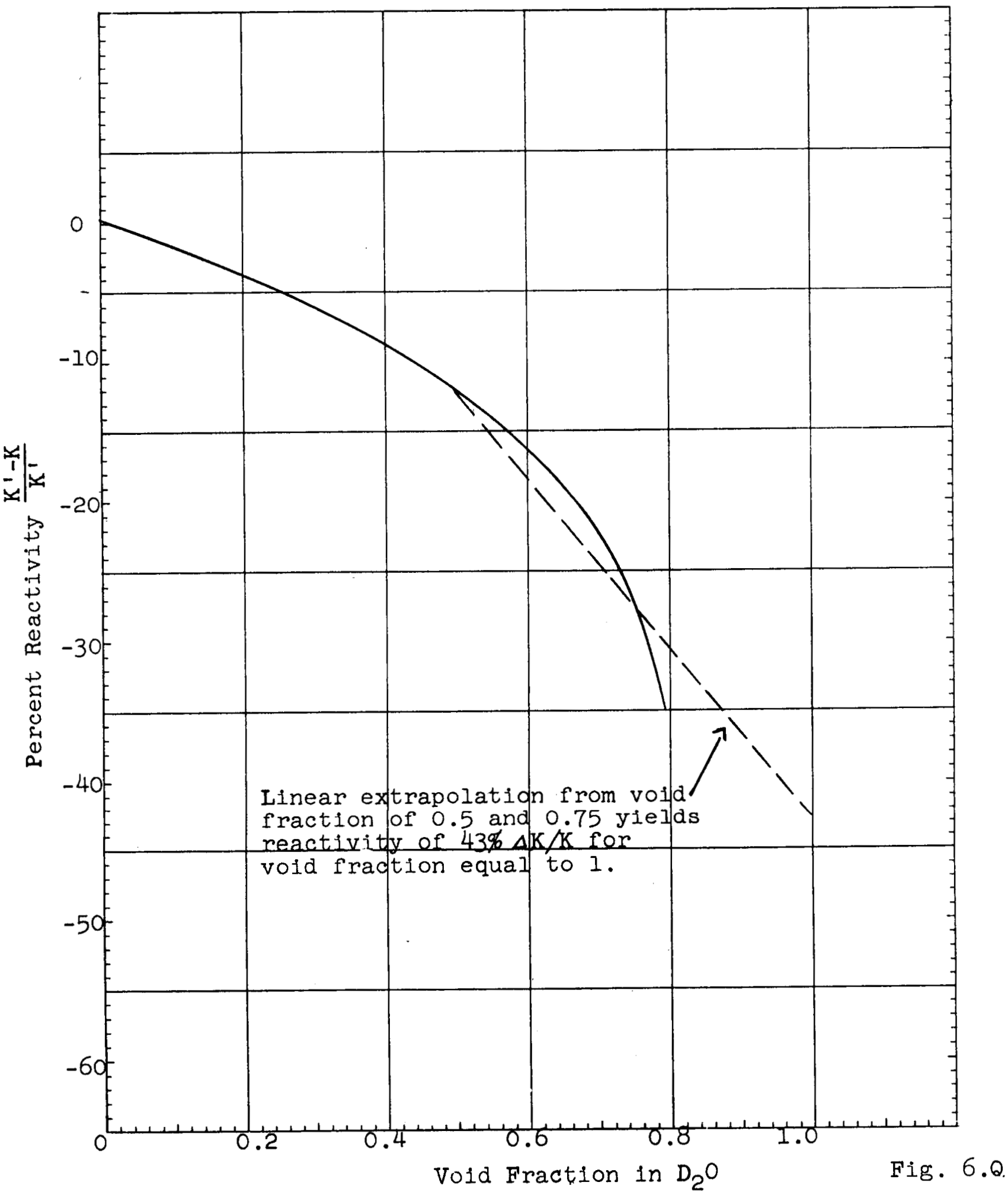


124

Figure 6.R Reactivity Effect of a $75 \%$ Void $\mathrm{D}_{2} \mathrm{O}$ Annulus Adjacent to the Core Wall.

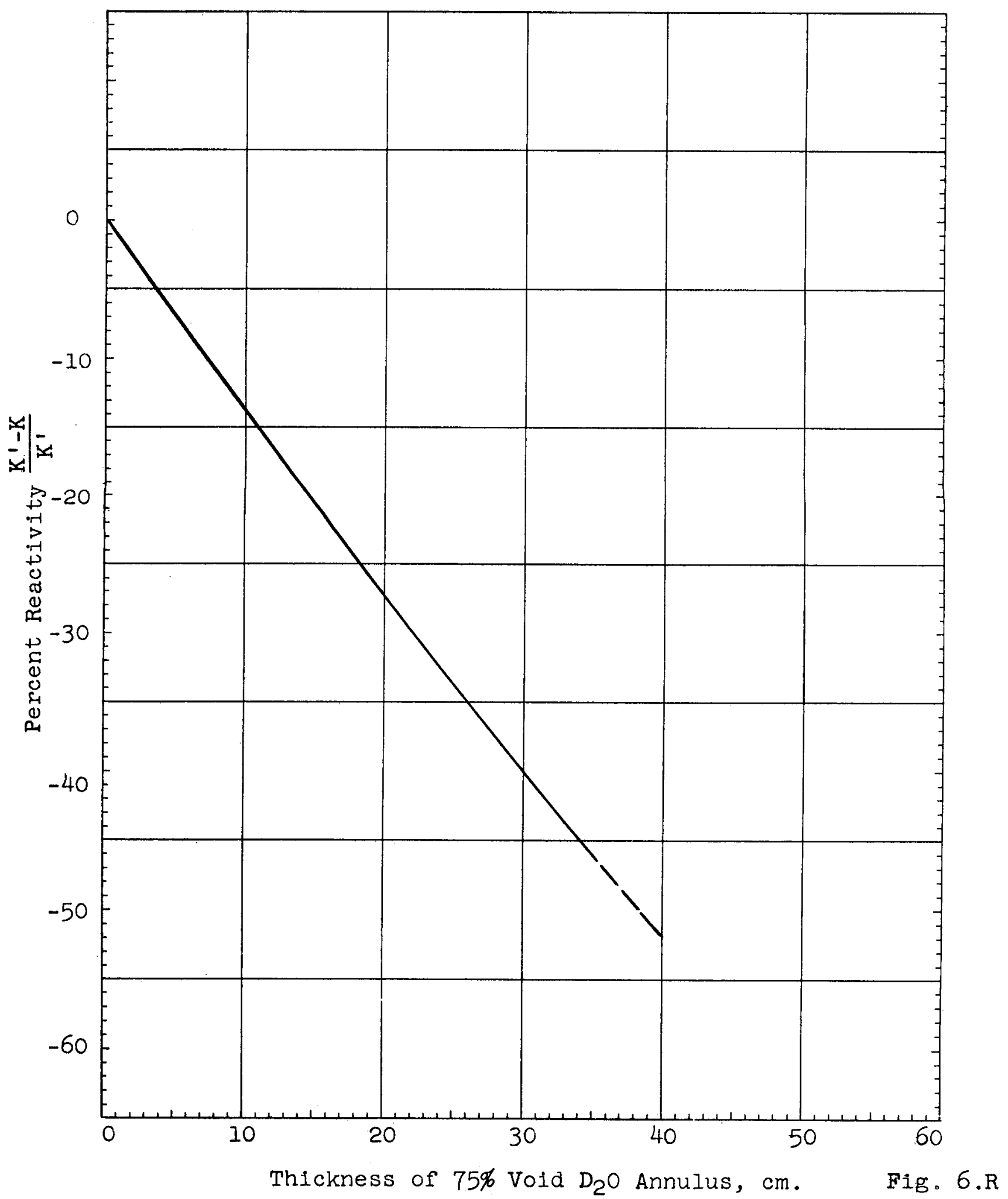




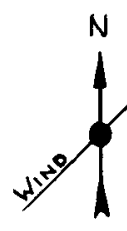

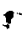

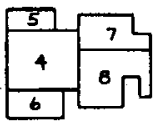

BUILDING LEGEND

EXISTING BUILDINGS SHOWN

I. M.T.R. REACTOR BLDG.

2. M.T.R. REACTOR BLDG. WING

3. M.T.R. SERVICE BLDG.

4. E.T.R. REACTOR BLDG.

5. OFFICE BLDG.

6. Electrical Bldg

7. Compressor BldG.

8. HEAT EXEMANGER BLDG.

9. E.T.R. COOLING TOWERS

10. Fan house STACK

11. E.T.R. Waste Gas Stack

12. PRocess Water Bldg.

13. ADMINISTRATION BLDG.

14. SERVICES BLDG

15. STEAM BLDG.

16. Demineralizer BLDG.

17. Pump House Raw Storage tanks

18. M.T.R. Pump Mouse Well \#3

19. FUEL OIL TANKS

20 M.T.R. COOLING TOWERS

Proposco A.E.T.R. BuIloings Shown,

51. A.E.T.R. REACTOR BLDG.

52. OFFICE BLDG.

53. Permanent Waste storage

54 TRANSFORMER YARD

55. FAN HOUSE STACK

56. COOLING TOWERS

57. RETENTION BASIN 
Figure 8.B Reactor Building Unit-Vertical Section

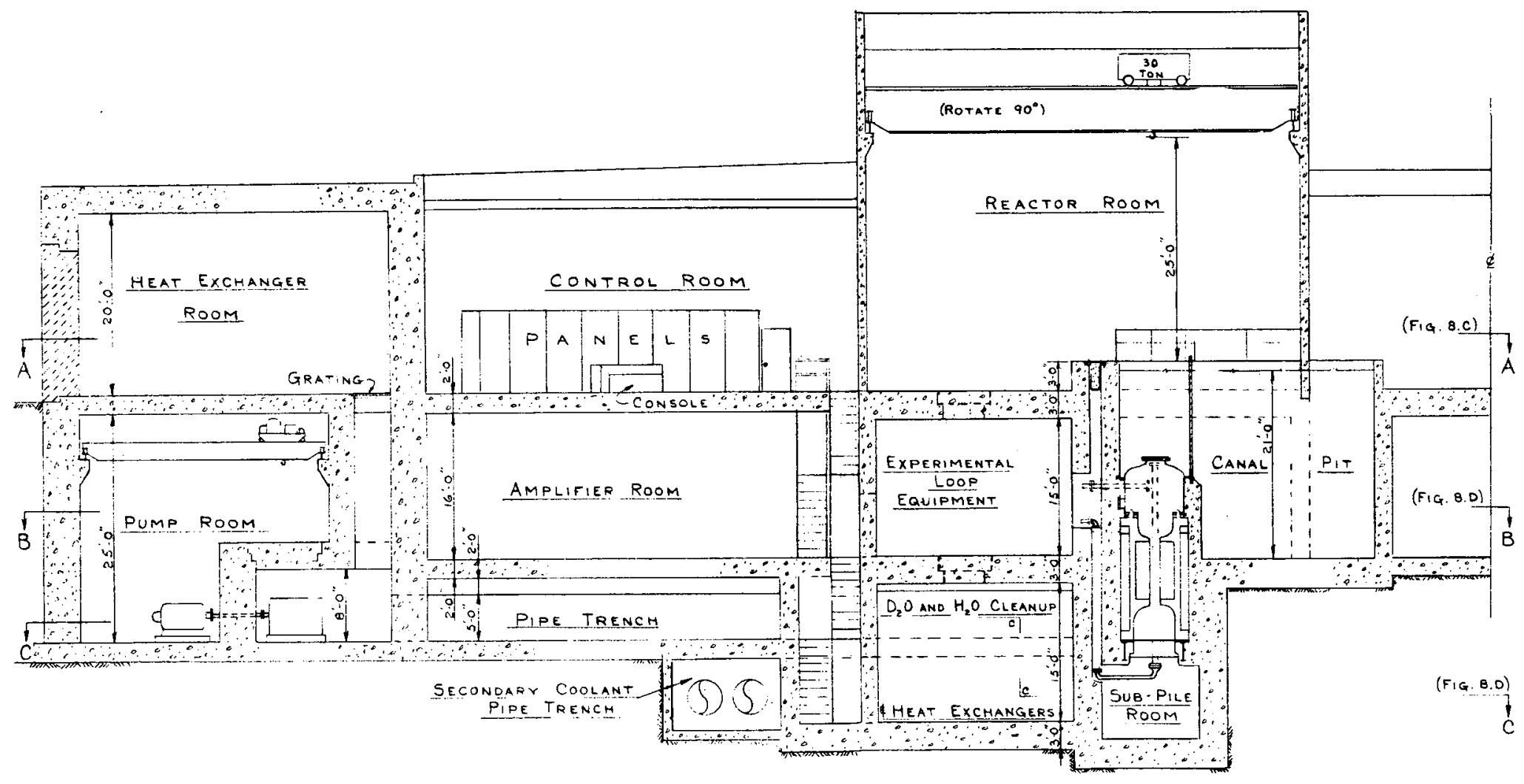

SECTIONAL ELEVATION

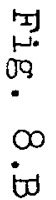

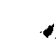


Figure 8.C Reactor Building Unit-First Floor Plan

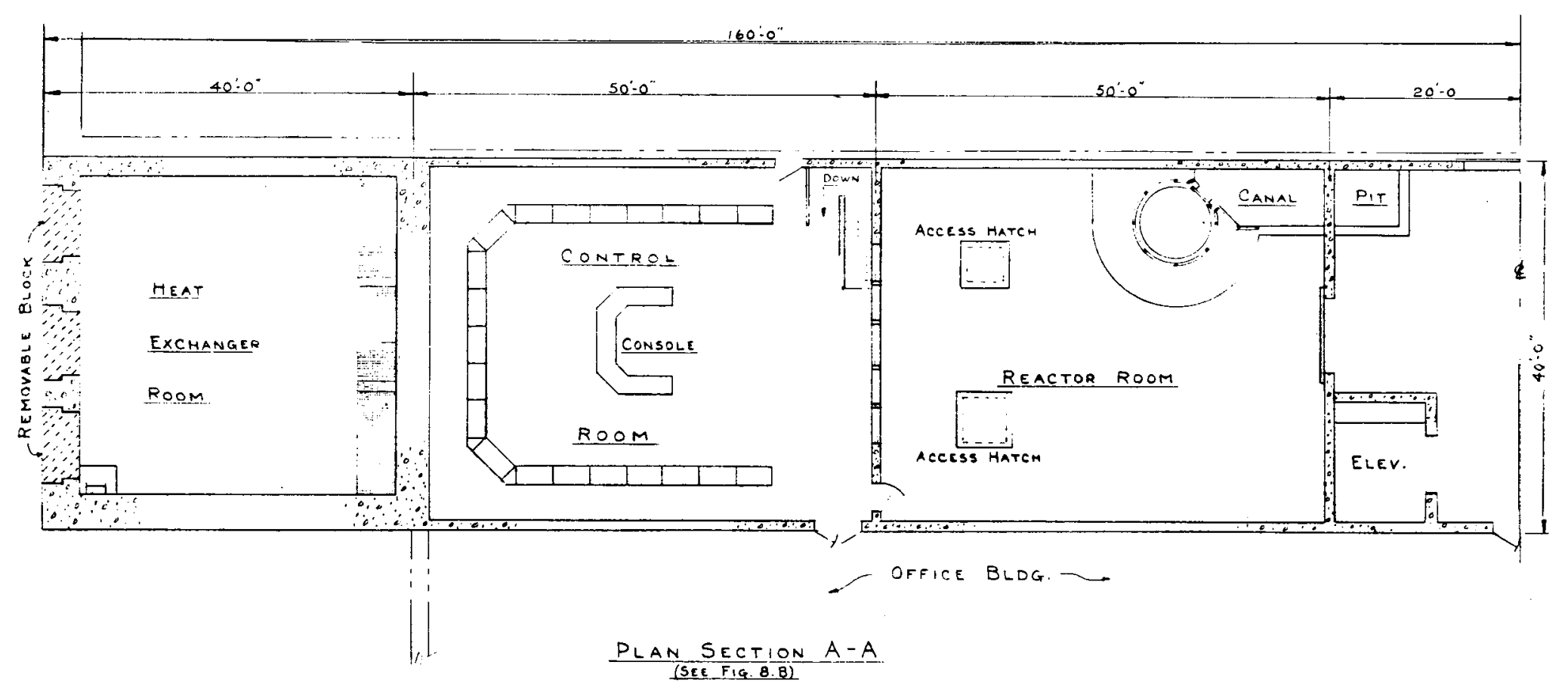

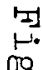


Figure 8.D Reactor Building Unit-Lower Floor
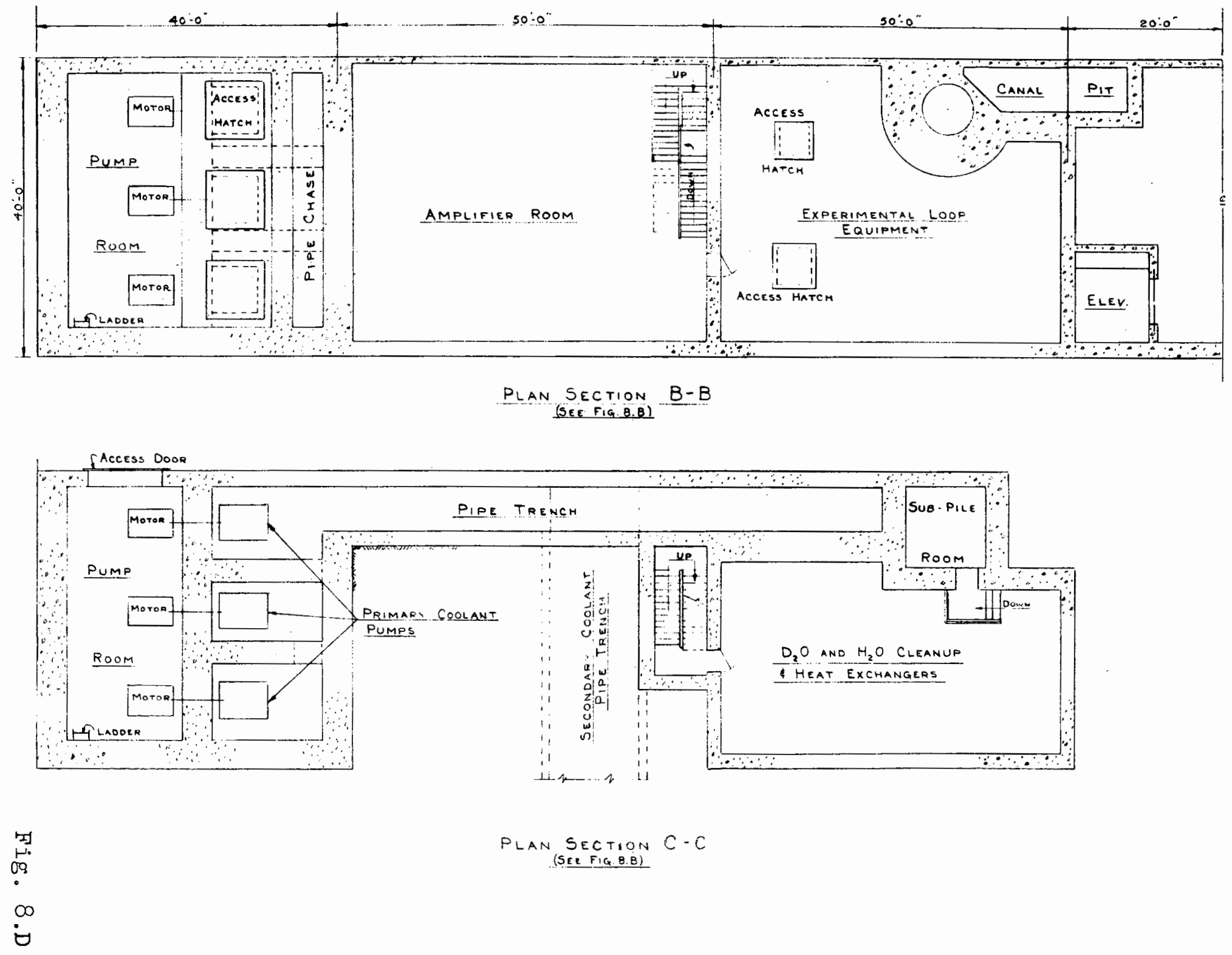
Figure 8.E Reactor Building - Plan

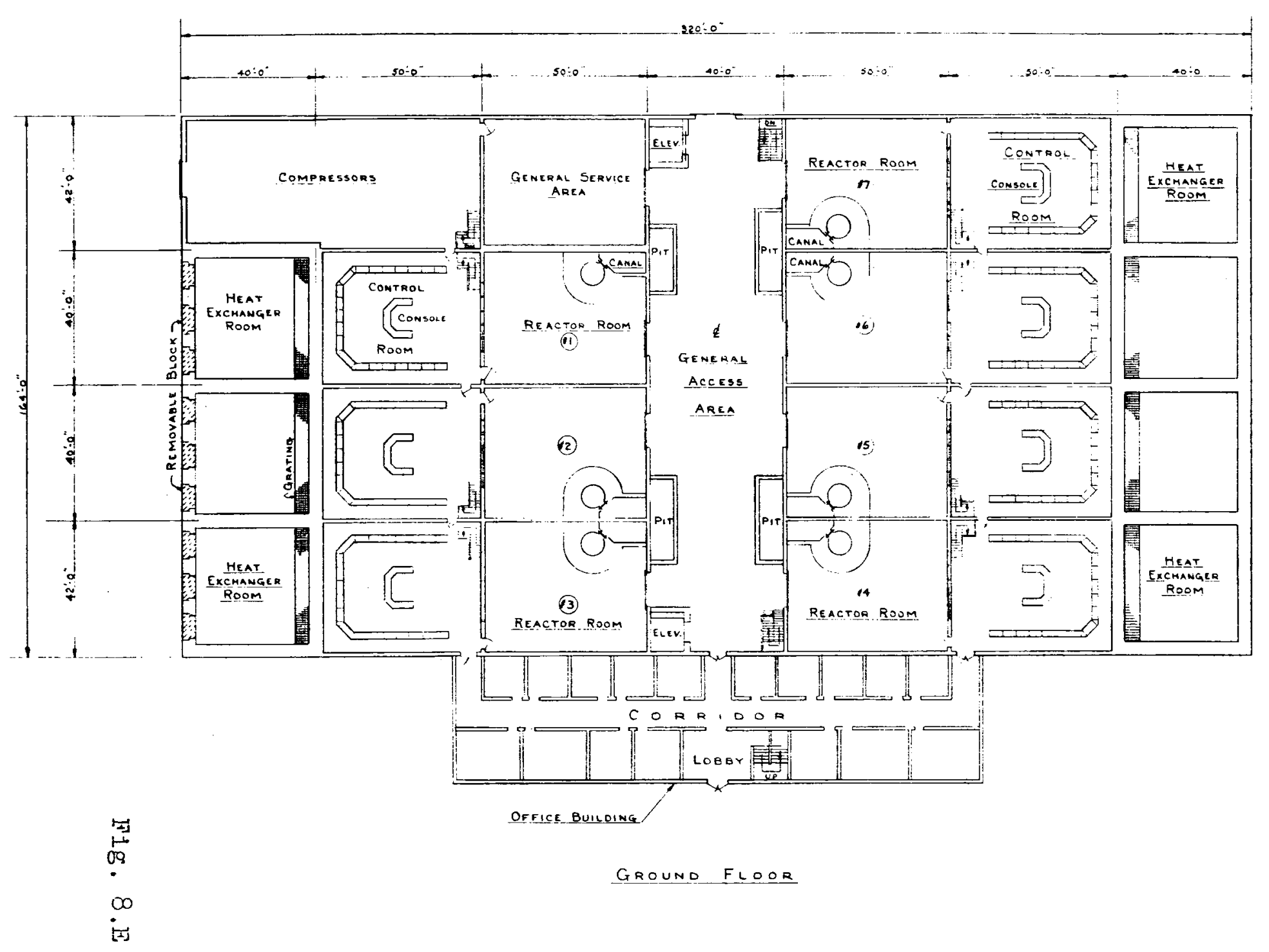


Figure 11. A Radioactive Liquid Water Storage and Treatrient Facilities.

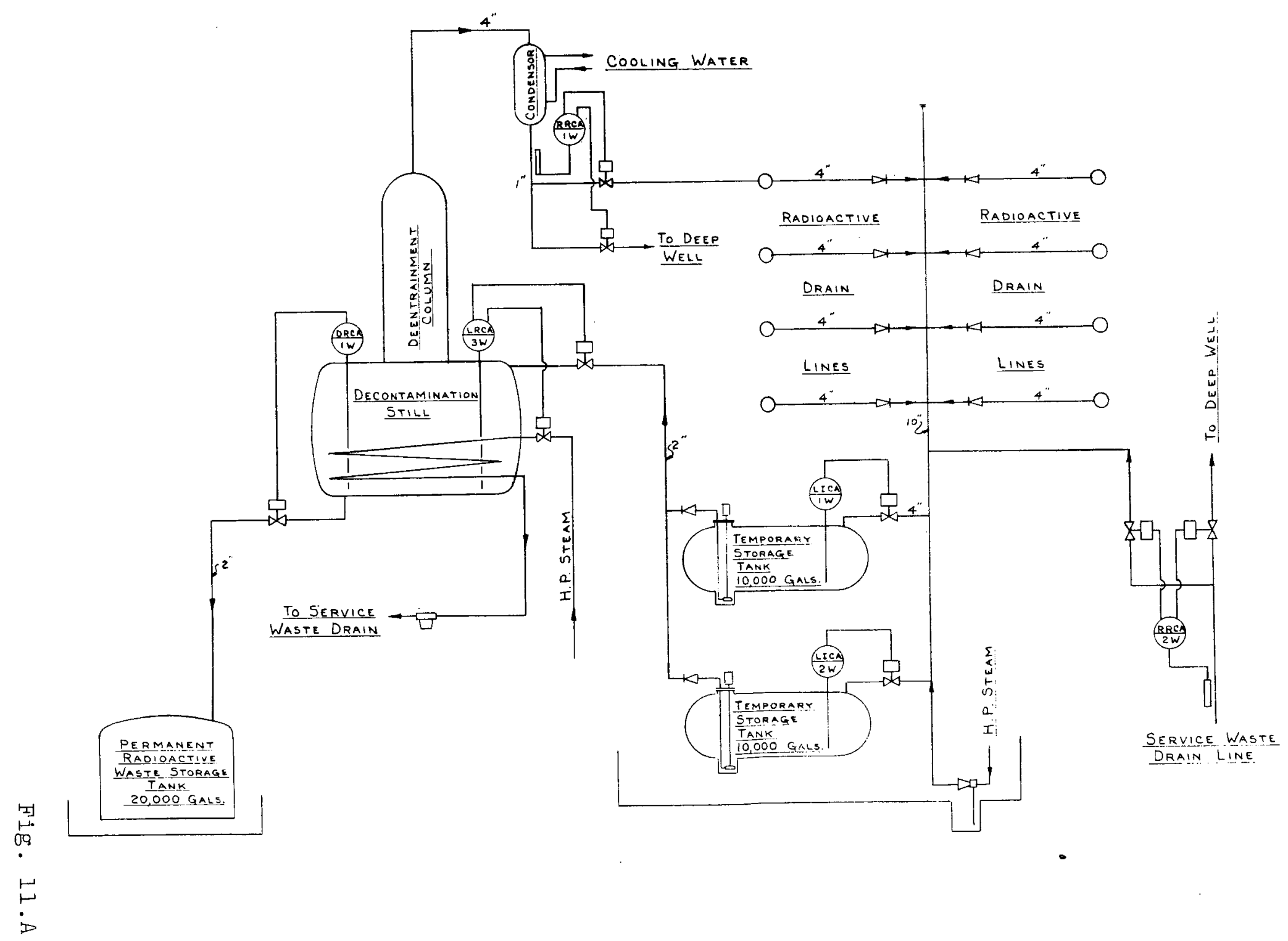


Figure 14.A Thimble Design Reactor-Elevation

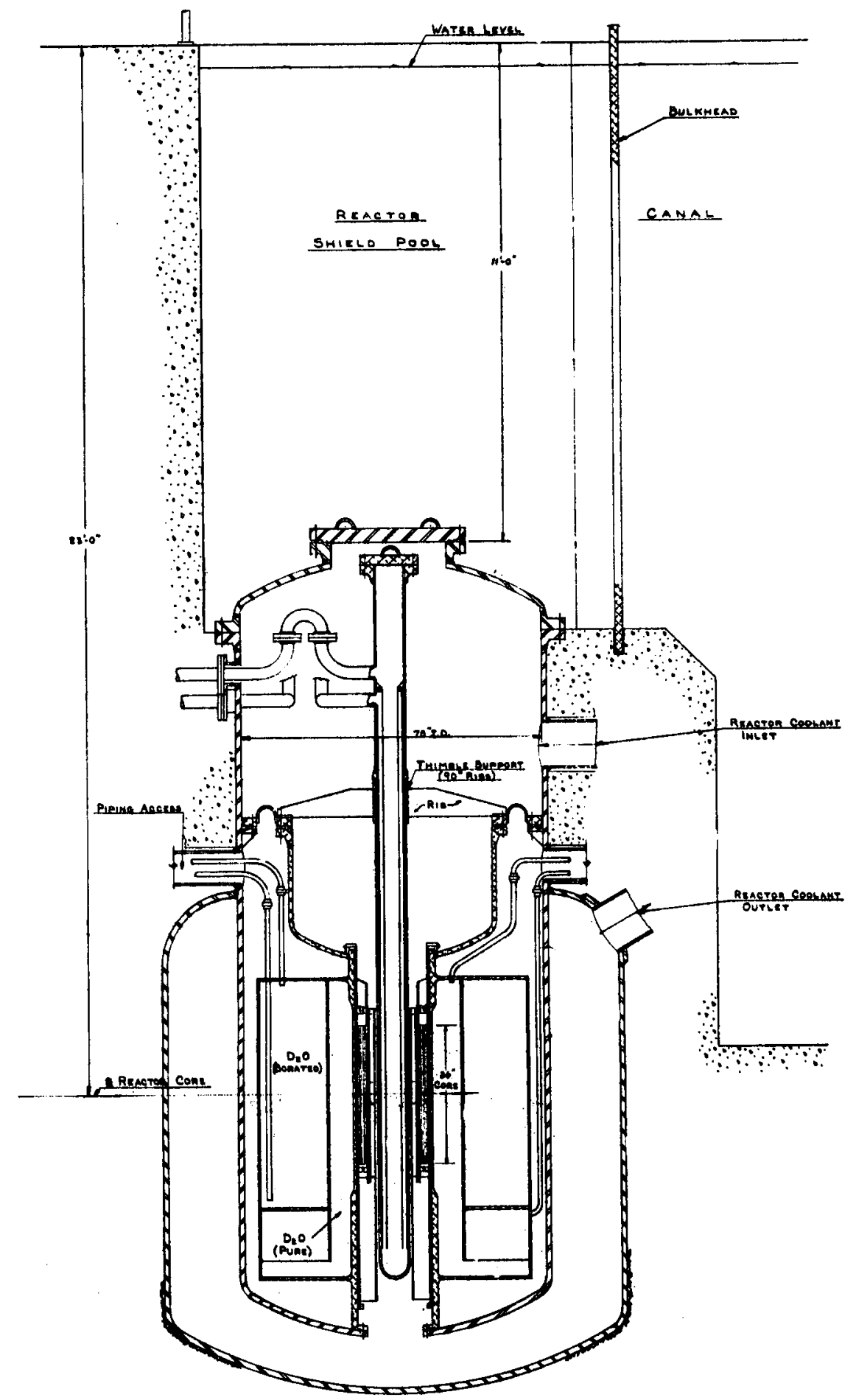

F1g. 14.A 


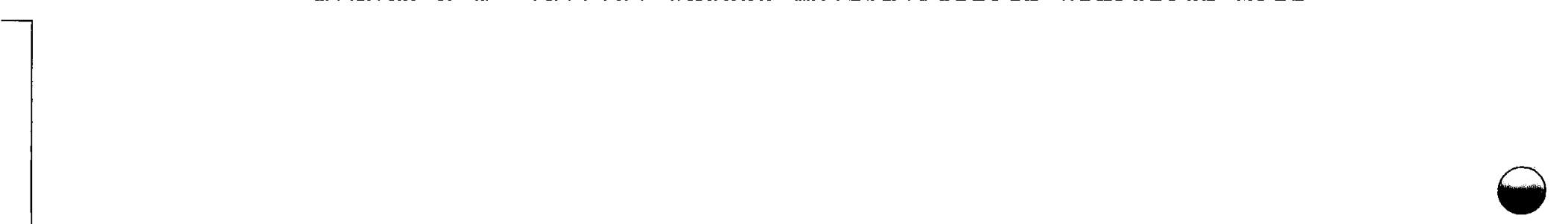

$\theta$

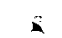
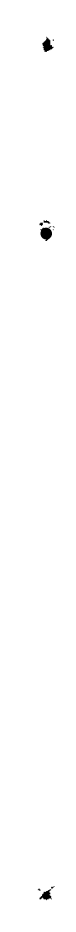

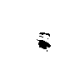

- 


\author{
PART B \\ SELECTION OF AN \\ ADVANCED ENGINEERING TEST REACTOR
}

\title{
1.0 INTRODUCTION
}

Part $B$ of this report presents information on the optimization with respect to certain design parameters and the comparisons of certain design alternatives. The design decisions made from these comparisons result in the concept presented in Part $A$.

The studies reported are directed toward the optimization of the flux and power level to produce unperturbed thermal neutron fluxes of $1.5 \times 1015 \mathrm{n} / \mathrm{cm}^{2}-\mathrm{sec}$ in test holes as outlined in Appendix 1.0. Comparisons are made of various types and sizes of fuel assemblies on the basis of their power density capability, ability to be readily fabricated, and cost. The problems of nuclear heating of materials in the reactor, particularly as they affect the reactor vessel and test loop pressure tube are investigated. The relative merits of separate reactors and a composite reactor are compared on the basis of reactor power, versatility, control, and cost. Chemical methods of reactor control are compared with a conventional mechanical control system. The advantages of through-tubes for the loop facilities are compared with the advantages of thimble-type facilities. Comparisons are made of several alternate arrangements of the system controls, and the overall arrangement of the reactor facility. 


\subsection{SELECTION SUMMARY}

In order to arrive at the design which is recommended in Part A of this report, a number of studies were made to examine and evaluate alternative concepts. These studies compared important materials, reactor configurations, arrangements, and cooling systems, etc.

2.1 General Characteristics

The general features of the AETR are based upon meeting the design flux objectives with a useful facility that is economical to build using the manufacturing and reactor operating capability of the present.

The selection of general core characteristics is briefly described below before summarizing the major design decision.

2.1.1 Core-Reflector Assembly

The AETR is a testing reactor built around a single large test hole. Annuli which consecutively surround the test hole are the test loop tube, water moderator annulus, fully-enriched plate-type water-cooled core, and a thick $\mathrm{D}_{2} \mathrm{O}$ reflector.

In the range of core thicknesses investigated the flux. peaking in the test hole increases for successively thinner cores. Therefore, in the two cores optimized, the maximum power density of $2.9 \mathrm{Mw} /$ liter sets a lower limit on core thickness. Thus the selected core thicknesses are 2.07 and 2.47 inches.

A slight power saving results with $\mathrm{D}_{2} \mathrm{O}$ as a core coolant, but this does not justify the additional complications encountered in its use as a primary coolant. Use of $\mathrm{H}_{2} \mathrm{O}$ as the reactor coolant is a design requirement, (See Appendix 1.0) which was based on the result of previous work.*

Nuclear calculations indicate that for most experiments maximum test hole thermal neutron flux per unit reactor power occurs when the water moderator thickness is $4 \mathrm{~cm}$. Metal-water ratio has little effect on the test hole flux and the resulting ratio $(0.685)$ was determined entirely on the basis of heat transfer and fuel loading needs.

Core height is 36 -in because with this height the average thermal neutron test flux varies less than $50 \%$ over a 30 -in long test assembly. This latter is a design requirement (See Appendix 1.0).

* Elgert, 0.J., et al, INTERNUC-9 "Preliminary Investigations for an Advanced Engineering Test Reactor", February 22, 1957. 
The use of $\mathrm{D}_{2} \mathrm{O}$ as the reflector material is a design requirement (See Appendix 1.0), which is also based on INTERNUC-9* results. The 24-in thickness is chosen for the reflector since it is highly efficient and feasible from an arrangement point of view. The $\mathrm{D}_{2} \mathrm{O}$ reflector offers two effective means of control which are simple and safe and which do not seriously impair the test assembly thermal neutron flux or the core power distribution.

\subsubsection{System Pressure}

The higher the system pressure, the hotter the primary coolant water must be to boil. Hence, increasingly greater power, power density and temperature drop across the core all tend to require higher primary cooling system pressures. However, the corrosion properties and strength of aluminum fuel plates suffer above $460^{\circ} \mathrm{F}$. Moreover, the burnout heat flux decreases with increasing system pressure so that the relative margin of safety for a high-performance core is less at high pressures.

Evaluating all these factors, along with the pressure drop through the core and the margin between design and burnout heat fluxes, a system pressure of $300 \mathrm{psi}$ is adopted. This gives a maximum plate temperature of $405^{\circ} \mathrm{F}$ at the hot spot for a power density which is $27 \%$ of the burnout heat flux. This pressure (300 psi) represents a standard pressure for valves and piping, and does not require unusual mechanical design for the pressure vessel or heat exchangers.

\section{1 .3 Core Coolant Flow}

The velocity of the water through the core is $40 \mathrm{ft} / \mathrm{sec}$. This represents a slight advance over the $35 \mathrm{ft} / \mathrm{sec}$ planned for the ETR, but is less than the $50 \mathrm{ft} / \mathrm{sec}$ at which several

aluminum plate-type fuel assemblies have been successfully flowtested. The curved plates, the absence of end boxes, and coldrolled fuel plates all enhance the fuel assembly design for use with this water velocity.

The downflow direction is selected for the core to simplify fuel assembly support, clamping, and installation. Down flow also makes the water above the core slightly more effective as a bulk shield and minimizes the heat transferred to the pool water above the reactor. Natural circulation if needed can take place without reversal regardless of flow direction with heat exchangers 24 feet above the core midplane.

* Elgert, O.J., et al, INTERNUC-9 "Preliminary Investigations for an Advanced Engineering Test Reactor", February 22, 1957. 
2.2 Fuel Assembly

Because of their relatively low cost there is no question that aluminum-uranium fuel plates with aluminum side plates are best for the AETR. The 30-40 wt.\% uranium in the aluminumuranium meat alloy is in the upper range of present technology, but is low enough to preclude unusual difficulty in manufacture. With 13 mils minimum cladding thickness, a 50-mil fuel plate is selected. This thickness is consistent with present ETR and MTR practice. The water gap used is 73 mils since this gives a convenient number of core fuel plates and heat transfer rates ciose to the optimum.

The fuel plates are stamped to an involute curve so that plates of uniform thickness, width, and spacing completely fill the core annulus. For a given power density, this fuel assembly gives a higher total power than other types. One other feature of the fuel plates is that the meat and clad thicknesses are tapered to place more fuel in the low-flux central portion of the core for a radial power distribution.

Assembly of the fuel plates uses the roll-swaging process. This gives strength equivalent to brazing, but without the corrosive brazing alloy and the annealed condition of brazed fuel assemblies. The process costs less than brazing.

\subsection{Reactor Control}

For a reactor as compact as the AETR where flux perturbation should be limited, control rods are difficult to incorporate. Therefore, a number of control schemes were investigated. The principal comparison is shown in Table 2.a.

on the basis of this data and as elaborated in chapter 6.0, the two reflector controls are selected. They are an improvement over control rods for this small, highly loaded core. The reflector safety and chemical shim appear less expensive even when including development costs. Two regulating rods are planned for the reactor since only operational experience can show whether they are unnecessary.

\subsection{Test Loops}

The two test loops evaluated are the reentrant thimble and the through-tube. The relative merits are compared in Table $2 . b$.

There is no strong preference between the two loop tubes. For lower reactor power, lower operating costs, and better strength, the through-tube is selected for the AETR.

For a test facility with minimum capital cost, the thimble-type test loop tube is preferred since it can eliminate the need for a sub-pile room and can simplify experiment handling. 
Table 2.a

Comparison of Control Systems

Mechanical Control Rods

Reflector Level \& Chemical Shim

$+$

Components Required

\begin{tabular}{l|l}
\hline 3 safety rods & Reflector tank separator \\
3 shim-safety rods & Eductors \\
& Bas bypass piping and valves \\
& Boron injection and cleanup \\
& system \\
& Extra coding, cleanup, and \\
blanket gas system
\end{tabular}

Rate of Scram

Time for removal of:

$3 \%$ reactivity $-0.22 \mathrm{sec}$

$30 \%$ reactivity -0.43 sec

$0.09 \mathrm{sec}$

0.26

Installed Costs (per reactor)

\begin{tabular}{l|l}
\hline $\begin{array}{l}\text { Equipment } \\
\$ 94,000\end{array}$ & $\$ 42,000$ \\
\hline
\end{tabular}

Flux Perturbation

\begin{tabular}{l|cc} 
& (without reg.rod)(with reg.rod) \\
Shim control - moderate & none & none \\
Perturbation of test flux & none & very slight \\
\hline
\end{tabular}


Table 2.b

Comparison of Thimble-Type and Through-Type Test Loops

Thimble Through-Tube

Reactor Power (preliminary values)

$\begin{array}{clll}\text { Test Hole ID-in } & & \text { Coolant } & \text { MW } \\ 3 & \text { Water } & 68 \\ 4 & \text { Sodium } & 100 \\ 5 & \text { Water } & 68 \\ 7 & \text { Sodium } & 138 \\ 7 & \text { Sodium } & 183\end{array}$

$$
\begin{aligned}
& \text { MW } \\
& 68 \\
& 89 \\
& 68 \\
& 119 \\
& 153
\end{aligned}
$$

\section{Loop Tube Size}

The thimble ID is 20\% larger than the test hole in order to make the annulus area for return water flow equal to half the test hole. An additional area allowance for inner surface insulation or cooling is also needed.
The through-tube ID is larger than the test hole by a small amount for inner surface insulation or cooling.

Maximum Operating Stresses for

Optimum Tube Design

Test Hole ID-in Coolant psi

psi

$\begin{array}{llr}7 & \text { Sodium } & 11,442 \\ 4 & \text { Water } & 15,070 \\ 4 & \text { Sodium } & 6,755\end{array}$

\section{Maximum External Pressure Safe for Buckling}

7-in Gas-Cooled, psi 300 


\section{Table 2.b (continued)}

Thimble

Through-Tube

Thermal Expansion

The thimble is anchored to the reactor vessel at only one point so that vertical expansion is no problem.
A bellows or a sliding seal is required at one of the points where through-tube passes through the reactor vessel to allow for vertical expansion.

Effect on Facility

A thimble requires no flow connection beneath the reactor. This simplifies piping and construction. No sub-pile room is needed for the thimble.
A through-tube requires permanently installed piping beneath the reactor. This may limit the types of experiments for each reactor.

\section{Handling}

Thimble experiments can be contained within the thimble before, during, and after irradiation. They can also be inserted separately.
Through-tube experiments are changed individually and the through-tube is seldom changed.

Loop Tube Replacement

Thimbles can be changed for different loop coolant by unbolting a flange at the upper end of the thimble, above the reactor core.
To remove the through-tube, the loop tube flange is unbolted from above the reactor and the loop tube unscrewed at the joint below the reactor.

Operating Costs

With 20\% greater power for sodium or gas-cooled experiments, operating costs are probably higher than they are for the through-tube. For water-cooled loops, the power is slightly less with the thimble.
The reactor fuel costs will be about $15 \%$ less than that of reactor with thimbletype test holes. 


\subsection{Reactor Assemb1y (Separate versus Composite)}

With seven reactor test loops specified, the options of separate reactors and a composite reactor assembly were explored and the results stated in Table $2 . c$.

The preference for separate cores is very clear. The better utilization, simpler core maintenance, and better control of test loop neutron flux make separate reactors superior to the composite reactor.

\subsection{Reactor Shield}

With separate reactor cores there is the possibility of a saving lowering the construction cost of a seven reactor facility by combining the relatively massive reactor shields. The shield types are compared in Table $2 . d$.

Separately-shielded reactors offer the better combination of accessibility, radiation containment, and efficient coordination at a very slight cost in additional concrete. Hence, separate reactor shields are used in the AETR.

\subsection{Primary Coolant Loop}

With seven reactors, the merits of using a single common reactor primary coolant system for all was investigated. This scheme can be used with reactors located together or some distance apart. The relative advantages and disadvantages compared with separate reactor primary coolant systems are indicated in Table $2 . e$.

The advantages of individual primary coolant loops for each reactor are the simpler, better control permitted, the absence of throttling and isolation valves, simpler maintenance, and better containment of fission product contamination. The operating cost difference is not significant when compared to the difference in usefulness of the separate systems chosen.

\subsection{Secondary Coolant Loop}

The secondary cooling system can be separate for each reactor, or all seven reactors can use a common system. General features of these two schemes are compared in Table 2.f.

For smaller cost, more efficient operation, and simpler maintenance, the common secondary cooling system is selected. The transient performance has not been thoroughly studied, but it appears that a common secondary has a temperature level which is sufficiently stable to prevent troublesome temperature transients in the primary cooling loop. 
Table 2.c

Comparison of Separate and Composite Reactors

Separate Reactors

Composite Reactor

Power, Mw

Full Power, Mw

Average Test Hole Thermal Flux, $1015 \mathrm{n} / \mathrm{cm}^{2}-\mathrm{sec}$
849

1.5
853

1.5 in 5 cores

2.1 in 2 cores

\section{Flux Perturbation}

It is probable that a single reactor can be controlled without distorting a symmetrical thermal flux patters.
Interaction between experiments and control devices is more likely for the composite reactor core and thermal fluxes may be perturbed.

\section{Fuel Burnup}

A separate reactor operates as needed by one experiment for minimum fuel burnup.
The composite reactor has a relatively constant power level and fuel burnup, even with loop tubes vacant.

\section{Maintenance}

Single reactors are maintained as needed, on an individual basis.
With the composite reactor, all cores must be maintained reloaded, and experiments replaced at one time during collective shutdown.

\section{Utility}

A separate reactor shuts down on $1 \mathrm{y}$ as required for servicing the core and the single test 100p. Difficulties with test loop experiments do not affect other test loops.
Malfunction or replacement of any individual core or test loop with shut down the entire composite reactor. These shutdowns are multiplicative and reactor operation time is thus limited. 


$$
\text { Table 2.d }
$$

Comparison of Reactor Shielas

Common Shield

Individual Shields

Accessibility

As seen in Figure $12 . D$, access to any reactor is adequate. However simultaneous access to several reactors may be more difficult.
Access is best at all times to individually-shielded reactors. See Figures $8 . B$ and $8 . E$.

\section{Contamination}

Due to the nature of contaminants it is very much more difficult to limit the spread of radioaction when seven potential source areas are all in the same large reactor room.
Individual reactors in vaportight portions of the same building can better limit the spread of radioactivity from adjacent reactors.

Construction Cost

Concrete required for the common shield will probably be less. However, all the shield and pool concrete represents only $2 \%$ of the AETR construction cost.

Somewhat more shielding concrete may be required for the individual reactors, even though "siamesed" in adjacent shields. (See Figure 8.E.

Operation

It is probable that there may be occasional confusion between various men in the common reactor room and their respective control rooms.
When there is a separate room for each reactor, coordination appears simplest between control room and reactor area. 
Table 2.e

Comparison of Common and Individual Primary Coolant Loops

Common

Individual

Control

Startup or shutdown of any reactor will alter the power level of every other operating reactor due to temperature coefficient effects.

With an individual primary, changes in the power level of one reactor are less likely to effect others.

\section{Access}

It is impossible to service any test loop unit in the common primary coolant loop without depressurizing the 10op unless large isolation values are installed
Individual reactors can be depressurized and shut down at will without affecting others.

Containment

A fuel element failure will contaminate all the heat exchangers and all the test loop units. A ruptured element may also be difficult to locate in a common primary loop
Fission products are confined to one loop and will not cause shutdown of other test loops. Decontamination is simpler and faster.

Reactor Service

For shutdown servicing of one reactor the flushing of the system and shutdown cooling required a separate independent system
Cooling and flushing for shutdown circulation are simpler for individual primary loops. 
Table 2.f

Comparison of Common and Individual

Secondary coolant Loops

Individual

\section{Capacity}

Considering occasional cooling tower maintenance, the common secondary needs less total capacity than do individual secondary loops.
An individual secondary cooling loop must be sized for the maximum reactor power plus the power of an experiment. Unless there are additional towers, cooling tower maintenance will require reactor shutdown or partial-power operation.

Cost

The common system with less total capacity costs less to build. Common system piping may also be cheaper even though large (48-in).
Individual secondary cooling systems (two or three towers) do not have the flexibility to run all cooling towers, fans and pumps at optimum conditions as can be done with secondary consisting of 16 cooling towers.

\section{Transient Effects}

The startup and shutdown of one reactor may affect the operation of the others through changes in the secondary coolant flow and temperature.
Has no effect on the operation of other reactors.

Maintenance

Since each of the 16 cooling towers has its own valves and coolant circulating pump, one or two towers can be shutdown at all times without affecting reactor operation.
Unless substantial excess capacity is built in, any maintenance of secondary loop equipment or cooling towers requires a reduction in reactor power. 
2.9 Controls and Instrumentation

As described more fully in Chapter II.0, there are many ways to combine reactor controls with controls for the experimental loop. Some of these can be disregarded, but two were investigated. One scheme placed the controls for all seven reactors in one room while the other placed the controls for each reactor and its test loop in the same room. The conclusions are listed in Table 2.g.

Although supervision of all reactors at one time may be more difficult with a separate control room for each reactor and its test loop, the actual operation is more effective and possibly less supervision is needed when the loop operators can assist or cooperate with the reactor operator. For this reason and the simplification in communication, there is one complete, "integrated" control room for each reactor-test unit in the AETR building.

\subsection{General Arrangement}

In regard to suitability, versatility, and cost, the specifications for the AETR are best met by several single-1oop, individually shielded reactors in an arrangement similar to that shown by Figures $8 . B, 8 . E$ of Part A. The seven reactors are housed in one building but are independent of each other with individual test facilities, shielding, control, and primary coolant systems. With such an arrangement, each reactor can be operated at maximum efficiency and as called for by a single testing program. Fuel element testing can be carried out under optimum conditions since each loop test is entirely independent of the others. The reactor can be started up or shut down and reactor power level varied to suit the individual experiment with no concern for affects on other test loops. Neutron flux distributions in the test elements are not subject to perturbations from changes in other test loops. Furthermore, the concept selected allows imple access to change experiments and replace fuel elements. The test holes, cores, and control systems are all physically separate. 
Comparison of Common and Combined Controls

Common

Combined

\section{Communications}

With several reactor controls in the same area, there is apt to be confusion in the alarms and communications between reactor consoles and the varlous test loop consoles.
Communications are simpler where there is only one reactor console in an area. They are simplest when the reactor control is adjacent to the controls for the test loop of the same reactor.

Supervision

With several reactors in one room, supervision can be better.
With reactor controls in separate rooms, a more responsible reactor operator is required. With a single test loop per reactor, the amount of operation required may be less for the AETR than for other testing reactors.

\section{Effectiveness}

Reactor operators cannot aid one another since their tests are unrelated
The operator of a single reactor can assist and be assisted by the test loop operator if in the same room. This is impossible with the common reactor control room. 


\subsection{NUCLEAR CHARACTERISTICS}

The purpose of this study is to select a reactor arrangement which is capable of irradiating test fuel assemblies at very high thermal neutron fluxes. The test assemblies are cooled with gas, liquid metal or $\mathrm{H} 2 \mathrm{O}$ and may be as large as 7 inches O.D. and 30 inches long. The study of the annular core flux-trap reactor arrangement, which was developed in the preliminary work*, is continued in order to arrive at a radial reactor arrangement around an individual test hole which gives the highest neutron flux in the test hole with minimum reactor power. The test hole requirements for the AETR, according to the scope of work given in Appendix 1.0, are as follows:

\begin{tabular}{ccrl} 
Number of Tests & I.D. & Coolant \\
\cline { 2 - 4 } 3 & 7 & 17.78 & gas-liquid metal \\
1 & 5 & 12.70 & gas-liquid metal \\
1 & 4 & 10.16 & $\mathrm{H}_{20}-600^{\circ} \mathrm{F}$ \\
1 & 3 & 7.62 & $\mathrm{H}_{2} \mathrm{O}-600^{\circ} \mathrm{F}$ \\
1 & 3 & 7.62 & gas-1iquid metal
\end{tabular}

\footnotetext{
"Unperturbed" fluxes of $1.5 \times 1015 \mathrm{n} / \mathrm{cm}^{2}$-sec are required in the test regions. For this study, the "unperturbed" flux is defined as the flux in the test hole when it is filled with test coolant only (e.g. $\mathrm{H}_{2} \mathrm{O}$, void, liquid metal). This definition should be carefully noted because under certain conditions the perturbed flux may exceed the unperturbed flux. For example, a liquid metal test assembly with good moderating properties can conceivably cause the "perturbed" thermal neutron flux to be greater than this "unperturbed" thermal neutron flux. It is intended that one or, at most, two core sizes will be selected which will satisfy or somewhat exceed these requirements. Also, an investigation is made of a reactor arrangement in which seven of the individual annular reactor cores are incorporated in one large reactor.
}

\subsection{General Considerations}

Preliminary investigations* showed that reactors with annular cores around $\mathrm{H}_{2} \mathrm{O}$ islands are superior to reactors with $\mathrm{D}_{2} \mathrm{O}$ islands in minimizing the core power required to attain a given thermal neutron flux in the island. For optimimum island sizes, the maximum thermal flux in light water islands is almost twice that in heavy water islands. Further investigations are

* Elgert, O.J., et. al, Report INTERNUC 9, "Preliminary Investigations for an Advanced Engineering Test Reactor."(1957) 
therefore limited to reactors in which the central test hole is surrounded consecutively by annuli of $\mathrm{H}_{2} \mathrm{O}$, fully-enriched core, and $\mathrm{D}_{2} \mathrm{O}$ reflector. The reactor core consists of aluminum plate-type fuel assemblies. The effects of reactor height, core thickness, core metal-to-water ratio, coolant, moderator annulus thickness, test hole size and composition, fuel loading, and reflector thickness are investigated.

\subsubsection{Basic Geometry and Reactor Calculations}

The basic radial geometry for reactor valculation is illustrated in Figure 3.A. Regions 1, 2, and 3 represent the test loop portion of the reactor. The subdivisions are made so that a portion of the test hole may be conveniently examined without altering the entire basic geometry. The composition of the test hole region is either sodium at $1000^{\circ} \mathrm{F}, \mathrm{H}_{2} \mathrm{O}$ at $600^{\circ} \mathrm{F}$, or void for all calculations performed in this study. All regions other than the test hole are assumed at 1700\%. Region 4 is a 3-cm thick aluminum shell which is intended to account for the stainless steel liner, insulation void, aluminum tube or other structural material which might be used between the test hole and water annulus in the final reactor design. Region 5 is the $\mathrm{H}_{2} \mathrm{O}$ moderator annulus. The primary function of this region is to provide a source of thermal neutrons by moderating the fast neutrons which enter this region from the reactor core. Region 6 is a $1-\mathrm{cm}$ thick aluminum shell to account for the inner side plates of the fuel assembly and the aluminum wall between the moderator annulus and the core. Region 7 is the reactor core, which is assumed to consist of a homogeneous mixture of aluminum, $\mathrm{H}_{2} \mathrm{O}$, and $\mathrm{U}^{235}$ at $170^{\circ} \mathrm{F}$. Region 8 is a $2-\mathrm{cm}$ thick aluminum shell to account for the outer side plates of the fuel assembly and the pressure vessel around the core. Region 9 is the reflector which contains $\mathrm{D}_{2} \mathrm{O}$.

The basic theories, assumptions, and constants used in the nuclear calculations are included in Appendix 2.0, with appropriate notations appearing in the text. All reactor calculations performed in the parameter study are made using three-group neutron diffusion theory as solved numerically on an IBM 704 electronic computer. The general description of the reactor theory and machine codes is given in Appendix 2.1. The nuclear constants are derived and tabulated in Appendix 2.2 .

3.1.2 Core Height

The AETR specifications require that the neutron flux variation should not exceed $50 \%$ over a 30 -inch length of the test hole. It appears that this requirement can be met with a 36-inch ( $91.44-\mathrm{cm})$ long core. This length is used for the reactor core height but is subject to revision if results from two-dimensional calculations indicate this to be desirable. 
The axial reflector savings is arbitrarily chosen as $23.0 \mathrm{~cm}$ in order to be consjstent with the choice made in the preliminary study * The effective core length is therefore equal to $137.44-\mathrm{cm}$ according to the relationship $\mathrm{H}^{\prime}=\mathrm{H}+2 \delta_{\mathrm{h}}$, which is discussed in Appendix 2.1.1. The transverse or axial buckling is then equal to $(\pi / 137.44)^{2}$ or $0.0005225 \mathrm{~cm}^{-2}$. Since two-dimensional calculations are expensive, it was decided to perform the radial calculations using this estimate for axial buckling. The use of two-dimensional calculations is therefore reserved for additional calculations after the radial arrangement has been selected. For normalization purposes, the axial power distribution is assumed to have a chopped. cosine distribution about the reactor midplane using the above effective length. The maximum-to-average axial power distribution is therefore equal to 1.21. The longitudinal maximum-toaverage flux distribution over 30 inches or $76.20-\mathrm{cm}$ length of the test is found to be 1.14 using the same assumption.

This rather fortuitous choice of buckling and axial maximumto-average power and flux was later found to be remarkably proper. A subsequent two-dimensional calculation, which is more fully described in Section 6.4 of Part A yields an effective multiplication factor which agrees within $1 \%$ with its one-dimensional counterpart. For all practical purposes, the normalized radial centerline flux distributions from the onedimensional and two-dimensional calculations are identical. The calculated axial maximum-to-average power distribution is 1.26. The results of the two-dimensional calculation support the assumption that the flux variation does not exceed $50 \%$ over a 30-inch length of the test hole in a 36-inch long core. The maximum-to-average flux ratio is 1.15 over a 30-inch length of a sodium-filled test hole, and the flux varies from $+15 \%$ to $-28 \%$ from the average.

\section{1 .3 Core Thickness}

The maximum thermal neutron flux in the island or test hole decreases with increasing core thickness for constant core power. This effect is illustrated in Figure 3.B, which is based on results of the preliminary AETR study*. The curves, which are normalized to unity for the 6-cm thick cores, show the relative effects of increasing or decreasing the core thickness. Curves 1 and 4 represent reactors which are identical except that the coolant is $\mathrm{H}_{2} \mathrm{O}$ and $\mathrm{D}_{2} \mathrm{O}$, respectively. When the coolant is $\mathrm{H}_{2} \mathrm{O}$, the variations are more pronounced than when the coolant is $\mathrm{D}_{2} \mathrm{O}$. Therefore, in reactors with $\mathrm{H}_{2} \mathrm{O}$ islands and $\mathrm{H}_{2} \mathrm{O}$-cooled cores, a thin core and high power density are desired in order to obtain the maximum thermal neutron flux in the test hole

* Elgert, O.J., op. cit. 
for a given reactor power. The choice of core thickness is made on the basis of heat transfer and fuel loading restrictions which indicate that the minimum practical core thickness is about $6 \mathrm{~cm}$.

\subsubsection{Core Metal-Water Ratio and Coolant}

The results of the initial AETR studies* indicate that in general, the metal-water ratio of aluminum plate-type cores has a small or negligible effect on the average thermal neutron flux achieved in the island. Figure 3.C shows the relative effects of changes in the core metal-water ratio. The curves are normalized to unity for a metal-water ratio of 0.7 . For the $\mathrm{H}_{2} \mathrm{O}$-cooled core, the average thermal flux in the test hole increases as the metal-water ratio increases. The opposite effect occurs for $\mathrm{D}_{2} \mathrm{O}$-cooled cores. In each case, the test hole flux changes only a few percent for wide variations in the metalwater ratio. Therefore, the selection of the core metal-water ratio is based upon the heat transfer and fuel plate fabrication requirements. From preliminary study, it appears that a metalwater ratio of one is satjsfactory for the nuclear calculations which are described in the following sections.

3.1.5 Moderator Annulus Thickness, Test Hole Size, and Test Hole Composition.

The effects of the moderator annulus thickness on the thermal neutron flux attainable in the test hole were studied for $\mathrm{H}_{2} \mathrm{O}$-filled, sodium-filled, and empty test holes of various sizes.

The results for the sodium-filled and empty test holes indicate that an optimum average thermal flux in the test hole is achieved when the moderator annulus thickness is about $4-\mathrm{cm}$. This is illustrated in Figure 3.D, which shows the ef'fect of moderator annulus thickness on the average thermal neutron flux in the test hole. The curves are plotted for several test hole sizes and in each case the flux increases with H2O annulus thickness to a maximum value at about $4-\mathrm{cm}$ of $\mathrm{H}_{2} \mathrm{O}$, after which a graduail decrease occurs. The behavior of the flux in the empty test hole is very similar to that in the sodium-filled test holes and for practical purposes the radial flux distribution may be assumed flat. The curves indicate that about $10 \%$ greater flux can be obtained in an empty test hole than in a sodium-filled hole. For reasons discussed in Appendix 2.2.6, the numerical values of the flux in the void region are treated with some reservation. The moderator annulus thickness is very important for poorly moderating test materials as evidenced by the steep slope of the curves with small moderator annulus thickness. This behavior is expected because of the mechanism

* Elgert, O.J., op. cit. 
by which the thermal flux in the test region is created. Fast neutrons from the core are rapidly thermalized in the moderator annulus, and the thermal neutron flux peaks in the moderator causing a net thermal neutron diffusion into the test region. When the moderator annulus is made very thin, maximum peaking does not occur in the moderator and the diffusion gradient toward the test region is reduced. However, when the moderator annulus becomes thicker than $4-\mathrm{cm}$, the flux in the test hole decreases because the neutron absorption by the added water becomes more significant than the additional thermal neutron production by moderation. For a fixed moderator annulus thickness, the maximum thermal neutron flux which may be obtained in empty and sodium-filled test holes decreases steadily with increasing test hole sizes. This is illustrated in Figure $3 . E$.

The function and importance of the $\mathrm{H}_{2} \mathrm{O}$ moderator annulus is changed when the test hole contains an excellent moderator, such as water. As opposed to the non-moderating test case, where the thermal neutron flux is dependent on diffusion from the adjacent moderator region, the principal source of neutrons in the water-filled test region may be from moderation of fast neutrons in the region itself. Under some circumstances the presence of a moderator region reduces the average thermal flux that is attained in the test region. This effect is shown in Figure 3.F where the average thermal neutron flux in the test region is shown as a function of water moderator annulus thickness. For a test hole radius of $5-\mathrm{cm}$, a peak in the thermal flux is reached when the moderator thickness is about $2.5-3 \mathrm{~cm}$. However, for the 7-, 9-, and 13-cm test holes, the curves indicate that the greatest average thermal flux in the test hole is reached when no moderator annulus is present. The average test hole thermal flux per Mw of core power is shown as a function of test hole radius in Figure $3 . G$. For a $2-\mathrm{cm}$ thick moderator annulus, the thermal flux reaches a maximum value for about a $5-\mathrm{cm}$ radius test hole after which it decreases with increasing radius. For test holes having radii greater than about $6-7 \mathrm{~cm}$, the flux appears to decrease steadily with increasing hole size for all moderator annulus thicknesses.

The thermal neutron flux in the water-filled test hole varies considerably with radius, in contrast to the empty and sodium-filled test holes. The maximum flux occurs at the center when the test hole radius plus moderator thickness is equal to or less than about $15 \mathrm{~cm}$. The radial variation in the test hole thermal flux is minimized as the moderator annulus thickness increases, since the thermal flux is depressed immediately adjacent to the highly absorbing core. Figure $3 . \mathrm{H}$ illustrates this effect by showing the radial average-tomaximum thermal flux in the test as a function of $r / R$, where $r$ is the partial radius of the test hole to which the average-to-maximum applies, and $R$ is the outer radius of the test hole. For a $2-\mathrm{cm}$ thick moderator annulus the average- 
to-maximum over the entire test hole is approximate 0.8 . This can be improved appreciably by increasing the moderator annulus thickness. However, referring again to Figure $3 . F$, it should be noted that this improvement is accompanied by a considerable decrease in the average thermal neutron flux (per Mw of core power) for a given test hole size.

The study of the effects of the moderator annulus thickness on flux in the test region is performed using the same core fuel density in each case. Therefore, the total fuel mass varies as the moderator thickness is changed because of the accompanying change in the core volume. The noncritical cases were used for reasons of expediency and economy as discussed in Appendix 2.1.4. The effect of moderator annulus thickness on reactivity for constant fuel density is shown in Figure 3.I. A moderator annulus thickness of $4 \mathrm{~cm}$ is chosen for the reference point. In each case, the reactivity change is negative as the moderator thickness increases. This occurs even though the total fuel mass also increases. If the curves were shown for constant fuel mass rather than constant fuel density, the reactivity effects would be even greater. The curves numbered $1,2,3,4$, and 9 which are very closely grouped, correspond to cases having empty or sodium-filled test holes of various radii. The curves numbered $5,6,7$, and 8 correspond to reactors having $\mathrm{H}_{2} \mathrm{O}-\mathrm{fill}$ led test holes.

A comparison of the effective multiplication factor for identical reactors containing different test hole materials is shown in Table $3 . a$.

Table $3 . \mathrm{a}$

The Effect of Test Hole Content on the Effective Multiplication Factor*

Test Hole Material

Test Hole Radius

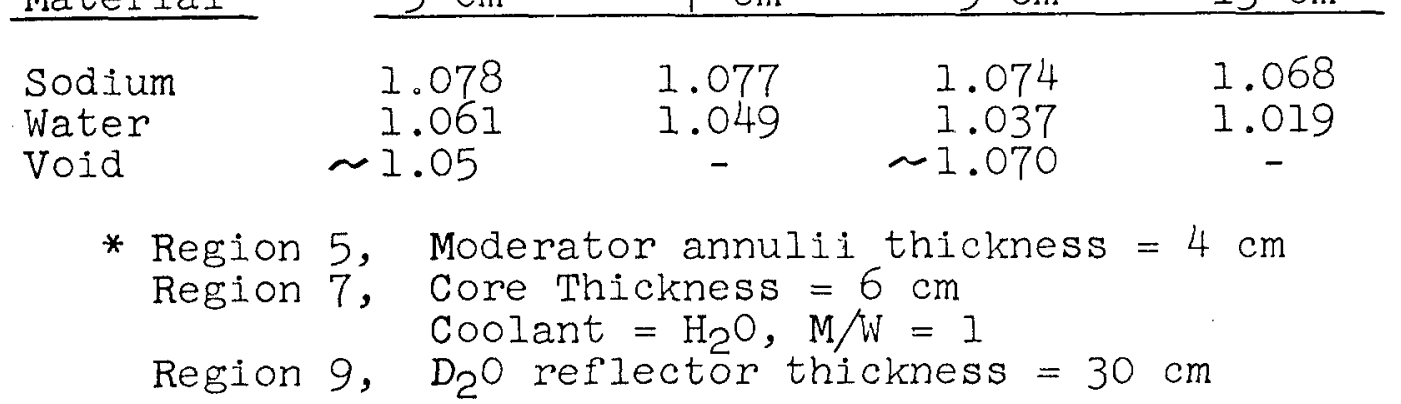




\subsubsection{Fuel Loading Effects}

When the $\mathrm{H}_{2} \mathrm{O}$ moderator annulus is $4 \mathrm{~cm}$ or more in thickness, the effect of core absorption cross section, and hence fuel loading, upon the test hole flux is greatly minimized. This is illustrated in Figure 3.J. in which the average test hole thermal flux is shown as a function of the core thermal absorption cross section. This investigation is limited to the sodium-filled and empty test holes because the flux requirements are most difficult to meet in these. This is demonstrated by the results of the previous sections. These curves represent cases in which a "l/v" absorber is added, to cores having different fuel loadings, to make the assemblies critical. Slight differences in the magnitude of the test hole flux occur for different reflector thicknesses because of the accompanying power distribution changes in the core. The test hole flux is dependent upon the core power density. Therefore, a slight test hole flux increase occurs as the reflector thickness decreases because the power distribution in the core is shifted slightly toward the inside radius of the core. This increase is not, therefore, interpreted as a real gain, because the core thickness is selected on the basis of the maximum permissible heat flux. For a reduced reflector thickness the maximum-to-average core power density is increased and an increase in the core thickness is required to avoid excessive heat fluxes. The slight gain in the test hole flux is thereby lost. The effect of core absorption on the maximum-to-average core power density is tacitly neglected because the basis for comparing curves is the maximum core power density. The cases described by curves A, B, C, and D, in Figure 3.J all have $\mathrm{H}_{2} \mathrm{O}$ annulus thicknesses equal to $4 \mathrm{~cm}$. Curve E, which has a lesser slope, represents a case in which the $\mathrm{H}_{2} \mathrm{O}$ moderator thickness is $6 \mathrm{~cm}$.

Figure $3 . K$ shows the relationship between the total macroscopic thermal absorption cross section of the core and the U235 fuel concentration. When the fuel concentration is equal to zero, the absorption cross section equals 0.01436 $\mathrm{cm}^{-1}$ due to the aluminum and water in the core.

\subsubsection{Reflector Thickness and Criticality}

The variation of the effective multiplication factor with reflector thickness is shown in Figure 3.I. The behavior of the reactors with empty test holes is similar to those with sodium-filled test holes, as expected from the previous results.

The choice of reflector thickness is seen to be important in determining the fuel loading. In the final reactor design 10-20\% excess $k$ may be required to offset experimental and burnout effects. The reflector appears to offer some interesting possibilities for reactor control. This is discussed 
further in section 6.0. As previously illustrated in Figure 3.J, the effect of reflector thickness on the average test hole flux per Mw of core power is insignificant. Therefore the major importance of the reflector is to reduce the core fuel loading. Figure 3.M, which contains the same data appearing in Figure 3.L, shows the variation of the effective multiplication factor with fuel concentration for various reflector thicknesses.

\section{1 .8 Control Effects}

In order to determine more about the relationship of the reflector material to the reactor behavior three calculations were performed using different reflector materials.

$\begin{array}{llc}\text { Reflector } & \Delta \mathrm{k} / \mathrm{k} & \text { Change in Test Thermal Flux } \\ 30 \mathrm{~cm} \mathrm{D}_{2} \mathrm{O} & 0 & 0 \\ 30 \mathrm{~cm} \mathrm{H}_{2} \mathrm{O} & -11 \% & -28 \% \\ 10 \mathrm{~cm} \mathrm{Be}-20 \mathrm{~cm} \mathrm{D} \mathrm{D}_{2} \mathrm{O} & +1.5 \% & +17 \% \\ 4 \mathrm{~cm} \mathrm{Al}-30 \mathrm{~cm} \mathrm{D} \mathrm{O} & -6.0 \% & +2 \%\end{array}$

The reactivity effects result from the neutron economy features of the material, while the changes in the test region thermal flux occur because of the differences in the fast neutron reflection properties of the materials. For example, a larger proportion of the total reflected neutrons have high energies when the beryllium reflector is used than when the $\mathrm{D}_{2} \mathrm{O}$ is used, even if the reactivity effects are identical. The results show that a considerable reduction in reactor power can be realized through the use of a beryllium reflector. However, the core power distribution shifts such that the maximum-to-average core power density is raised about 10 per cent when a beryllium rather than a $\mathrm{D}_{2} \mathrm{O}$ reflector is used.

If the $60-\mathrm{cm}$ thick $\mathrm{D}_{2} \mathrm{O}$ reflector is uniformly poisoned with a "l/v" type absorber so that the effective thermal absorption cross section is $0.00515 \mathrm{~cm}^{-1}$ the reactivity is reduced 15.6 per cent.

A 3-cm thick annular poison region with $0.5-\mathrm{cm}$ thick aluminum walls was placed in the $\mathrm{D}_{2} \mathrm{O}$ reflector, $16 \mathrm{~cm}$ from the outside core wall. The aluminum alone reduces the reactivity 2.1 per cent. The addition of "l/v" absorber until the thermal macroscopic cross section of the poison region is $0.255 \mathrm{~cm}^{-1}$ decreases the reactivity 12.9 per cent.

The inclusion of a 1/4-inch thick stainless steel annulus adjacent to the outside core wall reduces the reactivity about 45 per cent if borated ( 2 per cent) and about 12 per cent if not borated. 
The thermal flux distributions in the test and core regions appear to be nearly identical for the cases in which the reactor is controlled by a stainless steel blade, uniform reflector region poisoning, or by the poison region. This is illustrated in Figure 2.N. The fast and intermediate fluxes, which are omitted, nearly coincide in all regions for the cases shown and are about the same as those shown in Figure 6.G of Part A.

\subsection{Single Loop Reactor}

The purpose of this study is to examine the total power necessary to satisfy the flux requirements in each of the seven required test holes. This is done assuming that individual reactor cores are used for each of these major test loops. The numerical data is taken from the results of the general study conducted in section 3.1. The numbers tabulated should be used for comparison between the arrangements rather than for their absolute values. The powers given refer to clean systems having a keff of unity. The additional fuel loading and control effects required to make the system operational may increase the total reactor power required to meet the neutron fluxes desired in the test holes. (See Section 3.1.6). The results for the cases in which the test hole is empty or filled with sodium indicate that the power required for the same unperturbed test hole thermal flux is about the same for both, and the effective multiplication factors are also almost equal. (See Section 3.1.5). Therefore the behavior of reactors with sodium-filled test holes is taken to be also representative of the reactors with empty test holes. Through-type and thimble-type arrangements are examined, the latter requiring an effectively larger test hole to provide a retum passage for the coolant.

\subsubsection{Through-Type Loops}

It is intended that one or, at most, two reactor sizes be selected to satisfy the flux and test hole requirements which are discussed in section 3.0. In order to evaluate the increased total power requirements which accompany this choice, Tables 3.b, 3.c, 3.d, and 3.e are presented.

Table $3 . b$, in which five reactor sizes are utilized, represents a system which is optimized for minimum power requirements. The test hole size for each reactor corresponds to that specified (Appendix 1.0) and the water annulus thickness is the optimum for that arrangement. Only five reactor sizes are required because three of the test hole requirements are 1dentical. Each reactor has a core thickness of 6 -cm so that considerable variation occurs in the average core power density from one type to the other. If the assumption is made that the 
same average core power density of 2.1 . Mw/liter is permitted in every case, two alternatives are permitted for reactor types $b, \underline{c}, \underline{d}$, and $\underline{e}$. First, the core size may be reduced until the power density is 21 Mw/Iiter. This is accompanied by a reduction in the power required for a thermal flux of $1.5 \times 1015 \mathrm{n} / \mathrm{cm}^{2}-\mathrm{sec}$, as discussed in section 3.1.3. The second alternative is to leave the reactor dimensions constant in which case greater neutron fluxes can be obtained. For a reactor power of about $115 \mathrm{Mw}$, the average power density in the reactor types $c$ and $\mathrm{d}$ is 2.1 Mw/liter and the average test hole flux is increased to about $2.5 \times 1015 \mathrm{n} / \mathrm{cm}^{2}-\mathrm{sec}$. This latter alternative is accepted hecause the higher flux feature is desirable and also because reactivity and fuel loading difficulties may be encountered if the core thickness is made much less than 6-cm.

Table 3.c indicates the power requirements for the system of seven reactors if two reactor core sizes are used. The system consists of four large and three small reactor cores having test hole inside radii of 8.9 and $5.1 \mathrm{~cm}$ respectively. The total power requirements are increased only about $7 \%$ above the system shown in Table $3 . b$ which contains four or five reactor sizes.

Table 3.d shows an alternate two-size reactor system in which three reactors have test holes of $8.9 \mathrm{~cm}$ radius and four reactors have test holes of $6.3 \mathrm{~cm}$ radius. This system also requires only a small power increase over that of the five reactor sizes shown in Table $3 . \mathrm{b}$. The difference in power requirement between the systems of Tables $3 . c$ and $3 . b$ is not significant because of uncertainties in the data.

A seven-reactor system composed of only one basic reactor core size is described by Table 3.e. All these reactors have test holes of $8.9 \mathrm{~cm}$ radius. This is necessary if only one reactor core size is used and the large test hole requirements are to be met. The total power requirement is seen to be about $18 \%$ greater for the system described in Table 3 .e having a single reactor core size than for the system described by Table 3.b which requires five reactor sizes. Of significant importance in these comparisons is the fact that while the decrease in the number of reactor sizes increases the total reactor power, it also increases the total test space.

A special arrangement consisting of a $4-\mathrm{cm}$ radius sodiumfilled test region surrounded by a solid BeO annulus within the large type-a reactor was investigated. In this case, the reactor power necessary to achieve an average thermal flux of $1.5 \times 1015$ $\mathrm{n} / \mathrm{cm}^{2}-\mathrm{sec}$ in the test region is about two-thirds of that required for the entire sodium-filled hole. In this calculation 
materials to account for cooling of the $\mathrm{BeO}$ and containment of the sodium were not included, and therefore the magnitude of the power reduction is optimistic. However, it demonstrates that for small test requirements, the large test holes can be modified to reduce the reactor power necessary to meet the desired neutron flux. This reduction is obviously not equivalent to the power saved by optimizing the reactor design to the small experiment size.

\subsubsection{Thimble-Type Loops}

In addition to the thru-type loop system which is discussed in Section 3.2.1, a system is examined in which the test coolant passes thru the test region, reverses flow, and returns via a concentric annulus around the test region. The size of the coolant return annulus is such that its cross sectional area is one-half that of the test hole. Table $3 . f$ provides the information necessary to compare this arrangement with the thru-type arrangement having the same test hole sizes (Table 3.b). Table 3.f represents a system with five reactor sizes and therefore gives the minimum total reactor power for a system with thimble-type loops. The total power requirements are about 15 percent greater for this thimble-type arrangement than for the corresponding through-type arrangement. If the number of reactor sizes is reduced, the total reactor power necessary for the thimble-type arrangement increases similar to the increases in the through-tube.

\subsection{Composite Reactor}

The discussion in section 3.2 is limited to a reactor system in which an individual reactor is used for each major test loop. It was shown in section 3.1.5 that a $\mathrm{D}_{2} \mathrm{O}$ reflector thickness of $1-2$ feet is desirable from the standpoint of reactor criticality and fuel loading requirements. An obvious alternate arrangement is one in which the seven major test loops and associated annular reactor cores are incorporated in a single large reactor. This arrangement is illustrated in Figure 12.C, and is hereafter referred to as a composite reactor. The individual annular reactor core assemblies are called test loop units.

The results of the general study of the individual reactors in section 3.1 are used in predicting the power requirements for the composite reactor. This is possible because of the relationships which exist between test hole flux, core power, fuel loading, and reflector thickness. The test hole flux per Mw of power is shown in section 3.1 .6 to be a function of the core neutron absorption and hence the fuel concentration. The primary effect of the reflector is to decrease the fuel loading requirements as discussed in Section 3.1.7. Therefore, it appears that the total power requirement for a composite reactor 
consisting of several test loop units of the type discussed in Section 3.2 can be evaluated if the critical fuel concentration is known. The composite reactor arrangement results in an increased neutron economy over the individual reactors because of the reduced neutron leakage. Therefore, the required fuel loading is expected to be less.

The analytical model for the individual test units, which is shown in Figure 3.A, is somewhat less detailed than the reactor shown in Figure 12.C. Four of the seven test loops units are identical to the large Type a reactor described in Table 3.c and the other three are identical to the smaller Type f reactor.

One Type a unit is located at the center of the large $\mathrm{D}_{2} \mathrm{O}$ containment vessel and the remaining six units have their centers $60^{\circ}$ apart on a circle of 27.56 inches radius. Since it was impractical to do a two-dimensional analysis of this system, the critical fuel concentration was estimated by representing the six outer units by a series of concentric regions about the 27.56 inch radius in such a way that the total area (volume) of each material is preserved. This model is then solved in one-dimension assuming the same fuel concentration in the central and "smeared" outer test units. This approach yields an estimate of the critical fuel concentration. The test hole flux has been shown to be only slightly dependent on the core absorption cross section and therefore, the use of this estimate in determining the composite reactor power requirement is not expected to result in excessive error. The critical fuel concentration found by this method is $10^{20}$ atoms $\mathrm{U}^{235} \mathrm{cc}$ which is about one-fourth less than that required for the individual reactors.

The reactor powers for each of these test loop units and the total power for the composite reactor are shown in Table 3.g. The data is based on the assumption that the fuel concentration and power density are the same in each test 10op unit. This composite arrangement, which involves the use of two basic test loop unit sizes may be compared with the arrangement shown in Table 3.c which uses seven comparable individual reactors. The total reactor power is almost the same for both. However, since all units are assumed to have the same power density in the composite reactor, thermal neutron fluxes in excess of $1.5 \times 1015 \mathrm{n} / \mathrm{cm}^{2}-\mathrm{sec}$ are produced in the three Type f units. If the same flux levels are attained in the individual reactors as in the units of the composite reactor, the total reactor power is raised from $858 \mathrm{MW}$ to $957 \mathrm{Mw}$. 
The above method of estimating the reactor power of the composite core is believed to give an overestimate. While the composite reactor results is a considerable gain in neutron economy, a thorough nuclear investigation of this type of arrangement was not undertaken because the arrangement is rot attractive from the standpoint of reactor utility.

3.4 General Summary

A study is made in section 3.1 of the nuclear and dimensional effects for an annular reactor arrangement in which the test hole is surrounded by a moderator annulus, core annulus, and reflector annulus, respectively. The effects of the structural materials are simulated by aluminum walls between these regions. The major conclusions reached in this study are as follows:

1. The effective multiplication factor varies only a few percent between cases in which the test hole is empty, sodiumfilled, or water-filjed.

2. For a fixed power the unperturbed thermal neutron fiux attained in the test hole decreases as the test hole size increases. An exception is found for small water-filled test holes with thin moderator annulus thicknesses.

3. The radial thermal neutron flux distribution in the test holes is almost flat for sodium-filled and empty test holes. Large peaking effects may occur in water-filled test holes.

4. The power requirements are greatest for the sodiumfilled and empty test holes. The behavior of the reactor with an empty test hole is similar to that with a sodium-filled test hole

5. The average thermal neutron flux in the empty and sodium-filled test holes is highest when the moderatcr thickness is about $4 \mathrm{~cm}$. This optimum moderator annulus thickness appears to be independent of test hole size.

6. The average thermal neutron flux in the water-filled test hole is highest when the test hole radius plus moderator annulus thickness is about 7 or $8 \mathrm{~cm}$.

7. The test hole thermal neutron flux for a given reactor power increases as the core annulus thickness decreases, i.e., the efficiency of the system as a thermal flux-trap is increased when the core power density is increased. 
8. The neutron flux in the test region is only slightly dependent on the core absorption (fuel concentration).

9. The principal function of the reflector is to increase the neutron economy of the system and reduce the fuel loading requirements.

In Sections 3.2 and 3.3 various multiple reactor systems and one composite system were examined to determine the total reactor power necessary to satisfy the specified test hole size and flux requirements with the various arrangements. The primary results of this study are summarized in Table 3.h. Each system is capable of meeting the minimum requirements specified in the work scope. However, in order to decrease the number of reactor core sizes, some of the systems provide more irradiation volume and flux than required. The purpose of Table $3 . \mathrm{h}$ is to provide a tabulation which permits convenient comparison of the systems on this basis as well as on a total power basis. System-1 and System-5 are tailored to meet the exact test hole requirements, but the others provide more test space than required. Systems-1 through 5 incorporate individual reactors for each major test loop and the power indicated is required for an average thermal neutron flux of $1.5 \times 1015 \mathrm{n} / \mathrm{cm}^{2}-\mathrm{sec}$ in all test holes. System-6, the composite reactor, consists of seven test units with reactor cores identical, except for fuel loading, to those of the reactors in System-2. Since they are coupled to each other by the $\mathrm{D}_{2} \mathrm{O}$, the power density rather than the test hole flux is assumed to be the same in each of the individual test units. The power level is set so that the minimum thermal flux in any test loop unit is $1.5 \times 1015 \mathrm{n} / \mathrm{cm}^{2}-\mathrm{sec}$. At this power level the thermal flux in the two small waterfilled units is $2.6 \times 1015 \mathrm{n} / \mathrm{cm}^{2}-\mathrm{sec}$, and the flux in the small sodium-filled unit is $1.8 \times 1015 \mathrm{n} / \mathrm{cm}^{2}-\mathrm{sec}$. The product of the thermal neutron flux and test hole cross section area is shown to provide a common basis for comparing all six systems. Although the test hole cross section area and system power are about the same for System-2 and System-6, the product of the test hole cross section area and the thermal flux is about 8.5\% higher for the latter. 
Table 3.b

Minimum Power Through-Tube System Using Five Reactor Sizes

\begin{tabular}{|c|c|c|c|c|c|c|c|c|c|}
\hline \multirow{2}{*}{\multicolumn{2}{|c|}{$\begin{array}{l}\text { Reactors } \\
\text { Type No. }\end{array}$}} & \multicolumn{2}{|c|}{$\begin{array}{c}\text { Test Hole } \\
\text { Radius }\end{array}$} & \multirow{2}{*}{$\begin{array}{l}\text { Test Hole } \\
\text { Composit- } \\
\text { ion }\end{array}$} & \multicolumn{2}{|c|}{$\begin{array}{l}\text { Moderator } \\
\text { Annulus } \\
\text { Thickness }\end{array}$} & \multirow{2}{*}{$\begin{array}{l}\text { Test Hole } \\
\text { Thermal } \\
\text { Flux* } \frac{\mathrm{n}}{\mathrm{cm}^{2} \mathrm{sec}} \\
1013\end{array}$} & \multirow{2}{*}{$\begin{array}{c}\text { Reactor } \\
\text { Power** } \\
\text { Mw }\end{array}$} & \multirow{2}{*}{$\begin{array}{c}\text { Average Core } \\
\text { Power Density } \\
\text { Mw/liter }\end{array}$} \\
\hline & & $\mathrm{cm}$ & in. & & $\mathrm{cm}$ & in. & & & \\
\hline$a$ & 3 & 8.9 & 3.5 & sodium & 4 & 1.6 & 0.98 & 153 & 2.2 \\
\hline $\mathrm{b}$ & 1 & 6.3 & 2.5 & sodium & 4 & 1.6 & 1.26 & 119 & 2.0 \\
\hline$c$ & 1 & 5.1 & 2.0 & water & 3 & 1.2 & 2.20 & 68 & 1.3 \\
\hline$d$ & 1 & 3.8 & 1.5 & water & 4 & 1.6 & 2.20 & 68 & 1.3 \\
\hline e & 1 & 3.8 & 1.5 & sodium & 4 & 1.6 & 1.69 & 89 & 1.7 \\
\hline & & & & & al & er $f$ & 7 Reactors & $803 \mathrm{MW}$ & \\
\hline & & & & & & Table & $3 . c$ & & \\
\hline PO & $r F$ & dire & ents & for a Sever & Rea & or $\mathrm{Sy}$ & em Using Tw & Basic Re: & or Sizes ( $a$ and $f$ \\
\hline a & 4 & 8.9 & 3.5 & sodium & 4 & 1.6 & 0.98 & 153 & 2.2 \\
\hline$f$ & 2 & 5.1 & 2.0 & water & 4 & 1.6 & 2.1 & 71 & 1.3 \\
\hline$f$ & 1 & 5.1 & 2.0 & sodium & 4 & 1.6 & 1.44 & 104 & 1.9 \\
\hline & & & & To & & $r \mathrm{fc}$ & 7 Reactors & $858 \mathrm{Mw}$ & \\
\hline$*$ & $\begin{array}{l}\text { eact } \\
\text { ower } \\
\text { ore } \\
\text { oola } \\
\text { on r } \\
\text { ongi } \\
\text { ongi } \\
\text { ore }\end{array}$ & $\begin{array}{l}r \text { Pow } \\
\text { for a } \\
\text { nnulu } \\
t=5 \\
\text { flect } \\
\text { udina } \\
\text { udina } \\
\text { ength }\end{array}$ & $\begin{array}{l}\text { er }-1 \\
\text { jerage } \\
\text { s thic } \\
\text { o } \mathrm{M} / \mathrm{h} \\
\mathrm{or} \text { thi } \\
1 \mathrm{Maxi} \\
1 \mathrm{Maxi} \\
=36\end{array}$ & $\begin{array}{l}\text { Mw } \\
\text { thermal ne } \\
\text { kness }=6 \\
=1 \\
\text { ckness }=30 \\
\text { mum-to-ave } \\
\text { mum-to-ave } \\
\text { in. }\end{array}$ & $\begin{array}{l}\mathrm{cm} \\
\text { age } \\
\text { age }\end{array}$ & $\begin{array}{l}\text { wer } \\
\text { st ho }\end{array}$ & $\begin{array}{l}\text { nsity }=1.21 \\
\text { e thermal fl }\end{array}$ & $=1.14$ & est hole \\
\hline
\end{tabular}


Table $3 . d$

Power Requirements for a Seven Reactor System Using Two Basic Reactor Sizes ( $a$ and b)

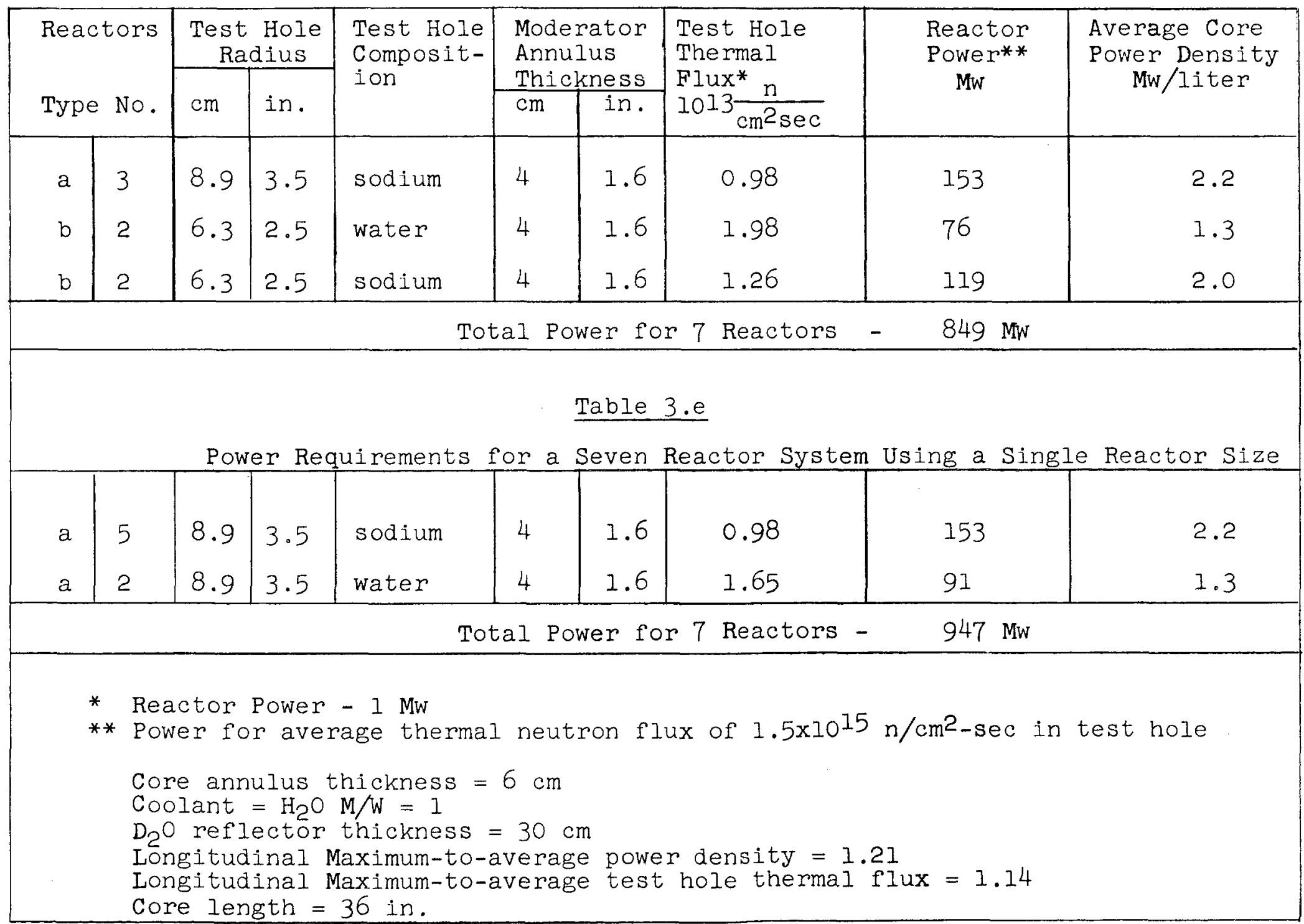


Minimum Power Thimble-Type Loop System Using Five Reactor Sizes

\begin{tabular}{|c|c|c|c|c|c|c|c|c|c|c|c|}
\hline \multirow{3}{*}{\multicolumn{2}{|c|}{$\begin{array}{l}\text { Reactors } \\
\text { Type No. }\end{array}$}} & \multicolumn{2}{|c|}{$\begin{array}{c}\text { Test Hole } \\
\text { Radius }\end{array}$} & \multirow{2}{*}{\multicolumn{2}{|c|}{$\begin{array}{c}\text { Return Flow } \\
\text { Annulus } \\
\text { O.R. }\end{array}$}} & \multirow{3}{*}{$\begin{array}{l}\text { Test Hole } \\
\text { Composit- } \\
\text { ion }\end{array}$} & \multirow{2}{*}{\multicolumn{2}{|c|}{$\begin{array}{l}\text { Moderator } \\
\text { Annulus } \\
\text { Thickness }\end{array}$}} & \multirow{3}{*}{$\begin{array}{l}\text { Test Hole } \\
\text { Thermal } \\
\text { Flux* } \\
1013 \frac{\mathrm{n}}{\mathrm{cm}^{2} \mathrm{sec}}\end{array}$} & \multirow{3}{*}{$\begin{array}{l}\text { Reactor } \\
\text { Power }{ }^{* *} \\
\text { Mw }\end{array}$} & \multirow{3}{*}{$\begin{array}{c}\text { Average Core } \\
\text { Power Density } \\
\text { Mw/Iiter }\end{array}$} \\
\hline & & \multirow[b]{2}{*}{$\mathrm{cm}$} & \multirow{2}{*}{ in. } & & & & & & & & \\
\hline & & & & $\mathrm{cm}$ & in. & & $\mathrm{cm}$ & in. & & & \\
\hline $\mathrm{g}$ & 3 & 8.9 & 3.5 & 10.9 & 4.3 & sodium & 4 & 1.6 & 0.83 & 183 & 2.4 \\
\hline $\mathrm{h}$ & $I$ & 6.3 & 2.5 & 7.7 & 3.0 & sodium & 4 & 1.6 & 1.09 & 138 & 2.3 \\
\hline$i$ & 1 & 5.1 & 2.0 & 6.3 & 2.5 & $\mathrm{H}_{2} \mathrm{O}$ & 2 & 0.8 & 2.2 & 68 & 1.3 \\
\hline$j$ & 1 & 3.8 & 1.5 & 4.7 & 1.9 & $\mathrm{H}_{2} \mathrm{O}$ & 3 & 1.2 & 2.2 & 68 & 1.3 \\
\hline$k$ & 1 & 3.8 & 1.5 & 4.7 & 1.9 & sodium & 4 & 1.6 & 1.5 & 100 & 1.9 \\
\hline & & & & & & Total & & or 7 & Reactors & - $923 \mathrm{Mw}$ & \\
\hline * & $\begin{array}{l}\text { React } \\
\text { Power } \\
\text { Core } \\
\text { Coola } \\
\mathrm{D}_{2} \mathrm{O} \\
\text { Longi } \\
\text { Longi } \\
\text { Core }\end{array}$ & $\begin{array}{l}\text { or } P \\
\text { for } \\
\text { annu } \\
\text { nt = } \\
\text { efle } \\
\text { tudir } \\
\text { tudir } \\
\text { leng }\end{array}$ & $\begin{array}{l}\text { ver - } \\
\text { avera } \\
\text { is th } \\
\mathrm{H}_{2} \mathrm{O} ; \\
\mathrm{tor} \mathrm{t} \\
\mathrm{l} \mathrm{Ma} \\
\mathrm{ll} \mathrm{Ma} \\
\mathrm{I}=3\end{array}$ & $\begin{array}{l}\text { Mw } \\
\text { ther } \\
\text { ckness } \\
M / W= \\
\text { icknes } \\
\text { imum-t } \\
\text { imum-t } \\
\text { in. }\end{array}$ & $\begin{array}{l}\text { mal ne } \\
=7 \mathrm{cr} \\
1 \\
\mathrm{~s}=30 \\
\text { o-aver } \\
\text { o-aver }\end{array}$ & $\begin{array}{l}\text { utron flux } \\
\text { m } \\
\text { cm } \\
\text { age power } \\
\text { age test } h\end{array}$ & $\begin{array}{l}\text { dens } \\
\text { ole }\end{array}$ & cy $=$ & $\begin{array}{l}1.21 \\
\text { flux }=1.1\end{array}$ & in test & hole \\
\hline
\end{tabular}


Power Requirements for a Composite Reactor Using Two Basic Loop Unit Sizes (a and f)

\begin{tabular}{|c|c|c|c|c|c|c|c|c|c|c|}
\hline \multirow{2}{*}{$\begin{array}{l}\text { Test } \\
\text { Loop } \\
\text { Unit } \\
\text { Type }\end{array}$} & \multirow[t]{2}{*}{$\begin{array}{l}\text { Number } \\
\text { Units }\end{array}$} & \multicolumn{2}{|c|}{$\begin{array}{c}\text { Test Hole } \\
\text { Radius }\end{array}$} & \multirow[t]{2}{*}{$\begin{array}{l}\text { Test Hole } \\
\text { Composit- } \\
\text { ion }\end{array}$} & \multicolumn{2}{|c|}{$\begin{array}{l}\text { Moderator } \\
\text { Annulus } \\
\text { Thickness }\end{array}$} & \multirow{2}{*}{$\begin{array}{l}\text { Thermal Flux } \\
\text { in Test per } \\
\text { Mw of Loop } \\
\text { Unit Power, } \\
\text { n/cm²sec }\end{array}$} & \multirow{2}{*}{$\begin{array}{l}\text { Test } \\
\text { Loop } \\
\text { Unit } \\
\text { Power } \\
\text { Mw }\end{array}$} & \multirow{2}{*}{$\begin{array}{l}\text { Average } \\
\text { Test } \\
\text { Flux } \\
1015 \\
\mathrm{n} / \mathrm{cm}^{2} \text { sec }\end{array}$} & \multirow[t]{2}{*}{$\begin{array}{l}\text { Average Core } \\
\text { Power Density } \\
\text { Mw/liter }\end{array}$} \\
\hline & & $\mathrm{cm}$ & in. & & $\mathrm{cm}$ & in. & & & & \\
\hline a & 4 & 8.9 & 3.5 & sodium & 4 & 1.6 & 1.13 & 133 & 1.5 & 1.9 \\
\hline$f$ & 2 & 5.1 & 2.0 & water & 4 & 1.6 & 2.43 & 107 & 2.6 & 1.9 \\
\hline $\mathrm{f}$ & 1 & 5.1 & 2.0 & sodium & 4 & 1.6 & 1.66 & 107 & 1.8 & 1.9 \\
\hline \multicolumn{11}{|c|}{ Total Power in 7 Test Loop Units $-853 \mathrm{Mw}$} \\
\hline \multicolumn{11}{|c|}{$\begin{array}{l}\text { Core annulus thickness }=6 \mathrm{~cm} \\
\text { Coolant }=\mathrm{H}_{2} \mathrm{O} ; \mathrm{M} / \mathrm{W}=1 \\
\mathrm{D}_{2} \mathrm{O} \text { reflector thickness }=30 \mathrm{~cm} \\
\text { Longitudinal Maximum-to-average } \\
\text { Longitudinal Maximum-to-average } \\
\text { Core length }=36 \text { in. }\end{array}$} \\
\hline
\end{tabular}


Table $3 . h$

Comparison of Power Requirements for Various Reactor Systems

\begin{tabular}{|c|c|c|c|c|c|c|c|c|c|}
\hline \multirow[t]{2}{*}{$\begin{array}{l}\text { System } \\
\text { Number }\end{array}$} & \multirow[t]{2}{*}{ System Description } & \multirow[t]{2}{*}{$\begin{array}{l}\text { Number of } \\
\text { Reactor or } \\
\text { Unit Sizes }\end{array}$} & \multirow{2}{*}{$\begin{array}{l}\text { Total } \\
\text { Power } \\
\text { Require- } \\
\text { ments, Mw }\end{array}$} & \multicolumn{3}{|c|}{$\begin{array}{l}\text { Test-Hoie Cross } \\
\text { Section Area, } \mathrm{cm}^{2}\end{array}$} & \multicolumn{3}{|c|}{$\begin{array}{l}\text { Test Hole Thermal Flux } \\
\text { Cross Section Area Pro- } \\
\text { duct, } 1015 \mathrm{n} / \mathrm{sec}\end{array}$} \\
\hline & & & & $\mathrm{H}_{2} \mathrm{O}$ & sodium & total & $\mathrm{H}_{2} \mathrm{O}$ & sodium & total \\
\hline 1 & $\begin{array}{l}\text { Min.Power Through } \\
\text { Tube (Table } 3 . \mathrm{b})\end{array}$ & 5 & 803 & 127 & 917 & 1044 & 121 & 1375 & 1566 \\
\hline 2 & $\begin{array}{l}\text { Through Tube } \\
\text { (Table 3.c) }\end{array}$ & 2 & 858 & 163 & 1077 & 1240 & 245 & 1615 & 1860 \\
\hline 3 & $\begin{array}{l}\text { Through Tube } \\
\text { (Table 3.d) }\end{array}$ & 2 & 849 & 249 & 996 & 1245 & 374 & 1494 & 1868 \\
\hline 4 & $\begin{array}{l}\text { Through Tube } \\
\text { (Table } 3 . e)\end{array}$ & 1 & 947 & 498 & 1244 & 1742 & 747 & 1866 & 2613 \\
\hline 5 & $\begin{array}{l}\text { Min.Power Thimble } \\
(\text { Table } 3 . f)\end{array}$ & $\begin{array}{l}5 \\
\therefore\end{array}$ & 923 & 127 & 917 & 1044 & 191 & 1375 & 1566 \\
\hline 6 & $\begin{array}{l}\text { Composite Reactor } \\
\text { (Table } 3 . \mathrm{g} \text { ) }\end{array}$ & 2 & 853 & 163 & 1077 & 1240 & 397 & 1629 & 2026 \\
\hline
\end{tabular}




\subsection{REACTOR CORE HEAT TRANSFER}

The core geometry is a right circular annulus. Nuclear calculations (Chapter 3.0) show that, for the same reactor power, the thermal neutron flux in the test hole increases as the thickness of the annular core decreases. However, for a given decrease in the annular core thickness, the percentage increase in the test hole flux is less than the percentage decrease in the core volume. Since, for a given reactor power, the average core power density varies inversely to the core volume, it is desirable to design the core for the maximum reasonable power density. Core cooling is therefore one of the major design considerations.

Reactor cooling is obtained by pressurized water flowing downward through the annular core. In order to determine the limiting operating characteristics of the reactor with such a cooling system, a heat transfer study was conducted. Included in the study were heat transfer by the mechanisms of (1) non-boiling forced convection, (2) forced convection with nucleate boiling. Burnout conditions were also determined. Results, shown graphically in Figures 4.A-4.K, allow selection of the optimum heat transfer characteristics.

\subsection{Non-Boiling Forced Convection}

For non-boiling forced convection heat transfer, the maximum fuel element surface temperature at any point is assumed to be limited to the saturation temperature at that spot. The maximum permissible power density is then defined as that power density at which the surface temperature of any plate is at the saturation temperature of the water at that point. With this definition, the maximum permissible power density is dependent upon the absolute pressure and the parameters of coolant velocity, coolant gap thickness and metai-to-water ratio. Calculations with these parameters were made to determine the maximum permissible power density.

The heat transfer film coefficient used in the calculations is shown by Figure 4.A, where the film coefficient is plotted as a function of the coolant gap for velocities of $25,30,35$, and $40 \mathrm{ft} / \mathrm{sec}$. The equations used for the calculations are given in Appendix 4.0

The frictional pressure drop across the core, plotted versus the coolant gap and with the coolant velocity a parameter, is shown by Figure 4.B. Figure 4.C shows the entrance and exit pressure losses versus the metal-to-water ratio. The frictional pressure losses to the "hotspot", plotted versus the coolant gap are shown by Figure 4.D. 
The fuel element surface temperature at any point is assumed to be limited to the saturation temperature at that point. For aluminum fuel plates, it is desirable and conservative to limit the surface temperature to approximately $400^{\circ} \mathrm{F}$ (Bonilla* states that a surface temperature $464^{\circ} \mathrm{F}$ is permissible with aluminum in contact with water). For a saturation temperature of $400^{\circ} \mathrm{F}$ an absolute pressure of $248 \mathrm{psi}$ is required; this is then the approximate pressure required at the hotspot. Considering pressure drop to the hotspot, $300 \mathrm{psia}$ is selected as the approximate pressure at the core entrance. The hotspot surface temperature versus coolant velocity for an entrance pressure of $300 \mathrm{psia}$ is shown by Figure $4 . \mathrm{E}$.

To account for possible variations in fuel concentrations, fuel plate thickness, coolant gap dimensions, flow rate, and the uncertainty in the calculated heat-transfer coefficient, hot channel factors are used. The two allowances, Ffilm (for variations in the film temperature drop). and Fbulk (for variations in the bulk water temperature rise through a channel), are given in Table 4. a

Table $4 . a$

Hot Channel Factors

$\underline{F_{\text {bulk }}} \underline{F_{\text {film }}}$

1. Power distribution

2. Power measurements

3. Heat transfer calculations

4. Fuel concentration tolerance

5. Fuel dimension tolerance

6. Channel width tolerance

Total (product)

$1.100 \quad 1.100$

1.0401 .040

$1.100 \quad 1.100$

$1.010 \quad 1.010$

$1.020 \quad 1.030$

$1.080 \quad 1.030$

$1.275 \quad 1.350$

The maximum permissible power densities as functions of the coolant gap for water velocities of 30,35 , and $40 \mathrm{ft} / \mathrm{sec}$ are shown by Figure 4.F, 4.G, and 4.H respectively. Cross plots of the fuel plate thickness are also shown on these curves. The graphs indicate that relatively thin plates should be used to maximize the permissible power density. However, based on the present technology of uranium-aluminum alloy fuel plates with regard to fabrication and structural stability, 50 mils is selected as a reasonable minimum thickness for the fuel plates. In determining the maximum permissible power densities shown by Figure 4.F, 4.G, and 4.H, a reflector savings of $23 \mathrm{~cm}$. is assumed. Nuclear calculations show this assumption to be valid.

* Bonilla, C.F., "Nuclear Engineering," McGraw-Hill Book Company, Inc., New York, 1957, p.469. 
A 300-psia entrance pressure and 50-mil thick fuel plates have been selected. Then considering the metal-to-water ratio and frictional pressure losses, a 75-mil coolant gap and a coolant velocity of $40 \mathrm{ft} / \mathrm{sec}$ are selected. With coolant gaps larger than $75 \mathrm{mils}$, the maximum permissible power density decreases. For coolant velocities greater than $40 \mathrm{ft} / \mathrm{sec}$ in 75-mil gaps the pressure drop across the core becomes excessive. For the above geometry and coolant velocity, and with 300 psia entrance pressure, the maximum permissible power density is $2.90 \mathrm{Mw} /$ liter (Figure 4.H) for non-boiling heat transfer. This power density corresponds to a maximum heat flux of $1.44 \times 10^{6}$ Btu/hr-ft2. For comparison, this maximum is only $26 \%$ greater than the $1.15 \times 106 \mathrm{Btu} / \mathrm{hr}-\mathrm{ft}^{2}$ maximum heat flux in the ETR. The AETR design seems reasonable in comparison since the coolant pressure is increased from 200 to 300 psi, the flow velocity is increased from 35 to $40 \mathrm{ft} / \mathrm{sec}$, and the AETR has a more uniform power distribution due to its geometry and the absence of control rods.

\subsection{Forced Convection Nucleate Boiling}

Heat transfer by the mechanism of forced convection nucleate boiling is examined. For the study, fuel plate surface temperatures are calculated by means of the Jens and Lottes equation given in Appendix 4.0. Results are shown by Figure 4.I which is a plot of the fuel plate surface temperature as a function of the pressure and with the power density as a parameter. It should be noted that Jens and Lottes fitted their equation to data for stainless steel and nickel surfaces. The correlation to aluminum surfaces is not known. One other uncertainty is the transition from nucleate to film boiling. However, it is believed that the power densities of Figure 4 .I have not exceeded the limits of nucleate boiling. When correlating their data Jens and Lottes summarized experiments where the pressure ranged from 85 to 2500 psia, water temperatures from $229^{\circ}$ to $636^{\circ} \mathrm{F}$, coolant velocities from 3 to $40 \mathrm{ft} / \mathrm{sec}$, and heat fluxes as high as $4 \times 106 \mathrm{Btu} / \mathrm{hr}-\mathrm{ft2}$. This heat flux is equivalent to a volumetric power density of $8.0 \mathrm{Mw} /$ liter for a 50-mil plate and 75-mil coolant gap. Velocity does not enter into the nucleate boiling heat transfer equation but must be sufficient to keep the bulk coolant temperature below saturation.

\subsection{Burnout}

The results of burnout calculations for 50-mil plates and 75-mil coolant gaps are shown in Figure 4.J.Figure 4.K shows an axial profile of bumout power density with coolant velocity of $40 \mathrm{ft} / \mathrm{sec}$, and also the reactor axial power density profile. The reactor power density profile is based on a maximum permissible power density of $2.90 \mathrm{Mw} /$ liter and a power distribution obtained from the nuclear calculations of Section A2.1.2 of the Appendix. At the point of maximum reactor power density ( $2.9 \mathrm{Mw} /$ liter) the burnout power density is $10.6 \mathrm{Mw} / 1$ iter. The 
maximum reactor power density is then about $27 \%$ of the burnout value and is low enough for safety.

\subsection{Summary}

From the heat transfer study the following core characteristics are recommended:

\section{Table $4 . \mathrm{b}$}

Fuel Core Heat Transfer Characteristics

Pressure at entrance to core, psia 300

$\begin{array}{ll}\text { Maximum permissible power density, Mw/liter } & 2.90 \\ \text { Coolant velocity, ft/sec } & 40 \\ \text { Plate thickness, mils } & 50 \\ \text { Coolant gap thickness, mils } & 75 \\ \text { Metal-to-water ratio } & 0.685\end{array}$

With this geometry and with a coolant velocity of $40 \mathrm{ft} / \mathrm{sec}$, the maximum permissible power density is about $27 \%$ of the calculated $10.6 \mathrm{Mw} /$ liter burnout power density. This is low enough for safety. According to Bonilla* the permissible power density should not be greater than $67 \%$ of the burnout value. The 2.90 Mw/liter maximum permissible density corresponds to a heat flux of $1.45 \times 10^{6}$ Btu/hr-ft2.

The $2.90 \mathrm{Mw} /$ liter maximum permissible power density is obtained by the forced convection non-boiling mechanism. Higher power densities are obtainable without excessive increases in the fuel plate surface temperature by forced convection nucleate boiling. This is shown by Figure 4 .I. However, the coolant velocity must be sufficient to prevent the water from reaching saturation temperature. An axial profile of the saturation temperature, at a coolant velocity of $40 \mathrm{ft} / \mathrm{sec}$, is shown by Figure 4.J. A plot of the coolant exit temperature versus the power density, at a coolant velocity of $40 \mathrm{ft} / \mathrm{sec}$ is shown by Figure $4 . \mathrm{K}$. These graphs show that an average power density of about $4 \mathrm{Mw} /$ liter may be attained without the coolant being heated to saturation.

* Bonilla, C. F., Nuclear Engineering, McGraw-Hill Book Company, Inc., New York, 1957, p. 417 
The AETR is designed for an average power density of 2.11 Mw/Iiter with a 1.37 maximum-to-average power ratio (section 5.1 .2 Part A). The resulting maximum power density is 2.90 $\mathrm{MW} /$ liter and is considered safe. If the maximum-to-average power ratio should prove to be larger, the hotter areas will be safely cooled by the mechanism of nucleate boiling. Maximumto-average power ratios in the range of 1.37 to 2.50 are not out of question. With the $2.11 \mathrm{Mw} / 1$ iter average power density and 2.50 maximum-to-average power ratio (and resulting maximum power density of $5.28 \mathrm{Mw} / 1$ iter), the hot spot surface temperature would only increase to approximately $460{ }^{\circ} \mathrm{F}$ with nucleate bolling. 


\subsection{FUEL ASSEMBLIES}

The objective of the following comparisons is to select the type of fuel assembly best suited for the AETR annular core. Since the efficiency of the AETR in producing high thermal neutron fluxes in the test hole increases as the thickness of the core decreases (See Section 3.1.3); a fuel assembly which is capable of operating at high power densities is needed. Also, since the core life of the AETR is relatively short (about three weeks) a fuel assembly of relatively low cost is essential.

5.1 Fuel Assembly Geometry

The size and shape of the fuel assemblies must be suited to a right circular annular core 10-13 inches $I_{0} D_{0}, 2-3$ inches thick, and 36 inches long. Since a previous report* has shown that coolant cross-flow through rods in an annular core does not permit power densities comparable to those attainable with axial flow, the comparisons herein are limited to fuel assemblies designed for axial flow. The four types of fuel assemblies considered for the AETR, which are shown by Figures 5.A through 5.D, are an involute plate design, a tubular design; a circular segment design, and a flat plate design.

The involute plate design (Figure 5.A) is preferred since such fuel assemblies completely fill the core annulus with fuel plates of uniform thickness and coolant channel width. This is accomplished by a constantly changing curvature in the plates, i.e., the plates are radial at the inner diameter of the annulus but curve away from an initial radial line with an ever increasing angle. An equation for the curvature is given in Appendix 4.0 .

The involute plate design has an added advantage in that lateral heat transfer along the plate will help reduce the maximum surface heat flux. Nuclear calculations show that the thermal neutron flux rises sharply at the inner and outer diameters of the core, with the result that in a uniformly loaded core the power density is greater at the edges of the core than at the center. With radial fuel plates lateral heat transfer to the side plate and along the plate reduces the maximum heat flux appreciably while radial mixing in the water channel reduces the bulk water temperature at the high heat flux regions.

Tubular fuel assemblies (Figure 5.B) have merit for the flux-trap reactor because they can readily be assembled into an annular core. However a number of disadvantages are apparent.

* Elgert, O.J., et al, INTERNUC-9 "Preliminary Investigations for an Advanced Engineering Test Reactor", February 22, 1957. 
1. Tubular fuel assemblies have an inherently low metal-towater ratio resulting in a fuel loading problem for criticality and useful burnup.

2. A reasonable metal-to-water ratio necessitates the use of small diameter tubes. This results in a large $\mathrm{L} / \mathrm{D}$ ratio with an accompanying doubtful axial mechanical stability. Fluttering and vibration may cause the tubes to touch which could adversely affect fuel integrity and fission product containment

3. Although a thinner wall can be used in tubes due to the greater structural rigidity of a cylinder compared to a plate, the minimum wall thickness is limited to $50 \mathrm{mils}$, which represents best current practice with aluminum fuel assemblies. The 50-mils consists of 12-15 mils cladding on each surface and a meat thickness of about $20 \mathrm{mils}$ so as to not exceed $40 \mathrm{wt}$. \% $\mathrm{U}^{23} 3 \mathrm{in}$ the meat. For a given metal-to-water ratio the heat transfer surface increases as the gauge of the material decreases, but tubular assemblies have no relative advantage over plate type assemblies in this respect since 50-mil plates are successfully used in plate-type assemblies.

4. In order to derive the maximum benefit from tubular fuel assemblies, it is necessary to space them properly in bundles. Since the fuel tubes are both internally and externally cooled, there must be a proper distribution of coolant flow so that both surfaces are equally effective. This distribution is obtained by spacing the tubes so that the equivalent diameter of the flow passage on the outside of the tubes is equal to the inside diameter of the tubes. The axial mechanical instability of the small diameter tubes necessary in the AETR causes difficulty in maintaining these equivalent diameters equal.

5. Experience at the MTR has shown that foreign materials in the primary coolant often collect on the tops (entrance) of the fuel assemblies. While such foreign objects cause only minor reductions of the flow through plate-type assemblies, they can easily stop completely the flow through one or more tubes of a tubular fuel assembly. In that event the heat that must be removed from the outer surface of the tube is almost doubled.

6. There is no radial heat conduction such as there is with the radial plate assembly.

In order to determine the relative merits of a tubular design and a involute plate design a comparison is made in Table $5 . a$. 


\section{Table $5 . a$}

Comparison of Involute Plate and Tubular Fuel Cores

Involute Plate Tubular

Core annulus thickness

Length (active)

Number of plates

Plate thickness

Spacing between plates

Number of tubes

2.83 in

36 in

320

2.86 in

0.050 in

0.075 in

Tube dimension

Outside diameter

Inside diameter

Wall thickness

Tube spacing (triangular pitch)

1770

Equivalent diameter

Cross sectional area of metal

Cross section area for flow

Metal-to-water ratio

Heat transfer surface

$\begin{array}{ll} & 0.250 \mathrm{in} \\ & 0.150 \mathrm{in} \\ & 0.050 \mathrm{in} \\ & 0.300 \mathrm{in} \\ 0.150 \mathrm{in}^{2} & 0.150 \mathrm{in}^{2} \\ 55.44 \mathrm{in}^{2} & 55.58 \mathrm{in}^{2} \\ 80.93 \mathrm{in}^{2} & 82.65 \mathrm{in}^{2} \\ 0.685 \mathrm{ft}^{2} & 0.672 \\ 554 \mathrm{ft}^{2} & 555 \mathrm{ft}^{2}\end{array}$

The two fuel assembly types described above can be compared on the basis of heat transfer and fluid flow. For the comparison, the assumptions are made that the coolant velocity is kept constant and that the physical properties of the coolant and flux pattern in the fuel assemblies are the same in both cases. Therefore:

$$
\triangle P \propto \frac{V^{1.8}}{D^{1.2}} \text { or } \triangle P \quad \propto \frac{1}{D^{1.2} A_{F}^{0.8}}
$$

and

$$
\mathrm{h} \propto \frac{\mathrm{V}^{0.8}}{\mathrm{D}^{0.2}} \text { or } \propto \frac{\mathrm{l}}{\mathrm{D}^{0.2} \mathrm{AF}^{0.8}}
$$

where:

$$
\begin{aligned}
\Delta P & =\text { pressure drop, psi } \\
h & =\text { film coefficient, Btu/hr-ft }{ }^{2}-{ }^{\circ} \mathrm{F} \\
D & =\text { equivalent diameter, ft } \\
A_{F} & =\text { area for flow, ft } \\
V & =\text { coolant velocity, ft/sec }
\end{aligned}
$$


Taking the ratios of pressure drop and film coefficients for the two cases gives the result:

$$
\begin{aligned}
& \frac{\Delta \mathrm{P}_{t}}{\Delta \mathrm{P}_{\mathrm{P}}}=\frac{\left(\mathrm{D}^{1.2} \mathrm{AF}^{1.8}\right)_{\mathrm{P}}}{\left(\mathrm{D}^{1.2} \mathrm{~A}_{\mathrm{F}}^{1.8}\right)_{t}}=\left(\frac{0.15}{0.15}\right)^{1.2}\left(\frac{80.93}{82.65}\right)^{1.8} \\
& \frac{\Delta \mathrm{P}_{t}}{\Delta \mathrm{P}_{\mathrm{P}}}=0.96 \\
& \frac{\mathrm{h}_{\mathrm{t}}}{\mathrm{hp}_{\mathrm{p}}}=\left(\frac{\mathrm{D}_{\mathrm{p}}}{\mathrm{D}_{\mathrm{t}}}\right)^{0.2}\left(\frac{\mathrm{A}_{\mathrm{FP}}}{\mathrm{A}_{\mathrm{Ft}}}\right)^{0.8}=\left(\frac{0.15}{0.15}\right)^{0.2}\left(\frac{80.93}{82.65}\right)^{0.8} \\
& \frac{\mathrm{h}_{t}}{\mathrm{~h}_{\mathrm{p}}}=0.98
\end{aligned}
$$
The ratio of heat transfer areas is $\frac{A_{t}}{A_{p}}=1$. The following re-
lationship then holds.

$$
\frac{\left(\frac{q}{t_{W}-t_{c}}\right)_{t}}{\left(\frac{q}{t_{W}-t_{c}}\right)_{p}}=\frac{(h A)_{t}}{(h A)_{p}}=(0.98)(I)=0.98
$$

where

$$
\begin{aligned}
A & =\text { area for heat transfer, } \mathrm{ft}^{2} \\
\mathrm{q} & =\text { heat transfer rate, Btu/hr } \\
t_{\mathrm{W}} & =\text { full element wall temperature, }{ }^{\circ} \mathrm{F} \\
t_{c} & =\text { coolant temperature, }{ }^{\circ} \mathrm{F}
\end{aligned}
$$

These results show that the tubular fuel elements offer no advantage in heat transfer. If the temperature difference between the fuel assembly wall and the coolant is the same for the two cases, the power output of the involute plate core is $2 \%$ greater than for the tubular core. This type of comparison does not necessarily show either fuel assembly to its full advantage, but it is indicative of the Ir relative merits.

The circular segment design (Figure 5.C) has a number of disadvantages, including: 
1. As shown by Figure 5.C, each plate is of a different size and curvature, and ideally the width of the meat in each plate is different. This results in high fabrication costs. While some compromise can be made in the number of different meat widths that are used in the fuel plates of an assembly, each such compromise lowers the effective heat transfer area of the core.

2. The side plates in the core annulus lower the efficiency of the core since it must be made thicker to provide the same heat transfer area as the core with involute plates.

3. There is no radial mixing of the cooling water and no radial heat conduction since the plates are oriented circumfirentially and there is no difference in heat generation latterally along a plate.

4. Preferential loading of the fuel plates to obtain a flat radial power distribution requires fuel alloys of several different U235 concentrations or fuel plates with different meat thicknesses.

The flat-plate fuel assembly (Figure 5.D) is undesirable primarily because of the loss of active core volume (approximately 15\%) between adjacent fuel assemblies. As in the circular segment design, this makes a thicker, less efficient core necessary to meet the specified neutron flux in the central test role.

5.2 Materials and Costs

Currently, fuel plates are fabricated commonly from three metals: aluminum, zirconium, or stainless steel。 Reasonable temperature limits for continuous service with $\mathrm{H}_{2} \mathrm{O}$ coolant and costs for these materials are shown in Table 5.2 .

$$
\text { Table 5.b }
$$

Temperature Limits and Costs of AI, $\mathrm{Zr}$, and SS Fuel Assemblies

Material

A]

$\mathrm{Zr}$

$\mathrm{SS}$
Temperature Limit Cost/Assembly, $\$$

$460^{\circ} \mathrm{F}$
$650^{\circ} \mathrm{F}$
$1200^{\circ} \mathrm{F}$

500 tc 10,000 to 20,000 1,000 to 1,800

Use of aluminum rather than stainless steel or zirconium fuel assemblies is recommended on the basis of relative cost. As discussed in Section 4.0, the surface temperature of the fuel plate is approximately $400^{\circ} \mathrm{F}$ and there appears to be little reason to operate the fuel assemblies at temperatures above those permissible with standard aluminum alloys. However, aluminumnickel alloys ( 1\% $\mathrm{Ni}$ ) developed by Argonne National Laboratory 
permit operation at surface temperatures in the $500-550^{\circ} \mathrm{F}$ range.

\subsection{Construction}

Alternate methods of assembly that can be used for the AETR fuel assemblies are brazing, pinning, or roll-swaging.

The preferred construction is roll-swaging, a technique recently developed by General Electric Company whereby the fuel plates are inserted into slots in the side plates and secured by running a swaging tool along a groove between the slots. The effect is shown by Figure 3.F of Section 3.0 Part A. This method of securing fuel plates in the side plates is stronger, probably less expensive than brazing, and leaves the fuel plates in a coldworked condition. This makes them stronger and more resistant to mechanical damage. Although brazed fuel assemblies could be used, they are less desirable because the fuel plates are in the annealed condition after brazing. Also, they require brazing fluxes that are high in chlorides and fluorides, which when in solution with stagnant water are highly corrosive to aluminum.

Consideration was also given to pinned fuel assemblies developed by Babcock and Wilcox Company. However for the AETR, the pinned assembly is not as attractive because a thicker side plate is necessary due to its curvature. This heavier section adversely affects the peak thermal neutron flux that can be achieved in the island. For comparison cross sections of a roll-swaged and a pinned fuel assembly are shown by Figure 5.E.

\subsection{Summary}

For the AETR, involute plate, roll-swaged, aluminum fuel assemblies are recommended because of their simple design and low cost. The fuel assembly is particularly suited to an annular flux-trap reactor since the core is completely and uniformly filled with plates of one size, shape, and spacing.

Little or no research or development costs are anticipated in forming the involute plates since industry has considerable experience with curved MTR-type plates. However, there will be an added capital cost due to the special equipment required to produce the particular curvature of the plates.

Fabrication of curved plates into a fuel assembly by the rollswaged method also should require little or no development. ETR plates have been fabricated by this method with satisfactory results. The only problem anticipated with the involute plate, roll-swaged fuel assembly is the machining of the side plates. However, this is not research or development but is more in the nature of a jigging problem. 


\subsection{REACTOR CONTROL SCHEMES}

In any reactor designed for fuel assembly testing there are at least two types of control necessary. For rapid, dependable shutdown, a safety control is necessary. For gradual burnup and long-term changes in reactivity, a shim control is needed. A third type of control has been planned, based on previous reactor practice, although its necessity for the AETR is uncertain. This is a regulating-type control to provide rapid compensation for occasional small variations in reactivity.

For the AETR, it is desirable that each of the above control schemes minimize the amount of flux perturbation, so as to maintain test assembly neutron flux constant. Several ways to secure each of these types of control were examined for the AETR.

The control speed requirements for the AETR appear less stringent than in other high-power testing reactors. The ETR for example has a prompt neutron lifetime of $5.5 \times 10^{-5}$ seconds whereas the AETR prompt neutron lifetime is $3.2 \times 10^{-4}$ seconds.

The types of reflector control considered below inclose those suggested in the preliminary report.*

\subsection{Safety control}

Any safety control should have sufficient reactivity worth to make the reactor $15 \%$ subcritical at any time. Since there is about 15\% excess reactivity built into the core and possibly 10\% more in an experiment which contributes maximum reactivity, an adequate safety should have a worth of about $40 \%$. Two schemes were devised which can quickly remove this amount of reactivity.

\subsection{Mechanical Shim-Safety Rods}

Because of the small core size and also because of insufficient reactivity effects it is not practical to incorporate rods in the core. The scheme considered herein utilizes six shim-safety rods. The rods are curved plates which fit in an annulus between the core and the reflector. The upper portion of the rod contains poison while the lower section is unpoisoned. Using $2 \%$ boron in the plates, their total reactivity worth is $40 \%$, as required. The $40 \%$ is based on results presented in section 3.1 .8 which show that a full annulus of boron steel

Elgert, 0. J., et al, Report INTERNUC-9, "Preliminary Investigations for an Advanced Engineering Test Reactor", February, 1957. 
around the core gives about $45 \% \Delta \mathrm{k} / \mathrm{k}$. Allowing for space between the control blades, the reactivity worth of all six blades is estimated to be $40 \%$.

The drive mechanism is located below the core in the large water plenum. A rack and pinion coupled to an alternating current motor by a magnetic clutch drives the rod. When energized, this mechanism moves the rod up or down, removing or inserting poison. For startup, the shim-safety rods are driven out, one at a time, at a speed of 5 inches/ minute. These withdrawals are intermittent and, naturally, all precautions normally taken in startup of a reactor are observed. The control rods are cooled by maintaining a bypass flow of primary water around the core and over the control rods.

When a scram signal occurs, the magnetic clutches are deenergized and release the rods. The rods are then accelerated by gravity and by the force of the coolant flowing down past the rods. The rate of insertion of poison into the core by all six rods dropping simultaneously during a scram from their uppermost positions is shown in Figure 6.A. This curve is based upon friction losses in the drive system just equal to the force of the cooling water friction, resulting in a net acceleration of $l \mathrm{~g}$. It is also assumed that the rod is uniformly poisoned. The effect of decelerating the rod by a dash pot is neglected since this effect is very small. At any time after scram, the difference in total rod worth, with and without the dashpot, is less than 1\%. From Figure 6.A, it is evident that the rods can be almost completely inserted 0.4 seconds after de-energizing the magnetic clutch. Faster insertion requires spring assistance, which is readily available in some types of control rods.

A major disadvantage of this system is the perturbation of the thermal neutron flux in the test hole. When the shim rods are partially inserted both the axial and radial flux distributions are upset. Since a primary design goal for this reactor is a uniform flux distribution in the test hole it is desirable to find a system of control which does not distort the flux as much as control rods.

A second disadvantage of this system is the mechanical complexity introduced by the control rod, which must always be able to move freely between the core fuel assemblies and the reactor shell. In addition to the control rod itself, an extra aluminum structure is required to protect the fuel assemblies from abrasion or damage, and to support guide rollers along the control rod length. These structures in turn require a flow of cooling water which further separates 
the core from its reflector. The added materials for the control rod annulus reduce the reactivity of the reactor about $6 \%$ from that of a reactor without the control rod annulus.

\subsubsection{Reflector-Level Safety Control}

A second safety control scheme drops the $\mathrm{D}_{2} \mathrm{O}$ reflector from around the core for emergency shutdown, as shown in Figure 6.B. As discussed in Section 6.7 of Part A, calculations indicate that loss of the inner $20 \mathrm{~cm}$ of reflector removes about $47 \%$ reactivity.

The performance of a $\mathrm{D}_{2} \mathrm{O}$ reflector as a safety control depends on the time $D_{2} O$ takes to fall and the rate at which this reduces neutron multiplication in the reactor. Therefore the time to drop the reflector from various heights was calculated (see Appendix 5.0). The position of the reflector as a function of time and the height from which the reflector starts to fall are shown in Figure 6.C.

Obviously the worth of the initial reflector removal is increased if the reflector starts to fall from near the reactor midplane where the reactivity worth is relatively high. This results in the subsequent reflector travel being less effective. Assuming that the reflector worth varies with height similar to a uniformly poisoned control rod, the reactivity withdrawn as a function of time and height from which the reflector falls is shown in Figure 6.D. The best point from which to drop the reflector is therefore selected from these figures as one foot below the top of the core. Figure 6.E shows that the reflector can remove reactivity faster than rods of the same total worth accelerated with $1 \mathrm{~g}$. In this figure the reflector tends to level off at a lower reactivity since the upper part of the safety reflector is emptied slowly through a perforated plate at a level one foot below the top of the core.

In operation, the safety reflector is raised by initiating flow in a water-jet eductor. Eductor vacuum raises the reflector and then provides circulation of $\mathrm{D}_{2} \mathrm{O}$ for cooling to remove heat from gamma attenuation and fast neutron moderation. To scram the reactor, the bypass valves are opened and gases from the safety reflector reservoir pass to the safety reflector region, allowing the reflector to drop. The $\mathrm{D}_{2} \mathrm{O}$ reflector falls two feet in about 0.4 seconds. The heavy water in the top of the reflector following scram gradually empties in 13 seconds through 100 holes of 0.5 -in I.D. in the horizontal plate dividing the safety reflector annulus.

The major advantage of reflector safety control is its simplicity compared to mechanical control rods. In worth, the 
single reflector-level safety is equivalent to six rods. The rate of reactivity removal exceeds that of gravity-actuated control rods and the costs are very much less since the reactor utilizes a $\mathrm{D}_{2} \mathrm{O}$ reflector regardess.

The major disadvantage of reflector safety control is that it has not been widely used and requires some development before construction can begin. Additional piping is required, but this costs less than the equipment needed for mechanical control rods.

The major advantage of control systems employing mechanical shim-safety rods is that much experience has been gained in the design, manufacture, and operation of such systems, since they are the only type in wide usage. However, it is not unusual to have difficulties which require modifications to the control rod drives, latches, bearings, etc., especially during the startup phases of a reactor.

\subsection{Shim Control}

The shim control requires less reactivity worth than the safety control, but must be capable of gradual changes to compensate for long term reactivity variation due to burnup, xenon, etc. Each of the schemes investigated has a total worth of $17 \%$ or more in order to satisfy a minimum 19-day core I1fe.

\subsubsection{Mechanical Shim-Safety Rods}

By using the control rod scheme described under section 6.1.1 an adequate mechanical shim control can be developed. The operation and the major advantages and disadvantages of this system are outlined in section 6.1.1.

\subsubsection{Reflector-Level Shim}

A reflector level control can reduce the perturbation of test hole neutron fluxes by use of two or more concentric annular $\mathrm{D}_{2} \mathrm{O}$ reflectors. By raising the levels of reflectors successively farther from the core, increasingly fine or gradual control over reactivity can be obtained. The reflectors are arranged as shown in Figure 6.F. Only the outer two reflectors are used for shim control since the inner reflector must be raised for criticality.

The reflector levels are maintained by the circulation of reflector water through water-jet eductors. Obviously power failure will cause gradual reactor shutdown. However, failopen scram bypass valves are used for rapid shutdown. An advantage of the reflector shim control is its simplicity since 
it uses the reflector which is already part of the reactor design. It is inherently safe. It does not seriously perturb the test hole neutron flux.

There, however, are difficulties with reflector shim control. For any reflector control there has to be a blanket gas system to recombine dissociated $\mathrm{D}_{2}$ and $\mathrm{O}_{2}$. If liquid levels in each reflector annulus are to be maintained independently, great care is required in the design of a single blanket gas system; otherwise separate blanket gas systems are necessary. Another difficulty is in the mechanics of maintaining liquid level. When a reflector annulus is only partially filled, the eductor draws vapor from above the reflector annulus and the $\mathrm{D}_{2} \mathrm{O}$ heats progressively as a result of gamma and neutron heating until it boils. Although use of a boiling reflector may have some advantages in reactor self-control, the development program necessary to prove such a system may not be warranted for the AETR. By use of flexible connections for level control the reflector $\mathrm{D}_{2} \mathrm{O}$ could be cooled without boiling, but this would undoubtediy lead to a more complicated system.

6.2 .3 Reflector-Chemical Shim

A chemical shim control in which soluble poison is added or removed from a portion of the $\mathrm{D}_{2} \mathrm{O}$ reflector is also considered. A schematic diagram is shown in Figure 6.G. Poisoned heavy water is pumped through a heat exchanger to remove heat generated by fast neutrons and gamma radiation. The poisoned heavy water returns to the reflector directly or it may be purified in an ion exchange column which removes dissolved poison as well as corrosion products. The system also has an injection device which can meter saturated poison solutions into the heavy water returning to the reflector whenever necessary.

With feasibility of the scheme dependent on the availability of suitable poisons, a study was undertaken to compare compounds of elements with useful neutron absorption of the basis of solubility, radiation stability, neutron capture products, and cost. Compounds of boron, cadmium, europium, gadolinium, and samarium were examined (see Tabie 6.a). The three most suitable compounds are boric acid, mixed nitrate solutions of samarium and gadolinium, and mixed chloride salt solutions of samarium and gadolinium. These nitrate and chloride solutions have both higher cross sections and solubilities than the boric acid has, but they cost 10-20 times more and in addition introduce undesirable contaminants into the system. Therefore boric acid is selected as the soluble poison.

The amount of boric acid poison required was estimated along with its corrosion characteristics. To overide $15 \%$ 
excess reactivity using only the outer $40-\mathrm{cm}$ reflector thickness, a uniform concentration of $1.066 \mathrm{gm} /$ liter of deuterated boric acid $\left(\mathrm{D}_{3} \mathrm{BO}_{3}\right)$ is needed. This concentration is from $0.5 \%$ to $5 \%$ the solubility of boric acid over a temperature range from $200{ }^{\circ} \mathrm{F}$ down to $32 \% \mathrm{~F}$. Hence precipitation should not occur. The required solution of $1.066 \mathrm{gm} /$ liter is mildly acidic $(\mathrm{pH}=5.5)$, but this causes no serious corrosion problem with aluminum or stainless steel.

The operating characteristics of a borated reflector were also investigated. When boric acid is added to the system at the rate of $\mathrm{v}_{\mathrm{a}} \mathrm{gm} / \mathrm{sec}$,

$$
\frac{\Delta \mathrm{C}}{\mathrm{C}_{\mathrm{o}}}=\frac{\mathrm{C}_{\mathrm{a}}}{\mathrm{C}_{\mathrm{O}}} \frac{\mathrm{v}_{\mathrm{a}}}{\mathrm{V}} \mathrm{t}
$$

where:

$$
\begin{aligned}
& \Delta \mathrm{C}=\text { the change in boric acid concentration, } \mathrm{gm} / \mathrm{cc} \\
& \mathrm{C}_{\mathrm{a}}=\text { concentration of boric acid solution being added, } \mathrm{gm} / \mathrm{cc} \\
& \mathrm{C}_{\mathrm{O}}=\text { concentration of boric acid at criticality, } \mathrm{gm} / \mathrm{cc} \\
& \mathrm{V}=\text { volume of borated reflector, cc } \\
& t=\text { time of addition, sec }
\end{aligned}
$$

Similarily, when boric acid is being removed from the system by the ion exchange columns:

$$
\text { In } \frac{C_{i}}{C}=\frac{\beta V}{V} t
$$

where:

$$
\begin{aligned}
& C_{1}=\text { initial boric acid concentration, } \mathrm{gm} / \mathrm{cc} \\
& \mathrm{C}=\text { boric acid concentration at time } \mathrm{t}, \mathrm{gm} / \mathrm{cc} \\
& \mathrm{V}=\text { flow rate in reflector, cc/sec } \\
& \beta=\text { fraction of the flow rate in the reflector which } \\
& t=\text { passes through the resin column } \\
& t=\text { time of removal, sec }
\end{aligned}
$$

Solutions to equations 1 and 2 are shown in Figures $6 . \mathrm{H}$ and 6.I respectively. As can be seen, the system is very sensitive to increases in the boric acid concentration but not so sensitive to removals.

In summary therefore, this reflector shim control has large reactivity worth if necessary. It does not perturb test assembly flux appreciably and offers extremely smooth, gradual, ana stable control. It is compatible with either mechanical safety rods or a reflector-level safety. It can only "fail safe". Normal boron burnup is very slow and the 
poison is both cheap and readily available. The disadvantages of chemical shim control are that it requires extra equipment for poison addition and removal, and that some development is required.

Table 6.a

Comparison of Poisons for Chemical Shim System

Poison

Barns/gm

$$
7 \cdot 3 \times 10^{24}
$$

$\mathrm{D}_{3} \mathrm{BO}_{3}$

$\mathrm{Sm}$, Gd in mixed nitrate $21.7 \times 10^{24}$ solution (18\%

$\mathrm{Sm}, 10 \% \mathrm{Gd})$ as $\mathrm{SM}\left(\mathrm{NO}_{3}\right)_{3}$ and $\mathrm{GD}\left(\mathrm{NO}_{3}\right)_{3}$

$\mathrm{Sm}$, Gd in mixed chloride salt solution (20\%

$\mathrm{Sm}, 11 \% \mathrm{Gd}$ ) as $\mathrm{SmCl}_{3}$ and $\mathrm{GdCl}_{3}$

\subsection{Regulation}

With conventional control rod shim systems, a regulating rod is required to smooth out small oscillations in reactor power. However, with a chemical shim system it is not certain that such regulation is required. Until such is proven by actual operating experience, it is desirable to have regulating rods and two are located in two of the capsule irradiation tubes in the reflector.

6.4 Cost Comparison

In order to aid in selection, the cost of a fully mechanical control system is compared with an equivalent reflector control scheme.

In order to adapt the basic reactor to control rods, a core tank liner is necessary to support the Individual fuel assemblies and keep them away from the passage through which the control rod travels. This liner also supports many of the rollers which guide the control rod between the core and the reflector. 
Other changes and components are necessary for the reflector controls. The blanket gas system, cleanup equipment, and cooling system for the $\mathrm{D}_{2} \mathrm{O}$ reflector, must be separated into two systems. The reflector safety requires a larger circulating pump for use with the eductor. Considerable extra piping is necessary for the bypass valves on the safety reflector and a poison injection device is necessary for the shim control.

Omitting the conventional regulating rod which is common to both schemes, a cost comparison is made in Table 6.b.

Table 6.b

Comparison of Construction Cost for Mechanical and Reflector control Systems

Mechanical Control Rods

Core tank liner \& guide rollers

Shim-safety rods, (6) 84,000
Reflector Safety and Chemical Shim

Reflector tank modification $\$ 4,000$

Eductors

2,000

Circulating pumps, motors

3,000

Bypass valves

2,000

Blanket gas system

10,000

$\mathrm{D}_{2} \mathrm{O}$ cleanup system

10,000

Additional heat exchanger

2,000

Additional pipint

4,000

Poison injection device

5,000

$\$ 42,000$

Total $\$ 94,000$ Total

$\$ 42,000$

With the background of past practice, little or no development is necessary for the control rods. However, the estimated cost of development of the safety and shim reflector control is $\$ 75,000$. Then assuming the construction of seven reactors, the estimated total cost of the mechanical control system is $\$ 658,000$ while that of the chemical control system is $\$ 369,000$.

\subsection{Conclusion}

On the basis of simplicity and effectiveness, the reflectorlevel is selected for the AETR safety control. For this compact 
reactor, the absence of additional equipment and moving parts around the core is highly desirable. The reflector safety is fundamentally a safe control. Finaliy, use of a reflector safety does not impair the design reactivity.

Similarly, the reflector-chemical shim control is preferred for its simplicity. It is fail-safe, and does not perturb test assembly flux. Its cost is also less than the cost of shim rods, even with an allowance for the additional systems not needed in a single-reflector AETR. The reactivity worth of a weak boric acid solution appears sufficient to overcome the initial excess reactivity required for a 19-day operating cycle. The development required does not appear difficult.

The safety and shim reflector system is probably a factor of two less expensive than control rods, even including the cost of the development required, since a reflector with recombination, cooling, and cleanup systems is required regardless of the type safety control. 


\subsection{STRESSES IN REACTOR CORE VESSEL AND LOOP TUBES}

The AEC specifications for test loop pressure and neutron flux results in relatively high combined pressure and thermal stresses in both the reactor core vessel and the loop tubes. With high strength and potentially high thermal stresses involved, various materials were compared and a selection made before making detailed stress calculations.

7.1 Material Selection

As outlined in Appendix 6.0 , the internal heating rate is based on an average core and test assembly power density of 2.1 Mw/liter and a maximum power density at the horizontal midplane of $2.9 \mathrm{Mw} /$ liter. This results in a value of 90 watts/cc internal heat generation in aluminum adjacent to the core.

These rates of internal heating make it questionable whether steel is as good a loop tube or pressure vessel material as aluminum which has smaller gamma energy absorption characteristics. Also important are the thermal stress and strength characteristics. Table $7 . a$ gives a comparison of thermal stress factors and yield strengths of stainless steel zirconium, and aluminum.

Table $7 . a$

Thermal Stress Factors and Yield Strengths at $300^{\circ} \mathrm{F}$

Aluminum Alloys:

1100

$2014-\mathrm{T} 6$

$6061-\mathrm{T} 6$

$7075-\mathrm{T} 6$

Stainless Steel (type 347)

Zirconium

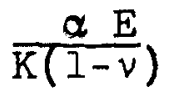

1.48

2.265

2.21

2.93

34

5.8 $\sigma$ Yield $\left(300^{\circ} \mathrm{F}\right)$

4,500

40,000

31,000

21,000

35,000

24,000

On the basis of the above and preliminary stress calculations it was decided to make the through-tube and reactor core vessel of aluminum alloy 2014-T6. A prominent aluminum fabricator also independently recommended this alloy. It is 
one of the strongest aluminum alloys at the temperatures expected near the AETR core and it can be forged, welded, and machined. It has a good record of previous application in alrcraft and vehicle structures. In the opinion of possible suppliers, the demineralized primary water should result in no corrosion problem with this material provided the rest of the primary loop is stainless steel.

Like most aluminum alloys, 2014 loses strength at high temperatures. Cooling is provided therefore to maintain this material below $2500 \mathrm{~F}$ at all points within the reactor complex. For this temperature the maximum allowable stress under section VIII of the ASME Boiler and Pressure Vessel Code is 14,000 psi. This stress, which represents about one-fourth the ultimate strength of the material, is not exceeded in the AETR design.

\subsection{Reactor Core Vessel}

Surrounding the core and separated from the fuel assembly side plates by a 0.045 -inch cooling water gap, the core pressure vessel is in a very high radiation field. In addition it must contain the primary coolant under 300 psi system pressure.

The pressure and thermal stresses as functions of wall thicknesses are shown by Figure 7.A. The combined stress is a maximum at the inner surface since the thermal stresses are compressive at the outside. A wall thickness of 0.50 inches is selected since the curve assumes cooling from the inner wall only and therefore overestimates thermal stresses. In this instance the indicated stress is still below the 14,000 psi maximum working stress allowable under the ASME code for unfired pressure vessels. Methods for making the calculation are given in Appendix 7.0. For the same thickness the pressure stresses in the Type-B core vessel are lower since they are approximately proportional to the diameter. Therefore the combined stress is lower than the combined stress shown in Figure 7.A for the Type-A core vessel.

\section{$7.3 \quad$ Loop Tubes}

There are two types of loop tubes. Simplest to visualize is the through-tube. As the name implies, this is a long cylinder of uniform diameter which passes from the bottom of the reactor vessel through the core as shown in Figure 3.A.

A second type of loop tube is the thimble. Here the test assembly coolant enters the loop tube from the top passing through the core in a relatively thin annulus around the test assembly. At the bottom of the thimble, the flow reverses direction to pass through the test assembly and out through the top of the thimble. This scheme is illustrated in Figure 4.A. The thimble has an important mechanical advantage in 
that connecting pipes pass through the reactor pressure vessel only above the core. Hence thermal expansion is no particular problem. The expansion problem is not so simple for the through-tube.

Each of the thimbles is designed so that the coolant inlet annulus has half the area of the specified test hole. This means that the coolant has the same velocity through the annulus as it has in a test assembly with $50 \%$ voids for coolant flow. Both the thimble and through-tubes have a 0.375 -in radial space between the test hole and the loop tube wall to provide for a .062-in stainless steel test hole liner and insulation or coolant to meet the demands of each test environment. Therefore, the following are the inner diameters used to select wall thicknesses for the loop tubes.

\section{Table $7 . b$}

\section{Loop Tube Inside Diameter}

\begin{tabular}{cc}
\multicolumn{2}{c}{ Diameter, in } \\
$\frac{\text { Through-Tube }}{4.75}$ & $\frac{\text { Thimble }}{7.65}$ \\
75 & 9.33
\end{tabular}

\subsubsection{Loop Tube Cooling}

Two factors necessitate a careful study of the loop tube wall cooling. First, the heat transmitted through the loop tube wall and the internal heat generation result in large thermal stresses. Second, the 2014-T6 aluminum alloy must be cooled in order to retain its strength. Arbitrarily, it was decided to keep the loop tube walls below $250^{\circ} \mathrm{F}$ if possible.

The liquid metal and gas-cooled test loops operate up to $2000{ }^{\circ}$. To reduce transfer of heat to the aluminum tube there is an insulating space between it and the stainless steel liner (see Figure 7.B). The amount of heat transferred was calculated with the space fllled with air at loop pressure (300 psi), and with the space filled with diatomaceous silica. See Table 7.c.

From the data in Table $7 . c$ no decision is made as to the better insulating technique. Superficially the insulation appears helpful. Actually, the heat generated in the insulation may cause higher temperatures next to the loop tube wall 
than when a void is used. Hence no decision is made as to the better scheme. For stress calculations however, a heat flow of $20,000 \mathrm{Btu} / \mathrm{hr}-\mathrm{ft}^{2}$ is assumed from the hot stainless steel tube to the cooler aluminum tube.

\section{Table $7 . c$}

Gas-Cooled Loop Tube Heat Transfer Data

Material between loop tube and liner

Air

300

1.5

Density, \#/ft3

Total temperature difference, ${ }^{\circ}$

1850

Heat flow, Btu/ft²-hr

Convection

19,100

Radiation

Conduction

Generated within material at $90 \mathrm{w} / \mathrm{cc}$

Total, Btu/ft2-hr
Insulation

300

18

Making calculations for only one arrangement, the 7-inch gas-cooled through-tube with primary coolant at $8.5 \mathrm{ft} / \mathrm{sec}$ cooling the outside of the loop tube, the following acceptable temperatures result.

\section{Table $7 . d$}

\section{Gas-Cooled Loop Tube Midplane Temperatures}

Location

cooling water

Loop tube outer wall

Loop tube inner wall:

90 watts/cc internal heat generation only

Conduction from test assembly included
Temperature, ${ }^{\circ} \mathrm{F}$

150

214

226

230 
The pressurized water loop tube has a generally similar cooling problem. Due to an increased wall thickness for reasons discussed in section 7.3 .3 , both surfaces of the tube are water-cooled in the core region as shown in Figure 7.C. High velocity water at $130^{\circ} \mathrm{F}$ passes over both surfaces for cooling. A single inner annulus may also be sufficient, but with uncertainty as to test assembly flow rate and test coolant inlet temperature, the scheme shown seems more effective. Ideally, the water annulus adjacent to the inside of the loop tube should be narrow with high water velocity for good cooling, and the annulus inside it wider and slow-moving to limit conduction of heat from the test assembly.

Using a 0.78 -inch thick inner annulus with $132 \mathrm{gpm}$ of cooling water flowing at $25 \mathrm{ft} / \mathrm{sec}$, the temperatures in the 7 -in pressurized water through-tube are as given in Table $7 . c$. The temperatures in the other loop tubes are expected to be similar, assuming the first coolant passage removes half the heat generated in the aluminum and half the heat generated in the two loop tube coolant passages.

\section{Table $7 . e$}

Pressurized Water-Cooled Loop Tube Midplane Temperatures

Location and Material

Inlet cooling water

cooling water starting second pass

Loop tube inside surface

Center of loop tube wall, maximum

\section{Temperature, ${ }^{\circ} \mathrm{F}$}

130

153

189

208

Lower cooling water velocities can be used here since the hot spot does not occur at the end of the first coolant passage.

From the above calculations, it is concluded that both the gas and pressurized water-cooled loop tubes can be cooled adequately. The results apply equally to the through-tube and thimble designs since heat transfer to and from the loop tubes is solely a function of temperature, materials, and spacing. All the loop tubes are about the same in this respect since the wall thicknesses are the same and only the diameters vary. 


\subsubsection{Liquid Metal and Gas-Cooled Loop Tubes}

The most severe pressure stresses occur when the loop tube is under its maximum operating pressure, 300 psi, and the primary coolant is depressurized. For various wall thicknesses therefore, the pressure stresses as functions of wall thickness, are shown in Figure 7.D and 7.E. The se figures also show the thermal and combined stresses for 90 watts/cc uniform internal heat generation. The combined stresses indicate there is considerable apparent latitude in the selection of wall thickness for the gas or liquid metal-cooled loop tubes, due in part to relatively low test loop pressures.

Unfortunately, there is a possibility that the test loop may be depressurized, in which event the reactor primary coolant system pressure ( 300 psi) can cause the loop tube to collapse. The wall thicknesses are increases so that they will not collapse under 300 psi external pressure, and also to give greater structural rigidity than the pressure stress wall thicknesses give. The final thicknesses selected are given below:

\section{Table $7 . f$}

Wall Thickness for Gas and Liquid Metal-Cooled Loop Tubes

Thickness-in

Test Loop Types

$$
\text { 4-in }
$$

$7-$ in
Through-Tube

0.300

0.375
Thimble

0.300

0.400

The allowable external pressures given in Table $7 . \mathrm{g}$ for these loop tubes are based on a loop tube wall temperature of $250^{\circ} \mathrm{F}$ and an unsupported length of ten feet.

Table 7.8

\section{Allowable External Pressure for Liquid and} Gas-Cooled Loop Tubes

Allowable Pressure, psi

Test Loop Type

4-in

7-in
Through-Tube

430

387
Thimble 410 300 
In order to determine the maximum operating stresses, the thermal stress contribution due to heat transmitted from the test assembly is determined. (see section 7.1.2 of the Appendix). The stresses for the 4-Inch gas-cooled loop tube are given below in Table $7 . \mathrm{h}$.

Table $7 . \mathrm{n}$

Tangential Stresses in Loop-Tubes for 4-in Gas-cooled Test Hole

Stresses, psi

Location and Type

Through-Tube Thimble

Outer Surface

Internal heat generation

3970

3525

Heat transmitted

413

411

Pressure

2433

2819

Combined

6816

6755

Inner Surface

Internal heat generation

$-1673$

$-1525$

Heat transmitted

$-442$

Pressure

2733

Comb1ned

$-618$

The stresses are not high, and the thimble and through-tube stresses are nearly equal

The stresses for the large gas-cooled loop tubes are given in Table 7.i. The maximum stresses in Table 7.1 indicate a small advantage for the through-tube although all the values are acceptable.

\subsubsection{Pressurized Water-Cooled Loop Tubes}

The pressure and thermal stresses were determined similarly for the through-type and thimble-type loop tubes which can accommodate 4 -in diameter water-cooled test assemblies at pressures up to $2000 \mathrm{ps}$. The stresses in the 4.75-inch I.D. through- 
Table 7.1

Tangential Stresses in Loop Tubes for 7 -in Gas-Cooled Test Hole

Location and Type

Outer Surface

Internal heat generation

Heat transmitted

Pressure

Combined

Inner Surface

Internal heat generation

Heat transmitted

Pressure

Combined
Through-Tube

6250

610

2957

9817

$-3300$

$-650$

3257

$-693$
Thimble

7170

650

3622

11,442

$-3580$

$-685$

3924

$-341$

\section{Table $7 \cdot j$}

Dimensions for 4-in Pressurized-Water Loop Tubes

Dimensions, in

I.D.

Wall thickness

O.D.
Through-Tube

4.75

0.5

$5 \cdot 75$
Thimble

5.65

0.6

6.85 
tube are based on the assumption that cooling occurs from the outer wall only, similar to the gas-cooled loop-tubes. The results, shown by Figure 7.F indicate there is no wall thickness for which an acceptable stress level can be achieved. Accordingly, there must be cooling at both surfaces of the pressurized water loop tubes. Therefore, the cooling schemes previously discussed and shown in Figure 7.C were devised and the stresses calculated. The results for the 4 -in test $100 p$ through-tube are shown in Figure $7 . \mathrm{G}$. This curve also compares aluminum alloy 7075 with the alloy 2014 , the latter being selected.

A wall thickness of 0.50 inches is selected for the 4-in through-tube and 0.60 inches for the 4 -in thimble. The final dimensions are given in Table $7 \cdot j$.

The stresses for the sizes are given in Table 7.k. They are based on 2000 psi within the 100p, no external pressure, and 90 watts/cc internal heat generation.

\section{Table $7 . k$}

Tangential Stresses in Loop Tubes for a 4-in Pressurized Water Test Hole

Stresses, psi

Location and Type

Through-Tube

Thimble

Outer Surface

Internal heat generation

2780

4120

Pressure

8595

8510

Combined

11,375

12,630

Inner Surface

Internal heat generation 3060 4560

Pressure 10,595 10,510

Combined

Based on the above, the through-tube is stronger. With the 14,000 psi allowable under the code, the limits for loop tube size and pressure are thus approached. For this reason the design of an all-purpose loop tube to accommodate every 
type of experiment up to 7-in was not considered. Likewise, 7 -inch pressurized water loop tubes appear impractical.

The above figures do not rule out the thimble concept. Stresses higher than the allowable stresses have been accepted in the past if special manufacturing precautions are observed and vessels proof-tested upon completion. Both the thimbletype and through-type tubes for the 4-in pressurized water loop appear feasible, with a mild preference for the throughtube.

\subsection{Summary}

For the pressure vessels subject to unusual thermal and mechanical stresses, aluminum alloy $2014-\mathrm{T} 6$ is best. Its selection is based on its strength, good thermal properties, and acceptable forging, welding, and corrosion characteristics.

The core pressure vessel appears to be simple and straightforward to design and bulld. The loop tubes can be designed and built in a conventional manner, although the stresses in the pressurized water loops approach the limit of normal design. Because of lower stresses, the through-tube has a small advantage over the thimble. 


\subsection{TEST LOOPS}

Two alternative ways to enclose and cool an experimental test assembly are compared. The first method consists of a through-tube with the top end directly beneath the reactor vessel head, and extending down through the core and the lower reactor vessel closure (see Figure. 3.A of Part A).

The alternate method, a thimble, has its top located approximately the same as the through-tube, but does not penetrate the bottom of the reactor vessel (see Figure 14. A of Part A). Test section coolant flows down through a reentrant outer annulus, reverses direction to rise through the test section and pass out to the external portion of the loop. Flow in the reverse direction can also be used.

These two schemes are compared on the basis of reactor power required to produce the specified flux, the relative strengths, the handling problems, and costs. In comparing the two types of loop facilities, the size of the return flow annulus of the thimble is such that its flow area is one-half the cross sectional area of the test hole.

The comparison shows that the through-tube type facility is better if compared on the basis of operating costs, while if compared on the basis of capital cost the thimble type is better. Except for the thimble offering some advantages in experiment handling, other factors do not indicate a clear choice for either type of loop facility.

\subsection{Reactor Power}

The study conducted in section 3.2 examines the minimum reactor power requirements to give the specified fluxes in thimble and through-tube test loops. The total power required for the seven reactors with through-tubes in each is $803 \mathrm{Mw}$ (Table 3.b) while the power required if thimble type loops are used is $923 \mathrm{Mw}$ (Table 3.f), about 15\% greater. The higher power level required for the thimble loops is due solely to the reactors with sodium-filled test holes. The power requirements for water-cooled thimble loops are slightly lower than for their through-tube counterparts. The reason for this is that, in the thimble-type loop the water in the return annulus of the thimble serves as the moderator annulus of the reactor. The thick aluminum pressure tube is adjacent to the core where it does not affect the test hole thermal flux as much as when it is adjacent to the test hole.

\section{2 strength}

The detailed statement of stresses for both the throughtube and the thimble design is given in Section 7.0. A summary is included here. 
For a given size testi assembly the through-tube can be made smaller in diameter than the thimble since the latter utilizes a return flow annulus around the test assembly. The smaller diameter tube can be made thinner and yet withstand the same pressure. Since the thinner-walled tube is subject to lower thermal stresses, this consideration tends to favor the through-tube arrangement. Also, if the thermal and pressure stresses are combined by adding their full values, the maximum feasible size thimble for $2000^{\circ} \mathrm{psi}, 650^{\circ} \mathrm{F}$ water-cooled experiments will not accommodate test assemblies larger than 4 -inches in diameter.

Both the through-tube and the thimble are constructed with an aluminum pressure tube and an inner stainless steel liner as a thermal barrier. When liquid metal is used as the test assembly coolant, these two tubes operate at greatly different temperatures (the SS line up to $2000^{\circ} \mathrm{F}$ and the aluminum at $250^{\circ} \mathrm{F}$ ) and a seal between them is required. The differential expansion may cause difficulty in attalning a satisfactory seal. This problem is nonexistent in the thimble type arrangement.

The thimble type unit is difficult to forge in one piece. Yet, this type of construction seems desirable since welded joints cannot be stressed to the same degree as one-piece construction.

\subsection{Experiment Handling}

As they affect experiment handling the arrangements of the reactors are similar in that both the through-tube and the thimble terminate directly beneath the pressure vessel head (Figures 3.A and 14.A of Part A). The reactor vessel head is eleven feet below the top of the canal. After removal of the reactor vessel head, a water-cooled test assembly can be removed from both the through-tube and the thimble directly to the canal. To change a gas-cooled or liquid-metal-cooled test assembly, it is necessary to lower the reactor pit water level to below the top of the through-tube or thimble. After removal of the through-tube or thimble closure the test assembly is removed to a coffin provided for this purpose. However, such experiments can also be removed from the reactor while contained within the thimble. The entire thimble can be disconnected from the loop system, connected to an auxiliary cooling unit if necessary and, after the reactor-pit water level has been raised, removed from the reactor and transferred to the canal without use of a shielding coffin. As seen in Figure 14.A, the test loop coolant connections can easily be connected togethej at the flanges or by installing a bypass valve. After the reactor has been shut down, either of these can permit natural circulation within the thimble. Depending upon the amount of decay heat and the test assembly design, this may provide adequate cooling. If it does not, a cooling unit can be connected to the thimble. The removal of a test assembly 
within the thimble is particularly advantageous in the event of a fission break in the test assembly. A hot cell above the canal of a thimble-type reactor facility may prove very valuable since it would simplify transfer of irradiated material to the hot cell.

While simpler, the thimble concept does require extra thimbles for the experiments which are kept in thimbles following reactor irradiaion. Nevertheless, no special shielding coffins or hot cell equipment is needed to remove the experiment from the reactor.

8.4 Costs

Comparing the cost of one through-tube and its auxiliary handling, cooling, and shielding equipment with the cost of a thimble and its auxiliary equipment indicates that there is probably not much difference between the two. However, if the overall costs of the reactors are compared, significant differences in costs are apparent. In the through-tube type reactor, excavation beneath the reactor for a "sub-pile" room for use during loop tube changes is necessary. However, the thimbletype reactor requires no excavation beneath the reactor and thus its capital cost is less than that of the through-tube type reactor.

For liquid metal-cooled and gas-cooled loops, operating costs strongly favor the through-tube because of the lower power required to reach the specified thermal neutron flux in the test hole. For the 7-inch test holes the thimble-type reactor requires about 30-35 Mw more reactor power than the through-tube type reactor. Based on 300 operating days per year the annual costs for U235 burnup alone are about $\$ 200,000$ higher for one thimble-type reactor with a 7 -inch test hole than for one through-tube type reactor. The differences in operating costs, aside from the costs of the U235 burnup, are not great. For the water-cooled loops, the reactor power requirements for the thimble type reactor are very slightly less than those of the through-tube type reactor.

8.5 Conclusions

Both thimble and through-tubes can be readily designed, built, and operated from a purely structural and operating view point. There is no great preference between them for strength or ease of handling. Nevertheless the reactor power, fuel burnup and reprocessing cost is decidedly less for the through-tube than for the thimble design. Accurdingly, the through-tube is recommended if operating costs are the primary criterion.

Markedly superior, for a minimum facility at least, the thimble scheme offers a worthwhile saving in construction cost over any of the through-tube concepts. A second recommenation is therefore made: The thimble design is preferred for a facility with minimum construction costs. 


\subsection{REACTOR ASSEMBLY}

The specifications for seven similar flux-trap reactor test loops presents the possibility of either separate reactors or one composite reactor consisting of seven annular cores in a single reactor pressure vessel filled with $\mathrm{D}_{2} \mathrm{O}$ as a reflector. This composite scheme is illustrated in Figure 12.C.

The two concepts are compared on the basis of the power required to meet the specified thermal flux in the test hole. Other comparisons are discussed below on the basis of utility, operating staff required, and construction cost.

\subsection{Reactor Power}

The study reported in Sections 3.2 and 3.3 indicates that the total power required to meet the neutron flux specifications in the seven test holes is $858 \mathrm{Mw}$ using two different core sizes. For the composite reactor, the power required is nearly the same, $853 \mathrm{Mw}$, but in the smaller test holes and particularly those with water-filled test holes the flux will exceed the flux specifled. Taking this difference into account and comparing the two arrangements on the basis of the flux-volume integral of the test holes shows the composite reactor to be about $10 \%$ better than the single reactors in terms of usable thermal neutron flux per $\mathrm{Mw}$ of power.

9.2 Utility

The seven cores of the composite reactor are coupled in two ways, by neutron diffusion between the various cores and by the coolant which flows through all the cores. This has several undesirable aspects for the composite reactor compared to a single core reactor.

A highly absorbing experiment or a control rod tends to depress the thermal neutron flux in adjacent cores and test loops. It is conceivable thus that an annular core may sometimes operate at higher power density on one side of the test hole than it does on the other. A control to compensate for this would undoubtedly be complex.

In the composite reactor cooled by a single primary coolant loop the spread of radioactive fission products in event of fuel assembly rupture becomes much more widespread, and loop flushing and decontamination become much more difficult. 
A third factor, the unscheduled shutdowns which are characteristic of testing reactor operation, tends to limit the time at full power for a composite reactor. Every difficulty which affects one core tends to affect or shut down all the other cores. As with other multi-loop test facilities, it is hard to secure a high proportion of operating time with the composite core.

\subsection{Operating Staff}

The seven cores in the composite reactor will not require as many reactor operators as seven separate reactors. This represents a saving in the operating staff.

However with all the reactor maintenance and refueling to do on seven cores at one time during their collective shutdown, there will have to be more personnel on hand for maintenance, repair, and refueling for the composite core. This unfortunately is perhaps the only time all these are fully utilized.

For the separate reactors with individual shutdowns, fewer men are needed since they can work on one core at a time during non-simultaneous maintenance periods.

Overall, there is little apparent difference between the two arrangements on the basis of the personnel required.

\subsection{Costs}

The construction cost for separate reactors is somewhat higher due to the fact that a greater number of pressure vessels are required along with a greater total amount of shielding and probably a larger building.

With the same operating cycle and the same burnup, the operating costs of the two schemes are comparable. However, the composite reactor must be operated at full power even if not fully loaded with test fuel assemblies, while only those single reactors with test assemblies in their test holes need be operated. Thus the efficiency of the single units in terms of irradiations accomplished versus fuel burned would be appreciably higher than that of the composite reactor.

\subsection{Conclusion}

In attaining maximum experiment time at full power, the separate reactors are superior to the composite reactors. In addition they are much more flexible in meeting the needs of the experimenters. Although the construction costs of the 
single reactors can be expected to be higher than those of the composite reactor, the operating costs will probably be

* less is compared on the basis of irradiations accomplished. For these reasons, the separate reactors are more attractive, and are selected for the AETR. 


\subsection{COOLING SYSTEMS}

The following comparison of cooling systems is based on the use of seven separate reactors, which have been selected for other reasons over the composite reactor containing seven test holes. The comparison is therefore primarily concerned with the relative merits of common versus individual loops for the primary and secondary cooling systems.

This comparison indicates that individual primary cooling systems and a common secondary cooling system are preferable. The selected operating conditions for the cooling towers in the secondary system consist of "on tower" and "off tower" temperatures of $160^{\circ} \mathrm{F}$ and $900 \mathrm{~F}$, respectively, at the highest anticipated wet bulb temperature of $650 \mathrm{~F}$.

\subsection{Primary Cooling System}

Since the primary cooling system has little effect on the selection of the optimum reactor concept, the choice of individual primary loops or a common primary cooling system is made on the basis of their effect on the versatility, utility, and cost of the reactor complex. The relative effects of the individual vs common primary coolant systems on the versatility and utility of the entire system are weighed by examining some common operational difficulties and determining the effects of these on the entire system. See Table 10.a.

In the case of difficulties (1), (2), and (3) the common primary cooling system is more versatile and results in less loss of utility than the individual primary cooling systems. In the case of difficulties (4), (5), and (6), however, the individual primary cooling system is the more versatile of the two and the loss of utility is relatively slight whereas with the common primary cooling system loss of utility is complete.

The difference in capital and operating costs of the two primary coolant systems should not be great. The same total amount of heat must be transferred from the primary water to the secondary water in either case so the number and size of pumps and heat exchangers would be about the same. It would be possible to use larger pumps and heat exchangers with the common primary coolant system than with the individual primary coolant system. However, it is doubtful whether this would result in any appreciable savings since standard sized units would be most economical in either case.

The individual primary coolant systems are chosen primarily because of their superiority. with respect to reactor 
Table 10.a

Comparison of Individual and Common

Primary Coolant Systems

Effect on Entire System with

\section{Operating Problem \\ 1. Failure of single primary pump}

2. Failure of several primary pumps

\section{Ruptured tube in heat exchanger}

4. Fuel element rupture fission products in primary water

\section{A. Individual Primary Cooling System}

Affected reactor must be run at considerably reduced power or shut down entirely. Only one reactor affected. Repairs can be made without affecting six other reactors.

Affected reactor must be shut down. Repairs can be made without affecting other reactors

Affected reactor must be operated at considerably reduced power or shut down entirely. Only one reactor affected. Repairs can be made without affecting other reactors

Affected reactor must be shut down. Necessity for immediate shut down dependent upon degree of contamination. Only one reactor affected. Decontamination possible without affecting (six other reactors)

\section{B. Common Primary Cooling} System

Al1 reactors must reduce power slightly. Necessity for shutting down any reactor very unlikely. All reactors must be shut down for pump repairs.

Capacity of remaining pumps sufficient to keep three or four reactors operating at full power or all reactors operating at considerably reduced power.

All reactors required to reduce power slightly. Necessity for shutting down any reactors very unlikely.

All reactors must be shut down immediately, regardless of degree of contamination, or entire system will have to be decontaminated. 
Operating Problem

5. Failure of primary coolant

instrumentation

6. Rupture of primary piping system or valve packing failure

7. Startup or shutdown of reactor
A. Individual Primary Cooling System

Affected reactor must be shut down. Only one reactor affected. Repairs can be made without affecting (six) other reactors.

Affected reactor must be shut down. Only one reactor affected. Repairs can be made without affecting (six) other reactors.

No immediate effects on other reactors

\section{B. Common Primary Cooling System}

All reactors must be shut down until repairs can be completed.

All reactors must be shut down until repairs can be completed.

Coolant temperature to all remaining reactors affected immediately. 
control. With a common primary cooling system the power and flow changes in one reactor may significantly affect the operation of another. This would be particularly true during startup or shutdown of one or more reactors. Since the reactors are designed for a high power density, significant fluctuations in the flow rate and inlet temperature of the primary cooling water are undesirable.

10.2 Secondary Cooling System

The basic secondary cooling system is a closed-cycle circuit consisting of pumps, piping, valves and forced convection cooling towers. The latter ultimately reject the heat from the reactor to the atmosphere by evaporating water. The evaporated water must be replaced by a make-up stream, the quantity of this stream being approximately equal to $Q / 1000$ pounds per hour, where $Q$ is the reactor heat rate in Btu/hour.

Since cooling towers are commonly supplied as modular units, a decision was made to locate all cooling towers, in banks of modular units, within a common area regardless of the type of primary coolant system chosen. Thereafter, the method of distributing the water from the cooling towers to the primary cooling systems depends on the effect of the type of distribution system on the versatility and utility of the reactor.

The relative effects of Individual and common secondary coolant systems on the versatility and utility of the entire system are weighed by examining common operational difficulties and determining how these affect the entire system (see Table 10.b). In the case of difficulties (1), (2), and (3) the common secondary coolant distribution system is the more versatile of the two and results in less loss of utility than the individual secondary coolant distribution systems. The only casualty for which the reactors with individual secondary coolant distribution systems do not suffer as greatly in utilization as those with the common secondary system is a rupture of the main secondary coolant headers. Loss of utility with the common secondary system is complete in this case. However, difficulties (1), (2), and (3) are more likely to occur with considerably greater frequency than the latter, and therefore, the common secondary coolant system is chosen as the type with greatest functional suitability.

There is relatively little difference in the total capital and operating costs of the two secondary coolant systems. Both systems are required to transfer the same total amount of heat from the heat exchangers to the cooling towers and pumping power costs are therefore nearly equivalent. Additional 
Comparison of Individual and Common

Secondary Coolantsystems

Effect on Entire System with

Operating Problem

1. Failure of single secondary pump

2. Failure of several secondary pumps

3. Combination of ruptured tube in $\mathrm{HX}$ and ruptured fuel element or fission products in primary coolant

4. Rupture of secondary coolant main distributor header or valve packing failure
A. Individual Secondary Cooling System

Affected reactor must be run at reduced power or shut down completely. Pump can be repaired while reactor is running at reduced power. Remaining reactors can continue operating

Affected reactor must be shut down. Pump repairs must be made before reactor can operate again. Remaining reactors can continue operating.

Affected reactor must be shut down. Decontamination and repair must be accomplished prior to restarting. Remaining reactors can continue operating.

Affected reactor must be shut down. Repairs must be effected before startup. Remaining reactors can continue operating.
B. Common Secondary Cooling System

Capacity of remaining pumps sufficient to keep all reactors at full power. Pump can be repaired while reactors are running at full power.

Capacity of remaining pumps sufficient to keep four or five reactors running at full power or all reactors running at reduced power. Pump repairs possible while reactors are muning.

Affected reactor and heat exchanger must be shut down and isolated from secondary system immediately. Remaining reactors can continue operating. Decontamination and repair must be accomplished prior to restarting affected reactor.

All reactors must be shut down. Repairs must be effected before any reactors start-up. 
enlargement and contraction head losses experienced in the common system undoubtedly make pumping power costs for this system slightly higher than those for the individual system but the difference is negligible. The cost of piping, valves, and fittings in both systems are approximately the same. The common system requires considerably larger diameter pipe in the main headers, but lises only about one-fourth as many Iineal feet of pipe as the individual header system. The sizes of valves and fittings are about the same for both systems since no valves are necessary in the main headers of the common secondary system.

\subsection{Selection of Cooling Tower Conditions}

Cooling tower capital and pumping power costs strongly favor the highest possible $\Delta T$ across the cooling tower. The rate at which a given cooling tower can reject heat to the atmosphere increases rapidly with increasing $\Delta T$ across the towerl. Therefore, larger $\Delta T^{\prime}$ 's across the tower result in lower cooling tower capital and pumping power costs per MW of heat rejected. However, standard cooling towers are so designed that a $700 \mathrm{~F} \Delta \mathrm{T}$ across the tower is almost all that can be expected. "On-tower" temperatures of greater than about $1600 \mathrm{~F}$ decrease considerably the life of the cooling tower.

Another factor strongly affecting capital costs per MW of heat rejected is the "approach $\Delta T$ " of the "off-tower" temperature to the maximum wet bulb temperature to be expected in the atmosphere surrounding the cooling tower. The heat rejection capacity of a given cooling tower increases rapidly With an increase in the "approach $\Delta T^{\prime \prime}$. Since the maximum "on-tower" temperature is limited to about $160^{\circ} \mathrm{F}$, it is necessary to make a judicious balance between the $\Delta T$ across the cooling tower and the "approach $\Delta \mathrm{T}$ ". This balance is simplified by the fact that the larger $\triangle T$ Ts across the cooling tower decrease pumping power costs as well as capital costs. In most systems, yearly pumping power costs exceed yearly capital amortization by a considerable amount.

A $70^{\circ} \mathrm{F} \triangle \mathrm{T}$ across the cooling tower is most nearly comparable With the AETR reactor heat removal conditions. Subtracting $70^{\circ} \mathrm{F}$ from the maximum permissable "on-tower" temperature of $1600 \mathrm{~F}$ sets the "off-tower" temperature at 900F. An "off-tower"

(1) From cooling tower data supplied by the Marley Company. Data available on request only by consent of the Marley Company. 
temperature of $90^{\circ} \mathrm{F}$ together with the maximum expected wet bulb temperature of 650F, set the minimum "approach $\Delta \mathrm{T}$ " at $250 \mathrm{~F}$. These conditions contribute to an extremely efficient and cheap heat disposal system. When the wet bulb temperature falls below $650 \mathrm{~F}$, considerable savings in pumping power costs may be achieved by maintaining the "ontowe $\mathrm{r}^{\prime \prime}$ temperature at $1600 \mathrm{~F}$ and increasing as much as possible the $\Delta T$ across the cooling tower. Velocities in the shell sides of the heat exchangers are sufficiently high at the design conditions that a considerable reduction in secondary coolant flow can be effected without appreciably lowering the heat transfer coefficients. 


\section{II.O REACTOR CONTROLS AND INSTRUMENTATION}

With several reactor test loops, a number of functional control combinations are apparent, assuming for this discussion that there is one reactor for each test $100 p$.

Based on practice at the MTR and the ETR, one can have a separate control room for control of each reactor, another separate control room for each experiment, and a third separate control for the process coolants of each reactor. The latter includes the instruments and equipment to control the primary and secondary flow rates, temperature levels, etc.

With several reactors, one can also combine the reactor controls to form what is termed here a common reactor control room for all the reactors. Similarly, one can form common experiment control and common process control rooms. This way three control areas operate the entire facility.

A third way to collect the controls is to combine the reactor, test loop, and process controls for each reactor in a separate area. This is termed a combined control room. Seven are needed for the AETR. form.

In the AETR, these variations can be shown in tabular

\section{Table $11 . a$}

Types of Possible AETR Controls

Scheme

a

$b$

$c$
Reactor

7 individual

1 common

\section{Process}

7 individual

1 common

7 combined
Test Loop

7 individual

1 common

The discussion which follows indicates that for the AETR the latter, scheme $c$, is definitely superior to the other two.

\section{1l.1 Individual Controls}

Individual controls result in considerable instrumentation duplicated throughout. Not only are there 21 control areas, but there must be very good communication between the three control areas associated with one test loop. 
The personnel for operation of such an arrangement are as follows. There must be one operator at each of the 21 control areas. With helpers provided for occasional relief and assistance, plus supervision, a minimum operating staff is 30 people. During shutdown, some of these operators will be available for other work.

Clearly this arrangement at best is no improvement over present reactor uperating practice. The expense of duplication of instruments in more than one area makes this scheme unattractive.

11.2 Common Control Rooms

It appears that there may be substantial economies in collecting similar controls into three common control rooms. The most obvious saving is in the capital cost for the facility. Common services such as telephones, alarms, and air conditioning contribute to the saving. Building layout and construction is probably simpler and cheaper even though greater lengths of instrumentation cable may be needed to connect control rooms with distant test loops.

The common control room permits a saving in operating personnel. While an operator is needed at each reactor control console, only two helpers are necessary to relieve all reactor operators. With a single supervisor, the common reactor control room needs ten men to operate it. Similarly, the common test loop control room on the same basis needs ten more men per shift. The process control room needs fewer people, about five per shift, since the control functions are simpler than they are for the test loops and reactors, with two supervisors this makes a total of 27 people required per shift.

The difficulty with the common reactor and test $100 \mathrm{p}$ control rooms is that they do not operate together. Since each reactor is separate, operating to suit its own experiment, the less interference the better. Putting controls for more than one reactor or more than one test 100 p in the same room is therefore a mistake. Audible alarms, for example, can be confused too easily to be worthwhile. A further disadvantage of the common control room is that it does little to relieve the burden of communication between the reactor, test $100 p$, and process water operators. It is thus not recommended, even though there may be a saving in the cost of construction of the facility.

\subsection{Combined Control Room}

The combined control room attempts to integrate all the controls for the reactor and test loop and process water of one 
reactor into a single unit in the same way that the reactor is physically designed around a single experimental test hole.

One advantage of the combined control room is that it improves the effectiveness of the facility. Experience at the MTR and ETR has been that most reactor shutdowns are due to the experimental loops. Hence it is likely that closer cooperation between the test loop and reactor controls should be helpful. Particularly during startup, the anticipation and coordination possible between operators who are physically close can be very helpful in decreasing the accidental shutdowns and subsequent unnecessary startups.

A further advantage of the combined control room is that it is simpler. For example, displays of reactor power, temperatures, etc., can be used by all the operators in the combined control room and duplication of instrumentation is avoided. Very little communication equipment is needed. In addition, a single control room can be located closer to its reactor than the common control rooms can. This is an advantage during reactor service.

With a reactor engineer and two technicians for normal operation and two supervisors, a total staff of 24 men is needed to operate the seven reactor test loops. This is less by a small amount than the number of men needed to operate either of the other two schemes. However a significant advantage in operating efficiency is realized.

11.4 Conclusion

There is little difference between the capital, operating costs, or personnel for the three schemes. In effectiveness, the combined control room for each reactor clearly surpasses the other two. On the basis of better control, the combined control room concept is selected for the AETR. 


\subsection{GENERAL ARRANGEMENTS}

The reactor selection studies resulted in a number of reactor facility concepts as well as various core designs. The best arrangements are compared on the basis of their loop capability, control feasibility, design and construction, and operating characterisitcs.

12.1 Descriptions

The four most promising reactor facility arrangements are described below. All the facilities envision a site plan like that of Figure 8.A in Part $A$ and all facility differences occur within the main reactor building.

\subsubsection{Composite Reactor Facility}

The seven annular flux-trap cores are arranged symmetrically, 30 inches center-to-center in a large pressure vessel filled with $\mathrm{D}_{2} \mathrm{O}$ as reflector, and comprise what is termed the "composite" reactor. This arrangement is shown in Figure 12.C.

This core, like all those following, is enclosed in a pressure vessel beneath a pit normally filled with water as a bulk shield. To reload the core or replace an experiment, a cover plate from the head of the reactor vessel, or the head itself, is removed using the water as both a shield and as a coolant to remove the decay heat.

A large working area is provided at the level of the top of the reactor pool. A crane suitable for coffin handing and the removal of heavy equipment such as the reactor head is also provided. In order to simplify experiment handling, a working and storage canal connects with the pool of water above the composite reactor.

This scheme is shown in Figure $12 . A$. The reactor room of the buildirg is very large (108'x 150'). This is primarily to furnish sufficient space in the basement for the seven test loop equipment rooms. These rooms must be large to be useful and preferably are shielded from one another so that the equipment maintenance can be accomplished even if adjacent loops are operating with highly radioactive test loop coolants.

The control room extends across the building as a long room $25^{\prime} \mathrm{x} 164^{\prime}$. This shape is used since a coordinated single reactor control room with the test loop controls in the same room is desirable.

The heat exchanger room is next to the control room, but on the side away from the reactor room. It contains all the 
reactor heat exchangers. The room is heavily shielded with concrete, but sections of the side wall can be removed if removal of heat exchangers is necessary. Heat exchangers on one side are suitable since with one composite core a common primary coolant system is used.

The amplifier room is beneath the control room and is the same size as the control room. It contains the power supply equipment for the control room as well as pump motor circuit breakers, transformers, and the electrical distribution system for the entire building. In addition, the amplifier room can serve as a maintenance corridor. This is shown in the vertical elevation, Figure 12.B.

The pump room is beneath the heat exchangers. The pumps are in separetely shielded cubicles to facilitate individual maintenance when necessary during reactor operation. The room beneath the loop equipment room is for D2O storage, cooling, and cleanup. It may be used for test coolant dump tanks and other auxiliary purposes.

\subsubsection{Common Shield Reactor Facility}

A similar building arrangement, with an almost identical vertical section, is used for the common shield reactor concept. The reactors are completely separate and are arranged in a circular array with centers about 14 feet apart. Each reactor is located beneath a separate pool of shielding water and each pool connects with a common storage canal by means of a removable bulkhead.

The plan for this arrangement is shown in Figure 12.D. The basement beneath the reactor room is used for experimental loop equipment rooms. Separate control rooms are employed along both sides of the reactor room. This permits the loop and reactor controls to be located together and personnel in each control room can observe the reactor area during reactor servicing.

The heat exchangers associated with each reactor are placed adjacent to it. The arrangement permits use of combined control rooms in which all controls and instruments associated with one reactor, its test $100 p$, and its process systems are contained.

12.1.3 Single Shield Reactor Facility

In order to enjoy the benefits of separate reactors, separately shielded reactors were studied. 
The essential difference of this reactor facility from the preceding one is that the seven reactors are separately shielded in the various reactor rooms, but the shields are adjacent to opposite sides of the wall between each pair of reactor rooms. As shown in Figure 8.E, Part A, this permits a saving in the shield concrete while separating the reactors effectively in every operational and reactor physics sense.

A second feature in which the single-shield facility differs from the one described previously is that each pair of reactors shares a storage canal. This T-shaped canal passes beneath a partially submerged partition which acts as a gas-tight vapor seal. It is also accessible from a general access area between the two rows of reactors.

Since this concept is the one selected for the AETR, it is further illustrated in Part $A$ by Figures $8 . B, 8 . C$ and $8 . D$

\subsection{Test Loops}

Each of the three arrangement concepts described can be used with either the through-tube or thimble-type loop tubes. (See chapter 8.0). All of the facilities permit a sub-pile room if necessary. The composite reactor may have some arrangement difficulty with seven through-tubes connecting to test loops in a small region beneath the reactor, but this is not a serious problem.

\subsection{Reactor Control Schemes}

Due to the close nuclear interaction between individual cores of the composite reactor, the individual cores cannot be shut down separately. In the composite reactor both the chemical and mechanical control systems are more difficult to install and operation is less satisfactory.

For the other reactor concepts, where there is 24 inches of $\mathrm{D}_{2} \mathrm{O}$ around each core, either control rods or the reflector shim and safety control combination can be used.

12.4 Design and Construction

All the schemes described are feasible to design and build if construction practice and capability are the only criterion. None of them requires unusual techniques. The composite reactor pressure vessel is 10 feet in diameter, but presents no unusual manufacturing problems since a thickness of $1.5-2$ inches (at $300 \mathrm{psi)}$ is sufficient assuming proper thermal shielding.

The buildings for the composite, common shield and single shield reactor have main floor areas of 31,$500 ; 49,200$; and $52,500 \mathrm{sq}$ ft respectively. These indicate that appreciable 
savings in building costs may be realized through construction of a composite reactor fac1lity.

With only $2 \%$ of the facility cost in the shielding concrete, the differences in shielding cost of the separate, singleshield reactors, and those reactors in common shields are very small.

12.5 Conclusion

The proportion of the reactor facility occupied by the reactors is small in any arrangement. All three arrangements described require large shielded areas for the test loop equipment. All can accommodate either the through-tube or the thimble-type loop tube. Each arrangement is reasonable and practicable for construction.

The one area where arrangement enters into selection between the various concepts is in their relative versatility. The composite reactor can only be serviced when shutdown as a whole. This obviously results in more down time than is required by the other arrangements.

From a feaslbility and versatllity point of view, the composite reactor is unacceptable since separate shutdowns of individual cores are 1 mpracticable. The remaining two, i.e., the common shield and the single, separately-shielded designs, are acceptable on most counts. The containment of contamination plus better isolation from a reactor operational aspect indicates a preference for the single shield design. 
Figure 3.A. Model for Radial Reactor Calculations

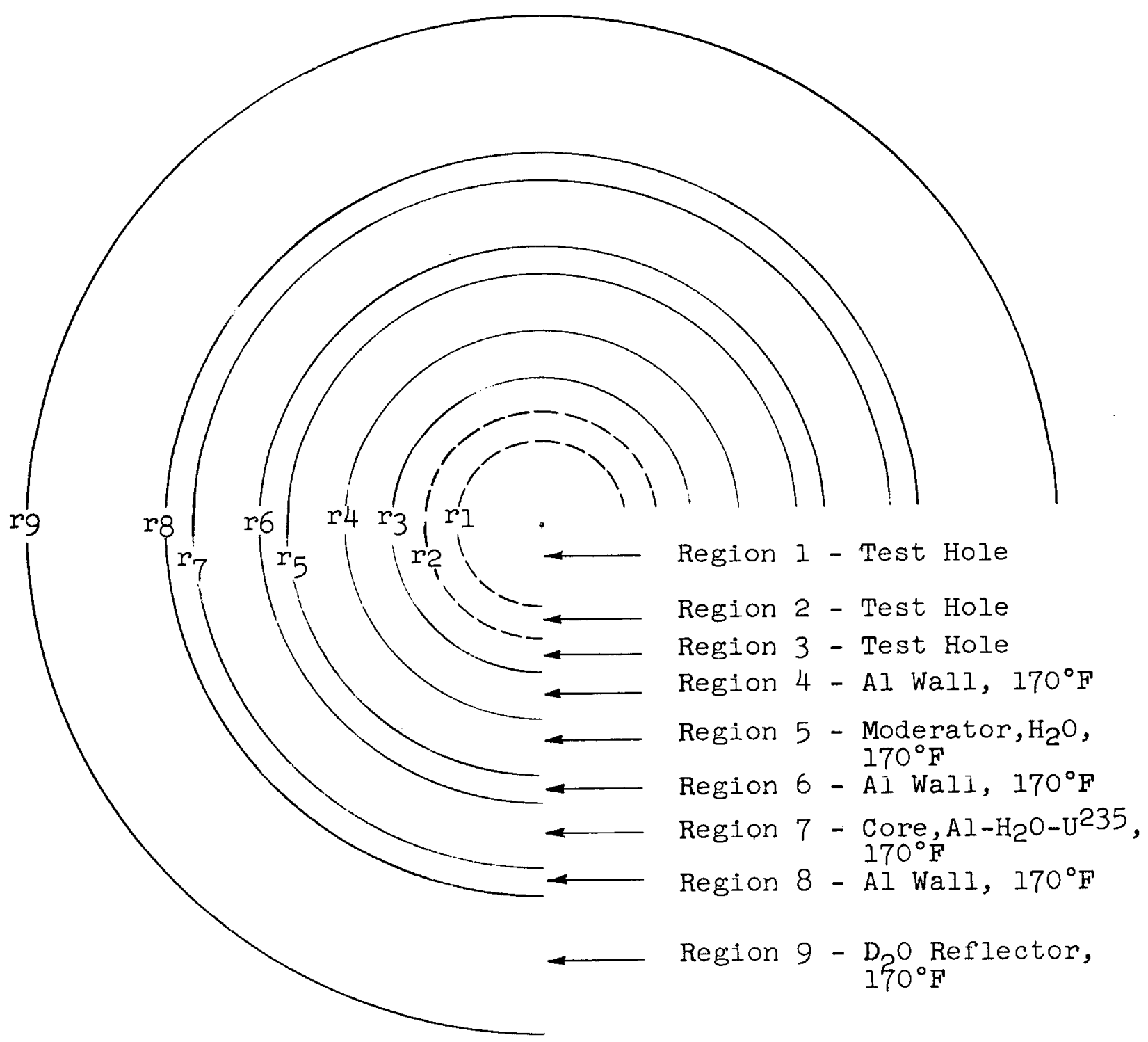

Fig 3.A 
Figure 3.B Effects of Core Thickness on Average Thermal Neutron Flux in the Test Hole

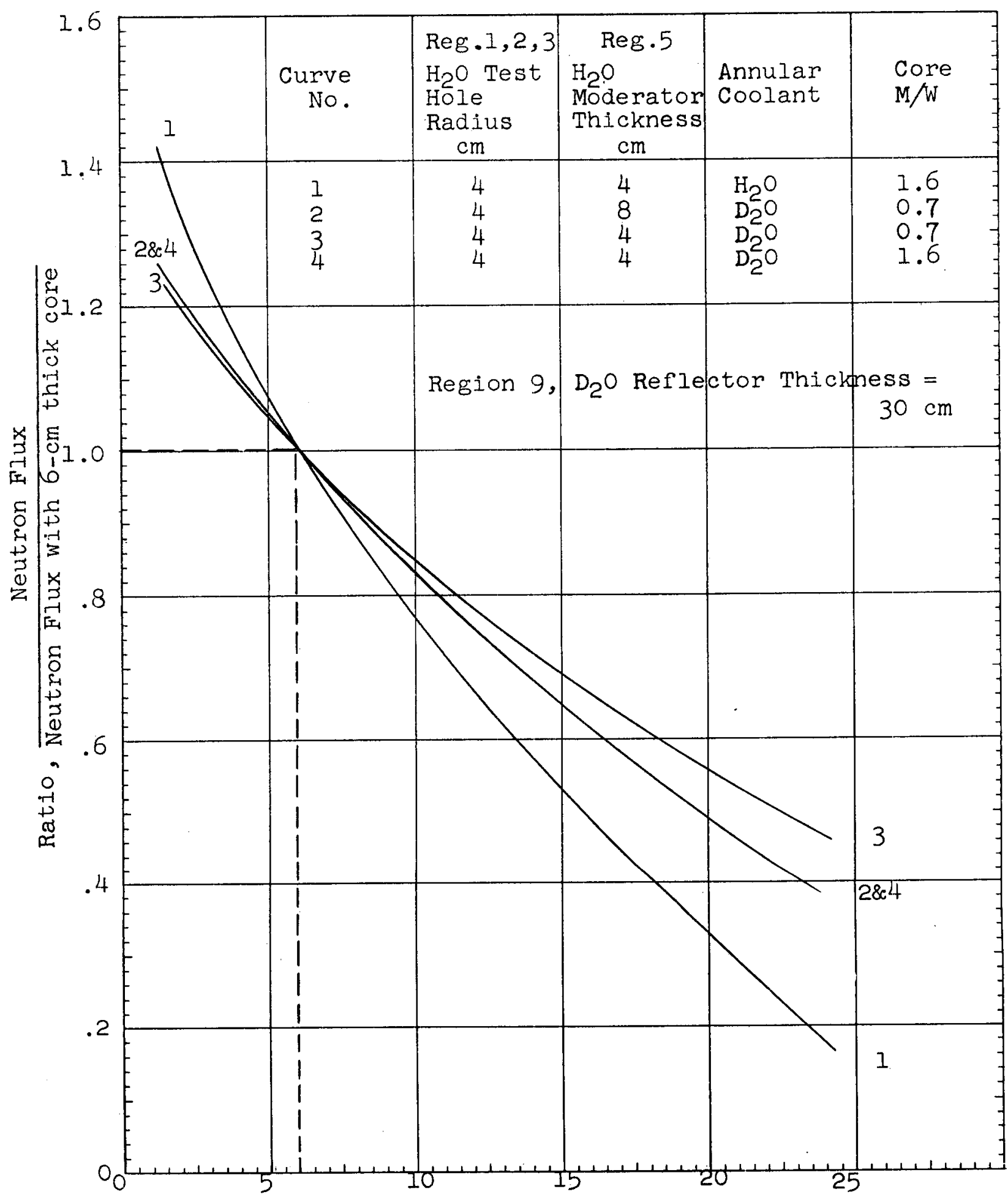

Thickness of Core, $\mathrm{cm}$.

Fig. $3 \cdot B$ 
Figure 3.C The Effects of Metal-Water Ratio on Average Thermal Neutron Flux in the Test Hole for Various Reactor Arrangements

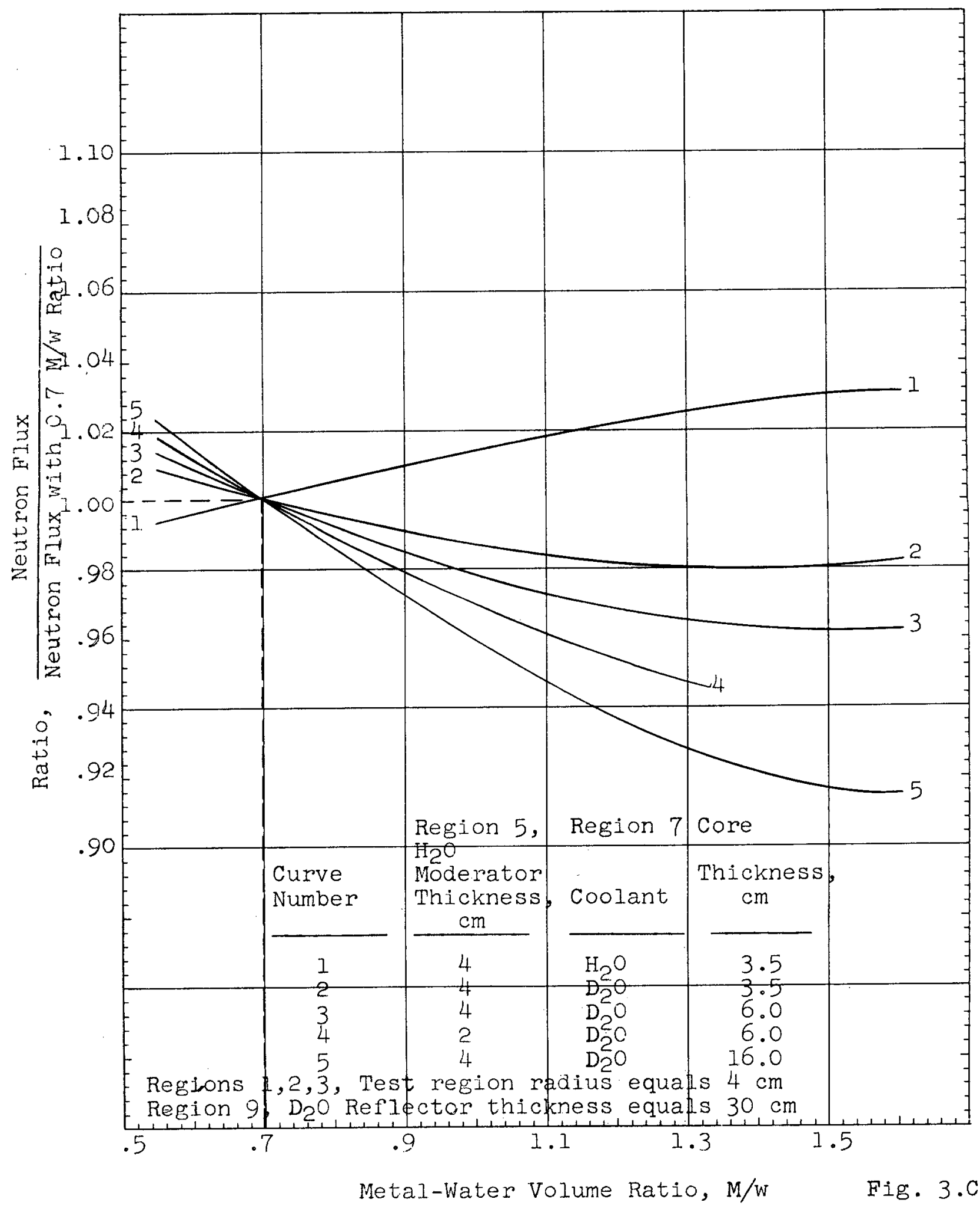


Figure 3.D Effect of $\mathrm{H}_{2} \mathrm{O}$ Moderator Annuius Thickness on Average Thermal Neutron Flux Test Holes in Empty and Sodium-Filled Test Holes

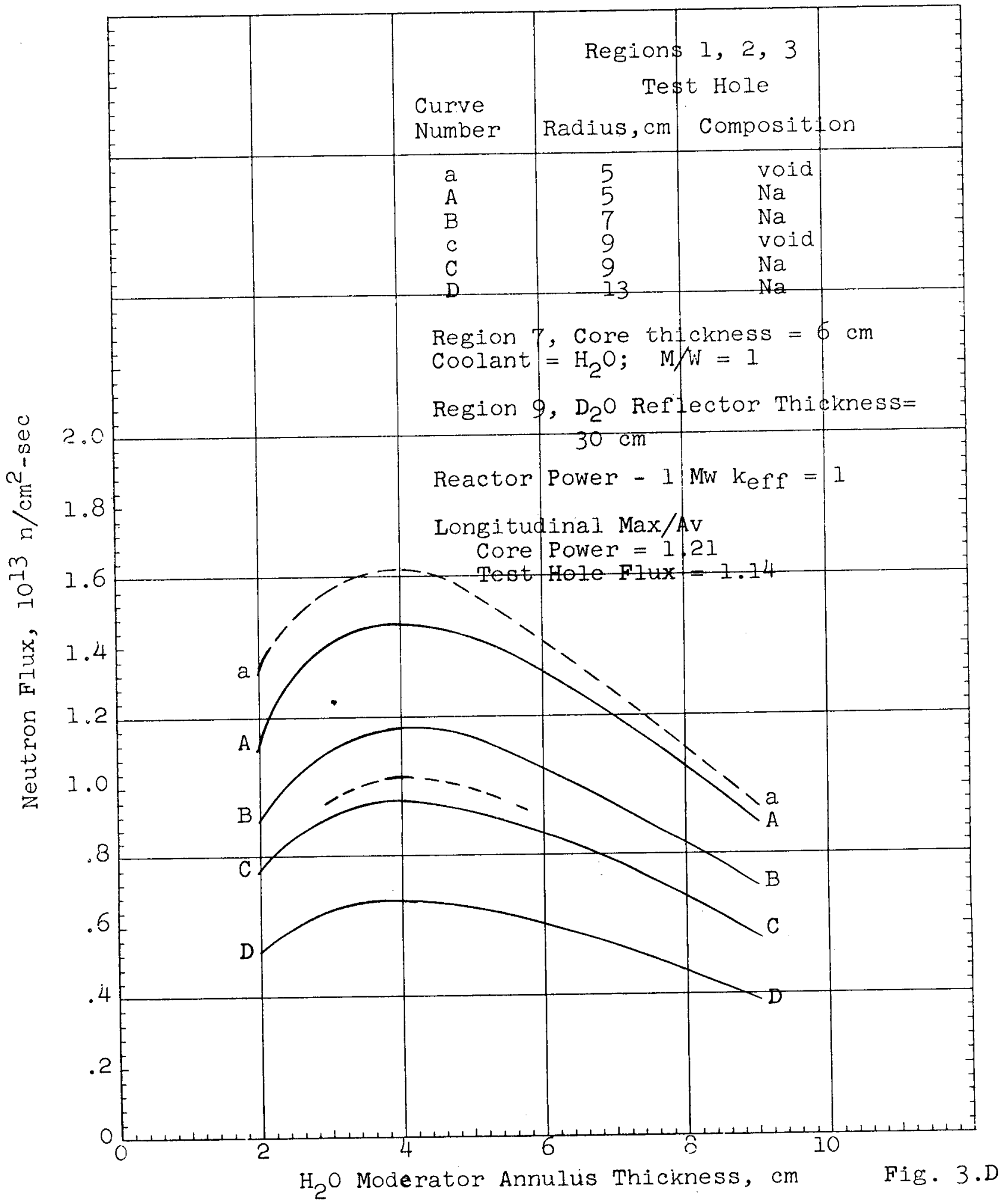


Figure 3.E Effect of Test Hole Radius on Average Thermal Neutron Flux in Empty and Sodium-Filled Test Holes

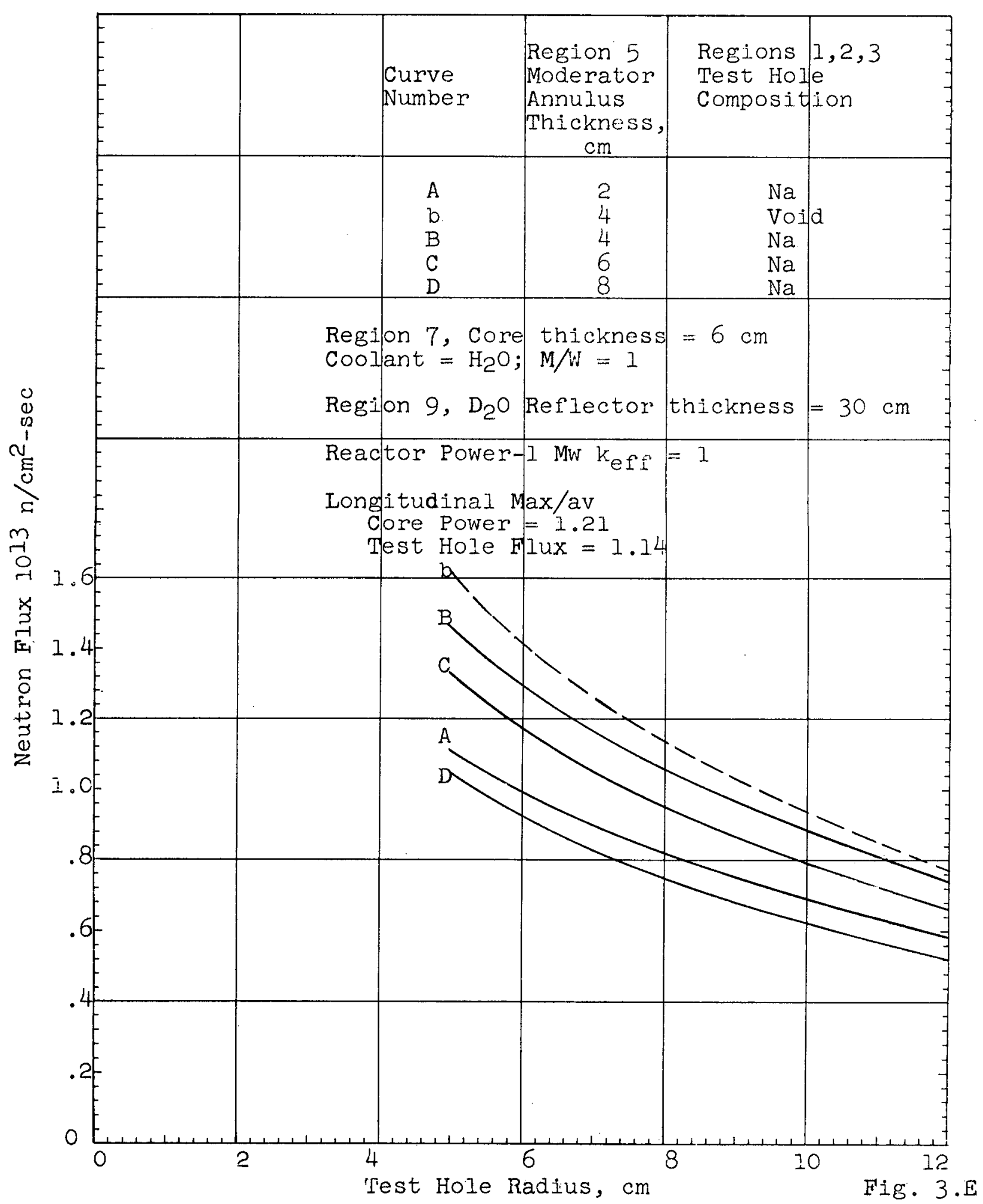


Figure 3.F Effect of $\mathrm{H}_{2} \mathrm{O}$ Moderator Annulus Thickness on Average Thermal Neutron $\mathrm{Flux}$ in $\mathrm{H}_{2} \mathrm{O}-\mathrm{Filled}$ Test Holes

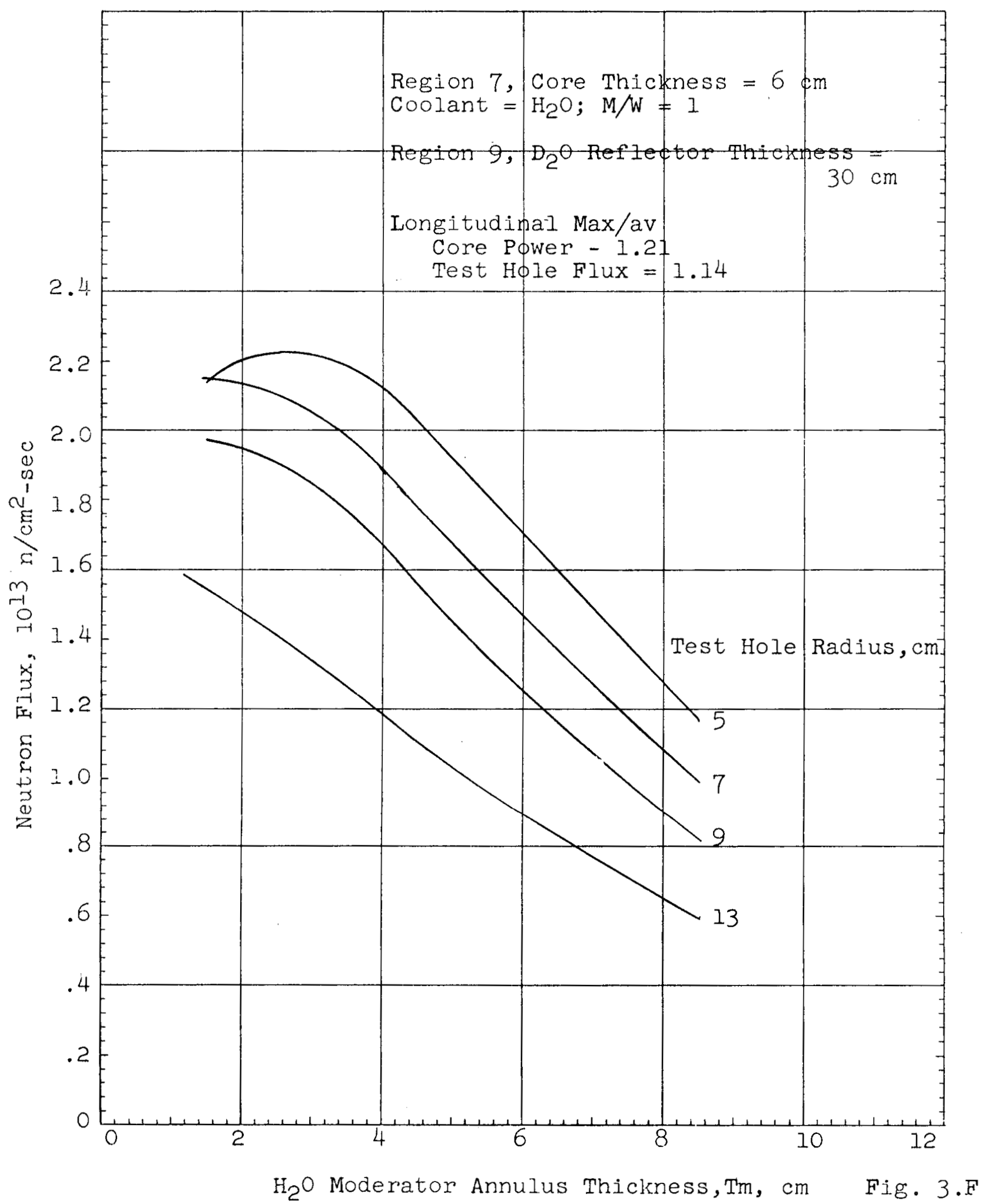




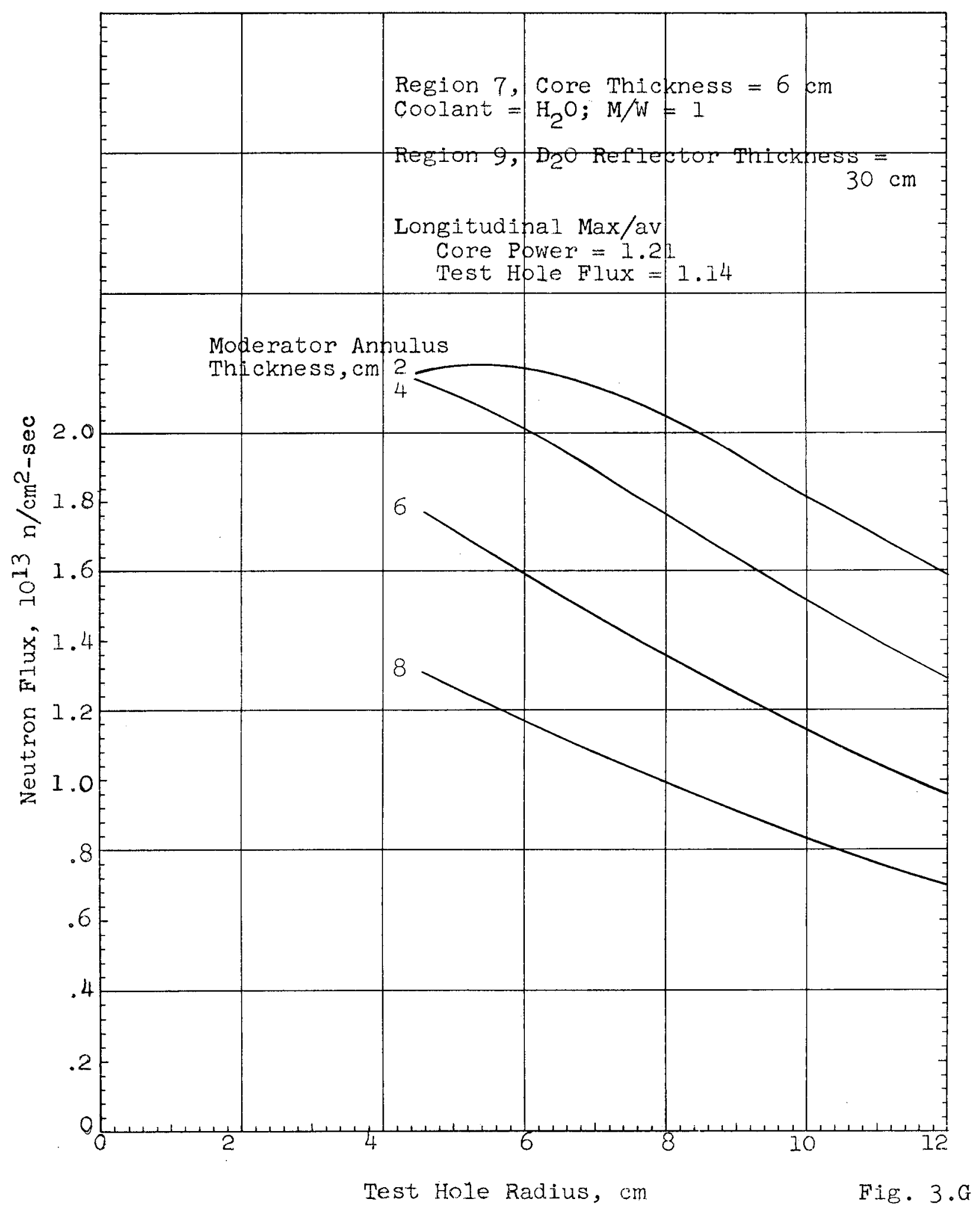



Figure 3.H Variation of Radial Average-to-Maximum Thermal
Neutron Flux with $\mathrm{H}_{2} \mathrm{O}-\mathrm{Fill}$ led Test Hole Radius

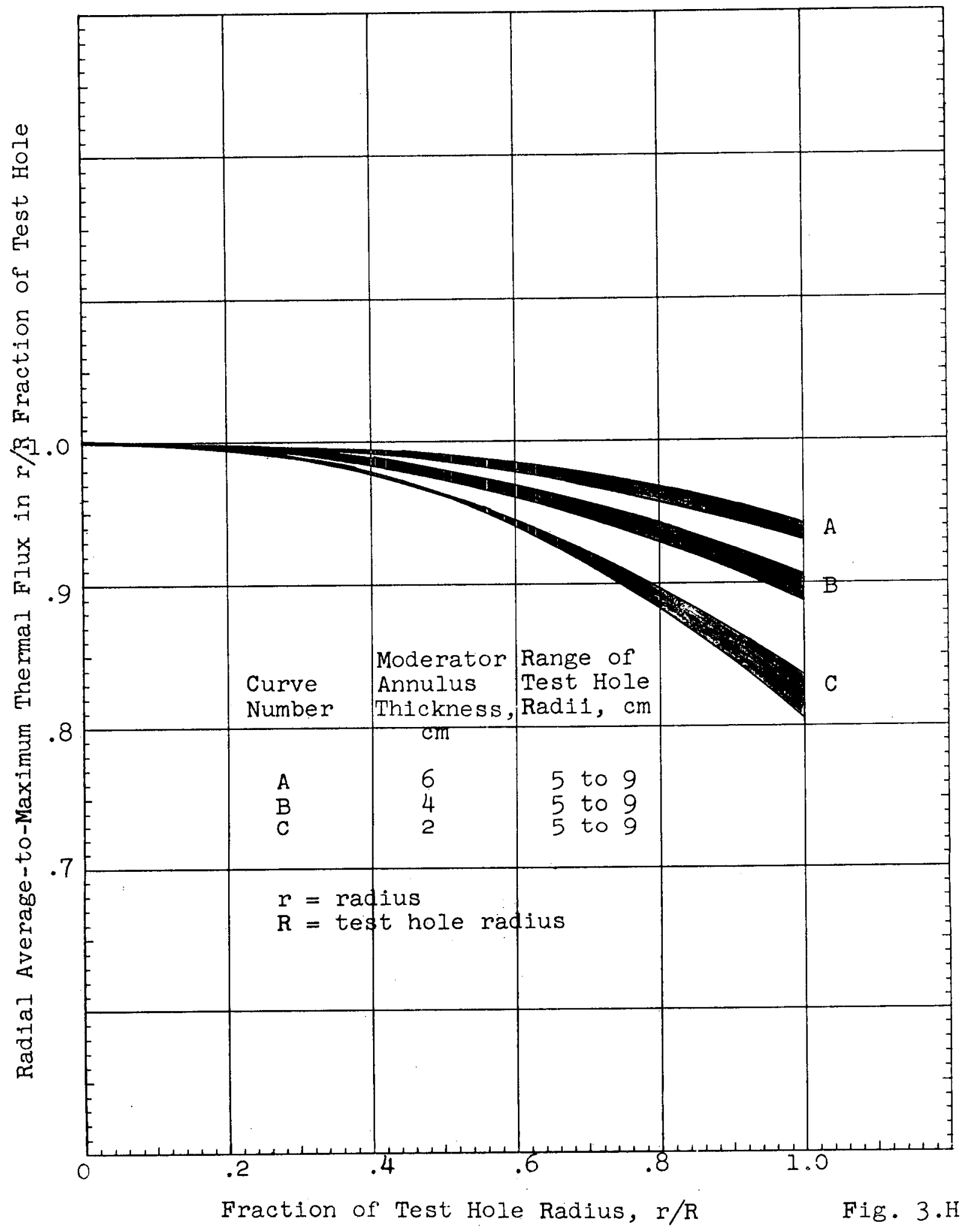


Figure 3.I Effect of Moderator Annulus Thickness on Reactivity for Constant Fuel Concentration in Core

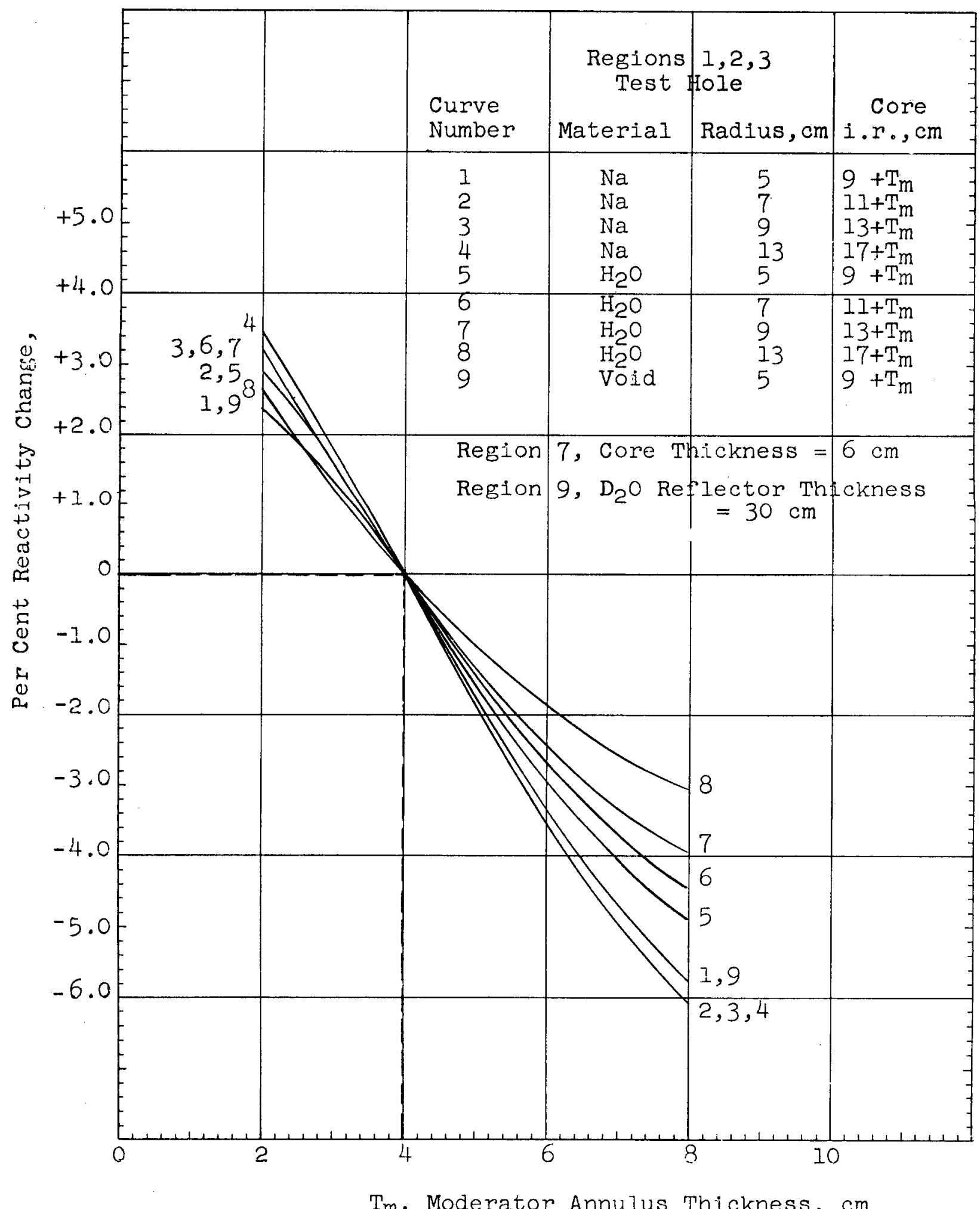

Fig. 3.I 
Figure 3.J Effect of Core Absorption Cross Section on Average Thermal Neutron Flux in Empty and SodiumFilled Test Holes

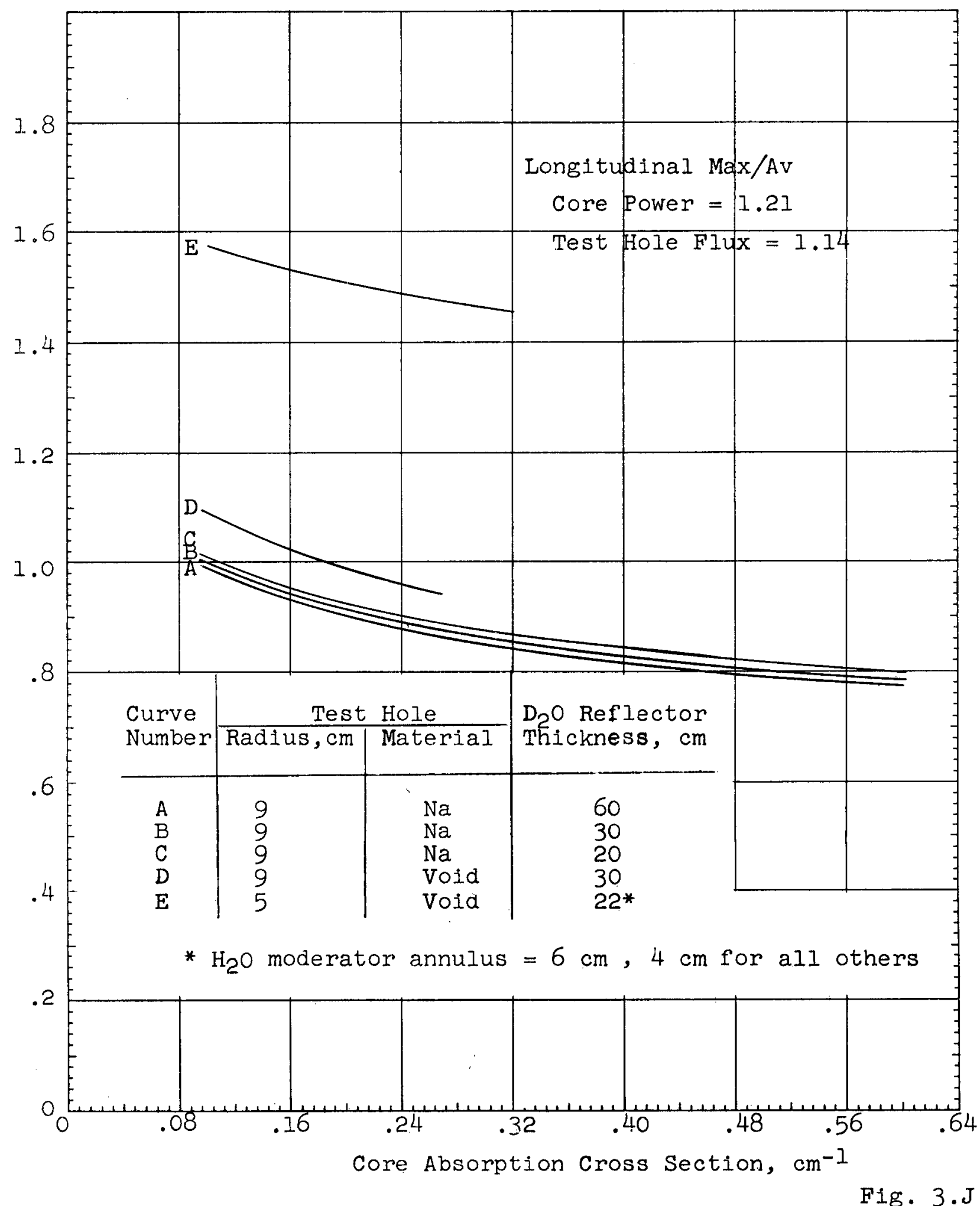


Figure 3:K Variation of Core Thermal Macroscopic Absorption Cross Section with Fuel Concentration

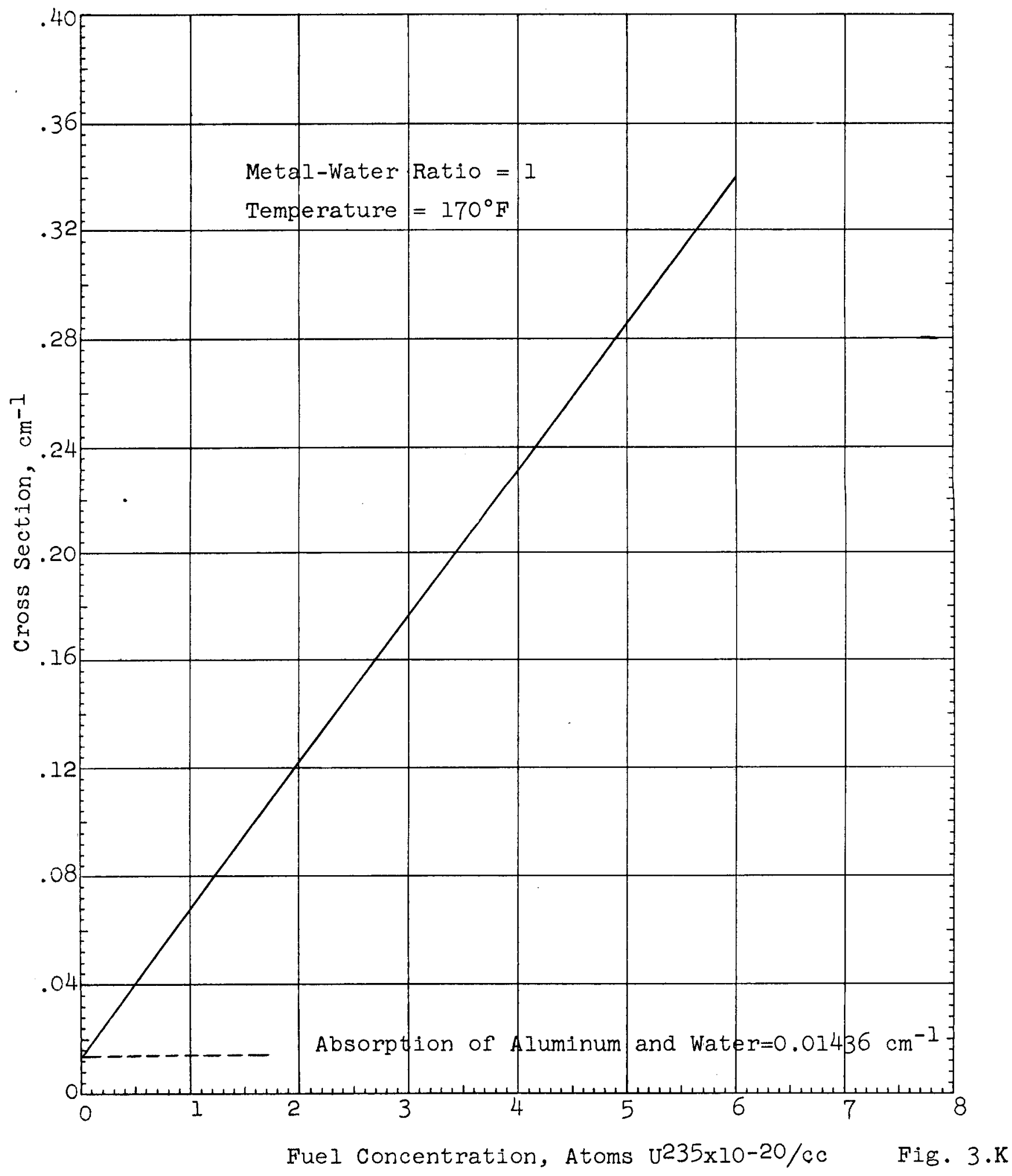


Figure 3.L Variation of the Effective Multiplication Factor with Reflector Thickness and Fuel Loading for a 9-cm Test Hole

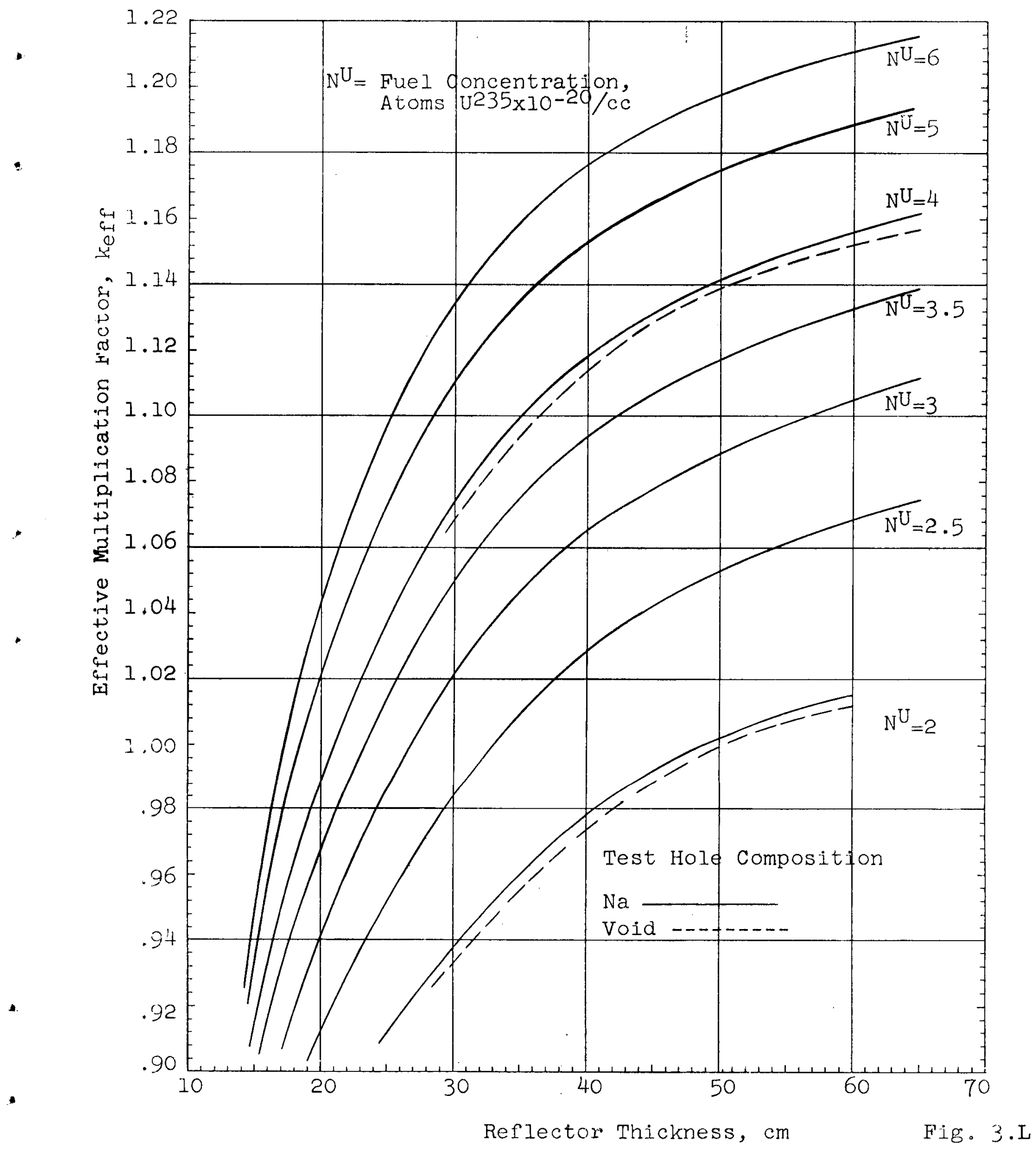




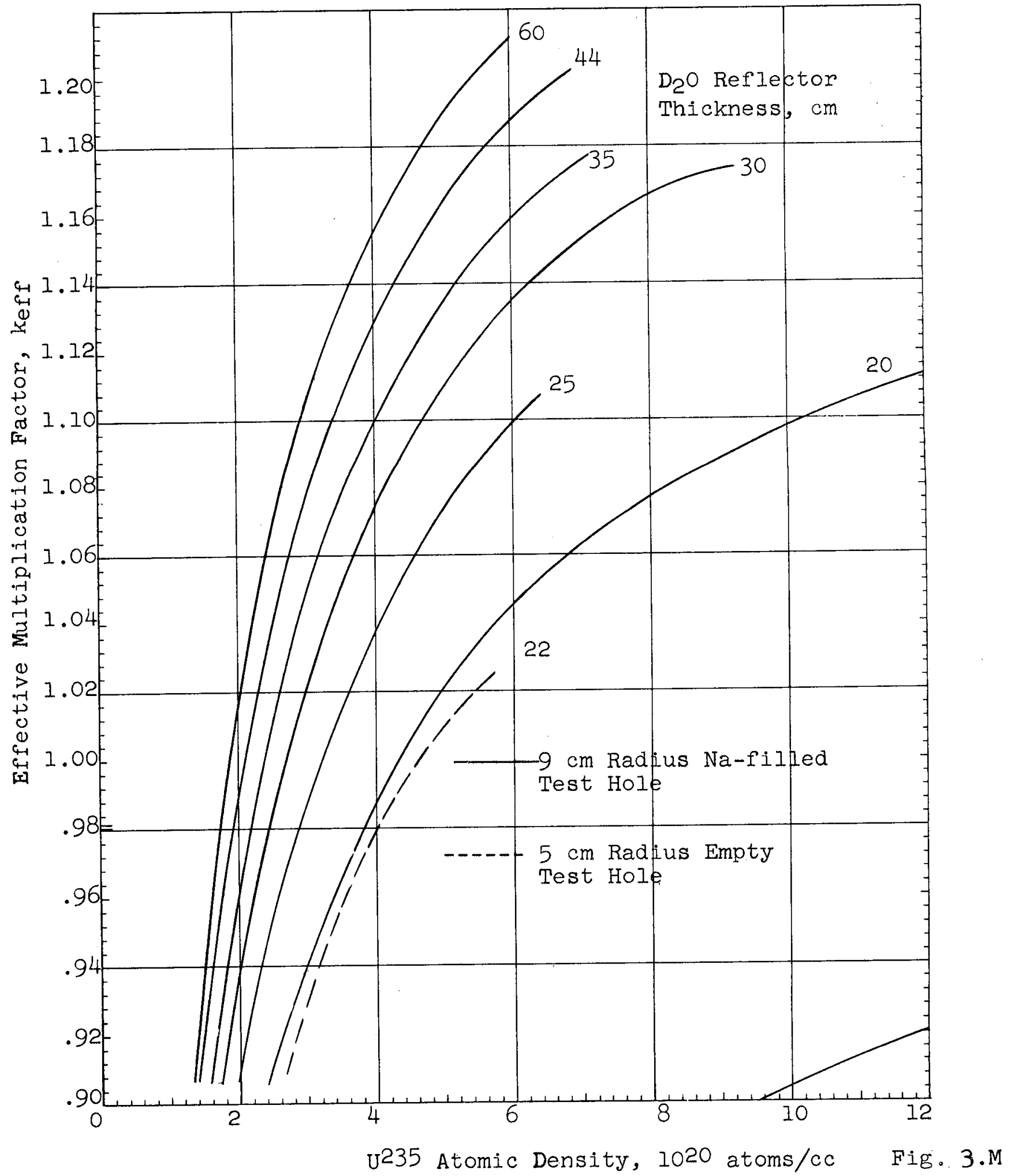


3.N Radial Thermal Neutron Flux Distribution at Midplane in Type-A Reactor Using Different Reflector Control Methods

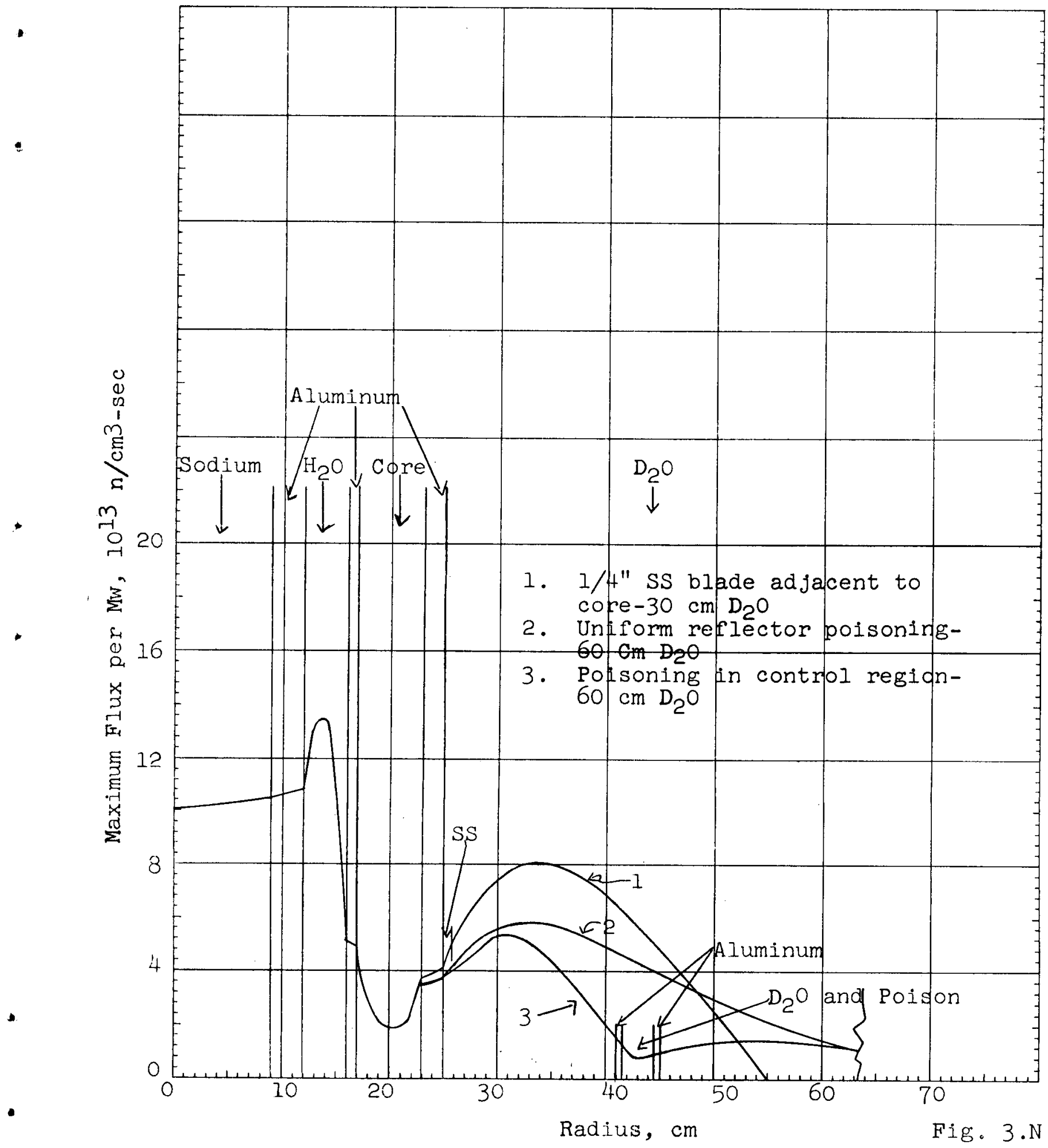


Figure 4.A Heat Transfer Film Coefficient versus Channel Gap

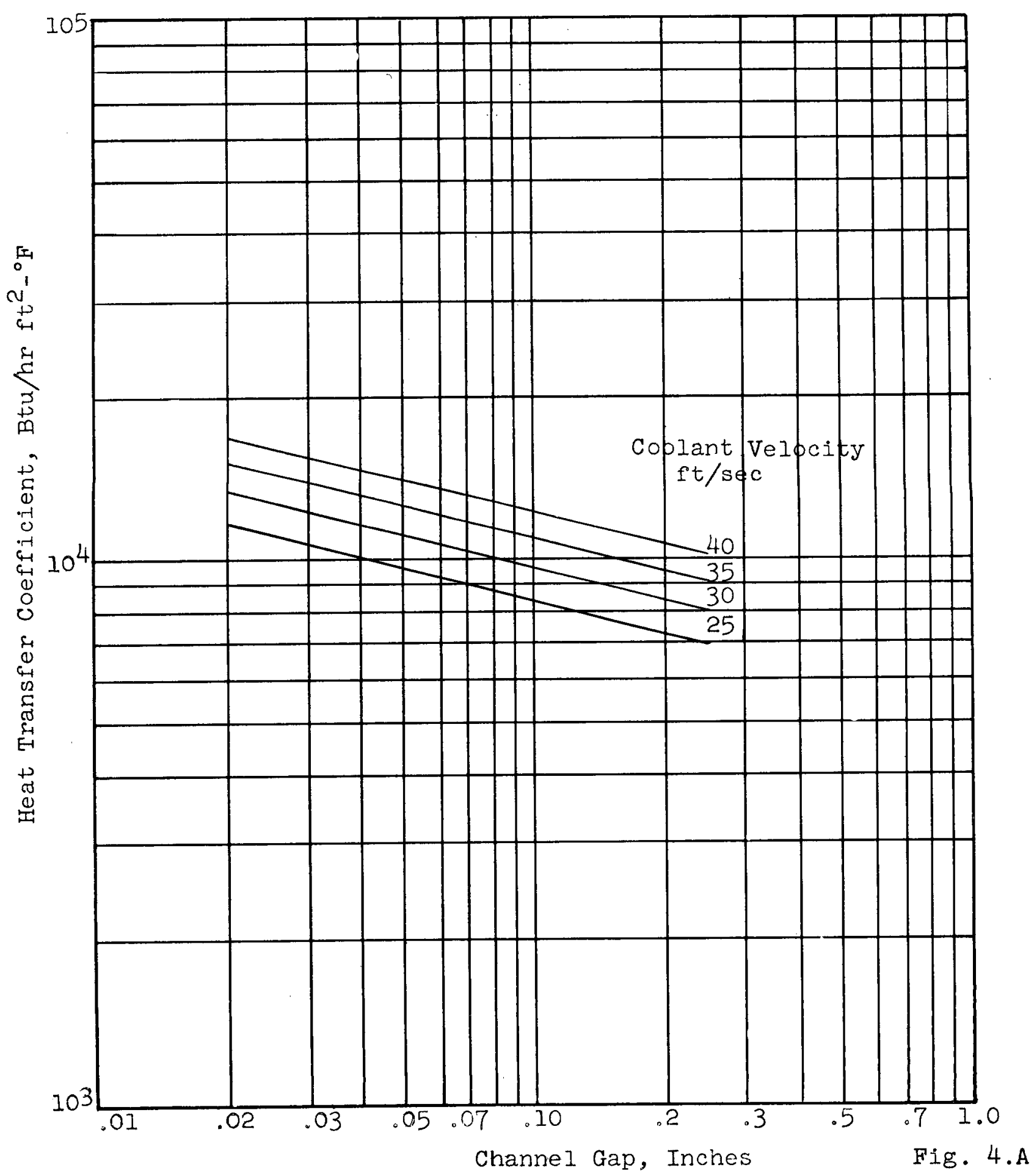


Figure 4.B Reactor Core Frictional Pressure Drop versus Channel Gap

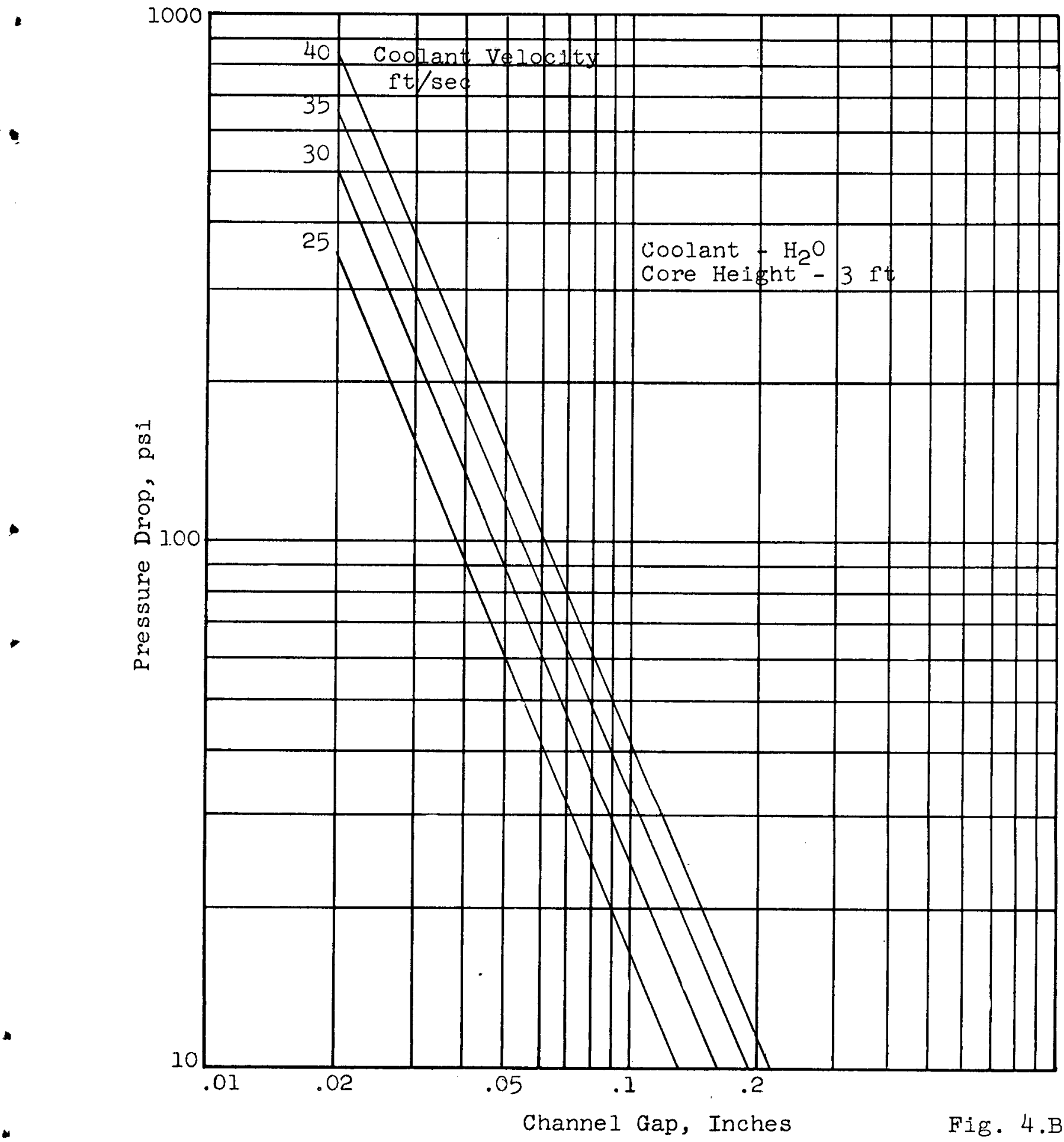



Figure 4.C Reactor Core Entrance $\left(\Delta \mathrm{P}_{c}\right)$ and Exit $\left(\Delta \mathrm{P}_{e}\right)$
Pressure Drops versus Metal-to-Water Ratio

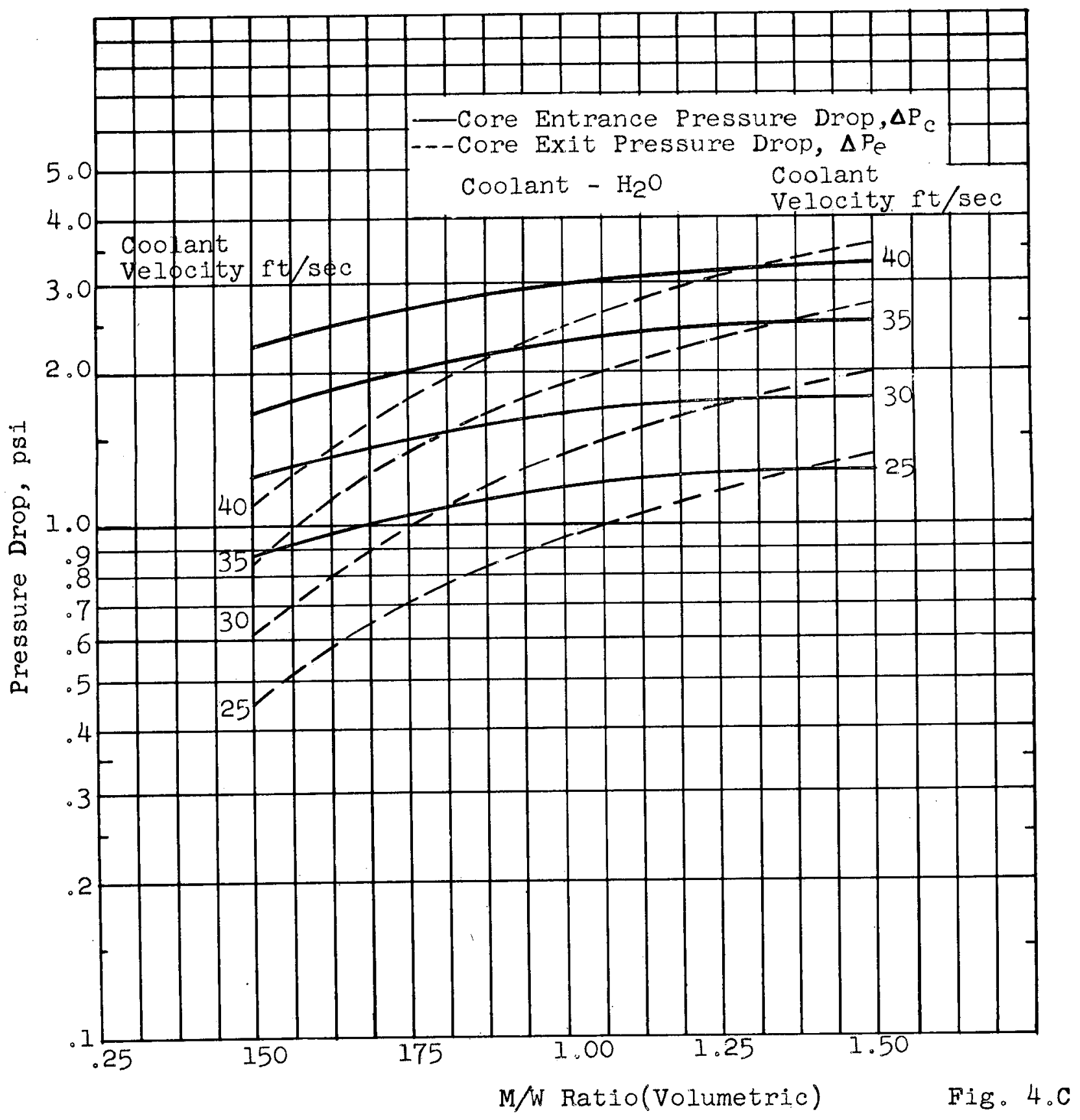


Figure 4.D Reactor Core Friction Pressure Drop to "Hot Spot" versus Channel Gap.

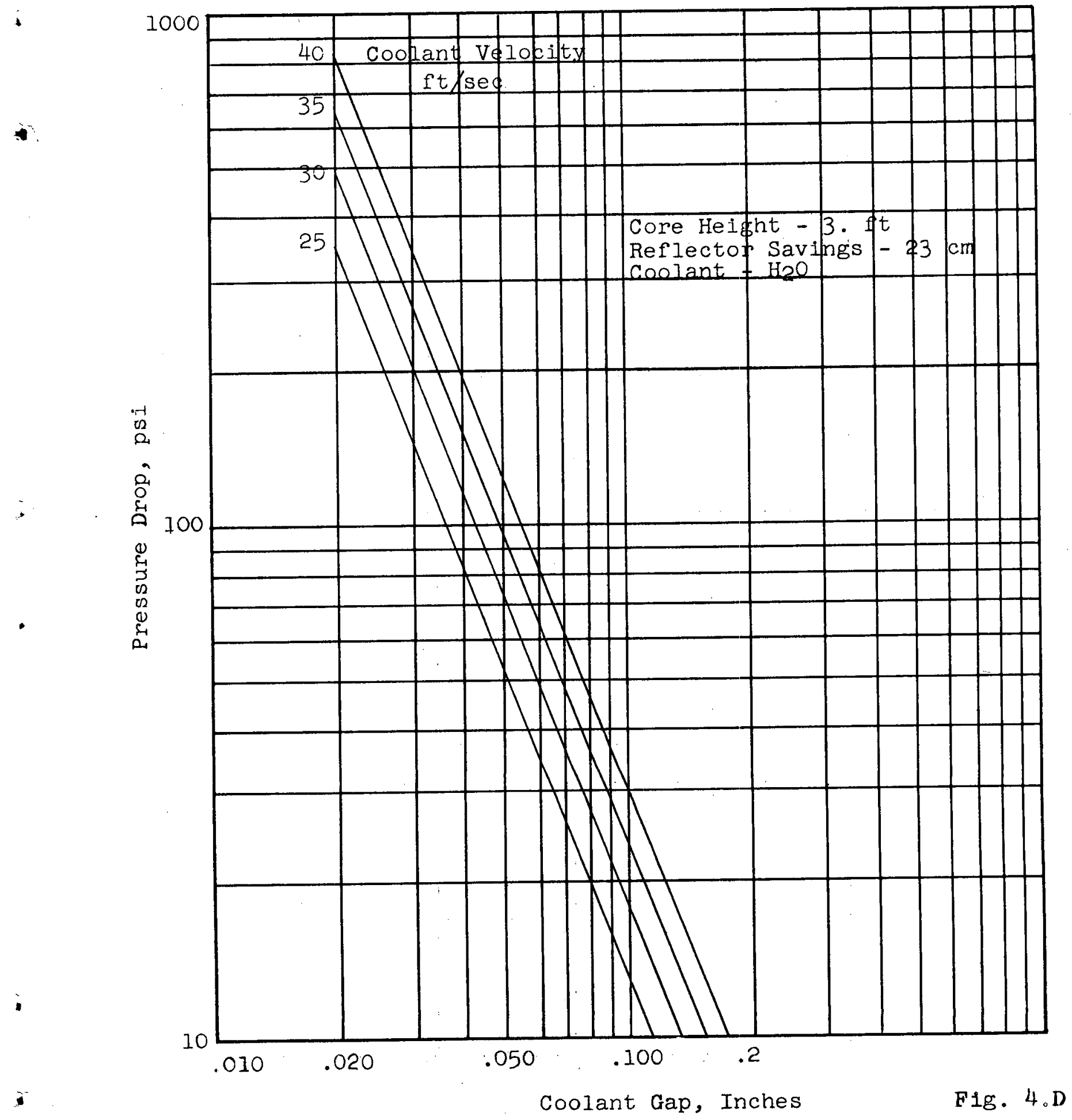


234

Figure 4.E Maximum Fuel Plate Surface Temperature versus Coolant Velocity

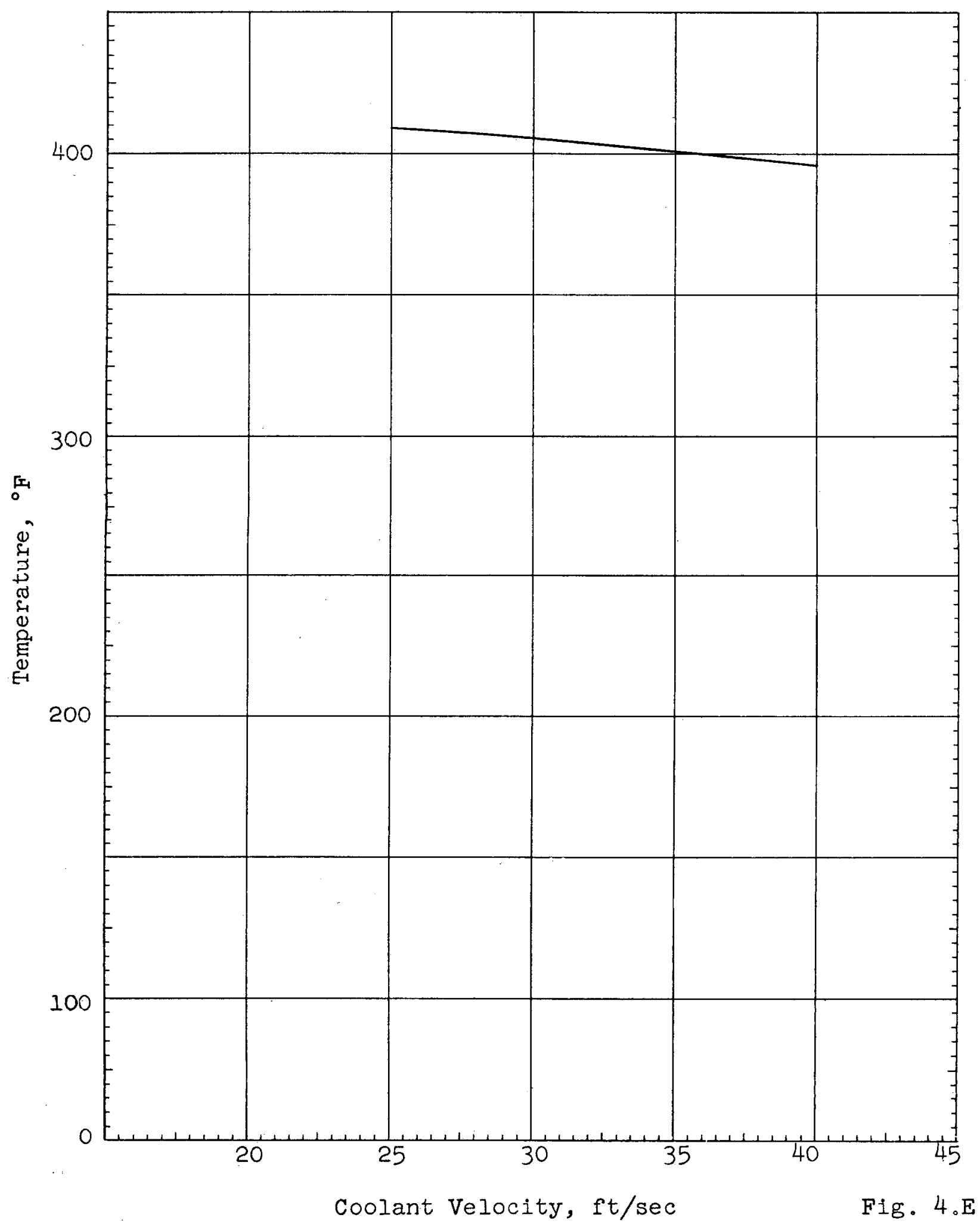


Figure 4.F Maximum Permissible Power Density versus Channel Gap $-\mathrm{H}_{2} \mathrm{O}$ at $30 \mathrm{ft} / \mathrm{sec}$.

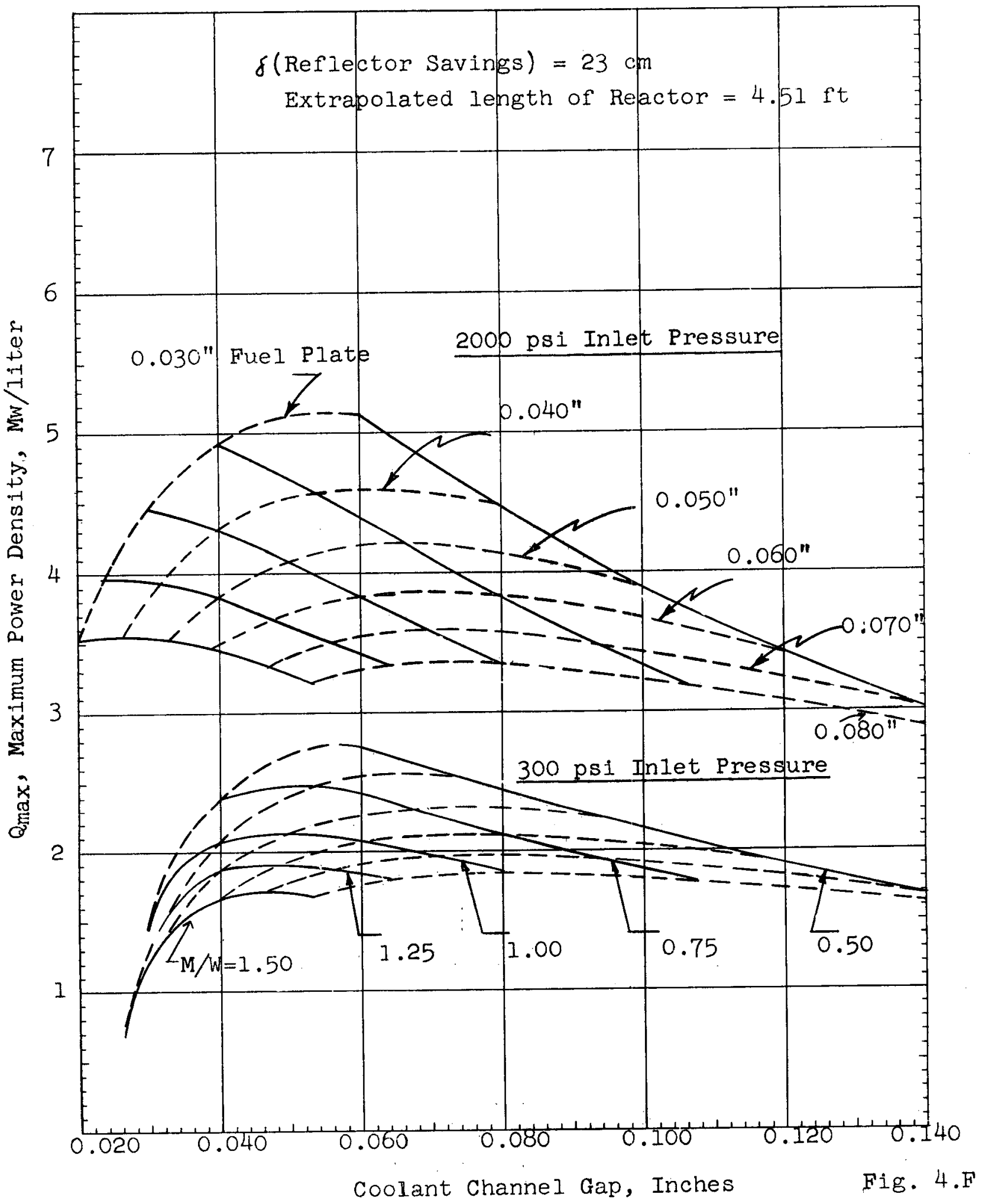


Figure 4.C Maximum Permissible Power Density versus Channel Gap $-\mathrm{H}_{2} \mathrm{O}$ at $35 \mathrm{ft} / \mathrm{sec}$

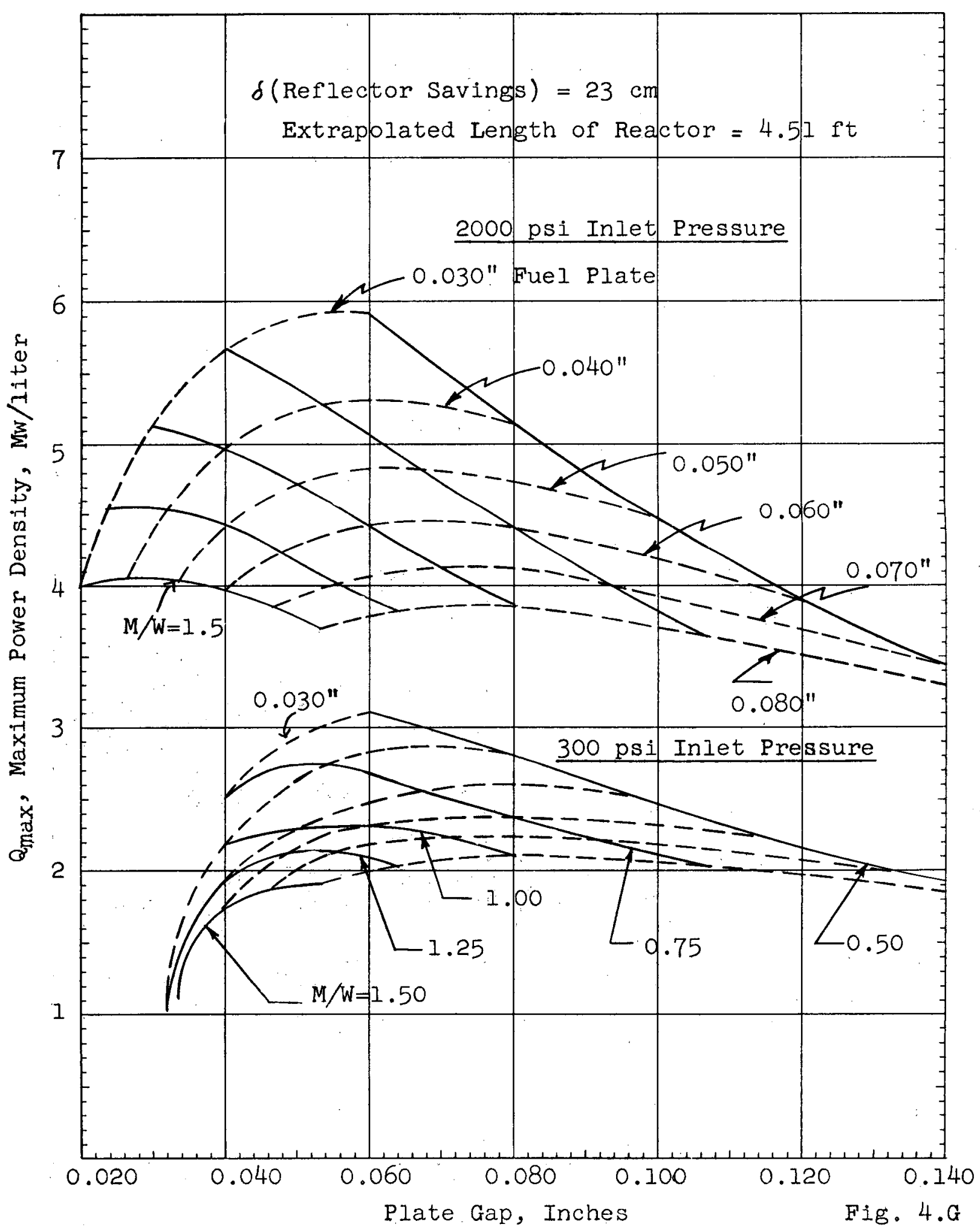


Figure 4.H Maximum Permissible Power Density versus Channel Gap - $\mathrm{H}_{2} \mathrm{O}$ at $40 \mathrm{ft} / \mathrm{sec}$

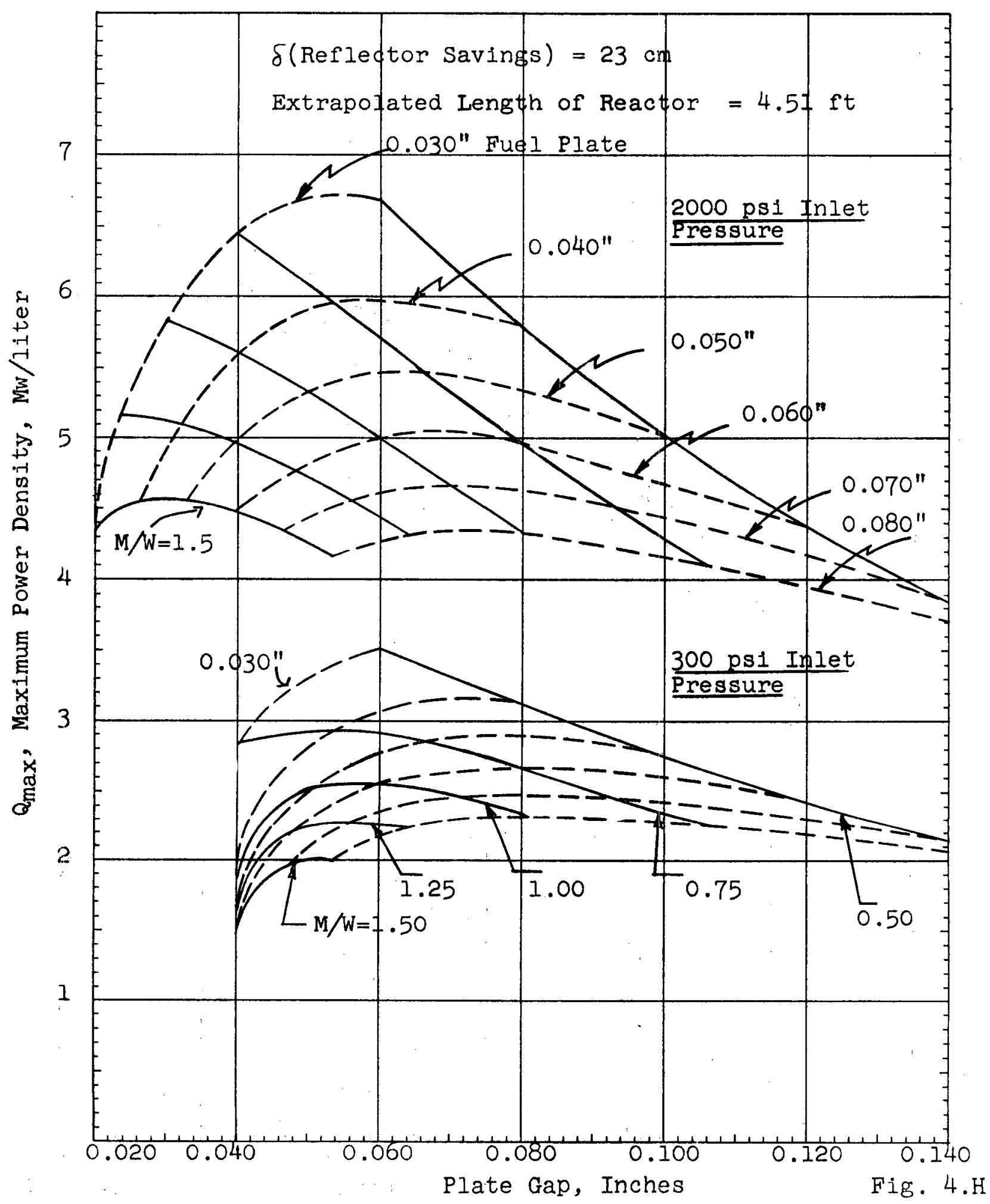


Figure 4.I Fuel Plate Surface Temperature versus Coolant Pressure with Nucleate Boiling Heat Transfer

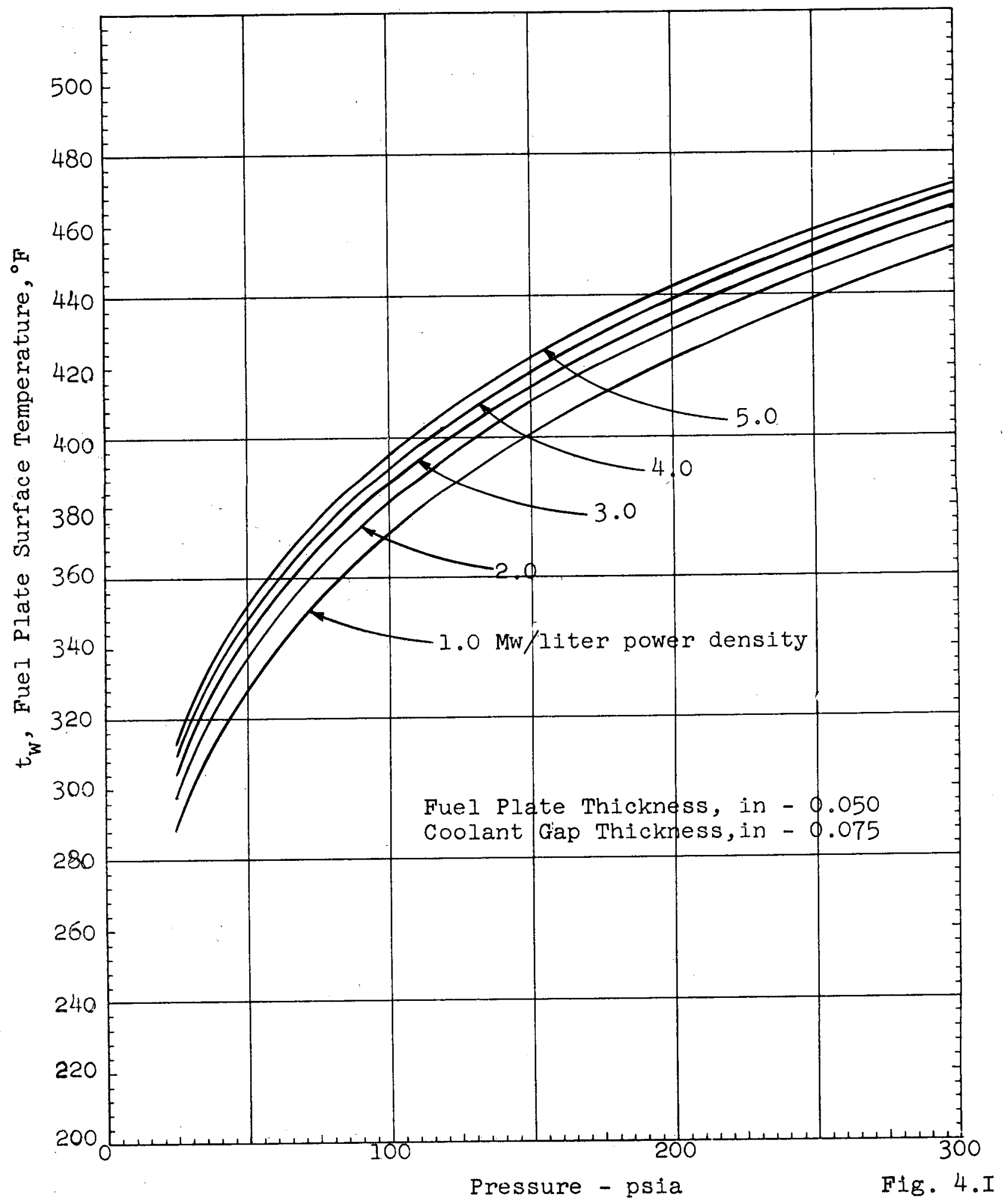




\section{Figure 4.J Burnout Power Density versus Coolant Pressure}

$\ominus$

$\cdot$

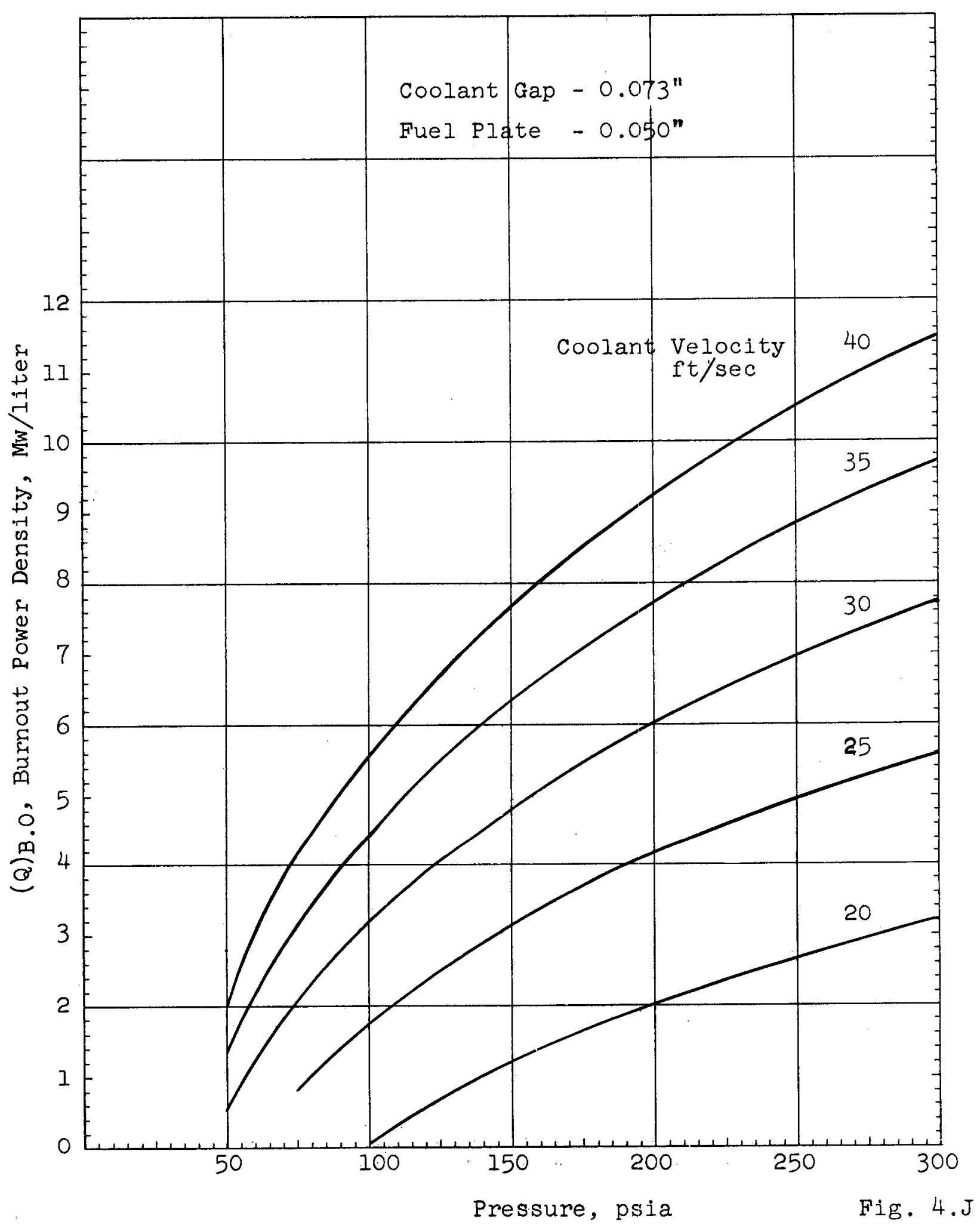


Figure 4.K Axial Power Density and Burnout Power Density Profiles

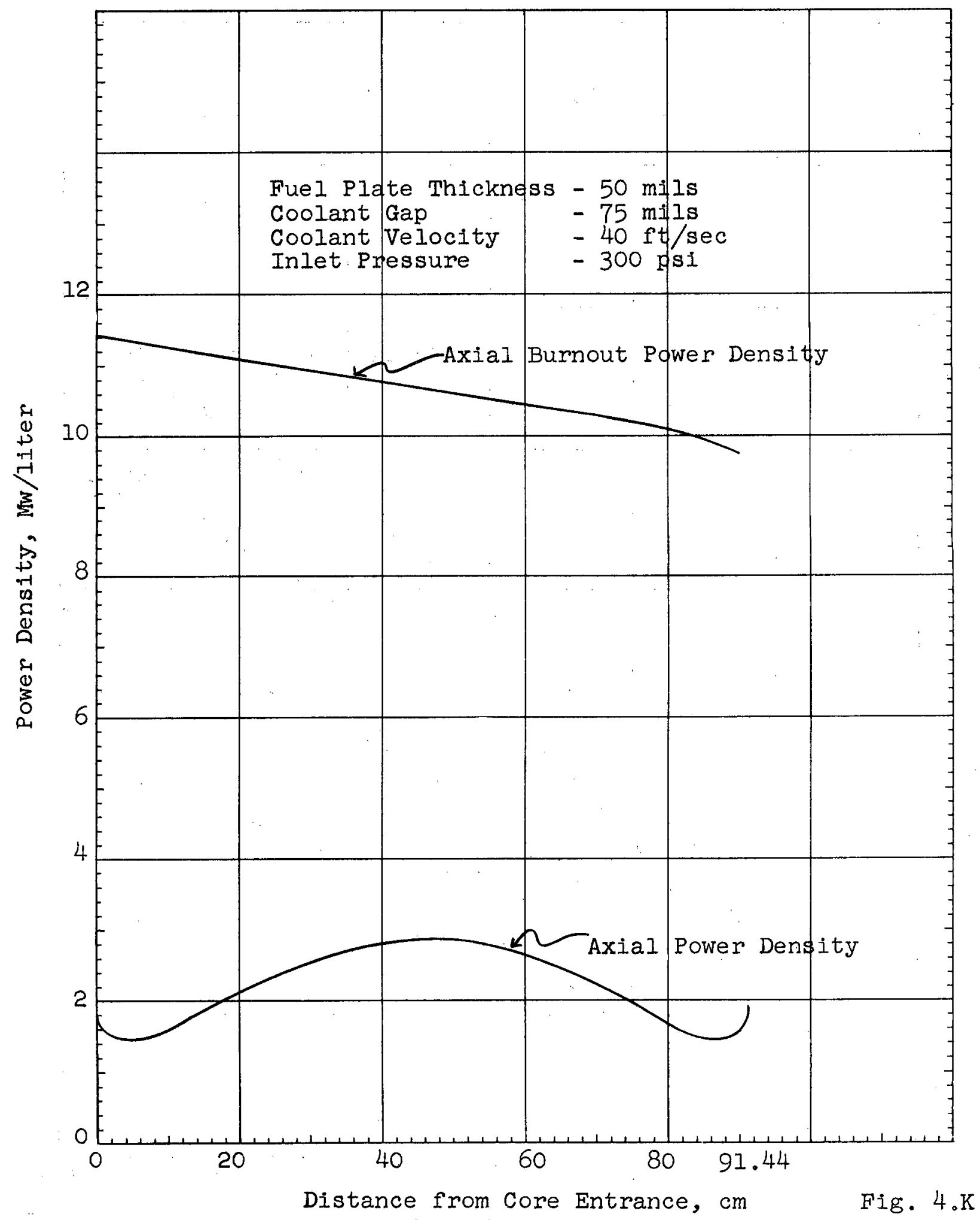


Figure 5.A Involute Plate Fuel Assembly

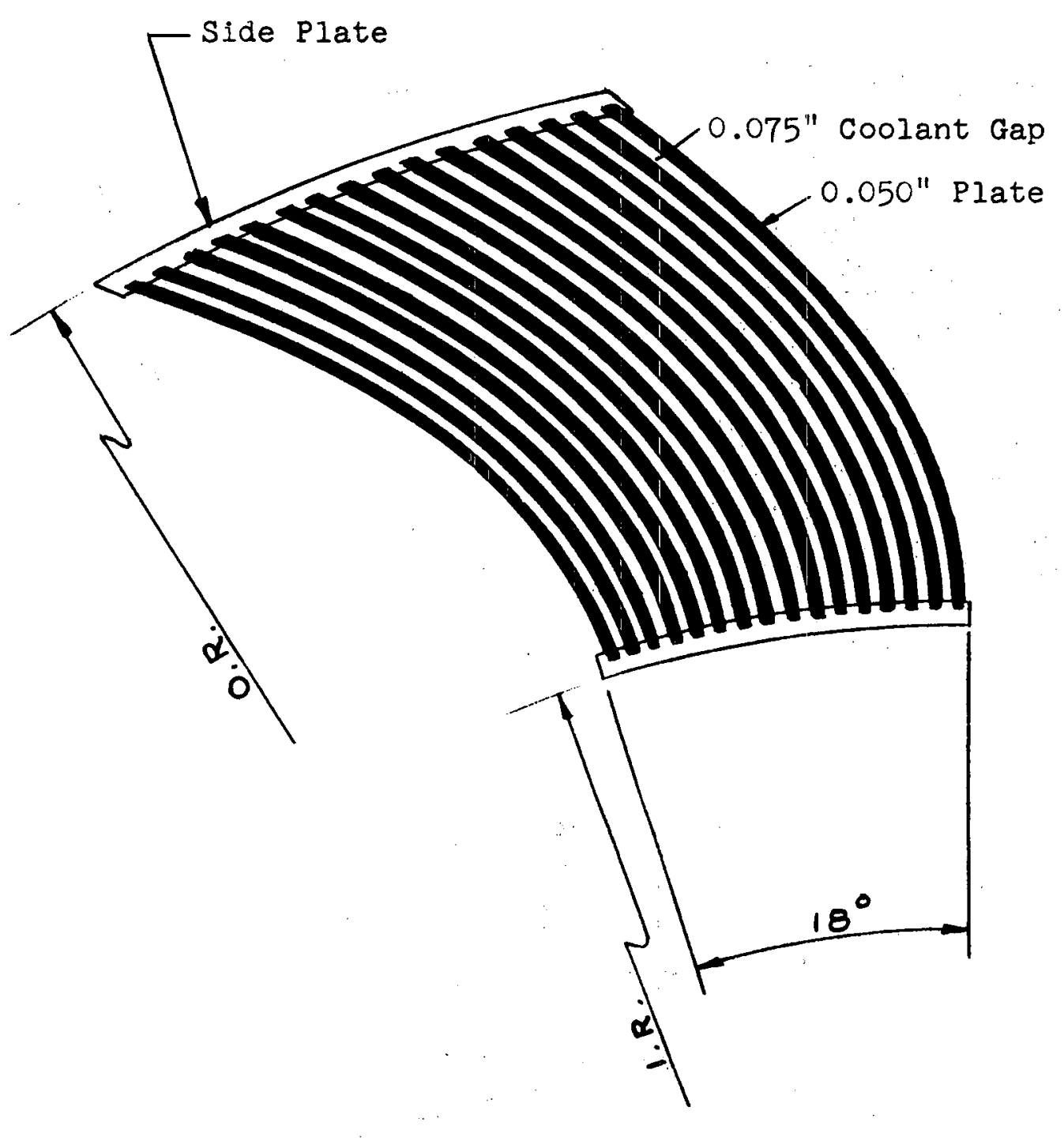

Fig. 5.A 
Figure 5.B Tubular Fuel Assembly

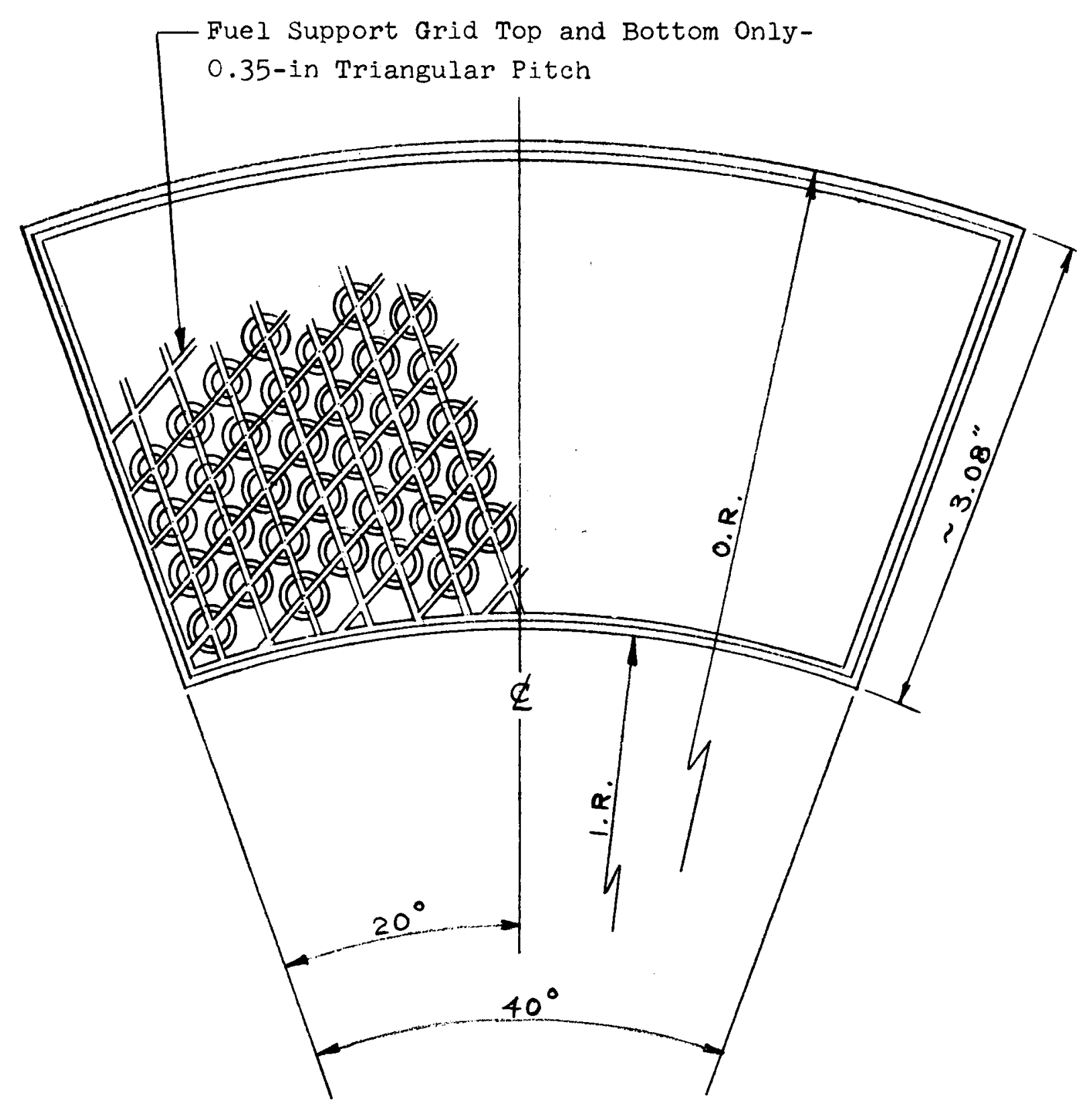

Fig. 5.B 
Figure 5.C Circular Segment Fuel Assembly

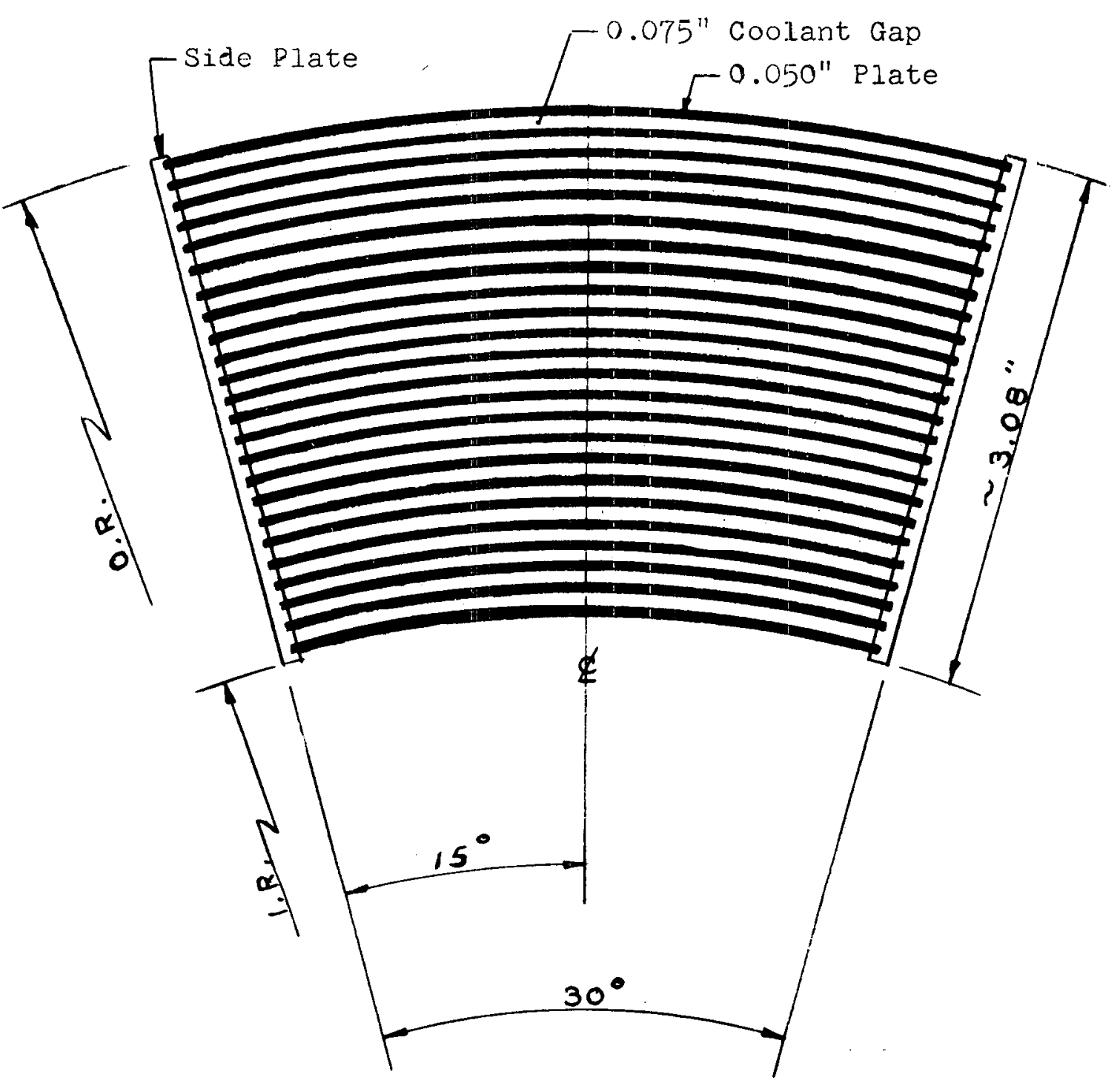




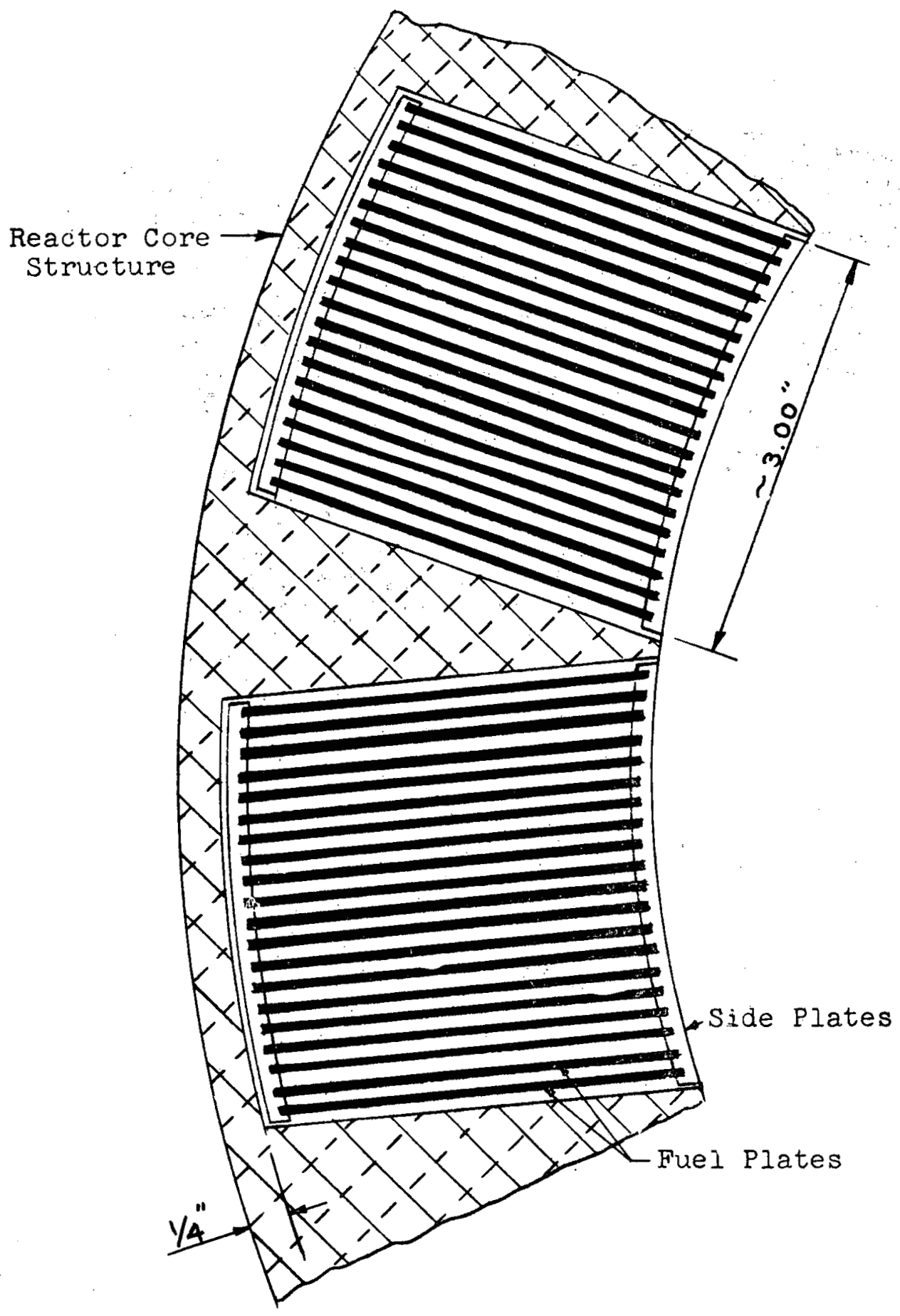

Fig. 5.D 
Figure 5.E Cross Sections of Pinned and Roll-Swaged Involute Plate Fuel Assembly
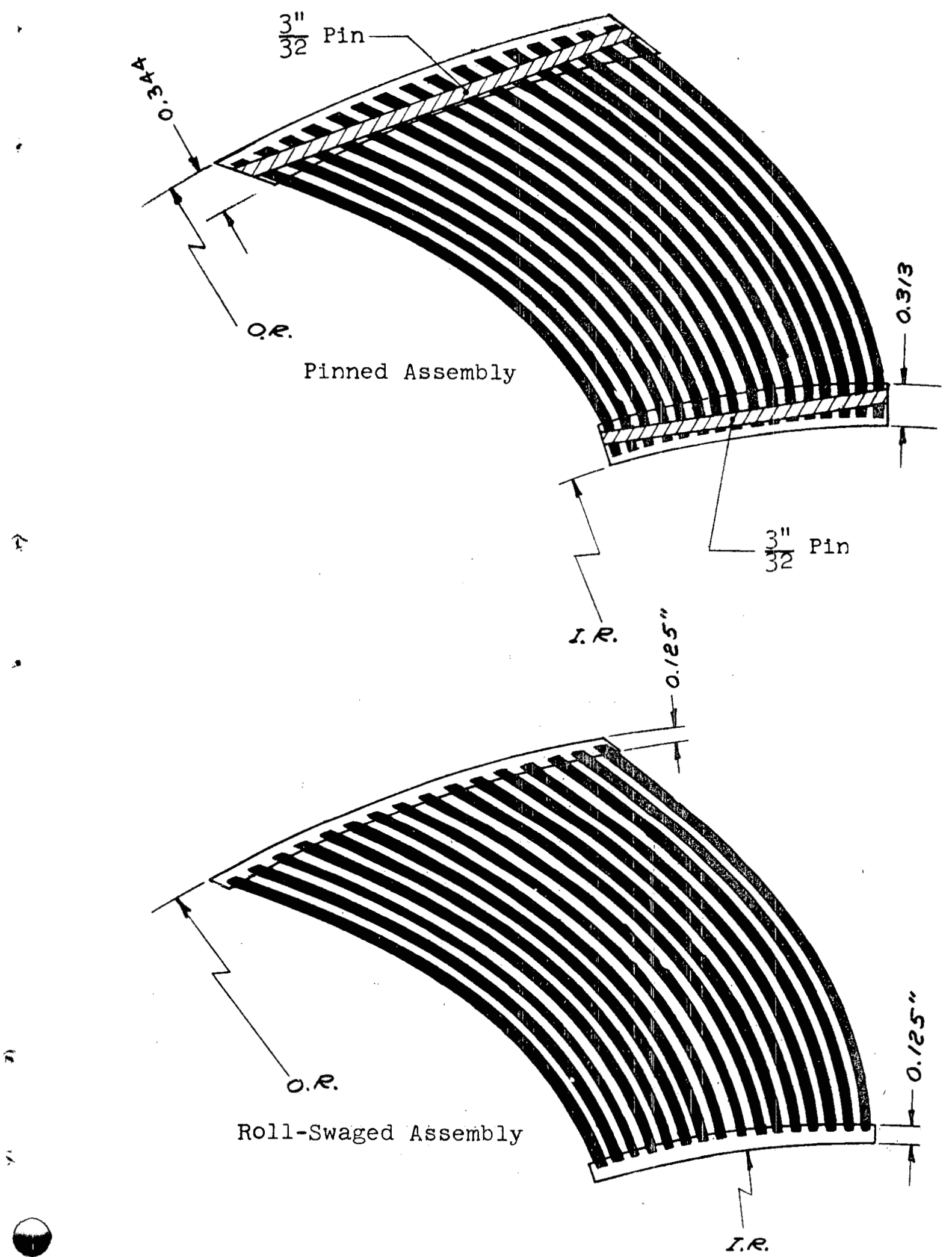

Fig. 5.E 
Figure 6.A Insertion of Poison with Mechanical Shim Safety Rods

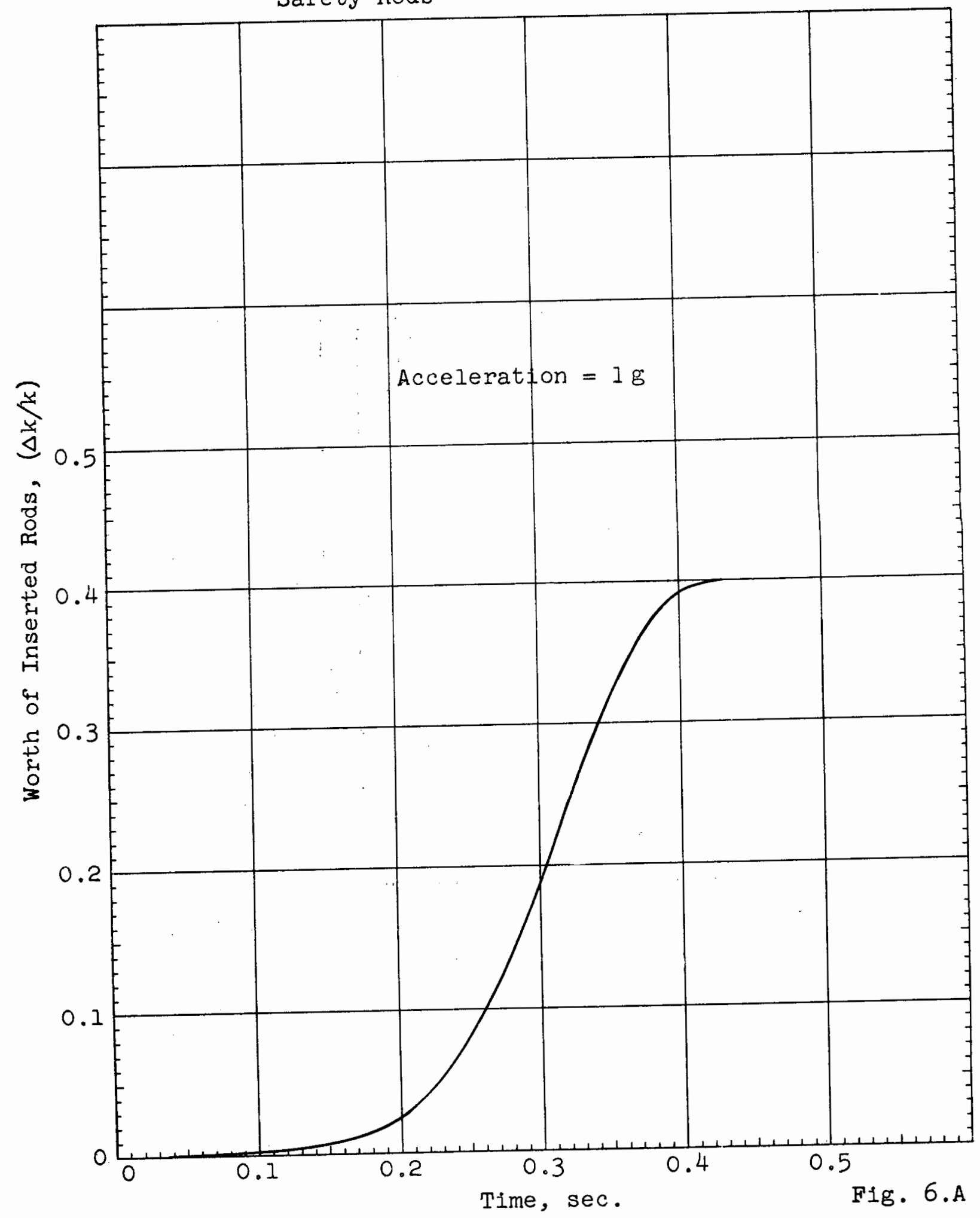


Figure 6.B Sketch of Reflector Safety

1

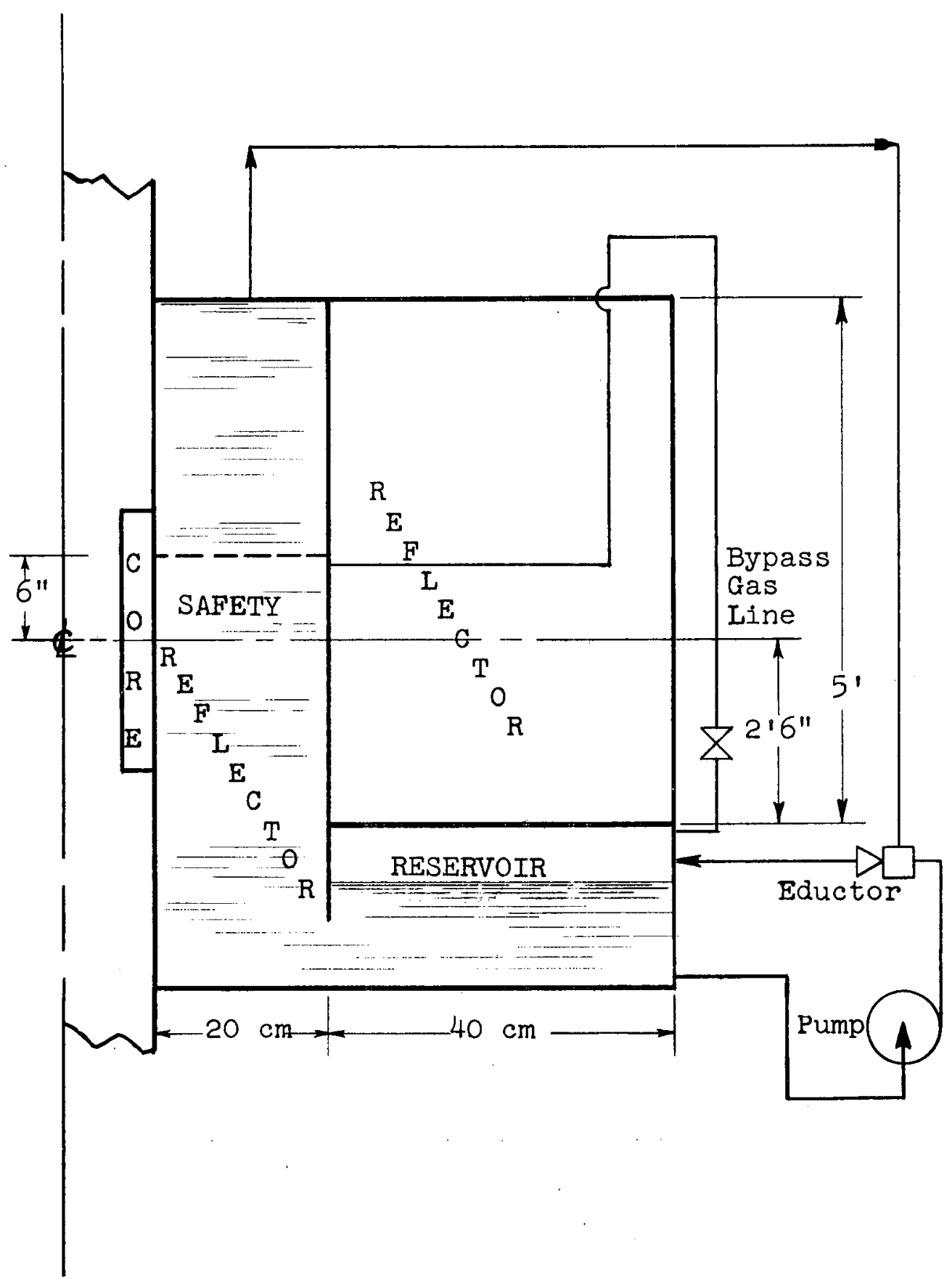

Fig. 6.B 
Figure 6.C Reflector Height versus Time from Start of Fall for Various Initial Reflector Heights

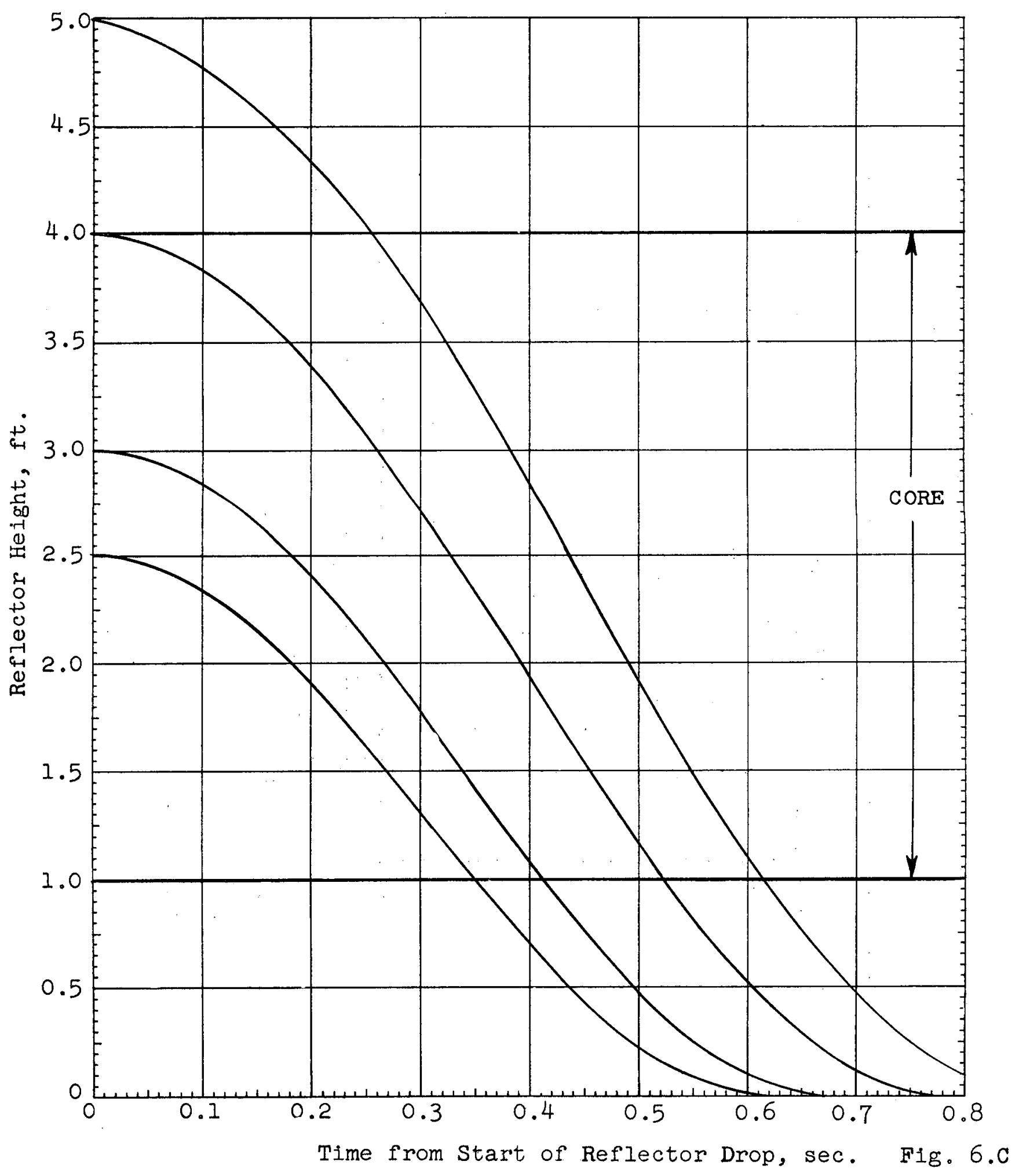


Figure 6.D Reactivity Loss versus Time from Start of Reflector Drop

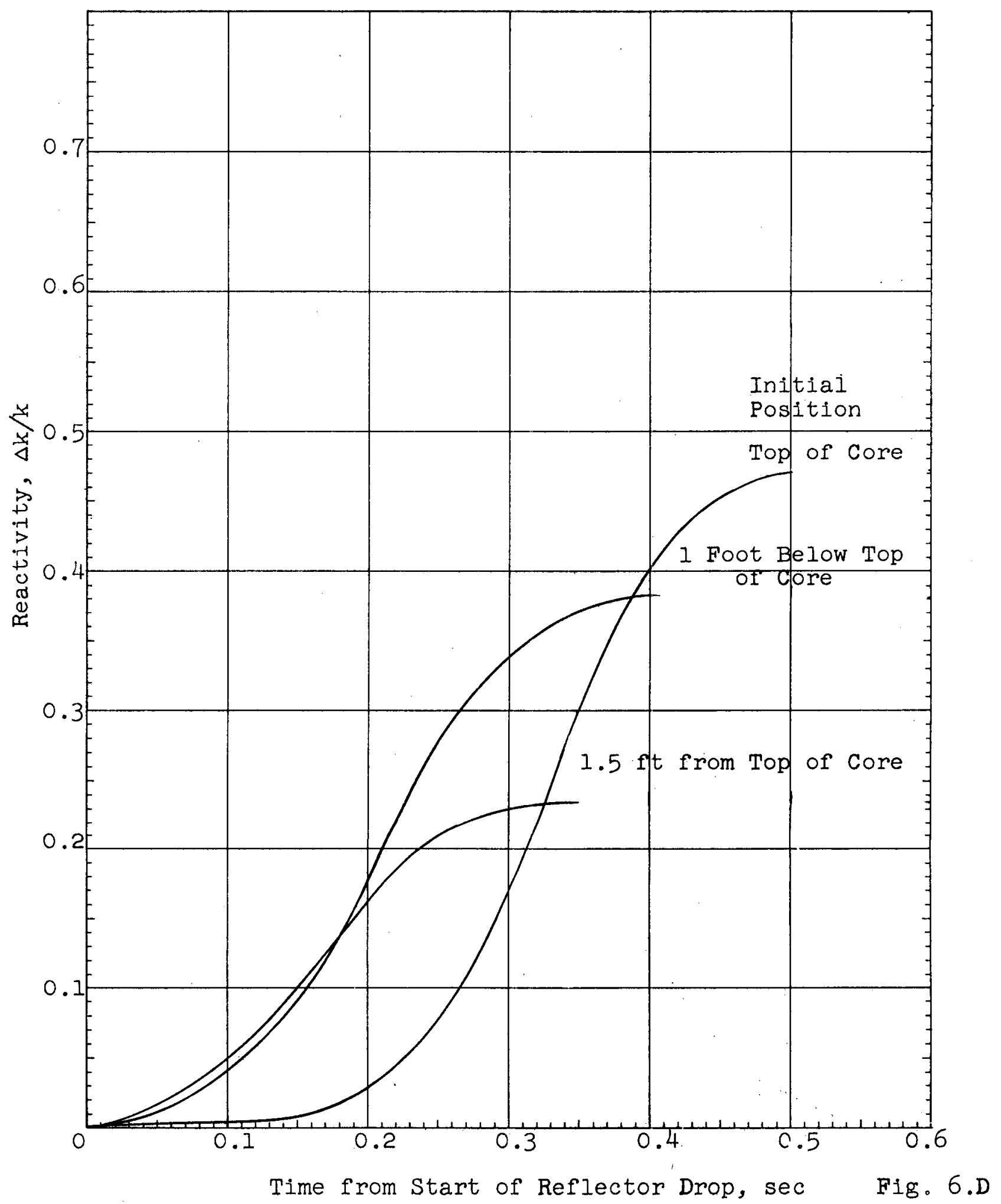


Figure 6.E Comparison of Reactivity Removal by ShimSafety Rods and Reflector Drop

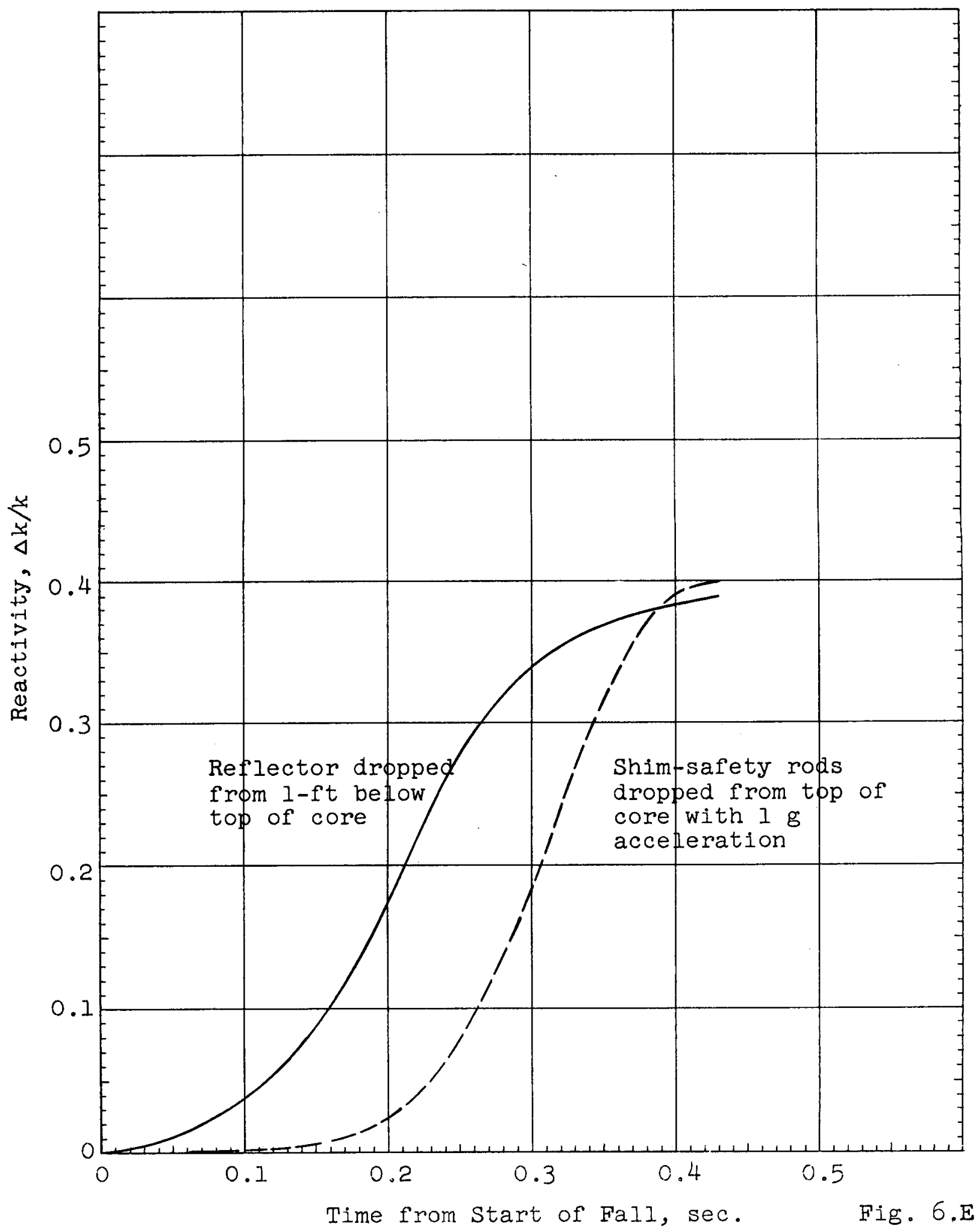


Figure 6.F Schematic of Variable Reflector Height Control System

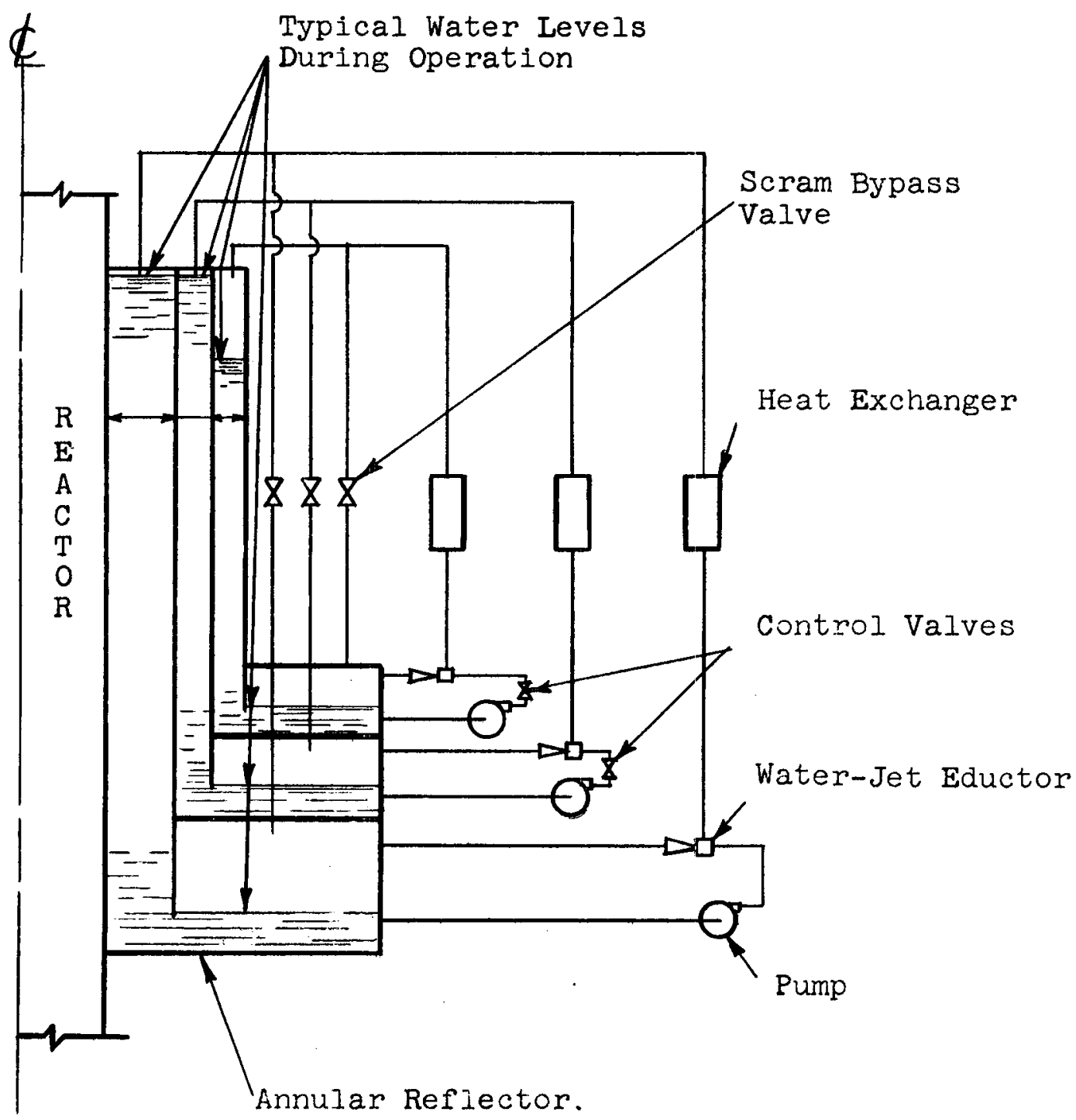

Fig. 6.F 
Figure 6.G. Sketch of Chemical Shim System

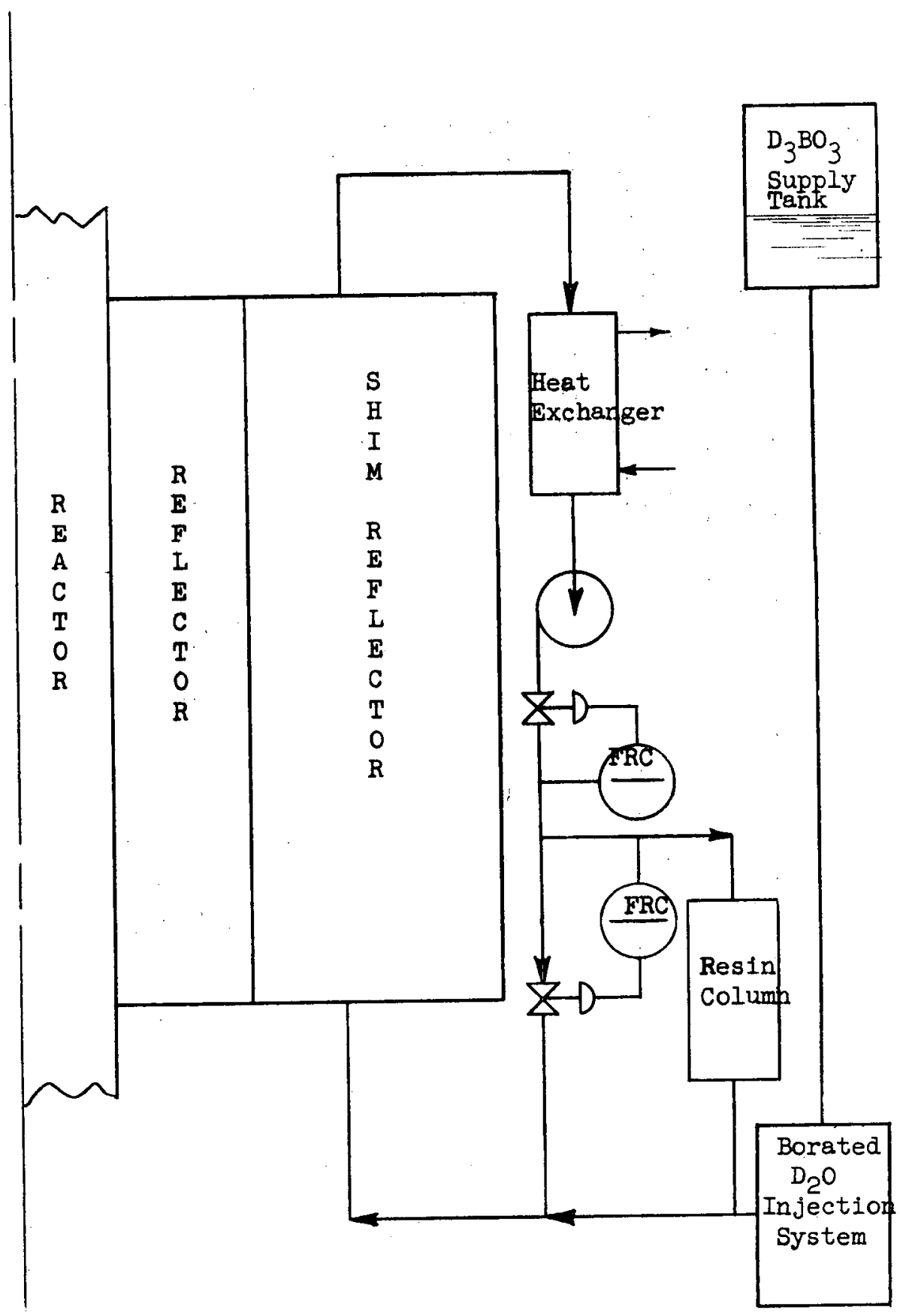

Fig. 6.G. 
Figure 6.H Effect of Boron Addition on Reactivity and Boron Concentration of the Reflector

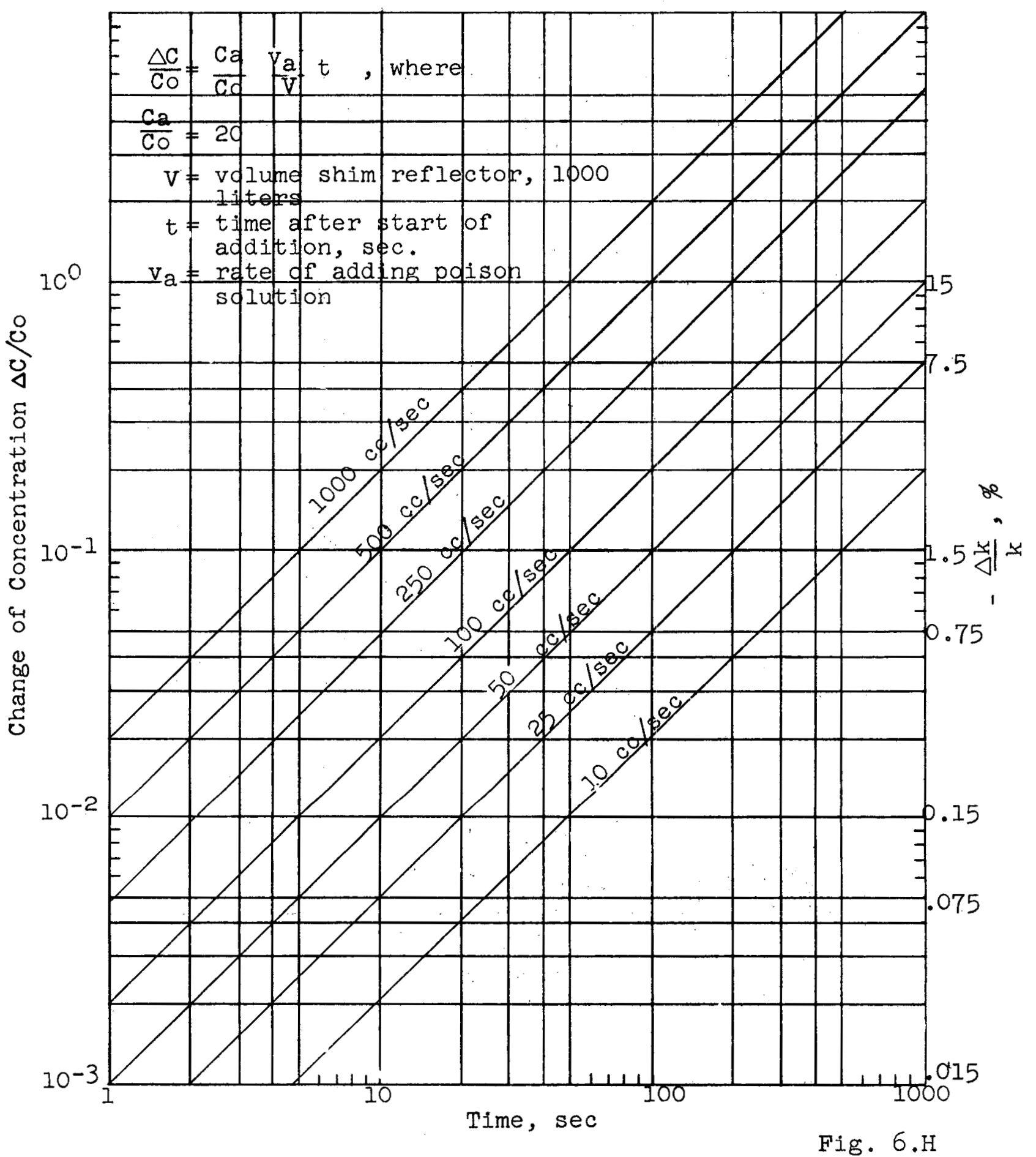


Figure 6.I Effect of Cleanup-Flow Rate on Boron Concentrations of the Reflector

$$
\text { In } \frac{C i}{C}=\frac{\beta v t}{v \ldots}
$$

$$
\text { where } \begin{aligned}
\beta & =\text { cleanup flow rate/total flow rate } \\
V & =\text { total flow rate, } 1.37 \text { gal/sec } \\
V & =\text { volume of borated reflector }=245 \text { gal } \\
t & =\text { time of removal, sec }
\end{aligned}
$$

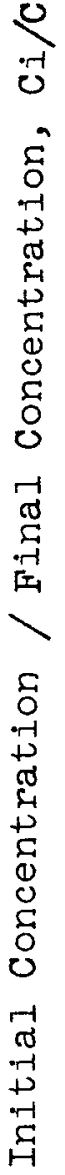

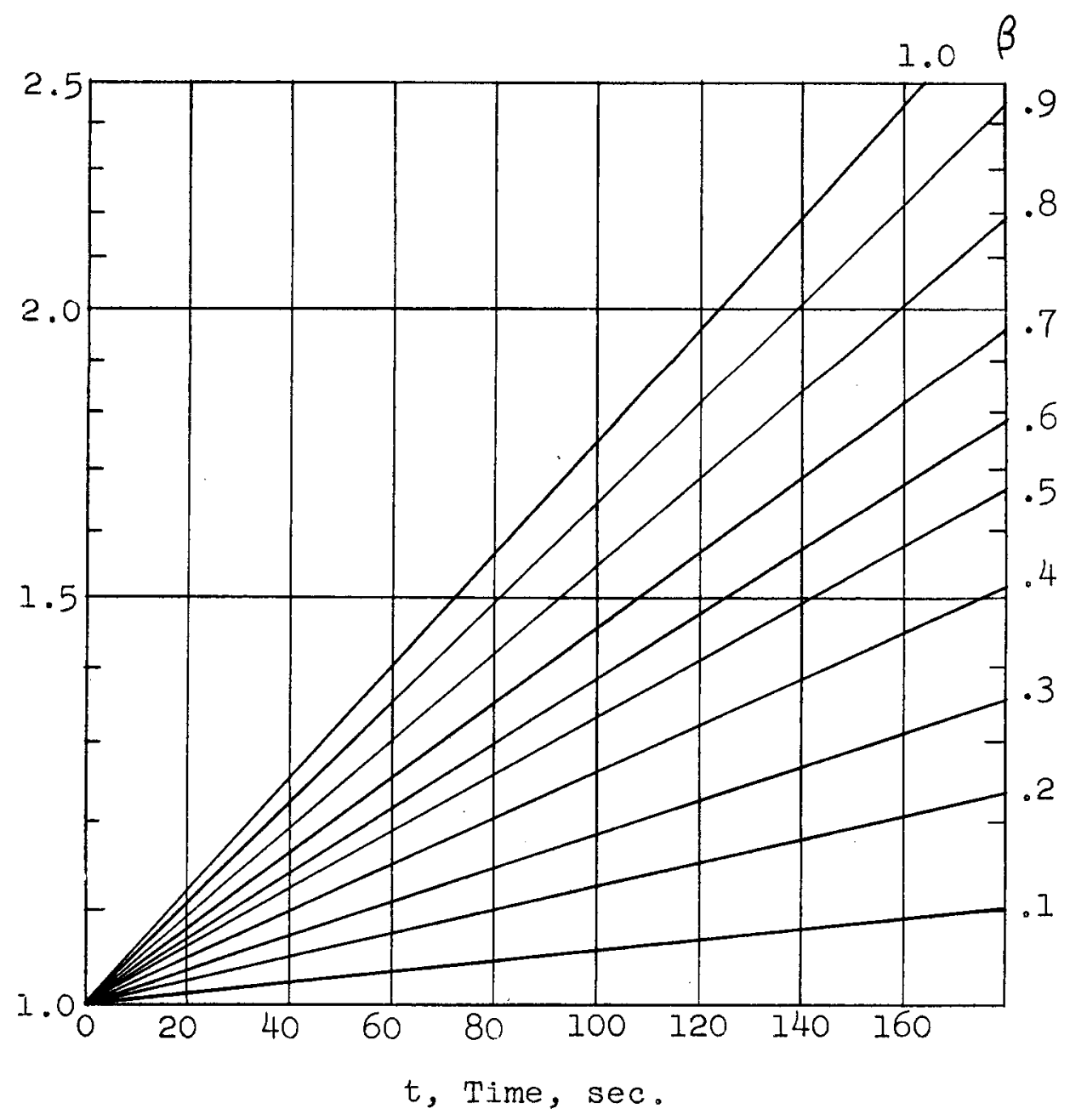

Fig. 6.I 
Figure 7.A Tangential Stresses in Reactor Core Vessel versus Wall Thickness in Type-A Reactor.

$\cdot$

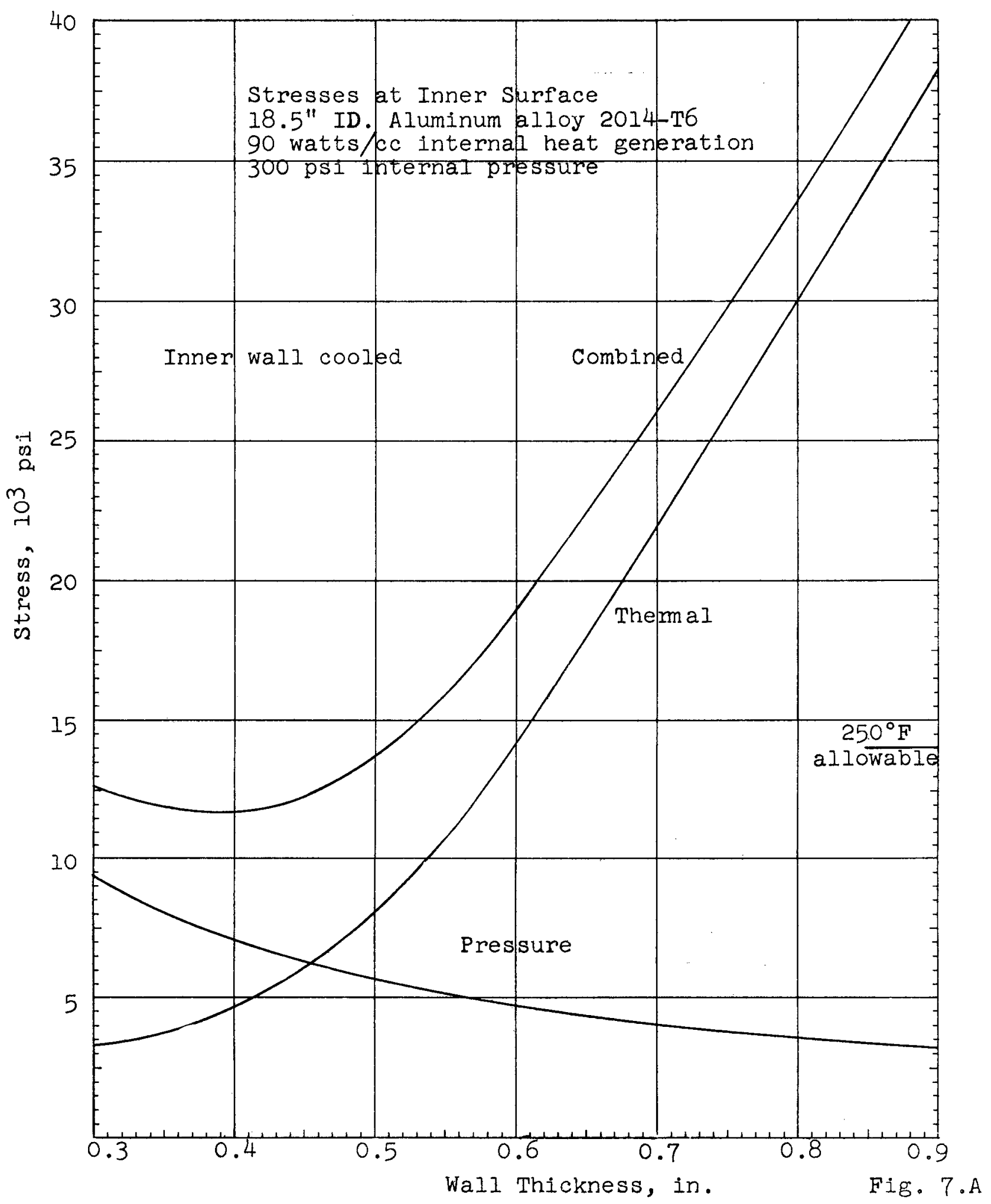


Figure 7.B Cooling Schemes for Liquid Metal or Gas-Cooled

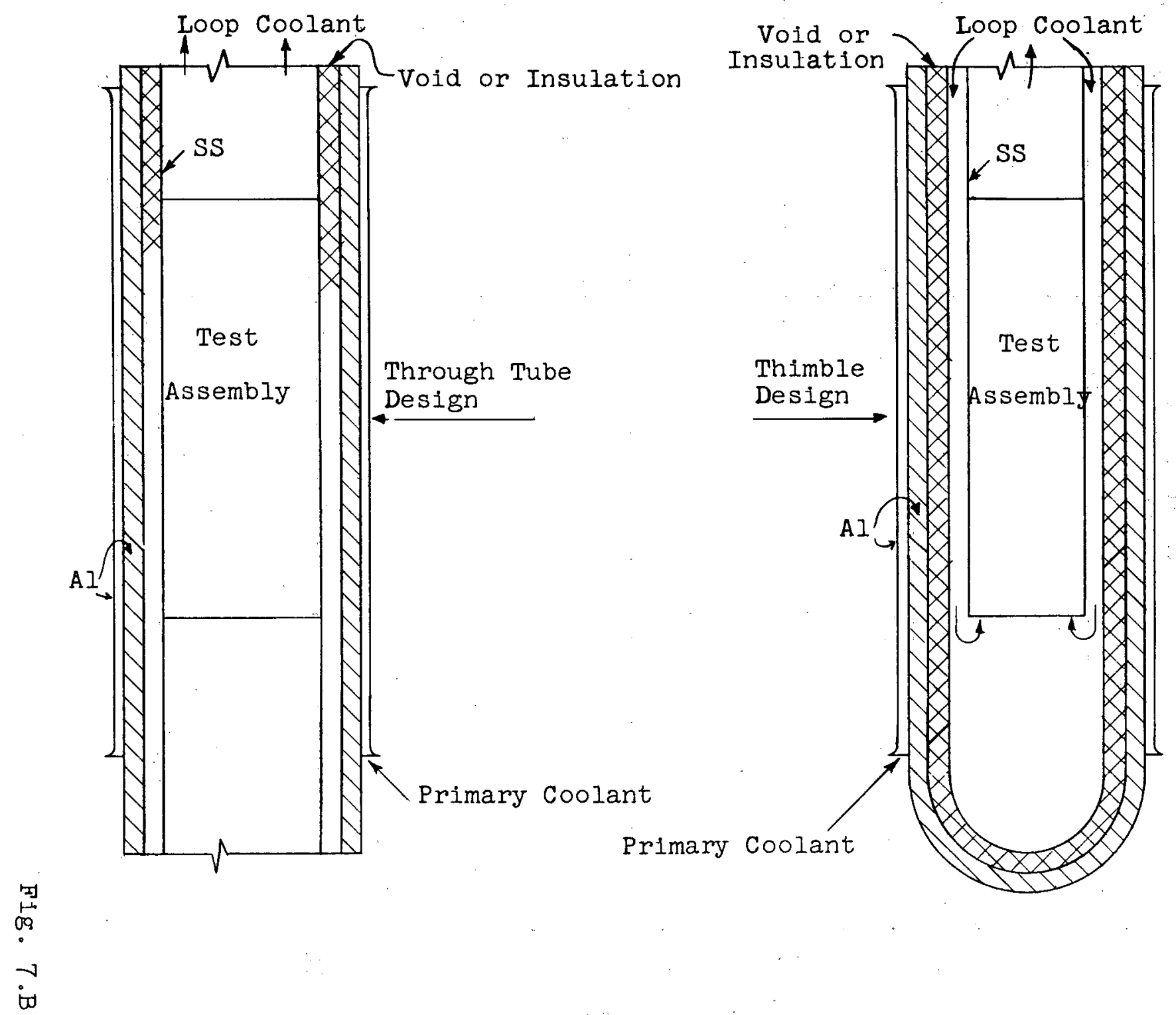


Figure 7.C Cooling Schemes for Pressurized Water Loop Tubes.

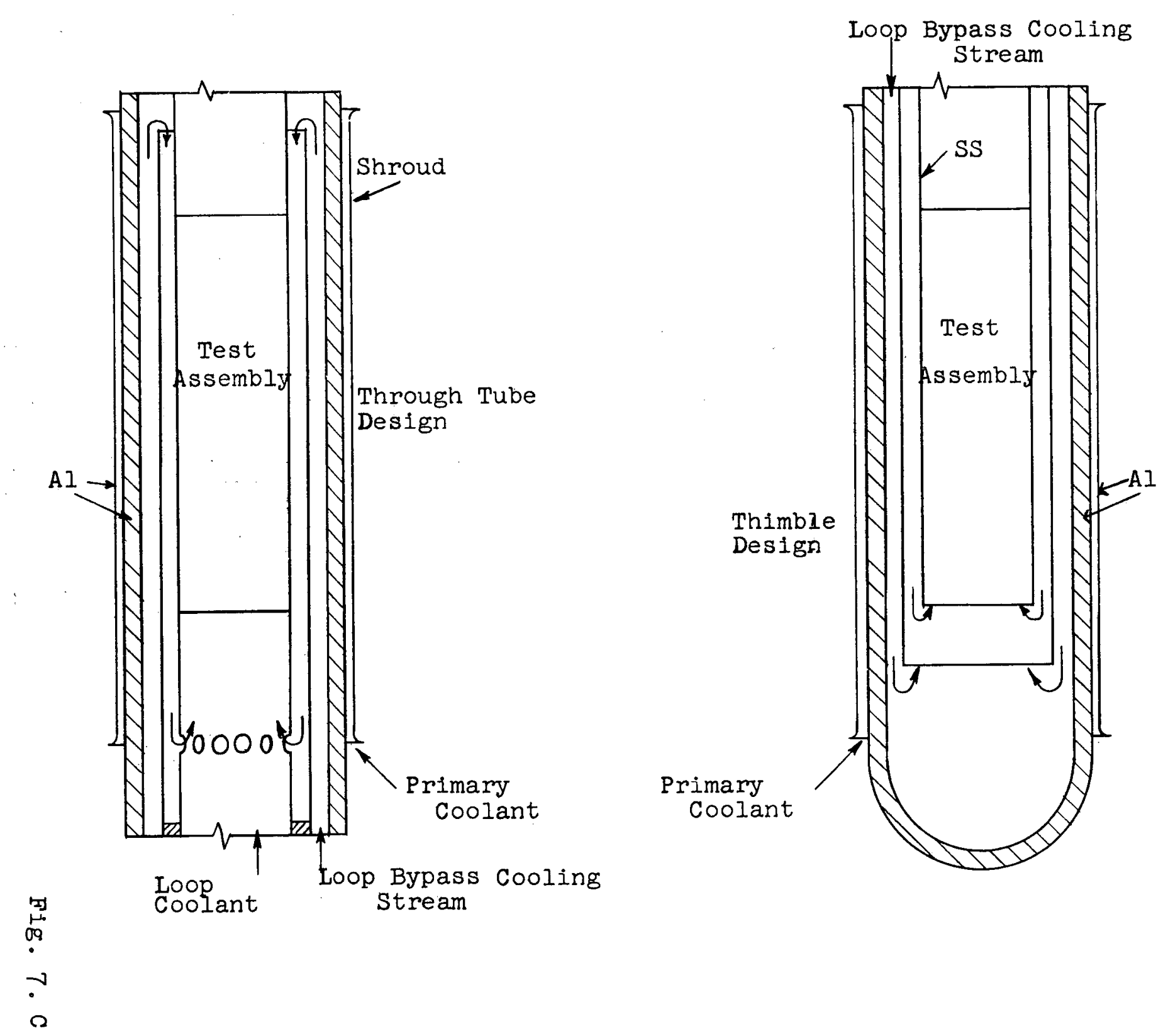


Figure 7.D Tangential Stresses versus Wall Thickness of Through-Tube in Type-A Reactor

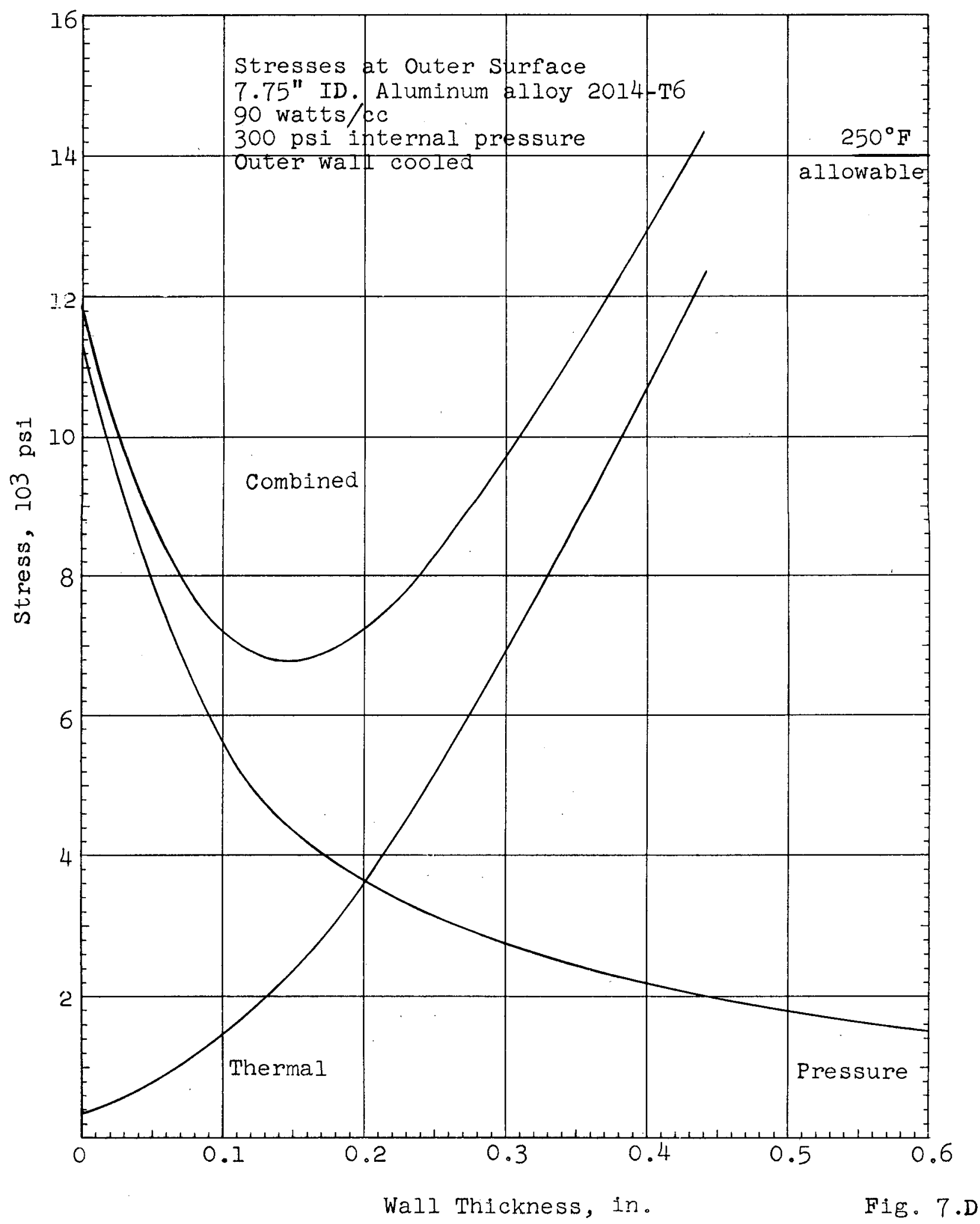


Figure 7.E Tangential Stresses versus Wall Thickness of Through-Tube in Type-B Reactor

$\cdot$

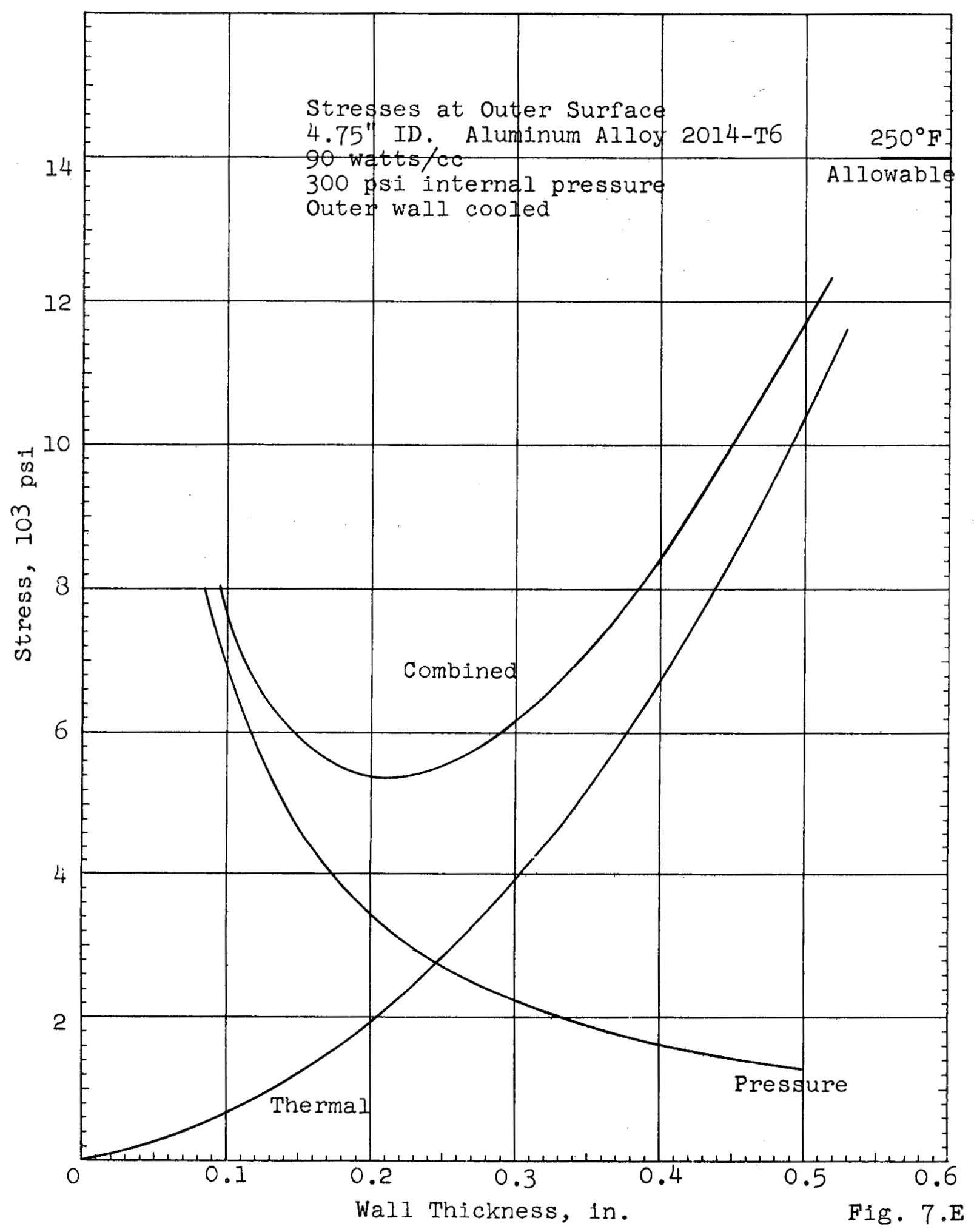


Figure 7.F Tangential Stresses versus Wall Thickness for Pressurized Water-Cooled Loop. Outside Cooling Only.

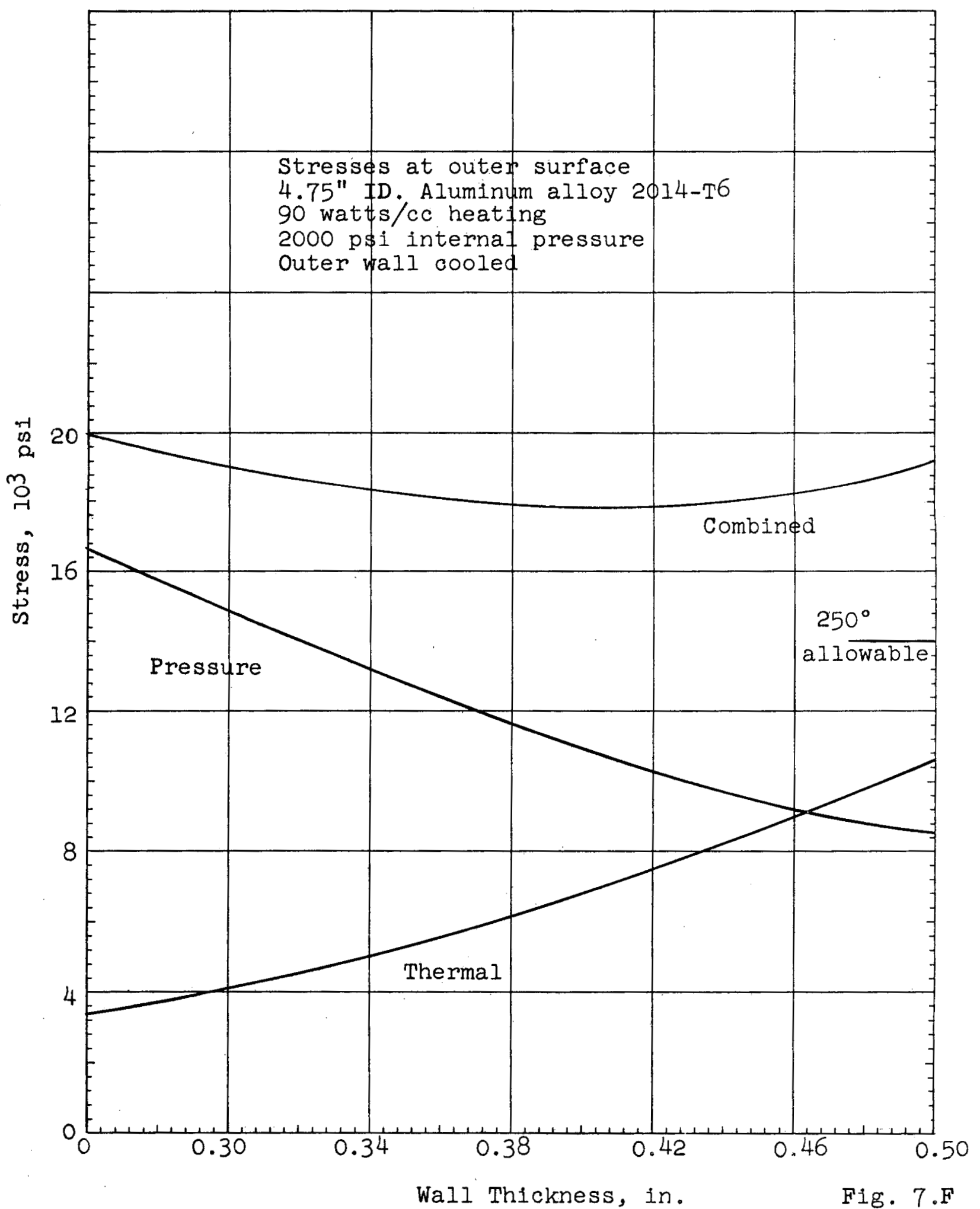



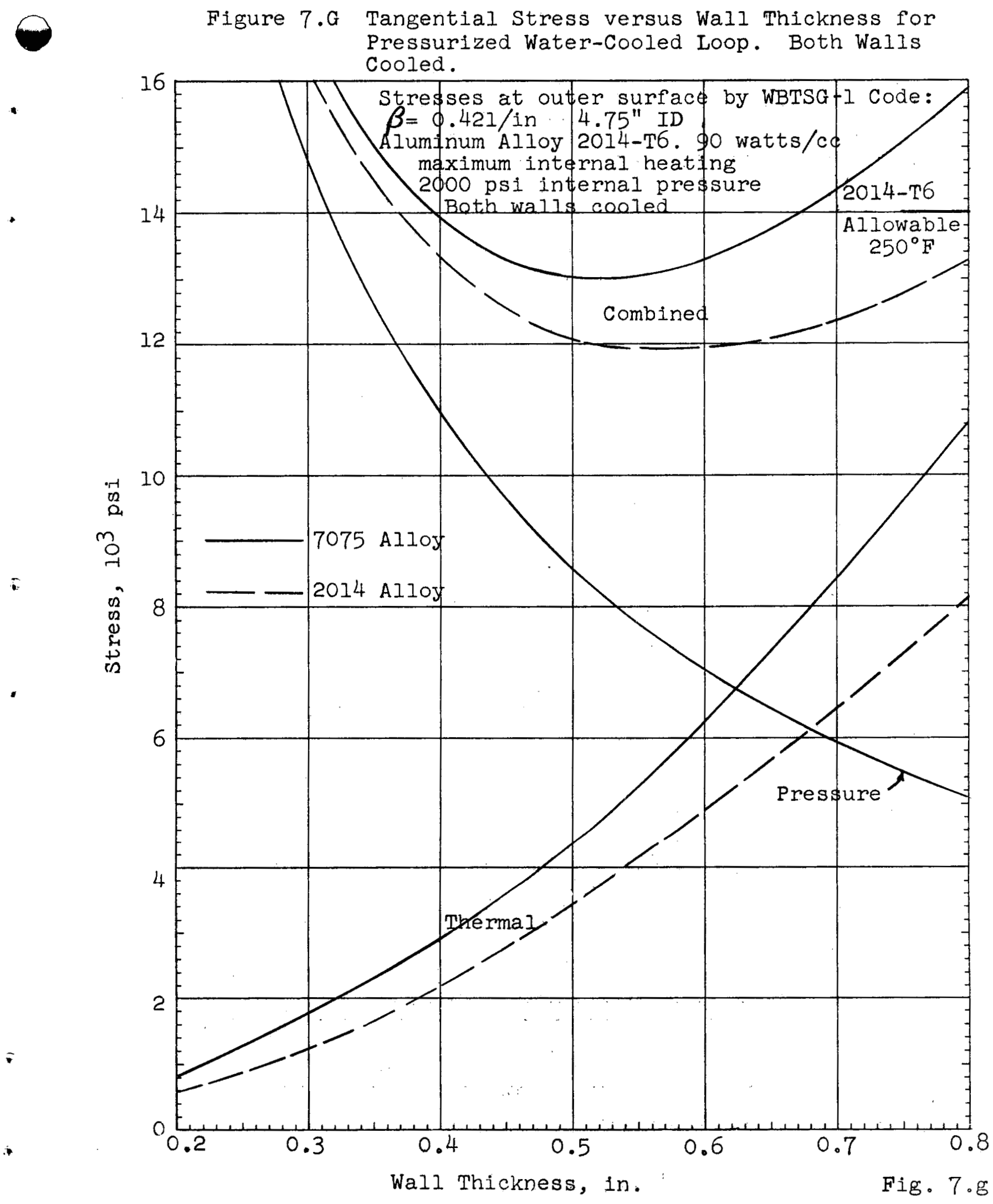
Figure 12.A Composite Reactor Building-Plan

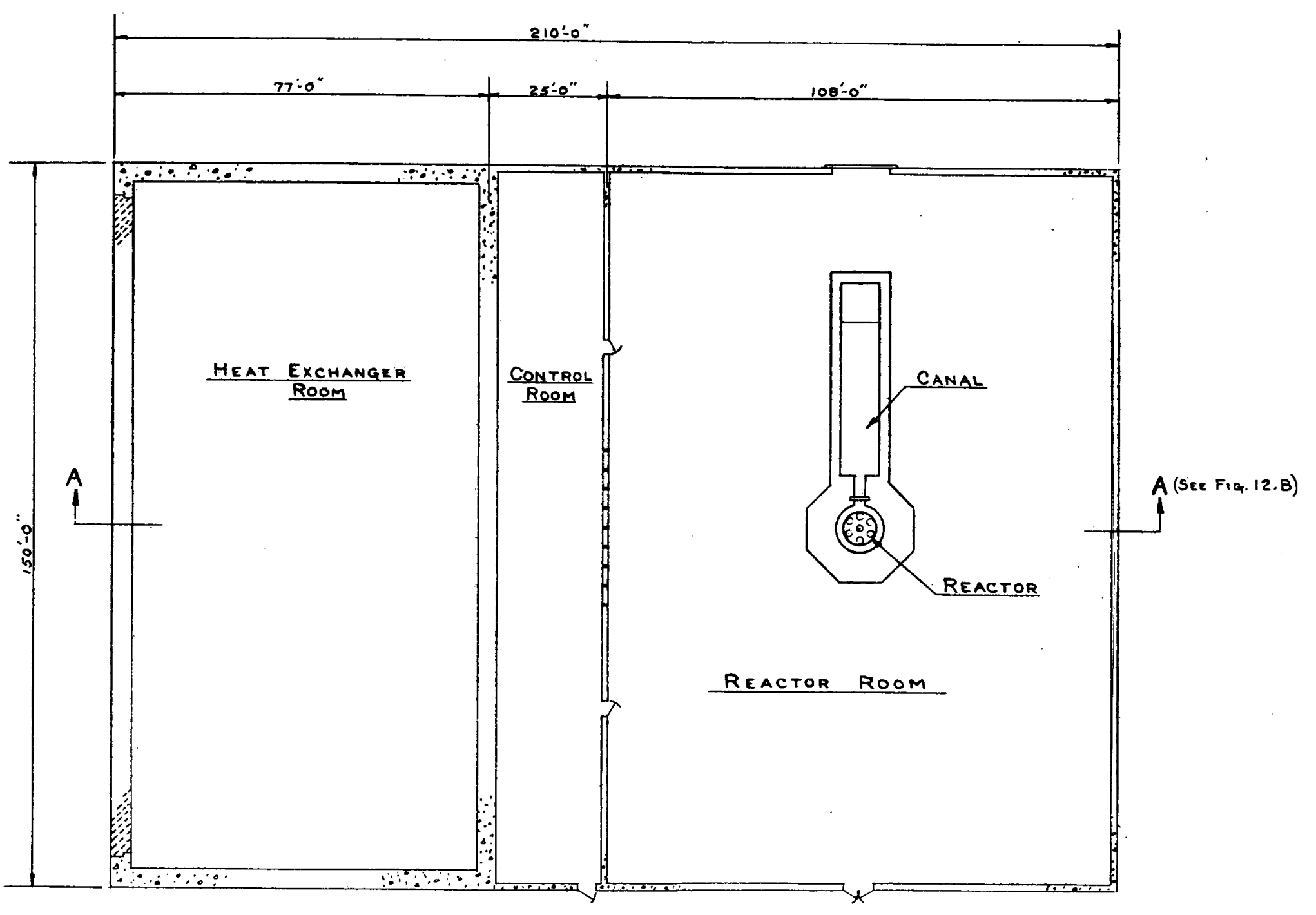

3
09
0
0
0
0 


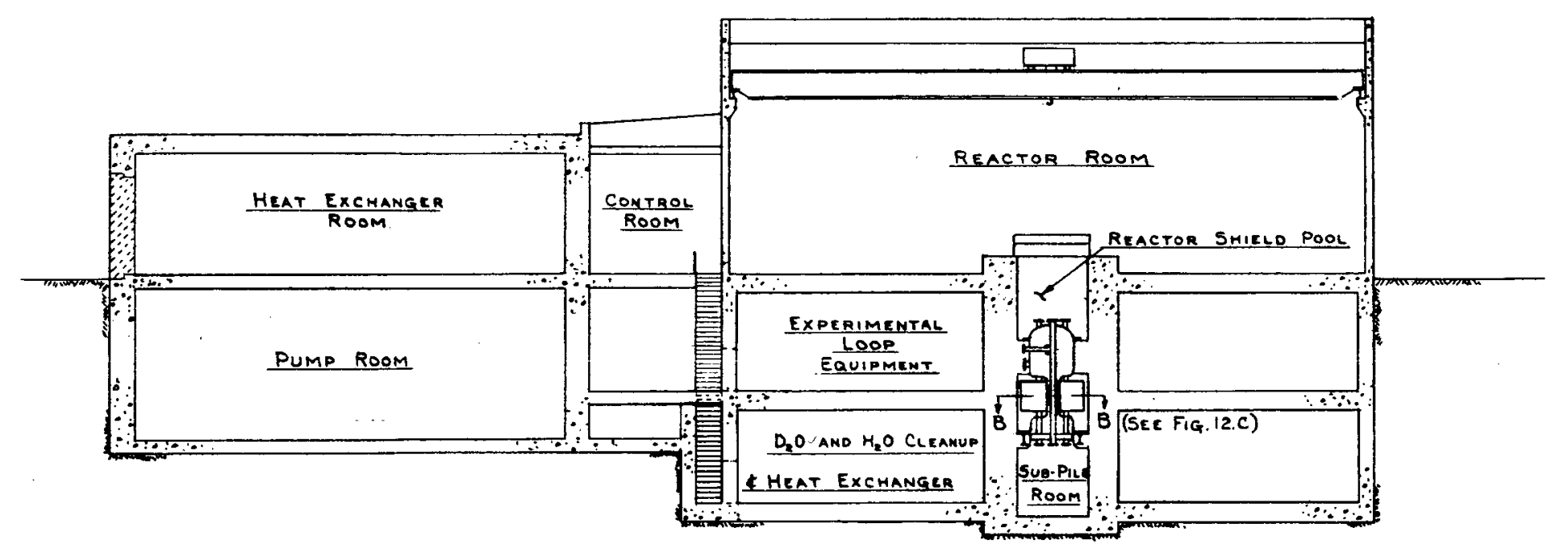

$$
\frac{\text { SECTION "A-A" }}{(\operatorname{SEE} \text { FIG. 12.A) }}
$$


Figure 12.C Composite Reactor Building-Plan Section

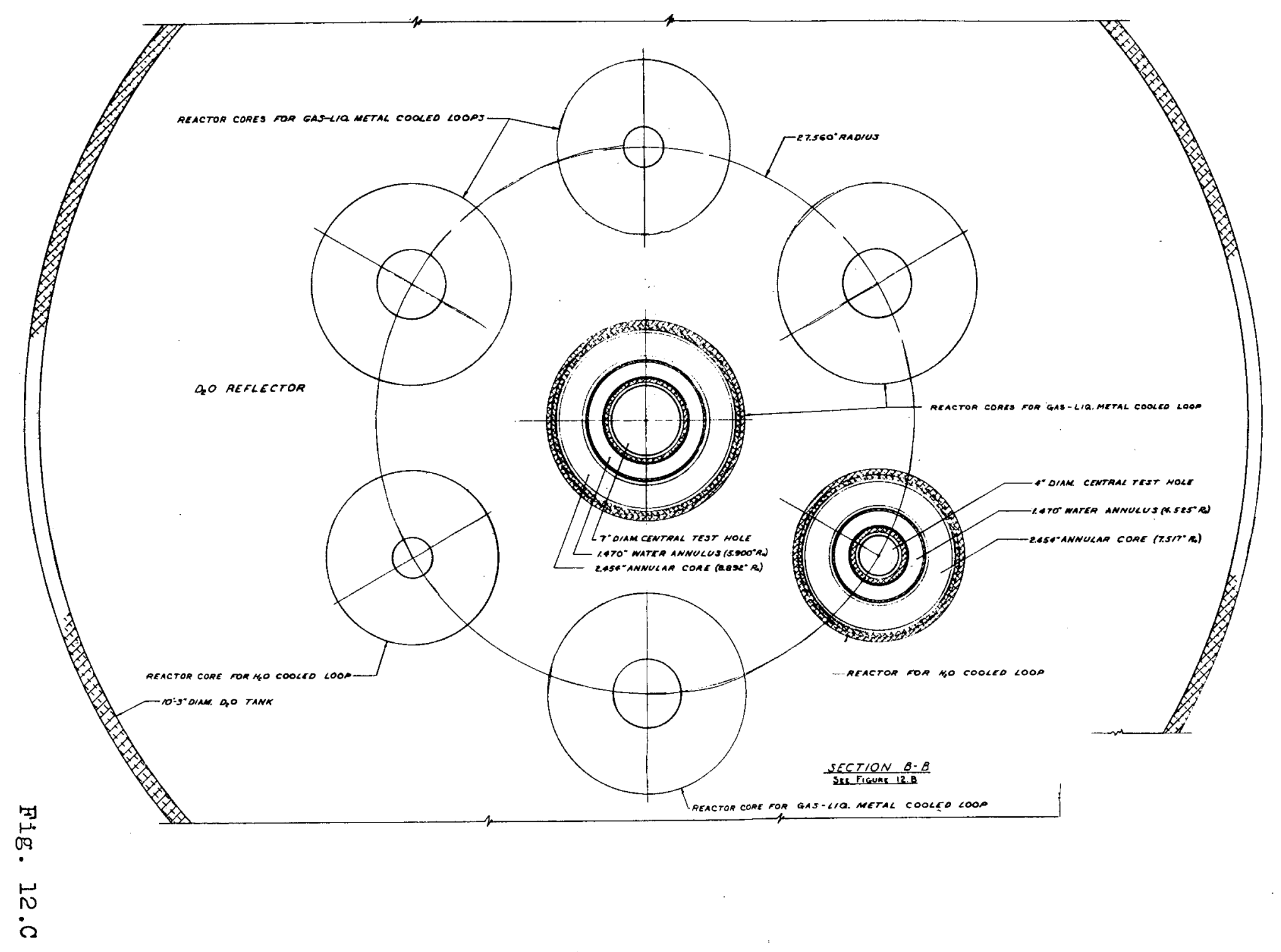


Figure 12.D Single Loop, Common Shield Reactor-Building Plan

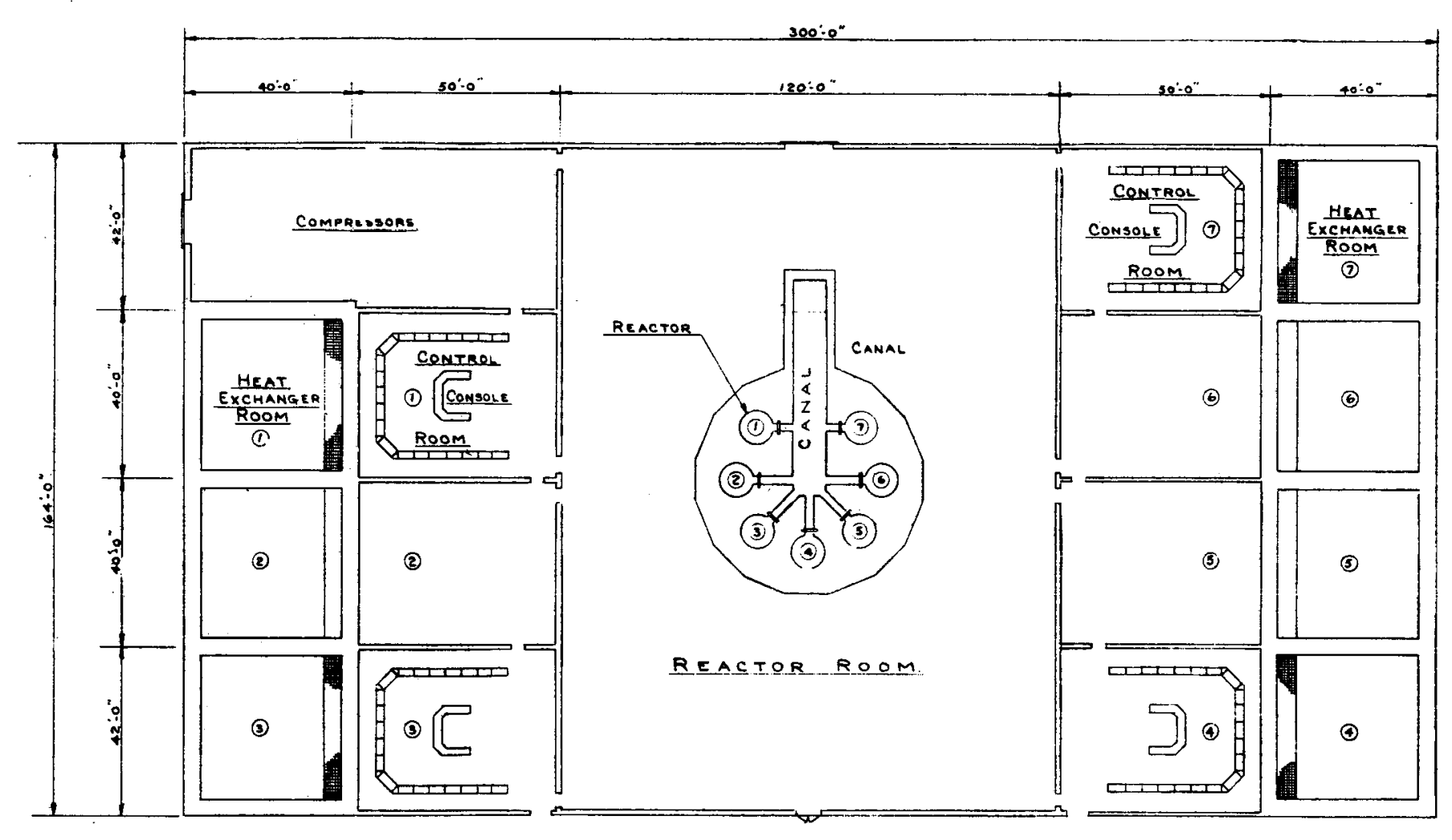

本
09
0
0
0
$\dot{0}$ 
.

1
$\mathbf{1}$

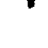

•

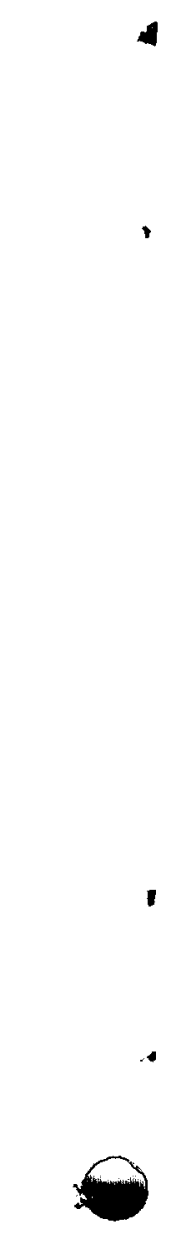

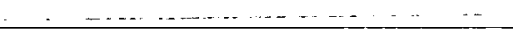


APPENDICES 
Homponstint 


\section{APPENDIX 1.0}

\section{TEST FACILITY REQUIREMENTS}

The test facility requirements, as outlined in the contract, are as follows:

The reactor(s) shall be a "flux-trap" type $D_{2} 0$ reflected, $\mathrm{H}_{2} \mathrm{O}$ cooled, heterogeneous reactor w1th an average unperturbed thermal neutron flux of $1.5 \times 1015 \mathrm{n} / \mathrm{cm}^{2}-\mathrm{sec}$ in the test holes. The required in-core test hole slzes, the loop coolants, and the coolant conditions are as tabulated below:

\section{Table Al.a Required Test Holes}

Number

1
1
1
1
3

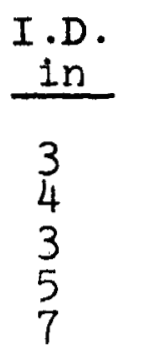

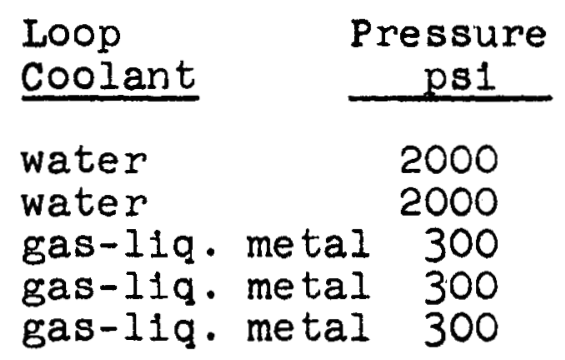

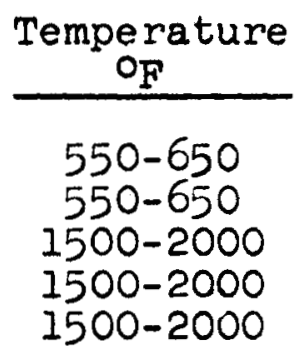

The test holes should accomodate test assemblies up to 30 inches long and the axlal flux variation should not exceed $50 \%$ over that length.

Unperturbed thermal neutron flux is interpreted to mean the thermal neutron flux in the test hole when it is filled with the test loop coolant only.

The principal difference between the above requirements and those for the initial studies (see Appendix 1.0 of INTERNUC-9) is that the unperturbed thermal neutron flux in the 4-1nch I.D. and the two 3-inch I.D. test holes has been increased to $1.5 \times 1015 \mathrm{n} / \mathrm{cm}^{2}-\mathrm{sec}$ from $1015 \mathrm{n} / \mathrm{cm}^{2}-\mathrm{sec}$. 


\section{APPENDIX 2.0 NUCLEAR CAICULATIONS}

Since interpretation of the nuclear studies depends on an understanding of the assumptions employed and values of the constants used, this section is a presentation of the more important nuclear data. Included in this section are brief explanations pertaining to the methods of computation and interpretations of the results in light of the specific methods used.

A2.I Nuclear Theory Applications

The conventional two-group treatment is generally developed using the assumption that all fission occurs in the thermal group. This, of course, is quite valid for many types of reactors. However, the fuel densities are quite high in the AETR and epithermal fission assumes greater importance. A three-energy group structure was selected for use because: (1) good empirical relationships for determining three-group constants have become avallable, (2) a three-group structure provides logical divisions for describing the neutron processes in a highly loaded reactor, and (3) the use of high speed digital computers relaxes the practical restrictions in solving few-group reactor equations.

A2.I.I One-Dimensional, Three-Group Multiregion Methods

The familiar diffusion equations for three neutron energy groups may be reduced to a one-dimensional set for a cylinurical reactor composed of a number of radial regions if the solutions for the axial flux distributions are assumed independent of the radial variable. The assumption is made that each radial region in the reactor has the same helght and that this helght is equal to the core height, $H$, plus twice the axial reflector savings value, oh, used for the core. In diffusion theory, it follaws from this assumption that the axial flux distribution in each single region of equivalent height, $\mathrm{H}+2 \delta \mathrm{h}$, is described by a cosine function such that the axial neutron flux, $\phi_{\text {hs }}$ is given by $\phi_{h}=\phi_{\text {ho }} \cos \pi(\mathrm{z} / \mathrm{H}+2 \delta \mathrm{h})$, where $\phi_{\text {ho }}$ is the flux at the axial centerline and $z$ is the axial distance from the center of the reactor. The three-group equations, reduced in this manner to a function of only the radial variable, $r$, may be written for any reactor region in the general form:

$$
-D_{1} \nabla^{2} \phi_{1}+\left(\Sigma_{a 1}+\Sigma_{S d 1}+D_{1} B_{1}^{2}\right) \phi_{1}=x_{1} S+\Sigma_{S d i-1} \phi_{i-1}
$$

where 1 is the neutron energy group index, and $I \leq i \leq I$. The various symbols used are defined as follows:

$$
\begin{aligned}
D & =\text { diffusion constant, } \mathrm{cm} \\
\mathrm{B}_{\perp} & =\text { the transverse buckling, } \pi^{2} /\left(\mathrm{H}+2 \delta_{\mathrm{h}}\right)^{2} \text { in the } \\
& \text { cylindrical geometry, } \mathrm{cm}-2 \\
\Sigma_{\mathrm{a}}= & \text { the absorption cross section, } \mathrm{cm}^{-1} \\
\boldsymbol{\Sigma}_{\mathrm{d} d}= & \text { the slowing down cross section, } \mathrm{cm}^{-1}
\end{aligned}
$$




$$
\begin{aligned}
\mathrm{X}_{1} & =\text { the fraction of fission neutrons born into the } \\
& \text { ith energy group } \\
\mathrm{S} & =\text { the normalized source density, fission neutrons } / \mathrm{sec} \\
\varnothing & =\text { the neutron flux, } \mathrm{n} / \mathrm{cm}^{2} \text { sec }
\end{aligned}
$$

Each of the above variables, with the exception of $\mathrm{X}$, is radially dependent. The notation has been omitted for simplicity.

The normalized radial source distribution of fission neutrons is given by

$$
S(r)=\frac{G(r)}{\lambda} \text {, where } G(r) \text { is }
$$

the non-normalized distribution of fission neutrons, and $\lambda$ is the eigenvalue of the system. The non-normalized fission neutron distribution is determined from the relationship

$$
G(r)=\sum_{i=1}^{i=I}\left[V \Sigma_{f}(r)\right]_{i} \phi(r)_{i} \text {, where }
$$

$\boldsymbol{\Sigma}_{\mathrm{f}}$ is the macroscopic fission cross section, and $\nu_{\text {is }}$ the average number of neutrons produced per fission. The source distribution, $S(r)$, is normalized to one fission neutron per second in a radial slice $1-\mathrm{cm}$ thick through the reactor core so that the eigenvalue of the system is given by

$$
\lambda=2 \pi \int_{R} G(r) r d r
$$

The assumptions and procedures followed in determing the radial flux distributions throughout the reactor are given in the following paragraphs.

In the calculations, three neutron energy groups are used. The thermal group ( $1=3)$ is the third group. The assumption is made that no absorption or fission occurs in the fast ( $i=1$ ) energy group. The group energy structure is selected so that virtually all fission neutrons are born in the fast group so that $\mathrm{x}_{1}=1, \mathrm{x}_{2}=0$, and $\mathrm{x}_{3}=0$. In order for equation (1) to be true for $i=1$ and $i=3$, $\Sigma_{\text {Sd }} i$ must be zero for $i=0$, and $l=3$. The number of fission neutrons produced per fission, $\nu$, is assumed identical for each energy group and numerically equal to 2.46 for $\mathrm{U} 235$. The constants referred to in equations (1) and (3) are derived for each reactor region. The various materials appearing in each region are homogenized for this purpose. In non-fuel containing regions, the fission cross section is zero and the radial source distribution terms in equation (1) and (3) disappear.

The equations for each region are coupled by continuous flux and current boundary conditions at each interface, with the restriction that all fluxes become zero at the outermost mesh point of the last region. 
The coupled set of differential equations (1) are solved numerically by an IBM 704 Data Processing Machine with the WANDA* code. An iterative technique is used in which an initial radial neutron source distribution, $S(r)$, is assumed. The program solves the differential equations for the spatial flux distribution for each neutron group. The flux distributions are then used to calculate a new source distribution according to equations (2), (3), and (4), and the procedure is repeated. The process is continued until the change in the source distribution from one iteration to the next reaches the desired degree of convergence.

During each source calculation, the eigenvalue of the system is also determined. A physical significance may be attached to the eigenvalue in the following way. The converged source distribution for any problem is normalized to one fission neutron per $\mathrm{cm}$ thick slice of radial core. The source neutron is allowed to undergo the various processes described by the multigroup equations, i.e., diffusion, absorption, slowing down, etc., which gives rise to the flux distributions calculated. This flux then creates $\lambda$ fission neutrons per cm thick slice of radial core, as determined by equations (3) and (4). This description traces a fission neutron through one cycle and the ratio of the number of neutrons at the end of the cycle to those at the beginning is $\lambda$, which has the same definition as the effective multiplication factor, keff. The system is critical when $\lambda=\operatorname{keff}=1$ 。

A2.1.2 Two-Dimensional, Three-Group, Multiregion Methods

The annular arrangement of the AETR precludes the use of a. simple geometrical model for axial calculations which can be handled by one-dimensional analysis. A two-dimensional code, CURE**, for the IBM-704 solves the set of equations discussed in $A 2.1 .1$ for either the $r-\theta$, or $r-z$ coordinate systems. The only difference in the equations (1) as written in section A2.1.1 is in the treatment of the transverse buckling term. The Laplacian operator, $\nabla^{2}$ is general and may be interpreted in any coordinate system. Since the AETR geometry is radially symmetric a three-dimensional solution is obtained by using the $r-z$ coordinate system. In this case, the transverse buckling term is zero. The cost of this type calculation is as much as one hundred times that of a one-dimerisional calculation, so that this method of calculation is used principally for the following purposes:

* Marlowe, O.J., et al., Report WAPD-TM-28, "WANDA-A OneDimensional Few Group Diffusion Equation Code for the IBM-704", (1956).

** Wachspress, E.L。, Report KAPL-1724, "CURE-A Generalized Two-Space Dimension Multigroup Coding for the IBM 704", (1957) 
a. Verification of the numerical value for transverse buckling, $\mathrm{Bh}^{2}$, used in the one-dimensional analysis.

b. Determination of the axial power distribution in the reactor core.

c. Determination of the axial flux distribution in the various reactor regions.

A2.1.3 One-Dimensional, One-Group, $P(3)$ Spherical Harmonics Solution to the Boltzmann Equation

Near a source or boundary between different media, neution angular distribution is highly anisotropic since it is influenced by the presence of the source or boundary. Under these conditions, simple diffusion theory equations do not accurately describe the reactor flux distributions and several terms of the spherical harmonic expansion of the angular distribution in the Boltzmann equation may be required. The derivations involved are tedious and many good references are avallable on the subject*. A code for the IBM 650 has been developed at KAPI which performs the $P(3)$ spherical harmonics solution to the Boltzmann equation to obtain a one-group flux distribution using a cylindrical geometry**. The $\mathrm{P}(3)$ solution has been shown to give good agreement with experimentally measured thermal flux distributions in graphite lattices containing lumps of $U$ metal.*** This $P(3)$ code is primarily useful for cell calculations because of physical limitations imposed by the code and machine restrict its use to geometries of small radii.

The preliminary calculations for the AETR are based on the assumption that the radial flux patterns are accurately described by diffusion theory. One of the configurations considered in the selection studies described in Part $B$ is sufficiently small to be solved using the $\mathrm{P}(3)$ code. This permits an evaluation of the validity of diffusion theory for application to the AETR.

The dimensions and region compositions of the reactor calculated are shown in Table A2.a.

* Fleck, J., Report BNL-1574, "The $\Psi(3)$ Approximation with Anisotropic Effects for Cylindrical Geometry", (1953)

** Weil, J.W., Report KAPL-1173, "Neutron Flux Distribution Calculations Using the $\mathrm{P}(3)$ Spherical Harmonics Method", (1954)

*** Fleck, J., op. cit. 
Table A2.a

Description of the Reactor Model Used in the P(3) Calculation

\begin{tabular}{|c|c|c|c|}
\hline $\begin{array}{l}\text { Region } \\
\text { Number } \\
\end{array}$ & $\begin{array}{l}\text { Composition and } \\
\text { Temperature }\end{array}$ & $\begin{array}{c}\text { Region Thickness } \\
\mathrm{cm}\end{array}$ & $\begin{array}{c}\text { Outside Radius } \\
\mathrm{cm}\end{array}$ \\
\hline $\begin{array}{l}1 \\
2 \\
3 \\
4 \\
5\end{array}$ & 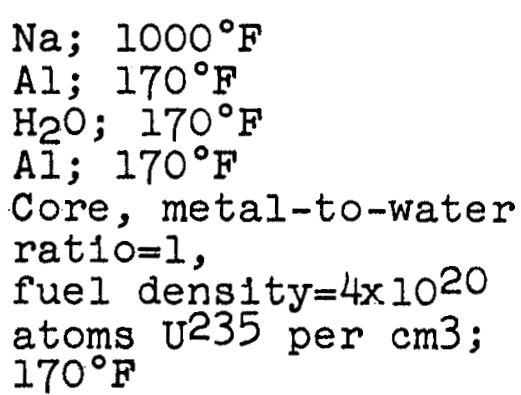 & $\begin{array}{l}5 \\
3 \\
4 \\
\frac{1}{6}\end{array}$ & $\begin{array}{l}5 \\
8 \\
12 \\
13 \\
19\end{array}$ \\
\hline $\begin{array}{l}6 \\
7\end{array}$ & $\begin{array}{l}\mathrm{AI} ; 170^{\circ} \mathrm{F} \\
\mathrm{D}_{2} \mathrm{O} ; 170^{\circ} \mathrm{F}\end{array}$ & $\begin{array}{l}2 \\
30\end{array}$ & $\begin{array}{l}21 \\
51\end{array}$ \\
\hline
\end{tabular}

The results of the calculation are presented in Figure A2.A in which the thermal flux distributions determined by diffusion theory calculations and by the $P(3)$ calculations are shown for comparison. The significant points important in evaluating these results are:

a. The curves are normalized to the same flux value at the reactor center.

b. The thermal neutron source distribution used in the one-group $P(3)$ calculation was determined from the three-group diffusion theory results.

c. The KAPL $P(3)$ code was intended primarily for cell calculations and therefore permitted only the use of a cell-type outer boundary condition. This means that the radial derivitive of the flux must be zero at the outer boundary of the system. In order to circumvent this apparent restriction, the point in the $\mathrm{D}_{2} \mathrm{O}$ reflector at which the derivative of the thermal flux is zero in the diffusion theory solution is assumed to be the outermost boundary point in the $\mathrm{P}(3)$ calculation. In other words, the assumption is made that the point or radius of maximum thermal flux in the moderator is the same whether diffusion theory or transport theory is used. This assumption seems reasonable, but the error may be significant enough to account for the considerable deviation between the two curves in the reflector region.

From these results, the conclusion is made that diffusion theory is sufficiently accurate for preliminary reactor calculations. 
A2.1.4 Normalization and Application of Non-E1genvalue Problem Solutions

Each of the computer codes discussed in the previous sections yields flux distributions which correspond to a certain volumetric fission neutron source rate. This fission neutron source rate may be converted to more conventional power units using the following basic relationships:

a. For each fission event, 2.46 fission neutrons (on the average) are created.

b. One $\mathrm{MW}$ of heat power is created by $3.1 \times 1016$ fission events per second.

The neutron flux values are, of course, directly proportional to the core power.

The one-dimensional code, when used radially, produces fluxes which correspond to a fission neutron source rate of one per second in a one $-\mathrm{cm}$ thick radial slice of the core. Assuming that the radial slice occurs at the point of average axial core power, the fluxes are easily normalized to the total core power. However, in developing the one-dimensional equations, the radial flux distributions are assumed to be independent of the axial flux distributions. This is not true when the core is reflected axially, with the result that the radial flux distributions are most accurate at the reactor centerline. For th1s reason, a maximum-to-average value of axial power 1s determined which when applied in the flux normalization gives normalized radial flux distributions along the axial centerline of the reactor.

The two-dimensional code produces fluxes wh1ch correspond to a source of one-fission neutron per second over the entire core volume, so that the normalization to reactor power is simple and straightforward. The normalized flux may easily be found for any point in the reactor. These results are very useful in determining the maximum-to-average axial power distribution which may be applied in normalizing the one-dimensional calculations.

For Part B of this report, many calculations are performed in order to determine the reactor configuration which produces the optimum average thermal flux in the test region for a given reactor power. Since reactor criticality is not of primary interest, 1t seems desirable for purposes of expediency and economy to use the results of non-critical calculations. This 1s permissible in some cases, the major consideration beling that any fuel adjustment made in the core to obtain criticality will not greatiy affect the distribution or magnitude of the flux in the test cell. The thermal neutron flux in the core 1s, of course, very sensitive to fuel changes and varles almost inversely with fuel loading for constant core power. However, if two or 
three migration lengths (slowing down plus diffusion lengths) of material separate the test region from the core, the flux in the test region is virtually unaffected by core changes as long as the core power is unchanged. This condition is only partially satisfied in many of the geometries of interest in developing the AETR cpncept. Therefore, an empirical relationship is used to make a second-order correction to the average test hole fluxes for non-critical systems.

\section{A2.2 Nuclear Constants}

The primary reasons for the selection of a three neutron energy group model are discussed in section A2.1. The three energy groups are divided so as to be characterized in the following ways. All neutrons caused by fission in the intermediate and thermal energy groups are born in the fast neutron energy group. These neutrons are either leaked from the physical bounds of the reactor or degraded into the intermediate energy group as a result of collisions with atoms of moderator and structural materials. The intermediate group receives all of its source neutrons from the fast group due to this slowing or degradation process. These neutrons may again be leaked or slowed in a manner similar to the fast neutrons. In addition, however, the intermediate energy neutrons may be lost by absorption. This may be caused by the resonance absorption characteristics exhibited by some of the reactor materials or by the $1 / v$ "tails" of the $1 / v$ absorbers. Some of the neutrons absorbed in the fuel cause fission in which case a neutron contribution is made to the fast group. The thermal neutrons which are produced by degradation in the intermediate group are absorbed or leaked and of course make the primary neutron contribution to the fast group by causing fission in the fuel.

The energy boundaries of the groups selected on the above basis are shown in Table. $A 2 . b$.

\section{Table A2.b}

Three Energy Group Structure for Determination of Nuclear Constants

$\begin{array}{lllc}\text { Group } & \text { Name } & \text { Energy Range } & \text { Lethargy } \\ 1 & \text { Fast } & 10 \mathrm{Mev}-10 \mathrm{kev} & 0-6.91 \\ 2 & \text { Intermediate } & 10 \mathrm{kev}-.26 \mathrm{ev} & 6.91-17.5 \\ 3 & \text { Thermal } & \begin{array}{l}\text { Maxwell-Boltzman } \\ \text { Distribution }\end{array} & --\end{array}$

The lethargy, $u$, is defined by the expression

$$
u=\ln \left(\frac{E_{0}}{E}\right),
$$

where $E_{O}$ is arbitrarily chosen to be numerically equal to $10 \mathrm{Mev}$. 
Recently, several good methods have been proposed for the calculation of three-group nuclear constants. Deutsch* at KAPL has advanced a method which predicts neutron flux distributions in homogeneous hydrogeneous reactors with good accuracy. Many of his suggestions are herein employed in the determination of group constants described briefly in the following sections.

A2.2.1 Atomic Densities and Temperature Correction Factors

The primary density data pertinent to the materials used in the AETR work are shown in Table A2.c.

Table A2. C

Density Data for Reactor Materials

p, A, N, Temperature Correction Density Atomic Atomic

Material gms/cm3 weight,gms density Factors

\begin{tabular}{|c|c|c|c|c|c|c|}
\hline \multirow[b]{2}{*}{ Material } & \multirow{2}{*}{$\begin{array}{l}\text { p, } \\
\text { Density } \\
\text { gms } / \mathrm{cm} 3 \\
\text { at } 68^{\circ} \mathrm{F}\end{array}$} & \multirow{2}{*}{$\begin{array}{l}\text { A, } \\
\text { Atomic } \\
\text { weight, gms } \\
\text { per mole }\end{array}$} & \multirow{2}{*}{$\begin{array}{l}\quad N, \\
\text { Atomic } \\
\text { density } \\
\text { atoms } \\
\text { barns-cm }\end{array}$} & \multicolumn{3}{|c|}{$\begin{array}{c}\text { Temperature Correction } \\
\text { Factors }\end{array}$} \\
\hline & & & & $g\left(170^{\circ} \mathrm{F}\right)$ & $g\left(600^{\circ} \mathrm{F}\right)$ & $8\left(1000^{\circ} \mathrm{F}\right)$ \\
\hline $\mathrm{H}_{2} \mathrm{O}$ & 1.0 & 18.016 & 0.03343 & 0.97568 & 0.68008 & - \\
\hline $\mathrm{D}_{2} \mathrm{O}$ & 1.103 & 20.0 & 0.033217 & 0.97568 & 0.68008 & - \\
\hline $\mathrm{Be}$ & 1.85 & 9.013 & 0.12353 & - & - & - \\
\hline $\mathrm{BeO}$ & 2.8 & 25.013 & 0.06743 & - & - & - \\
\hline $\mathrm{Fe}$ & 7.85 & 55.85 & 0.084897 & - & - & - \\
\hline$A 1$ & 2.699 & 26.97 & 0.06027 & - & - & - \\
\hline $\mathrm{Na}$ & 0.9684 & 22.997 & 0.025363 & - & - & 0.85192 \\
\hline
\end{tabular}

The reference or room temperature is assumed to be $68^{\circ} \mathrm{F}$. The water density is slightly less than one gm/c.c at this temperature, but for convenience sake it is assumed to equal one. Stainless steel is assumed to have the same atomic density as iron. The effect of temperature change on atomic density is neglected for solids because of the relatively small (compared to liquid) effects over the temperature ranges considered. The temperature effects on the density of sodium, which melts at 2080F, are taken into account. The factor by which the density of a material changes in going from $68^{\circ} \mathrm{F}$ to another temperature is defined as $\mathrm{g}(\mathrm{T})$ where $\mathrm{T}$ is the new temperature. Numerical values for the temperatures of interest are given in Table A2.C. The factor $\mathrm{g}(\mathrm{T})$ is determined accurately so that the data may be applied to temperature coefficient calculations.

* Deutsch, R.W., "Computing Three-Group Constants for Neutron Diffusion", Nucleonics 15, No.1, 47(1957) 
The atomic density of $\mathrm{U}^{235}$ in atoms per $\mathrm{cm}^{3}, \mathrm{~N}_{2} 5$, is determined for uniformly loaded cores by the expression

$$
\mathrm{N}_{25}=2.5634 \times 10^{21} \frac{\mathrm{M}_{25}}{\mathrm{~V}_{\mathrm{C}}}
$$

where $M_{25}$ is the total fuel mass in $\mathrm{Kg}$ and $\mathrm{V}_{\mathrm{c}}$ is the total core volume in liters. Much of the work in this report involves annular cores three feet in height in which case

$$
\mathrm{N}_{25}=8.9233 \times 1018 \frac{\mathrm{M}_{25}}{\mathrm{R}_{0}{ }^{2}-\mathrm{R}_{1}{ }^{2}}
$$

where $R_{0}$ and $R_{\mathcal{I}}$ are the outside and inside core radii in $\mathrm{cm}$, respectively.

A2.2.2 Absorption and Fission Cross Sections

The source for all the microscopic fission and absorption cross section data is BNL-325* and Supplement $1^{* *}$ thereto, unless otherwise noted.

Thermal Energy Group

The thermal absorption cross sections for all materials, other than $\mathrm{U}^{235}$, are assumed to vary inversely with the neutron velocity, 1.e., they are "l/v" in nature. A Maxwell-Boltzmann thermal flux distribution is assumed, with the most probable neutron energy occuring at the thermal temperature of the moderator. Under these circumstances, the effective (Maxwellized) cross sections are the point value cross sections corrected by the constant $\frac{\sqrt{\pi}}{2}$. The microscopic absorption cross sections for the various reactor materials are shown in Table A2.d.

The point values at $68^{\circ} \mathrm{F}, \sigma_{\mathrm{aO}}$, are shown along with the corresponding Maxwellized values, $\overline{\sigma a}$. The absorption cross section for stainless steel is assumed to be larger than that of iron by a factor of "1.115. As previously indicated, the $\mathrm{U} 235$ cross section is "non-1/v" in nature so that an additional correction factor is applied.

* Hughes, D.J. and Harvey, J.A., "Neutron Cross Sections", Report BNL 325 (1955)

* Hughes, D.J. and Schwartz, R.B., "Supplement Number 1 to Neutron Cross Sections", Report BNL 325 (1957) 
Table A2.d

Microscopic Absorption Cross Sections for

Various Reactor Materials

Material

$\mathrm{H}_{2} \mathrm{O}$
$\mathrm{D}_{2} \mathrm{O}^{*}$
$\mathrm{BeO}$
$\mathrm{Fe}$
$\mathrm{Al}$
$\mathrm{Na}$
$\mathrm{U}^{2} 35$

\%ao, barns
$68^{\circ} \mathrm{F}$ point value

0.660

0.00218

0.010

2.53

0.230

0.505

687 $\bar{\sigma}_{\text {ao }}$, barns

$68^{\circ} \mathrm{F}$ Maxwellized

0.58510

0.000993

0.0088652

2.2429

0.20390

0.44770

$609.04 * *$

* The $\mathrm{D}_{2} \mathrm{O}$ is assumed to contain $0.16 \% \mathrm{H}_{2} \mathrm{O}$

* Does not include non-1/v correction term

These so called "non-l/v" correction factors for $\mathrm{U}^{235}$ are shown in Table A2. $\epsilon$ together with the appropriate temperature correction factors, $f(T)$, for " $l / v$ " absorbers. This temperature correction factor accounts for the effective decrease in the thermal absorption corss section when the moderator temperature increases, and is defined by the expression $f(T)=\sqrt{\frac{T_{0}}{T}}$. Here,

$T$ is the absolute moderator temperature in degrees Rankine and the base or reference temperature, $\mathrm{T}_{\mathrm{O}}$ is $528^{\circ} \mathrm{R}\left(68^{\circ} \mathrm{F}\right)$.

Table A2.e

Temperature and "non-1/v" Correction Factors for U235 Thermal Cross Sections

\begin{tabular}{llc} 
Temperature & \multicolumn{1}{c}{$f(T)$} & $\begin{array}{c}\text { "non-1/v" correction } \\
\text { for U235 }\end{array}$ \\
\cline { 2 - 2 } $68^{\circ} \mathrm{F}=528^{\circ} \mathrm{R}$ & 1.0 & 0.981 \\
$170^{\circ} \mathrm{F}=630^{\circ} \mathrm{R}$ & 0.91548 & 0.978 \\
$600^{\circ} \mathrm{F}=1060^{\circ} \mathrm{R}$ & 0.70644 & 0.989
\end{tabular}

The ratio of absorption to fission in $\mathrm{U}^{235},(1+\alpha)$, is numerically equal to 1.184 in the thermal energy range. Therefore, the effective U235 fission cross section, $\sigma_{f}$, is found by dividing the effective absorption cross section by 1.184 .

Intermediate Energy Group

The intermediate absorption cross section is weighted by the energy dependent neutron flux over the intermediate energy range. The intermediate neutron flux is assumed to vary inversly 
with the neutron energy, i.e., the flux is " $1 / \mathrm{E}$ " in nature. The lower energy bound for the intermediate energy group, often referred to as the thermal cut-off, is chosed to be that energy at which the Maxwellian "tail" of the thermal neutron flux distribution is intersected by the "I/E" intermediate flux distribution. Deutsch* suggests the use of an effective Maxwellian distribution which is shifted upward from the thermal or moderator temperatures to determine this point in order to account for thermal flux "hardening". A method for calculating this shifted temperature is given by Cohen** The reason for this correction is the fact that neutrons are preferentially absorbed at the low end of the thermal flux distribution, so that the assumption of a thermal Maxwellian istribution is somewhat in error. The thermal cutoff energy using the Maxwellian flux distribution hardened for water at $170^{\circ} \mathrm{F}$ is $0.26 \mathrm{ev}$. This value is assumed to be valid for all reactor materials and is not changed each time the thermal temperature is changed.

With the energy limits of the intermediate energy group firmly established, a simple relationship may be derived for a " $I / v "$ absorber appearing in a " $I / E "$ neutron flux which gives the effective intermediate absorption cross section as a function of the point value cross section at the reference temperature. In this case, $\overline{\sigma_{2}}=0.0663185 \sigma_{20}$, where $\overline{\sigma_{2}}$ is the effective intermediate cross section and $\sigma_{\text {ao }}$ is the point value of the absorption cross section at $68^{8} \mathrm{~F}$, as given in Table A2.d. The determination of the intermediate $\mathrm{U} 235$ cross section is somewhat complicated by the many resonance absorption peaks in this energy range. The intermediate value is determined by numerically averaging the cross sections given in BNL $325^{* * *}$ over a "I/E" flux spectrum. The results of the integration strongly depend on the number of increments used and the care with which the resonances are treated.

This problem is not emphasized because the "I/E" flux assumption in itself is poor in the resonance absorption region. The numerical evaluations determined by three different individuals are averaged to give "best values for $\sigma_{f}$ and $\sigma_{\bar{a}}$. These are shown in Table A2.f.

* Deutsch, R.W., op.cit.

** "Research Reactors, Physics," p.375, McGraw-Hil1 Book Co., New York, (1955)

*** Hughes, D.J. and Harvey, J.A., op.cit. 
Table A2.f

Intermediate Energy Group U235 Cross Sections

Microscopic absorption cross section, $\sigma_{a}$, barns -52.5
Microscopic fission cross section, $\sigma_{f}$, barns -35.0
Absorption to fission ratio, $1+\alpha$

Fast Energy Group

As previously discussed, the group structure is so selected that the fast absorption cross sections may be neglected in the computations. Finite absorptions do, of course, occur but become insignificant in magnitude when compared with the competitive slowing and leaktng processes.

Macroscopic Cross Sections

The macroscopic absorption cross sections are summarized for the reactor materials of interest in Tables A2.h to A2.k, appearing at the end of Section A2.2.5. Table A2.h. gives macroscopic absorption and fission cross sections for a uniform distribution of U235 having an atomic density of $1 \times 1020$ atomc/cc. These quantities are scaled for other U235 concentrations and added to the absorption contributed by the other materials of the homogenized core. Tables A2.i to A2.k contain a general summary of the cross sections for all other materials of interest.

\section{A2.2.3 Absorption by Core Poisons}

In estimating the long term burnup effects and determing the reactor lifetime, it is necessary to make some assumptions regarding the fission product poisons. Hence, it is assumed that equilibrium Xe135 and Sml 49 are present with the low cross section fission products. In the following discussion, the poisoning is defined as the ratio of the microscopic thermal absorption cross section of the poison to that of $\mathrm{U}^{235}$. The poisoning expressed in this manner is an approximation of the reactivity effects due to the poison.*

Xenon-135

If uniform distribution of the Xe135 is assumed, the poisoning at equilibrium, $P_{x e}$, is given by

* Glasstone, $S_{\circ}$, and Edlund, $M_{0} C_{0} "$ The Elements of Nuclear Reactor Theory", D。Van Nostrand Company, Inc, New York (1952) 
282

$$
P_{x e}=\frac{\Sigma_{x e}}{\Sigma_{25}}=\frac{\sigma_{2}\left(\gamma_{1}+\gamma_{2}\right) \Phi}{\left(\lambda_{2}+\sigma_{2} \phi\right)(1+\alpha)}
$$

where $\gamma_{1}$ is the yield of I $135, \gamma_{2}$ is the yield of Xe135, $\sigma_{2}$ is the Maxwellian averaged Xel35 absorption cross section at $170^{\circ} \mathrm{F}, \lambda_{2}$ is the $\mathrm{Xe} 135$ decay constant, and $1+\alpha$ is the ratio of absorption to fission for thermal neutrons in U235. The average thermal flux, $\phi$, depends on the reactor power and fuel loading. The xenon poisoning as a function of average thermal flux is shown in Figure A2.B. The values of the constants used in the calculations are tabulated in Table A2.g.

Table A2.g

Constants for Xe135 and Sml49 Poisoning Calculations

\begin{tabular}{|c|c|c|c|}
\hline Constant & $\begin{array}{c}\text { Iodine } \\
(1)\end{array}$ & $\begin{array}{c}\text { Xenon } \\
(2) \\
\end{array}$ & $\begin{array}{l}\text { Promethium } \\
\text { (3) }\end{array}$ \\
\hline$\gamma$ & $5.6 \times 10^{-2}$ & $3.0 \times 10-3$ & $1.3 \times 10-2$ \\
\hline$\lambda, \sec ^{-1}$ & $2.882 \times 10^{-5}$ & $2.092 \times 10-5$ & $4.097 \times 10^{-6}$ \\
\hline$\overline{5} \mathrm{~cm}^{2}$ & - & $2.903 \times 10^{-18}$ & $4.097 \times 10^{-6}$ \\
\hline
\end{tabular}

$1+\alpha=1.184$ for $\mathrm{U}^{235}$

Samarium-149

Again, if the space distribution of fission is uniform, the samarium poisoning at equilibrium, $P_{\mathrm{sm}}$, is equal to $P_{\text {sm }}=\frac{\gamma_{3}}{1+\alpha}$, where $\gamma_{3}$ is the fission yield of the $\mathrm{Sm} 149$ precursor, promethium. Therefore, using the constants reported in Table A2.6, $\mathrm{P}_{\mathrm{Sm}}=0.01098$.

Low Cross Section Fission Products

The effective poisoning introduced by the low cross section fission product poisons may be estimated for thermal reactors by an empirical formula fitting the data of webster*. The formula correlates his experimental data including the effect of $\mathrm{U}^{236}$, but does not include the effects of xenon and samarium. The time dependent low cross section fission product poisoning, PLCFP, is given by

$$
P_{\text {LCFP }}=\frac{\sigma_{225^{F}}}{\Sigma_{a 25}}\left[0.152-0.02188 \ln \left(\frac{\Phi T}{10^{20}}\right)\right]
$$

where $\sigma_{\mathrm{a} 25}$ and $\Sigma_{\mathrm{a} 25}$ are the microscopic and macroscopic

* Webster, J.W. Report IDO-16100, "The Low Cross Section Fission Product Poisons" 
absorption cross section of $\mathrm{U}^{235}, \mathrm{~F}$ is the total number of fission/cc at the point of average thermal flux having occured during the life of the core, and $\overline{\phi T}$ is the time integral of the average thermal flux. The latter must fall in the range of 1019 to 1022 neutrons per $\mathrm{cm} 2$ for the formula to be valid. The positive term accounts for the poison buildup due to the fission events and the negative term relates to the poison depletion due to burnout.

If the initial fuel concentration is designated by $\mathrm{No}_{25}$ and by $\mathrm{N}_{25}$ after time of operation $\mathrm{T}$, the total number of fissions at time $\mathrm{T}$ is given by the relationship

$$
F=\frac{\mathrm{No}_{25}-\mathrm{N}_{25}}{(1+\alpha)}
$$

where $(1+\alpha)$ is the ratio of absorption to fission in U235. The time rate of change of $\mathrm{N}_{25}$ is described by the differential equation $d N=-\phi \sigma_{a 2} 5^{N} 25^{d t}$, which may be solved to yield

$$
\mathrm{N}_{25}=\mathrm{N}_{25} e^{-\sigma_{225}} \int_{0}^{\mathrm{T}} \not \mathrm{d} t
$$

By previous definition, the integral in the exponent is $\Phi \mathrm{T}$, in which case

$$
\Phi \mathrm{T}=\frac{1}{\sigma 25} \ln \left(\frac{\mathrm{N} 025}{\mathrm{~N} 25}\right)
$$

By combining equations (1), (2), and (4), the poisoning may be expressed by

$$
{ }^{{ }_{\text {LCFP }}}=\frac{x}{(1-x)(1+\alpha)}\left\{0.152-0.02188 \ln \left[\frac{\frac{1}{\sigma a 25} \text { ln }\left(\frac{1}{1-x}\right)}{1020}\right]\right\}
$$

where $x$ is the fraction of the initial $u^{235}$ burned, given by

$$
x=\frac{\mathrm{No}_{25}-\mathrm{N}_{25}}{\mathrm{~N}_{25}}
$$

The low cross section fission product poisoning is shown in Figure A2.C as a function of fuel burnup when $\sigma_{225}$ equals 545.3 barns.

The Total Core Absorption Cross Section

The foregoing definitions of the cross sections and the effective core poisons are such that the effective total thermal neutron absorption cross section, $\Sigma_{a c}$, is

$$
\Sigma_{a c}=\Sigma_{a 25}\left(1+P_{x e}+P_{\text {Sm }}+P_{\text {LCFP }}\right)+\Sigma_{a O},
$$

where $\Sigma_{a O}$ is the absorption cross section of the moderator and structural material in the core. 
Little error is introduced if the intermediate absorption cross sections are computed in the same manner. The intermedlate U235 absorption cross section has nearly the same relationship to the thermal cross section as does a $1 / \mathrm{v}$ absorber. The inclusion of intermediate absorption due to fission products probably results in a slight overestimate of the poisoning effects, since the basis of computation of thermal poisoning is that all fission occurs in the thermal group. For the sake of simplicity and consistency however, the same formula is followed to determine the intermediate absorption cross sections. The absorptions in the fast group are neglected.

A2.2.4 Diffusion Coefficients

The diffusion coefficient, $D$, is defined by $D=\left(\frac{1}{3 \Sigma_{t_{r}}}\right)$ av

where $\Sigma_{t r}$ is the macroscopic transport cross section appropriately averaged over the energy dependent neutron flux. The transport cross section is defined by $\Sigma_{t r}=\Sigma_{S}[1-\bar{\mu}]$ where $\Sigma_{s}$ is the macroscopic scattering cross section and $\bar{\mu}$ is the average cosine of the scattering angle. For mixtures, the macroscopic transport cross section is the sum over all constituents using the effective homogenized atomic densities. The diffusion coefficients for all materials of interest are sumarized in Table A2.i-A2.k, appearing at the end of Section A2.2.5. The diffusion coefficient for $\mathrm{Al}-\mathrm{H}_{2} \mathrm{O}$ mixtures is assumed to be unchanged by the addition of fuel to the mixture. The utility introduced by this assumption compensates for the slight inaccuracy which is introduced.

Thermal Energy Group

For most moderator and structural materials, the scattering cross section is not highly energy dependent in the thermal group. Therefore, the transport cross section and the diffusion coefficient are independent of the actual temperature and flux spectrum, and need only be corrected for density changes.

Two complicating effects occur when considering water. First, the scattering cross section of hydrogen has an energy dependence in this range. Second, the water molecule has some tendency to act as an entity at energies less than 1 ev due to chemical binding effects. The effect of this latter point is to make the average cosine of the scattering angle, $u$, energy dependent. Radkowsky* has treated this problem and has correlated calculations with experimental data. The results taken from this work are shown in Figure A2.D, in which the thermal diffusion coefficient is shown as a function of water temperature. Noderer** has treated the problem in a similar way for $\mathrm{D}_{2} \mathrm{O}$ and

* Report ANL 4476, "Quarterly Report April, May, June, 1950" * Noderer, L.C. Report CF 54-4-142, "Temperature Dependence of the Neutron Diffusion Coefficient in Heavy Water." 
his results are shown in Figure A2.E. In each case, a correction must be made for density effects.

Intermediate Energy Groups

The scattering cross sections vary only slightly with energy in this range, which makes the flux weighting relatively unimportant. However, cross section files are available which permit numerical averaging using an IBM-650. The code* assumes a "I/E" flux energy dependence with the additional refinement that the flux is inversely proportional to $\Sigma_{S}$ where $\xi_{i}$ is the average logarithmic energy decrement of the neutron in a neutron-moderator collison and $\boldsymbol{\Sigma}_{S}$ is the total scattering cross section of the material. This refinement has little effect when the scattering cross section is relatively independent of energy.

Fast Energy Group

The scattering cross sections become much more energy dependent in the high energy flux spectrum and the flux weighting becomes very significant. The fast diffusion coefficients are computed assuming that the energy dependence. of the neutron flux is identical with the MTR f'lux spectrum given by Webster.** For example, the diffusion coefficient for the fast group (10 Mev-10 kev), $D_{1}$ is calculated by numerically integrating the expression

$$
D_{1}=\frac{6.91 \frac{\phi(u)}{3 \Sigma_{S}(1-\bar{\mu} 0)} d u}{6.91 \int^{0} \phi(u) d u} \text {, }
$$

where $\phi(u)$ is the MTR lethargy dependent flux spectrum. A2.2.5 Ages and Slowing Down Cross Sections

The slowing down cross sections, $\Sigma_{\mathrm{Sd}}$, are determined from the relationship

$$
\Sigma_{\text {Sd }}=\frac{D}{\tau} \text { where } D \text { is }
$$

the group diffusion coefficient and $\tau$ is the partial age for the respective group. It becomes necessary to calculate the partial age in order to find the slowing down cross section.

* Hibbert, C.J., KAPL Memo-CJH-3, "LOST, A Numerical Cross Section Averaging Program for the IBM 650."

**Webster, J.W., IDO Report 16133 PPCO, "Reactivity Effect of Reducing the $\mathrm{Al} / \mathrm{H}_{2} \mathrm{O}$ Ratio in the MTR Core." 


\section{Age Theory Method}

The partial age for most materials may be calculated in the usual manner according to age theory, using the formula

$$
\tau=\int_{\Delta u} \frac{d u}{3 \zeta \Sigma_{s} \Sigma_{t r}} \text {, where }
$$

The integration is performed over the lethargy limits of the energy group being considered.

An IBM 650 Program, * which was discussed in connection with the calculation of aiffusion coefficients, was used also to perform the age calculation. The numerical integration is performed using a punched card file containing lethargy dependent cross sections. The respective ages of all materials of interest in this study are determined using simple age theory, with the exception of water, water mixtures, and heavy water.

\section{Age in Water}

The slowing of neutrons in hydrogeneous materials is poorly represented by age theory because of the large possible neutron energy loss per collision. The word "age" is used here synonomously with "slowing down length" even though simple age theory is not applicable. Marshak** has derived the equations for determining the rigorous solution for age in hydrogenous mixtures. The solution of these equations is laborious and usually a less elegant treatment is applied. One important conclusion from the rigorous solution is that age theory may be safely applied below energies of about $0.2 \mathrm{Mev}$ for water and water-mixtures. The partial age of pure water in the intermediate energy group is therefore determined by age theory and the fast age is determined by simply taking the difference between this value and the total measured age in water. Hil1***, et.al, determined that the age of fission neutrons in water was $30.9 \mathrm{~cm} 2$ measured to the indium resonance. This gives a value of $32.4 \mathrm{~cm}^{2}$ when corrected to the thermal cutoff energy, $0.26 \mathrm{ev}$. Thus, the fast and intermediate partial ages are determined to be $27.7 \mathrm{~cm}^{2}$ and $4.7 \mathrm{~cm}^{2}$ for every water at $68^{\circ} \mathrm{F}$. The partial ages in pure $\mathrm{D}_{2} \mathrm{O}$ are determined using a similar procedure.

\section{Age in Al-Water Mixtures}

Two methods are used in determing ages in metal-water mixtures. One method, suggested by Deutsch****, involves the use of metal equivalence factors to correct the pure water ages for

* Hibbert, C.J., op.cit.

* Marshak, R.E., "Theory of the Slowing Down of Neutrons with Elastic Collisions with Atomic Nuclei," Rev.Mod.Phys.19, 185 (1947)

*** Hill, J.E。, Roberts, L。D。, and Fitch, J.E., AECD 3392 (1948) ****Deutsch, R.W., op.cit. 
the presence of the Al. Another method suggested by Tittle* is a semi-empirical recipe which involves a separate description of the motion of fast neutrons in their first few collisions. The values calculated using each method agree remarkably well with the other, as illustrated in Figures A2.F and A2.G. The fast and intermediate ages are shown as functions of the core metal-to-water ratio. The values used in the calculations are those obtained using the method of Deutsch.

The ages shown in Figures $A 2 . F$ and A2.G are calculated assuming a water density of one $\mathrm{gm}$ per $\mathrm{cc}$. For other temperatures (water densities, an effective age, $\tau^{\prime}$, is found using the relationship

$$
\tau^{\prime}=\tau\left(n_{\mathrm{go}} \frac{\rho_{\mathrm{o}}}{\rho}\right)\left[\frac{\mathrm{n}_{\mathrm{go}}+1}{\mathrm{n}_{\mathrm{go}}+\frac{\rho}{\rho_{\mathrm{o}}}}\right]^{2},
$$

where $n_{g}$ is the original metal-to-water ratio, $\rho$ and $\rho$ are $\rho$ the initial and new water densities respectively and $\tau\left(n_{\mathrm{go}} \frac{\rho_{\mathrm{o}}}{p}\right)$ is the age taken from Figure A2.F or A2.G at an effective metal-to-water ratio equal to $n_{g \circ} \frac{\rho_{0}}{\rho}$. These temperature corrections are made with care so that the resulting values may be used in temperature coefficient calculations. The ages and slowing down cross sections are tabulated in Tables A2.i-A2.K.

\section{A2.2.6 Treatment of Void Regions}

The AETR conceptual design developed herein embodies an annular design in which a single major test loop or hole appears at the reactor center. One type of experiment to be placed in the test hole is gas cooled. An obvious problem which arises is to find a suitable means for predicting the neutron fiux in this test under the circumstances when the hole is empty. Since the design concept also assumes that the reactor may be used for other experiments, it is perhaps even more important to determine the relative reactivity effects with some accuracy.

When a neutron leaves one wall of the test hole headed into the void region, it will either continue across the void and enter the opposite test wall, or continue out of the reactor following the path of the test hole. In the latter case, the neutron is lost to the system. Obviously, diffusion theory is not applicable in the void region

*Tittle, C.W., "Nuclear Shielding Studies I: The Slowing Down and Diffusion of Neutrons in Hydrogeneous Media", Report NP-1418 (1948) 
Table A2.h

Specific* Cross Sections for U 235

Fast Energy Group

Macroscopic absorption cross section, $\Sigma_{\text {als }} \mathrm{cm}^{-1}$

Macroscopic fission cross section, $\Sigma_{\mathrm{fl}}, \mathrm{cm}^{-1}$

Intermediate Energy Group

Macroscopic absorption cross section, $\Sigma_{a 2}, \mathrm{~cm}^{-1}$

Macroscopic fission cross section, $\Sigma_{\mathrm{f} 2}, \mathrm{~cm}^{-1}$

Thermal Energy Group

Macroscopic absorption cross section, $\Sigma_{23}, \mathrm{~cm}^{-1}$

Macroscopic fission cross section, $\Sigma_{\mathrm{f} 3}, \mathrm{~cm}^{-1}$
Core Temperature

\begin{tabular}{ccc}
\multicolumn{3}{c}{ Core Temperature } \\
\hline$\frac{68^{\circ} \mathrm{F}}{0}$ & $\frac{170^{\circ} \mathrm{F}}{0}$ & $\frac{600^{\circ} \mathrm{F}}{0}$
\end{tabular}

0

0
0.00525
0.00525
0.00525
0.00350
0.00350
0.00350

0.059747

0.054530

0.042552

0.050462

0.046056

0.035939

* The cross sections given are for a homogenized fuel concentration of $10^{20}$ atoms U235/cc. 
Table A2.i

Fast Energy Group Nuclear Constants

(10 Mev-10 Kev)

\begin{tabular}{|c|c|c|c|c|}
\hline Material & $\begin{array}{l}\text { Diffusion } \\
\text { Coefficient } \\
D_{I}, \mathrm{~cm}\end{array}$ & $\underset{\mathrm{cm} 2}{\text { Age }}, \tau$, & $\begin{array}{l}\text { Slowing down } \\
\text { cross section } \\
\Sigma_{\text {sd }} \mathrm{cm}^{-1}\end{array}$ & Comments \\
\hline $\mathrm{H}_{2} \mathrm{O}$ & $\begin{array}{l}1.4550 \\
1.4912 \\
2.1390\end{array}$ & $\begin{array}{l}27.7 \\
29.096 \\
59.890\end{array}$ & $\begin{array}{l}0.052530 \\
0.051254 \\
0.035725\end{array}$ & $\begin{array}{r}68^{\circ} \mathrm{F} \\
170^{\circ} \mathrm{F} \\
600^{\circ} \mathrm{F}\end{array}$ \\
\hline Al & $\begin{array}{l}1.5330 \\
1.5330\end{array}$ & $\begin{array}{l}1101.0 \\
1101.0\end{array}$ & $\begin{array}{l}0.0013920 \\
0.0013920\end{array}$ & $\begin{array}{r}68^{\circ} \mathrm{F} \\
170^{\circ} \mathrm{F}\end{array}$ \\
\hline $\begin{array}{l}\mathrm{Al}+\mathrm{H}_{2} \mathrm{O} \\
\mathrm{V}_{\mathrm{A} 1} / \mathrm{V}_{\mathrm{H}_{2} \mathrm{O}} \\
=0.5\end{array}$ & 1.4801 & 43.0 & 0.034421 & $68^{\circ} \mathrm{F}$ \\
\hline $\begin{array}{l}\mathrm{AI}+\mathrm{H}_{2} \mathrm{O} \\
\mathrm{V}_{\mathrm{AI}} / \mathrm{V}_{\mathrm{H}_{2} \mathrm{O}} \\
=1.0\end{array}$ & $\begin{array}{l}1.4930 \\
1.5118 \\
1.7975\end{array}$ & $\begin{array}{l}56.800 \\
58.883 \\
98.219\end{array}$ & $\begin{array}{l}0.026285 \\
0.025675 \\
0.018301\end{array}$ & $\begin{array}{l}68^{\circ} \mathrm{F} \\
170^{\circ} \mathrm{F} \\
600^{\circ} \mathrm{F}\end{array}$ \\
\hline $\begin{array}{l}\mathrm{Al}+\mathrm{H}_{2} \mathrm{O} \\
\mathrm{V}_{\mathrm{Al}} / \mathrm{V}_{\mathrm{H}_{2} \mathrm{O}} \\
=1.5\end{array}$ & 1.5008 & $70 . I$ & 0.021409 & $68^{\circ} \mathrm{F}$ \\
\hline $\mathrm{D}_{2} \mathrm{O}$ & $\begin{array}{l}1.3210 \\
1.3539\end{array}$ & $\begin{array}{l}48.000 \\
50.419\end{array}$ & $\begin{array}{l}0.027520 \\
0.026850\end{array}$ & $\begin{array}{r}68^{\circ} \mathrm{F} \\
170^{\circ} \mathrm{F}\end{array}$ \\
\hline $\mathrm{B}_{2} \mathrm{O}$ & 1.4530 & 166.6 & 0.0087210 & $\begin{array}{l}6.2 \% \text { Void } \\
\text { Fraction }\end{array}$ \\
\hline $\mathrm{Na}$ & $\begin{array}{l}4.9287 \\
5.7854\end{array}$ & $\begin{array}{l}4,785.1 \\
6,593.0\end{array}$ & $\begin{array}{l}0.0010300 \\
0.00087750\end{array}$ & $\begin{array}{r}68^{\circ} \mathrm{F} \\
1000^{\circ} \mathrm{F}\end{array}$ \\
\hline Fe or S.S. & $\begin{array}{l}1.3070 \\
1.3070\end{array}$ & $\begin{array}{l}905.46 \\
905.46\end{array}$ & $\begin{array}{l}0.0014430 \\
0.0014430\end{array}$ & $\begin{array}{r}68^{\circ} \mathrm{F} \\
170^{\circ} \mathrm{F}\end{array}$ \\
\hline
\end{tabular}


Table A2.j

$\frac{\text { Intermediate Energy Group Nuclear Constants }}{(10 \mathrm{Kev}-0.26 \mathrm{ev})}$

Material Diffusion Age, $\tau 2$, Slowing down Absorption Comments Coefficient, $\mathrm{cm}^{2}$ cross section cross

$\mathrm{D}_{2}, \mathrm{~cm} \quad \Sigma_{\mathrm{sd} 2}, \mathrm{~cm}^{-1}$ section,

\begin{tabular}{|c|c|c|c|c|c|}
\hline & $\begin{array}{l}\text { Coefficient, } \\
\mathrm{D}_{2}, \mathrm{~cm}\end{array}$ & $\mathrm{~cm}^{2}$ & $\begin{array}{l}\text { cross section } \\
\Sigma_{\text {sd2 } 2,} \mathrm{~cm}^{-1}\end{array}$ & $\begin{array}{l}\text { cross } \\
\text { section, } \\
\Sigma_{\text {a2 }}, \mathrm{cm}\end{array}$ & \\
\hline $\mathrm{H}_{2} \mathrm{O}$ & $\begin{array}{l}0.58270 \\
0.59720 \\
0.85680\end{array}$ & $\begin{array}{r}4.7000 \\
4.9369 \\
10.162\end{array}$ & $\begin{array}{l}0.12400 \\
0.12099 \\
0.084331\end{array}$ & $\begin{array}{l}0.0012970 \\
0.0012655 \\
0.00088210\end{array}$ & $\begin{array}{l}68^{\circ} \mathrm{F} \\
170^{\circ} \mathrm{F} \\
600^{\circ} \mathrm{F}\end{array}$ \\
\hline $\mathrm{A} I$ & $\begin{array}{l}4.1694 \\
4.1694\end{array}$ & $\begin{array}{l}7326.0 \\
7326.0\end{array}$ & $\begin{array}{l}0.00056910 \\
0.00056910\end{array}$ & $\begin{array}{l}0.00081300 \\
0.00081300\end{array}$ & $\begin{array}{r}68^{\circ} \mathrm{F} \\
170^{\circ} \mathrm{F}\end{array}$ \\
\hline $\begin{array}{l}\mathrm{AI}+\mathrm{H}_{2} \mathrm{O} \\
\mathrm{V}_{\mathrm{Al}} / \mathrm{V}_{\mathrm{H}_{2} \mathrm{O}} \\
=0.5\end{array}$ & 0.81699 & 10.510 & 0.077735 & 0.0011356 & $68^{\circ} \mathrm{F}$ \\
\hline $\begin{array}{l}\mathrm{Al}+\mathrm{H}_{2} \mathrm{O} \\
\mathrm{V}_{\mathrm{Al}} / \mathrm{V}_{\mathrm{H}_{2} \mathrm{O}} \\
=0.5\end{array}$ & $\begin{array}{l}1.0225 \\
1.0448 \\
1.4371\end{array}$ & $\begin{array}{l}17.100 \\
17.933 \\
34.832\end{array}$ & $\begin{array}{l}0.059795 \\
0.058261 \\
0.041258\end{array}$ & $\begin{array}{l}0.0010550 \\
0.0010390 \\
0.0084800\end{array}$ & $\begin{array}{r}68^{\circ} \mathrm{F} \\
170^{\circ} \mathrm{F} \\
600^{\circ} \mathrm{F}\end{array}$ \\
\hline $\begin{array}{l}\mathrm{AI}+\mathrm{H}_{2} \mathrm{O} \\
\mathrm{V}_{\mathrm{A} I} / \mathrm{V}_{\mathrm{H}_{2} \mathrm{O}} \\
=1.5\end{array}$ & 1.2043 & 25.050 & 0.048076 & 0.0010066 & $68^{\circ} \mathrm{F}$ \\
\hline
\end{tabular}

$\begin{array}{llllll}\mathrm{D}_{2} \mathrm{O} & 1.1407 & 66.120 & 0.017250 & 0.0000021900 & 68^{\circ} \mathrm{F} \\ & 1.1691 & 69.452 & 0.016831 & 0.0000021400 & 170^{\circ} \mathrm{F}\end{array}$

$\mathrm{BeO}$

$\begin{array}{lllll}0.58290 & 58.170 & 0.010020 & 0.000037550 & 6.2 \% \\ \text { void }\end{array}$

fraction

$\mathrm{Na}$

$\begin{array}{ll}4.2528 & 5438.5 \\ 4.9920 & 7493.2\end{array}$

0.00078200

$0.00075304 \quad 68^{\circ} \mathrm{F}$

0.00066620

0.00064153

$1000^{\circ} \mathrm{F}$

*Fe or S.S. $\begin{aligned} & 0.46210 \\ & 0.46210\end{aligned}$

171.87
171.87

0.0026890
0.0026890

0.012623

$68^{\circ} \mathrm{F}$

$170^{\circ} \mathrm{F}$

*For stainless steel, multiply $\Sigma_{a 2}$ by 1.115 
Table A2.K

Thermal Energy Group Nuclear Constants

(below $0.26 \mathrm{ev}$ )

Material

$\longrightarrow$

$\mathrm{H}_{2} \mathrm{O}$

AI

$\mathrm{AI}+\mathrm{H}_{2} \mathrm{O}$

$\mathrm{V}_{\mathrm{AI}} / \mathrm{V}_{\mathrm{H}_{2} \mathrm{O}}$

$=0.5$

$\mathrm{Al}+\mathrm{H}_{2} \mathrm{O}$

$\mathrm{V}$ A $1 / \mathrm{N}_{2} \mathrm{O}$

$=1.0$

$\mathrm{Al}+\mathrm{H}_{2} \mathrm{O}$

$\mathrm{V}_{\mathrm{AI}} / \mathrm{V}_{\mathrm{H}_{2} \mathrm{O}}$

$=1.5$

$\mathrm{D}_{2} \mathrm{O}$

$\mathrm{BeO}$

$\mathrm{Na}$

Fe or S.S.*

0.84400

0.88499

0.58430

4.0111

4.7083

0.39620

0.39620
Absorption cross section

$\Sigma_{23}, \mathrm{~cm}$

0.019560

0.017470

0.0093970

0.012289

0.011250

0.017136

0.015925

0.014360

0.0088775

0.013241

0.000072400

0.000064700

0.00022340

0.011355

0.0058173

0.19042

0.17433
Comments

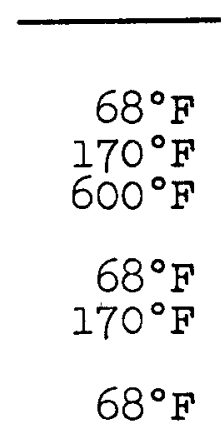

*For stainless steel, multiply $\Sigma_{a_{3}}$ by 1.115 
Table A2.I

Description of the Reactor Models Used in the Void Diffusion Coefficient Evaluation

\begin{tabular}{|c|c|c|c|c|c|}
\hline $\begin{array}{l}\text { Region } \\
\text { Number }\end{array}$ & $\begin{array}{l}\text { Composition and } \\
\text { Temperature }\end{array}$ & $\begin{array}{l}\quad \text { Case } \\
\text { Region } \\
\text { Thickness } \\
\mathrm{cm} \\
\end{array}$ & $\begin{array}{l}\text { I* }^{*} \\
\text { Outside } \\
\text { Radius } \\
\quad \mathrm{cm} \\
\end{array}$ & $\begin{array}{l}\quad \text { Case } \\
\text { Region } \\
\text { Thickness } \\
\text { cm } \\
\end{array}$ & $\begin{array}{l}2 * * \\
\text { Outside } \\
\text { Radius } \\
\quad \mathrm{cm} \\
\end{array}$ \\
\hline $\begin{array}{l}1 \\
2 \\
3 \\
4 \\
5\end{array}$ & $\begin{array}{l}\text { Void; } \\
\text { Al; } 170^{\circ} \mathrm{F} \\
\mathrm{H}_{2} \mathrm{O} ; 170^{\circ} \mathrm{F} \\
\mathrm{Al} ; 170^{\circ} \mathrm{F} \\
\text { Core, metal-to } \\
\text { water ratio=1; } 170^{\circ} \mathrm{F}\end{array}$ & $\begin{array}{l}5 \\
3 \\
4 \\
1 \\
6\end{array}$ & $\begin{array}{l}5 \\
8 \\
12 \\
13 \\
19\end{array}$ & $\begin{array}{l}9 \\
3 \\
4 \\
1 \\
6\end{array}$ & $\begin{array}{l}9 \\
12 \\
16 \\
17 \\
23\end{array}$ \\
\hline $\begin{array}{l}6 \\
7\end{array}$ & $\begin{array}{l}\mathrm{Al} ; 170^{\circ} \mathrm{F} \\
\mathrm{D}_{2} \mathrm{O} ; 170^{\circ} \mathrm{F}\end{array}$ & $\begin{array}{l}2 \\
30\end{array}$ & $\begin{array}{l}21 \\
51\end{array}$ & $\begin{array}{l}2 \\
3\end{array}$ & $\begin{array}{l}25 \\
55\end{array}$ \\
\hline & $\begin{array}{l}\text { * Fuel density } \\
\text { * Fuel density }\end{array}$ & $\begin{array}{l}\text { in core } \\
\text { in core }\end{array}$ & $\begin{array}{l}=2 \times 10^{20} \\
=4 \times 10^{20}\end{array}$ & $\begin{array}{ll}\text { atoms } & U 235 \\
\text { atoms } & U 235\end{array}$ & $\begin{array}{l}/ \mathrm{cm}_{3}^{3} \\
/ \mathrm{cm}^{3}\end{array}$ \\
\hline
\end{tabular}

The variation of the effective multiplication factor, keff and test hole themal neutron flux per unit power are shown in Figure A2.H and A2.I, respectively. In both cases, the effects are shown as percent changes. The reference points are at $D=6.5 \mathrm{~cm}$ for the $5-\mathrm{cm}$ test hole and $D=9.1 \mathrm{~cm}$ for the $9-\mathrm{cm}$ test hole. These are the values determined using the above relationship. As shown by Figure A2.H, the effective multiplication factor does not depend strongly on the diffusion coefficient. However, according to Figure A2.I considerable doubt must be cast upon the calculated power required to meet a given flux in the void region because of the high sensitivity of these calculations to the diffusion coefficlent.

A2.2.7 Critical Experiment Calculations

Two critical assemblies for which experimental data is available, are calculated using the general methods, procedures, and constants herein described. The intent in performing the calculations is to provide a means by which the accuracy of the results of this study might be more fully evaluated. The assemblies calculated have annular type reactor cores which are similar to the geometries considered in the AETR concept. The experiments, however, have light water reflectors while heavy water reflectors are used in the AETR.

The experimental work was performed at ORNL*.

* ORNL-1926-Physics Division Progress Report Period Ending March 10, 1955 
Referring to the discussion appearing in Section A2.1.1, concerning the one-dimensional reactor equations, it was pointed out that a factor $\mathrm{DB}^{2} 2$ was used to describe the transverse (axial) neutron leakage from any reactor region. As mentioned, $\mathrm{B \perp}^{2}$ is determined from the actual core height, $H$, and an assumed reflector savings, $\delta_{h}$, so that

$$
\mathrm{BI}^{2}=\left(\frac{\pi}{\mathrm{H}+2 \delta_{n}}\right)^{2}
$$

This value determined by this method is applied to all reactor regions and groups. Since the only loss of neutrons in the void region is caused by axial leakage, the approach taken in solving the problem is to develop a diffusion coefficient, $D$, which properly accounts for the neutron loss when used with this buckling. Wachspress* has developed the equations for finding this value of D, using similar logic. The final equation involves a rather cumbersome integral which has no simple closed form solution. However, for large ratios of core height to void hole radius, the equation is approximated by the relation

$$
D=\frac{a}{2}\left[\ln \frac{H^{\prime}}{a}-0.705\right] \text {, }
$$

where $a$ is the radius of the void region and $H^{\prime}$ is the effective reactor height, $\left(\mathrm{H}^{\prime}=\mathrm{H}+2 \delta_{h}\right)$. The primary assumptions made in developing this equation follow: function.

b. All neutrons leaving the hole-wall interface are distributed isotropically.

c. The effective reactor height, $\mathrm{H}^{\prime}$ is used in determining the probability of neutron excape from the reactor ends.

The diffusion coefficient calculated in this manner is used in all three neutron energy groups. This approach provides a means for estimating the effects caused by the void region. Since the evaluation is based on the use of an artifical diffusion coefficient, two different reactor geometries are calculated in which the numerical values of $\mathrm{D}$ were varied. This provides some measure by which to judge the importance of estimating $D$ correctly. The reactor dimensions and compositions describing the cases calculated are shown in Table A2.I. The core height is $91.44 \mathrm{~cm}$ and the reflector savings, $\delta_{\mathrm{h}}$, is $23 \mathrm{~cm}$, so that the effective height $\mathrm{H}^{\prime}$, is $137.44 \mathrm{~cm}$.

*Wachspress, E.L. Report KAPL 164I, "Two-Dimensional r- $\theta$ Multigroup Calculations." (1954) 
One arrangement has a cylindrical water island two inches in radius, which is surrounded radially by a two-inch thick fuel annulus containing a homogeneous aqueous U235 fuel solution. These concentric regions are $50.05 \mathrm{~cm}$ high and are surrounded by an (effectively) infinite water reflector, both radially and axially. The other case is identical to the first except that the water island has a three-inch radius and the height is $64.13 \mathrm{~cm}$.

The calculations are performed using the experimentally determined critical fuel concentrations with an assumed axial reflector savings, $\delta_{h}$, equal to $8.5 \mathrm{~cm}^{*}$. The criticality in each case was predicted within two percent using the methods and constants outined in this report.

* Private Communication from J.W.Webster. 


\author{
APPENDIX 3.0 REACTOR HEAT \\ IRANSFER AND FLUID FLOW EQUATIONS
}

In the determination of heat transfer characteristics, consideration is given to the steady state axial temperature distribution along a fuel plate. The reactor design involves regularly distributed fuel assemblies in an annular core; these are cooled by the flow of water through parallel longitudinal channels. The longitudinal distribution of the bulk coolant temperature is given by:

$t_{b}(z)-t_{\text {in }}=\frac{S}{\operatorname{VpACp}_{p}} 6^{z} Q(z) d z$

where

$$
\begin{aligned}
& Q(z)=\text { volumetric heat generation rate, } B t u / h r-f t^{3} \\
& \mathrm{~S}=\text { cross sectional area of the fuel core, } \mathrm{ft}^{2} \\
& \mathrm{~V}=\text { coolant velocity, } \mathrm{ft} / \mathrm{hr} \\
& p=\text { coolant density, } 1 \mathrm{~b} / \mathrm{ft}^{3} \\
& \mathrm{~A}=\text { coolant flow cross-sectional area, } \mathrm{ft}^{2} \\
& \mathrm{C}_{\mathrm{p}}=\text { coolant heat capacity, Btu/lb-OF } \\
& \mathrm{dz}=\text { differential (axial) length in which heat is } \\
& \text { generated, ft } \\
& \mathrm{Z}=\text { axial distance along the core, } \mathrm{ft} \\
& t_{\text {in }}=\text { inlet temperature of the water, }{ }^{\circ} \mathrm{F}
\end{aligned}
$$

The local (fuel plate) surface temperature, $t_{W}$, is related to the bulk coolant temperature, $t_{b}$ by:

$$
t_{w}(z)-t_{b}(z)=\frac{S Q(z)}{h p}
$$

where

$$
\begin{aligned}
& \mathrm{h}=\text { heat transfer coefficient, Btu/hr-ft } \mathrm{f}^{2} \mathrm{O}_{\mathrm{F}} \\
& \mathrm{p} \quad=\text { Heated perimeter, ft }
\end{aligned}
$$

$\frac{h D_{e}}{k}=0.020\left(N_{R}\right)^{0.8}\left(N_{P}\right)^{0.4}$

where

$$
\begin{aligned}
& \mathrm{D}_{e}=\text { equivalent diameter of the coolant channel, ft } \\
& \mathrm{N}_{\mathrm{R}}=\text { Reynolds number, dimensionless } \\
& \mathrm{NP} \text { = Prandt number, dimensionless } \\
& \mathrm{k} \text { = thermal conductivity of the coolant, Btu/hr-ft-oF }
\end{aligned}
$$


For the parametric heat transfer study, a sinusoidal power distribution is assumed. The equation for the maximum power density is then (from 1 and 2):

$Q_{\max }=\frac{t_{W}-t_{\text {In }}}{\frac{F_{f}(\Delta X+\Delta Y)}{2 h} \sin \frac{\pi Z_{\max }}{\bar{H}}+\frac{F_{b}(\Delta X+\Delta Y) H}{\pi V p C_{p} \Delta X}\left[\cos \frac{\pi(\bar{H}-L)}{2 \bar{H}}-\cos \frac{\pi Z_{\max }}{\bar{H}}\right]}$

where

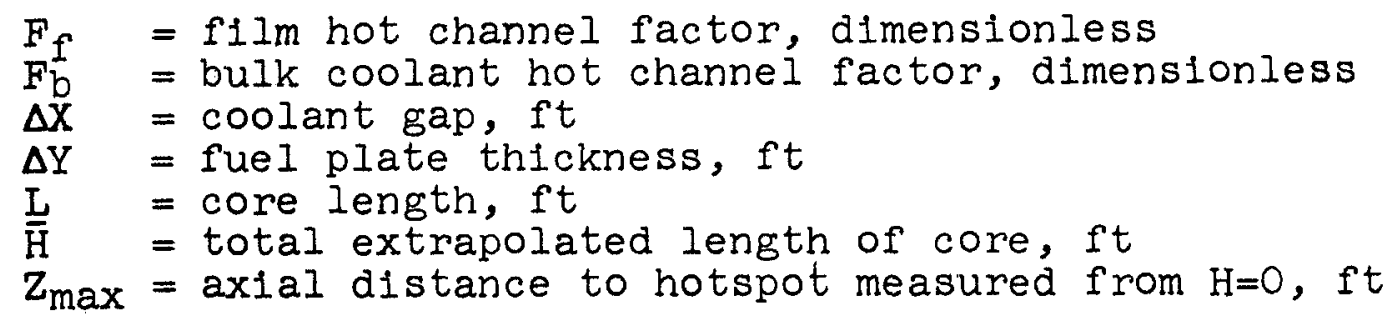

$Z_{\max }$ is obtained by differentiating equation (4) and equating the derivative to zero and is given by

$\mathrm{Z}_{\max }=\frac{\overline{\mathrm{H}}}{\pi} \tan ^{-1}\left(\frac{-\pi V \rho C_{p} \Delta \mathrm{X}}{2 \mathrm{~h} \overline{\mathrm{H}}}\right)$

The bulk coolant temperature water rise is given by

$$
\Delta t_{b}=\frac{(\Delta X+\Delta Y) L Q a v e}{V_{p} \Delta X_{p}}
$$

For the parametric study, the points of maximum wall temperature, $\mathrm{Z}_{\max }$, are calculated $\mathrm{w} i \mathrm{th} \mathrm{V}$ and $\Delta \mathrm{X}$ as variables. These values are inserted into equation (I) to obtain $Q \max$ as a function o.' channel width, metal-to-water ratio, and coolant velocity. The relation between channel gap and plate thickness is given by

$\Delta \mathrm{Y}=\Delta \mathrm{X}\left(\frac{\mathrm{M}}{\mathrm{W}}\right)$

The average bulk temperature rise, $\Delta t_{b}$, is for an average channel. To obtain the bulk temperature rise in the hot channel, it is necessary to multiply the average $\Delta t_{b}$ by $F_{b}$, the bulk coolant hot channel factor. All physical properties are evaluated for an average film temperature of $350^{\circ} \mathrm{F}$. 
equation

The pressure drop across the core is calculated with the

$$
\Delta \mathrm{P}=\frac{\left(\mathrm{K}_{\mathrm{c}}+\mathrm{K}_{e}\right.}{2 \mathrm{~g}} \cdot \mathrm{V}^{2} \mathrm{p}+\frac{0.0065}{2 \mathrm{~g}}\left(\frac{\mathrm{V}}{\mathrm{D}_{\mathrm{e}}}\right)^{1.865} \mathrm{p}^{0.865 \mu} \mu^{0.135 \mathrm{z}}
$$

where

$D_{e}=$ equivalent diameter, ft

$\Delta \mathrm{P}=$ pressure drop across the core, $\mathrm{lb} / \mathrm{ft}^{2}$

$\mathrm{K}_{c}=$ entrance loss coefficient, dimensionless

$\mathrm{K}_{\mathrm{e}}=$ exit loss coefficient, dimensionless

$\mu=$ viscosity, $I \mathrm{~b} / \mathrm{hr}-\mathrm{ft}$

$\mathrm{g}=$ gravitational constant, $\mathrm{ft} / \mathrm{hr} / \mathrm{hr}$

$P=$ density, $1 \mathrm{~b} / \mathrm{ft} 3$

Equation (8) includes a dimensional relationship for the friction factor based on the experimental data of Moody as reported in the Crane Handbook

$F=\frac{0.0065}{D_{e} 0.73}\left(N_{R}\right)-0.135$

Where the equivalent diameter, $D_{e}$, is in feet.

The Jens and Lottes relation is used for the nucleate boiling study and is given by*

$$
\Delta \mathrm{T}_{\text {sat }}=\frac{1.9\left(\frac{\mathrm{q}}{\mathrm{A}}\right)}{\mathrm{e} \frac{\mathrm{P}}{300}}
$$

where

$$
\begin{array}{ll}
\left(\frac{\mathrm{q}}{A}\right) & =\text { heat flux, Btu/hr-ft }{ }^{2} \\
\mathrm{P} & =\text { pressure, psia } \\
\Delta \mathrm{T}_{\text {sat }} & =\mathrm{t}_{\text {wall }}-\mathrm{t}_{\text {saturation, }} \mathrm{O}_{\mathrm{F}}
\end{array}
$$

The limits of the equation are: $P=85$ to 2500 psia and velocity 3 to $40 \mathrm{ft} / \mathrm{sec}$.

The bumout conditions were calculated from Bernath's relation**

* Jens, W. H. and Lottes, P. A., "Analysis of Heat Transfer, Burnout, Pressure Drop and Density Data for High Pressure Water", ANL-4627, May 1951

** Bonilla, C. F. Nuclear Engineering, McGraw-Hill Book Company, Inc., New York 1957 
$\left(\frac{q}{A}\right)_{\text {B.0 }}=\left[5710\left(\frac{D_{e}}{D_{h}}\right)^{0.6}+48 \frac{V}{D_{e}} 0.6\right]\left[102.6\right.$ In $P-97.1 \frac{p}{\bar{P}+15}-$

where

$$
\left.\frac{v}{2.22}\left(\frac{D_{h}}{D_{e}}\right)^{0.6}+32-t_{b}\right]
$$

$\begin{aligned}\left(\frac{g}{A}\right)_{B . O} & =\text { burnout heat blux, Btu/hr-ft }{ }^{2} \\ D_{h} & =\text { (heated perimeter) } / \pi, f t / \pi \\ P & =\text { absolute pressure, psi } \\ t_{b} & =\text { bulk coolant temperature, } O_{F}\end{aligned}$

The limits of the equation are: $P=14$ to 3000 psia, $V=1$ to $54 \mathrm{ft} / \mathrm{sec}$, and $\Delta t_{\text {sub }}$ (saturation temperature - bulk coolant temperature) $=65$ to $3800 \mathrm{~F}$. 


\section{APPENDIX 4.0}

\section{FUEL ASSEMBLY PLATE CURVATURE CALCULATIONS}

The fuel plates of the AETR fuel assembly are radial at the inner diameter of the core but curve away from the intial radil line gradually increasing the angle they make with that radial line (see Figure 2.c). The result is that at a given radius each plate subtends an equal angle from the reactor center. The water gap and plate thickness are constant at all points.

A4.1 Derivation of Equation

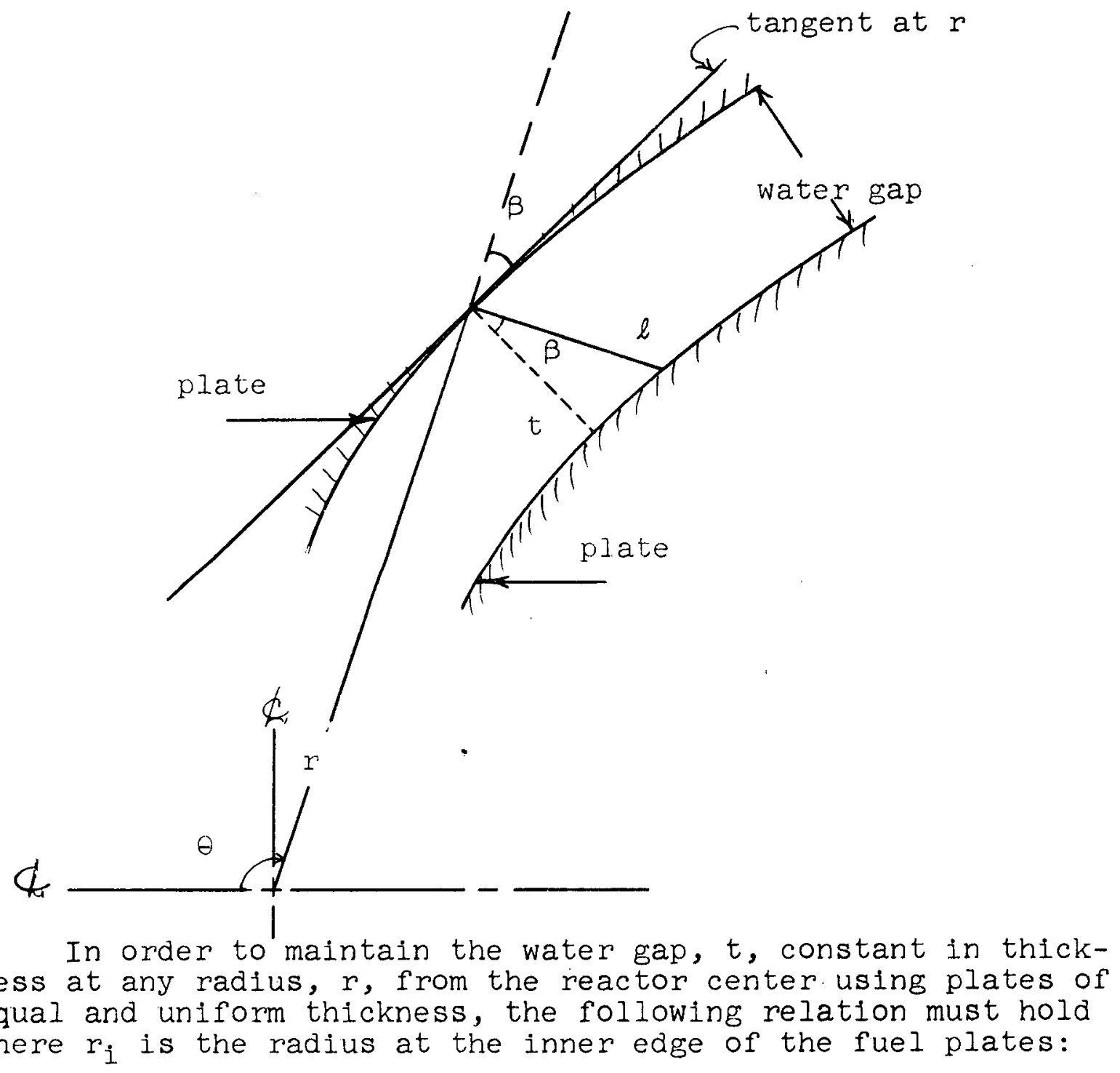




$$
\begin{aligned}
\frac{t}{\ell} & =\frac{r_{1}}{r} \\
& =\cos \beta
\end{aligned}
$$

Considering the tangent at $r$, the slope of the plate is $\tan (\pi / 2-\beta)$, or cot $\beta$. Expressing this in polar coordinates, $\frac{\mathrm{dr}}{\mathrm{rd} \theta}=\cot \beta$

$$
\begin{aligned}
& =\frac{\cos \beta}{\left(1-\cos ^{2} \beta\right)^{1 / 2}} \\
& =\frac{r_{1} / r}{\left(1-\left(r_{1} / r\right)^{2}\right)^{1 / 2}}
\end{aligned}
$$

or, $\quad \int_{0}^{\theta} d \theta=\frac{1}{r_{1}} \int_{r_{i}}^{r}\left(1-\left(r_{1} / r\right)^{2}\right)^{1 / 2} d r$

Substituting $\mathrm{x}=\mathrm{r}_{1} / \mathrm{r}$,

$$
1
$$

$$
\theta=\int_{r_{1} / r} \frac{\left(1-x^{2}\right)^{1 / 2} d x}{x^{2}}
$$

Using trigonometric substitution, $\mathrm{x}=\cos \varnothing$

$$
\begin{aligned}
& \theta=\int_{0}^{\operatorname{arc} \cos r_{1} / r} \tan ^{2} \varnothing \mathrm{d} \phi \\
& \theta=\tan \phi-\varnothing \text { where } \\
& \varnothing=\cos ^{-1} \frac{r_{1}}{r}
\end{aligned}
$$

This is the equation of an involute in normal form.

\section{A4.2 Numerical Evaluation}

Since the stated form is inconvenient for design, certain values for AETR-2 were computed in terms of the offset (y) from the initial radius at appropriate radil. 


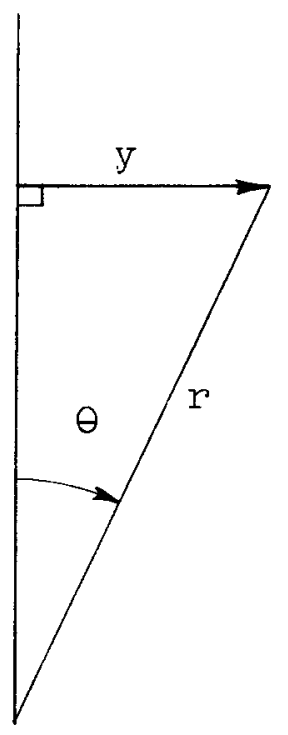

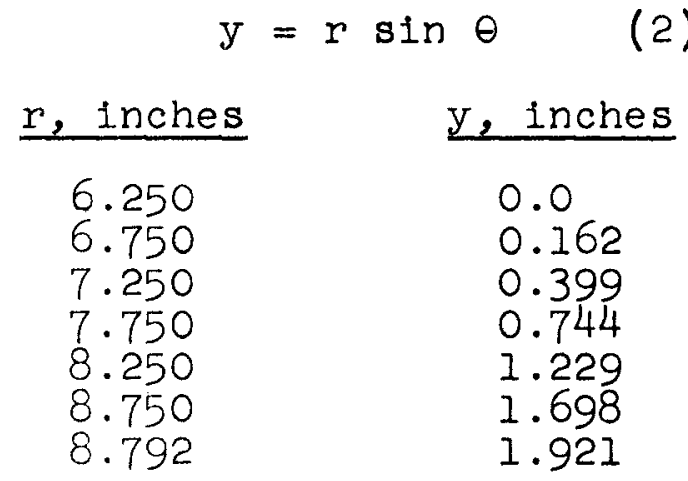

\section{A4.3 Accuracy}

The design attempts to maintain constant the water gap at all radil. The above derivation assumes that the quantity $l$ equals the arc subtended by the water gap. This is only an approximation however. For an angle subtended by a water gap of width $t$,

$$
\begin{aligned}
\ell=r & \tan \alpha \\
\operatorname{arc}=r & \alpha \\
\text { Error in } \ell & =r(\tan \alpha-\alpha) \\
\text { Since } t & =\ell \frac{r_{1}}{r} \\
\text { Error in } t & =r(\tan \alpha-\alpha) \frac{r_{1}}{r} \\
& =r_{1}(\tan \alpha-\alpha)
\end{aligned}
$$

In the AETR Type-A deslgn, each plate and water gap combined subtend on angle of one degree. For a 75-mil gap, 40-mil plate and an inside radius 6.25 inches, equation (3) gives the error in water gap spacing as $6 \times 10^{-5}$ inches. This is negligible and equation (2) is accurate enough for design purposes. 


\section{APPENDIX 5.0 \\ REFLECTOR DROP TIME CALCULATION}

The rate at which the liquid level of the safety reflector arops determines the suitability of this method of scramming the reactor. The position of this liquid level at any time after initiating a scram may be determined by making a force balance on the liquid and solving the resultant differential equation (See Figure A5.A).

$m \frac{d^{2} x}{d t^{2}}=F_{g}-F_{r}$

where

$$
\begin{aligned}
& \mathrm{m}=\text { mass of water dropping, slugs } \\
& \mathrm{F}_{\mathrm{g}}=\text { force of gravity, } 1 \mathrm{~b} \\
& \mathrm{~F}_{\mathrm{r}}=\text { Resistance forces, } \mathrm{lb} \\
& \mathrm{x} \text { = distance which water falls (ft) } \\
& t \quad=\text { time since start of fall, sec }
\end{aligned}
$$

The resistance term is made up of the pressure drop of the gas flowing through the by-pass line, the pressure drop due to the flow of heavy water in the raised annulus, and other resistances to fall of the reflector such as the change of momentum of the gas and liquid. Of the resistance terms, the only one of importance if the pressure drop due to gas flow in the by-pass. The pressure drop in the bypass line may be approximated by the equation.

$F_{r}=c_{1} v^{2}=c_{1}\left(\frac{d x}{d t}\right)^{2}$

where

$$
\begin{aligned}
\mathrm{V}= & \text { gas velocity (ft/sec) } \\
\mathrm{C}_{1}= & \text { a constant dependent upon the plpe diameter and } \\
& \text { length }
\end{aligned}
$$

Equation (1) may now be written:

$$
\frac{d^{2} x}{d t^{2}}=g-\frac{c l}{m}\left(\frac{d x}{d t}\right)^{2}
$$

The mass of water dropping is 
$m=\frac{p}{g c}(K-x) A=C_{2}(K-x)$

where

$$
\begin{aligned}
& \mathrm{p}=\text { density of neavy water (lbs/ft3) } \\
& \mathrm{K}=\text { total distance which the water must fall (f,t) } \\
& \mathrm{A}=\text { cross sectional area of reflector (ft2) }
\end{aligned}
$$

Equation (3) is now written:

$\frac{d^{2} x}{d t^{2}}=g-\frac{c}{(K-x}-\left(\frac{d x}{d t}\right)^{2}$

where

$$
\mathrm{C}=\frac{\mathrm{C}_{1}}{\mathrm{C}_{2}}
$$

Thus the constant $\mathrm{C}$ is determined by the size of the reflector and the length and size of the gas bypass plping.

Integrating equation (4), the velocity of the water as a function of position in the revlector when $c>0.5$ is

$$
\frac{d x}{d t}= \pm\left[\frac{2 g(K-x)}{2 C-1}\right]^{1 / 2}\left[1-\left(\frac{K-x}{K}\right) 2 C-1\right]^{1 / 2}
$$

The general solution to this equation cannot be obtained analytically except for a few values of $C$. When $C=1$, the solution to equation (5) is:

$t=\left[\frac{2 K}{g}\right]^{1 / 2}\left[\sin ^{-1}\left(\frac{K-x}{K}\right)^{1 / 2}-\frac{\pi}{2}\right]$

Since $\mathrm{C}=1$ gives a desirable rate of fall for the reflector, the gas bypass lines are sized accordingly. 


\author{
APPENDIX 6.0 \\ HEAT GENERATION AND SHIELDING CALCULATIONS
}

The AETR concept for high neutron flux results in a high power density and a high gamma flux. The experimental loop tube passing through the core and the reactor vessel surroundIng the core are subjected to significant amounts of heat deposited internally by gammas and neutrons.

A shielding study is required to see that only an acceptable small proportion of the reactor radiation can escape to cause biological damage during full-power operation.

A6.1 Gamma Heating

Four methods are used to estimate the internal heat generation in structures near the reactor core. Each method employs a source energy spectrum identical to the data reported for the Oak Ridge $\mathrm{BSR}^{*}$. This data is similar to that reported in Glasstone**, but is more recent. This data is used in all the calculations wherein the source spectrum is divided into five discrete energy groups.

Preliminary estimates used a geometric transformation for an infinite plane isotropic source.** Probably more reliable is the method of Taylor and Obenshaln*** for uniform, selfabsorbing cylindrical sources of infinite length. Their "exact" numerical integrations are available in graphs plotted in terms of geometry and mean free paths. In order to apply the method to an annulus, the annulus is divided into a circular array of twelve equivalent cylinders. The assumption of infinite length for all these cylinders probably introduces a slight but negligible conservative factor for points near the core.

To allow for the heating due to secondary gammas from neutron captures in aluminum, these gamma heating results were

* Claiborne, Copenhaver, Bertini, Fowler; "Calculating Gamma. Heating in Reactor Structures", Nucleonics 15, No. 10-115 (1957).

* S. Glasstone, "Principles of Nuclear Reactor Engineering", D. Van Nostrand Company, Inc., 1955.

*** J. J. Tayior and F. E. Obenshain, WAPD RM-213, "Fiux from Homogeneous Cylinders Containing Uniform Source Distributions". 
increased by $20 \%$. This corresponds to the magnitude of capture gamma heating measured in aluminum at similar distances from a plate-type water reactor.* The same proportionate increase was also used for the other calculations of heating in structures which are mentioned below.

An Internuclear IBM-650 computer program for slab geometry was first applied to this configuration by making an equivalent core from many small cubical source volumes. This is approximate for cylindrical geometry however, and the program is not economic for the AETR.

A similar program which had been under development for cylindrical geometry was then applied using the IBM 704 computer. This calculation treats cylindrical elements of small ( 0.65 cubic inch) volume as mathematical point sources. The contribution of each of these sources is then calculated for each of a number of "dose" or heating points using the shielding kernel which is exact in the limit as each source volume approaches zero.

This program calculates the attenuation through each material layer of the reactor, including core self shielding, along the straight line between the source and the particular heating point. A buildup factor is then applied depending on the attenuation length to each heating point and the average core composition.

This machine calculation includes spatial variation in the reactor power density taken from two-dimensional neutron diffusion calculations. The basic physical model, 1.e., straight-ahead scattering, lacks finesse, but seems to be more reliable than any other method for regions close to the source. Here the choice of buildup has little effect on the calculated result. Overall, the stralght-ahead approximation gives an over-estimate of the scattered (or heating) contribution for most, but not all geometries.**

The constants for the gamma heating and shielding calculations are summarized in Table A6.a.

* Claiborne, et al, loc. cit.

* Herbert Goldstein, "The Attenuation of Gamma Rays and Neutrons in Reactor Shields", Chapter 5, p.'141, U. S. Atomic Energy Commission, May 1, 1957. 
Table A6.a

Gamma Heating and Shielding Constants

Average Group Energy, Mev

Source energy

$\underline{0.5}$

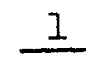

2

$4 \quad 6$

8.8

12.4

14.5

5.46

1.19

$1013(\mathrm{Mev} / \mathrm{kW}-\mathrm{sec})$

Core:<smiles>O[Te][Al]</smiles>

Aluminum:<smiles>[Te][Te]</smiles>

.176

.119
.0545

.080

.058 $.0433 \quad .0382$

.051

.0728

.17

.23
.077

$.143 \quad .0836$

.072

Atasnless

Stainless steel (Fe): $\mu$

.228

.073

.0607

.054

.0513

$\mathrm{H}_{2} \mathrm{O}$ and

$(2000 F): \mu$
$\left(\mu-\sigma_{S}\right)$

.0932

.208

.179

.179

.188

Barytes concrete: $\mu$

$$
\left(\mu-\sigma_{s}\right)
$$

.30
.12

.0682
.030

.0474

.0323

.0262

.025

.020

.0179

Buildup factors (ordinary concrete, $=2.3$ )

$\begin{array}{lrrrrc}\mathrm{A}_{1} & 12.5 & 9.9 & 6.4 & 3.9 & 3.2 \\ \mathrm{~A}_{2} & -11.5 & -8.9 & -5.4 & -2.9 & -2.2 \\ \alpha_{1} & -.11 & -.088 & -.069 & -.059 & -.058 \\ a_{2} & .01 & .029 & .058 & .058 & .083\end{array}$

where

$$
B=A_{1} e^{-\alpha_{1} \mu x}+A_{2} e^{-\alpha_{2} \mu x}
$$


Gamma heating is analyzed for the Type-A reactors $w 1$ th the 7-inch test holes. The results of several detalled calculations for these configurations are shown in Table A6.b.

Table A6.b

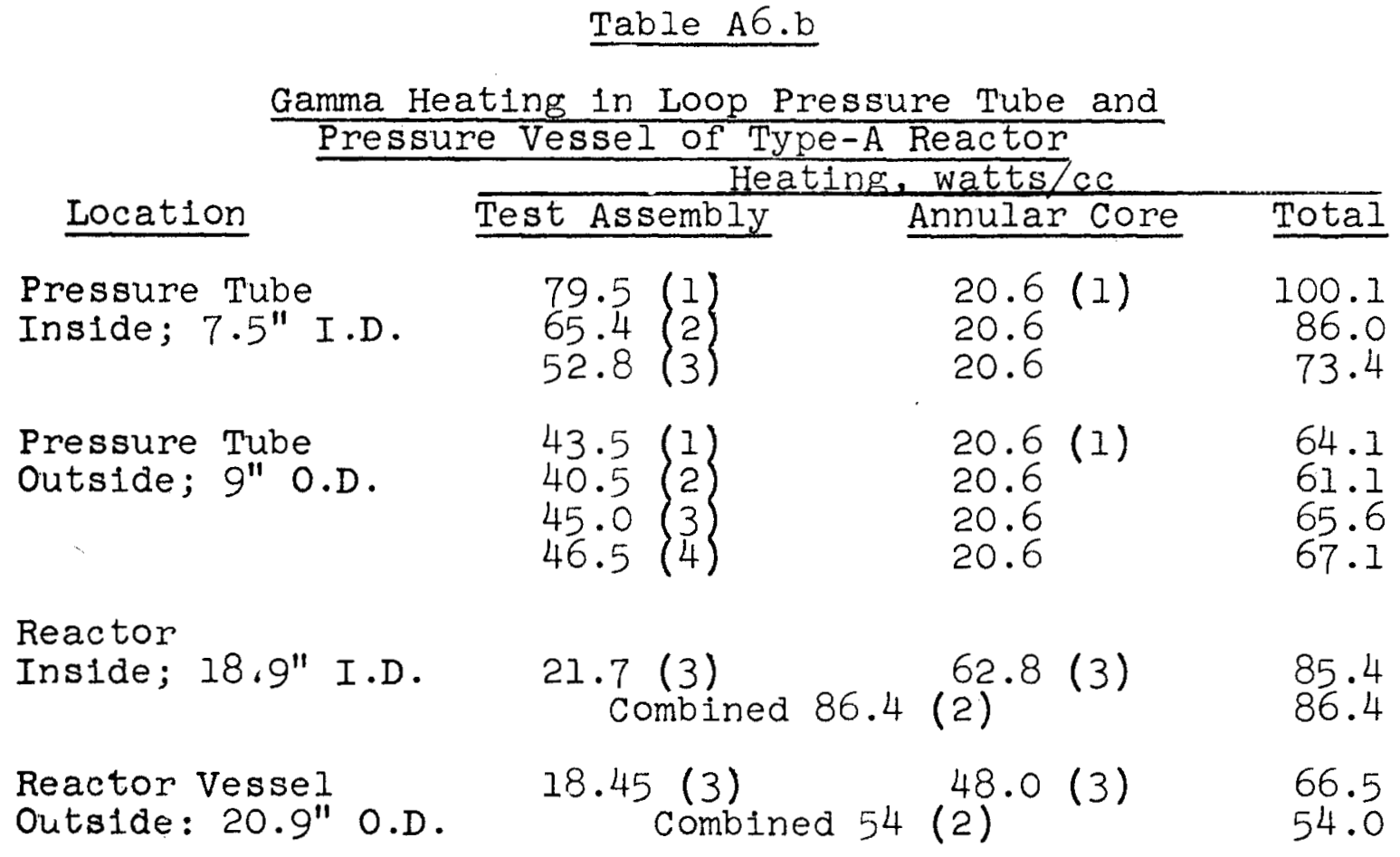

Methods: (1) WAPD 213

(2) IBM 650 Program

(3) IBM 704 Program

(4) Cylindrical Source Approximation, Manual Calculations

In evaluating these results, the two machine programs prabably furnish the most reliable data. They treat the actual core length and power distribution with a relatively large number of small volume sources.

\section{A6.2 Neutron Heating}

Neutron heating is primarily a function of the fast neutron flux. This is clear when it is realized that the intermediate group has an average neutron energy which is about three orders of magnitude less than the average neutron energy in the fast group. 
On this basis, values of fast neutron flux are obtalned from standard three-group diffusion theory using the WANDA code. These give a fast flux of $2.44 \times 10^{15} \mathrm{n} / \mathrm{cm}^{2}-\mathrm{sec}$ in the reactor shell outside the annular core, for example. The interaction between fast neutrons and structure such as aluminum is easily computed as the product of the average macroscopic scattering cross section and the average fast flux.

In each interaction, the neutron can lose energy as a function of the angle between 1ts path before and after the interaction or colision. The maximum amount of energy lost, for complete reversal of direction, is easily found from particle mechanics. Exactly half this loss occurs on the average if one assumes that the structure atom scatters neutrons isotropically. In terms of the material acting as a moderator of atomic mass $A$, the average relative energy loss is then $2 A /(A+1)^{2}$. This is known to overestimate the neutron heating. Multiplying this proportionate energy loss by the mean energy in the fast group gives an average energy loss per interaction. The product of the interaction rate and this energy loss then gives a reasonable indication of neutron heating provided a properly averaged neutron energy and scattering cross section is used.

Using the above method, the heating of reactor components by neutrons is calculated for the Type-A reactors. The results are summarized in Table A6.C.

\section{Table A6.c}

Neutron Heating in Components of Type-A reactor Location Heat, watts/cc

Pressure Tube, Aluminum

Inside Surface

Outside Surface

4.4

4.6

Reactor Vessel, Aluminum

Inside Surface

6.1

Outside Surface

$4 \cdot 7$

Reflector, $\mathrm{D}_{2} \mathrm{O}$

Inside Surface

16.3

Center

Outside Surface

0.16

Average

20

0.78 


\section{A6.3 Total Heating in Reactor Components}

The values of total heating in various reactor components are shown in Table A6.d and in Figure A6.A. The values given for gamma heating are the highest of the two values obtained by machine calculations (Methods 2 and 3 of Table A6.b) since these are believed to be the most reliable.

\section{Table A6.d}

Total Heating in Components of Type-A Reactor

\section{Location}

Pressure Tube, Aluminum

Inside Surface

Outside Surface

Reactor Vessel, Aluminum

Inslde Surface

Outside Surface
86.0

65.6

86.4

66.5

2.12

1.4

0.17

0.22 Heating, watts/cc Neutron

Total

Reflector, $\mathrm{D}_{2} \mathrm{O}$

$\begin{array}{llcc}\text { Inside Surface } & 2.12 & 16.3 & 37.5 \\ \text { Center } & 1.4 & 0.16 & 1.56 \\ \text { Outside Surface } & 0.17 & 20 & 0.17 \\ \text { Average } & 0.22 & 0.78 & 1.00\end{array}$

Based on the above, a uniform heating of 90 watts/cc is used in the thermal stress calculations for the test loop pressure tube and the reactor of both the Type-A and Type-B reactors. This value is slightly conservative for the Type-B reactors since the core thickness is about $20 \%$ less than that of the Type-A reactors.

A6.4 Shielding

Since the AETR core is surrounded radially and vertically by hydrogeneous material, fast neutrons are effectively shielded and the gamma radiation alone determines shield thickness.

For radial shlelding of gammas, the previously described IBM 704 machine program is used. The buildup factors for ordinary concrete are used as an approximate representation of the average core and shield composition. Buildup factors, mass absorption coefficients, and energy absorption coefficients are taken from Rockwell* and shown in Table A6.a. The results are shown in Figure A6.B and indicate that a four-foot thick-

* Rockwell, Theodore, III, TID-7004, Reactor Shielding Design Manual, D. Van Nostrand Company, Inc., New York, 1956. 
ness of barytes concrete outside the thermal shields is a minimum to keep the biological dose rate below the tolerance of $2.5 \mathrm{mr} / \mathrm{hr}$ for a normal 40-hour weekly exposure. Good design dictates a lower level, commonly l/loth tolerance. Hence all plans show five feet barytes concrete for an indicated dose rate of $0.1 \mathrm{mr} / \mathrm{hr}$.

For vertical shield calculations, where water is the principal shield material, the core is divided vertically into three equal point-sources, for each of the five energy groups.

The calculations show that 21.5 feet of water at $130^{\circ} \mathrm{F}$ with a.5-inch iron slab at the top gives a maximum biological dose rate of about $1.6 \mathrm{Mw} / \mathrm{hr}$ during operation with $170 \mathrm{Mw}$ in the reactor core and $50 \mathrm{Mw}$ in a test assembly. This is slightly less than the allowable dose rate for continuous exposure forty hours per week. With regard to vertical shielding it is important in the design of test loop tubes to minimize streaming from the test assembly and core. Alternatively additional iron or concrete slabs can be placed above the reactor. 


\section{APPENDIX 7.0 \\ EQUATIONS FOR STRESS CALCULATIONS}

Both the through-tube and the reactor pressure vessel operate under pressure and in radiation fields producing high rates of internal heat generation. Therefore each of these components was studied to determine the thermal and pressure stresses. The methods of calculation are briefly described below.

A7.I Thermal Stress Calculations

The properties assumed for the aluminum alloy, 2014-T6, from which both the through-tube and the core pressure vessel are made are temperature-dependent. The properties used in calculations are averages between $68^{\circ} \mathrm{F}$ to $300^{\circ} \mathrm{F}$. These values are given below.

Table A7.a

Properties of 2014-T6 Aluminum Alloy for Thermal stress calculations

Coefficient of thermal expansion, in/in-OF

$12.8 \times 10^{-6}$

Modulus of elasticity, psi $10.6 \times 10^{6}$

Poisson's ratio

0.33

Thermal conductivity, Btu/hr-ft- ${ }^{\circ} \mathrm{F}$ $89 \cdot 5$

\section{A7.1.1 Uniform Internal Heating}

Where the rate of internal heat generation is uniform, the formulas for thermal stresses from a standard text can be applied.* The formulas used assume that the cylindrical vessel is free to expand in an axial direction, that the vessel is relatively long, and that there is no end closure. The forms of expression used in this work are:**.

* S. P. Timoshenko and J. N. Goodier, "Theory of Elasticity", 2nd ed., McGraw Hill Book Company, Incl, 1951, p. 409

* C. F. Leyse, Phillips Petroleum Company, IDo-16074, March 18, 1953 


$$
\begin{aligned}
& \sigma_{r}=\frac{a E}{(I-v)} \frac{\left(r^{2}-a^{2}\right)}{r^{2}} \quad \frac{q}{4 K}\left[\frac{r^{2}-b^{2}}{4}+r m^{2}\left\{\frac{\left(b^{2} \ln b-a^{2} \ln a\right)}{b^{2}-a^{2}}\right.\right. \\
& \left.\left.-\frac{\left(r^{2} \ln r-a^{2} \ln a\right)}{r^{2}-a^{2}}\right\}\right] \\
& \sigma_{\theta}=\frac{\alpha E}{(1-v)} \frac{\left(r^{2}+a^{2}\right)}{r^{2}} \frac{q}{4 K}\left[\frac{r^{2}-b^{2}}{4}+\frac{r^{2}\left(r^{2}-a^{2}-2 m^{2}\right)}{2\left(r^{2}+a^{2}\right)}\right. \\
& \left.+r_{m}^{2}\left\{\frac{\left(b^{2} \ln b-a^{2} \ln a\right)}{b^{2}-a^{2}}-\frac{\left(r^{2} \ln r+a^{2} \ln a\right)}{r^{2}+a^{2}}\right\}\right] \\
& \sigma_{z}=\frac{a E}{(1-v)} \frac{q}{4 K}\left[r^{2}-\frac{\left(b 2+a^{2}\right)}{2}+\frac{2 m^{2}}{\left(b^{2}-a^{2}\right)} \quad\left(b^{2} \ln b-a^{2} \ln a\right)\right. \\
& \left.-r_{m}^{2}(1+2 \ln r)\right]
\end{aligned}
$$

where

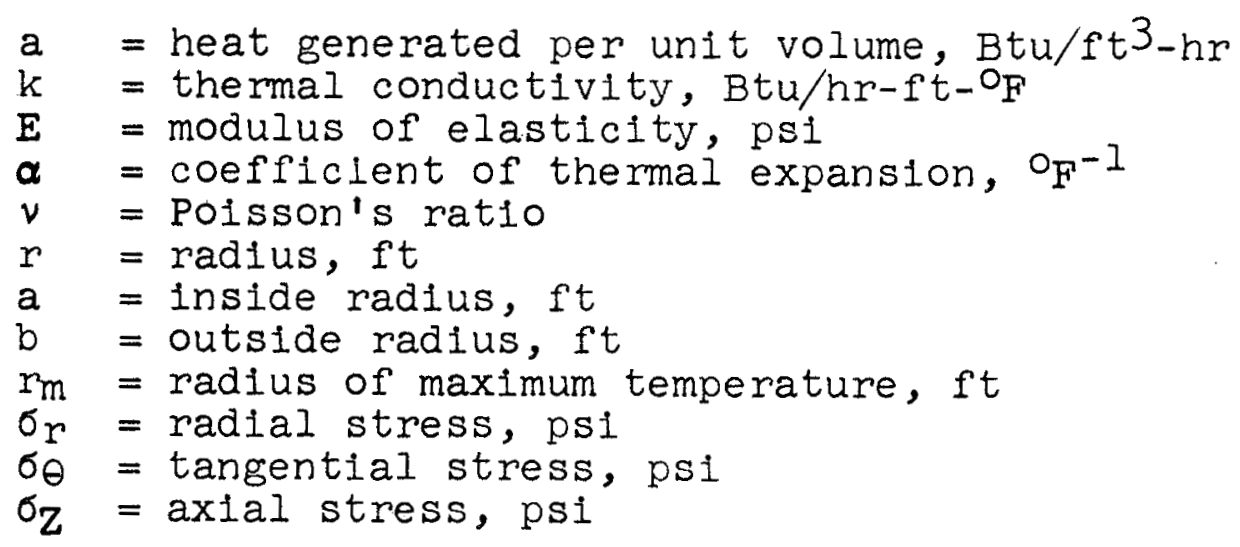

In this formulation, the radius of maximum temperature, $r_{m}$ must be determined. Generally,

$$
r_{m}^{2}=\frac{\frac{b^{2}-a^{2}}{2 k}+\frac{a}{U_{a}}+\frac{b}{U_{b}}+\frac{2(t c b-t c a)}{q}}{\frac{\ln b / a}{k}+\frac{1}{a U_{a}}+\frac{1}{b U_{b}}}
$$


where

$$
\begin{aligned}
t & =\text { temperature, } O_{F} \\
t_{a} & =\text { temperature at } a, O_{F} \\
t_{b} & =\text { temperature at } b, O_{F} \\
t_{c a} & =\text { temperature of coolant at } a, O_{F} \\
t_{c b} & \text { temperature of coolant at } b, O_{F} \\
U_{a}= & \text { overall film heat transfer coefficient at } a, \\
U_{b}= & \text { overall f film heat transfer coefficient at } b, \\
& \text { Btu/ft2-hr-oF }
\end{aligned}
$$

For cooling from the exterior only, $r_{m}$ equals a. For internal cooling only, $r_{m}$ equals $b$.

\section{A7.1.2 Stresses Due to Heat Transmitted}

When there is a thermal gradient across a cylindrical wall, entirely aside from the heat generated internally, thermal stresses are set up. These are computed as stated in TimoshenkoGoodier* in terms of $\mathrm{T}_{i}$, the temperature difference between the inner and outer radii, as follows:

$$
\begin{aligned}
& \sigma_{r}=\frac{a E}{(I-v)} \frac{T_{i}}{2 \ln b / a}\left[\ln b / r+\frac{a^{2}}{b^{2}-a^{2}}\left(1-\frac{b^{2}}{r^{2}}\right) \ln b / a\right] \\
& \sigma_{\theta}=\frac{a E}{(1-v)} \frac{T_{i}}{2 \ln b / a}\left[1-\ln b / r-\frac{a^{2}}{b^{2}-a^{2}}\left(1+\frac{b^{2}}{r^{2}}\right) \ln b / a\right] \\
& \sigma_{z}=\frac{a E}{(1-v)} \frac{T_{i}}{2 \ln b / a}\left[1-2 \ln b / r-\frac{2 a^{2}}{b^{2}-a^{2}} \ln b / a\right]
\end{aligned}
$$

where

$$
\mathrm{T}_{i}=\frac{\mathrm{Q}}{2 \pi}\left(\frac{1}{\mathrm{k}} \ln \mathrm{b} / \mathrm{r}+\frac{1}{\mathrm{~b} U_{\mathrm{b}}}\right), \mathrm{O}_{\mathrm{F}}
$$

and

$$
\begin{aligned}
Q= & \text { heat conducted through material (not due to internal } \\
& \text { generation), Btu/hr-ft of length }
\end{aligned}
$$

* Ibid, p. 413 


\section{A7.1.3 Variable Internal Heating}

When the rate of internal heat generation across a cylindrical wall varies, the calculation of thermal stresses is tedious. Therefore the WBTSGI code* for the IBM 704 computer was used.

\subsection{Stresses Due to Pressure}

When hydrostatic pressures are applied to either surface of the cylinder, the stresses are computed by the standard formulas:

$$
\begin{aligned}
& \sigma_{r}=\frac{a^{2} P_{a}-b^{2} P_{b}}{b^{2}-a^{2}}-\frac{\left(P_{a}-P_{b}\right) a^{2} b^{2}}{r^{2}\left(b^{2}-a^{2}\right)} \\
& \sigma_{\theta}=\frac{a^{2} P_{a}-b^{2} P_{b}}{b^{2}-a^{2}}+\frac{\left(P_{a}-P_{b}\right) a^{2} b^{2}}{r^{2}\left(b^{2}-a^{2}\right)} \\
& \sigma_{z}=v\left(\sigma_{r}+\sigma_{\theta}\right)
\end{aligned}
$$

where

$$
P_{a}=\text { pressure on internal surface, psi }
$$

and

$$
\mathrm{P}_{\mathrm{b}}=\text { pressure on external surface, psi }
$$

As is conventional, negative stress values are to be interpreted as compressive and positive values as tensile.

\section{A7.3 Combined Stresses}

Where stresses in a structure occur as a result of more than one type of load, the actual stress in the material is obtained bv superposition. Due to rotational symmetry, it is

* D. M. Davis and B. H. Mount, The Calculation of Thermal Stress in Cylinders with Internal Heat Generation (Description of the WBTSGI code), WAPD-TM-59, Westinghouse Electric Company. 
seen that any two radial stresses above can be colinear and also that any two axial or tangential stresses can be respectively colinear. Therefore, the thermal and pressure stresses can be added algebraically to find the combined stress. If this combined stress is the numerical maximum, it can be compared with the allowable or ultimate strength of the material to evaluate the design. 


\section{APPENDIX 8.0 FUEL LOADING IN CORES WITH PLATE- TYPE FUEL ASSEMBLIES}

Parameters which can be varied in a reactor fuel region are metal-to-water ratio, thickness and volume of the fuel region, and fuel concentration. Figure A8.A shows uranium atom density variation with $\%$ uranium in the fuel plate meat for various metal-to+water ratios and fuel plate meat thicknesses. This figure is useful in determining the fuel assembly geometries that are practical from the standpoint of fuel loading.

Data for the calculation of these curves is as follows:

Fuel assemblies

Fuel enrichment

Fuel cladding

Density of uranium

Density of aluminum

$\mathrm{N}_{\mathrm{O}}$, Avogadro's number

$A$, atomic weight, U235
Plate-Type

15 mils

$1167.4 \mathrm{lb} / \mathrm{ft}^{3}$

$168.51 \mathrm{~b} / \mathrm{ft3}$

$6.025 \times 1023$

235

The conversion of grams to atoms is given by;

$$
\text { atoms }=\frac{N_{O}}{A} \times \text { grams }
$$

The density of the fuel plate core alloy is given by;

$$
P_{\text {alloy }}=\frac{1}{\frac{x}{P_{\text {al }}}+\frac{y}{p_{u}}}
$$

where

$$
\begin{aligned}
P_{a l l o y} & =\text { density of alloy } \\
P_{a l} & =\text { density of aluminum } \\
P_{u} & =\text { density of uranium } \\
\mathbf{x} & =\% \text { aluminum in alloy } \\
\mathbf{y} & =\% \text { uranium in alloy }
\end{aligned}
$$

The relation between the fuel plate thickness, $\Delta y$, and coolant gap thickness, $\Delta \mathrm{x}$, is given by

$$
\Delta \mathrm{y}=\Delta \mathrm{x} \frac{\mathrm{M}}{\mathrm{W}}
$$

where $\frac{M}{W}=$ metal-to-water ratio 
Figure A2.A Comparison of Radial Thermal Neutron Flux

Distributions Determined by Diffusion Theory and the $\mathrm{P}(3)$ Method.

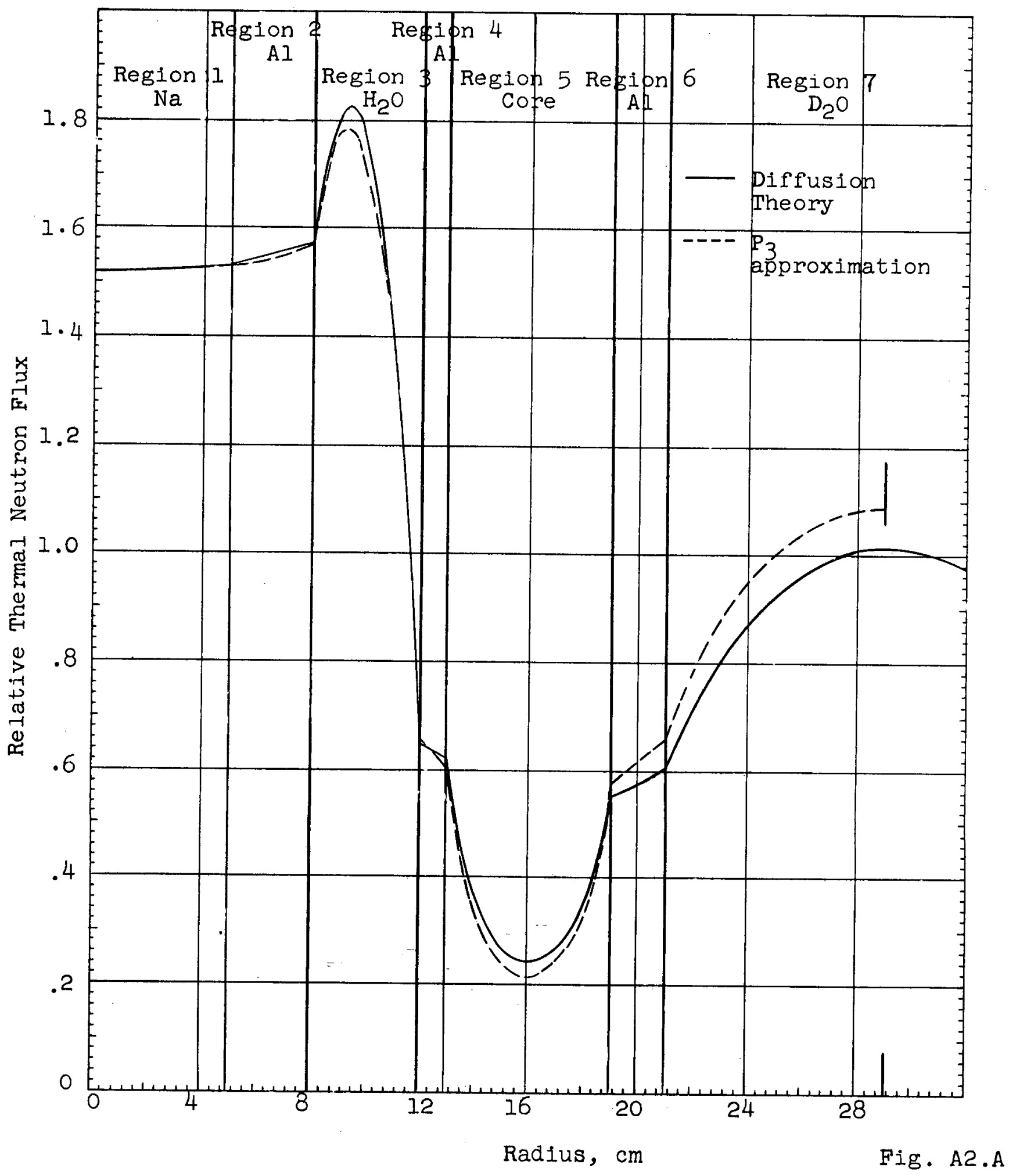


Figure A2.B Variation of Equilibrium Xenon Poisoning with Average Thermal Neutron Flux.

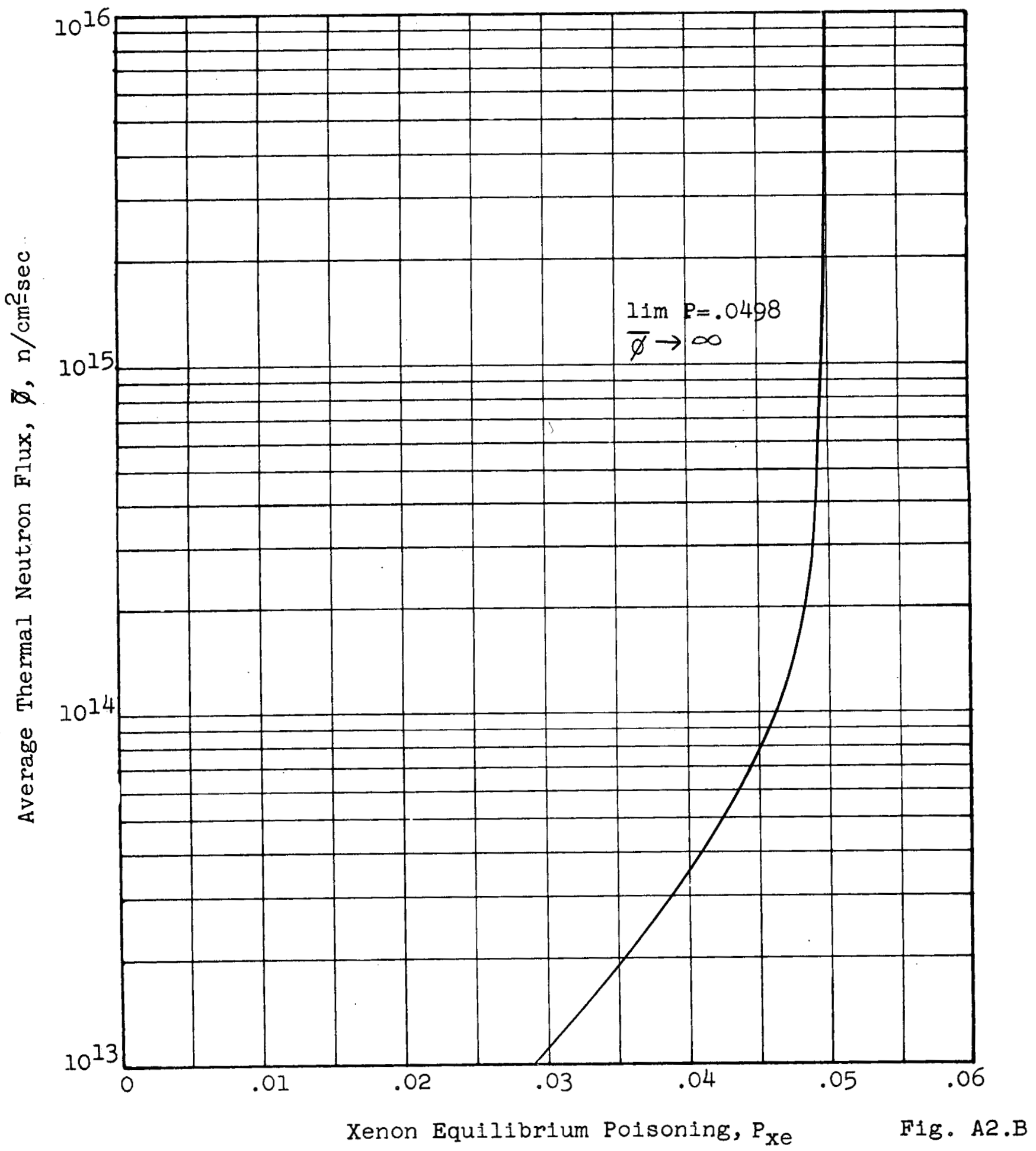



Figure A2.D Thermal Diffusion Coefficient in $\mathrm{H}_{2} \mathrm{O}$ as a Function of Absolute Temperature*

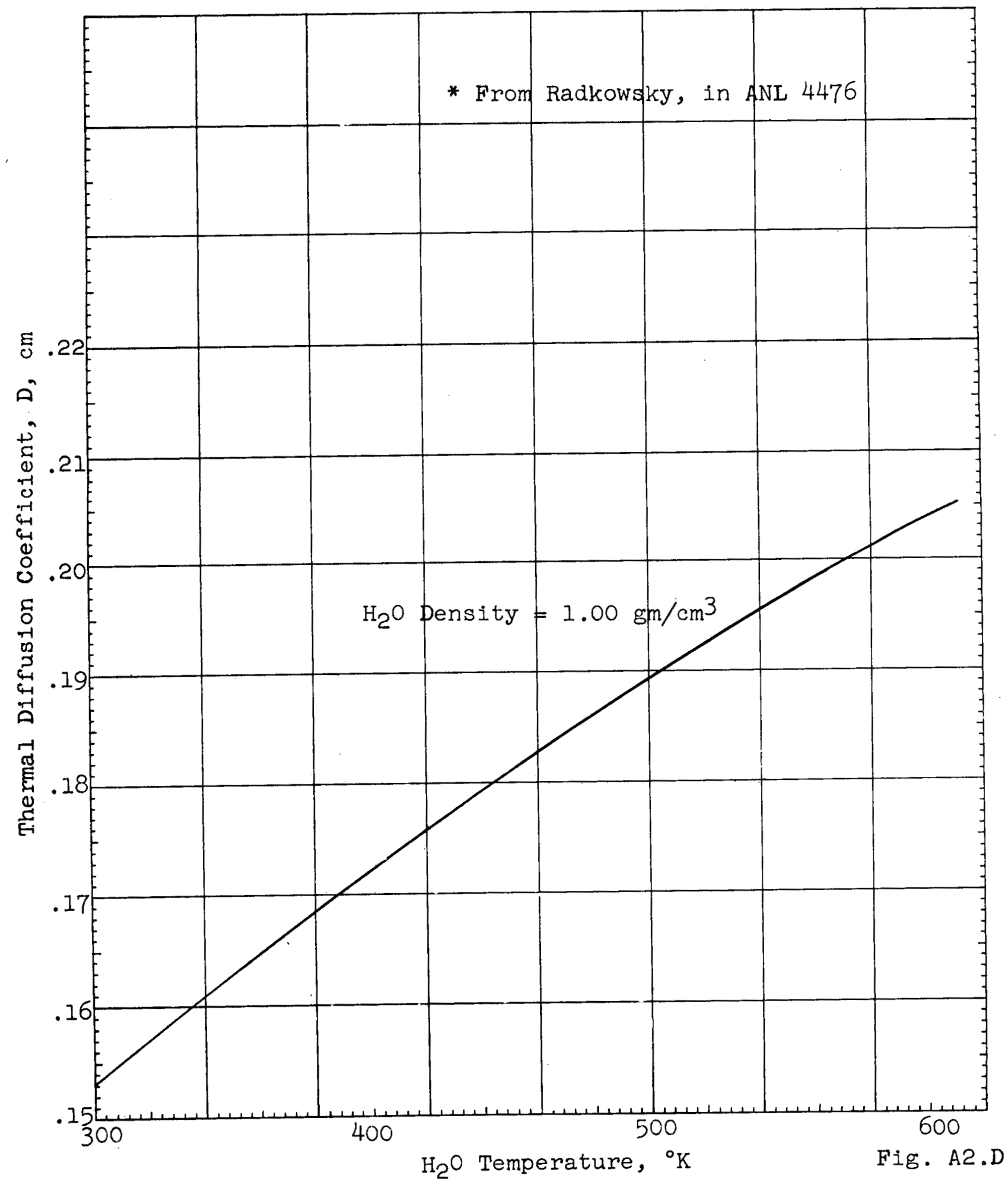



Figure A2.E Thermal Diffusion Coefficient in $\mathrm{D}_{2} \mathrm{O}$ as a
Function of Absolute Temperature*

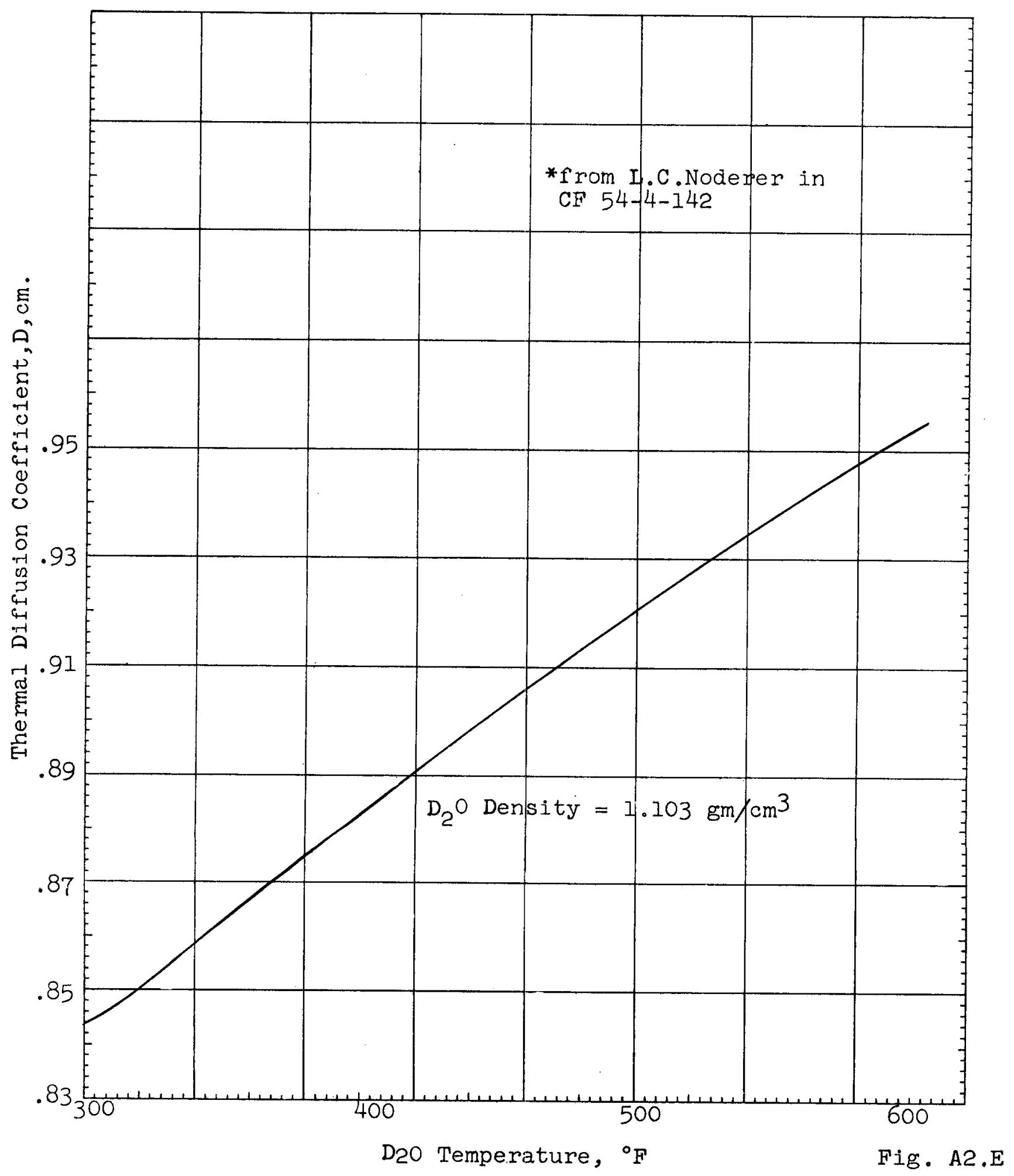


Figure A2.F Fast Age for $\mathrm{Al}-\mathrm{H}_{2} \mathrm{O}$ Mixtures

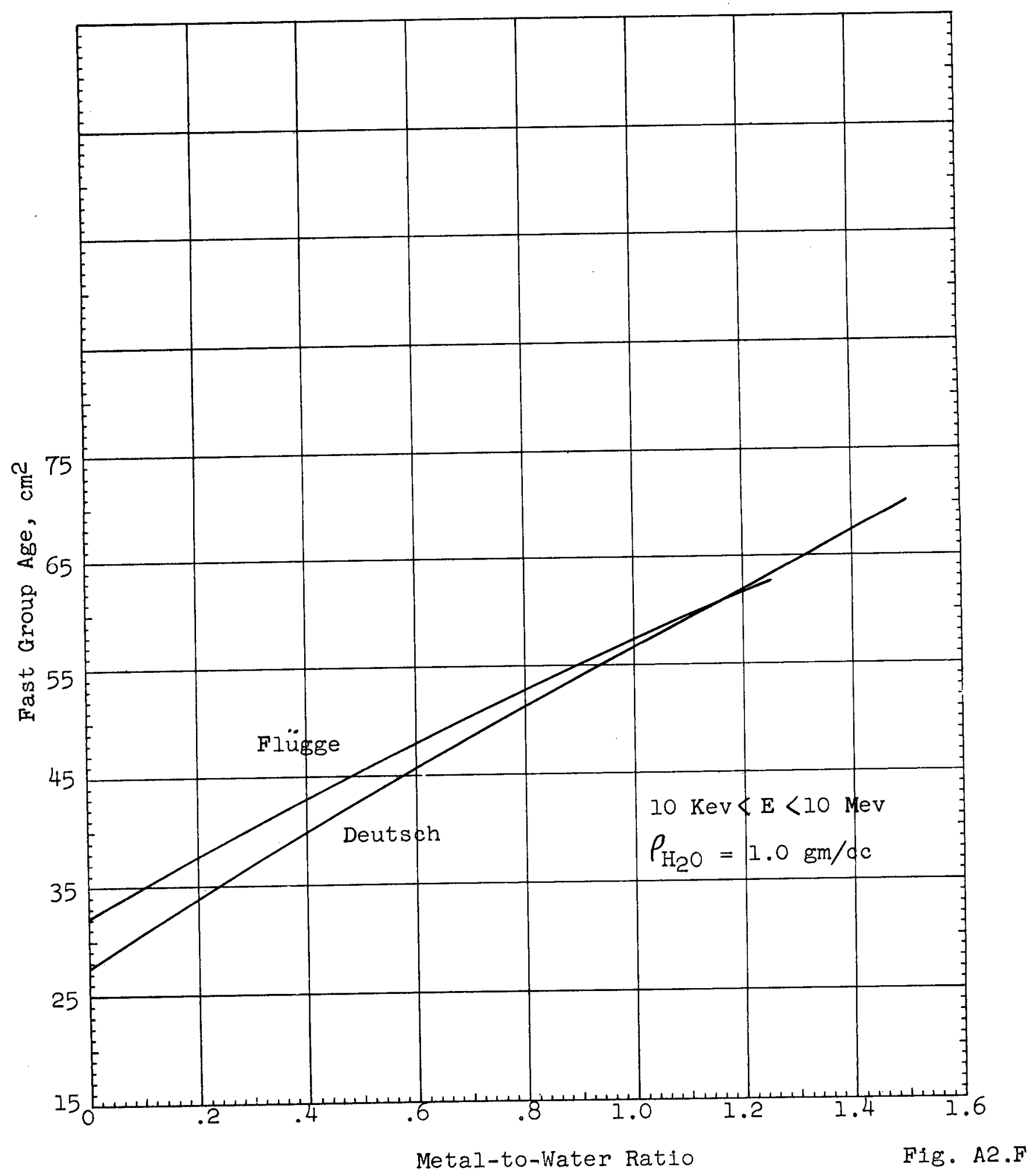


Figure A2.G Intermediate Age for $\mathrm{Al}-\mathrm{H}_{2} \mathrm{O}$ Mixtures

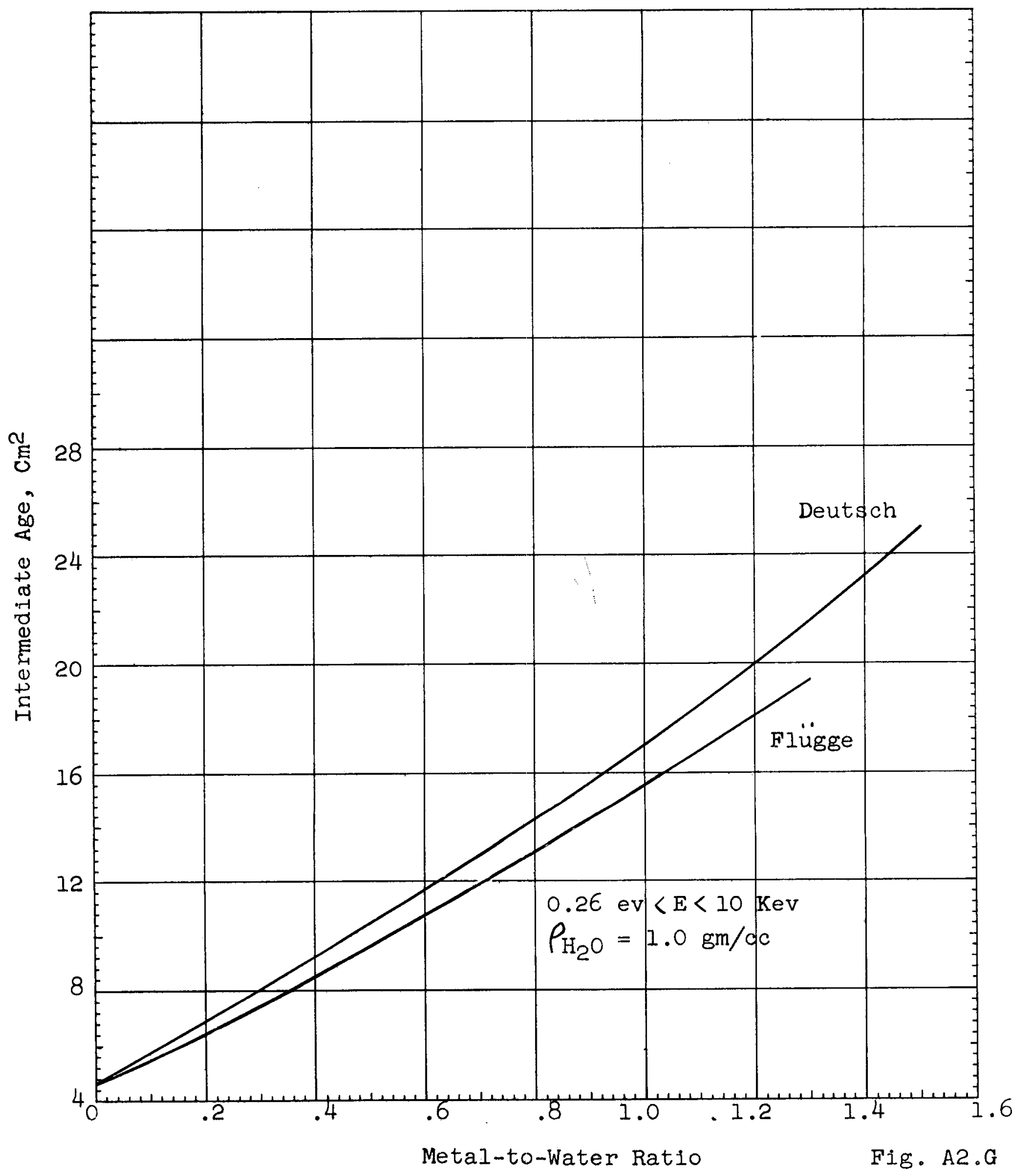


Figure A2.H Effects of the Diffusion Coefficient in an

Empty Test hole on the Effective Multiplication Factor

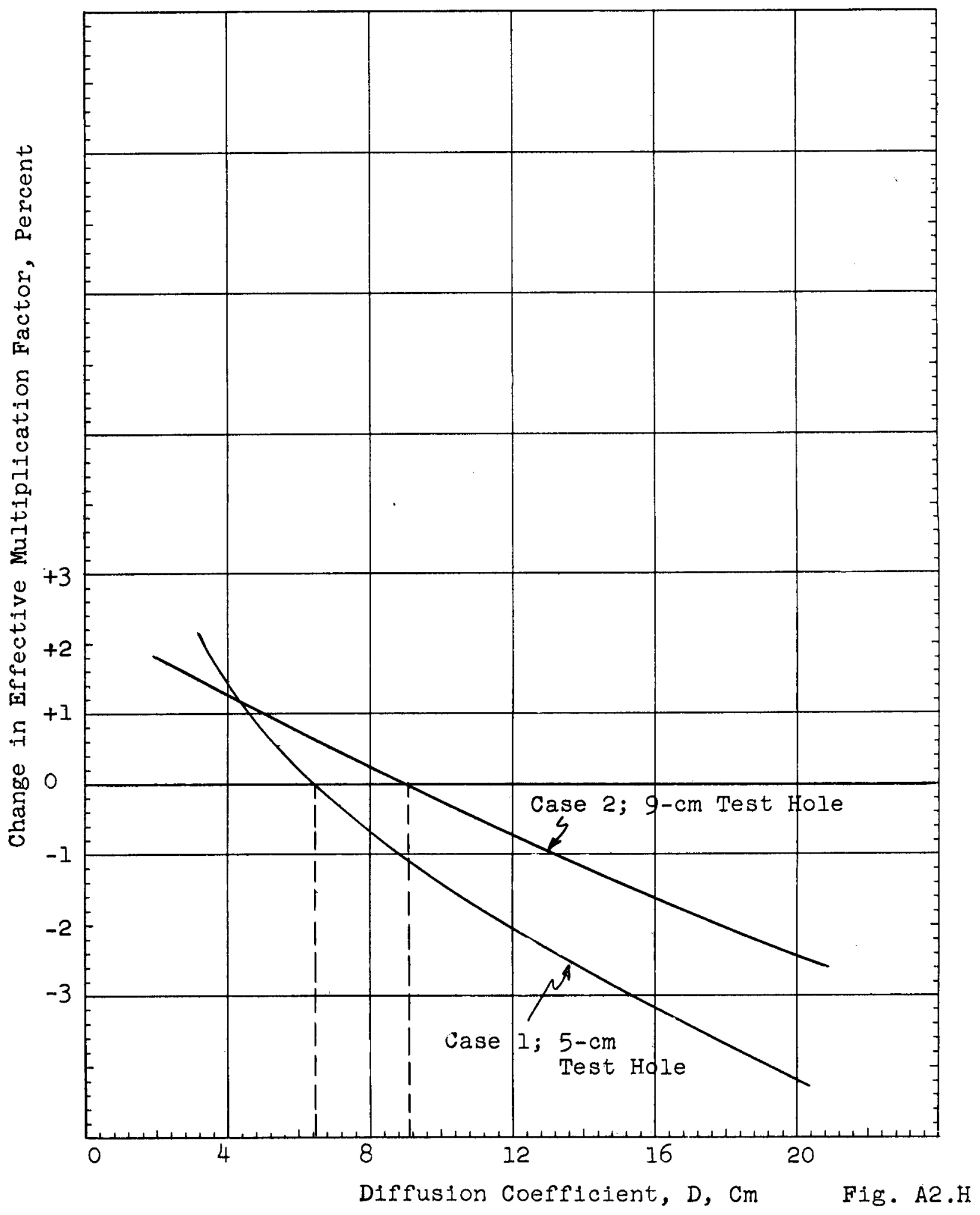


Figure A2.I Effects of the Diffusion Coefficient in an Empty Test Hole on the Test Hole Thermal

Neutron Flux at constant Power

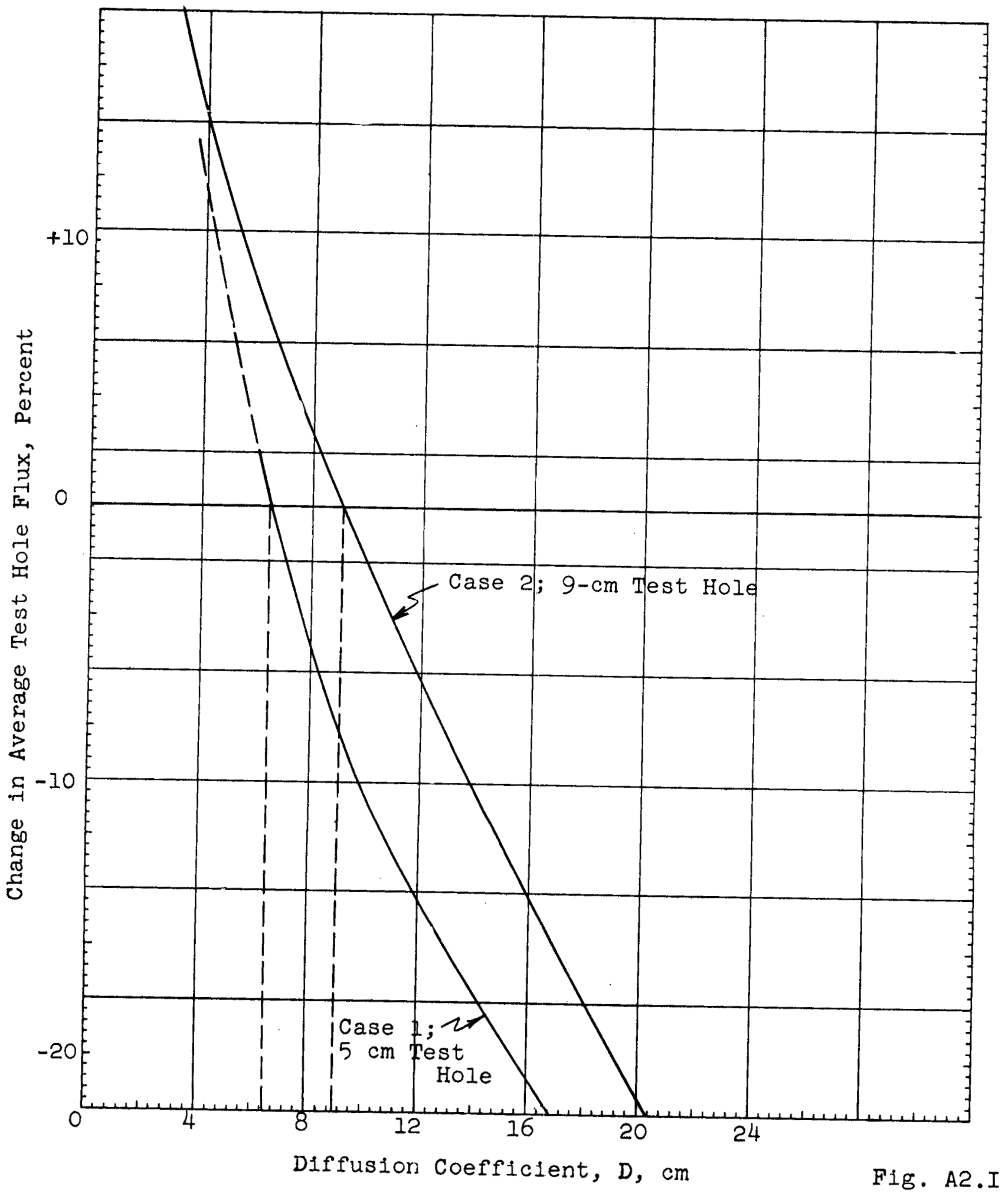


326

Figure A5.A Sketch of Safety Reflector

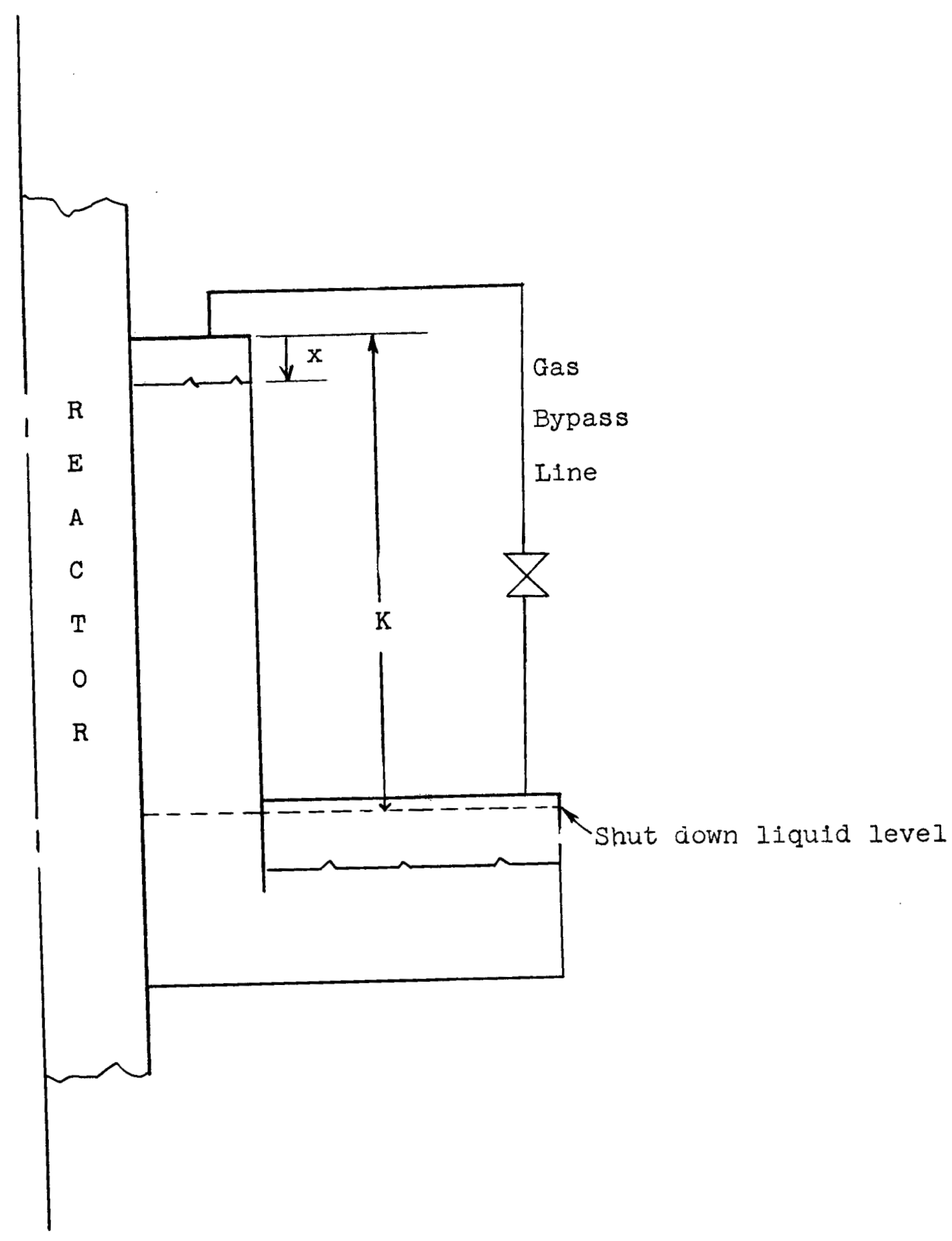

.

Fig. A5.A 
Flgure A6.A Total Heating versus Radius for Type-A Reactor.

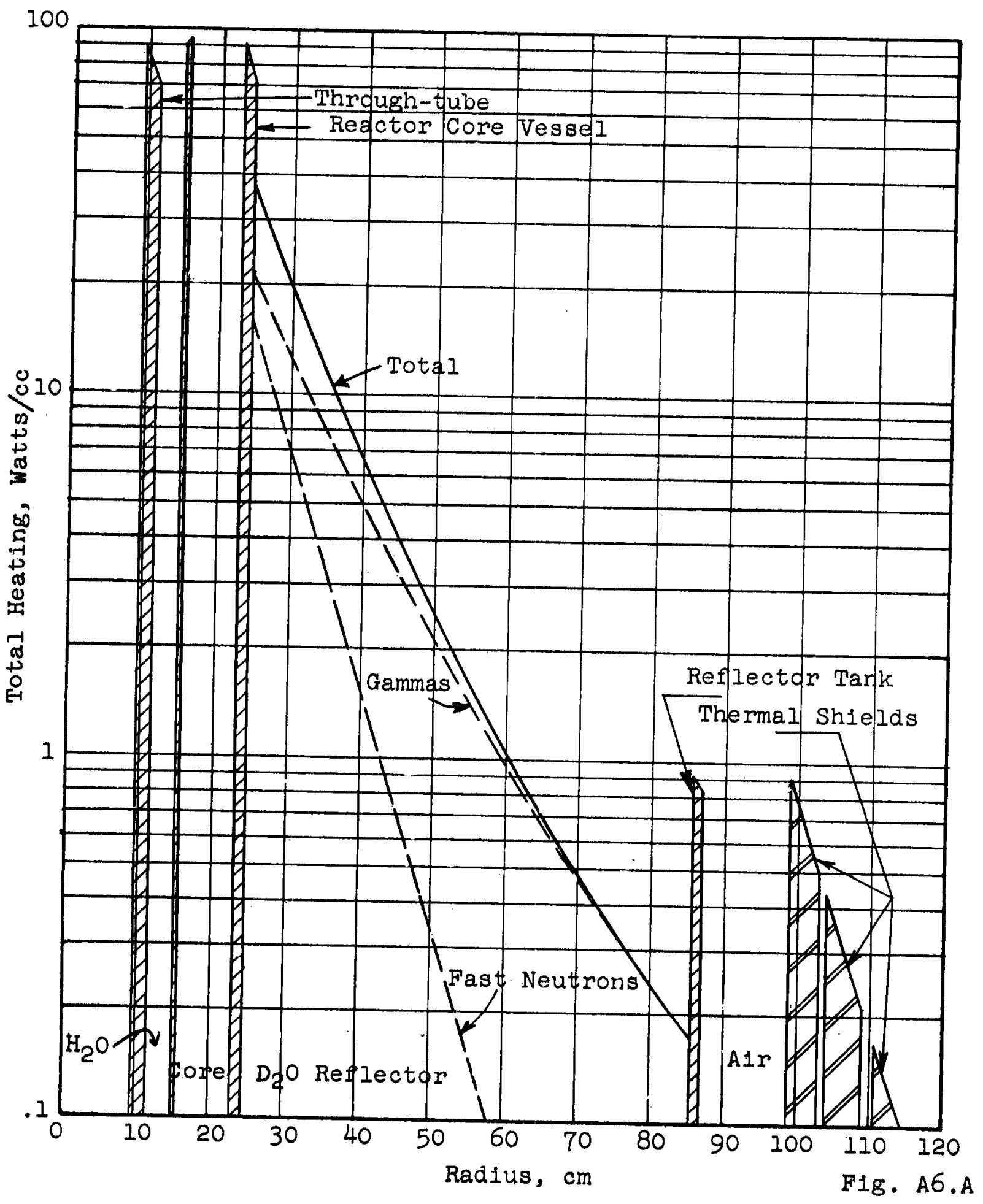


Figure A.6.B Dose Rate vs Concrete Thickness for Type-A Reactor.

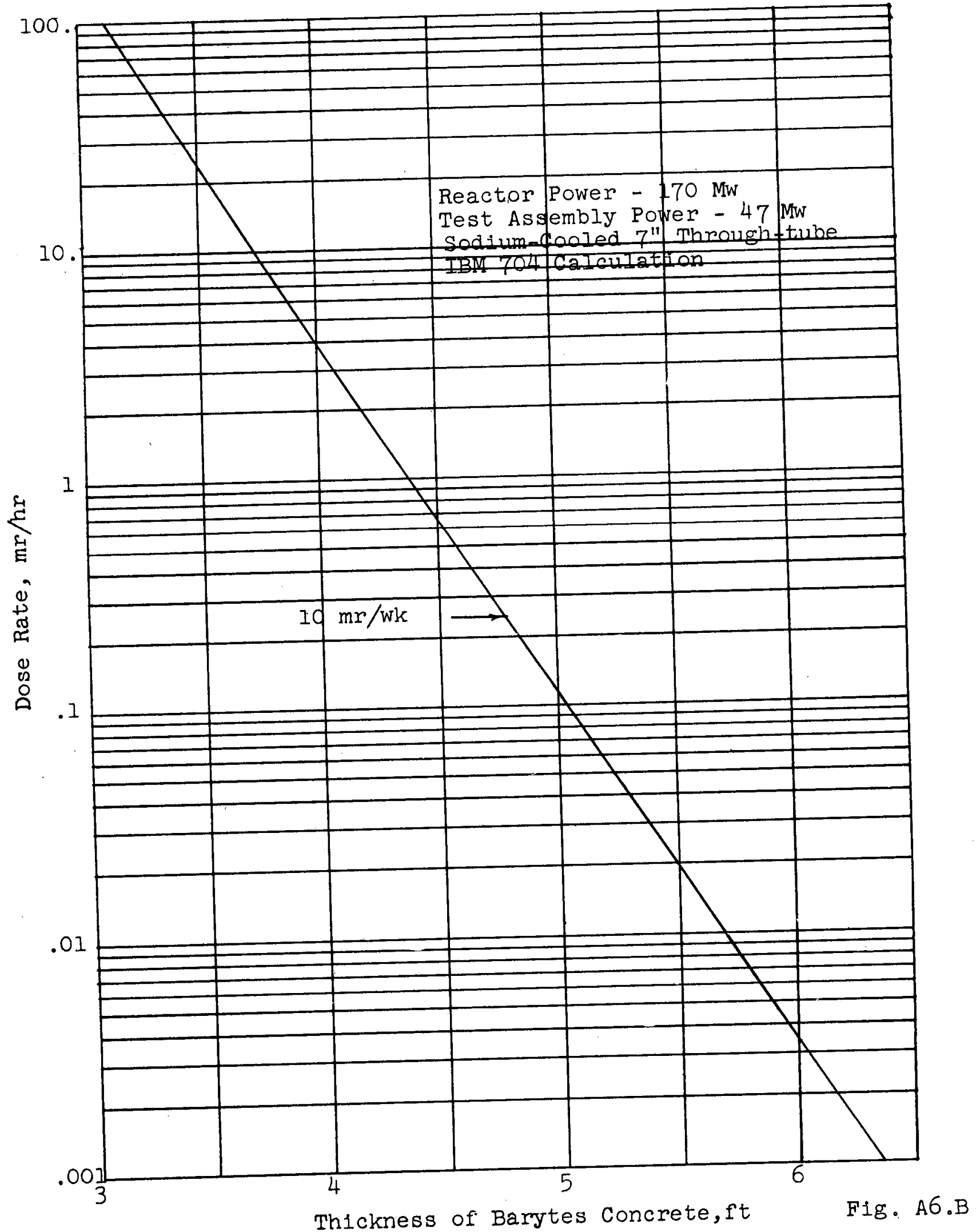


Figure A8.A Atom Density versus Uranium in Fuel-Plate Meat -- Wrought Alloy Only.

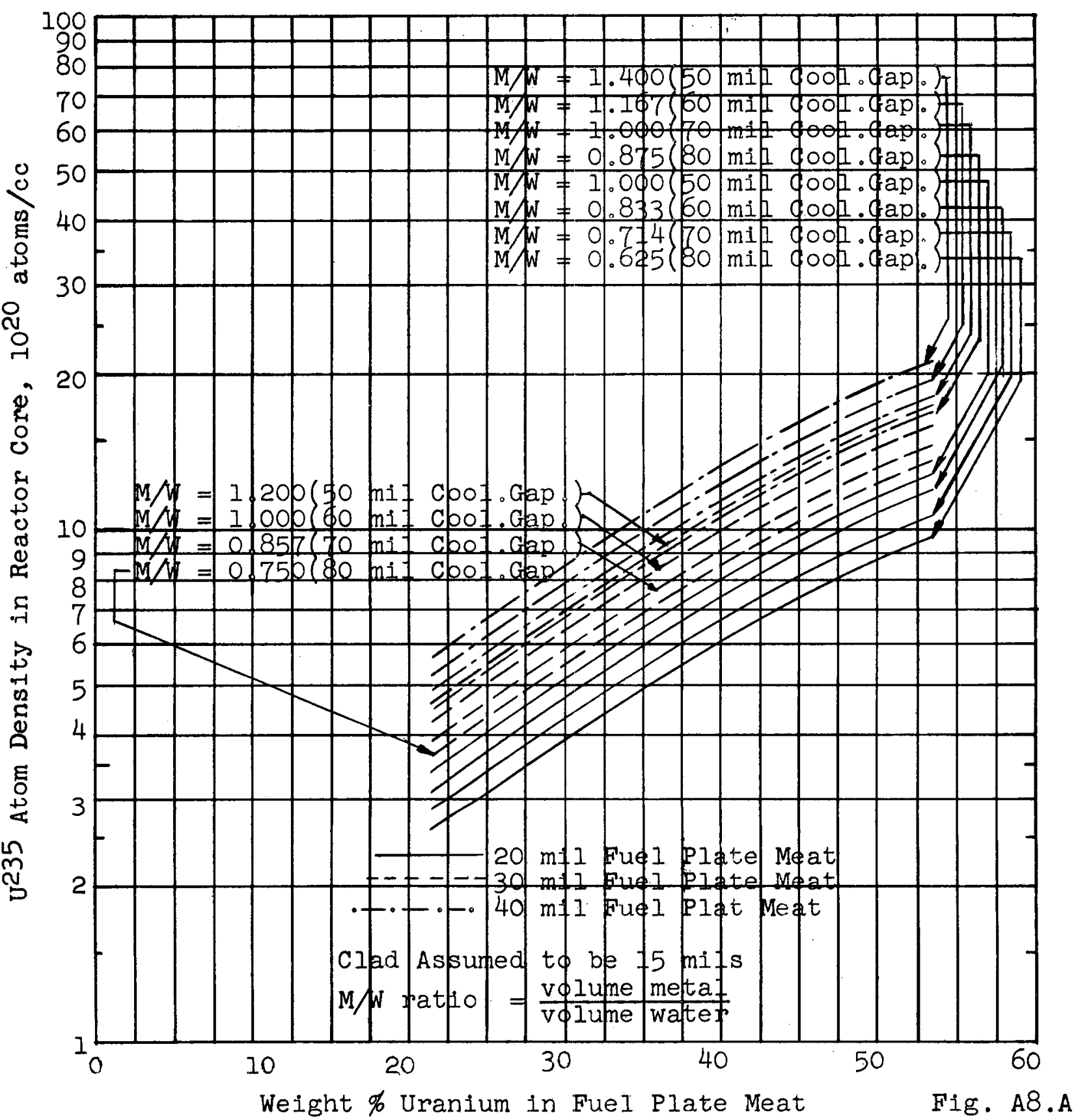

